\title{
REVISTA
}

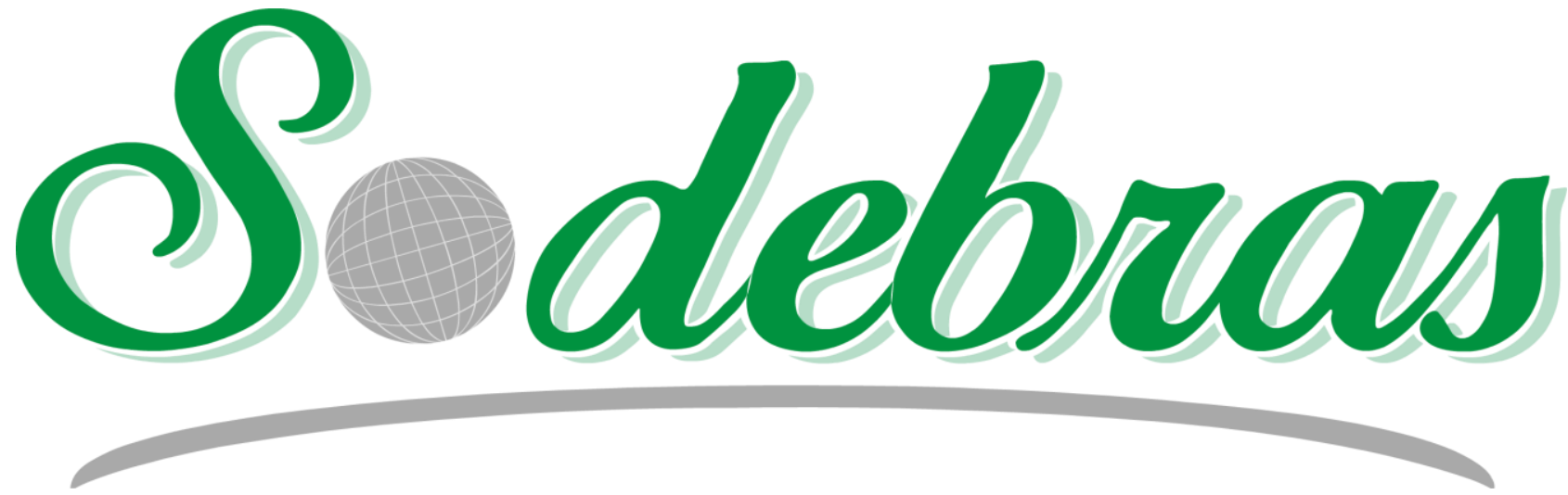

SOLUÇÕES PARA O DESENVOLVIMENTO DO PAÍS 


\title{
ARTIGOS PUBLICADOS
}

\author{
PUBLICAÇÃO MENSAL \\ Nesta edição
}

\section{A TRANSFERÊNCIA DE TECNOLOGIA DAS ICTs FRENTE AO DECRETO № 9.283/2018}

ICT'S TECHNOLOGY TRANSFER TO DECREE No. 9.283/2018 - Luana Esteche Nunes Korocoski; Cláudia

Crisostimo; Paulo Rogério Pinto Rodrigues; Julianno Pizzano Ayoub

INOVAÇÃO TECNOLÓGICA NA MICRORREGIÃO DE CAPANEMA NO SUDOESTE DO PARANÁ: DA PROSPECÇÃO A INOVAÇÃO

TECHNOLOGICAL INNOVATION IN THE CAPANEMA MICROREGION IN SOUTHWEST PARANÁ: FROM PROSPECTION TO INNOVATION - Marcos Fernando Schmitt; Paulo Rogério Pinto Rodrigues; André

Lazarin Gallina

O REGISTRO DE MARCAS NO BRASIL: UM PANORAMA NACIONAL

THE REGISTRY OF BRANDS IN BRAZIL: A NATIONAL PANORAMA - Andréia Camargo; Douglas Kais Da Silva; Julianno Pizzano Ayoub; Cláudia Crisostimo; Paulo Rogério Pinto Rodrigues

USO DA MINERAÇÃO DE DADOS PARA DETECÇÃO DE FATORES QUE INFLUENCIAM O DESEMPENHO DOS ALUNOS NO ENEM

USING DATA MINING TO DETECT FACTORS THAT INFLUENCE STUDENT PERFORMANCE IN ENEM Raphael Magalhães Hoed; Pedro Fábio Saraiva; Lara Fernada Nunes Dourado

OS DESAFIOS DE UM LABORATÓRIO DE ANÁLISES CLÍNICAS PRIVADO EM TRABALHAR COM O SUS: UM CASO DE GESTÃO EM SAÚDE

THE CHALLENGES OF A LABORATORY OF PRIVATE CLINICAL ANALYZES IN WORKING WITH THE SUS: A CASE OF MANAGEMENT IN HEALTH - Clarice Costa Custódio; Beatriz Marcondes De Azevedo; Fred Leite Siqueira Campos; Rolf H. Erdmann

AVALIAÇÃO DOS NÚCLEOS DE INOVAÇÃO (NIT) DO INSTITUTO FEDERAL DO PARANÁ EVALUATION OF INNOVATION CLUSTERS (IC's) OF THE FEDERAL INSTITUTE OF PARANÁ Clayton Pereira De Sá; Guilherme José Alves Turcatel; Paulo R. P. Rodrigues

OS DESAFIOS DA GOVERNANÇA CORPORATIVA NA ERA DA TECNOLOGIA GLOBAL

THE CHALLENGES OF CORPORATE GOVERNANCE IN THE AGE OF GLOBAL TECHNOLOGY - Ligia Kaori Matsumoto Hirano; Luana Lopes De Oliveira; Marianna Konyosi Miyashiro; Paula Massako Bernardes Suda

A LINGUAGEM JURÍDICA COMO PORTA DE ACESSO À JUSTIÇA

LEGAL LANGUAGE AS A DOOR ACCESS TO JUSTICE - Jhônatha Magalhães Silva; Carmen Gean Veras De Meneses 
O IMPACTO DA IMPLEMENTAÇÃO DA FERRAMENTA POWER BI NO ATUAL CENÁRIO CORPORATIVO DE PERNAMBUCO

THE IMPACT OF POWER BI TOOL IMPLEMENTATION ON THE PERNAMBUCO CORPORATE SCENARIO - Marcelo André Esteves Barbosa Júnior, Milena Grasielle Viana Gomes, Thaiane Araújo Dos Santos, Euri Charles Andrade Da Silva

A CONVERSA SOLIDÁRIA PARA PENSAR UMA EDUCAÇÃO EMPREENDEDORA

A CONVERSATION SOLIDARITY TO THINK AN ENTREPRENEURIAL EDUCATION - Giuliana Cavalcanti Vasconcelos, Gabriela Vasconcelos Barbosa

O POTENCIAL MÚLTIPLO DA INTELIGÊNCIA PARA O MUNDO DO TRABALHO NO SÉCULO XXI

THE MULTIPLE POTENTIAL OF INTELLIGENCE FOR THE WORLD WORK IN THE 21ST CENTURY Giuliana Cavalcanti Vasconcelos, Gabriela Vasconcelos Barbosa .....

HISTOPATOLOGIA DE LESÕES ORAIS DECORRENTES DE TERAPIA IMUNOSSUPRESSORA RELACIONADA À TRANSPLANTE DE FÍGADO

HISTOPATHOLOGY OF ORAL INJURIES ARISING FROM IMMUNOSPRESSOR THERAPY RELATED TO LIVER TRANSPLANTATION - Gabriel Ricardo Dionísio Do Nascimento; Maria Eduarda Dias Monteiro Bispo; Luciana Maria Silva De Seixas Maia; Juliana Pinto De Medeiros

GORDURA SATURADA DIETÉTICA E SISTEMA NERVOSO: REVISÃO SISTEMÁTICA DA LITERATURA

DIETARY SATURATED FAT AND NERVOUS SYSTEM: SYSTEMATIC LITERATURE REVIEW - Isabel Michely Da Silva Galvão De Melo; Hericles Cleyton De Jesus Santana; Jeymesson Raphael Cardoso Vieira; Luciana Maria Silva De Seixas Maia

ASPECTOS AGRONÔMICOS EM HÍBRIDOS DE MILHO SUBMETIDOS AO TRATAMENTO DE SEMENTES COM NANOPARTÍCULAS DE COBRE

AGRONOMIC ASPECTS IN CORN HYBRIDS SUBMITTED TO TREATMENT OF COPPER NANOPARTIC Cristiano Reschke Lajús; Gean Lopes Da Luz; Nédio Luiz Verdi; Luciano Luiz Silva

QUALIDADE DE SEMENTES DE MILHO APÓS TRATAMENTO COM NUTRIENTES À BASE DE ZINCO E ARMAZENAMENTO

QUALITY OF CORN SEED AFTER TREATMENT WITH ZINC NUTRIENTS AND STORAGE - Gean Lopes

Da Luz; Cristiano Reschke Lajús; Ana Cristina Lopes; Adriana Cioato Ferrazza

TÉCNICAS DE NUCLEAÇÃO PARA RESTAURAÇÃO DE CERRADO DEGRADADO

NUCLEATION TECHNIQUES FOR RESTORATION OF DEGRADED CERRADO - Gildomar Alves Dos

Santos; David Francis R. P. Burslem; Milton Serpa De Meira Jr

ALGORITMO PARA OTIMIZAR HEURÍSTICO COMPLEXO ENTRE AS TAREFAS

ALGORITHM TO SIMPLIFY HEURISTIC OF COMPLEX PROCESSES BETWEEN TASKS - Koichi Sanoki;

Bráulio Alturas; Isabel Machado Alexandre

CONSTRUINDO MOSAICOS COM O GEOGEBRA: EXPERIMENTAÇÕES E APRENDIZAGENS

BUILDING MOSAICS AS A GEOGEBRA: EXPERIMENTATION AND LEARNING - Náyra Milla Da Silva

Santos; Joilma Silva Carneiro

LINGUAGEM DO PARADIGMA ORIENTADO A NOTIFICAÇÕES: COMPARATIVOS VIA SIMULADOR DE TRÁFEGO

NOTIFICATION ORIENTED PARADIGM LANGUAGE: COMPARISONS THROUGH TRAFFIC SIMULATOR -

Fabio Negrini; Leonardo Faix Pordeus; Robson Ribeiro Linhares; Jean Marcelo Simão 
PARÂMETROS CRÍTICOS NA AVALIAÇÃO GEOMÉTRICA DE VIAS DE TRANSPORTE DE MINA A CÉU ABERTO: UMA ABORDAGEM MULTIVARIADA

CRITICAL PARAMETERS IN THE GEOMETRIC ASSESSMENT OF OPEN PIT MINE HAUL ROADS: A MULTIVARIATE APPROACH - Navarro Torres, V.F; Silveira, L.G.C; Cunha, F.P.; Ayres, J.

UMA ABORDAGEM TEÓRICA E PRÁTICA EM UM PROTOCOLO PARA IOT

A THEORETICAL AND PRACTICAL APPROACH TO AN IOT PROTOCOL - Nepomuceno, César; Chen, Daniel; Lopes, Diego; Albuquerque, Jesus; Neves, Nayra; Soares, André; Valenzuela, Walter

REDES BAYESIANAS APLICADAS A PRIORIZAÇÃO DE TESTE DE SOFTWARE NA ABORDAGEM AADSP

BAYESIAN NETWORKS APPLIED TO SOFTWARE TEST PRIORIZATION - Vitor Souza Silva Santana;

Antonio Carlos Santos Souza .....

SMDCIC - SISTEMA PARA MONITORAMENTO DE DATA CENTERS BASEADO NA INTERNET DAS COISAS

SMDCIC - SYSTEM OF DATA CENTER MONITORING IOT-BASED - Carlos Alicio Andrade Carvalho; Márcio Macedo; Antonio Carlos Dos Santos Souza

CÉLULA SOLAR PRODUZIDA COM CORANTE EXTRAÍDO DA CAPSICUM ANNUUM PRODUCTION

SOLAR CELL WITH DYE EXTRACTED FROM CAPSICUM ANNUUM - Julianno Pizzano Ayoub; Gideã T.

Tractz; Everson P. Banczek; Luana E. N. Korocoski; Paulo R. P. Rodrigues

CONTAMINAÇÃO DE RECURSOS HÍDRICOS DA AMAZÔNIA: ESTUDO DE CASO NA REPRESA DE TUCURUÍ - PA

CONTAMINATION OF AMAZON WATER RESOURCES: A CASE STUDY IN TUCURUÍ DAM - Simone De

Fátima Pinheiro Pereira; Davis Castro Dos Santos; Cléber Silva E Silva; Erivan Sousa Cruz

HISTÓRIA EM QUADRINHOS COMO INSTRUMENTO NA EDUCAÇÃO AMBIENTAL EM REGIÃO IMPACTADA POR AGROTÓXICO

COMICS AS AN INSTRUMENT IN ENVIRONMENTAL EDUCATION IN REGION IMPACTED BY PESTICIDE - Simone De Fátima Pinheiro Pereira; Janilce Lirne Da Silva; Cléber Silva E Silva; Erivan Sousa Cruz

INFLUÊNCIA DA PREPARAÇÃO DO CORANTE N719 EM CÉLULAS SOLARES DE TIO2: UMA ANÁLISE ELETROQUÍMICA

N719 DYE PREPARATION INFLUENCE IN TIO2 SOLAR CELLS: AN ELECTROCHEMICAL ANALYSE Julianno P. Ayoub; Gideã T. Tractz; Everson P. Banczek; Paulo R. P. Rodrigues

PLANO DE ADEQUAÇÃO DAS ESTRUTURAS FÍSICAS DE CALÇADAS DO CENTRO DE SÃO MIGUEL DOS CAMPOS - AL

ADEQUACY PLAN FOR THE PHYSICAL STRUCTURES OF THE SIDEWALKES FRON SÃO MIGUEL DOS CAMPOS DOWNTOWN - Talita Maria Gomes De Morais; Bruna Dos Santos; Geovânia Dos Santos Almeida .

ESTUDO SOBRE TECNOLOGIAS EM VEÍCULOS ELÉTRICOS: UM REVIEW

STUDY ON TECHNOLOGIES IN ELECTRIC VEHICLES: A REVIEW - Felipe Venturini Cavali; Teófilo Miguel De Souza

IMPLEMENTAÇÃO DE UM SISTEMA DE SENSORIAMENTO ULTRASSÔNICO PARA APLICAÇÕES EM IOT NO CONTEXTO DE SMART CITIES

IMPLEMENTATION OF AN ULTRASONIC SENSING SYSTEM FOR IOT APPLICATIONS IN THE SMART CITIES CONTEXT - Coelho, Vinícius; Almeida, Thiago; Pereira, Luis; Santos, Italo; Dinardi, Phellipe;

Vermehren, Victor; Valenzuela, Walter ..... 
CONTROLE DE VIBRAÇÕES EM LAVRA DE MINAS PRÓXIMO A ZONAS URBANAS

MINING VIBRATION CONTROL NEAR URBAN ZONES - Leonardo Chaves; Fabiano Ferreira; Leandro

Silveira; Vidal Torres

REUTILIZAÇÃO DE AREIA DE FUNDIÇÃO ATRAVÉS DA REGENERAÇÃO MECÂNICA: ESTUDO DE CASO EM UMA FUNDIÇÃO LOCALIZADA EM PERNAMBUCO

REUSE OF FOUNDRY SAND THROUGH MECHANICAL REGENERATION: CASE OF A PERNAMBUCO FOUNDRY COMPANY - Thiago H. B. Santana; Guilherme G. S; Ivan B. M. Picchi; Tiago F. A. Santos

SISTEMA TERMICO ASISTIDO DE SECADO DE CAFÉ

COFFEE DRYING ASSISTED THERMAL SYSTEM - Mauricio Hernandez Sarabia; Liliana Delgadillo 176

A REALIDADE DO TRABALHADOR RURAL EXPOSTO AOS AGROTÓXICOS

THE REALITY OF THE RURAL WORKER EXPOSED TO THE AGROCHEMICALS - Jéssica Priscila Da Silva Lima; Talita Maria Gomes De Morais

O PROCESSO DECISÓRIO: A SISTEMATIZAÇÃO DO PROCESSO DECISÓRIO PARA TOMADAS DE DECISÃO MULTICRITÉRIO

THE DECISION-MAKING PROCESS: THE SYSTEMATIZATION OF THE DECISION-MAKING PROCESS FOR MULTIRITHERARY DECISION-MAKING - Manoel Messias Domingos Da Silva; Lesso Benedito Dos Santos 


\section{Área: Interdisciplinar}

\begin{tabular}{|c|c|}
\hline $9-0$ & $\begin{array}{l}\text { A TRANSFERÊNCIA DE TECNOLOGIA DAS ICTS FRENTE AO DECRETO № } \\
9.283 / 2018 \\
\text { ICT'S TECHNOLOGY TRANSFER TO DECREE No. 9.283/2018 } \\
\text { Luana Esteche Nunes Korocoski; Cláudia Crisostimo; Paulo Rogério Pinto Rodrigues; } \\
\text { Julianno Pizzano Ayoub }\end{array}$ \\
\hline $9-0$ & 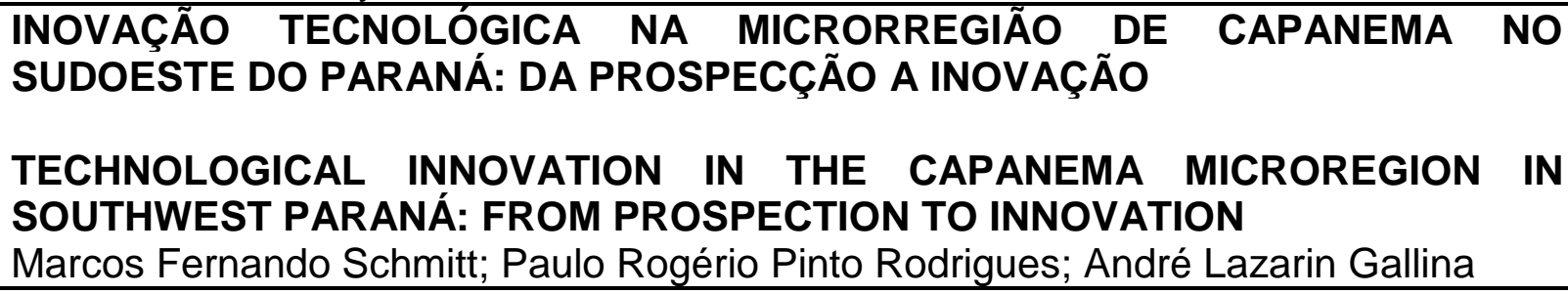 \\
\hline $9-0$ & $\begin{array}{l}\text { O REGISTRO DE MARCAS NO BRASIL: UM PANORAMA NACIONAL } \\
\text { THE REGISTRY OF BRANDS IN BRAZIL: A NATIONAL PANORAMA } \\
\text { Andréia Camargo; Douglas Kais Da Silva; Julianno Pizzano Ayoub; Cláudia } \\
\text { Crisostimo; Paulo Rogério Pinto Rodrigues }\end{array}$ \\
\hline $9-5$ & $\begin{array}{l}\text { USO DA MINERAÇÃO DE DADOS PARA DETECÇÃO DE FATORES QUE } \\
\text { INFLUENCIAM O DESEMPENHO DOS ALUNOS NO ENEM } \\
\text { USING DATA MINING TO DETECT FACTORS THAT INFLUENCE STUDENT } \\
\text { PERFORMANCE IN ENEM } \\
\text { Raphael Magalhães Hoed; Pedro Fábio Saraiva; Lara Fernada Nunes Dourado }\end{array}$ \\
\hline $9-6$ & $\begin{array}{l}\text { OS DESAFIOS DE UM LABORATÓRIO DE ANÁLISES CLÍNICAS PRIVADO EM } \\
\text { TRABALHAR COM O SUS: UM CASO DE GESTÃO EM SAÚDE } \\
\text { THE CHALLENGES OF A LABORATORY OF PRIVATE CLINICAL ANALYZES IN } \\
\text { WORKING WITH THE SUS: A CASE OF MANAGEMENT IN HEALTH } \\
\text { Clarice Costa Custódio; Beatriz Marcondes De Azevedo; Fred Leite Siqueira } \\
\text { Campos; Rolf H. Erdmann }\end{array}$ \\
\hline $9-8$ & $\begin{array}{l}\text { AVALIAÇÃO DOS NÚCLEOS DE INOVAÇÃO (NIT) DO INSTITUTO FEDERAL DO } \\
\text { PARANÂ } \\
\text { EVALUATION OF INNOVATION CLUSTERS (IC's) OF THE FEDERAL INSTITUTE } \\
\text { OF PARANÁ } \\
\text { Clayton Pereira De Sá; Guilherme José Alves Turcatel; Paulo R. P. Rodrigues }\end{array}$ \\
\hline
\end{tabular}




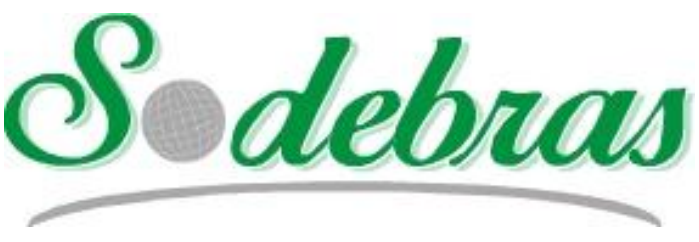

Volume 15 - $\mathrm{N}^{\mathrm{o}} 169$ - Janeiro / 2020

XLI International Sodebras Congress

31 de outubro a 02 de novembro de 2019 - Maceió - AL.

\title{
A TRANSFERÊNCIA DE TECNOLOGIA DAS ICTs FRENTE AO DECRETO $\mathrm{N}^{\circ}$ 9.283/2018
}

\section{ICT'S TECHNOLOGY TRANSFER TO DECREE No. 9.283/2018}

\author{
LUANA ESTECHE NUNES KOROCOSKI'; CLÁUDIA CRISOSTIMO ${ }^{1}$; PAULO ROGÉRIO PINTO \\ RODRIGUES $^{1}$; JULIANNO PIZZANO AYOUB ${ }^{1}$ \\ 1 - UNIVERSIDADE ESTADUAL DO CENTRO OESTE; \\ luanaesteche@yahoo.com.br; crisostimoadv@gmail.com; prprodrigues@gmail.com; juliannopa@hotmail.com
}

\begin{abstract}
Resumo -A Lei $n^{o}$ 13.243/2016, que alterou artigos da Lei $n^{o}$ 10.973, de 2004, bem como instituiu o Marco Legal da Ciência, Tecnologia e Inovação, possuía dispositivos carentes de regulamentação. Por intermédio do Decreto Federal $n^{o}$ 9.283/2018, supriu-se lacunas e conceituou-se dispositivos necessários para o emprego da legislação inaugurada, com o fim de alcançar a autonomia tecnológica $e$ desenvolvimento do sistema produtivo nacional. Dentre os institutos jurídicos tratados pelo decreto regulamentador, encontra-se regras de transferência de tecnologia entre as ICTs e iniciativa privada, bem como requisitos essenciais do extrato da oferta tecnológica e requisitos mínimos para participação do interessado.
\end{abstract}

Palavras-chave: 1. Transferência de Tecnologia 2. ICT 3. Lei de Inovação

Abstract - Law No. 13,243 / 2016, which amended articles of Law No. 10,973 of 2004, as well as instituted the Legal Framework for Science, Technology and Innovation, had provisions that lack regulation. Through Federal Decree No. 9,283 / 2018, gaps were filled and the necessary devices were conceptualized for the use of the inaugurated legislation, in order to achieve technological autonomy and development of the national productive system. Among the legal institutes dealt with by the regulatory decree, there are technology transfer rules between the ICT's and the private initiative, as well as essential requirements of the technology offer extract and minimum requirements for the participation of the interested party.

Keywords: 1. Technology Transfer 2. ICT 3. Innovation Law

\section{INTRODUÇÃO}

A Lei $n^{\circ} 13.243 / 2016$, alterou artigos da Lei $n^{\circ} 10.973$, de 2004, bem como instituiu o Marco Legal da Ciência, Tecnologia e Inovação, que possuía dispositivos carentes de regulamentação para sua aplicação. A regulamentação necessária se deu através do Decreto Federal nº 9.283/2018, sendo medida essencial para o alcance da autonomia tecnológica e apoio ao desenvolvimento do sistema produtivo nacional.

O Decreto Regulamentador foi dividido em dez capítulos, trazendo novos conceitos, medidas de estímulo à construção de ambientes especializados de inovação, estímulo à participação de instituições científicas e tecnológicas no processo de inovação, estimulo à inovação nas empresas, instrumentos jurídicos de parceria, alterações orçamentárias, prestação de contas, contratação de produtos para pesquisa e desenvolvimento e importação.

As Universidades atuam como vetor do desenvolvimento econômico e social, na medida de que o conhecimento científico $\mathrm{e}$ as pesquisas induzem a transformação da sociedade. São consideradas como um dos maiores celeiros de inovação, posto possuir diversos pesquisadores e linhas de pesquisas variadas, gerando o desenvolvimento de produtos, serviços e tecnologias inovadoras. É apenas mediante uma parceria entre empresa, universidade, governo e sociedade que possibilitará que as pesquisas realizadas saiam do âmbito acadêmico e alcancem a sociedade. (AGUSTINHO; GARCIA,2018)

Dados publicados pelo Instituto Nacional de Propriedade Industrial, refletem os indicadores de Propriedade Industrial no ano de 2017 e demonstram que as Universidades ocupam nove de dez posições entre as entidades que mais depositam patentes no Brasil. Sendo considerada como uma das maiores geradoras de produtos e processos inovadores e, por consequência detentora dos direitos parciais ou integrais da propriedade intelectual dos produtos desenvolvidos.

Não podemos olvidar que a transferência de tecnologia desempenha papel de suma importância no desenvolvimento tecnológico e sustentável da iniciativa privada, bem como das Universidades, sendo um elo entre empresa que necessita manter a competitividade global e universidade/instituição de pesquisa que precisa subsidiar suas pesquisas. (ROMAN; LOPES, 2012).

A implantação de inovação mediante compra de tecnologia desenvolvida nas universidades tem se tornado um atrativo para empresas privadas, diante do alto custo de investimento em capital intelectual, laboratórios e pesquisas, o que tornaria inviável o desenvolvimento de tecnologia de forma isolada.

Pesquisas desenvolvidas no âmbito da academia quando aplicadas diretamente ao setor produtivo, geram ganhos competitivos para as empresas, as quais conseguem transformar o conhecimento científico desenvolvido em inovações industriais. (CHIARINI; RAPINI; VIEIRA, 2014)

As parcerias realizadas entre a iniciativa privada com universidades e instituições de pesquisas são usualmente seladas mediante a transferência da tecnologia, que representa um elo entre a empresa, que necessita ser subsidiada para manter a competitividade global, e a 
universidade (ou instituição de pesquisa), detentora e promotora de conhecimento. (DIAS; PORTO, 2013)

Segundo Roger (2001, apud Carvalho e Cunha 2013), transferência de tecnologia é definida como "a movimentação da inovação tecnológica de uma organização de P\&D para uma organização receptora", como uma forma de colocar na prática estudos e projetos desenvolvidos no âmbito acadêmico.

Questões burocráticas dificultavam a transferência ou licenciamento da tecnologia produzida pelas ICTs, o que atrasa o desenvolvimento industrial e por consequência o nacional.

Este artigo tem como escopo analisar a transferência de tecnologia entre as Instituições de Ciência e Tecnologia e a iniciativa privada, frente ao Decreto Regulamentador $\mathrm{n}^{\mathrm{o}}$ $9.283 / 2018$, bem como os avanços alcançados e seus reflexos.

\section{METODOLOGIA}

A metodologia utilizada no presente artigo parte de uma abordagem qualitativa, mediante a análise de fontes primárias como as disposições trazidas pelo Decreto Lei $\mathrm{n}^{\circ}$ 9.283/2018, em especial aos artigos que dispõe sobre transferência de tecnologia.

De forma complementar realiza-se uma pesquisa de dados obtidos através de fontes de informações secundárias, de forma qualitativa, mediante a análise de artigos, revistas e livros já publicados.

A análise bibliográfica se deu mediante a busca de artigos e publicações científicas a respeito das Universidades como geradores de tecnologia, integração Universidade-Empresa e transferência de tecnologia.

Como uma segunda etapa, buscou-se analisar o Decreto Lei $\mathrm{n}^{\circ} 9.283 / 2018$ e suas consequências para a transferência de tecnologia e efeitos jurídicos.

A conclusão compreendeu uma compilação dos dados levantados nas mais diversas fontes mencionadas, analisando de uma forma descritiva e avaliativa a respeito do processo de Transferência de Tecnologia por parte das ICTs.

\section{RESULTADOS}

A Lei $n^{\circ} 10.973 / 2004$, com alterações trazidas pela Lei $\mathrm{n}^{\mathrm{o}} 13.243 / 2016$, prevê em seu art. $6^{\circ}$ a possibilidade de transferência da tecnologia por ela produzida de forma isolada ou por meio de parceria.

$\mathrm{O}$ art. $9^{\circ}$ da Lei $\mathrm{n}^{\mathrm{o}} 10.973 / 2004$, assegura a possibilidade das ICTs em celebrar acordos com instituições públicas e privadas para a realização de atividades de pesquisa científica e tecnológica, bem como desenvolvimento de tecnologia, produto e serviço. ${ }^{1} \mathrm{O}$ intercâmbio de informações, profissionais, experiências e know how entre entidades públicas e privadas enriquecem o processo de desenvolvimento da tecnologia, bem como fortalece a hélice tripla, mediante interação entre EstadoUniversidade e iniciativa privada.

\footnotetext{
${ }^{1}$ Art. $9^{\circ}$ É facultado à ICT celebrar acordos de parceria com instituições públicas e privadas para realização de atividades conjuntas de pesquisa científica e tecnológica e de desenvolvimento de tecnologia, produto, serviço ou processo. (Redação pela Lei $\mathrm{n}^{\circ}$ 13.243, de 2016).
}

Apesar da Lei no 10.973/2004 prever a possibilidade de realização de parceria público-privada para o desenvolvimento da tecnologia, não existia qualquer conceito normativo que esclarecesse o significado de tecnologia desenvolvida de forma isolada e ou em parceria.

O Decreto Regulamentador, no art.12 supriu a lacuna conceitual quanto ao termo, definindo "tecnologia em parceria", o que é essencial para melhor compreensão e aplicação do instituto:

Art. 12. A realização de licitação em contratação realizada por ICT ou por agência de fomento para a transferência de tecnologia e para o licenciamento de direito de uso ou de exploração de criação protegida é dispensável.

$\S 3^{\circ}$ Para os fins do disposto no $\S 1^{\circ}$-A do art. $6^{\circ}$ da Lei $\mathrm{n}^{\circ}$ 10.973, de 2004, considera-se desenvolvimento conjunto as criações e as inovações resultantes de parcerias entre ICT ou entre ICT e empresa, incluídas as incubadas oriundas de programa de empreendedorismo da ICT.

Para os fins do art. 12, do Decreto Lei $n^{\circ}$ 9.283/2018, para que uma tecnologia seja desenvolvida mediante parceria, deve haver como autores duas ICTs, uma ICT e empresa e/ou ICT e incubadora.

Não menos importante do que a definição de tecnologia de inovação desenvolvida de forma isolada ou em parceria é a previsão e definição do instrumento jurídico apto a regulamentar a relação jurídica estabelecida.

A Lei n ${ }^{0} 10.973 / 2004$, e suas alterações, não previa de forma específica quais eram os instrumentos jurídicos aptos a regulamentar as parcerias realizadas. $\mathrm{O}$ capítulo $\mathrm{V}$ do Decreto Lei $\mathrm{n}^{\mathrm{o}} 9.283 / 2018$, não apenas previu os instrumentos jurídicos, como também os conceituou, estabeleceu requisitos e demais disposições a eles inerentes.

Dessa forma, são instrumentos aptos a regular as relações público-privada os acordos de parceria para pesquisa, desenvolvimento e inovação, termo de convênio para pesquisa, desenvolvimento e inovação e termo de outorga, os quais, mediante análise simplificada, devem regular os termos do contrato estabelecido, juntamente com a participação nos resultados da exploração comercial das criações resultantes da parceria.

O processo de transferência de tecnologia oriunda de ICT, apesar de legalmente previsto era lacunoso, na medida de que não estavam presentes instrumentos de contratação e gestão da tecnologia, sendo omisso ainda quanto a questões essenciais para o relacionamento Universidade-iniciativa privada.

Para Benevides Júnior et al (2019), o Decreto $\mathrm{n}^{\circ}$ 9.283/2018, mesmo trazendo diretrizes para a transferência de tecnologia, não apresenta uma definição expressa de contratos de transferência de tecnologia:

O Decreto No. 9.283/2018 que regula o Novo Marco Legal de CT\&I (Lei 13. 243/2016), o qual dispõe sobre estímulos ao desenvolvimento científico, à pesquisa, à capacitação científica e tecnológica e à inovação, estabelece diretrizes para a transferência de tecnologia, disposto no Capítulo III, Seção 1. Observa-se que não se apresenta uma definição de contratos de transferência de tecnologia, bem como dos tipos de contratos. Fica 
evidente apenas as formas de transferência de tecnologia ao longo do dispositivo, sendo elas: transferência de tecnologia, licenciamento para outorga de direito de uso ou de exploração e cessão dos direitos.

Como forma de supressão da lacuna existente o autor utiliza-se para construção do conceito do contrato de transferência de tecnologia a conjugação dos conceitos de cada palavra de forma isolada, ou seja, as palavras contrato, transferência e tecnologia, restando da seguinte forma:

Contrato - É o acordo estabelecido entre duas ou mais partes para constituir, regular ou extinguir uma relação jurídico- patrimonial.

Transferência - É a transmissão de direitos patrimoniais sobre bens imateriais juridicamente protegidos.

Tecnologia - É um bem imaterial com valor econômico (patrimonial), juridicamente protegido. Podendo ter um ou mais titulares. (Benevides Júnior et al, 2019)

Nos âmbitos das ICTs, a gestão de inovação restou a cargo dos Núcleos de Inovação Tecnológica, os quais possuem competência expressa por intermédio do art. 16 da Lei $\mathrm{n}^{\circ} \quad 10.973 / 2004$ com suas devidas alterações, estabelecendo como função precípua do NIT zelar pela manutenção da política institucional de estímulo à proteção das criações, licenciamento, inovação e outras formas de transferência de tecnologia, bem como negociar e gerir os acordos de transferência de tecnologia oriunda da ICT.

Com o advento do Decreto Lei $\mathrm{n}^{\circ}$ 9.283/2018 as ICTs ganharam voz ativa no processo de transferência de tecnologia, sob gestão do NIT. Para que haja a transferência da tecnologia entre ICT e o criador, a título não oneroso, este deverá manifestar-se por escrito junto à autoridade máxima da Instituição, a qual determinará a instauração de procedimento administrativo, submetendo à apreciação do NIT. A decisão do pedido realizado fica a cargo da ICT, o que deverá ocorrer no prazo de seis meses, com a oitiva do NIT, agora como órgão consultor. ${ }^{2}$

Na hipótese enunciada, considera-se como criador a pessoa física que seja inventora, obtentora ou autora de criação, podendo estes serem empregados ou não das ICTs, servidores ou prestadores de serviço.

${ }^{2}$ Art. 13. A ICT pública poderá ceder os seus direitos sobre a criação, por meio de manifestação expressa e motivada e a título não oneroso, ao criador, para que os exerça em seu próprio nome e sob a sua inteira responsabilidade, ou a terceiro, mediante remuneração, nas hipóteses e nas condições definidas na sua política de inovação e nas normas da ICT pública, nos termos da legislação pertinente. $\S 1^{\circ} \mathrm{O}$ criador que se interessar pela cessão dos direitos da criação encaminhará solicitação ao órgão ou à autoridade máxima da instituição, que determinará a instauração de procedimento e submeterá a solicitação à apreciação do Núcleo de Inovação Tecnológica - NIT. $\S 2^{\circ}$ A ICT pública decidirá expressamente sobre a cessão dos direitos de que trata o caput no prazo de seis meses, contado da data do recebimento da solicitação de cessão feita pelo criador, ouvido o NIT. $\S 3^{\circ}$ A cessão a terceiro mediante remuneração de que trata o caput será precedida de ampla publicidade no sítio eletrônico oficial da ICT pública, na forma estabelecida em sua política de inovação.
Cabe destacar que os instrumentos jurídicos estabelecidos no Decreto, além de reafirmar as alterações realizadas pela Lei $\mathrm{n}^{\circ} 13.243 / 2016$, permite que as ICT ceda ao parceiro privado, mediante compensação financeira ou não, os direitos de propriedade intelectual, desde que economicamente mensurável, inclusive quanto ao licenciamento da criação à administração pública sem o pagamento de royalty ou de outro tipo de remuneração, em matéria de interesse público $\left(\operatorname{art} .30, \S 1^{\circ}\right)$.

A condição de desburocratização na transferência de tecnologia também foi tratada pelo Decreto Regulamentador $\mathrm{n}^{\circ}$ 9.283/2018 que, de forma expressa no art. 12, prevê a condição de dispensabilidade de licitação na hipótese de contratação realizada por ICT ou agência de fomento para transferência de tecnologia, mantendo-se apenas a necessidade de publicação do extrato da oferta tecnológica em sítio eletrônico oficial da ICT, em caso de exclusividade, conforme art. $6^{\circ}, \S 1^{\circ}$ da Lei $n^{\circ} 10.973 / 2004$, desde que a transferência seja referente ao direito de uso ou de exploração da criação protegida. Para tanto, o Decreto Regulamentador, estabeleceu os requisitos mínimos presentes no extrato da oferta tecnológica, bem como definiu conceitualmente criações e inovações conjuntas.

$\mathrm{O}$ art. $12, \S 4^{\circ}$ do Decreto Federal, estabelece como conteúdo essencial de uma oferta tecnológica: o tipo, o nome e a descrição resumida da criação e da oferta; modalidade da oferta a ser adotada. De forma complementar, o art.12, §5 $5^{\circ}$ impôs requisitos de participação de terceiros interessados na oferta, devendo eles comprovarem sua regularidade jurídica e fiscal, bem como qualificação técnica e econômica para exploração da inovação. Expressamente dispões que os critérios e as condições para a escolha da contratação mais vantajosa serão estabelecidos de acordo com a política de inovação da ICT pública.

$\mathrm{Na}$ transferência do direito de uso e exploração de criação protegida, sem cláusula de exclusividade, os contratos previstos poderão ser celebrados de forma direta, ou seja, sem dispensa licitação nem publicação da oferta tecnológica, demonstrando a simplificação de processos.

Nota-se que o Decreto Regulamentador trouxe ao instituto da transferência de tecnologia entre ICT e iniciativa pública e ou privada, metodologias simplificadoras do processo, estabelecendo quais objetos são passíveis de transferência, conferindo ainda maior segurança jurídica por ocasião da definição dos institutos jurídicos aplicáveis, bem como suas disposições essenciais.

\section{CONCLUSÃO}

O desenvolvimento do presente estudo possibilitou uma análise dos dispositivos trazidos pelo Decreto Regulamentador $\mathrm{n}^{\circ}$, no que se refere a transferência de tecnologia entre ICT e iniciativa privada.

Apesar da Lei $\mathrm{n}^{\mathrm{o}} 10.973 / 2004$, com alterações realizadas pela Lei ${ }^{\circ} 13.243 / 2016$, prever a possibilidade de transferência de tecnologia por parte da ICT, seu instituto necessitava de regulamentação. $\mathrm{O}$ Decreto $\mathrm{n}^{\circ}$ 9.283/2018, veio para suprir lacunas legislativas, simplificando a relação entre as Universidades e a iniciativa privada.

$\mathrm{O}$ estudo realizado demonstrou o protagonismo das Universidades no desenvolvimento científico, posto ser 
atualmente os maiores depositantes de patentes no Brasil, de produtos e processos inovadores.

Por intermédio da transferência da tecnologia ou do desenvolvimento conjunto de novas tecnologias, as empresas poderão almejar maior desenvolvimento tecnológico e competitividade no mercado nacional ou mundial como oportunidade. A transferência de tecnologia entre as Universidades e a inciativa privada visa reduzir os custos para o desenvolvimento de tecnologia, posto dispensar a necessidade de investimentos em laboratórios e capital intelectual nas empresas.

O Decreto Regulamentador conceituou termos como criações e inovações conjuntas, estabelecendo os requisitos mínimos do extrato da oferta tecnológica, bem como simplificou processos de transferência de tecnologia, deixando, entretanto, de definir o conceito de contrato de transferência de tecnologia, a partir de suas especificidades.

Apesar disso, o Decreto Federal $n^{\circ}$ 9.283/2018 estabeleceu os instrumentos jurídicos aptos a regular as relações público-privada, trazendo maior segurança e clareza nas relações estabelecidas, buscando ainda reduzir processos burocráticos.

A facilitação na transferência da tecnologia produzida, fomenta o desenvolvimento tecnológico, sendo a transferência de tecnologia utilizada como um elo de ligação entre pesquisa e desenvolvimento econômico.

\section{REFERÊNCIAS BIBLIOGRÁFICAS}

AGUSTINHO, E.; GARCIA, E. Inovação, transferência de tecnologia e cooperação. Direito e Desenvolvimento, v. 9, n. 1, p. 223-239, jul. 2018.

BENEVIDES JÚNIOR, Acursio Ypiranga, et al. Os contratos de transferência de tecnologia no novo marco legal da inovação: análise primária para políticas de inovação em ICTS. Revista de Propriedade Intelectual - Direito Contemporâneo e Constituição, Aracaju/Se, Ano VIII, Volume $13 \mathrm{n}^{\mathrm{o}}$ 03, p.001 a 021 Out/2019. Disponível em: http://dx.doi.org/10.16928/2316-8080.V13N2p.01-21, acessado em 22/09/2019.

BRASIL. Lei no 10.973, de 2 de dezembro de 2004. Disponível

http://www.planalto.gov.br/ccivil 03/ ato2004-

2006/2004/lei/110.973.htm, acessado em 04/02/2019.

BRASIL. DECRETO No 9.283, DE 7 DE FEVEREIRO DE 2018. Disponível

http://www.planalto.gov.br/ccivil_03/_ato2015-

2018/2018/decreto/d9283.htm, acessado em 04/02/2019.

CARVALHO, Vivian; VIANA, Neila Conceição. Proposta de um modelo de transferência de tecnologia para as universidades públicas brasileiras. Disponível em: http://www.altec2013.org/programme_pdf/384.pdf, acessado em 22/09/2019.

CHIARINI, Tulio; RAPINI, Márcia Siqueira; VIEIRA, Karina Pereira. Produção de novos conhecimentos nas universidades federais e as políticas públicas brasileiras recentes de CT\&I. Revista Economia \& Tecnologia, v. 10, n. 3, 2014.
DIAS, Alexandre Aparecido; PORTO, Geciane Silveira. Gestão de transferência de tecnologia na Inova Unicamp. Revista de Administração Contemporânea, v. 17, n. 3, p. 263-284, 2013.

DIAS, Alexandre Aparecido; PORTO, Geciane Silva. Como a USP transfere tecnologia? Revista Organizações \& Sociedade. Salvador, v. 21, n. 70, p. 489-507, Setembro $2014 . \quad$ Disponível em http://www.scielo.br/scielo.php?script=sci_arttext\&pid=S19 84-92302014000300008. Acesso em set/2019.

INPI, Instituto Nacional da Propriedade Industrial. Indicadores de Propriedade Industrial 2017. Marina Filgueiras Jorge, Felipe Veiga Lopes, Vívian Íris Barcelos, Fernando Linhares de Assis, Gustavo Travassos, Vicente Freitas, Ana Claudia Nonato, Vitória Orinde Sergio Paulino de Carvalho. Rio de Janeiro: INPI, 2017.

LOPES, Marco Túlio de Paula; ROMAN, Vinícius Bortolussi. Importância da Transferência de Tecnologia Realizada nas Universidades Brasileiras para a Alavancagem da Competitividade do País no Cenário Econômico Mundial. Revista Iberoamericana de Engenharia Industrial, Brasil, v. 4, n. 1, p. 111-124.

\section{COPYRIGHT}

Direitos autorais: $\mathrm{O}(\mathrm{s})$ autor(es) é(são) o(s) único(s) responsável(is) pelo material incluído no artigo. 


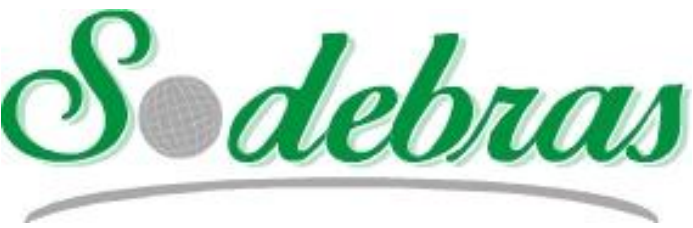

Volume 15 - $\mathrm{N}^{\mathrm{o}} 169$ - Janeiro / 2020

XLI International Sodebras Congress

31 de outubro a 02 de novembro de 2019 - Maceió - AL.

\title{
INOVAÇÃO TECNOLÓGICA NA MICRORREGIÃO DE CAPANEMA NO SUDOESTE DO PARANÁ: DA PROSPECÇÃO A INOVAÇÃO
}

\section{TECHNOLOGICAL INNOVATION IN THE CAPANEMA MICROREGION IN SOUTHWEST PARANÁ: FROM PROSPECTION TO INNOVATION}

\author{
MARCOS FERNANDO SCHMITT ${ }^{1,3}$, PAULO ROGÉRIO PINTO RODRIGUES ${ }^{1}$; ANDRÉ LAZARIN \\ GALLINA $^{1,2}$ \\ 1 - UNIVERSIDADE ESTADUAL DO CENTRO OESTE - UNICENTRO; 2 - UNIVERSIDADE \\ FEDERAL DA FRONTEIRA SUL - UFFS; 3 - INSTITUTO FEDERAL DO PARANÁ - IFPR \\ marcos.mfs@msn.com; prprodrigues@gmail.com; andregallina@gmial.com
}

\begin{abstract}
Resumo - Um dos grandes desafios das Instituições de Ensino, principalmente em regiões mais distantes dos grandes centros, é de tentar interagir o setor produtivo local com o de pesquisa, extensão e inovação ligados ao sistema educacional. Aliar conhecimentos tecnológicos ao cotidiano da comunidade é essencial, de modo que, o atrelamento das inovações em processos, produtos e equipamentos contribuem para alavancar economicamente o setor. Este trabalho promoveu um conjunto de eventos extensionistas tecnológicos, onde o setor produtivo pode levar a demanda aos pesquisadores. Registradas as demandas $e$, uma vez escolhido o processo elou o produto a ser desenvolvido, foram realizadas pesquisas do estado da arte sobre o assunto $e$ averiguado se a demanda solicitada $e$ o processo a ser desenvolvido eram ou não um ato inventivo (PI). Um dos eventos gerou a demanda de um produto de baixo custo que fora desenvolvido para auxiliar na ventilação de aviários.
\end{abstract}

Palavras-chave: Setor produtivo. Eventos. Agricultura.

\begin{abstract}
The great challenge of educational institutions, especially in the most distant regions of the major educational centers, are more attractive for research, extension and innovation to the educational system and systems that would leverage the sector economically. This work promoted a set of technological extensionist events, where the productive sector had a demand to the researchers. Registered as a demand and a decision process and / or a developed product, while market-state research was carried out and ascertained in a demand demanded and the process of being developed was an inventive act (PI). One of the events generated a demand for a low-cost product for the development of emergency assistance.
\end{abstract}

Keywords: Productive sector. Events. Agriculture.

\section{INTRODUÇÃO}

Segundo o Instituto Paranaense de Desenvolvimento Econômico e Social - IPARDES (2009), na região Sudoeste do Paraná, a grande maioria da renda está relacionada às atividades fins ou, de forma indireta, ao agronegócio, mais precisamente, às agroindústrias e a outras atividades relacionadas à agricultura familiar). Ao considerar essa particularidade, torna-se relevante uma instituição de ensino voltar seus esforços para conciliar a inovação tecnológica com a vocação regional.

Todavia, um dos grandes problemas enfrentados pelas instituições de ensino superior - incluindo os institutos federais e outras instituições de pesquisa - é a interação com o setor produtivo local, pois as pesquisas são comumente desenvolvidas, principalmente, com foco na área de atuação do docente/pesquisador e não nos arranjos produtivos locais.

Para tanto, torna-se importante conhecer os arranjos e as demandas dos setores produtivos locais, em especial, as demandas de tecnologia e/ou inovações voltadas à agricultura ou à agroindústria, através de apresentação de gargalos pela comunidade, com intuito de desenvolver projetos que possam auxiliar o produtor em suas práticas e para que os estudantes possam propor soluções a tais problemas, como a ventilação de aviários, por exemplo; além disso, ampliar os estudos sobre tais demandas, torna-se relevante como estratégia para a inovação voltada ao desenvolvimento de tecnologias agroindustriais de forma a impulsionar o conhecimento gerado pelos estudantes promovendo inovação educacional. Inclusive, é possível, avaliar esse procedimento como método de ensino e geração de conhecimentos baseados na resolução de problemas.

A relação entre a prática das famílias e a aprendizagem transformadora tem como propósito a construção de sentidos, pois, como bem lembra Pedro Demo (2007), é importante a valorização do conhecimento popular em pesquisas em que se propõe a autonomia dos sujeitos, destacando que os envolvidos devem ter claro o fato de que, assim como a comunidade não tem todas as respostas, os pesquisadores também não, deste modo, deve-se reconhecer a relevância, não apenas do conhecimento científico, mas também do conhecimento popular, pois estes não são concorrentes, apenas complementares. Em consonância, Meyer et al. defendem que:

\begin{abstract}
“[...] a intencionalidade de construir estratégias educativas que permitam investir em possibilidades de transformação das condições de vida, nas quais crenças, hábitos e comportamentos ganham sentido, demanda aprender, compreender e dialogar com a multiplicidade de aspectos que modulam as crenças, os hábitos e os comportamentos dos indivíduos e grupos com os quais interagimos (MEYER et al. 2006, p. 1340)."
\end{abstract}

Esse envolvimento, além de proporcionar a interação e a troca de saberes, favorece, inclusive, o fortalecimento dos envolvidos como sujeitos sociais e a tomada de consciência, 
pois, ao interagir com os pesquisadores e com outras pessoas que vivenciam situações semelhantes, as representações desses sujeitos são reconhecidas ou transformadas.

O conjunto de eventos e de atividades propostas nos encontros entre comunidade e escola promoveu a introdução da inovação tecnológica no IFPR Campus Capanema, assim como na região em que está inserido. A ação de colocar a tecnologia presente na vida da comunidade foi proporcionada utilizando-se de algumas técnicas de prospecção tecnológica na interação e integração dos pesquisadores com o setor produtivo. Através do evento IFAgroTECH, por exemplo, realizou-se a aplicação desta metodologia, sendo possível também trazer a inovação para a comunidade agrícola, por meio da qual, docentes e alunos do ensino médio do IFPR Capanema, conseguiram, em conjunto com a comunidade, aperfeiçoar e implementar uma solução, barata e sustentável, para um dos gargalos encontrados e relatados na avicultura da região - a ventilação inteligente dos aviários.

\section{METODOLOGIA}

O produto foi desenvolvido após o levantamento de requisitos por meio dos eventos realizados pelo IFPR, destacando um evento em especial, o qual envolveu e interagiu com o principal setor produtivo da microrregião a avicultura, atrelando revisões bibliográficas específicas do setor agrícola com pesquisas e levantamentos sobre o estado da arte, por meio de buscas em bancos de dados de depósitos de patentes, principalmente INPI e USPTO, e em periódicos, como Capes e Scielo, por exemplo.

Com o desenvolvimento de um conjunto de eventos, a interação entre o setor produtivo, alunos e professores pesquisadores foi possível, principalmente ao considerar que os eventos tinham um fluxo determinado pela equipe de planejamento, demonstrado na figura abaixo:

Figura 1 - Fluxograma dos eventos

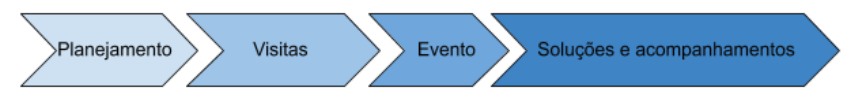

Fonte: Arquivo pessoal do autor (2019).

A base fundamental da metodologia foi pautada no diálogo entre microprodutores, agricultores familiares e proprietários das agroindústrias com estudantes e professores, visando o levantamento dos problemas enfrentados no processo de produção agrícola e sua reflexão coletiva. Os agricultores familiares apresentaram para alunos e professores suas atividades de subsistência, apontaram seus principais problemas e suas carências na área de tecnologias e, a partir deste diálogo, definiram com mais clareza os gargalos tecnológicos e as possíveis soluções.

Em suma, o processo foi, e é, construído para facilitar a interação e a integração da instituição de ensino com o setor produtivo local, considerando que o conjunto de eventos desenvolvidos instigam a prospecção tecnológica através de entrevistas, palestras, e apresentações das demandas com os participantes. Após essa etapa, o estado da arte de cada um dos problemas é investigado nas pesquisas para buscar soluções inovadoras já existentes ou perceber a oportunidade de criação de uma invenção através da solução apontada, bem como, se esta apresenta os requisitos de patenteabilidade, ou seja, se ela pode se tornar realmente um ato inventivo e posteriormente depositada como uma patente industrial (PI).

\section{RESULTADOS}

A principal questão abordada foi como introduzir a inovação tecnológica em uma microrregião pouco desenvolvida tecnologicamente, através de uma instituição de ensino pública, empregando a prospecção tecnológica na interação entre essa instituição e o setor produtivo? É importante ressaltar que o estímulo e o fomento dos profissionais envolvidos foram necessários e de extrema importância, pois a interação entre os professores (pesquisadores), alunos e representantes do setor produtivo é o ponto-chave para que a aprendizagem e a transformação ocorram. Levar em consideração que, situações que podem ser corriqueiras para as empresas e para os produtores como o acionamento manual do sistema de ventilação dos aviários - podem ser transformadas em pequenas, ou mesmo, grandes inovações com o auxílio de profissionais e estudiosos da área.

Para tanto, o ponto inicial é empregar ferramentas de inovação, englobando o ensino e a prospecção aos professores e alunos, principalmente em um ambiente em que isso possa ser uma novidade. Depois de conhecer os gargalos, a inovação tecnológica - mesmo que em um nível básico - foi levada ao conhecimento do setor produtivo, através de eventos realizados que levassem à prospecção tecnológica considerando os arranjos produtivos locais. Foram seis eventos, entre o segundo semestre de 2016 e o primeiro semestre de 2019, envolvendo mais de 300 alunos, 30 professores/pesquisadores e 50 empresas e representantes do setor produtivo, além das autoridades públicas que apoiaram a realização de cada um deles.

Ressalta-se, então, que, embasado na sugestão de que a construção coletiva é a melhor forma de resolver alguns anseios e problemas encontrados na comunidade escolar, interna e externa, alguns eventos foram chaves $e$ importantíssimos para os resultados alcançados.

Tratam-se especificamente da Feira de Inovação Tecnológica do IFPR (IFTECH) e do Workshop de Tecnologias Agroindustriais (IFAgroTECH).

É importante observar que as dificuldades encontradas na primeira feira, não se repetiram nas outras edições, pois este evento foi realizado em todos os anos, sequencialmente a 2016, com a previsão também de realização da $4^{\text {a }}$ edição registrada em calendário para o ano de 2019. Observou-se, inclusive, um aumento gradativo de projetos, ou esboços, apresentados pelos discentes, conforme apresenta a Figura 2 , que demonstra o quantitativo de projetos apresentados pelos alunos nos anos de 2016, 2017 e 2018.

O aumento de alunos que ingressaram no IFPR Campus Capanema pode ser encarado como um fator que tenha contribuído para o crescente número de projetos, mas, ressalta-se que as feiras tornaram-se mais conhecidas, inclusive pela comunidade externa, uma vez que, conforme foram demonstrando resultados, os projetos passaram a ser analisados por profissionais das mais diversas áreas e setores da sociedade, inclusive com profissionais ligados ao setor produtivo local. 
Figura 2 - Projetos sobre inovação apresentados no IFTECH do Campus Capanema do IFPR

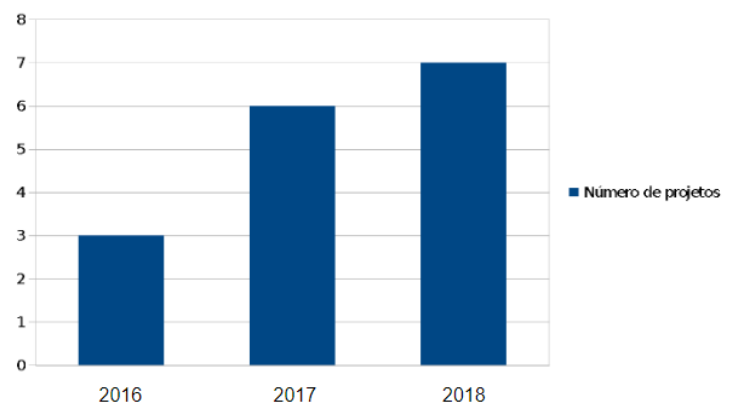

Fonte: Autor (2019).

Já como resultado da primeira edição do IFAgroTECH, na sequência das atividades propostas, houve uma videoconferência sobre sugestões e propostas de projetos. Nesta ocasião, desenvolveu-se um brainstorming sobre possíveis projetos, discutindo objetivos, breve descrição da problemática e propostas de solução e recursos necessários.

Dando seguimento às atividades, selecionaram-se as propostas viáveis para a pesquisa, conforme descrições a seguir, considerando as demandas apontadas pelos representantes dos setores produtivos envolvidos.

\section{- Problemática 1:}

Objetivo: Prover uma ventilação automática do aviário;

Descrição: Para manter o aviário em uma temperatura adequada, quanto o ambiente alcançar acima de 26 graus, o proprietário aciona manualmente um ou mais ventiladores;

Proposta de Solução: Desenvolver em um equipamento que, ao alcançar a temperatura de 26 graus, acione automaticamente o exaustor. Quando a temperatura baixar de 26 graus o sistema desliga automaticamente;

Recursos Necessários: Placas, sensor de temperatura, dispositivos de acionamento.

\section{- Problemática 2:}

Objetivo: Proporcionar iluminação gradual para o aviário;

Descrição: O timer de luz do aviário acende e apaga bruscamente, podendo provocar traumas ou, até mesmo, a morte dos pintainhos;

Proposta de Solução: Desenvolver um dispositivo que possa acender e apagar gradualmente a luz no período noturno;

Recursos Necessários: Placas, sensor de luminosidade, timer, dispositivos elétricos.

\section{- Problemática 3:}

Objetivo: Proporcionar um dispositivo automático de abre/fecha para um galinheiro;

Descrição: Ao anoitecer, todas as galinhas entram no galinheiro, mas a porta tem de ser fechada manualmente. Pela manhã, a porta necessita ser aberta manualmente. Essa medida é importante para evitar que animais entrem e matem as galinhas;

Proposta de Solução: Desenvolver um dispositivo que, ao anoitecer e ao nascer do sol, a porta abra e feche automaticamente;

Recursos Necessários: Placas, sensor de luminosidade, dispositivos de acionamento.

\section{- Problemática 4:}

Objetivo: Informar as previsões de temperatura;
Descrição: Existe a necessidade de sistema de previsão meteorológica para ajudar no plantio, na colheita e na criação de animais nas pequenas propriedades dos agricultores da região;

Proposta de Solução: Criar uma estação meteorológica utilizando Arduino de forma que as informações sejam disponibilizadas online e em tempo real no site oficial;

Recursos Necessários: Placas, sensor de temperatura, humidade, pressão, internet, cabos.

\section{- Problemática 5:}

Objetivo: Desenvolver um alimentador automático de ração para o aviário;

Descrição: O proprietário do aviário, diariamente tem que repor o alimentador de ração no aviário, demandando força física e grande disponibilidade de tempo;

Proposta de Solução: Utilizar canos de $100 \mathrm{~mm}$ com um motor e uma mola em espiral para levar a ração até alguns pontos principais ( 5 pontos) dentro de cada aviário para, então, facilitar o despejo dentro do comedor;

Recursos Necessários: Placas, molas, canos, motores, sensores.

Com isso, as demandas puderam ser alcançadas e compreendidas pelos envolvidos, com possíveis soluções para o setor produtivo através de inovações junto a instituição de ensino. Uma delas resultou em um invento para aprimorar a ventilação dos aviários, principalmente os de pequeno porte, pois a solução apontada é de baixo custo.

A solução escolhida foi baseada no número de patentes depositadas no Brasil sobre o assunto, pois o levantamento de informações sobre o estado da arte no INPI aponta que existem poucas patentes registradas relacionadas à ventilação, sendo que o número é menor ainda quando se trata de uma combinação de palavras, ventilação inteligente, e que nenhuma delas está relacionada com aviários. O mesmo ocorre na busca na base de dados da USPTO, considerando que quando se combina as palavras smart vent, no título, o retorno é de apenas 4 registros, mas nenhum relacionado diretamente à aviários (aviary ou fowl).

Figura 3 - Busca de palavras-chave no INPI e USPTO

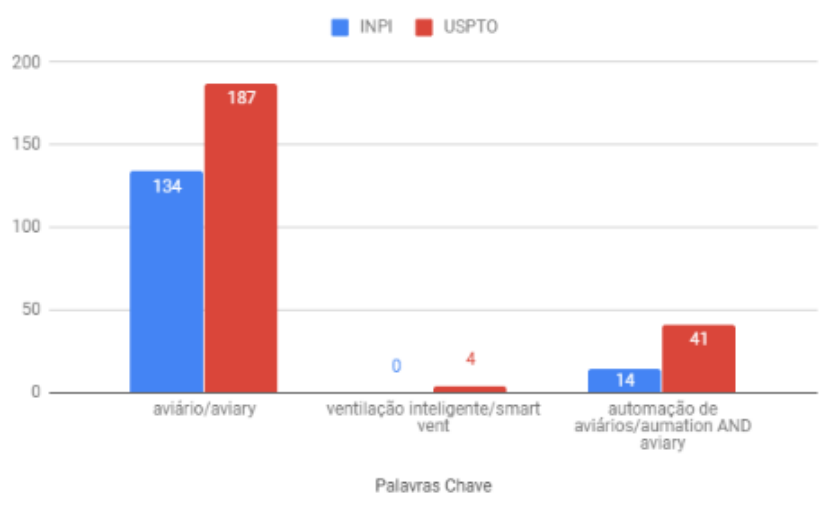

Fonte: Autor (2017).

A patente depositada foi a primeira, e a única até o momento, do Campus Capanema do IFPR, e tem como inventores 5 professores e 4 alunos do IFPR, mas é importante lembrar que, em todo o processo, desde o planejamento do evento até o depósito da patente, houve o envolvimento de mais de 20 professores e técnicos da instituição, 80 alunos e 10 interessados representando o setor produtivo local. 
De acordo com levantamentos do Instituto Brasileiro de Geografia e Estatística (IBGE), e os apresentados pelo Instituto de Pesquisa Econômica Aplicada (IPEA), as pequenas propriedades rurais dominam as estatísticas em número de estabelecimentos rurais e em geração de empregos. Do total de cerca de 5 milhões de estabelecimentos existentes no país, 4,3 milhões são de agricultura familiar (84\%) e 807 mil (16\%) são de agricultura não familiar ou patronal. Os pequenos produtores ocupam 12,3 milhões de pessoas (74\%), e os grandes, 4,2 milhões (26\%).

Por já existirem inúmeros sistemas de automação de ventilação no mercado, os métodos, materiais e processos de inovação desses sistemas são constantemente aprimorados. Contudo, ainda são onerosos aos pequenos produtores. Dessa forma, é primordial a implementação de novas tecnologias de baixo custo.

\section{CONCLUSÃO}

$\mathrm{O}$ arranjo produtivo local e a realidade regional em que o IFPR Campus Capanema está inserido, é a busca de solução para diversos problemas agroindustriais, que, como foi relatado neste trabalho, nas problemáticas que o IFAgroTECH levantou e apontou, cinco destes gargalos que já estão sendo alvos de protótipos, e outros mais poderão vir a ser beneficiados futuramente.

Um dos resultados mais relevantes, é o fomento à inovação tecnológica, mesmo que em um nível inicial de discussão. Já que este é de extrema importância para auxiliar no desenvolvimento local e regional e, por sua finalidade, pode e deve ser coordenado por uma das instituições públicas de ensino localizadas no município de Capanema.

Conclui-se que os objetivos foram alcançados, principalmente observando que a inserção ocorreu, e ainda ocorre, embasada em eventos criados com o intuito de favorecer um espaço amplo para a participação da comunidade interna e externa nas discussões de variados temas, sempre considerando que o protagonismo deve estar na comunidade externa envolvida em cada um dos processos, como os produtores rurais, por exemplo, formando, assim, a base da construção coletiva.

Considerando ainda que a demanda, bem como a solução apontada nos eventos, possui uma preocupação não apenas econômica, mas também social, pois está relacionada com a economia de energia elétrica, ou pelo menos a otimização da utilização da mesma. O pedido de PI foi depositado demonstrando que possui capacidade inventiva. Todo o processo demonstra, também, uma capacidade de alterar o cenário que estamos acostumados a acompanhar no país.

A partir da importância dada à elaboração e aos meios de divulgação da inovação, com a interação entre as instituições públicas, principalmente as de ensino, e o setor produtivo local, a tendência é o aumento do interesse, além da ampliação do conhecimento, o envolvimento dos pesquisadores e a geração de mais produtos e processos inovadores, fomentando mais registros de patentes, marcas, desenhos industriais, entre outros.

Este conjunto de eventos e o produto desenvolvido, além dos que ainda estão em fase de planejamento e construção, demonstram que o processo de ensino aprendizagem com o envolvimento e protagonismo voltados ao setor produtivo, com quaisquer que sejam os arranjos produtivos locais, estimula e passa a obter resultados positivos na região em que todos estão inseridos.

\section{REFERÊNCIAS BIBLIOGRÁFICAS}

MAZZUCATO, M. O Estado Empreendedor: desmascarando o mito do setor público vs. setor privado. Portfolio-Penguin, 2014.

MEYER, D.E.E. et al. "Você aprende. A gente ensina?": interrogando relações entre educação e saúde desde a perspectiva da vulnerabilidade. Cadernos de Saúde Pública, Rio de Janeiro, v. 22,n. 6, p. 1335-1342, 2006.

RIBEIRO, N. M., org. Prospecção tecnológica. Salvador, BA: IFBA, 2018.

SAnTOS, W. P. C., org. Conceitos e Aplicações de Propriedade intelectual. Salvador, BA: IFBA, 2018.

SOUZA, E. R., org. Políticas públicas de CT \& I e o estado brasileiro. Florianópolis, SC: [S. n.] : Salvador, BA: IFBA, 2018.

\section{AGRADECIMENTOS}

À Universidade Estadual do Centro-Oeste (UNICENTRO) e ao Instituto Federal de Educação, Ciência e Tecnologia do Paraná (IFPR).

O presente trabalho foi realizado com apoio da Coordenação de Aperfeiçoamento de Pessoal de Nível Superior - Brasil (CAPES) - Código de Financiamento 001.

\section{COPYRIGHT}

Direitos autorais: $\mathrm{O}(\mathrm{s})$ autor(es) é(são) o(s) único(s) responsável(is) pelo material incluído no artigo. 


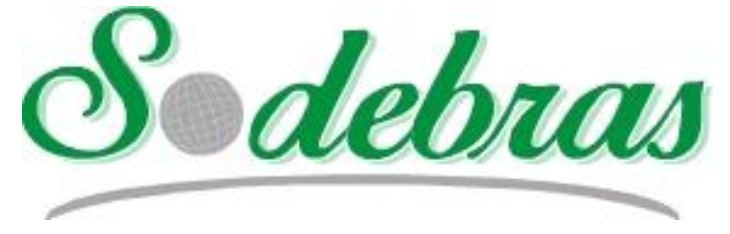

Volume 15 - No 169 - JANEIRO / 2020. XLI International Sodebras Congress 31 de outubro a 02 de novembro de 2019 - Maceió - AL

\title{
O REGISTRO DE MARCAS NO BRASIL: UM PANORAMA NACIONAL
}

\author{
THE REGISTRY OF BRANDS IN BRAZIL: A NATIONAL PANORAMA
}

\author{
ANDRÉIA CAMARGO ${ }^{1}$, DOUGLAS KAIS DA SILVA ${ }^{1}$ JULIANNO PIZZANO AYOUB ${ }^{1}$; CLÁUDIA \\ CRISOSTIMO $^{1}$; PAULO ROGÉRIO PINTO RODRIGUES ${ }^{1}$ \\ 1 - PROGRAMA DE PÓS GRADUAÇÃ̃O EM PROPRIEDADE INTELECTUAL E TRANSFERÊNCIA DE \\ TECNOLOGIA - PROFNIT - UNIVERSIDADE ESTADUAL DO CENTRO OESTE \\ andreia.camargo23@outlook.com; douglasks@gmail.com; juliannopa@hotmail.com; claudia@unicentro.br; \\ prprodrigues@gmail.com
}

\begin{abstract}
Resumo - Propriedade intelectual, enquanto marca, estabelece o direito de proteger a especificidade de um produto ou serviço. $O$ objetivo desta pesquisa foi realizar o levantamento de dados acerca do registro de marcas no Brasil no período de 2008 a 2017, a fim de caracterizar o panorama deste cenário. A metodologia envolveu um estudo exploratório de abordagem quantitativa, com análise de relatórios do INPI para o período mencionado. Os resultados demonstraram que houve um crescimento progressivo do pedido de registro de marcas no Brasil entre os anos de 2008 a 2017, com destaque para o estado de São Paulo, que detém quase metade dos pedidos no país. Conclui-se que o Brasil precisa avançar mais para que a capacidade de inovação e registros de marcas no Brasil seja maior.
\end{abstract}

Palavras-chave: Empresas. Marca. Propriedade intelectual.

Abstract - Intellectual property, as a trademark, establishes the right to protect the specificity of a product or service. The objective of this research was to collect data about trademark registration in Brazil from 2008 to 2017, in order to characterize the panorama of this scenario. The methodology involved an exploratory study of quantitative approach, with analysis of INPI reports for the mentioned period. The results showed that there was a progressive growth of the trademark application in Brazil between 2008 and 2017, especially the state of São Paulo, which holds almost half of the applications in the country. It is concluded that Brazil needs to advance further so that the capacity for innovation and trademark registrations in Brazil is greater.

Keywords: Companies. Brand. Intellectual property.

\section{INTRODUÇÃO}

Entre os vários ativos intangíveis da empresa, a marca é um dos mais importantes, pois é através dela que a pessoa física ou jurídica consegue o direito de possuir um nome específico que irá refletir no produto ou serviço oferecido e em como o mercado consumidor irá identificá-lo (NASCIMENTO; GOMES; MATTOS, 2016). Nesse sentido, o registro da marca se tornou uma necessidade real para as empresas que desejam que o mercado identifique e direcione as atividades oferecidas (CHRISTMANN, 2006).

De acordo com a legislação brasileira (BRASIL, 1996), o registro de marcas dá a empresa titular a exclusividade a fim de impedir que terceiros vendam produtos semelhantes ou idênticos com a mesma marca, evitando confusão entre os consumidores. Ademais, uma boa marca com registro tem inúmeros benefícios, como por exemplo captar recursos junto às instituições de crédito (NASCIMENTO; GOMES; MATTOS, 2016).

Historicamente, a primeira lei para proteção de marcas no Brasil surgiu em 1875 e até os dias atuais muitas transformações ocorreram com o intuito de garantir direitos ao titular com proteção jurídica acerca da criação de intelecto (CHRISTMANN, 2006). De acordo com a Confederação Nacional da Indústria (CNI, 2017) quando o direito autoral é reconhecido, o detentor da marca tem monopólio de exploração de tal coisa para o adequado fim. Entretanto, para que possa ter este monopólio, é necessário realizar o pedido da marca no Instituto Nacional de Propriedade Industrial (INPI) (CNI, 2017).

Voltando-se para as empresas, o Brasil caracteriza-se por ser um dos países com o empreendedorismo mais acentuado e onde as micro e pequenas empresas têm importante papel na economia e na geração de renda (OMPI, 2005). Entretanto, nem sempre os empreendedores e empresários relacionam as atividades da empresa com a necessidade de inovação, ou seja, principalmente as empresas menores não apresentam capacidade de inovação, significando a falta de diferenciação e vulnerabilidade à concorrentes, afetando assim a competitividade (OMPI, 2005).

Pensando em todos os benefícios que o registro de marcas e a proteção à propriedade intelectual podem gerar, visto que o reconhecimento de uma marca é a ligação efetiva entre o cliente e o negócio como forma de identificação e diferenciação, este estudo teve por objetivo realizar um levantamento de dados acerca do registro de marcas no Brasil no período de 2008 a 2017, a fim de caracterizar o panorama deste cenário nos últimos dez anos.

\section{METODOLOGIA}

Este estudo caracterizou-se por ser do tipo exploratório e com abordagem quantitativa. De acordo com Gil (2008), a pesquisa exploratória tem por objetivo familiarizar-se com o tema, onde, ao final, deverá ser possível conhecer mais sobre determinado assunto e estar apto a construir hipóteses. Em relação a abordagem quantitativa, Fonseca (2002) explica que os resultados deste tipo de pesquisa podem ser 
quantificados, sendo tomados como se constituíssem um retrato real de toda a população alvo.

Enquanto metodologia utilizou-se a revisão bibliográfica sobre marca e registro de marcas e demais questões que a fundamentação do trabalho envolveu. Outro método utilizado foi a pesquisa documental, baseando-se em informações encontradas em relatórios disponibilizados no endereço eletrônico do INPI - Instituto Nacional da Propriedade Industrial (www.inpi.gov.br). Especificamente buscou-se analisar o relatório intitulado Indicadores de Propriedade Intelectual dos anos de 2008 a 2018, a fim de traçar um panorama da situação de produção intelectual do Brasil nos últimos dez anos.

As respostas e as conclusões possíveis e relevantes serão descritas a seguir.

\section{RESULTADOS}

Inicialmente, o relatório do INPI aborda o item "Marcas" subdividindo-o em dois subitens: pedidos de marcas depositados; registros de marca. Em pedidos de marcas depositados ocorre mais uma divisão, que considera os seguintes tópicos: por origem do depositante, por tipo de depositante, por natureza do pedido, por classe de Nice, principais depositantes. A análise aqui considerou os itens pedidos de marcas; origem do depositante - estado e município brasileiro. Ademais, voltou-se para a situação do estado do Paraná.

De acordo com os dados do INPI, no ano de 2008 houve 121.903 pedidos de registro de marcas, com $17 \%$ de aumento em relação a 2007; em 2009 houve queda de 7\% no número de pedidos, resultando no valor de 112.793; em 2010 o aumento de pedidos para marcas foi de $13 \%$ e alcançou o valor de 127.634 pedidos; em 2011 o aumento foi ainda maior $(20 \%)$ com pedidos de registro de marcas chegando ao valor de 152.645; em 2012 houve queda novamente com $-1 \%$ e o número de pedidos para registro de marcas ficou em 151.833; o ano de 2013 registrou aumento de $9 \%$ com o montante de 165.613 pedidos; 2014 a taxa de pedidos caiu em 4\% e o valor ficou em 159.263; 2015 trouxe um aumento de $1 \%$ e o total de pedidos para registro de marca ficou em 160.802; no ano 2016 houveram 166.638 pedidos de registro de marcas com $3,5 \%$ de aumento em relação ao ano anterior; em 2017 houveram 186.103 pedidos de registro de marcas e isso representou um aumento de $11,9 \%$ em relação ao ano anterior. Os dados estão dispostos no Quadro 1.

Figura 1. Evolução do número de pedidos de registro de marca de 2008 a 2017.

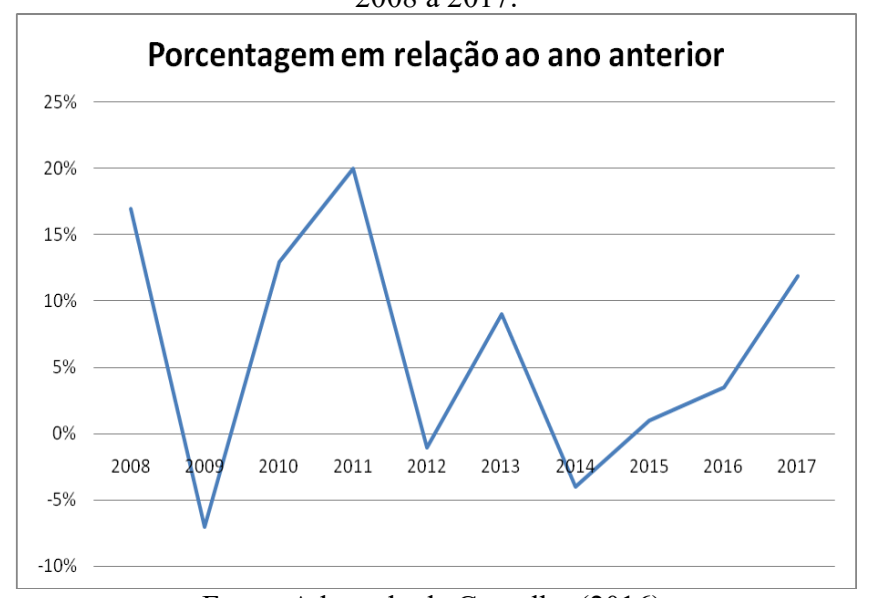

Fonte: Adaptado de Carvalho (2016).
Analisando o quadro e considerando o período de 2008 a 2017 houve ascensão dos pedidos de registro de marca com expansão de 52,7\% na quantidade. Esses dados demonstram que este nicho de mercado tem potencial para se tornar promissor no Brasil, ou seja, a propriedade intelectual é importante para que a empresa alcance crescimento e a mesma deve considerar possuir profissionais que conheçam esta parcela do mercado e trabalhem para proteger marcas e patentes de interesse da empresa.

Dando continuidade à análise dos relatórios, o próximo item foi a origem dos pedidos. Para residentes no país, entre os anos de 2008 a 2017 os valores foram os seguintes: em 2008 do total de pedidos para registro de marca, 81,50\% foram de residentes; em 2009 a taxa foi de 83,56\%; em 2010 o valor alcançado foi $81,47 \%$; no ano de 2011 o valor foi de 80,22\%; em 2012 a taxa de pedidos por residentes alcançou 79,31\%; no ano de 2013 os pedidos para registro de marcas de residentes somaram 81,20\%; no ano de 2014 a taxa foi de 81,70\%; em 2015 o valor alcançado foi 82,57\%; já em 2016 a participação de residentes foi de $83 \%$ e, por fim, em 2017 86\% dos pedidos de registro de marca foram provenientes de residentes do Brasil.

Esses dados mostram uma curva acentuada de declínio entre os anos de 2009 a 2012 para pedidos de registro de marcas, podendo ser justificado pela situação política e econômica do Brasil neste período. Já entre os anos de 2013 a 2017 houve aumento dos pedidos de registro de marcas no Brasil em 4,80\%. Este dado demonstra que os investimentos na área de educação, como o surgimento do primeiro mestrado em propriedade intelectual que se iniciaram em 2011/2012 começaram a dar frutos.

Quanto a distribuição de pedidos de propriedade intelectual no Brasil, entre os anos de 2008 a 2015 o Paraná teve 90.350 pedidos, correspondendo a $8,2 \%$ da fatia nacional e $3^{\circ}$ lugar no país. Os primeiros lugares ficaram com os estados de São Paulo (455.083 pedidos, 41,4\%) e Rio de Janeiro (116.424 pedidos e 10,6\%). Para completar o ranking dos estados com mais pedidos de registro de marcas tem-se da $4^{\mathrm{a}}$ a $12^{\mathrm{a}}$ posição, respectivamente: Minas Gerais ( 90.306 pedidos e $8,2 \%$ ); Santa Catarina (66.918 pedidos e 6,1\%); Rio Grande do Sul (66.829 pedidos e 6,1\%); Goiás (29.799 pedidos e 2,7\%); Bahia (29.603 pedidos e 2,7\%); Ceará (25.544 pedidos e 2,3\%); Pernambuco (23.322 pedidos e 2,1\%); Distrito Federal (21.971 pedidos e 2\%); Espírito Santo (15.912 pedidos e 1,4\%); outros estados (67.193 pedidos e $6,1 \%$ ).

No ano de 2016, no ranking dos dez estados brasileiros com maior número de pedidos de registro de marca, o Paraná ficou na $4^{\circ}$ posição com 11.596 pedidos que corresponderam a $8,4 \%$ do total. As primeiras posições foram ocupadas por São Paulo (53.055 pedidos e 38,5\%), Rio de Janeiro (14.268 pedidos e $10,3 \%$ ) e Minas Gerais (12.765 pedidos e 9,3\%). Os estados que ocuparam as posições de $5^{\circ}$ ao $10^{\circ}$ foram: Rio Grande do Sul $(8.558$ pedidos e 6,2\%); Santa Catarina (8.249 pedidos e 6\%); Goiás (4.166 pedidos e 3\%); Bahia (3.902 pedidos e 2,8\%); Distrito Federal (3.404 pedidos e 2,5\%); Ceará $(3.245$ pedidos e $2,4 \%$ ). Os outros estados corresponderam a $10,6 \%$ do total ou 14.670 pedidos.

Já no ano de 2017, os dez estados brasileiros que se destacaram por terem depositado pedidos de registro de marcas e nacionalmente foram responsáveis por $89 \%$ do total de pedidos, são: São Paulo com 37,8\% de participação 
(60.195 pedidos); Rio de Janeiro com 10,1\% (16.116 pedidos); Minas Gerais com 9,4\% (15.028 pedidos); Paraná com 8,3\% (13.201 pedidos); Santa Catarina com 6,3\% (10.089 pedidos); Rio Grande do Sul com 5,9\% (9.321 pedidos); Goiás com 3,2\% (5.088 pedidos); Bahia com 3,1\% (4.881 pedidos); Pernambuco com 2,3\% (3.650 pedidos); Distrito Federal com 2,3\% (3.638 pedidos) e demais estados corresponderam a $11,3 \%$ (17.985 pedidos).

Os dados resumidos do período 2008-2017 estão dispostos na Figura 1.

Figura 1 - Pedidos de Registro de marca nos estados brasileiros de 2008 a 2017.

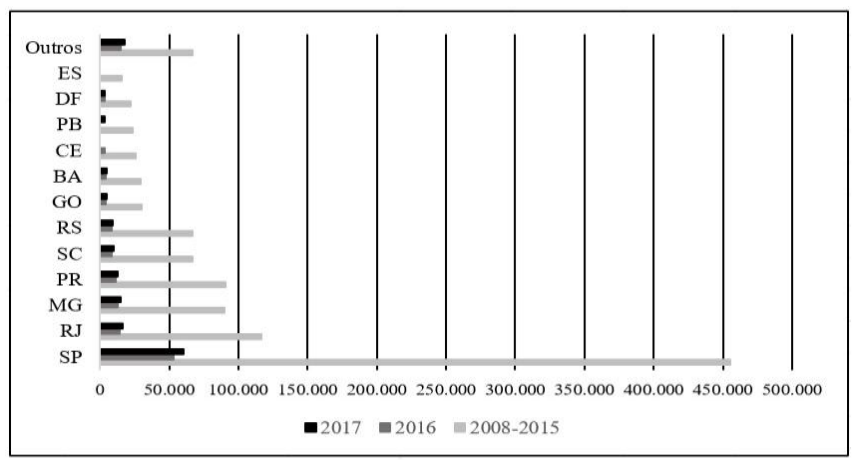

Fonte: Adaptado de INPI (2018).

Ao observar a figura supracitada, pode-se perceber que o estado de São Paulo detém as maiores taxas para registros de marca no Brasil. Analisando mais a fundo os anos de 2016 e 2017, os pedidos do estado de São Paulo foram maiores em 2017, assim como os demais estados, demonstrando assim um crescimento gradativo com o correr dos anos. Os estados de Pernambuco, Ceará e Espírito Santo que estiveram presentes no ranking nacional entre 20082015, sofreram alterações. Para 2016 apenas Ceará consta na lista dos estados brasileiros (entre estes três estados citados); já em 2017 apenas o estado de Pernambuco aparece. Dessa forma, o Espírito Santo ficou fora da lista nos últimos anos.

Dando seguimento a análise, o relatório do INPI traz os municípios brasileiros que fizeram solicitação de pelo menos uma marca. Para os anos de 2008-2015 este registro não foi encontrado. Em 2016, os municípios que tiveram pedidos de registro de marcas foram, por ordem decrescente: São Paulo (18,8\% dos pedidos); Rio de Janeiro (7,2\%); Belo Horizonte (3,5\%); Curitiba (3,2\%); Brasília $(2,5 \%)$; Porto Alegre (2\%); Goiânia $(1,8 \%)$; Fortaleza $(1,6 \%)$; Salvador $(1,4 \%)$ e Campinas $(1,3 \%)$.

Para o ano de 2017 percebeu-se centralização destes pedidos nas regiões sudeste, sul e nordeste. O destaque foi para quatro municípios: São Paulo (18,5\% dos pedidos); Rio de Janeiro (7,0\%); Belo Horizonte $(3,2 \%)$ e Curitiba (3,1\%). Em $5^{\circ}$ lugar tem-se Brasília (2,3\%) seguida de Goiânia $(1,9 \%)$; Porto Alegre (1,8\%); Fortaleza (1,6\%); Salvador $(1,4 \%)$; Campinas $(1,2 \%)$.

Estes dados apontam que em praticamente todos os municípios mencionados houve queda na taxa de pedidos de registro de marca do ano de 2016 para 2017. Apenas Goiânia teve alta de $1 \%$, saindo de $1,8 \%$ em 2016 e indo para $1,9 \%$ em 2017. Já os municípios Fortaleza e Salvador mantiveram o índice nos dois anos: $1,6 \%$ e $1,4 \%$ respectivamente. Essa queda nos pedidos pode ser justificada pela demora do INPI em realizar a análise e fazer com que tenha muitos pedidos de registro de marcas em espera para ser examinado.

\section{CONCLUSÃO}

Para que a empresa se mantenha no mercado de forma competitiva é preciso que esteja disposta ao aprendizado e busca pelo conhecimento constantes. O papel da propriedade intelectual neste cenário é garantir que a empresa consiga inovar e tenha direito sobre suas inovações através de registro de marcas ou patentes, que atualmente é indispensável para alcançar a conquista de novos mercados.

Entendendo-se que a propriedade intelectual apoia o desenvolvimento tecnológico do país, este trabalho procurou analisar o registro de marcas no Brasil num panorama de dez anos, correspondente ao período de 2008-2017. Como resultado, observou-se que o Brasil teve um aumento progressivo no número de pedidos de registro de marcas, saindo de 121.903 para 186.103 pedidos. Entretanto, se comparado ao cenário internacional, a produtividade do Brasil em relação a marcas ainda é baixa, com pouco investimento das empresas brasileiras em inovação e desenvolvimento.

No que se refere ao cenário nacional, os estados que mais tem registro de pedidos para marcas é São Paulo, Rio de Janeiro, Minas Gerais e Paraná, com os seguintes municípios: São Paulo, Rio de Janeiro, Belo Horizonte e Curitiba. Percebe-se que os pedidos estão centralizados na região sul, sudeste e nordeste. Neste sentido, o estado de São Paulo é uma região inovadora do país, pois seus registros representam quase a metade dos pedidos do Brasil.

Por fim, ainda há muito que evoluir no campo da ciência e tecnologia no sentido de promover maior capacidade de inovação e registros de marcas no Brasil.

\section{REFERÊNCIAS BIBLIOGRÁFICAS}

BRASIL. Lei $\mathrm{n}^{\circ}$ 9.279, de 14 de maio de 1996, que regula direitos e obrigações sobre a propriedade industrial. Brasília: $1996 . \quad$ Disponível em: $<$ http://www.planalto.gov.br/ccivil_03/leis/L9279.htm> Acesso em 22 abr. 2019.

CARVALHO, S.M.P. Indicadores de Propriedade Industrial: lançamento do anuário estatístico de patentes, marcas e desenhos industriais. In: ENCONTRO ACADÊMICO DA PROPRIEDADE INTELECTUAL, INOVAÇÃO E DESENVOLVIMENTO, 9., 2016. Anais do IX ENAPID, Florianópolis, Santa Catarina, SC, 2016.

CHRISTMANN, D. A importância do Registro da Marca. $2006 . \quad$ Disponível em: $<$ https://www.univates.br/media/graduacao/direito/IMPORT ANCIA_DO_REGISTRO_DA_MARCA.pdf $>$ Acesso em 22 abr. 2019.

CNI. Confederação Nacional da Indústria. Propriedade Intelectual para pequenas e microempresas. Brasília: 2017. Disponível em: $<$ http://www.fiemt.com.br/arquivos/2913_CNI_Cartilha_Pr opriedade_Intelectual.pdf $>$ Acesso em 22 abr. 2019.

FONSECA, J.J.S. Metodologia da pesquisa científica. Fortaleza: UEC, 2002. 
GIL, A.C. Como elaborar projetos de pesquisa. 5. ed. São Paulo: Atlas, 2008.

INPI. Instituto Nacional da Propriedade Industrial. Indicadores de Propriedade Industrial 2018. Rio de Janeiro: Instituto Nacional da Propriedade Industrial - INPI, 2018, 66p.

NASCIMENTO, R.L.L.; GOMES, I.M.A.; MATTOS, R. Análise custo-benefício do registro de marcas pelas pequenas e médias empresas. Revista Cadernos de Prospecção, v.9, n.1, 2016, p.9-17.

OMPI. Organização Mundial de Propriedade Intelectual. Sistema de propriedade intelectual e as pequenas e médias empresas no Brasil. Campinas, 2005. Disponível em:

$<$ https://www.wipo.int/edocs/pubdocs/pt/sme/858/wipo_pub _858.pdf> Acesso em 22 abr. 2019.

\section{AGRADECIMENTOS}

$\mathrm{O}$ presente trabalho foi realizado com o apoio da coordenação de aperfeiçoamento de pessoal de nível superior-Brasil (Capes) código de financiamento 001. Os autores agradecem a FAU/UNICENTRO pelo apoio financeiro, e também ao CNPq, FINEP, Fundação Araucária e SETI/UGF.

\section{COPYRIGHT}

Direitos autorais: $\mathrm{O}(\mathrm{s})$ autor(es) é(são) o(s) único(s) responsável(is) pelo material incluído no artigo. 


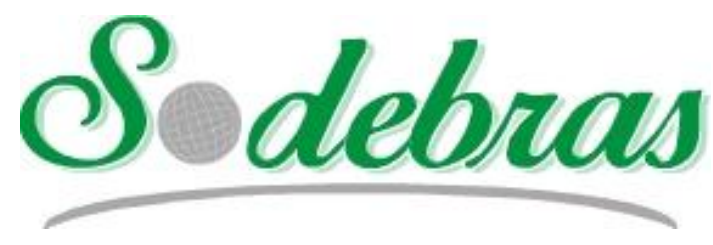

Volume 15 - $\mathrm{N}^{\mathrm{o}} 169$ - Janeiro / 2020

XLI International Sodebras Congress

31 de outubro a 02 de novembro de 2019 - Maceió - AL.

\title{
USO DA MINERAÇÃO DE DADOS PARA DETECÇÃO DE FATORES QUE INFLUENCIAM O DESEMPENHO DOS ALUNOS NO ENEM
}

\section{USING DATA MINING TO DETECT FACTORS THAT INFLUENCE STUDENT PERFORMANCE IN ENEM}

\author{
RAPHAEL MAGALHÃES HOED ${ }^{1}$; PEDRO FÁBIO SARAIVA ${ }^{1}$; LARA FERNADA NUNES DOURADO ${ }^{1}$ \\ 1 - INSTITUTO FEDERAL DO NORTE DE MINAS GERAIS \\ raphael.hoed@ifnmg.edu.br; pedro.fabio@ifnmg.edu.br; lara.dourado@ifnmg.edu.br.
}

\begin{abstract}
Resumo - A mineração de regras de associação via algoritmo Apriori foi aplicada neste artigo, usando os microdados do Exame Nacional do Ensino Médio (ENEM). Esse artigo verifica os fatores que influenciam o desempenho do aluno no ENEM, tomando como base as respostas dos candidatos no questionário socioeconômico. A partir do emprego da técnica de mineração de regras de associação, espera-se obter maior entendimento sobre os fatores que podem contribuir para o desempenho positivo dos discentes, propondo assim formas de ampliar o bom desempenho.
\end{abstract}

Palavras-chave: Apriori. ENEM. Aluno.

\begin{abstract}
Mining of association rules via the Apriori algorithm was applied in this paper using the National High School Examination (ENEM) microdata. This paper examines the factors that influence student performance in ENEM, based on the candidates' answers in the socioeconomic questionnaire. From the use of the association rules mining technique, it is expected to gain a better understanding of the factors that can contribute to the positive performance of the students, thus proposing ways to expand the good performance.
\end{abstract}

Keywords: Apriori. ENEM. Student.

\section{INTRODUÇÃO}

Nos últimos anos o Brasil passou por alterações no processo de seleção para ingressar em universidades. $\mathrm{O}$ tradicional vestibular deu espaço ao Exame Nacional do Ensino Médio (ENEM). O ENEM foi criado inicialmente como um instrumento para avaliar o desempenho dos estudantes ao concluir a educação básica, sendo que a partir de 2009 começou a ser utilizado como forma de acesso ao ensino superior.

O Instituto Nacional de Estudos e Pesquisas Educacionais Anísio Teixeira (INEP) disponibiliza os dados individuais (microdados) dos alunos que realizaram a prova do ENEM. Esses dados são bastante ricos e podem ser estudados por meio de técnicas de mineração de dados. A mineração de dados consiste em analisar dados e aplicar algoritmos que produzirão um conjunto de padrões de certos dados (FAYYAD; PIATETSKY-SHAPIRO; SMYTH, 1996).

O presente trabalho tem por objetivo estudar os microdados do ENEM disponibilizados gratuitamente pelo INEP, afim de verificar quais os fatores estão relacionados ao desempenho dos alunos. Para isso, foi adotada a mineração de regras de associação via algoritmo Apriori.

Este artigo segue a seguinte organização: A Seção II mostra a fundamentação teórica, explorando trabalhos correlatos sobre o desempenho dos alunos no ENEM e discorrendo sobre a técnica de mineração de dados empregada; A Seção III mostra a metodologia empregada no estudo; A Seção IV mostra os estudos realizados e os resultados obtidos. A Seção V exibe as conclusões obtidas. A Seção VI exibe as referências bibliográficas.

\section{FUNDAMENTAÇÃO TEÓRICA}

Esta seção está dividida em duas subseções: a subseção 2.1 trata de estudos similares feitos sobre o desempenho de alunos no ENEM usando os microdados disponibilizados pelo INEP e a subseção 2.2 discorre sobre o algoritmo Apriori usado para mineração de regras de associação.

\subsection{Microdados do ENEM}

De acordo com Silva, Morino e Sato (2014) o ENEM tem como objetivo, além de avaliar o ensino médio, atuar como substituto do tradicional vestibular para ingressar em diversas universidades do país.

Infelizmente, de acordo com dados do Programme for International Student Assessment (PISA) referentes ao ano de 2015, o desempenho dos estudantes do Brasil em áreas como ciências, leitura e matemática é inferior ao de vários países membros da Organização para Cooperação e Desenvolvimento Econômico (OCDE) (SIMON e CAZELLA, 2017). Isso reforça a importância de se conhecer as causas que levam ao baixo desempenho no ENEM, tendo em vista mitiga-las.

A Tabela 1 apresenta uma compilação de alguns autores que estudaram os dados do ENEM, algumas evidências obtidas e as respectivas técnicas de mineração de dados empregadas no estudo: 
Tabela 1 - Estudos Envolvendo Dados do ENEM

\begin{tabular}{|c|c|c|}
\hline Autor & $\begin{array}{c}\text { Técnica } \\
\text { Empregada }\end{array}$ & $\begin{array}{c}\text { Resultados } \\
\text { Obtidos }\end{array}$ \\
\hline $\begin{array}{c}(\text { SIMON e } \\
\text { CAZELLA, 2017) }\end{array}$ & Árvore de Decisão & $\begin{array}{c}\text { Os melhores } \\
\text { desempenhos de } \\
\text { candidatos nas } \\
\text { provas de ciências } \\
\text { da Natureza e suas } \\
\text { Tecnologias foram } \\
\text { de alunos de } \\
\text { escolas privadas e } \\
\text { nível } \\
\text { socioeconômico } \\
\text { muito alto. }\end{array}$ \\
\hline $\begin{array}{c}\text { (SILVA, MORINO } \\
\text { E SATO, 2014) }\end{array}$ & Algoritmo Apriori & $\begin{array}{l}\text { Baixa renda, baixa } \\
\text { escolaridade dos } \\
\text { pais e número } \\
\text { elevado de pessoas } \\
\text { residentes na } \\
\text { mesma casa } \\
\text { influenciam no mau } \\
\text { desempenho no } \\
\text { ENEM (estudo } \\
\text { realizado com } \\
\text { alunos de São } \\
\text { Paulo). }\end{array}$ \\
\hline $\begin{array}{c}\text { (STEARNS et al., } \\
\text { 2017) }\end{array}$ & Árvore de Decisão & $\begin{array}{c}\text { Indicadores } \\
\text { socioeconômicos } \\
\text { podem auxiliar na } \\
\text { predição da nota do } \\
\text { aluno }\end{array}$ \\
\hline $\begin{array}{c}\text { (ALVES, } \\
\text { CECHINEL E } \\
\text { QUEIROGA, 2018) }\end{array}$ & Árvore de Decisão & $\begin{array}{c}\text { O tipo de escola e } \\
\text { nível } \\
\text { socioeconômico } \\
\text { influenciam o } \\
\text { desempenho do } \\
\text { aluno na prova do } \\
\text { ENEM }\end{array}$ \\
\hline
\end{tabular}

A Tabela 1 apresentada não esgota o tema referente ao estudo dos microdados do ENEM. Diversos autores exploraram o assunto e foi possível encontrar evidências de que os fatores socioeconômicos estão relacionados ao desempenho dos candidatos neste exame. Todos os trabalhos correlatos encontrados utilizam dados do ENEM anteriores a 2017 (que é o ano adotado neste estudo). A comparação entre os trabalhos correlatos e a pesquisa conduzida nesse trabalho pode ser encontrada na Seção V (Conclusões).

\subsection{Mineração de Regras de Associação}

O algoritmo Apriori será usado nesse trabalho para mineração das regras de associação. Procura-se descobrir associações importantes entre o desempenho do aluno na prova do ENEM e os dados presentes no questionário preenchido pelos estudantes.

De acordo com Romão et al (1999):

"Uma das técnicas mais atraentes é a Mineração de Regras de Associação, que tem como destaque o algoritmo Apriori. Ele pode trabalhar com um número grande de atributos, gerando várias alternativas combinatórias entre eles. (ROMÃO et al.,1999). '

De acordo com Hoed (2016), a mineração de regras de associação tem muitas aplicações comerciais em se tratando, por exemplo, de supermercados, quando se pode averiguar, a partir de um banco de dados, se a venda de um determinado produto também está associada à venda de outro produto. A descoberta de regras de associação desse tipo podem subsidiar decisões como melhor disposição das mercadorias no supermercado, colocando estrategicamente os produtos correlacionados uns próximos aos outros. Romão et al. (1999) afirmam que:

"O objetivo, então, é encontrar todas as regras de associação relevantes entre os itens, do tipo $\mathrm{X}($ antecedente $) \Rightarrow \mathrm{Y}$ (consequente) (ROMÃO et al.,1999)."

De acordo com Hoed (2016), a mineração de regras de associação não é útil apenas no contexto de transações comerciais, mas pode ser empregada também para análise de dados do ensino. No que diz respeito ao contexto desse artigo, pode-se verificar, por exemplo, quais fatores se correlacionam ao bom ou ao mau desempenho dos alunos no ENEM.

A descoberta de regras de associação pode ser decomposta em duas etapas, de acordo com AGRAWAL et al. (1993 apud ROMÃO et al., 1999): localizar os conjuntos de itens (itemsets) que apresentam suporte superior ao mínimo definido à partida; utilizar os itemsets obtidos na etapa 1 para gerar as regras de associação do banco de dados. Algumas definições importantes sobre mineração de regras de associação: "A toda regra de associação $\mathrm{A} \rightarrow \mathrm{B}$ associamos um grau de confiança, denotado por conf $(\mathrm{A} \rightarrow$ B)" (de AMO, 2004). O grau de confiança seria a probabilidade de que uma transação que tenha um item, também contenha o outro item. A Equação (1) a seguir, formaliza essa definição (de AMO, 2004):

conf $(A \rightarrow B)=$ número de transações que suportam $(A \cup$ $B) /$ número de transações que suportam $A$

Uma outra definição importante seria que:

"A toda regra de associação $\mathrm{A} \rightarrow \mathrm{B}$ associamos um suporte, denotado por $\sup (\mathrm{A} \rightarrow \mathrm{B})$ definido como sendo o suporte do itemset $\mathrm{A} \cup \mathrm{B}$ (de AMO, 2004)."

O suporte seria a proporção de transações que contém os itens. Ao definir um grau mínimo de confiança e um grau mínimo de suporte, uma regra de associação interessante seria então aquela que possui um suporte igual ou superior ao mínimo definido e aquela que possui uma confiança igual ou superior ao mínimo definido.

De acordo com Ribeiro (2015), para encontrar regras consideradas fortes, além do suporte e da confiança é também utilizada a medida Lift, que é definida pela Equação 2:

$$
\begin{aligned}
\operatorname{Lift}(A, B)= & P(A \cup B) \\
& \overline{P(A) P(B)}
\end{aligned}
$$


Ainda de acordo com Ribeiro (2015):

"A ocorrência de um item A é independente de um item $\mathrm{B}$ se $\mathrm{P}(\mathrm{A} U \mathrm{~B})=\mathrm{P}(\mathrm{A}) \mathrm{P}(\mathrm{B})$. Se não, existe uma correlação entre os itens (RIBEIRO, 2015)."

Desta forma, se o valor da Equação 2 for menor que 1, então a ocorrência de A correlaciona-se negativamente com a ocorrência de B. Se o resultado for superior a 1 , A e B se correlacionam positivamente, evidenciando que a ocorrência de A implica na ocorrência de B. Desta forma, no âmbito desse estudo só serão consideradas como válidas as regras obtidas cujo Lift seja superior a 1.

As fases de execução do algoritmo Apriori compreendem geração, poda e validação (de AMO, 2004). Resumidamente, sem entrar em detalhes sobre cada fase, na fase de geração são gerados os itemsets que tenham alguma chance de serem frequentes, na fase de poda são descartados os itemsets sem chances de serem frequentes, e na última é calculado o suporte de cada um dos itemsets do conjunto (de Amo, 2004). O funcionamento do algoritmo Apriori é descrito da seguinte forma:

"Na primeira passagem, o suporte para cada item individual (conjuntos-de-1-item) é contado e todos aqueles que satisfazem o suporte_mínimo são selecionados, constituindo-se os conjuntos-de-1-item freqüentes (F1). Na segunda iteração, conjuntos-de-2-itens candidatos são gerados pela junção dos conjuntos-de-1-item (a junção é feita através da função apriori-gen) e seus suportes são determinados pela pesquisa no banco de dados, sendo, assim, encontrados os conjuntos-de-2-itens freqüentes. $\mathrm{O}$ algoritmo Apriori prossegue iterativamente, até que o conjunto-de-k-itens encontrado seja um conjunto vazio (de VASCONCELOS e de CARVALHO, 2018).”

\section{METODOLOGIA}

A metodologia de estudo a ser aplicada para analisar os microdados do ENEM segue as etapas previstas na metodologia de mineração de dados Cross Industry Standard Process for Data Mining (CRISP-DM) (CHAPMAN et al., 2000) compreendendo as seguintes etapas: compreensão do negócio, compreensão dos dados, preparação dos dados, modelação (aplicação das técnicas de mineração de dados), avaliação dos resultados e desenvolvimento.

A etapa de compreensão do negócio envolve a compreensão do objetivo da pesquisa, conforme foi apresentado anteriormente na Seção I (Introdução).

Durante a compreensão dos dados, foi necessário analisar os microdados do ENEM, disponibilizados no Portal do INEP (http://portal.inep.gov.br/microdados) para verificar quais as variáveis disponíveis na base de dados, identificando quais delas serão úteis no estudo. No âmbito desse estudo foram utilizadas as variáveis do questionário socioeconômico e notas dos alunos nas provas. Nessa fase, foi utilizado um software de planilha eletrônica (Microsoft Excel) pois a maioria dos microdados fornecidos encontrase em formato Comma Separated Values (CSV). Foram utilizados os microdados correspondentes ao ano de 2017. O arquivo CSV analisado possui um total de 6731341 registros.

Durante a preparação dos dados, foi realizada a limpeza com remoção das variáveis que não serão úteis para o estudo (aquelas que não compreendem dados socioeconômicos ou notas nas provas) e adequação para que as técnicas de mineração de dados sejam empregadas. Nessa fase o software de planilha eletrônica Microsoft Excel também foi usado.

Ainda em relação à fase de preparação, algumas variáveis foram discretizadas para facilitar a análise dos dados:

- Idade: foram usadas as classificações jovens-adolescentes (de 15 a 17 anos), jovensjovens (de 18 a 24 anos), jovens-adultos ( 25 a 29 anos) e adultos (30 anos ou mais). Classificação similar foi utilizada por Kummer e Colognese (2013) em seu trabalho.

- Desempenho: para classificar o desempenho, verificou-se os quartis estatísticos para as notas nas seguintes áreas do conhecimento: Ciências da Natureza, Ciências Humanas, Linguagens e Códigos, Matemática e Redação. Notas compreendidas abaixo do primeiro quartil foram classificadas como "Muito Baixas"; Notas compreendidas entre o primeiro e o segundo quartis foram classificadas como notas "Baixas"; Notas compreendidas entre o segundo e o terceiro quartis foram classificadas como "Acima da Média"; Notas acima do terceiro quartil foram classificadas como notas "Altas".

Durante a fase de modelação foi aplicado o algoritmo Apriori usando o Software R versão 3.1.2. Foram filtradas as regras considerando os seguintes parâmetros:

- Suporte entre 0,01 e 0,02.

- Confiança mínima foi definida em 0,90.

- Lift maior ou igual a 5.

Embora regras interessantes possam ser encontradas com parâmetros menos rígidos do que os apresentados, deve-se ressaltar que, nesse caso, obteria-se uma quantidade de regras muito grande, inviabilizando a apresentação de todas elas nesse trabalho.

Durante a fase de avaliação, os resultados obtidos na fase de modelação foram discutidos e analisados. Isso será detalhado na Seção IV.

$\mathrm{Na}$ fase de desenvolvimento, avaliou-se os resultados obtidos, apresentando sugestões diante dos resultados encontrados, conforme será apresentado na Seção V.

\section{ESTUDOS REALIZADOS E RESULTADOS OBTIDOS}

Com o uso do algoritmo Apriori, aplicando-se os parâmetros já mencionados na Seção III (Metodologia) foram obtidas um total de 157 regras. Como essa quantidade de regras é inviável para ser apresentada neste artigo, serão exibidas apenas as 10 regras com maior valor obtido para o parâmetro Lift, filtrando-se assim apenas aquelas com maior correlação positiva entre as suas partes. Todas as regras a seguir apresentam confiança superior a 0,90 , suporte abaixo de 0,02 e Lift superior a 5: 


\section{REGRA 1:}

$\left\{\mathrm{Q} 025=\mathrm{B}, \mathrm{Q} 027=\mathrm{D}, \mathrm{CLASSIFICACAO \_ ETARIA}=\right.$ jovemjovem,

CLASSIFICACAO_CIENCIAS_HUMANAS=ALTA,

CLASSIFICACAO_LINGUAGENS=ALTA,

CLASSIFICACAO_MATEMATICA=ALTA,

CLASSIFICACAO_REDACAO $=$ ALTA $\}$

\{CLASSIFICACAO_CIENCIAS_NATUREZA=ALTA $\}$

\section{REGRA 2:}

$\{$ Q027=D,CLASSIFICACAO ETARIA=jovem-jovem, CLASSIFICACAO_CIENCIAS_HUMANAS=ALTA, CLASSIFICACAO_LINGUAGENS $=$ ALTA, CLASSIFICACAO MATEMATICA=ALTA, CLASSIFICACAO_REDACAO=ALTA

$\{$ CLASSIFICACAO_CIENCIAS_NATUREZA=ALTA

\section{REGRA 3:}

$\{\mathrm{Q} 025=\mathrm{B}, \mathrm{Q} 027=\mathrm{D}, \mathrm{CLASSIFICACAO}$ _ETARIA=jovemjovem,

CLASSIFICACAO CIENCIAS HUMANAS=ALTA,

CLASSIFICACAO_MATEMATICA=ALTA,

CLASSIFICACAO_REDACAO=ALTA

$\{$ CLASSIFICACAO_CIENCIAS_NATUREZA=ALTA $\}$

\section{REGRA 4:}

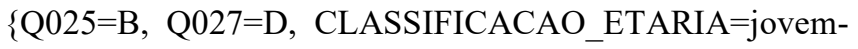
jovem, CLASSIFICACAO_LINGŪAGENS=ALTA, CLASSIFICACAO MATEMATI $\bar{C} A=A L T A$, CLASSIFICACAO ${ }^{-}$REDACAO=ALTA $\}$

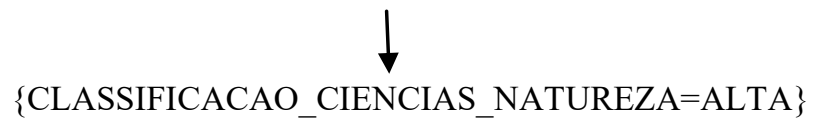

\section{REGRA 5}

$\{$ Q027 $=\mathrm{D}, \quad$ CLASSIFICACAO ETARIA=jovem-jovem, CLASSIFICACAO_CIENCIAS_HUMANAS=ALTA, CLASSIFICACAO_MATEMATICA $=$ ALTA ,CLASSIFICACAO_REDACAO=ALTA

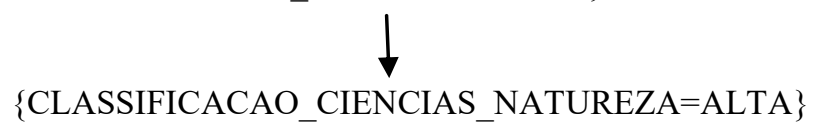

\section{REGRA 6}

$\{$ Q027=D, CLASSIFICACAO_ETARIA=jovem-jovem, CLASSIFICACAO LINGUAGENS $=$ ALTA, CLASSIFICACAO MATEMATICA=ALTA, CLASSIFICACAO ${ }^{-}$REDACAO $=$ALTA $\}$

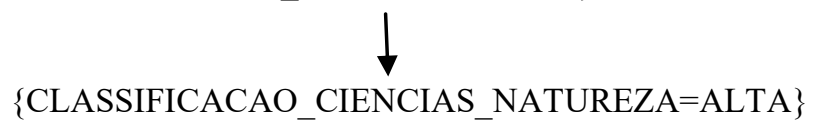

\section{REGRA 7}

$\left\{\mathrm{Q} 025=\mathrm{B}, \mathrm{Q} 027=\mathrm{D}, \mathrm{CLASSIFICACAO \_ ETARIA=jovem}-\right.$ jovem,

CLASSIFICACAO_CIENCIAS HUMANAS=ALTA, CLASSIFICACAO ${ }^{-}$LINGUAGENS=ALTA, CLASSIFICACAO MATEMATICA=ALTA $\}$

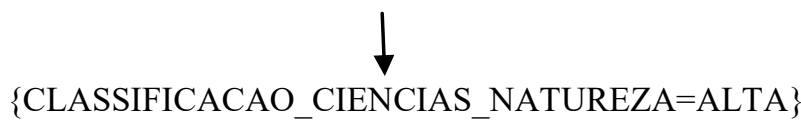

\section{REGRA 8}

$\{\mathrm{Q} 027=\mathrm{D}, \quad$ CLASSIFICACAO ETARIA=jovem-jovem, CLASSIFICACAO_CIENCIAS_HUMANAS $=$ ALTA, CLASSIFICACAO ${ }^{-}$LINGUAGENS=ALTA, CLASSIFICACAO_MATEMATICA=ALTA

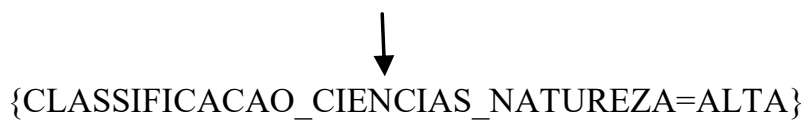

\section{REGRA 9}

$\{\mathrm{Q} 002=\mathrm{G}, \mathrm{Q} 025=\mathrm{B}$, CLASSIFICACAO_CIENCIAS_HUMANAS=ALTA, CLASSIFICACAO_LINGUAGENS=ALTA, CLASSIFICACAO_MATEMATICA=ALTA, CLASSIFICACAO_REDACAO=ALTA

$\{$ CLASSIFICACAO_CIENCIAS_NATUREZA=ALTA $\}$

\section{REGRA 10}

$\{\mathrm{Q} 002=\mathrm{G}$,

CLASSIFICACAO_CIENCIAS_HUMANAS $=$ ALTA, CLASSIFICACAO ${ }^{-}$LINGUAGENS=ALTA, CLASSIFICACAO_MATEMATICA=ALTA, CLASSIFICACAO_REDACAO=ALTA

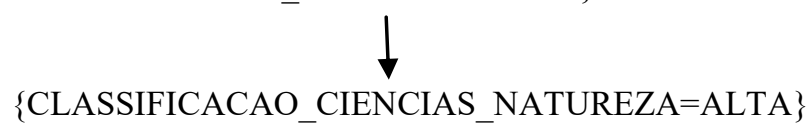

Seguem algumas explicações sobre as regras apresentadas:

- A variável Q025=B indica que o candidato tem acesso à internet em sua residência.

- $\quad$ A variável Q027=D indica que o candidato cursou o ensino médio somente em escola privada sem bolsa de estudo integral.

- $\quad$ A variável Q002=G indica que a mãe do candidato, ou mulher responsável por ele, tem como grau de escolaridade a pós-graduação.

As regras obtidas são similares entre si e evidenciam, em suma, que os alunos com rendimento mais levados nas provas do ENEM são aqueles: 
- $\quad$ Em que o pai ou mãe cursaram graduação ou a pósgraduação.

Que estudaram o ensino médio em escolas privadas e com faixa etária entre 18 e 24 anos.

- $\quad$ Com idade entre 18 e 24 anos, que cursaram o ensino médio em escola privada e que tem acesso à internet em casa.

Para facilitar a compreensão das regras apresentadas, segue a explicação da Regra 1, em que o suporte obtido foi de 0,01 e a confiança 0,93: 93\% (valor correspondente à confiança) dos alunos que tem acesso à internet em sua residência, com idade entre 18 e 24 anos e que obtiveram nota alta nas provas de Ciências Humanas, Linguagens, Matemática e Redação, também obtiveram nota alta na prova de Ciências da Natureza. Como o suporte dessa regra é de 0,01 , isso mostra que a proporção de transações que contém os itens descritos na regra é de $1 \%$. Conforme descrito no início dessa seção, todas as regras apresentadas nesse estudo possuem suporte abaixo de 0,02. A vantagem em se definir um suporte mínimo pequeno é a possibilidade de localizar regras envolvendo conjuntos menos frequentes, sendo essas de difícil deteç̧ão se relacionadas àquelas em que o suporte é maior.

\section{CONCLUSÕES}

O presente trabalho mostrou, utilizando a técnica de mineração de regras de associação, fatores relacionados ao bom desempenho no ENEM. Encontrou-se evidências de que o grau de instrução mais elevado dos pais, acesso à internet e escolas privadas contribuem para o bom desempenho do aluno neste exame. Verificou-se ainda que os alunos que apresentam bom rendimento em uma avaliação, tendem a repetir o bom desempenho nas demais provas. Isso aponta para a necessidade de se investir na educação pública de nível básico em nosso país, que ainda se apresenta deficiente em relação ao ensino privado, tal como no acesso a tecnologias como a internet e no uso de novas metodologias de ensino focadas no uso de Tecnologias da Informação e Comunicação (TICs). Essas TICs não se limitam ao simples uso do computador em laboratórios de informática, precisando atingir também o uso de outros dispositivos eletrônicos que fazem parte do cotidiano dos estudantes, como os smartphones. No que diz respeito ao emprego de softwares no processo de ensino e aprendizagem, há diversas opções gratuitas e de qualidade: Google for Education, Geogebra, Stellarium, Google Art Project, GoConqr, Trello, etc. Esses são apenas alguns dos vários exemplos disponíveis para romper com o tradicional modelo de ensino, onde apenas quadros de aula e livros eram utilizados.

Os estudos correlatos exibidos na seção 2.1 apontam resultados similares sobre a influência dos fatores socioeconômicos sobre a evasão obtidos por outros autores. Interessante notar que, nesses estudos, são analisados os microdados em períodos anteriores ao que foi utilizado no presente trabalho (2017). Isso evidencia que, mesmo muitas das causas já tendo sido exploradas pela comunidade científica, vários problemas que contribuem para o mau desempenho dos alunos permanece. Espera-se que trabalhos como esse contribuam para conscientização de dirigentes escolares e autoridades políticas, no sentido de desenvolver estratégias que coloquem a educação pública em um patamar de qualidade.

\section{REFERÊNCIAS BIBLIOGRÁFICAS}

ALVES, Rafael Damiani; CECHINEL, Cristian; QUEIROGA, Emanuel. Predição do desempenho de Matemática e Suas Tecnologias do ENEM utilizando técnicas de Mineração De Dados. In: Anais dos Workshops do Congresso Brasileiro de Informática na Educação. 2018. p. 469.

CHAPMAN, Pete et al. CRISP-DM 1.0: Step-by-step data mining guide. SPSS inc, v. 16, 2000.

De AMO, Sandra. Técnicas de mineração de dados, XXIV Congresso da Sociedade Brasileira de Computação, vol. 11, Jul/Ago 2004, pp. 43.

DE VASCONCELOS, Lívia Maria Rocha; DE CARVALHO, Cedric Luiz. Aplicação de regras de associação para mineração de dados na web. Revista Telfract, v. 1, n. 1, 2018.

FAYYAD, Usama; PIATETSKY-SHAPIRO, Gregory; SMYTH, Padhraic. From data mining to knowledge discovery in databases. AI magazine, v. 17 , n. 3, p. 37-37, 1996.

HOED, Raphael Magalhães. Análise da evasão em cursos superiores: o caso da evasão em cursos superiores da área de Computação. Brasília, DF: Universidade de Brasília, 2016.

KUMMER, Rodrigo; COLOGNESE, Silvio Antônio. Juventude rural no Brasil: entre ficar e partir. Tempo da Ciência, v. 20, n. 39, p. 201-220, 2013.

RIBEIRO, Adriano Cesar. Correlação e visualização de alertas de segurança em redes de computadores. São José do Rio Preto, SP: Universidade Estadual Paulista - Campus de São José do Rio Preto, 2015.

ROMÃO, Wesley et al. Extração de regras de associação em C\&T: O algoritmo Apriori. XIX Encontro Nacional em Engenharia de Produção, v. 34, p. 37-39, 1999.

SILVA, Leandro A.; MORINO, Anderson Hideki; SATO, Thiago Massahiro Conti. Prática de mineração de dados no exame nacional do ensino médio. In: Anais dos Workshops do Congresso Brasileiro de Informática na Educação. 2014. p. 651.

SIMON, Augusto; CAZELLA, Sílvio. Mineração de Dados Educacionais nos Resultados do ENEM de 2015. In: Anais dos Workshops do Congresso Brasileiro de Informática na Educação. 2017. p. 754.

STEARnS, Bernardo et al. Prevendo Desempenho dos Candidatos do ENEM Através de Dados Socioeconômicos. In: $36^{\circ}$ Concurso de Trabalhos de Iniciação Científica (CTIC 2017). SBC, 2017.

\section{COPYRIGHT}

Direitos autorais: Os autores são os únicos responsáveis pelo material incluído no artigo. 


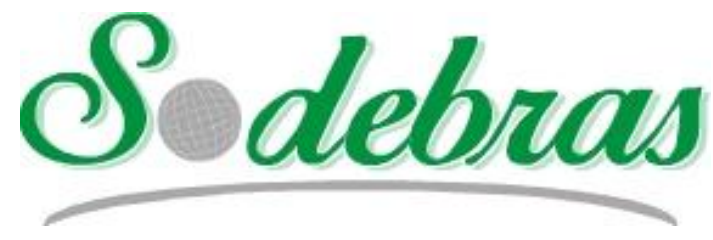

Volume 15 - $\mathrm{N}^{\mathrm{o}} 169$ - Janeiro / 2020

XLI International Sodebras Congress

31 de outubro a 02 de novembro de 2019 - Maceió - AL.

\title{
OS DESAFIOS DE UM LABORATÓRIO DE ANÁLISES CLÍNICAS PRIVADO EM TRABALHAR COM O SUS: UM CASO DE GESTÃO EM SAÚDE
}

\author{
THE CHALLENGES OF A LABORATORY OF PRIVATE CLINICAL ANALYZES \\ IN WORKING WITH THE SUS: A CASE OF MANAGEMENT IN HEALTH
}

\author{
CLARICE COSTA CUSTÓDIO ${ }^{1}$; BEATRIZ MARCONDES DE AZEVEDO ${ }^{1}$; FRED LEITE SIQUEIRA \\ CAMPOS $^{2}$; ROLF H. ERDMANN ${ }^{1}$ \\ 1 - UNIVERSIDADE FEDERAL DE SANTA CATARINA; DEPARTAMENTO DE CIÊNCIAS DA \\ ADMINISTRAÇÃO; 2 - UNIVERSIDADE FEDERAL DE SANTA CATARINA; DEPARTAMENTO DE \\ DE ECONOMIA E RELAÇÕES INTERNACIONAIS. \\ claricecostacustodio@hotmail.com; biabizzy@gmail.com; fred.campos@ufsc.br; rolf.erdmann@ufsc.br
}

\begin{abstract}
Resumo - O presente estudo teve por objetivo analisar a percepção da gestora de um laboratório de análises clínicas, do extremo sul catarinense, a respeito do processo de gestão em saúde relativo aos serviços prestados pelo Sistema Único de Saúde que possuem ligação direta com o desempenho das suas atividades. Trata-se de pesquisa qualitativa que apresentou resultados onde se observou que o Sistema Único de Saúde é um dos melhores sistemas do mundo, porém, apresenta problemas de gestão que precisam ser corrigidos para otimizar os seus resultados.
\end{abstract}

\begin{abstract}
Palavras-chave: SUS; Gestão; Análises Clínicas; Laboratório. Abstract - The present study aimed to analyze the management of a process of analysis of the extreme tasks of Santa Catarina in relation to the process of management of services provided by the Unified Health System. This is a qualitative research that presents the results that the Sistema Unico de Health is one of the best systems in the world, however, it presents management problems that can be corrected to optimize results.
\end{abstract}

Keywords: SUS; Management; Clinical analysis; Laboratory.

\section{INTRODUÇÃO}

Atualmente tem se observado um aumento na melhoria das condições de vida e saúde da população. Este processo tem ocorrido graças a avanços obtidos em vários âmbitos: políticos, econômicos, sociais, ambientais, na própria medicina e na saúde pública (BUSS, 2000).

No entanto, a OMS e OPAS (1998) afirmam que ainda que os números estejam cada vez melhores, as taxas de desigualdade continuam subindo. Para ambas as organizações, existem expressivos níveis de desigualdade nas condições de vida e, consequentemente, este fato causa reflexos significativos nas condições de saúde da população. Em função do aumento da desigualdade e de outras necessidades, o Brasil conta com o apoio do Sistema Único de Saúde (SUS) desde 1988. O SUS é um sistema dinâmico e complexo que segue princípios que descrevem o direito à saúde como um direito do cidadão e um dever do Estado. Não obstante aos princípios, há referência sobre a abrangência dos atendimentos. Neste quesito, o sistema preconiza um atendimento humanizado e universal, atendendo a todos que precisam, sem distinção de raça, credo ou cor (PAIM et al., 2011).

Para conseguir atender a população da melhor maneira e abranger todas as linhas de cuidado, o Ministério da Saúde publicou em 1993, a Portaria GM/MS no 1.286/93, que normatiza a contratação de serviços de saúde por gestores do SUS. Neste documento estão presentes os direitos e deveres do contratando, sempre preservando o paciente (MINISTÉRIO DA SAÚDE, 2016).

A área de análises clínicas como serviço de auxilio diagnóstico está em amplo crescimento no país. Conforme, dados do Sistema de Informações Ambulatoriais do Sistema Único de Saúde (SIA/SUS), no ano de 2009 foi gasto em torno de R\$ 1,8 bilhão de verba federal destinada a procedimentos realizados em laboratórios clínicos. Segundo dados obtidos da Secretaria de Saúde de Pelotas (2002), no período de um mês foram realizados em média 55 mil exames de análises clínicas. Já dados dos Parâmetros Assistenciais do Sistema Único de Saúde, do Ministério da Saúde do Brasil, em média 30 a $50 \%$ das consultas ambulatoriais acabam gerando pedidos médicos para a realização de exames de laboratório (RIPSA, 2002).

$\mathrm{Na}$ maioria dos casos, o setor público não possui laboratório de análises clínicas próprio, seja por uma questão de redução de custo, aumento da oferta dos serviços, fazendo com que as análises laboratoriais sejam terceirizadas, ou ainda, visando aumentar a qualidade do serviço prestado, optar por sua terceirização se torna algo atrativo. No entanto, essa ação do setor público é muitas vezes vista como uma atitude tardia adotada para alcançar modelos anteriormente implantados pelo setor privado (PREKER, 2005).

Atualmente, é crescente a quantidade de estudos que discutem sobre o SUS, em seus processos, a própria preocupação com a terceirização de serviços por conta do financiamento e subfinanciamento do sistema, sem considerar a preocupação com a privatização de diversos de seus serviços. Tais estudos têm sido desenvolvidos por pesquisadores como, Marcelino (2007), Carvalho e Barbosa (2010), Polignano (2001). No entanto, observa-se que quase não se aborda as dificuldades encontradas por empresas 
terceirizadas, que buscam realizar dignamente o seu serviço, mas que encontram no próprio SUS um empecilho para o seu desempenho com excelência.

Desta forma, a presente pesquisa objetivou analisar a percepção da gestora de um laboratório de análises clínicas, do extremo sul catarinense, sobre o processo de gestão em saúde referente aos serviços prestados pelo SUS que possuem ligação direta com o desempenho do laboratório. Além disso, o estudo procurou descrever as atividades do Sistema Único de Saúde que possuem ligação direta com o desempenho das atividades laboratoriais da organização investigada e também, descrever, de acordo com a gestora, os pontos positivos e negativos da gestão em saúde do SUS que possuem ligação direta com o desempenho das suas atividades.

\subsection{O SUS}

O descaso com a saúde pública sempre foi um fator notório no cenário brasileiro. No início do século XX o Brasil apresentava um contexto caótico, a então capital do país, Rio de Janeiro, estava sob surtos de varíola, malária, febre amarela e a peste. Foi neste contexto que o presidente Rodrigues Alves nomeou Oswaldo Cruz como Diretor do Departamento Federal de Saúde Pública (POLIGNANO, 2001). Segundo Luz (1991), Oswaldo Cruz buscou combater, em primeiro lugar, as epidemias urbanas e mais tarde, quando estas já estivessem finalizadas, as rurais. Para o mesmo autor, nessa mesma época a estrutura organizacional da administração da saúde pública era centralista, tecnoburocrática e corporativista.

Nos anos que seguiram, o país passou por sérias dificuldades, visto a falta de gestão consciente, a terceirização descabida e a ineficiência da fiscalização. Neste mesmo período, foram criados diversos programas como INAMPS, CONASP, SAMHPS, AIS, entre outros, que muito colaboraram, porém não se mostraram efetivamente eficazes (POLIGNANO, 2001).

Em 1986, houve a VIII Conferência Nacional da Saúde que visava a disseminação de um projeto de reforma sanitária no país, cujos objetivos seguiam desde universalização do acesso, equidade, integralidade hierarquização, descentralização, regionalização e a participação social (CARVALHO; BARBOSA, 2010). No ano seguinte, houve a criação do Programa de Desenvolvimento de Sistemas Unificados de Saúde (SUDS). Mendes (1993) comenta sobre as principais mudanças geradas pelo SUDS, assinalando que houve uma desconcentração do Estado para os Municípios, bem como o aumento de repasse a esses e restrição dos poderes da Instituição Sustentadora do Modelo Médico-Assistencial Privatista, entre outros.

Anos mais tarde, em 1990, no governo de Fernando Collor de Melo, foi aprovada a Lei Orgânica da Saúde $(8.080 / 90)$ e a Lei 8142. Ambas davam sustentação à implantação do SUS, descrevendo suas atribuições e sua organização (CARVALHO; BARBOSA, 2010). Para o Ministério da Saúde (2016), o SUS conta com três princípios doutrinários: Universalização; Equidade; Integralidade. Além destes, o Ministério da Saúde cita que existem ainda os princípios organizacionais do SUS. São eles: Regionalização; Hierarquização; Descentralização e Participação Social.

Atualmente, não somente os princípios organizacionais do SUS propõem os rumos da saúde no Brasil, mas também a Constituição de República Federativa do Brasil (CF) de 1988. Neste mesmo texto, a CF pontua que a saúde é um direito de todos os cidadãos e que é dever do Estado promovê-la. Desta forma, nota-se que é na carta magna que está estabelecida a base legal jurídica que constitui a política de saúde deste país. Principalmente nos artigos anteriormente referidos é que esta base se dá, de forma que nela fica evidente o processo de organização do SUS e suas diretrizes (TEIXEIRA, 2016).

\subsection{Terceirização}

Conforme Marcelino (2007), o processo de terceirização é caracterizado pela contratação de trabalhadores ou serviços por uma empresa interposta. Nesta direção tem-se o art. 199 da CF, que em seu primeiro parágrafo propõe que a contratação de serviços de saúde de forma complementar das instituições privadas devem ser estabelecidas de maneira formal. Neste mesmo artigo, há a especificação de que a contratação de tais serviços deve suprir a insuficiência dos serviços no setor público (BRASIL, 1988).

Sendo assim, em 1993, foi publicada pelo Ministério da Saúde a portaria GM/MS n ${ }^{\circ} 1.286 / 93$, que apresentava as cláusulas que deveriam se fazer presentes em um contrato de prestação de serviços de saúde, contratados pelo gestor em saúde do município, atualmente revogada. Nesta portaria se fazia presente os direitos e deveres do contratante e do prestador do serviço, sendo que este último poderia ser um dos níveis do governo, pessoas físicas, jurídicas, entidades com ou sem fins lucrativos, de forma a ficar claro e objetivo (BRASIL, 1993).

Perante a contratação desenfreada que surgiu, sem a devida observância da legislação, o Ministério da Saúde se atentou à elaboração de uma portaria capaz de estabelecer os critérios para tais contratações (Portaria GM/MS n ${ }^{\circ} 1.034$, de 05 de maio de 2010). Neste documento foram pontuados os critérios para que seja aceita a participação de entidades privadas na prestação de serviços para o SUS. Para tanto, ali está descrito que para que isso seja efetivado o gestor de saúde do município deve elaborar um documento que relate a insuficiência do próprio serviço prestado em determinada área, a fim de justificar a contratação do serviço complementar (BRASIL, 2010).

Dentre as várias legislações vigentes, algumas assumem destaque quando o assunto é o SUS e as suas atividades. Assinala-se a Lei Orgânica 8.080/90, que como sua própria ementa diz, "Dispõe sobre as condições para a promoção, proteção e recuperação da saúde, a organização e o funcionamento dos serviços correspondentes e dá outras providências". Sendo esta então, uma lei norteadora também das questões de contratação e terceirização de serviços. De acordo com essa mesma Lei, o SUS fica livre para realizar a contratação de serviços de iniciativas privadas, toda vez que a disponibilidade do serviço ofertado por si próprio for insuficiente para garantir a assistência à saúde da população. Neste mesmo capítulo, em seus artigos e parágrafos que o seguem, ficam apresentadas as condições para tais contratações (BRASIL, 1990).

\subsection{Laboratório de Análises Clínicas}

Os laboratórios de análises clínicas estão, cada vez mais, assumindo um importante papel no sistema de saúde brasileiro. Estes estabelecimentos vem oportunizando a 
prevenção e a avaliação dos estados de saúde da população. Com isso favorecem o diagnóstico clínico adequado pelo médico, amplia as chances de cura, visto a rápida constatação do quadro clinico, facilitando o acompanhamento de quadros que possuem alterações, fazendo com que as intervenções, quando necessárias, sejam realizadas o mais rápido possível e com a maior certeza, esses e diversos outros benefícios são oportunizados (ANTUNES; CHIARI; LUCENA, 1984).

Conforme o Conselho Federal de Farmácia, representado pelo farmacêutico Gabriel Lima-Oliveira (2011), os laboratórios de análises clínicas possuem um processo dinâmico e adequadamente paramentado à realização de suas atividades, visto a ampla quantidade de procedimentos realizados, bem como a relevância das mesmas para os pacientes e demais serviços de saúde. Para o Conselho, tal processo tem início com a coleta do material biológico que se buscará fazer o diagnóstico e finda-se com a emissão do laudo, contendo o resultado da análise realizada. Sendo assim, o processo é subdividido em três fases principais: a pré-analítica, a analítica e a pós-analítica.

A fase pré-analítica é composta por uma série de atividades que antecedem a fase de análise da amostra e que possuem tanta importância quanto à própria análise do material. Sendo assim considera-se como fase pré-analítica: a recepção e checagem da requisição, a orientação de coleta, a coleta propriamente dita, o armazenamento e o transporte da mesma (PARANÁ, 2015).

Para Sumita (2014), a fase analítica é aquela na qual se dá a realização dos exames previamente solicitados, cadastrados, coletados. Chaves (2010) completa esta descrição, propondo que é nesta fase que o laboratório deve agir, mais do que nunca, com atenção, visto que qualquer erro cometido pode gerar um resultado não fidedigno à realidade do paciente, sendo que será esse resultado que dará uma base ao médico para realizar um possível tratamento.

$\mathrm{Na}$ fase pós-analítica é onde ocorre a validação e liberação de laudos e se encerra no momento em que o médico recebe o resultado. Assim, é nesta fase que ocorre o contato laboratório-médico quando há resultados alterados ou duvidosos, e também médico-laboratório, quando o médico precisa tirar alguma dúvida sobre metodologias ou o resultado propriamente dito (PLEBANI, 2007).

\subsection{Gestão em Saúde}

O sistema de saúde tem se mostrado cada vez mais complexo e reconhecido por englobar um expressivo número de serviços e colaboradores. Além disto, tal sistema tem sofrido contínuas mudanças e lidado com novos desafios, sendo que os reflexos destes fatores se apresentam na gestão em saúde. Assim, há um aumento significativo de cobrança aos gestores frente à necessidade de promover educação continuada e processos inovadores. Portanto, a formação acadêmica de gestores na área se apresenta como ponto culminante para o bom desempenho da gestão (REIS, 2004).

Do ponto de vista histórico, gestão em saúde é um desdobramento do planejamento estratégico, que surgiu desde a formulação da Saúde Pública, englobando várias áreas. Com sua evolução, gerou-se a necessidade de um dispositivo capaz de solucionar problemas de saúde no âmbito coletivo, dando início a "administração sanitária e de práticas em saúde". Seguindo a história, pouco antes do século XX houve a mudança de conceitos, da administração sanitária e de práticas em saúde, para a Gestão em Saúde, trocando ações de prevenção em guerras e afins, por Ciência Política, Sociologia e pela Teoria Geral da Administração (CAMPOS; CAMPOS, 2009).

Para tanto, Reis (2004) descreve que a preocupação com todas essas mudanças irá exigir dos gestores uma profissionalização ainda maior e um comprometimento para com o serviço e com a população. É neste momento que as aptidões, competências e adaptabilidade irão se transformar no maior fator de sucesso para as gestões da atualidade.

\section{METODOLOGIA}

Esse estudo é caracterizado como uma pesquisa qualitativa, em forma de estudo de campo. Num primeiro momento a empresa escolhida foi submetida à uma carta de aceite, para fins de realização da entrevista, análise e observações in loco. Quanto aos fins de investigação, a mesma foi de caráter descritivo, visto que não foram quantificados dados numéricos, apenas entrevistas, análises e observações.

Para realizar a análise dos dados obtidos, a técnica selecionada foi a de análise de conteúdo. A análise se deu com o olhar crítico do pesquisador tendo em mente o seu conhecimento acerca do tema. Com isso houve a descrição do que foi relatado, de forma objetiva e, em seguida, confrontou-se os levantamentos bibliográficos consultados com a realidade estudada.

\section{RESULTADOS}

\subsection{Apresentação da empresa}

A laboratório estudado surgiu no ano de 1991, onde a já experiente farmacêutica, resolveu se lançar no ramo empreendedor, inaugurando sua primeira unidade. Desde então o empreendimento não para de crescer, hoje conta com seis unidades espalhadas pelo extremo sul catarinense, atendendo diferentes microrregiões.

A empresa é exemplo de seriedade e garantia de resultados em todos os municípios que atua. Atualmente, possui a ISO 9001, cadastro em programas de controle de qualidade como Qualichart, e é membro participante das rodadas de controle interno e externo no PNCQ (Programa Nacional de Controle de Qualidade).

Assim, para seguir o seu caminho de sucesso, o laboratório possui diretrizes organizacionais bem paramentadas, dando embasamento para seus funcionários no labor diário. A empresa atende clientes, particulares, conveniados aos planos de saúde ou encaminhamentos do SUS, da mesma maneira, sem distinções. Semelhantemente, a manipulação das amostras e resultados dos pacientes é realizada igualitariamente.

Em seu quadro funcional estão mais de vinte colaboradores distribuídos em todas as unidades. Dentre eles, seis são analistas clínicos com especialização (sendo cinco farmacêuticas bioquímicas e uma biomédica). A equipe de analistas clínicos busca frequentemente cursos e novos aprendizados, para cada vez mais superar as expectativas dos clientes e garantir a qualidade de seus resultados. Os outros colaboradores são divididos entre técnicos em análises clínicas ou auxiliares de laboratório. Como consta nas diretrizes organizacionais, todos são 
submetidos constantemente a treinamentos e aperfeiçoamentos oferecidos pelo próprio laboratório. Com isso, a empresa busca renovar os conhecimentos e ir se adaptando as novidades do setor.

É importante assinalar que, por uma questão de logística, este trabalho se deu em uma única unidade do laboratório, sendo esta a matriz.

\subsection{Contratação}

De acordo com a gestor, o processo de contratação mudou há algum tempo, pois nem sempre foi no formato que é agora. Segundo ela, assim que começou a trabalhar com o SUS, era feita uma espécie de concurso, onde o vínculo era com o Estado e este por, sua vez, era quem administrava toda a verba e locais para investimento. Atualmente, o processo é chamado de vigência plena, onde a administração do repasse de verbas que era feito e gerido pelo Estado, agora é realizado pelo município. Sendo assim, os gestores municipais e de saúde, fazem aplicações que julga prioritárias, tendo autonomia sobre a gestão e sobre as finanças. Sendo a secretaria municipal da saúde o principal setor responsável pela administração da verba destinada a este setor. Tal mudança está descrita na norma operacional da assistência à saúde/ SUS - NOAS-SUS 01/2001. A referida norma cita que foi elaborada com o intuito de promover uma integração entre as esferas do governo e uma descentralização, principalmente no que diz respeito à autonomia dos municípios sobre suas responsabilidades, deveres e gestão de recursos.

Desta forma ela explica que o SUS, em âmbito municipal, propõe uma série de pré-requisitos básicos para os laboratórios que querem se vincular a ele. Dentre os prérequisitos destaca-se a apresentação de todos os alvarás comprovando que não haver pendências com o INSS; além de documentos que comprovam sua credibilidade no mercado. A gestora ainda explica que, apesar de existir essa vigência plena e o município possuir maior autonomia, ele é parte de um todo do Sistema Único de Saúde, e sendo assim, segue as mesmas leis, normas e a Constituição Federal, havendo, portanto, padronização dos procedimentos, independente da gestão.

Após isso, se o laboratório apresentar todos os documentos pedidos, o SUS submete o mesmo a um termo de aceite, um contrato, que estipula todos os pré-requisitos que devem ser seguidos, tendo vigência de um ano. Nesta mesma linha, a secretária municipal de saúde, que neste caso é quem gere o SUS, questiona se o laboratório aceita trabalhar com a tabela SUS. Se todos os documentos forem entregues de acordo com o pedido, e se o laboratório acordar em trabalhar com o SUS e com a sua tabela, iniciase o trabalho.

Sendo assim, com relação a este item a gestora relata que tudo é seguido conforme as leis e normas vigentes. Não tem do que reclamar quanto ao processo de contratação.

\subsection{Financeiro}

Posteriormente ao tema contratação, foi debatida a questão financeira em se trabalhar com o SUS. Para a gestora, a tabela de preços está desatualizada, com valores aquém do real valor de mercado, frequentemente acaba nem cobrindo os custos com a realização do próprio exame. Segundo ela, o retorno financeiro é um ponto que merece reflexão a cada renovação de contrato com o sistema, visto que o custo envolvido com os procedimentos estão em constante aumento e, em contrapartida, o valor atribuído aos exames pelo SUS, não são modificados. Sendo assim, trabalhar com o SUS não é financeiramente interessante para o laboratório.

Para tanto, a mesma salienta que apesar de o valor do pagamento pelos exames ser baixo, trabalhar com o SUS acaba sendo um bom negócio para os laboratórios, principalmente para os que estão começando. A mesma afirma que o SUS encaminha aos laboratórios clientes, que se bem atendidos e satisfeitos com os resultados, podem acabar por se tornar fieis e, em uma próxima vez que necessite fazer exames, ali retorne. A gestora pondera que "temos que lembrar que hoje o paciente está realizando o seu exame pelo SUS, mas amanhã, ele ou algum membro da sua família, pode voltar para fazer exames particular".

Com base no exposto, fica evidente que o sistema acaba por ser um provedor de possíveis clientes para o laboratório, basta o mesmo realizar o seu trabalho da melhor maneira possível.

\subsection{Instruções de coleta}

As instruções de coleta são importantes e devem ser realizadas com excelência, para que não comprometam os resultados dos exames. Desta forma, como visto anteriormente, elas fazem parte do processo pré-analítico, que, no entanto é realizado, parte pela UBS (Unidade Básica de Saúde), na figura do médico, da enfermeira ou atendente e parte pelo paciente.

Deste modo, o correto é, quando a UBS não souber instruir o paciente da melhor forma possível, que esta, por sua vez, o encaminhe ao laboratório para pegar as instruções. No entanto, segundo a gestora, isso muitas vezes não acontece. Existem diversos casos em que os pacientes são instruídos de maneira correta, porém, existe também uma gama de erros que acontecem. Segundo a gestora, um erro comum é com relação ao exame de pesquisa de sangue oculto nas fezes. Este exame necessita, para a sua realização pela metodologia autorizada pelo SUS, que o paciente cumpra três dias de restrição alimentar e colete a amostra fecal no quarto dia.

Para tanto, quando a UBS não sabe instruir como o paciente deve realizar a dieta, como deve fazer a coleta da amostra, a mesma deve indicar ao paciente que se dirija ao laboratório para ser instruído. Vale lembrar que na guia de autorização de exames, está descrito apenas que o paciente deve realizar dieta, enquanto para outros exames, há descrição das especificações completas como, por exemplo, o tempo de jejum. $\mathrm{O}$ que a gestora explica a UBS não menciona que o paciente tem que realizar uma dieta, ou o mesmo não compreende que deve se encaminhar ao laboratório para ser instruído ou, é instruído erroneamente.

Como tratado anteriormente, outra divergência comum é em relação aos cuidados que o paciente tem que ter, que vem descrito na guia de autorização dos exames. Nesta, em um campo específico, consta o nome do exame e, abaixo dele, os cuidados que devem ser seguidos. Porém, em alguns casos esta instrução não está correta ou está incompleta, a exemplo o hemograma, que é de conhecimento científico, não necessitar de jejum a não ser em casos onde o paciente realize uma refeição pesada momentos antes da coleta que, neste caso, são pedidas de 3 a 4 horas de jejum. No entanto, 
nesta guia consta que o paciente deve realizar de 8 a 12 horas de jejum.

\subsection{Autorização}

Neste quesito a gestora relatou como acontece o processo. Partindo da consulta, o médico, quando necessário, monta uma requisição de exames para o paciente. Após, espera-se a autorização pelo SUS. Desta forma, a gerente explica que o paciente deverá ter duas folhas quando se encaminhar ao laboratório, o pedido médico e a guia de autorização do SUS. A mesma lembra que a autorização dos exames se dará de acordo com a cota de exames disponibilizada pelo sistema, sendo assim, o laboratório confere se todos os exames solicitados pelo médico foram autorizados pelo SUS.

Se nas duas folhas estiverem todos os exames, o laboratório cadastra o paciente e realiza o procedimento analítico. No entanto, segundo a mesma, existem algumas incongruências neste processo, comumente quem trabalha no setor responsável por autorizar os exames não tem conhecimento específico nessa área e é neste momento que as falhas acontecem. A gerente expõe que já houve casos de o exame ser autorizado errado (nomes serem parecidos), ou mesmos erros ainda maiores. Uma mesma requisição médica pode ser autorizada para dois laboratórios, onde parte dos exames serão realizados em um e parte em outro, no entanto, ela relata que já aconteceu casos de o SUS autorizar um único exame cujo nem tinha sido pedido pelo médico e todos os demais não serem autorizados.

\subsection{Processos analíticos e pós-analíticos}

Os processos de análises de transporte, triagem e análise de amostras são realizados igualitariamente entre todos os pacientes, sem distinção por convênio. Desta forma, segundo a gestora, desmistifica-se a ideia de que os pacientes do SUS são tratados diferente, e que os seus exames não são realizados com o mesmo zelo.

De acordo com ela, a liberação de laudos também é feita de forma igual para todos os convênios. Os exames são impressos, assinados e dispostos em envelopes específicos, os quais são entregues aos pacientes na data prevista.

\section{CONCLUSÃO}

Esta pesquisa objetivou analisar a percepção da gestão de um Laboratório de Análises Clínicas, do extremo sul catarinense, a respeito do processo de gestão em saúde relativo aos serviços prestados pelo SUS que possuem ligação direta com o desempenho das suas atividades. Para alcançar este objetivo foi aplicado um roteiro de entrevista com a gestora do laboratório selecionado e houve a observação in loco das variáveis investigadas. Neste processo houve a explanação do que realmente acontece no cotidiano de quem trabalha com o SUS.

Ficou evidente no trabalho que existe falha na gestão do SUS, apesar de o mesmo ser considerado um sistema bem paramentado, a gestão ainda não é realizada da melhor maneira. Como pode-se observar, há vários processos que apresentam erros, sendo os de autorização de exames e o de instruções de coletas, os mais perturbadores. Frequentemente, a gestão tenta realizar o seu papel de uma maneira adequada, no entanto, enquanto alguns acham que estão acertando, não se preocupam em ter um feedback da instituição que estão contratando. Neste ponto, fica exposto que essa falta de comunicação acaba por restringir o melhoramento do sistema e de suas ações.

O laboratório se mostrou em conformidade com as atribuições pré-estabelecidas tanto pela legislação vigente, em especial a Lei 8080/90, quanto com as solicitações propostas pela gestão municipal de saúde. Com base nos dados coletados, ficou claro que o laboratório pesquisado trata todos os seus clientes da mesma maneira, sem distinções e que segue, principalmente a orientação de se portar como SUS tendo escolhido ser terceirizado pelo mesmo. Não só isso, o SUS se apresenta como ponto positivo no início do processo de consolidação da marca de um laboratório. É neste ponto que o Sistema Único de Saúde encaminha pacientes para os laboratórios, e neste processo os mesmos tem a sua divulgação. Com isso, se o atendimento e os resultados do processo agradarem os pacientes, estes poderão se tornar fiéis ao estabelecimento.

Conclui-se que o SUS não é criterioso ao contratar pessoas para os setores de autorização de exames e para instruir os pacientes para a realização de exames. Talvez o que falte, além de uma gestão preocupada com a contratação de pessoas experientes e qualificadas, seja uma política pública que garanta a sequência dos trabalhos de alguma maneira, não restringindo aos quatro anos da vigência do mandato do prefeito.

\section{REFERÊNCIAS}

ANTUNES, Carlos M. F.; CHIARI, Cléa de A.; LUCENA, Bertolino, N.C. Laboratórios de análises e patologia clínica em Belo Horizonte, MG (Brasil): classificação quanto ao atendimento e exames realizados. Revista de Saúde Pública, Belo Horizonte, v. 1, n. 19, p.79-87, nov. 1984.

BRASIL. Constituição (1988). Artigo $\mathrm{n}^{\circ} 200$, de 05 de outubro de 1988. Ao sistema único de saúde compete, além de outras atribuições nos termos da lei. Brasília, Seção 2, p. 62-62.

BRASIL. Lei $\mathbf{n}^{\circ} \mathbf{8 . 0 8 0}$, de 19 de setembro de 1990. Dispõe sobre as condições para a promoção, proteção e recuperação da saúde, a organização e o funcionamento dos serviços correspondentes e dá outras providências. Brasília.

BRASIL. Ministério da Saúde (1993). Portaria no 1.286, de 26 de outubro de 1993. GM/MS N 1.286/93. Brasília.

BRASIL. Portaria $\mathbf{n}^{\mathbf{0}} \mathbf{1 . 0 3 4}$, de 05 de maio de 2010. Dispõe sobre a participação complementar das instituições privadas com ou sem fins lucrativos de assistência à saúde no âmbito do Sistema Único de Saúde. Brasília.

BUSS, Paulo Marchiori. Promoção da saúde e qualidade de vida. Ciência \& Saúde Coletiva, Rio de Janeiro, v. 1, n. 5, p.63-177. 2000. Disponível em: $<$ https://www.scielosp.org/pdf/csc/2000.v5n1/163-177/pt>. Acesso em: 23 set. 2018

CAMPOS, Gastão Wagner de Sousa; CAMPOS, Rosana Teresa Onocko. GESTÃO EM SAÚDE. Dicionário da Educação Profissional em Saúde: Fiocruz, Rio de Janeiro, $2009 . \quad$ Disponível em: $<$ http://www.sites.epsjv.fiocruz.br/dicionario/verbetes/gessa u.html>. Acesso em: 02 nov. 2018. 
CARVALHO, Antônio Ivo de; BARBOSA, Pedro Ribeiro. Políticas de saúde: fundamentos e diretrizes do SUS. Florianópolis: Departamento de Ciências da Administração / UFSC; CAPES: UAB, 82p. 2010.

CHAVES, Carla D. Controle de qualidade no laboratório de análises clínicas. Jornal Brasileiro de Patologia e Medicina Laboratorial, [s.1.], v. 46, n. 5, p.352-352, out. 2010. FapUNIFESP (SciELO). http://dx.doi.org/10.1590/s1676-24442010000500002.

LUZ, Madel Therezinha. Notas sobre as políticas de saúde no Brasil de "transição democrática" - anos 80. PHYSIS - Revista de Saúde Coletiva. v.1, n 1, 1991.

MARCELINO, Paula. Afinal, o que é terceirização? Em busca de ferramentas de análise e de ação política. Pgada, São Paulo, v. 2, n. 8, p.1-17, dez. 2007.

MENDES, Eugênio Vilaça. As políticas de saúde no Brasil nos anos 80; a conformação da reforma Sanitária e a construção de hegemonia do projeto neoliberal. In: MENDES, Eugênio Vilaça (org.) Distrito Sanitário: o processo de mudança das práticas sanitárias do Sistema Único de Saúde. HUCITEC/ ABR. 1993.

MINISTÉRIO DA SAÚDE. Manual de orientações para contratação de serviços de saúde. Brasília: Governo Federal, 2016. 63 p.

OLIVEIRA, Gabriel Lima (Brasil). Gestão da qualidade laboratorial: é preciso entender as variáveis para controlar o processo e garantir a segurança do paciente. São Paulo: Conselho Federal de Farmácia, 2011. 12 p.

OPAS, Organização Pan Americana de Saúde. La Salud en las Américas, v. 1. OPAS. Washington. 368 p. 1998.

PAIM, Jairnilson et al. O sistema de saúde brasileiro: história, avanços e desafios. The Lancet, Salvador, p.11-31, 09 maio 2011.

PARANÁ. Etienne Wessler Coan. Secretaria do Estado da Saúde. Processos operacionais: Paraná: Imagem, 2015. 57 slides, color. Disponível em: $<$ http://www.lacen.saude.pr.gov.br/arquivos/File/SESLAB/ Col_Env.pdf $>$. Acesso em: 28 out. 2018.

PLEBANI, M. Errors in laboratory medicine and patient safety: the road ahead. Clin Chem Lab Med, v. 45, n. 6, p. 700-7, 2007.

POLIGNANO, Marcus Vinícius. Histórias das políticas de saúde no Brasil: uma pequena revisão. Cadernos do Internato Rural - Faculdade de Medicina/UFMG, 2001.

PREKER, Alexander, S. Managing scarcity through strategic purchasing of health care in spending wisely: buying health services for the poor (A.S Preker \& John C. Langenbrunner). Washington D.C.: The World Bank, 2005.

REIS, Vasco Pinto dos. Gestão em saúde. Revista Portuguesa de Saúde Pública, Rio de J, v. 22, n. 1, p.7-17, jun. 2004. Rio de Janeiro.

RIPSA. Rede Interagencial de Informações para a Saúde. Indicadores básicos de saúde no Brasil: conceitos e aplicações. Brasília (DF): Organização Pan-Americana de Saúde; 2002.
SUMITA, Nairo Massakazu. Exames laboratoriais e a importância dos cuidados pré-analíticos. 2014. Disponível em: $<$ http://www.fleury.com.br/medicos/educacaomedica/artigos/Pages/exames-laboratoriais-e-a-cuidadospre-analiticos.aspx>. Acesso em: 01 nov. 2018.

TEIXEIRA, Carmen. Os princípios do sistema único de saúde. $2016 . \quad$ Disponível em: $<$ https:/www.almg.gov.br/export/sites/default/acompanhe/e ventos/hotsites/2016/encontro_internacional_saude/docume ntos/textos_referencia/07_principios_sistema_unico_saude. pdf $>$. Acesso em: 22 out. 2018.

\section{COPYRIGHT}

Direitos autorais: $\mathrm{O}(\mathrm{s})$ autor(es) é(são) o(s) único(s) responsável(is) pelo material incluído no artigo. 


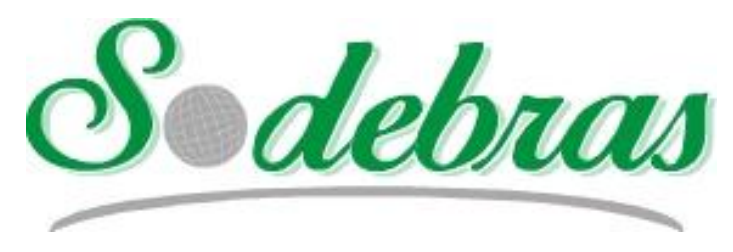

Volume 15 - No 169 - Janeiro / 2020

XLI International Sodebras Congress

31 de outubro a 02 de novembro de 2019 - Maceió - AL.

\title{
AVALIAÇÃO DOS NÚCLEOS DE INOVAÇÃO (NIT) DO INSTITUTO FEDERAL DO PARANÁ
}

\section{EVALUATION OF INNOVATION CLUSTERS (IC'S) OF THE FEDERAL INSTITUTE OF PARANÁ}

\author{
CLAYTON PEREIRA DE SÁ ${ }^{1}$; GUILHERME JOSÉ ALVES TURCATEL ${ }^{2}$; PAULO R. P. RODRIGUES ${ }^{3}$ \\ 1 - INSTITUTO FEDERAL DO PARANÁ; 2-UNIVERSIDADE ESTADUAL DO CENTRO OESTE. \\ clayton.sa@ifpr.edu.br; guilhermeturcatel@gmail.com; prprodrigues@gmail.com
}

\begin{abstract}
Resumo - Este trabalho apresenta o resultado da pesquisa sobre os Núcleos de Inovação Tecnológica do Instituto Federal do Paraná. O IFPR conta com vinte e seis Campi espalhados pelo estado do Paraná, sendo seis deles avançados e um centro de referência. O NIT tem a função de incentivar $e$ assessorar o processo de proteção intelectual produzida pela instituição. Através da pesquisa foi possível identificar quais ações a instituição está executando para melhorar a gestão da inovação. $O$ estudo traz dados importantes sobre as necessidades que os NIT apresentam no curto e médio prazo. A metodologia utilizada é quali e quantitativa, exploratória e documental. Para levantar os dados foi utilizado formulário eletrônico. Portanto, este artigo possibilita avaliar como os NIT estão trabalhando e quais medidas podem ser adotadas para fomentar a inovação no IFPR.
\end{abstract}

Palavras-chave: Inovacão. Tecnologia. Propriedade intelectual.

Abstract - This work presents the result of the research on the Nuclei of Technological Innovation of the Federal Institute of Paraná. The IFPR counts on twenty and six Campi spread by the state of the Paraná, being six of advanced them and center of reference. NIT has the function to stimulate and to assist the process of intellectual protection produced by the institution. Through the research it was possible to identify to which actions the institution is executing to improve the management of the innovation. The study backwards important data on the necessities that NIT presents in the short and average stated period. The used methodology is quali and quantitative, exploratória and documentary. To raise the data electronic form was used. Therefore, this article makes possible to evaluate as NIT is working and which measures can be adopted to foment the innovation in the IFPR.

Keywords: Innovation. Technology. Intellectual Property.

\section{INTRODUÇÃO}

Este trabalho tem como objetivo avaliar a influência das políticas de inovação desenvolvidas no Instituto Federal do Paraná (IFPR). Estas ações são aplicadas pelos Núcleos de Inovação Tecnológica (NIT). O órgão tem como principal finalidade a gestão da política institucional de inovação e proteção das tecnologias desenvolvidas. Os NIT estão presentes nas universidades e institutos de pesquisa, auxiliando o empreendedorismo e a geração de vantagem competitiva para o Brasil. Tal fato tem previsão na Lei 13.243, de 11 de janeiro de 2016.

A lei de criação dos NIT estabelece que estes podem ser constituídos por uma ou mais estruturas instituídas por uma ou mais Instituição Científica, Tecnológica e de
Inovação (ICT), com ou sem personalidade jurídica própria. Assim, o órgão busca promover a inovação e a proteção gerada nas instituições públicas de pesquisa, bem como o processo de transferência de tecnologia ao setor privado. A gestão do processo de inovação no Instituto Federal do Paraná é coordenada pela Agência de Inovação do IFPR (AGIF), que é vinculada à PROEPPI (Pró-reitoria de Extensão, pesquisa, Pós-graduação e inovação). Segundo Koberg et al. (1996), a gestão da inovação envolve um nível de complexidade que desafia as organizações

O IFPR possui 26 campi espalhados pelo estado do Paraná, tornando a gestão uma atividade complexa. Os campi avançados não possuem coordenadores de NIT. Nesse caso, a gestão da inovação é conduzida pelo campus ao qual a unidade avançada está vinculada. Portanto, este trabalho tem por objetivo avaliar como os NIT do IFPR estão atuando, sua infraestrutura e, principalmente, identificar quais são os principais desafios encontrados pelos coordenadores dos referidos núcleos. Dessa forma, este estudo visa diagnosticar o processo de gestão da inovação do IFPR, bem como quais os direcionamentos e rumos que a instituição vem adotando para se tornar mais eficiente e inovadora.

Para levantar as informações necessárias para este estudo foi aplicado um questionário eletrônico aos NIT/IFPR, os quais responderam os questionamentos, permitindo analisar o processo de gestão da inovação desenvolvido pela instituição e comparar com indicadores de inovação de outras instituições públicas do estado do Paraná.

\section{METODOLOGIA}

A metodologia utilizada para elaborar este trabalho é qualitativa e quantitativa, associada à pesquisa bibliográfica e documental.

Este trabalho, quanto à pesquisa qualitativa, fundamenta-se pela utilização de formulários de pesquisa aplicados. Os dados obtidos através destes formulários permitiram levantar informações relevantes junto aos coordenadores de cada NIT do IFPR. Dessa forma, segundo Creswell (2007), a pesquisa qualitativa permite ao pesquisador coletar dados e informações abertas, tendo como objetivo principal o desenvolvimento de temas a partir de dados. Para Goldenberg (1997, p. 34) "a pesquisa qualitativa não se preocupa com representatividade 
numérica, mas, sim, com o aprofundamento da compreensão de um grupo social, de uma organização".

Ainda sobre pesquisa qualitativa, Deslauriers (1991, p. 58) afirma que:

$\mathrm{Na}$ pesquisa qualitativa, o cientista é ao mesmo tempo o sujeito e o objeto de suas pesquisas. O desenvolvimento da pesquisa é imprevisível. O conhecimento do pesquisador é parcial e limitado. O objetivo da amostra é de produzir informações aprofundadas e ilustrativas: seja ela pequena ou grande, o que importa é que ela seja capaz de produzir novas informações.

Com relação à pesquisa quantitativa, esclarece Fonseca (2002, p. 20):

Diferentemente da pesquisa qualitativa, os resultados da pesquisa quantitativa podem ser quantificados. Influenciada pelo positivismo, considera que a realidade só pode ser compreendida com base na análise de dados brutos, recolhidos com o auxílio de instrumentos padronizados e neutros. A utilização conjunta da pesquisa qualitativa e quantitativa permite recolher mais informações do que se poderia conseguir isoladamente.

A pesquisa bibliográfica e documental foi utilizada para fundamentar a análise e pesquisar conhecimentos publicados por autores da área de estudo.

Para Fonseca (2002, p. 32)

A pesquisa bibliográfica é feita a partir do levantamento de referências teóricas, já analisadas e publicadas, Qualquer trabalho científico inicia-se com uma pesquisa bibliográfica, que permite ao pesquisador conhecer o que já se estudou sobre o assunto.

A pesquisa documental também fundamenta a metodologia utilizada neste estudo. Segundo Fonseca (2002, p. 32) a referida pesquisa é importante por que:

A pesquisa documental trilha os mesmos caminhos da pesquisa bibliográfica, não sendo fácil por vezes distingui-las. A pesquisa bibliográfica utiliza fontes constituídas por material já elaborado, constituído basicamente por livros e artigos científicos localizados em bibliotecas. A pesquisa documental recorre a fontes mais diversificadas e dispersas, sem tratamento analítico, tais como: tabelas estatísticas, jornais, revistas, relatórios, documentos oficiais, cartas, filmes, fotografias, pinturas, tapeçarias, relatórios de empresas, vídeos de programas de televisão, etc.

A primeira etapa consistiu na realização de uma revisão bibliográfica e documental sobre gestão da inovação. Esta etapa foi importante para identificar o fluxo processual da gestão da inovação do IFPR. Assim, instruções normativas e minutas foram consultadas para levantar informações sobre as políticas executadas pela instituição. Também foram consultadas bibliografias da área da inovação e de gestão da inovação.
A segunda etapa desta pesquisa consistiu na aplicação de um questionário usando o Google Forms. O formulário foi enviado para os coordenadores dos NIT do IFPR pelo email e demais mídias sociais. $\mathrm{O}$ referido documento continha 23 perguntas, algumas abertas e outras fechadas. As respostas dos questionários da pesquisa foram enviadas no e-mail do pesquisador, que analisou e interpretou os dados levantados.

A Terceira etapa consistiu de pesquisa no site do INPI (Instituto Nacional de Propriedade Industrial). Nesta etapa foi realizada uma busca no banco de dados do INPI para levantar a quantidade de pedidos de patentes e programas de computador realizados pelas universidades e instituições públicas. Para tanto, foi utilizado o CNPJ (Cadastro Nacional de Pessoa Jurídica) para realizar as buscas. O CNPJ foi encontrado no site do MEC (Ministério da Educação). Para calcular a taxa de aproveitamento dos pedidos de patente, programas de computador e registros de marcas, foi dividido o total de pedidos protocolados pelo IFPR no INPI pelo total de pedidos realizados pelos campi do IFPR na AGIF, e o resultado multiplicado por 100 (dados da tabela 2).

A tabela 3 foi utilizada para calcular a Taxa de Produção Intelectual. Conforme Gutemberg et al (2018), esse indicador considera o ano do primeiro registro no INPI de cada instituição e a quantidade de pedidos protocolados neste referido órgão. Esses parâmetros foram consolidados em uma métrica denominada "Taxa de produção intelectual registrada no INPI" por anos de atuação. Considerando $\mathrm{p}(\mathrm{x})$ a taxa de produção intelectual registrada no INPI, identificase, matematicamente, o ranking das universidades e institutos públicos, [x], que desenvolvem inovação.

Após este levantamento, foi comparada a taxa de produção intelectual com o indicador de inovação publicado no ranking universitário da folha, que publica os indicadores de inovação de universidades públicas e privadas. Nessa comparação foram considerados, somente, os indicadores das universidades públicas do Paraná. O Ranking Universitário Folha (RUF) relaciona o número de patentes pedidas pela universidade em dez anos (2007-2016) e as parcerias com empresas, ou seja, quantidade de estudos publicados pela universidade em parceria com o setor produtivo, de 2011 a 2015, nos periódicos da Web of Science.

Por fim, alguns dados qualitativos foram compilados em uma tabela para facilitar a interpretação das informações coletadas. Para tanto, foi utilizado programa que gera uma "nuvem de palavras". Tal fato facilita a visualização dos principais arranjos produtivos que interagem com os campi do IFPR.

\section{RESULTADOS}

Em geral, os campi do IFPR estão em regiões com características agroindustriais. Os arranjos produtivos locais estão ligados ao agronegócio, agroindústria, comércio e indústria. Essa informação permite verificar se a inovação gerada até o momento recebeu alguma influência das demandas locais. Este conceito é importante para entender se a inovação gerada é puxada ou empurrada.

A inovação puxada é orientada pelo mercado. Os pesquisadores identificam uma necessidade ou demanda e, a partir dela, desenvolvem as soluções inovadoras. Já a 
empurrada é aquela que nasce de uma ideia, sem ter sido diretamente influenciada pela necessidade ou demanda. Para Lotufo (2009) as universidades contribuem com o desenvolvimento e com a capacidade de inovar do Brasil em, ao menos, dois aspectos: a formação de alunos para inovação, com a incorporação pelas empresas dos graduados, aumentando a cultura da inovação e o empreendedorismo; e o aumento das chances de transferências dos resultados das pesquisas e criações universitárias em benefícios da sociedade.

A pesquisa identificou que a inovação no IFPR, em grande parte, nasce das necessidades e demandas apresentadas pelas comunidades em que a instituição interage. A inovação, segundo o Manual de Oslo (2005), pode ser:

Produto: A introdução de um bem ou serviço novo ou significativamente melhorado no que concerne a suas características ou usos previstos.

Processo: É a implementação de um método de produção ou distribuição novo ou significativamente melhorado.

Organizacional: É a implementação de um novo método organizacional nas práticas de negócios da empresa, local de trabalho ou em suas relações externas.

Marketing: É a implementação de um novo método de marketing com mudanças significativas na concepção do produto ou em sua embalagem, no posicionamento do produto, em sua promoção ou na fixação de preços.

\section{1 - Resultados da Pesquisa}

A figura 1 identifica os principais arranjos produtivos locais nas regiões em que o IFPR atua. A nuvem de palavras traz a palavra agricultura como a mais evocada pelos pesquisados. Tal fato demonstra que a instituição pode direcionar seus pesquisadores e alunos para atuarem no desenvolvimento de inovação, especialmente, para o agronegócio e para a agricultura familiar. Assim, respeitando as características locais, o IFPR pode contribuir para melhorar a produtividade da zona rural.

Figura 1: Nuvem de Palavras - Principais áreas produtivas das localidades em que o IFPR atua. (Arranjos Produtivos Locais).

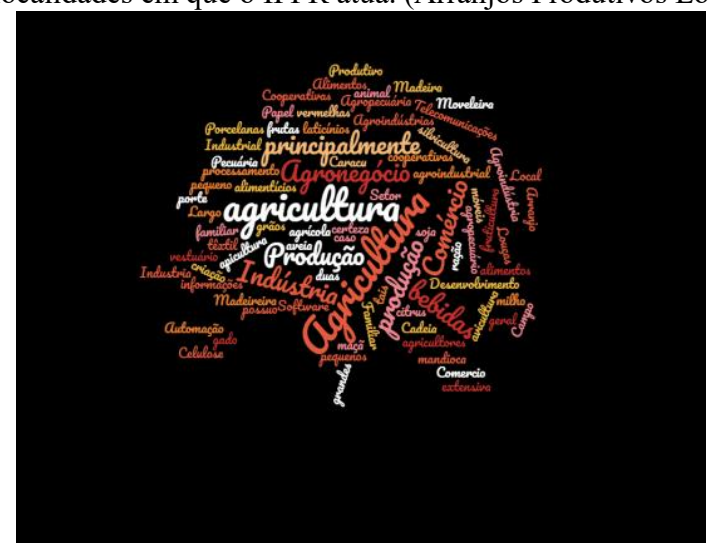

Fonte: Dados da Pesquisa -Autor

Identificou-se que $14,3 \%$ dos pesquisados não conhecem a política de inovação do IFPR. A figura 2 apresenta esses dados. É importante destacar que esses profissionais estão à frente dos NIT e têm a função de apoiar e incentivar o desenvolvimento da inovação no seu respectivo campus. Assim, percebe-se que há uma necessidade de capacitação para esses servidores. No entanto, $85,7 \%$ responderam que conhecem a política de inovação institucional. A política de inovação implantada nos últimos 3 anos resultou em quase uma centena de pedidos de proteção junto ao INPI.

Figura 2: Quantos dos gestores de NIT do IFPR conhecem a política de Inovação Tecnológica do IFPR?

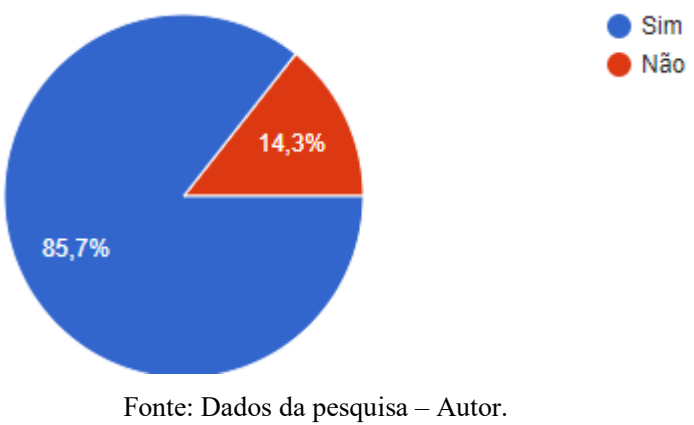

O IFPR ainda não possui uma política de incentivo para bolsista produtividade tecnológica. A figura 3 apresenta o resultado da pesquisa sobre a existência de bolsista produtividade tecnológica nos campi. Identificou-se que, em sua grande maioria, os NIT não possuem bolsistas. A instituição pode incentivar a inovação e a melhoria da gestão através de politicas de bolsas focadas na tecnologia e inovação.

Figura 3: Percentual de Bolsista produtividade tecnológica do IFPR

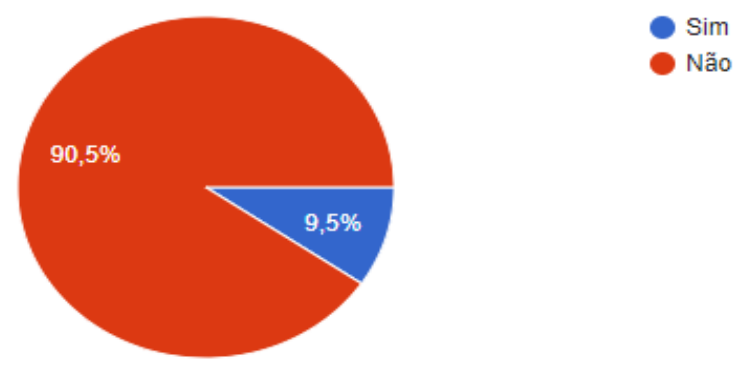

Fonte: Dados da Pesquisa - Autor.

A capacitação é uma etapa importante para desenvolver pessoas, fazendo parte da gestão de recursos humanos. A figura 4 demonstra que, uma parcela significativa dos chefes dos NIT, no momento da pesquisa, ainda não tinha participado de capacitação. A AGIF (agência de inovação do Instituo Federal do PR) realizou no dia 28 e 29 de agosto/2019, curso de capacitação, visando disseminar conhecimento e capacitar os chefes dos NIT do IFPR. Portanto, como a pesquisa foi realizada antes da capacitação, estes percentuais, provavelmente já se modificaram. É importante que os novos gestores dos NIT sejam capacitados antes de exercerem de fato sua função. Dessa forma, a instituição poderia criar cursos on-line e materiais de divulgação visando capacitar todos os servidores envolvidos na gestão dos NIT. 
Figura 4: Você já participou de cursos de capacitação oferecidos pela Instituição?

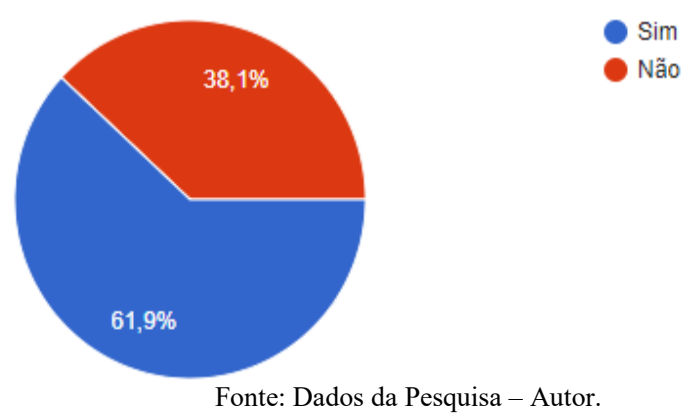

Com relação ao grau de formação, a figura 5 apresenta o grau de formação dos coordenadores dos NIT. Pode-se identificar que os pesquisados, em sua maioria, possuem mestrado ou doutorado. São $85,7 \%$ dos pesquisados, formados em áreas, como: Física; Informática; Biologia; Matemática e Administração. Portanto, os recursos humanos que atuam nos NIT são um ponto forte da instituição devido ao fato que estes profissionais podem colaborar tanto na gestão da inovação, como no desenvolvimento de pesquisa e novas tecnologias.

Figura 5: Qual é o seu grau de formação?

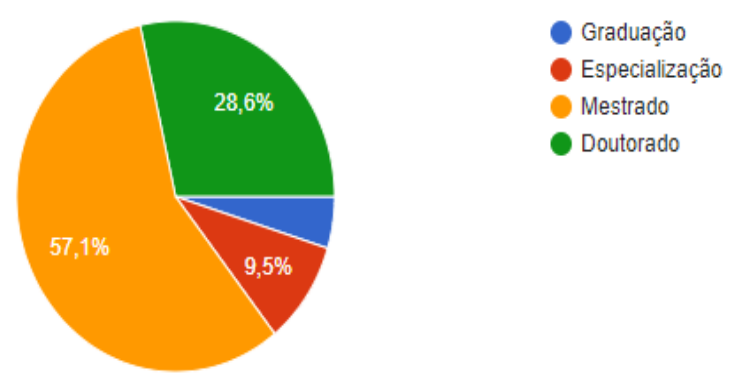

Fonte: Dados da Pesquisa - Autor

Tabela 1: Pedidos de Patentes, Programas de computador e pedidos de registro de Marcas protocolados na AGIF/IFPR

\begin{tabular}{|c|c|c|c|}
\hline Instituição & $\begin{array}{l}\text { Tipo de } \\
\text { pedido }\end{array}$ & Ano & Quantidade \\
\hline \multirow{9}{*}{ IFPR/Proeppi/AGIF } & \multirow{3}{*}{ Patentes } & 2017 & 14 \\
\hline & & 2018 & 20 \\
\hline & & 2019 & 21 \\
\hline & \multirow{3}{*}{$\begin{array}{l}\text { Registros de } \\
\text { Programas de } \\
\text { Computador }\end{array}$} & 2017 & 8 \\
\hline & & 2018 & 5 \\
\hline & & 2019 & 17 \\
\hline & \multirow{3}{*}{ Marcas } & 2017 & - \\
\hline & & 2018 & 1 \\
\hline & & 2019 & 7 \\
\hline \multicolumn{3}{|c|}{ Total (Pedidos protocolados na AGIF) } & 93 \\
\hline
\end{tabular}

A tabela 1 demonstra que, após a instituição da AGIF e da política de inovação, o IFPR conseguiu incentivar seus pesquisadores e alunos a protegerem seus projetos de inovação. Os dados da referida tabela demonstram a quantidade de pedidos de patentes, programas de computador e registros de marcas que foram solicitados junto à AGIF. É uma quebra de paradigma institucional, pois em um passado recente os pesquisadores priorizavam publicações cientificas. Muitas vezes essas publicações impediam a proteção intelectual. Portanto, percebe-se que a instituição está desenvolvendo uma cultura voltada para inovação. Essa nova forma de gestão está fomentando os indicadores ligados ao processo inovativo.

Tabela 2: Resultados do IFPR

\begin{tabular}{c|c|c}
\hline & $\begin{array}{c}\text { Pedidos } \\
\text { realizados pelos } \\
\text { campi do IFPR } \\
\text { na AGIF }\end{array}$ & $\begin{array}{c}\text { Protocolados no } \\
\text { INPI }\end{array}$ \\
\hline Patentes & 55 & 28 \\
\hline $\begin{array}{c}\text { Programas de } \\
\text { Computadores }\end{array}$ & 30 & 12 \\
\hline Marcas & 08 & 02 \\
\hline Total & 93 & 42 \\
\hline
\end{tabular}

$\mathrm{Na}$ tabela 2, verifica-se que os pedidos de patentes aumentaram, significativamente, nos últimos dois anos. Para calcular a taxa de aproveitamento dos pedidos de patente, programas de computadores e marcas, foi dividido o total de pedidos protocolados pelo IFPR no INPI, pelo total de pedidos realizados pelos campi do IFPR na AGIF, o resultado multiplicado por 100 .

Com relação ao pedido de patentes, foram feitos 55 pedidos de proteção para a AGIF; desses 28 foram protocolados no INPI (Instituto Nacional da Propriedade Intelectual), representando um aproveitamento de 50,90\% dos pedidos protocolados na AGIF. Já com relação a Marcas, chegaram 8 pedidos de registro na AGIF, sendo que 2 foram protocolados no INPI, resultando em $25 \%$ de aproveitamento de pedidos enviados para AGIF.

Estes dados referem-se aos dois últimos anos. No que diz respeito a Programas de Computador, foram solicitados 29 pedidos de proteção para AGIF, desses, doze foram protocolados no INPI, isto é, $41,38 \%$ dos programas protocolados tinham potencial de proteção.

Portanto, percebe-se que a referida Agência faz um trabalho de anterioridade nos bancos de dados do INPI, evitando assim que recursos públicos sejam gastos desnecessariamente.

Tabela 3: Taxa de produção intelectual registrada no INPI

\begin{tabular}{|c|c|c|c|c|c|}
\hline $\begin{array}{l}\text { Tipo de } \\
\text { pedido }\end{array}$ & Instituição & Total & Anos & Taxa & Ranking \\
\hline \multirow{11}{*}{ Patente } & UNIOESTE & 56 & 15 & 3,73 & $8^{\circ}$ \\
\hline & IFPR & 36 & 3 & 12 & $2^{\circ}$ \\
\hline & UEL & 167 & 20 & 8,35 & $4^{\circ}$ \\
\hline & UEM & 139 & 35 & 3,97 & $7^{\circ}$ \\
\hline & UEPG & 110 & 15 & 7,33 & $5^{\circ}$ \\
\hline & UFPR & 495 & 19 & 26,05 & $\mathbf{1}^{\mathbf{0}}$ \\
\hline & UNICENTRO & 60 & 11 & 5,45 & $6^{0}$ \\
\hline & UFFS & 4 & 6 & 0,66 & $10^{\circ}$ \\
\hline & UTFPR & 198 & 17 & 11,64 & $3^{\circ}$ \\
\hline & UENP & 1 & 1 & 1 & $9^{\circ}$ \\
\hline & UNESPAR & 1 & 1 & 1 & $9^{\circ}$ \\
\hline \multirow{11}{*}{$\begin{array}{l}\text { Programas } \\
\text { de } \\
\text { Computador }\end{array}$} & UNIOESTE & 24 & 10 & 2,4 & $5^{\circ}$ \\
\hline & IFPR & 14 & 1 & 14 & $2^{\circ}$ \\
\hline & UEL & 39 & 11 & 3,54 & $4^{\circ}$ \\
\hline & UEM & 29 & 19 & 1,52 & $7^{\circ}$ \\
\hline & UEPG & 12 & 6 & 2 & $6^{0}$ \\
\hline & UFPR & 53 & 12 & 4,75 & $3^{\circ}$ \\
\hline & UNICENTRO & 2 & 6 & 0,33 & $9^{\circ}$ \\
\hline & UFFS & 1 & 6 & 0,16 & $10^{\circ}$ \\
\hline & UTFPR & 250 & 9 & 27,77 & $\mathbf{1}^{\mathbf{0}}$ \\
\hline & UENP & 1 & 1 & 1 & $8^{\circ}$ \\
\hline & UNILA & 2 & 1 & 2 & $6^{0}$ \\
\hline
\end{tabular}

Fonte: Reditec (2018); INPI (2019) / Adaptado pelo autor. 
Uma fotografia dos pedidos de proteção da propriedade intelectual (patentes e programas de computador) registrados no INPI pelas principais instituições de ensino do estado do Paraná caracteriza o destaque das pesquisas do IFPR, conforme se observa na Tabela 3 .

Para a elaboração da tabela citada foi considerado o ano do primeiro registro no INPI de cada instituição e a quantidade de pedidos. Esses parâmetros foram consolidados, segundo Gutemberg et al (2018), em uma métrica denominada "Taxa de produção intelectual registrada no INPI" por anos de atuação. Considerando $\mathrm{p}(\mathrm{X})$ a taxa de produção intelectual registrada no INPI, identificase, matematicamente, o ranking das universidades $\mathrm{e}$ institutos públicos, [x], que desenvolvem inovação.

$\mathrm{p}(\mathrm{X})$

$p($ UFPR $)>p($ IFPR $)>p($ UTFPR $)>p($ UEL $)>p($ UNICENTRO $)>$ $p($ UEM $)>p($ UNIOESTE $)>p($ UENP $)=p($ UNESPAR $)>p(U F F$ $\mathrm{S})$.

No caso do IFPR, o primeiro pedido de patente depositado foi feito em 2017. Nesse período foram 35 pedidos, uma média de 11,7 pedidos por ano. O IFPR foi superado, somente, pela Universidade Federal do Paraná (UFPR) que depositou 495 pedidos em 19 anos, o que representa uma média de 26,05 pedidos de patente por ano.

Com relação aos programas de computador, o IFPR fez junto ao INPI o pedido de registro de 14 programas (software), sendo o primeiro pedido realizado em 2018. No que diz respeito ao registro de programas, o IFPR ocupa a $2^{\circ}$ colocação no ranking de avaliação, que compara as instituições públicas que trabalham com tecnologia e inovação. A instituição melhor ranqueada é a UTFPR (Universidade Tecnológica Federal do Paraná), que possui 250 pedidos de patentes solicitadas junto ao INPI em 9 anos, o que resulta em uma taxa de produção intelectual registrada de 27,77. Entre as instituições públicas, no quesito pedido de programas de computador, o IFPR é superado, somente, pela UTFPR. Nesse sentido, hoje, o IFPR ocupa um lugar de destaque no cenário estadual, mesmo sendo uma instituição com apenas 11 anos de existência.

Tabela 4: Ranking universitário folha - RUF

\begin{tabular}{c|c|c|c}
\hline Ranking & Nome & $\begin{array}{c}\text { Patentes } \\
\text { depositadas }\end{array}$ & $\begin{array}{c}\text { Indicador } \\
\text { de inovação }\end{array}$ \\
\hline $2^{\circ}$ & UFPR & 196 & 3.59 \\
\hline $20^{\circ}$ & UNICENTRO & 143 & 3.05 \\
\hline $22^{\circ}$ & UTFPR & 169 & 3.04 \\
\hline $32^{\circ}$ & UNIOESTE & 13 & 2.75 \\
\hline $35^{\circ}$ & UEPG & 153 & 2.61 \\
\hline $37^{\circ}$ & UEL & 167 & 2.60 \\
\hline $50^{\circ}$ & UEM & 155 & 2.33 \\
\hline $90^{\circ}$ & UNILA & - & 1.66 \\
\hline $105^{\circ}$ & UFFS & - & 1.37 \\
\hline
\end{tabular}

Fonte: RUF- Ranking universitário folha - 2018/Adaptado pelo autor.
O IFPR ainda não aparece no RUF 2018 devido ao fato que suas patentes serem depositadas recentemente e porque relaciona o número de patentes pedidas pela universidade em dez anos (2007-2016) e as parcerias com empresas, ou seja, quantidade de estudos publicados pela universidade em parceria com o setor produtivo, de 2011 a 2015, nos periódicos da Web of Science. Portanto, como a métrica do RUF 2018 utiliza parâmetros anteriores ao ano de 2017, não há como o IFPR, por este indicador, estar entre as instituições mais inovadoras. Segundo Silva et al (2018) a capacidade que as estruturas organizacionais tem de inovar colaboram para melhorar o processo de gestão da inovação e $\mathrm{o}$ atingimento dos objetivos estratégicos.

É importante destacar o desempenho da UFPR e da UNICENTRO, respectivamente federal e estadual, classificadas em $1^{\circ}$ e $2^{\circ}$ no ranking em relação às IES (Instituições de Ensino Superior) do Estado do Paraná, instituições públicas que fazem um trabalho de fomento da inovação relevante.

Quando questionados sobre quais são as sugestões para melhorar a gestão da inovação no IFPR, os coordenadores dos NIT, responderam:

- Mais profissionais envolvidos com inovação nos campi;

- Parcerias com outras instituições federais e empresas que possuem experiência na produção tecnológica;

- Treinamentos e apoio financeiro para eventos inovadores;

- Aproximação da gestão da instituição com os NIT

- Compartilhamento de experiências e ideias entre os campi;

- Recursos financeiros direcionados a incentivar a inovação;

- Mais cursos de formação em inovação para os membros do NIT e os demais professores;

- Fomentar as parcerias público-privadas e entrada de capital privado na instituição para financiar editais internos de apoio às ações de inovação;

- Capacitação e encontros dos coordenadores dos NIT com frequência semestral para demonstração das atividades realizadas e troca de experiências;

- Desenvolvimento de capacitações EaD para professores e estudantes que desejam investir na inovação tecnológica;

- Uma rede de compartilhamento entre campus de uma estrutura laboratorial, para que a produção tecnológica seja compartilhada e os recursos materiais sejam aplicados a diversas pesquisas correlacionadas;

- Estruturar devidamente os NIT, tanto em pessoal, quanto em equipamentos;

- Trabalho em conjunto pelos NIT e não da maneira individualizada

- Aproximação maior entre os campi;

- Alinhar e definir responsabilidade dos agentes envolvidos

\section{CONCLUSÃO}

Após análise dos dados da pesquisa, é possível identificar que o IFPR está conseguindo desenvolver 
inovação e tecnologia. Este fato é demonstrando pelo indicador, expressivo, de pedidos de patentes, programas de computador e pedidos de registro de marcas.

A política de inovação implantada recentemente tem fomentado e incentivado à pesquisa e o desenvolvimento de inovações em diversas áreas. Como a missão institucional também está ligada à tecnologia e inovação faz-se necessário que o ambiente acadêmico do ensino, pesquisa, extensão e inovação sejam planejados para melhorar a vida das pessoas, gerando vantagem competitiva para o país.

No entanto, ainda existem vários desafios institucionais para potencializar os indicadores de inovação, como exemplo, pode-se citar: melhorar a infraestrutura dos NIT nos campi, disponibilizando espaço adequado para os servidores e discentes poderem desenvolver e gerir o processo de inovação; aumentar os investimentos disponibilizados via edital de inovação; aproximar a instituição das empresas interessadas em investir em pesquisa, através de parcerias e cooperações. Além disso, a instituição deve instalar e desenvolver seu parque tecnológico, incubadoras e STARTUPS.

\section{REFERÊNCIAS BIBLIOGRÁFICAS}

BRASIL. Lei $\mathrm{n}^{\mathrm{o}}$ 10.973, de 02 de dezembro de 2004. Dispõe sobre incentivos à inovação e à pesquisa científica e tecnológica no ambiente produtivo e dá outras providências. Disponível em: http://www.planalto.gov.br/ccivil_03/_ato20042006/2004/lei/110.973.htm. Acesso em: 14/09/2019.

BRASIL. lei $n^{\circ} 13.243$, de 11 de janeiro de 2016. Dispõe sobre estímulos ao desenvolvimento científico, à pesquisa, à capacitação científica e tecnológica e à inovação. Disponível http://www.planalto.gov.br/ccivil_03/_Ato2015-

2018/2016/Lei/L13243.htm. Acesso em: 14/09/2019.

DESLAURIERS J. P. Recherche Qualitative. Montreal: McGraw Hill, 1991.

FONSECA, J. J. S. Metodologia da pesquisa científica. Fortaleza: UEC, 2002. Apostila.

GIL, A. C. Como elaborar projetos de pesquisa. 4. ed. São Paulo: Atlas, 2007.

GOLDENBERG, M. A arte de pesquisar. Rio de Janeiro: Record, 1997.

KOBERG, C. S., UHLENBRUCK, N. \& SARASON, Y. Facilitators of organizational innovation: the role of lifecycle stage. Journal of Business Venturing, v. 11, n. 2, p. 133-149, 1996.

LOTUFO, R. A. A institucionalização do Núcleo de inovação tecnológica e a experiência do Inova UNICAMP. In: SANTOS, M. E. R.; TOLEDO, P. T. M.; LOTUDO, R. A. Transferência de tecnologia: estratégias para a estruturação e gestão de Núcleo de Inovação tecnológica. Campinas: Komedi, 2009, p. $41-73$.
MANUAL de Oslo: diretrizes para a coleta e interpretação de dados sobre inovação. 3. ed. [S.1]: FINEP, c1997. Disponível em: finep.gov.br/imagens/apoio-efinanciamento/manualoslo.pdf. Acesso em: 22/09/2019.

RANKING Universitário Folha: ranking de inovação Universidades Públicas do Paraná. Folha de São Paulo. Disponível em: http://ruf.folha.uol.com.br/2018/ranking-deuniversidades/ranking-por-inovacao/. Acesso em: 22/09/2019.

RIBEIRO, G. et. al. IFAGROTECH: a forma inovadora de inclusão tecnológica do pequeno e médio produtor rural. Experiências exitosas da Reditec 2018: trabalhos premiados. Disponível em: submissão.2018.reditec.org.br/ckeditor_assets/attachmentes/ 64/ifagrotech.pdf. Acesso em: 22/09/2019.

SILVA, .M.; AIHARA, C. H.; SALVETTI, N.; FERNANDES, T. C. M.; MAURO, M. H. Modelando impactos das tecnologias de informação e comunicação na relação entre gestão do conhecimento, capacidade de inovação e eficiência organizacional. Revista Sodebras [on line]. v. 13, n. 147, mar. 2018, p.124-128. Disponível em: http://www.sodebras.com.br/edicoes/N147.pdf. Acesso em: 14/09/2019.

\section{AGRADECIMENTOS}

Ao Programa de Pós-graduação em Propriedade Intelectual e Transferência de Tecnologia para Inovação -PROFNIT; A Capes; Ao CNPq; A UNICENTRO; Ao IFPR; Ao FORTEC.

\section{COPYRIGHT}

Direitos autorais: Os autores são os únicos responsáveis pelo material incluído no artigo. 


\section{Área: Ciências Humanas e Sociais}

\begin{tabular}{|c|c|}
\hline $6-0$ & $\begin{array}{l}\text { OS DESAFIOS DA GOVERNANÇA CORPORATIVA NA ERA DA TECNOLOGIA } \\
\text { GLOBAL } \\
\text { THE CHALLENGES OF CORPORATE GOVERNANCE IN THE AGE OF GLOBAL } \\
\text { TECHNOLOGY } \\
\text { Ligia Kaori Matsumoto Hirano; Luana Lopes De Oliveira; Marianna Konyosi } \\
\text { Miyashiro; Paula Massako Bernardes Suda }\end{array}$ \\
\hline $6-1$ & $\begin{array}{l}\text { A LINGUAGEM JURÍDICA COMO PORTA DE ACESSO À JUSTIÇA } \\
\text { LEGAL LANGUAGE AS A DOOR ACCESS TO JUSTICE } \\
\text { Jhônatha Magalhães Silva; Carmen Gean Veras De Meneses }\end{array}$ \\
\hline $6-7$ & $\begin{array}{l}\text { O IMPACTO DA IMPLEMENTAÇÃO DA FERRAMENTA POWER BI NO ATUAL } \\
\text { CENÁRIO CORPORATIVO DE PERNAMBUCO } \\
\text { THE IMPACT OF POWER BI TOOL IMPLEMENTATION ON THE PERNAMBUCO } \\
\text { CORPORATE SCENARIO } \\
\text { Marcelo André Esteves Barbosa Júnior, Milena Grasielle Viana Gomes, Thaiane } \\
\text { Araújo Dos Santos, Euri Charles Andrade Da Silva }\end{array}$ \\
\hline $7-8$ & $\begin{array}{l}\text { A CONVERSA } \\
\text { EMPREENDEDORA }\end{array}$ \\
\hline $7-8$ & $\begin{array}{l}\text { O POTENCIAL MÚLTIPLO DA INTELIGÉNCIA PARA O MUNDO DO TRABALHO } \\
\text { NO SÉCULO XXI } \\
\text { THE MULTIPLE POTENTIAL OF INTELLIGENCE FOR THE WORLD WORK IN } \\
\text { THE 21ST CENTURY } \\
\text { Giuliana Cavalcanti Vasconcelos, Gabriela Vasconcelos Barbosa }\end{array}$ \\
\hline
\end{tabular}




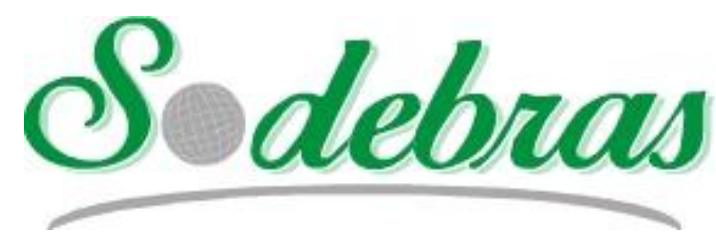

Volume 15 - $\mathrm{N}^{\mathrm{o}} 169$ - Janeiro / 2020

XLI International Sodebras Congress

31 de outubro a 02 de novembro de 2019 - Maceió - AL.

\title{
OS DESAFIOS DA GOVERNANÇA CORPORATIVA NA ERA DA TECNOLOGIA GLOBAL
}

\section{THE CHALLENGES OF CORPORATE GOVERNANCE IN THE AGE OF GLOBAL TECHNOLOGY}

\author{
LIGIA KAORI MATSUMOTO HIRANO; LUANA LOPES DE OLIVEIRA; MARIANNA KONYOSI \\ MIYASHIRO; PAULA MASSAKO BERNARDES SUDA \\ PONTIFÍCIA UNIVERSIDADE CATÓLICA DE SÃO PAULO
}

matsumoto.lkh@gmail.com; luana2012projetos@gmail.com; marikmiy@gmail.com;

paula.suda@gmail.com

\begin{abstract}
Resumo - As concentrações de grupos econômicos nas decisões que impactam a vida de muitas pessoas, e a perda de controle devido a financeirização da lógica da tomada de decisões corporativas impacta a produtividade. É objetivo desse artigo expor as fontes externas que estão minando a governança corporativa, e como a crescente desigualdade social tende a aumentar a pressão de forças externas.
\end{abstract}

Palavras chave: tecnologia, governança corporativa, produtividade, capital, impacto social

Abstract - Many conglomerates are concentering more and more decisions that have impacts on daily lives of many people, and even them are losing their own capacity of decision making, as the financialization logic's becomes predominant, even impacting productivity. Is the main goal of this article point out that social tensions will rise if the inequality of the current mind set is not changed, increasing the external pressure on decision making that many companies already have.

Keywords: Technology. Corporate governance. Productivity. Capital. Social impact.

\section{INTRODUÇÃO}

O ensaio teórico tem por objetivo, trazer a clareza das dificuldades sociais por meio de ações corporativas de tomada de decisão na produção de suas riquezas.

Por este motivo, este artigo cita o monopólio que há das empresas para a produção de riquezas que vem do ambiente eletrônico e como isso, pode afetar a sociedade.

São citados crimes ambientais que tiveram como base o foco corporativo na riqueza, deixando a deriva ações sociais em seu processo produtivo. Gestão do conhecimento e uso do bitcoin e blockchain também são assuntos levados em consideração na construção deste artigo.

Por isso, as informações ajudam a sociedade a se posicionar em alguns de seus âmbitos econômicos e sociais para suas tomadas de decisões em meio a um ambiente corporativo em que o acúmulo de riqueza aumenta de acordos em transições financeiras mais do que em produção de bens e serviços.
O relacionamento entre corporações que dominam o capital mundial, faz as empresas possuírem poder de decisão sobre o futuro humano. As corporações possuem mais capital e maior poder nas relações mundiais que os próprios governos mundiais.

A sociedade está oprimida pelas grandes corporações que muitas vezes, atingem e ultrapassam o PIB de vários países, Piketty (2014). É necessário entender o que as levam a decisões focadas essencialmente em grandes lucros, negligenciando demais aspectos envolvidos pela ação corporativa.

A governança corporativa em que é possível a utilização de tecnologia digital em escala mundial, torna os contatos cada vez mais rápidos e seguimento em tempo real, permitindo a ação por meio de algoritmos.

\section{GOVERNANÇA E TECNOLOGIA GLOBAL}

Neste contexto social, em que a produção não é mais de produtos tangíveis e sim de manipulação de informações, que produzem altos lucros, mas travam o potencial de desenvolvimento.

O Instituto Brasileiro de Governança Corporativa IBGC (2009), possui o seguinte conceito para governança corporativa: governança corporativa "é o sistema pelo qual as sociedades são dirigidas e monitoradas, envolvendo os relacionamentos entre acionistas e cotistas, conselho de administração, diretoria, auditoria independente e conselho fiscal." As boas práticas de governança corporativa têm a finalidade de aumentar o valor da sociedade, facilitar seu acesso ao capital e contribuir para a sua perenidade.

A governança corporativa surgiu para tentar atenuar o "conflito de agência" IBGC (2009). Decorrente da separação entre a propriedade e a gestão empresarial. Nesta situação, o acionista delega o poder de decisão a um agente especializado. No entanto, os interesses do acionista nem sempre estarão alinhados com os do agente. Isso ocasiona as decisões erradas ocorrente do entendimento incorreto dos problemas e dos vieses cognitivos mesmo que não intencionais. A governança apenas introduz motivadores para o alinhamento dos interesses dos agentes com os 
interesses dos proprietários. Não leva em consideração o interesse dos demais integrantes da sociedade. Esses interesses não necessariamente coincidem com os interesses sociais.

A ausência de regulação mundial não atinge as relações globais das grandes corporações com uso das tecnologias para aplicações e geração de mais capital, muito longe do processo produtivo, não beneficiando a sociedade de fato.

O FED (Federal Reserve), dos EUA, fracassou em seu papel regulatório nos anos que antecederam a Grande Recessão; por banqueiros privados que pediram confiança e defendiam a autorregulamentação, Stiglitz (2019).

Carys Roberts, economista-chefe do Instituto de Pesquisa de Políticas Públicas (IPPR) localizado nos EUA "A primazia dos acionistas é uma teoria desgastada que não serve aos interesses de longo prazo das empresas, da economia e das pessoas em que a economia deve trabalhar. Esta é uma intervenção importante dos líderes empresariais dos EUA em reconhecimento ao fracasso da primazia dos acionistas: mas o teste real será em ações, não em palavras, Googley (2019).

A Figura 1, a lógica do relacionamento das empresas, a empresa A controla duas subsidiárias $\mathrm{B}$ e $\mathrm{C}$, a $\mathrm{C}$ controla as D e E e são controladas nessa ordem.

Figura 1- Relacionamento de empresas subsidiárias

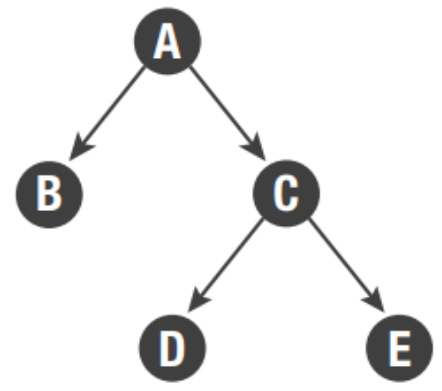

Fonte: Dowbor, 2017, p. 60.

As corporações com suas grandes dimensões, complexidade e falta de transparência em suas transações estão imersas em fraudes, corrupções, falhas de governança, corrupção de níveis mundiais desde a sua sede até a menor das suas filiais em um sistema de governança difícil de compreensão até por um próprio dirigente, Dowbor (2017).

Com maior impacto nos países mais pobres, informação e dinheiro circulando em nível mundial, acabam por se impor como algo autônomo em face da sociedade e da economia, tornando-se um elemento fundamental da produção, e ao mesmo tempo da geografia e política, isto é, apropriação financeira global e governamental das relações entre países e dentro de cada nação, Dowbor (2017).

De acordo com Dembinski (1993), da Universidade de Friburgo na Suiça, do Observatórie de la Finance, em Genebra "O financiamento das atividades produtivas e do comércio preocupa apenas marginalmente os mercados financeiros. No essencial, a sua atividade está centrada na gestão de patrimônio acumulado no passado. Forçando um pouco, podemos dizer que uma sociedade de rentistas assumiu progressivamente (em todo o caso do imaginário) o lugar da sociedade de produtores." (p.8)

Todos os contextos corporificam um contexto global, não há fronteira para o dinheiro e para a informação, o que leva ao enfraquecimento e à mudança de natureza dos Estados nacionais. Os condutores da globalização necessitam de um Estado flexível a seus interesses e privatizações, Dowbor (2017).

A informação é centralizada nas mãos de um número limitado de firmas, tanto em jornais, como em livros, é produzido a partir de poucas empresas que monopolizam a informação, mesmo tendo condições técnicas da informação para permitir o conhecimento do mundo, existe a limitação da intermediação. Conhecemos pouco sobre esse sistema porque eles limitam a informação, alinhando a estrutura de poder. Um exemplo de como a informação é afunilada nas mão de poucos conglomerados pode ser observado nos Estados Unidos, segundo levantamento feito por Lutz (2012), seis grupos empresariais concentravam 90\% da indústria de mídia em e entretenimento em 2010, os grupos são controlados pela General Electric (Controlada da Combcast, NBC), News Corp (Controladora da Fox, Wall Street Journal e New York Post), Disney (Controladora da ABC, ESPN, Miramax), Viacom (MTV, CMT), Time Warner (CNN, TIME) e CBS (Smithsonian Channel, 60 Minutes). O controle é inclusive internacional, com a News Corp tendo os jornais mais lidos na América do Norte (Wall Street Journal), na Europa (The Sun) e na Oceania (The Australian).

Outra liderança está a união da Bayer com a empresa Monsanto, confirmado em setembro de 2016, Streeck (2017).

A fusão da empresa Bayer com a empresa Monsanto em 2016, realiza alterações transgênicas nos grãos e cada vez se beneficia mais com uso de tecnologias na produção dos alimentos. Atuando em nível mundial, muito pouco controle governamental é possível devido ao valor financeiro. A atual dependência da agricultura moderna desses insumos também faz com que todos os envolvidos (Bayer-Monsanto, governos e agricultores) tenham de repensar nas suas relações, sobre a alta concentração do setor e as novas e criativas formas de inovação, Varela (2017).

Ambas as autoridades, a americana e a europeia, estão preocupadas por causa das possíveis restrições na oferta. Os proponentes argumentam que os benefícios combinados do negócio superam os custos, principalmente graças à integração do portfólio de produtos entre culturas e indicações com uma oferta abrangente de sementes e produtos de proteção de cultivos; a criação de uma plataforma líder no ambiente rural; e liderar as capacidades de inovação e plataformas de tecnologia de Pesquisa e Desenvolvimento (P \& D), com um orçamento anual proforma de $\mathrm{P} \& \mathrm{D}$ de cerca de 2,5 bilhões de euros. O impacto positivo para os consumidores é garantir preços mais baixos. Todos estão concentrados na redução de custos e implicam, direta ou indiretamente, uma redução na oferta de produtos. De fato, os negócios combinados têm como objetivo reforçar a adesão entre sementes de biotecnologia e "produtos de proteção de culturas", Varela (2017).

Durante a avaliação, as autoridades de concorrências devem levar em conta o impacto sobre os preços e a oferta de produtos atuais, mas também sobre a pesquisa, particularmente no desenvolvimento de novas sementes. A nova empresa controlará um orçamento de 2,5 bilhões de euros em pesquisa sobre alimentos biotecnológicos, o que representa cerca de 10 vezes o orçamento de pesquisa agrícola do Departamento de Agricultura dos Estados 
Unidos (United States Department of Agriculture - USDA) e 15 vezes o que o Horizonte 2020 investe anualmente na agricultura.

É um fato que a pesquisa biotecnológica foi desenvolvida e amadureceu alimentada pela indústria privada. Isso criou problemas de conflito de interesses para as autoridades reguladoras, particularmente em comitês de especialistas, e a suspeita contínua de manipulação da avaliação de riscos. A biotecnologia química foi comercializada como produto de risco.

\section{IMPACTO SOCIAL E AMBIENTAL}

O Banco Mundial classifica cerca de 3,5 bilhões de habitantes deste planeta, cerca de dois terços do total, na faixa de renda média de 350 dólares (de 1991) per capita. Mais de 150 milhões de crianças passam fome no mundo.

$\mathrm{O}$ mundo produz hoje mais de 5 mil dólares de bens e serviços por habitante, o suficiente para todos viverem com conforto e dignidade, Dowbor, 2017.

A aplicação financeira poderá, eventualmente, permitir que uma pessoa física ou jurídica use estes recursos para montar uma empresa e gerar produtos e também, ela poderá colocar esta sua poupança para render em títulos públicos de governo, cuja remuneração sairá sob forma de impostos que se paga para o governo. Ou seja, não se criou uma molécula de riqueza econômica a mais no país da aplicação financeira, Dowbor (2017).

Os intangíveis por meio de aplicações que enriquecem, geram mais recursos para aplicações financeiras e sempre aumentando seus dividendos, em uma estagnação econômica e social com poucos controles mundiais dos Estados. A política mudou de lugar: a globalização desafia radicalmente os quadros de referência da política, como prática e teoria, Ianni (2003).

Segundo o diretor da Diretoria de Uso Sustentável da Biodiversidade e Florestas, os acidentes ocorridos em Mariana (2015) e Brumadinho (2019) ocorridos no Brasil, à época do incidente, Paulo Fontes, em entrevista com Escobar (2015), estimou de pelo menos uma década a recuperação do Rio Doce. O sofrimento social causado pelos incidentes e a falta de preparo dos órgãos governamentais e das empresas envolvidas, e que se nada for alterado que a situação se repetirá e agravará as desigualdades sociais, dados da Sociedade Brasileira para o Progresso da Ciência, Zhouri (2016).

Do desastre provocado, 94\% reclamaram quanto à poluição das águas causada pelas operações da Samarco que administrava Mariana, 68\% dos entrevistados em Bento Rodrigues relataram em relação ao rompimento das barragens e $64 \%$ sobre suas propriedades pudessem ser desapropriadas pela empresa, Zhouri (2016).

No caso específico dos empreendimentos da Samarco (Vale/BHP Billiton), os riscos de um possível rompimento e as medidas que deveriam ter sido tomadas já eram conhecidos pelas autoridades ambientais anteriormente ao evento. Em perícia realizada a pedido do MP de Minas Gerais, o Instituto Prístino alertara, ainda em 2013, para o risco de colapso da barragem de Fundão. Recomendado um plano de contingência para situações de risco ou acidentes. Tais recomendações contrastam com a real inexistência, na área do empreendimento, população do entorno em casos de acidente ou agravamento dos riscos, Zhouri (2016).

A estratégia de identificar a ação como desastre ambiental, deslocando a responsabilidade da empresa, ficou evidente no debate sobre a toxicidade da lama que se espalhou ao longo do rio Doce, a sugestão da inexistência de nexo causal constituiu uma forma de, a um só tempo, desviar a atenção das reais consequências do desastre.

Enquanto os rejeitos eram inertes, ou seja, não continham metais pesados de forma livre que poderiam causar danos à saúde, os relatores especiais da Organização das Nações Unidas (ONU) encaminhados para a região afirmaram, três semanas após o desastre, que os "50 milhões de toneladas de resíduos de minério atingiram sistemas de água ao longo de mais de 850 quilômetros, Escobar (2015).

A Advocacia Geral da União acordou com as empresas e os governos dos estados envolvidos um termo de acordo extrajudicial que encerrou diversas ações civis públicas. Quanto mais hermético for o ambiente decisório sobre compensações, mais evidente será o propósito de legitimar os pleitos da parte forte entre os agentes em disputa.

Enquanto aguardam uma decisão final sobre as competências jurídicas para tratar do caso, as vítimas, decorridos mais de seis meses do desastre, continuam recebendo ações emergenciais e assistencialistas, sem perspectiva de retomada autônoma de suas vidas.

O Brasil poderia ter um banco nacional, uma vez que os juros de empréstimos para empresas no Brasil sejam muito altos, auxiliando a impedir o crescimento do país. Podendo ajudar a resolver questões sociais que são muitas vezes deixado de lado no setor privado, como meio ambiente e desigualdade social. Por isso, que o mais importante grupo de países de mercado emergente, os BRICS (Brasil, Rússia, Índia, China e África do Sul) criou o Novo Banco de Desenvolvimento, trazendo contribuição para o desenvolvimento, Stiglitz (2019).

\section{A CAPTURA DO PODER}

Aos principais financeiros, JPMorgan Chase, Bank of America, Citigroup, HSBC, Deutsche Bank, Santander, Goldman Sachs e outros, totalizando 28, foram estudados por Morin (2015), assessor do banco central da França.

Temos um comparativo entre o PIB mundial de 73 trilhões, com particular dívida pública mundial de 49 trilhões, paralelo a análise um balanço de mais de 50 trilhões de dólares em 2012 dos maiores financeiros, Morin (2015).

Como resultado desses dados trazidos pela análise, os Estados, fruto do endividamento público com privados, viraram reféns e tornaram-se incapazes de regular este sistema financeiro em favor dos interesses da sociedade.

"Face aos Estados fragilizados pelo endividamento, o poder dos grandes atores bancários privados parece escandaloso, em particular se pensarmos que estes últimos estão, no essencial, na origem da crise financeira, logo de uma boa parte do excessivo endividamento atual dos Estados", Morin (2015).

O executivo Howard Schultz disse que os EUA enfrentam uma "crise do capitalismo" como forma de tentar apaziguar, pediram impostos mais altos para os ricos. Googley (2019).

A sociedade em busca de novos caminhos de gestão com a expansão dos lobbies, a compra dos políticos, a invasão do judiciário, o controle dos sistemas de informação da sociedade e a manipulação do ensino acadêmico. Para citar alguns dos instrumentos importantes da captura do poder político geral pelas grandes corporações redirecionando as dinâmicas de poder político, econômico e 
cultural gera uma nova a ruptura destas fronteiras, a penetração dos interesses de grupos econômicos privados na esfera pública. Igualmente importante é a oligopolização do controle das publicações científicas no mundo.

Segundo estudo canadense, "nas disciplinas das ciências sociais, que incluem especialidades tais como sociologia, economia, antropologia, ciências políticas e estudos urbanos: enquanto os cinco maiores editores eram responsáveis por $15 \%$ dos artigos em 1995, este valor atingiu 66\% em 2013". Temos aqui o domínio de ReedElsevier (hoje boicotado por mais de 15 mil cientistas americanos), Springer, Wiley-Blackwell, e poucos mais (Larivière, 2015).

Streeck (2014) traz uma sistematização desta captura do poder público no nível dos próprios governos. Por meio do endividamento do Estado e dos outros mecanismos vistos acima, gera-se um processo em que o governo, cada vez mais, tem de prestar contas ao mercado, essencialmente os interesses financeiros, em vez de res publica, passamos a ter uma res mercatori.

Os contratos inteligentes são programas de computador que protegem, fazem cumprir e executam a liquidação de acordos registrados entre pessoas e organizações. Como no caso do uso do Bitcoin, entre outros, tentando minimizar o impacto dos intermediadores dos processos financeiros.

Desde 2009, o até hoje anônimo Satoshi Nakamoto publicava seu artigo Bitcoin: A Peer-to-Peer Electronic Cash System, onde detalhava as estruturas blockchain necessárias para criação de uma moeda inteiramente digital que não necessitava regulação por terceiros, em 31 de outubro de 2008, o codinome Satoshi Nakamoto lançava o artigo Bitcoin: A Peer-to-Peer Electronic Cash System, que daria o pontapé inicial em todos os projetos que hoje entendemos como bitcoins, criptomoedas e uso de blockchains. No estudo, disponível por meio do site bitcoin.org, o resumo fala sobre a criação de um sistema peer-to-peer para viabilizar transações de valores e pagamentos online sem a necessidade da mediação por instituições financeiras, propondo soluções para garantir que não ocorram gastos duplos na ausência de uma terceira parte atuando como reguladora. Como meio de novas perspectivas de mudança do controle mundial.

A mudança que um sistema descentralizado terá sobre as operações financeiras por meio de transações via blockchains e criptomoedas irão interferir não só nas relações de consumo entre cidadãos e instituições financeiras, mas impactarão profundamente relações de governança, modos de vida, modelos corporativos tradicionais, instituições em escala global e a sociedade como um todo.

\section{CONSIDERAÇÕES FINAIS}

$\mathrm{O}$ grande avanço da produtividade resulta essencialmente da revolução tecnológica que, não são os produtores destas transformações, desde a pesquisa fundamental nas universidades públicas e as políticas públicas de saúde, educação e infraestruturas, até os avanços técnicos nas empresas efetivamente produtoras de bens e serviços, que levam vantagem: pelo contrário, ambas as esferas, pública e empresarial, encontram-se endividadas nas mãos do sistema financeiro, que rendem fortunas a quem nunca produziu, e que conseguem, ao juntar nas mãos os fios que controlam tanto o setor público como o setor produtivo privado, nos desviar radicalmente do desenvolvimento sustentável hoje vital para o mundo.

Grandes organizações não produzem nada, mas, controlam, regulamentam, criam pedágios que lhe conferem um imenso poder de intermediação, o que altera os dados da transformação social. Importante lembrar a forma como estão se articulando hoje o aumento mundial de lucros financeiros e a redução das taxas de investimentos produtivos.

É esta associação de aumento de lucros com investimento estagnado, desemprego crescente e salários em queda que constitui os fatores que devem ser levados em conta para a administração futura do planeta. $\mathrm{O}$ aumento da desigualdade econômica levará com quase toda certeza a uma crise social, e com o mundo interligado, essa crise será global.

Este ensaio visa contribuir para o debate de como a manipulação de dados é mais atrativa para as organizações possuírem mais capital do que realizar a produção de bens e serviços.

\section{REFERÊNCIAS BIBLIOGRÁFICAS}

DEMBINSKI, Paul; Schoeneberger, Alan. Financial markets: impossible mission ? - Eco Diagnostic, Suiça 1993.

DOWBOR, Ladislau. A Era do Capital Improdutivo, 1 ed., São Paulo: Autonomia Literária, 2017.

ESCOBAR, Herton. Lama expõe histórico de degradação ambiental no Rio Doce, O Estado de São Paulo, 22/11/2015 - link: https:/ciencia.estadao.com.br/blogs/herton-escobar/lamaexpoe-degradacao-ambiental-historica-do-rio-doce/

GOOGLEY, Simon; Neate, Rupert (2019), Leading US bosses drop shareholder-first principle, The real test will be in deeds not words, IPPR thinktank tells Business Roundtable.

https://www.theguardian.com/business/2019/aug/19/leadi ng-us-bosses-group-drops-principle-of-shareholder-first

IANNI, Octávio - A política mudou de lugar - capítulo do livro Desafios da Globalização, L. Dowbor, O. Ianni e P. Resende (Orgs.), ed. Vozes, Petrópolis, 2003.

INSTITUTO BRASILEIRO DE GOVERNANÇA CORPORATIVA, Governança Corporativa: estrutura de controles societários, São Paulo: Editora Saint Paul, 2009.

LARIVIÈRE V, Haustein S, Mongeon P, The Oligopoly of Academic Publishers in the Digital Era, 2015.

LUTZ, Ashley - These 6 Corporations Control 90\% Of The Media In America - Business Insider, 2012 Digital: https://www.businessinsider.com/these-6-corporationscontrol-90-of-the-media-in-america-2012-6? $\mathrm{r}=\mathrm{US} \& \mathrm{IR}=\mathrm{T}$

MORIN, François - L'hydre mondiale: l'oligopole bancaire, LUX EDITIONS Kindle Edition, 2015

PIKETTY, Thomas. O capital no século XXI, 1 ed., Rio de Janeiro: Editora Intrínseca, 2014.

STIGLITZ, Joseph E., (2019), Ataque ao BNDES é perturbador e surpreendente. https://www1.folha.uol.com.br/mercado/2019/08/ataque-aobndes-e-perturbador-e-supreendente.shtml 
STREECK, Wolfgang. How will Capitalism end ? Verso Books, London 2017.

VARELA, Justo Corti - European Journal of Risk Management, $2017 \quad-\quad$ link: https://doiorg.ez338.periodicos.capes.gov.br/10.1017/S1867299X0001 0199

ZHOURI, Andréa, Valencio, Norma, Oliveira, Raquel, Zucarelli, Marcos, Laschefski, Klemens, \& Santos, Ana Flávia. (2016). O desastre da Samarco e a política das afetações: classificações e ações que produzem o sofrimento social. Ciência e Cultura, 68 (3), 36-40. https://dx.doi.org/10.21800/2317-66602016000300012

\section{COPYRIGHT}

Direitos autorais: Os autores são os únicos responsáveis pelo material incluído no artigo. 


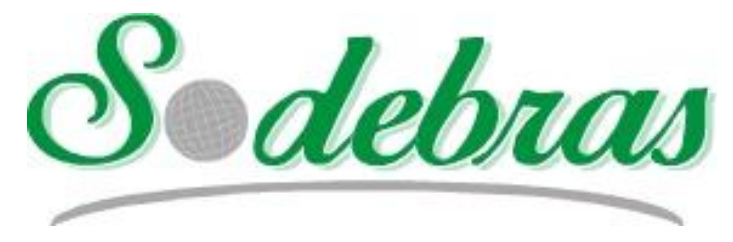

Volume 15 - No 169 - Janeiro / 2020

XLI International Sodebras Congress

31 de outubro a 02 de novembro de 2019 - Maceió - AL.

\title{
A LINGUAGEM JURÍDICA COMO PORTA DE ACESSO À JUSTIÇA
}

\author{
LEGAL LANGUAGE AS A DOOR ACCESS TO JUSTICE \\ JHÔNATHA MAGALHÃES SILVA; CARMEN GEAN VERAS DE MENESES \\ CRISTO FACULDADE DO PIAUÍ - CHRISFAPI \\ jhonathamagalhaes0708@gmail.com; carmengean@hotmail.com
}

\begin{abstract}
Resumo - A linguagem jurídica é utilizada como instrumento do repasse de informações ligadas ao Direito. Desse modo, é repassada aos interlocutores por meio do operador do Direito à resolução de dúvidas jurídicas ou questionamentos. Realizou-se pesquisa bibliográfica, onde o presente trabalho estudou $e$ baseou-se em uma prévia pesquisa em artigos disponibilizados na Internet e também em bibliografias, fundamentando o trabalho, desta forma adotou não somente o uso de um método, mas de vários métodos. Afinal, não basta um arcabouço de lei se o personagem principal dessa relação jurídica, o jurisdicionado, ou seja, o cidadão comum que clama por justiça, sentir-se marginalizado por não compreender as decisões judiciais voltadas para seus próprios pedidos. Democratizar a linguagem jurídica vai além de sua simplificação, significando verdadeira porta de acesso à Justiça!
\end{abstract}

Palavras-chave: Linguagem Jurídica. Jurisdicionado. Acesso à Justiça.

\begin{abstract}
Legal language is used as an instrument for the transfer of information related to law. Thus, it is passed on to the interlocutors through the right operator to resolve legal doubts or questions. A bibliographic research was carried out, where the present study studied and was based on a previous research on articles available on the Internet and also on bibliographies, supporting the work, thus adopting not only the use of one method, but of several methods. After all, a framework of law is not enough if the main character of this legal relationship, the jurisdictional, that is, the ordinary citizen who calls for justice, feels marginalized for not understanding the court decisions directed to their own requests. Democratizing the legal language goes beyond its simplification, meaning a real gateway to justice!
\end{abstract}

Keywords: Legal Language. Jurisdictional. Access to Justice.

\section{INTRODUÇÃO}

Em se tratando de Direito, para versar sobre a linguagem estabelecida no âmbito jurídico, faz-se imprescindível explanar que se pode observar que o mesmo está presente em qualquer situação vivida comumente por qualquer cidadão, mesmo que não observada de forma direta, por exemplo: na compra de produtos, no nascimento, isenções de taxas ou até mesmo no simples empréstimo de algum objeto. Assim sendo, observa-se que o Direito em si sempre acompanha os passos da sociedade, desde os casos mais simples até os mais complexos.

Destarte, a presente pesquisa estruturou-se em capítulos que abordassem da melhor forma possível o assunto em questão.
No primeiro capítulo, serão lustradas as peculiaridades, bem como as similaridades da linguagem jurídica, elucidando os principais aspectos que dificultam o repasse eficaz da mensagem forense aos interlocutores, ou seja, exemplificando as situações que impossibilitam a compreensão dos jurisdicionados, seja de forma parcial ou integral.

No segundo capítulo, avalia-se de suma importância relatar à existência do Projeto de Lei $n^{\circ} 7.448 / 2006$, possibilitando a informação referente à como a parte do dispositivo da sentença deve ser repassada aos jurisdicionados, de como a linguagem desta parte (dispositivo) deve ser simplificada aos interlocutores, haja vista a deficiência destes com relação a temas e assuntos jurídicos.

No terceiro e derradeiro capítulo, serão demonstrados alguns pensamentos de autores que defendem ou não defendem a simplificação da linguagem jurídica, trazendo à baila pensamentos divergentes, onde os contrários embasam seus argumentos na ideia de que tal democratização da mensagem jurídica, de certa forma banalizará o âmbito jurídico, e respaldam suas convicções na permanência da linguagem dos operadores do Direito no modo em que esta se encontra.

Faz-se cristalino o destaque existente entre Direito e linguagem, pois esta é intrínseca ao outro, visto que é o instrumento que os operadores do Direito utilizam a fim de repassar o real significado das informações contidas nas normas e regras jurídicas, objetivando sanar as dúvidas dos interlocutores por meio da linguagem diretamente ligada ao Direito. A linguagem é a própria existência e essência do Direito!

É evidente que a linguagem é a ponte entre o assunto que o operador do Direito almeja explanar em um diálogo voltado às dúvidas dos interlocutores, estabelecendo assim uma compreensão que tenha sido realmente aclarada de forma que não possa ter deixado/gerado nenhuma dúvida sobre tal pensamento.

Regina Toledo e Antonio Henrique (2004, p. 32) autores da obra "Curso de Português Jurídico", colocam que:

Prevalece hoje o entendimento hermenêutico de que a claridade é requisito essencial do ato comunicativo do emissor, que não completa a atividade do receptor, devendo este último, depois de compreender, julgar e avaliar a mensagem do emissor. 
Como mencionado acima, a simplificação da linguagem jurídica é relatada colocando na afirmação os pontos que são defendidos nesta democratização da elocução, e os pontos que são defendidos sob um olhar mais crítico, fomentando se a simplificação traz mais benefícios ou malefícios com relação ao domínio forense.

Quando se fala em relação entre operador do Direito e interlocutor/ouvinte, sabe-se que, na maioria das vezes, o último não terá conhecimento técnico na área jurídica, precisando assim de um maior cuidado e atenção no momento em que uma resposta for dada pelo operador jurídico ao ouvinte.

Ainda com base no pensamento anterior, é admissível a colocação de exemplos, como em relação ao ato processual de sentença exercido pelo juiz, em que, mesmo sendo escritas, as sentenças possuem linguagem técnica voltada para extinguir o processo sem exame do mérito, ou que decide o mérito, mesmo que não venha a extinguir o processo, porém, é notável que parte da sentença é voltada à linguagem jurídica visando estabelecer a procedência ou improcedência do pedido feito na inicial, ou na contestação, dentre outros.

Dessa forma, a assimilação dos conceitos jurídicos para o advogado enquanto operador do direito, por exemplo, é muito viável, tendo em vista seu conhecimento técnico acerca do assunto jurídico, mas, para os seus constituintes (que na maioria das vezes, não têm conhecimento na área jurídica) essa comunicação/linguagem contida na sentença, por exemplo, não será repassada de forma clara, mesmo que em um texto sucinto.

Diante dessas considerações, é possível até mesmo imaginar a seguinte inquietação: como os operadores do Direito e serventuários podem contribuir para a simplificação da linguagem jurídica de forma a permitir que os jurisdicionados possam entender de maneira satisfatória o conteúdo do discurso jurídico sem erros processuais?

\section{LINGUAGEM JURÍDICA E SUAS VERTENTES}

Para que possa ser possível o repasse da informação as pessoas que não têm base no âmbito jurídico, é necessário que tal repasse seja feito de forma clara e concisa, visando realmente estabelecer uma ponte segura entre o operador do Direito e o interlocutor da mensagem, não podendo insurgir ou permanecer nenhuma dúvida.

Os instrumentos necessários para manter uma boa relação entre as informações que os operadores do Direito visam repassar aos audientes devem ser pautados na linguagem simples, ou seja, na adaptação da linguagem aos ouvintes/interlocutores, tendo em vista a deficiência que os mesmos, na maioria dos casos, possuem com relação aos termos/assuntos que serão tratados sobre os questionamentos jurídicos.

Utilizar de uma linguagem culta e padronizada, com termos habituais do âmbito jurídico (desde que de forma comedida) é preciso a qualquer parte que se encontre como operador do Direito, o que não se pode haver é o uso exagerado de vocábulos arcaicos ou que dificultam a compreensão, pois o uso de tais termos são voltados aos operadores do Direito, aos aplicadores jurídicos, e por muitas vezes os jurisdicionados são "leigos" com relação a estes temas.

É sabido que ao transmitir uma mensagem aos destinatários desta, é necessário que seja feito o uso da linguagem culta em se tratando de qualidade na mensagem, porém ao "exagerar" no que concerne tal linguagem (vocábulos difíceis), certamente irá empobrecer a qualidade empregada no recado jurídico, pois nem sempre os interlocutores terão conhecimentos e a linha de raciocínio hábil para compreender o que está tentando ser repassado.

Sobre o pensamento exposto acima, é importante embasar e concretizar de acordo com as ideias do autor da obra "Qualidade da Linguagem Jurídica", Eduardo de Moraes Sabbag (2016, s.p.), onde o mesmo coloca em seu texto de forma compreensível a defesa de que uma linguagem "mal" falada torna a compreensão do ouvinte ou leitor da mensagem pobre, veja-se:

É claro que, para levar a cabo tal mister, não se pode utilizar a fala pedante, com dizeres mirabolantes, na qual sobeja a terminologia enrolativa, que vem de encontro à precisão necessária à assimilação do argumento aduzido. A linguagem hermética e "centrípeta" só agrada ao remetente, não ao destinatário. Com efeito, o preciosismo é vício de linguagem marcado pela afetação. Deve-se evitar sacrificar a ideia, fugindo do natural, a fim de causar "impressão", sem lograr transmitir o pensamento com clareza.

Na mesma linha de raciocínio do autor, é óbvio que não se deve jamais tornar impossível à compreensão acerca do pensamento do emissor da informação ao audiente a fim de somente "impressioná-lo", levando em consideração que o propósito do mesmo é sanar sua dúvida acerca do assunto/tema jurídico, dessa forma, a linguagem como instrumento jurídico deve ser utilizada com o intuito de ajudar o destinatário da informação em relação a sua dúvida, e não pôr um entrave entre a explanação (do emissor) e a compreensão (do receptor).

Em relação a não percepção nos casos em que há respostas, e mesmo assim a dúvida não é sanada, tudo se resume no método em que a informação é repassada ao interlocutor da mensagem, tendo em vista os pensamentos dos autores colocados onde os mesmos afirmam que embora a mensagem esteja sendo transferida, há uma deficiência na forma em que está sendo enviada, seja com linguagem contendo preciosismo (visando "impressionar" o audiente).

A conduta citada no parágrafo anterior (causar apenas impressão ao interlocutor) torna pobre a qualidade da informação inserida no discurso do emissor ou até mesmo a falta de harmonia entre o conjunto - língua portuguesa, Direito e preparação adequada do conhecimento técnico pois não adianta adaptar a linguagem jurídica ao receptor da mensagem sem que haja um preparo de conhecimento técnico-jurídico como coloca Miguel Reale.

\section{PROJETO DE LEI}

Destarte o que já fora mencionado e fixado de diversas formas, a linguagem jurídica é um instrumento pelo qual o operador do Direito irá repassar seus conhecimentos concernentes sobre os temas jurídicos aos receptores da mensagem, ou seja, aos jurisdicionados que necessitam desse repasse jurídico, haja vista que, em muitas situações os audientes da mensagem são aquelas pessoas que pouco ou até mesmo, desconhecem de forma integral o assunto a ser abordado, isto é, o tema jurídica.

Para que o objetivo principal do aplicador jurídico possa ser alcançado, necessita-se o uso simplificado da mensagem jurídica, visando sempre o bom esclarecimento aos ouvintes da mensagem. Também, como já colocado no 
decorrer do presente estudo, há obstáculos referente ao objetivo anteriormente mencionado, como por exemplo: linguagem excessivamente rebuscada; juridiquês; termos arcaicos, estrangeiros; o uso do latim, enfim, são inúmeros os entraves que impossibilitam o bom repasse da linguagem jurídica de forma clara.

No que diz respeito ao âmbito jurídico, a sentença judicial é a forma mais pura e simples de "decidir" o processo (em $1^{\text {a }}$ instância), dando ou negando o direito almejado na inicial, ou concordando ou discordando do que fora disposto na contestação, tendo em vista que ambas as peças devem ser analisadas pelo magistrado, pois a decisão a ser aplicada deve vir motivada para com que assim, a lide possa ser resolvida de forma equânime.

Faz-se necessário embasar o que fora dito através das palavras de Chiovenda (1998, p. 198) onde o mesmo conceitua de forma compreensível que sentença corresponde a:

\begin{abstract}
A provisão do juiz que, recebendo ou rejeitando a demanda do autor, afirma a existência ou inexistência de uma vontade concreta de lei que lhe garanta um bem ou respectivamente a inexistência ou existência de uma vontade de lei que garanta um bem ao réu.
\end{abstract}

Ou seja, ratificando as palavras do autor, a sentença consiste em um instituto que traz a "resolução" do processo em se tratando de primeira instância, pois o juiz ao deliberar sobre os pedidos formulados tanto na inicial como na contestação, tornam de forma concreta os desejos do autor/réu, sendo assim, a resposta mais esperada da demanda.

Tendo como principal aspecto a seriedade e o peso das palavras ditas acima que, frisa-se que a sentença é voltada as vontades do requerente e requerido, sendo assim, sua linguagem deve ser adaptada a eles, pois, é notório que em muitos casos as partes do processo não possuem embasamento técnico no que concerne o Direito em si, por isso precisam de auxílio técnico e jurídico dos advogados/defensores públicos/promotores de justiça.

E foi utilizando como justificativa as dificuldades encontradas pelos jurisdicionados, juntamente com pujança das sentenças, que o Projeto de Lei $n^{\circ}$ 7448/2006 teve início, pois o referido projeto visa tornar mais compreensível, por assim dizer, no que condiz o dispositivo da sentença.

O denominado - dispositivo da sentençall, ou também conhecido por "conclusão", corresponde à parte do ditame em que o juiz decide, ou seja, sem o dispositivo não existe sentença. É tido como a parte mais relevante da sentença, pois assume força de "coisa julgada". É na conclusão, como a palavra é autoexplicativa, que o magistrado irá resolver os questionamentos que as partes trouxeram ao longo de todo o processo.

Dessa forma, nota-se que o dispositivo é a parte que mais "interessa" aos componentes da lide, tendo em vista ser a parte que delimita o pedido de qual parte foi acatado. E é com essa relevância que o projeto de lei supramencionado se preocupa, pois o seu objetivo é alterar o caput do artigo 458 da Lei $\mathrm{n}^{\mathrm{o}} 5.869$, de 11 de janeiro de 11 de janeiro de 1973 - Código de Processo Civil.

Como se pode observar, o Projeto de Lei é do ano de 2006, dessa forma, a alteração estava pautada no artigo 458 do Código de Processo Civil de 1973 ainda, pois somente no ano de 2015 o CPC foi modificado, sendo imprescindível tal observação. Com o advento do NCPC de 2015, o artigo 458 do CPC de 1973, transformou-se no artigo 489 do NCPC com a edição necessária.

Sendo assim, é notório dispor e observar que, se o Projeto de Lei $\mathrm{n}^{\mathrm{o}} 7448 / 2006$ for aprovado pelos Legisladores, à alteração será feita no texto do artigo 489 do Novo Código de Processo Civil, e não mais no obsoleto artigo 458 do antigo CPC.

Destarte, o referido Projeto de Lei foi proposto pela Deputada Maria do Rosário em 05 de setembro de 2006, sendo necessário trazer à baila sua justificativa para a proposição, e consequente pedido de aprovação do PL, tendo em vista que o referido texto é de suma importância, dessa forma, imprescindível colocá-lo de forma expressa ao leitor do presente trabalho:

\section{JUSTIFICAÇÃO}

Diferentemente das decisões interlocutórias, que são destinadas ao conhecimento dos advogados, a decisão final do processo dirige-se principalmente às partes.

A exemplo do texto constitucional, cuja técnica de redação prioriza o uso de palavras de conhecimento geral e cuja hermenêutica recomenda a opção pelo sentido comum, assim também deve ser concebida a sentença judicial, já que tanto a Constituição como a sentença não podem ser reduzidas a um texto técnico.

Nesse passo, deve-se considerar que o Direito, de forma corriqueira, utilizasse de linguagem normalmente inacessível ao comum da população, apresentando, no mais das vezes, um texto hermético e incompreensível.

Assim, de pouco ou nada adianta às partes a mera leitura da sentença em seu texto técnico.

Desse modo, a tradução para o vernáculo comum do texto técnico da sentença judicial impõe-se como imperativo democrático, especialmente nos processos que, por sua natureza, versem interesses peculiares às camadas mais humildes da sociedade, como as ações previdenciárias e relacionadas ao direito do consumidor. Pelo exposto, conclamo meus pares a aprovar o presente projeto de lei. Sala das Sessões, em 05 de setembro de 2006. Deputada MARIA DO ROSÁRIO

Evidencia-se a preocupação da Deputada no que diz respeito à forma de como a sentença é voltada atualmente aos jurisdicionados, pois, ressalta-se que a linguagem "distribuída" aos interlocutores do Direito, não somente na sentença, mas nas demais peças processuais, é uma linguagem cheia de termos que dificultam a compreensão dos ouvintes/receptores da mensagem jurídica.

É necessário fazer um estudo minucioso das principais modificações visadas pelo projeto de lei $n^{\circ} 7448 / 2006$ no que se refere à linguagem utilizada no dispositivo da sentença em si, ou seja, denotar a importância da simplificação da mensagem jurídica trazida pelo texto do projeto.

No corpo do projeto, altera-se, como já mencionado, o artigo 458 do CPC/1973 (atual artigo 489 do NCPC/2015), trazendo como foco principal a ideia de que o dispositivo da sentença seja trabalhado em linguagem coloquial, não fazendo o uso de palavras exclusivas da Linguagem técnicojurídica e acrescentando as considerações que o magistrado inferir necessárias, de maneira que a decisão jurisdicional seja plenamente entendida por qualquer indivíduo do povo. Este texto é o que se quer no inciso IV do artigo mencionado, ou seja, era a inclusão do inciso IV à redação 
do artigo, que na época era o artigo 458 do antigo Código de Processo Civil.

O parágrafo primeiro do PL versa sobre o uso de expressões que possam dificultar a compreensão do jurisdicionado, fazendo a ressalva de que ao utilizar expressões de língua estrangeira, tal expressão possa vir seguida da devida tradução em língua portuguesa, porém, essa exigência é dispensada nos casos em a expressão ou o texto são inerentes à técnica jurídica.

Com base em tudo o que foi exposto neste capítulo, observa-se a necessidade de que a linguagem jurídica deve ser democratizada, principalmente em se tratando de assuntos de interesses das partes do processo, pois, o referido projeto de lei busca de uma forma mais preocupada, o repasse eficiente do que fora deliberado na decisão judicial, trazendo a discussão de que muitas vezes a parte interessada não consegue compreender o que está sendo decidido, justamente pela dificuldade na compreensão gerada pela linguagem hermética colocada na resolução jurídica (sentença).

\section{DEMOCRATIZAÇÃO OU BANALIZAÇÃO DA LINGUAGEM JURÍDICA?}

Não é surpresa que o uso da linguagem jurídica entre os operadores do Direito é feita de forma rebuscada, como visto anteriormente, em alguns casos o uso exagerado de termos jurídicos pode até mesmo impossibilitar o entendimento da sociedade para com certas explanações jurídicas.

Sobre o tema da simplificação ou banalização da linguagem jurídica, há uma discussão que toma de conta do âmbito jurídico, pois ao tempo em que há autores que defendem a simplificação da linguagem jurídica, há autores que sustentam que se ocorrer tal democratização, haverá consequentemente a vulgarização do Direito.

Um autor que pode ser citado como a favor da simplificação da linguagem jurídica é André Gonçalves Fernandes (2016, s.p), onde o mesmo sustenta que:

É hora de aposentar os substantivos de fraque e cartola e os adjetivos de luvas e polainas, em prol de uma linguagem acessível ao entendimento alheio. Em "juridiquês", malgrado minha reverência ao libelo de outrem, cuida-se do que especulo. Ou, em português, com respeito à divergência, é o que penso.

Com outras palavras, o autor demonstra que é necessário que seja "extinto" os termos que dificultam a compreensão do público, trazendo em seu texto termos carregados de juridiquês, demonstrando e asseverando que tais termos empobrecem o entendimento -alheioll, mostrando de forma sucinta no início e "cômica" ao final que a linguagem acessível deve ser implementada em prol da melhor percepção dos ouvintes.

Em contrapartida, há autores que, embora não defendam de forma absoluta que a linguagem jurídica deve ser rebuscada e hermética, defendem que a simplificação desta poderia acarretar certo prejuízo com relação ao pensamento dos operadores jurídicos, pois, ao modificar os vocábulos rebuscados e técnicos da mensagem jurídica, poderia levar, consequentemente, a modificação também, do que o operador jurídico estava almejando dizer.

$\mathrm{Na}$ essência das ideias de Augusto Francisco Mota ao relatar sua opinião à revista Consulex (2010) aduz que a incerteza da democratização da linguagem jurídica, renega e torna inválida a própria presença do arcabouço orgânico e formal do procedimento judicial brasileiro que, é feito com base nos debates entre os advogados ou pelo Ministério Público, sendo a parte que acusa. E esse antagonismo de argumentos é destacado, principalmente, pelo saber jurídico dos profissionais que atuam no processo, e através desses debates, há a insurgência da sentença judicial, contendo os fundamentos jurídicos e fáticos da referida decisão, onde estes fundamentos são dispostos dentro da lei processual como "motivos constitutivos do ato que decide" dessa forma, não devem ser descritos numa linguagem coloquial ou popular, correndo o risco de prejudicar de forma grave a pura intenção e raciocínio do magistrado.

De forma resumida, o autor destaca que havendo a simplificação da linguagem, haverá também a restrição do que o juiz raciocina ao motivar sua decisão, tendo em vista que, o mesmo apresenta sua motivação com base nos preceitos legais preestabelecidos no sistema jurídico-legal.

É claro que, em se tratando de mensagem jurídica, é necessário que seja feita uma análise para quem a referida mensagem está sendo voltada, haja vista que entre dois operadores do Direito não é necessária a simplificação da linguagem jurídica, pois parte do pressuposto que ambos estão totalmente adequados à linguagem técnica, rebuscada e até mesmo, hermética.

Aos jurisdicionados, por sua vez, partindo do ponto concreto que muitas vezes tais jurisdicionados não possuem embasamento jurídico para tratar de assuntos relacionados ao Direito, chega-se à conclusão de que os tipos de linguagem acima mencionados irão comprometer de forma direta a compreensão do ouvinte, pois quem não tem o "saber jurídico" para tratar de assuntos jurídicos, dificilmente compreenderá pensamentos carregados de termos jurídicos.

Com base nesses dois destinos da linguagem profissionais versus jurisdicionados - é possível se estabelecer que são dois pensamentos conflitantes, mas que cada um possui suas argumentações. Pois, ao tempo em que o operador utiliza da linguagem jurídica para estabelecer uma comunicação tanto entre outros profissionais do Direito, quanto para seus constituintes, é cristalino que aqueles não possuem dificuldade alguma para o claro entendimento do que está sendo dito por ele, e das respostas que está recebendo.

Dessa forma, os argumentos de profissionais do Direito, se baseiam, como mencionado, tanto no conhecimento - notável saber jurídico - quanto na preservação dos pensamentos primordiais do que se quis dizer (como no caso da motivação do juiz ao formular uma sentença). E é nessa linha de raciocínio que a defesa de que a simplificação da linguagem, de certo banalizará a fala jurídica dos profissionais que dela utilizam.

Vindo de encontro com tais argumentos, os ouvintes, interlocutores, receptadores, jurisdicionados, e até mesmo alguns operadores do Direito, sustentam que a linguagem simplificada e objetiva, visa, de forma principal, o bom entendimento do que está sendo exposto, sempre alegando que os que necessitam das informações jurídicas não possuem notável saber jurídico, por isso a linguagem deve ser voltada a compreensão límpida dos temas jurídicos.

É com base nesses argumentos que, os defensores, tomam como principal efeito da simplificação da linguagem jurídica, a democratização desta, pois, o objetivo é possibilitar que qualquer pessoa do povo tenha a 
"acessibilidade" de poder se comunicar com os operadores do Direito, tendo em vista que, atualmente essa acessibilidade é garantida, mesmo que não assumida, a apenas a quem possui base forense, ou seja, aos aplicadores do Direito, aos que trabalham diretamente com o âmbito jurídico em si.

Sobre o questionamento incitado, a Juíza de Direito do Tribunal de Justiça do Distrito Federal e dos Terrirórios TJDFT - Oriana Piske (2006) relata que é preciso abrir os olhos para a inevitável simplificação da linguagem jurídica, pois é passo pioneiro para o verdadeiro sentido de pluralização e democratização da Justiça.

A Juíza traz à baila sobre o assunto da acessibilidade à justiça, pois a democratização da linguagem jurídica é de certa forma o caminho ou a porta que dá acesso do jurisdicionado à justiça, fazendo perceber a necessidade dessa "desbanalização" que é a simplificação do discurso utilizado no ambiente jurídico, tudo isso pautado na carência que os audientes da mensagem forense possuem com relação aos conhecimento técnicos e específicos voltados ao Direito.

Por fim, é necessário trazer o brilhante raciocínio da ínclita Ma. Luciana Helena Palermo (2012, s.p.) sobre a democratização da linguagem jurídica, onde a mesma aconselha que o aplicador jurídico que escreve de forma certa, que repassa de forma harmônica suas convicções, com simplicidade, de maneira coesa e objetiva, exprime-se bem, pois alcança sua meta. Esse técnico ajuda no andamento eficaz ao acesso à Justiça, visto que gera Justiça.

Portanto, nota-se que, com relação ao âmbito jurídico, muitas são as visões que compartilham de pensamentos distintos, que para alguns não há necessidade da simplificação da linguagem jurídica, já que a linguagem estabelecida no âmbito forense é voltada aos conhecimentos dos profissionais do Direito, de molde que estes se entendem entre si, e que tal democratização modificaria de forma direta o real pensamento do autor da mensagem.

Observa-se também, que há uma intensa vontade entre operadores do Direito e jurisdicionados em que a simplificação da linguagem forense seja cada vez mais intensificada, visando a acessibilidade à justiça, e que de forma alguma seria um método de banalização do Direito, tendo em vista que o Direito como fato social se transforma em conjunto com a linguagem e com a sociedade.

Dessa forma, simplificar seria o mesmo que adequar/adaptar os cidadãos leigos (com relação ao conhecimento técnico-jurídico) ao ambiente forense.

De tal forma, os pensamentos divergentes são muitos, porém, é necessário destacar que a evolução com relação à adaptação da linguagem jurídica aos "leigos" dos conhecimentos jurídicos, é evidente que retratando novamente que a sociedade transforma o Direito, de modo que a linguagem sendo a essência deste, é refletida aos jurisdicionados, mesmo havendo alguns obstáculos, a simplificação é iminente, ainda que somente em alguns pontos, como é levantada a questão no projeto de lei $\mathrm{n}^{\circ}$ $7.448 / 2006$.

\section{METODOLOGIA}

O estudo proposto utilizou de uma pesquisa bibliográfica. Os métodos apresentados na pesquisa foram baseados em uma prévia pesquisa em artigos disponibilizados na internet e também em bibliografias, fundamentando o trabalho, desta forma, adotou não somente o uso de um método. De acordo com tal pensamento, Lakatos e Marconi (2003, p. 164) afirmam que:

Nas investigações, em geral, nunca se utiliza apenas um método ou uma técnica, e nem somente aqueles que se conhece, mas todo os que forem necessários ou apropriados para determinado caso. Na maioria das vezes, há uma combinação de dois ou mais deles, usados concomitantemente.

Com as pesquisas bibliográficas, foi possível explicitar os fins que o presente trabalho visava, ou seja, tornou possível a observação de como a linguagem é empregada em todo o âmbito jurídico, bem como analisou suas particularidades com relação não somente no impacto que o tema tem no antro forense, mas também com o desenvolvimento da sociedade em si.

\section{1-Benefícios}

Como já colocado no decorrer da pesquisa, os benefícios que o trabalho trouxe foram incalculáveis, tendo em vista a suma importância do tema abordado.

Vale ressaltar que desses benefícios, pôde-se extrair principalmente: os conhecimentos que foram levados não somente aos leitores que desconhecem a linguagem jurídica, mas também aos profissionais do Direito sobre a importância do policiamento que deve sempre ser feito ao se comunicar com os seus constituintes, não prejudicando o entendimento destes sobre assuntos jurídicos abordados sugestões, onde possibilitou o aumento na qualidade da oralidade do emissor da mensagem; adaptação da linguagem empregada no discurso ao ouvinte, onde se deve ter cuidado com os termos técnico-jurídicos utilizados a quem não possui conhecimento para entender tais termos.

\section{CONCLUSÃO}

Nesta etapa do presente trabalho, se faz imprescindível reproduzir algumas considerações finais sobre o cerne do assunto em comento, qual seja, como os operadores do Direito e serventuários podem contribuir para a simplificação da linguagem jurídica, objetivando uma forma de permitir que os jurisdicionados possam entender de forma satisfatória o conteúdo do discurso jurídico em atos processuais.

Todo o desenvolvimento da pesquisa se voltou para que $o$ pesquisador respondesse sobre $o$ principal questionamento do trabalho, trazendo temáticas $\mathrm{e}$ apontamentos condizentes com o tema abordado pelo autor. Temas estes de suma importância para o enriquecimento audaz, e ao mesmo tempo simplório aos futuros leitores do trabalho.

Fora demonstrado também, e reiterada as principais vertentes da linguagem jurídica, bem como suas particularidades, estabelecendo que aos audientes a mensagem jurídica tenha que ser pautada em argumentos claros e simples, visando à compreensão de forma integral do que foi exposto.

Isto é, defende-se a adaptação da linguagem jurídica aos jurisdicionados, deixando claro que entre os operadores do Direito, a linguagem técnica é totalmente aceitável, pois, os operadores jurídicos possuem conhecimento técnico e específico das questões que versam sobre temas de relevância jurídica. Porém, aos audientes da mensagem, que por muitas vezes, não possuem tal conhecimento, é 
necessário que a linguagem deva ser adaptada ao nível de instrução que estes têm sobre assuntos forenses.

Acerca das preocupações do autor com relação a qualidade das informações que são repassadas aos jurisdicionados, constatou-se a existência de um Projeto de Lei que versa sobre o tema em questão, onde o referido projeto de lei, se consubstancia na deficiência que os audientes possuem com relação ao embasamento que os mesmos possuem em se tratando de matérias ligadas ao Direito.

A essência do PL tem eixo no impacto que a parte do dispositivo da sentença traz ao ser prolatada pelo Juiz, pois, tal parte da sentença é a peça principal para que a mesma produza efeitos, sem dispositivo, não há sentença. $O$ objetivo do projeto de lei é a simplificação da parte do dispositivo, tendo em vista ser a parte mais "interessante" as partes componentes da lide processual.

Esta simplificação tem como sua justificativa a linguagem do Direito, que muitas vezes é inacessível à população, não no sentido de não ser repassada, mas no sentido de que a inacessibilidade se perfaz através de um vocabulário jurídico hermético, vocabulário este que é utilizado pelos operadores forenses.

Nesta linha de raciocínio, necessitou-se envolver questões acerca dos pensamentos dos autores que defendiam a simplificação da linguagem jurídica, e de autores que defendiam que esta simplificação, acabaria por banalizar o âmbito jurídico.

A divergência se dá por pensamentos contrários, onde os autores que defendem a simplificação da linguagem jurídica mantêm seus argumentos pautados na acessibilidade às justiças aos jurisdicionados, ou seja, no aspecto de democratização desta linguagem, tornando ampla a todos que dela necessitam.

Os defensores da democratização aduzem que termos herméticos, pedantes e arcaicos devem ser substituídos por vocábulos simples, por sinônimos que facilitem o entendimento da mensagem que esteja sendo repassada, tendo em vista que a linguagem como instrumento do operador do Direito, tem a finalidade primordial de repassar a mensagem de forma simples aos leitores/ouvintes da mensagem, dessa forma, mantém a intrínseca relação de porta de acesso à justiça.

Os autores que pensam de forma contrária, por sua vez, defendem que se ocorrer à simplificação da linguagem jurídica, consequentemente, ocasionará também a banalização do Direito, pois, enquanto operadores forenses, estes mantêm a finalidade principal de demonstrar o notável saber jurídico, e não há outra forma de demonstrá-lo a não ser através dos termos técnicos do âmbito do Direito.

Defendem ainda que, ao simplificar a mensagem jurídica, poderá incorrer na mudança dos aspectos das informações que os operadores queriam repassar, ou seja, poderá modificar o real pensamento do juiz, por exemplo, ao prolatar uma sentença.

Portanto, restou comprovada a importância que a linguagem jurídica tem nas relações do cotidiano na sociedade, pois fornece um diálogo entre o aplicador do Direito (seja juiz em atos processuais, advogados em peças processuais ou no atendimento ao público feito pelos servidores das Secretarias de Justiça) e os audientes menos experientes em se tratando de temas jurídicos.

Afinal, não basta um arcabouço de lei, não basta toda uma estrutura judiciária, formada por órgãos, juízes e serventuários, não basta tudo isso, se o personagem principal dessa relação jurídica, que é o jurisdicionado, ou seja, o cidadão comum que clama por justiça, sente-se marginalizado por não compreender as decisões judiciais voltadas para seus próprios pedidos, por sentir-se diminuído diante do não conhecimento dos termos jurídicos empregados. Democratizar a linguagem jurídica vai além de sua simplificação, significando verdadeira porta de acesso à Justiça!

\section{REFERÊNCIAS BIBLIOGRÁFICAS}

BRASIL. Lei 5.869, de 11 de janeiro de 1973. Institui o Código de Processo Civil. Diário Oficial da União, Brasília, 17 jan. 1973.

BRASÍLIA. Plenário. Projeto de Lei PL 7.448/2006. Altera o art. 458 da Lei ${ }^{\circ} 5.869$, de 11 de janeiro de 1973 - Código de Processo Civil. Disponível em: $<$ https://www.camara.leg.br/proposicoesWeb/prop_mostrari ntegra;jsessionid $=$ A40E11661789BAE073B43142A8BB04 22. proposicoes WebExterno1? codteor $=416293 \&$ filename $=P$ L+7448/2006>. Acesso em 20 abr. 2019.

CHIOVENDA, Giuseppe. Instituições de Direito Processual Civil. trad. Paolo Capitanio. Campinas: Bookseller, 1998, p. 198.

FERNANDES，ANDRÉ GONÇALVES. LINGUAGEM JURÍDICA NO DIVÃ. MMJ - MOVIMENTO MAGISTRADOS PARA A JUSTIÇA, $[S . l],$.9 maio 2016.

GUIMARÃES, Luciana Helena Palermo de Almeida. A SIMPLIFICAÇÃO DA LINGUAGEM JURÍDICA COMO INSTRUMENTO FUNDAMENTAL DE ACESSO À JUSTIÇA. Publicatio UEPG: Ciências Humanas, Linguística, Letras e Artes, Ponta Grossa, 2012.

LAKATOS, Eva Marine; MARCONI, Marina Andrade. Fundamentos de Metodologia Científica. 5a . ed. São Paulo. Atlas, 2003.

SABBAG, Eduardo. Jornal Carta Forense. Língua Portuguesa: Qualidade da Linguagem Jurídica - Parte I. $2016 . \quad$ Disponível em: $<$ http://www.cartaforense.com.br/conteudo/colunas/qualidad es-da-linguagemjuridica---parte-i/16806>. Acesso em: 09 out. 2018

PISKE, Oriana. SIMPLIFICAÇÃO DA LINGUAGEM JURÍDICA. TJDFT - Tribunal de Justiça do Distrito Federal e dos Territórios Poder Judiciário da União TRIBUNAL DE JUSTIÇA DO DISTRITO FEDERAL E DOS TERRITÓRIOS, Distrito Federal, 19 set. 2006.

ARRUDA, A. F. M. F. de. Reflexões sobre a proposta de simplificação da linguagem jurídica. Revista Consulex, Brasília, Ano XIV, 2010.

TOLEDO, R.; HENRIQUE, A. CURSO DE PORTUGUÊS JURÍDICO. 9.ed. São Paulo: Altas, 2004.

\section{COPYRIGHT}

Direitos autorais: Os autores são os únicos responsáveis pelo material incluído no artigo. 


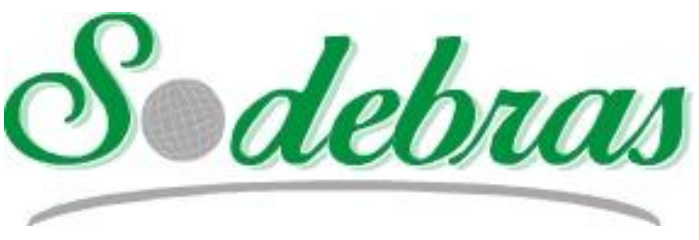

Volume $15-\mathrm{N}^{\mathrm{o}} 169$ - Janeiro / 2020

XLI International Sodebras Congress

31 de outubro a 02 de novembro de 2019 - Maceió - AL.

\title{
O IMPACTO DA IMPLEMENTAÇÃO DA FERRAMENTA POWER BI NO ATUAL CENÁRIO CORPORATIVO DE PERNAMBUCO
}

\author{
THE IMPACT OF POWER BI TOOL IMPLEMENTATION ON THE \\ PERNAMBUCO CORPORATE SCENARIO
}

\author{
MARCELO ANDRÉ ESTEVES BARBOSA JÚNIOR, MILENA GRASIELLE VIANA GOMES, \\ THAIANE ARAÚJO DOS SANTOS, EURI CHARLES ANDRADE DA SILVA \\ 1 - UNIVERSIDADE CATÓLICA DE PERNAMBUCO \\ mar_celo_esteves@hotmail.com, milenagvg7@gmail.com,thaiane_araujo1@hotmail.com
}

\begin{abstract}
Resumo - No atual cenário de Pernambuco encontra-se o Porto Digital, considerado o maior Polo Tecnológico do Brasil, além do Porto de Suape, o qual trouxe empresas como a Petrobrás e a Fiat Chrysler para o estado, tornando assim indispensável nas empresas a presença de tecnologias. O Power BI é uma ferramenta de Business Inteligence de análise de dados, com isso, o problema de pesquisa foi estudar o impacto da implementação desta ferramenta nas corporações que emergem o estado, com o objetivo de identificar sua funcionalidade nas empresas. Foi utilizado o método de pesquisa exploratória, e utilização de pesquisa qualitativa buscando entender a eficácia da ferramenta através de questionário com a ferramenta Google Formulários. Ao término do artigo, observa-se que a utilização do Power BI vem impactando de maneira positiva a rotina das organizações e que há uma escassez de profissionais dessa área.
\end{abstract}

Palavras-chave: Inovação; Análise; Tecnologia.

\begin{abstract}
In the current scenario of the state is the Digital Port, considered the largest Technology Hub in Brazil, in addition to the Suape Port, which brought companies such as Petrobras and Fiat Chrysler to the state, thus making the presence of technology indispensable in companies. . Power BI is a Business Intelligence tool for data analysis, so the research problem was to study the impact of implementing this tool on corporations that emerge from the state, in order to identify its functionality in companies. We used the exploratory research method, and use of qualitative research seeking to understand the effectiveness of the tool through questionnaire with the Google Forms tool. At the end of the article, it is observed that the use of Power BI has positively impacting the routine of organizations and that there is a shortage of professionals in this area.
\end{abstract}

Keywords: Innovation; Analyze; Technology.

\section{INTRODUÇÃO}

Atualmente o estado de Pernambuco, situado na região nordeste, é considerado o maior polo tecnológico do Brasil, devido principalmente ao Porto Digital, o qual ocasionou a vinda de grandes multinacionais como a Microsoft, a IBM, a Samsung, entre outras. Entretanto, o Porto Digital não surgiu em Pernambuco sem motivos, tendo em vista que o Porto de Suape vem crescendo em território nacional como um dos maiores portos públicos do Brasil e o maior da região nordeste, abrangendo os estados de Pernambuco,
Alagoas, Paraíba, além de parte do Rio Grande do Norte, do Ceará e do interior do Maranhão.

Com a criação de Suape, empresas como Petrobrás, Copergás, Fiat Chrysler e Minasgás tiveram oportunidade de implementar seus produtos, serviços e tecnologias em Pernambuco, consequentemente acarretando na criação de vínculos com o Porto Digital.

Esse Parque Tecnológico, por sua vez, foi criado a partir de uma ideia de um grupo de empresários e representantes do setor público, que tinham como objetivo integrar o Setor de Tecnologia da Informação e Comunicação (TIC) com organizações que agiam de forma independente e isolada, a fim de que a região se tornasse um atrativo para a inovação, estimulando a economia do estado, gerando empregos, renda e qualificação para a população (RAMPAZZO, 2014).

Com esse conjunto de eventos, o estado de Pernambuco consolidou-se como o maior Polo Tecnológico do Brasil, trazendo uma área onde as empresas buscam instalar-se, tendo em vista a utilização dos benefícios gerados por esse ambiente favorável, como a mão de obra qualificada e as tecnologias que provém dessas multinacionais presentes no estado.

Diante disso, como problema de pesquisa é pertinente estudar qual o impacto da implementação da ferramenta Power BI em empresas no atual cenário de Pernambuco, levando em consideração que tornou-se indispensável a presença de tecnologias na realidade corporativa do estado, pois as empresas desperdiçam bastante tempo dos seus colaboradores para compilar e analisar dados, além do fato de que a dinâmica atual do mercado não é favorável à empresas que não automatizam suas atividades, com isso muitas dessas perdem espaço e competitividade por não aderir o uso de tecnologias de gestão. Outro fator a ser considerado é o alto nível de exigência em relação aos resultados dos funcionários, já que o erro humano não é mais tolerado pelas organizações, pois ele ocorre devido a processos que são realizados de maneira independente e não integrada.

Diante disso, o objetivo do presente artigo é identificar como a ferramenta Power BI funciona nas empresas e quais são seus benefícios, visto que as organizações estão cada vez mais carecendo de programas que viabilizam uma maior 
rapidez nos processos cotidianos do ambiente de trabalho e mais precisão na visualização e análise de dados.

Em grandes empresas a utilização desse tipo de tecnologia está presente desde suas funções mais básicas, até elaborações de estratégias de expansão. Segundo a Microsoft, as ferramentas de Business Intelligence (BI) são primordiais para corporações, partindo da premissa da necessidade de gerenciamento, compartilhamento e análise de dados de diversas fontes.

Nesse sentido, organizações, principalmente do setor industrial, vem apresentando a necessidade de que suas informações sejam cada vez mais precisas para que possam tomar decisões de caráter substancial, e como consequência disso, a Microsoft, percebeu essa necessidade de apresentar uma ferramenta que diminuiria as dificuldades de análise das informações gerenciais das empresas.

\section{REFERENCIAL TEÓRICO}

De acordo com Maximiano (2004), toda empresa é uma organização, mas nem toda organização é uma empresa, com isso, a corporação é um tipo de organização, que consiste em um conjunto de pessoas trabalhando para alcançar um objetivo em comum, onde é necessário administrar tanto o patrimônio, como as pessoas.

A administração representa uma ciência social que estuda as formas de gerir as áreas referentes à pessoas, processos, negócios e/ou recursos, a fim de atingir metas e objetivos específicos (MONTANA, CHARNOV, 2001).

Para auxiliar no planejamento das metas e objetivos há um segmento de estudo conhecido como Sistema de Informação, o qual compreende em um conglomerado de ações, as quais em conjunto tem a finalidade de facilitar o planejamento, o controle e os processos dentro de uma organização, a fim de que a síntese desses dados possa fornecer métodos de análises para tomada de decisões. Isso tudo ocorre em algumas fases simples, mas que, no final, tem grandes resultados, ou seja, tudo começa no recebimento de dados, que posteriormente serão processados e terão disponibilidade de visualização para qualquer pessoa integrada à organização.

De acordo com Rezende (2002), os sistemas da informação consistem em um compilado de hardwares, que se resume em toda parte física da máquina.

Já os softwares são sistemas que compõem o interior do hardware e realizam diversas tarefas (KEEN, 1996). Assim, a integração deles permite a existência das ferramentas que tornam mais viáveis todo conjunto de elementos necessários para o funcionamento dos Sistemas de Informação, possibilitando a difusão desse tipo de ação no interior da empresa, além de recursos humanos e procedimentos que precedem ou sucedem um programa. A maior finalidade desses são o apoio nos processos estratégicos de tomada de decisão nas organizações.

Os sistemas de informações não têm a capacidade de atuar individualmente, já que os mesmos dependem da integração de diversas bases de dados, necessitando de elementos para organizar seu fluxo de operação. Para manter seu pleno funcionamento é necessário uma cadeia organizacional, onde há 3 níveis de planejamento, são eles: estratégico, tático, e operacional, que tem como origem as áreas de uma organização, como marketing, finanças, recursos humanos, comercial, entre outros. Na imagem 1 a seguir é possível identificar a pirâmide com os três níveis de planejamento.
Imagem 1 - Pirâmide de planejamento empresarial.

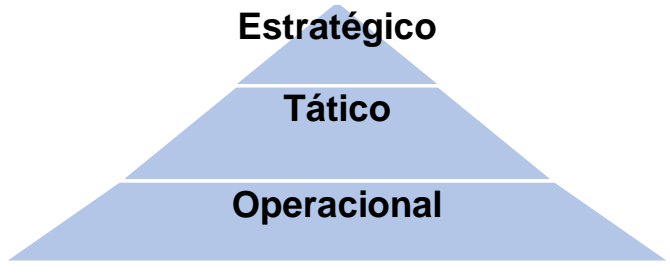

Fonte: Maximiamo (2004)

Segundo Maximiamo (2004), O planejamento estratégico consiste na definição de objetivos a longo prazo da empresa, além da missão e visão do ambiente. O planejamento tático é desenvolvido por níveis intermediários da organização, utilizando diretrizes do planejamento estratégico para otimizar uma área específica de resultado a médio prazo, já o planejamento operacional é feito no curto prazo, com tarefas rotineiras, executando as tarefas descritas no planejamento estratégico, sendo planos de ação ou planos operacionais. (OLIVEIRA, 2006).

Diante disso, podemos citar o ERP (Enterprises Resource Planning), o qual é um sistema que sintetiza toda a parte de processos de uma empresa, com intuito de oferecer aos gestores uma visão estratégica e detalhada de tudo que ocorre, permitindo que possam ser realizadas possíveis correções ou adequações para que exista uma otimização dos trabalhos relacionados (SOUZA, SACCOL, 2003). Portanto, observa-se que os benefícios deste sistema de gestão são de grande relevância, já que acarreta no aumento da eficiência e da produtividade do trabalho.

Outro sistema que se encontra em destaque no atual cenário corporativo é o Business Intelligence, que segundo Carvalho (2003, p. 103) "o objetivo de um sistema de BI é contribuir para gerar novos conhecimentos que resultem em efetivos resultados empresariais de negócio". Dentro do Business Intelligence há diversas ferramentas, uma delas é o Power BI, uma ferramenta empresarial facilitadora da tomada de decisão e da análise de dados e informações do ambiente corporativo interno e externo.

Segundo a Microsoft em 2018, o Power BI é uma gama de serviços, aplicativos e conectores. Esses que tornam viável a conexão de dados independente do local que estejam armazenados, também permitindo a utilização de filtros nas informações, e o compartilhamento delas com quem quer que seja.

Assim, é válido observar a importância dos sistemas de informação, tendo em vista que os mesmos trazem diversos benefícios para as organizações, possibilitando a divulgação da informação de maneira mais rápida e eficaz, facilitando a comunicação e integração das equipes, podendo gerenciar dados de forma dinâmica, automatizando os processos rotineiros, possibilitando maior vantagem sobre a concorrência e estando a frente de problemas, além de passar mais segurança com relação as informações que a tecnologia proporciona.

\section{METODOLOGIA}

Neste artigo será utilizado o método de pesquisa exploratória, a partir de experiências práticas e conteúdos bibliográficos acerca do uso do Power BI nas empresas, e utilização da pesquisa qualitativa buscando entender grupos específicos que utilizam a ferramenta através de formulários 
com perguntas objetivas, com a intenção de captar a satisfação dos usuários.

Segundo Gil (1991) a pesquisa exploratória tem o intuito de propiciar maior familiaridade com a problemática abordada, na finalidade de fazê-la explícita ou resultar no surgimento de hipóteses, dessa maneira, assumindo em geral, o formato de informação. Além disso, haverá a coparticipação da pesquisa qualitativa, a qual auxilia na validação da temática abordada na pesquisa exploratória.

Sendo assim, os pesquisadores qualitativos recusam o modelo positivista aplicado ao estudo da vida social, uma vez que o pesquisador não pode fazer julgamentos nem permitir que seus preconceitos e crenças contaminem a pesquisa (GOLDENBERG, 1997).

Nesse contexto, será aplicado um formulário com perguntas direcionadas ao tema estudado, visando mensurar a importância que a ferramenta Power BI está exercendo nas atividades desempenhadas pelos colaboradores e quais são os benefícios agregados.

Será aplicado um questionário utilizando a ferramenta Google Formulários com 4 perguntas objetivas, as quais serão computadas, em duas empresas do setor automobilístico (A e B) no estado de Pernambuco, o qual será respondido dentro de uma amostragem de 21 colaboradores dessas empresas, os quais utilizam as tecnologias do Power BI.

Após o prazo determinado de 1 semana para o públicoalvo responder o questionário, haverá uma coleta de dados, onde os mesmos serão tabulados e em seguida transformados em gráficos, facilitando a visualização dos resultados para compreender e constatar qual o real impacto que a utilização da ferramenta Power BI vem trazendo ao cenário corporativo de Pernambuco.

\section{RESULTADOS}

Dentro dos âmbitos citados, a utilização do Power BI foi, de fato, eficaz dentro de duas empresas do segmento automobilístico do estado de Pernambuco, onde os funcionários se mostraram muito satisfeitos com os resultados que a ferramenta proporciona.

Isso impacta diretamente na qualidade do trabalho exercido, como também na qualidade de vida do colaborador, o qual passa a não praticar com tanta frequência atividades repetitivas e manuais, acarretando uma considerável diminuição do nível de estresse e reduzindo potencialmente a chance de erro humano na tarefa desempenhada.

As respostas obtidas foram transformadas em gráficos que demostram o resultado da pesquisa. No gráfico 1, é possível identificar o número de entrevistados, no total de 21 colaboradores, destes $52,4 \%$ são da empresa A e 47,6\% da empresa B.
Gráfico 1 - Número de entrevistados.

Empresa

21 Respostas

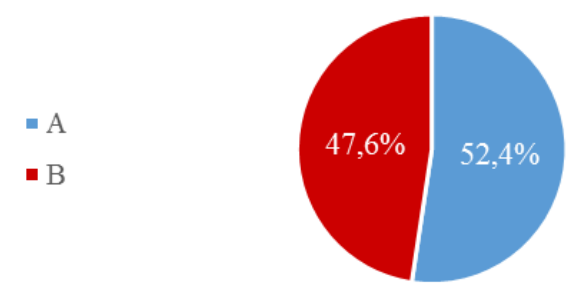

Fonte: Autores.

Primeiramente, identificou-se no gráfico 2 que 100\% dos funcionários entrevistados, enxergam o Power BI como uma ferramenta indispensável para o setor industrial, isso significa que existe a necessidade e consequentemente a aceitação da ferramenta por parte colaboradores.

Gráfico 2 - Aceitação do Power BI.

Você enxerga o Power BI como uma ferramenta indispensável para o setor industrial?

21 Respostas

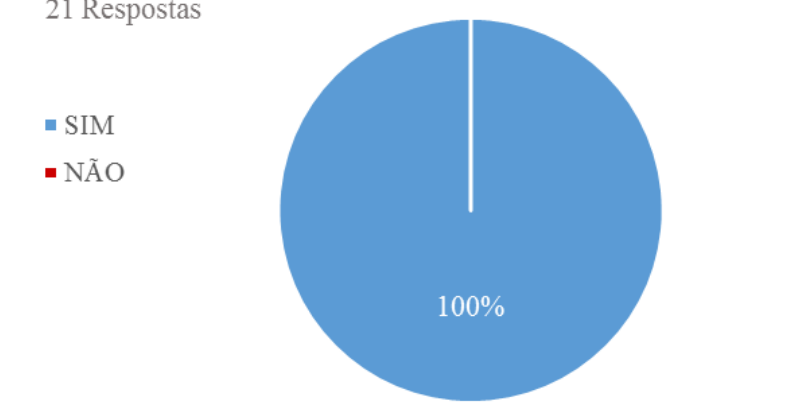

Fonte: Autores.

Em seguida, as informações obtidas conforme o gráfico 3 demonstram que $19 \%$ economizaram até 1 hora de trabalho por dia, 47,6\% economizaram de 2 a 4 horas e $33,3 \%$ economizaram mais de 4 horas por dia. Dessa, observa-se como o Power BI facilita e otimiza tempo de realização de atividades rotineiras nas organizações.

Gráfico 3 - Tempo Economizado após o uso do Power BI.

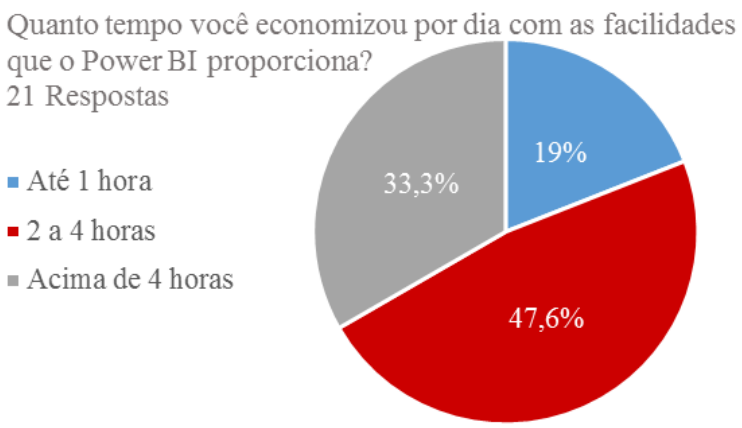

Fonte: Autores

Em seguida, dados adquiridos no gráfico 4 demonstram que 28,6\% deixaram de utilizar Microsoft Excel para gerar relatórios e gráficos manuais, 33,3\% deixaram de utilizar uma grande quantidade de planilhas 
para backup de dados, 9,5\% afirmaram que não tem necessidade de consolidar dados em um único arquivo e $28,6 \%$ responderam que deixaram de fazer todas as opções acima em decorrência da implementação do Power BI.

Gráfico 4 - Atividades extintas com o uso do Power BI.

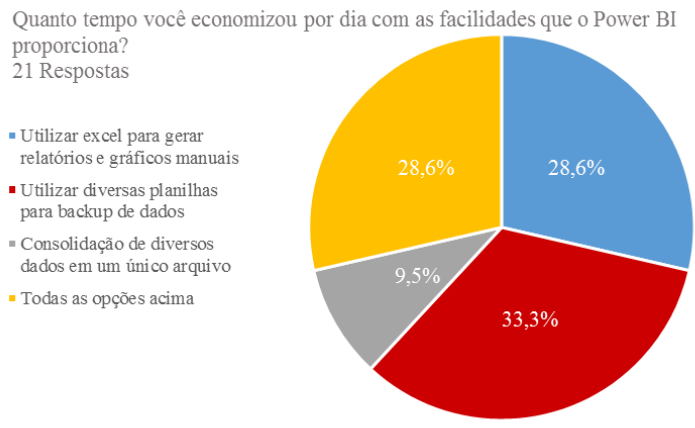

Fonte: Autores

Por fim, os dados coletados no gráfico 5 apontam que $100 \%$ dos funcionários entrevistados indicariam o Power BI para outras indústrias, mostrando a qualidade e a praticidade que a implementação dessa ferramenta traz para as empresas.

Gráfico 5 - Indicação do Power BI.

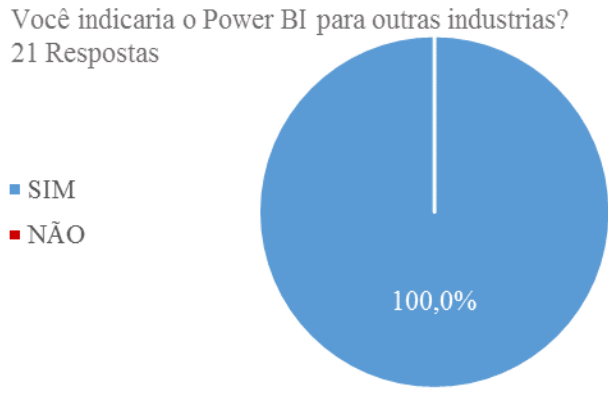

Fonte: Autores

De acordo com pesquisa realizada nas empresas de Pernambuco, foi possível identificar o impacto da ferramenta Power BI, visto que a mesma otimiza os processos, pois através dela é possível integrar todas as atividades, viabilizando uma maior rapidez nos processos cotidianos do ambiente de trabalho, ou seja, mais eficiência, eficácia e precisão na visualização de dados.

Com isso, é válido analisar que essa ferramenta traz benefícios como redução do tempo de trabalho, visto que toda interação dos dados é realizada no próprio aplicativo, dessa forma, diminuindo todo processo de edição de dados de fontes diversas, acarretando na maior acuracidade da informação, pois no momento em que os dados são atualizados sem que exista alterações manuais, há a menor possibilidade de erro humano, tendo em vista que o tempo de formatação é reduzido, além de facilitar no acompanhamento de indicadores gerenciais, trazendo maior clareza da informação e disponibilizando um leque de opções para que os gestores possam tomar decisões mais rápidas e eficazes.

É possível utilizar como base dados para a ferramenta desde uma planilha de Excel, até um banco de dados local, com informações desordenadas e complexas, como script da ferramenta da Linguagem $\mathrm{R}$, ou seja, uma linguagem programada, na qual necessita de uma tratativa de dados para padronizar os mesmos de forma a atender a necessidade do usuário.

Além de ser utilizado no computador, existe a opção de aplicativo para smatphones e tablets, facilitando a visualização em tempo real, onde é possível deixar de lado a utilização de uma máquina desktop para visualizar as informações, tomando decisões rápidas e assertivas em qualquer lugar, aplicando um de seus princípios, que consiste em disponibilizar visualmente o rápido acesso da informação, tanto disponível para IOS, como Android. Por conseguinte, é válido observar que além dessa redução de tempo e aumento da qualidade da informação, o custo que a empresa teria com mão de obra, material e sistemas diminuiriam expressivamente a longo prazo, após o investimento na ferramenta.

Diante do seu bom desempenho, vale salientar que o Power BI vem conquistando cada vez mais adesão dos setores das empresas, onde sua eficiência para analisar dados corriqueiros vem chamando bastante atenção e consequentemente despertando o interesse de organizações concorrentes que perceberam os êxitos alcançados com a utilização do programa. Desse modo, a ferramenta ganha mais espaço no mercado, tornando-se um elemento básico de planejamento e controle, assim como o Microsoft Excel e as ferramentas ERP funcionam para grandes corporações.

\section{CONCLUSÃO}

Ao término do presente artigo, conclui-se que a utilização do Power $B I$ no cenário empresarial de Pernambuco vem impactando de maneira positiva a rotina das organizações que aderiram essa tecnologia, e continuará agregando eficiência e velocidade a elas por um longo tempo, tornando-se cada vez mais imprescindível, uma vez que trata-se de uma ferramenta nova e versátil que está se moldando constantemente as necessidade dos seus usuários.

Em paralelo percebe-se que o Power BI ainda está no início da sua imersão no mercado, visto que o mesmo vem com a Indústria 4.0, onde os processos são autônomos proporcionados por sistemas ciber-físicos, e dessa maneira funciona a Internet das Coisas (IoT), que consiste em uma troca de dados do mundo físico com o mundo virtual, possibilitando ter as informações que ocorrem na indústria em tempo real através de sistemas.

Todo esse tipo de tecnologia avançada da Industria 4.0 está em seu pleno desenvolvimento e há poucos profissionais no mercado que trabalham com esta ferramenta, no Power BI há uma grande escassez de profissionais que dominem a ferramenta, por isso é uma área que as pessoas do mundo corporativo podem investir, visto que nos próximos anos a ferramenta estará no seu ápice e quem portar seu conhecimento terá um grande diferencial.

Espera-se que no futuro próximo a ferramenta possa se desenvolver mais e consiga ter maiores utilidades para que as pessoas continuem estudando e buscando seu desenvolvimento, pois além de agregar valor com a melhoria contínua, será um dos pilares mais importantes dos avanços tecnológicos da Indústria 4.0, onde há a possibilidade de analisar dados de forma dinâmica e em tempo real, influenciando diretamente no poder da tomada de decisão rápida e assertiva dos gestores. 


\section{REFERÊNCIAS BIBLIOGRÁFICAS}

Aprenda Virtual. Power BI: O que preciso saber? Disponível em: $<$ http://www.aprendavirtual.com/powerbi-o-que-preciso-saber/>. Acesso em: 19 de março de 2019.

CARVALHO, R. B. Tecnologia da informação aplicada à gestão do conhecimento. Belo Horizonte: Editora Arte, 2003.

GIL, Antonio Carlos. Como elaborar projetos de pesquisa. São Paulo: Atlas, 1991.

GOLDENBERG, M. A arte de pesquisar. Rio de Janeiro: Record, 1997.

KEEN, P. G. W. Guia gerencial para a tecnologia da informação: conceitos essenciais e terminologia para empresas e gerentes. Rio de Janeiro: Campus, 1996.

MAXIMIANO, Antônio César Amaru, Fundamentos de administração, São Paulo: Atlas, 2004.

Microsoft Tech. Power BI muito além de Business Intelligence. Disponível

$<$ https://www.microsofttech.com.br/ptbr/microsofttech/power-bi-muito-alem-de-businessintelligence/> . Acesso em: 19 de março de 2019.

Microsoft. Power BI Overview. Disponível em: $<$ https://docs.microsoft.com/pt-br/power-bi/power-bioverview $>$. Acesso em: 19 de março de 2019.

MONTANA, Patrick J.; CHARNOV, Bruce H. Administração $3^{\mathrm{a}}$ ed. São Paulo: Saraiva, 2001.

Ok Concursos. Hardware e Software: Conceitos básicos. Disponível

$<$ http://www.okconcursos.com.br/apostilas/apostilagratis/130-informatica-para-concursos/1687-hardware-esoftware-conceitos-basicos\#.XKEL75hKhPY $>$. Acesso em: 19 de março de 2019.

Olhar digital. Você conhece o Porto Digital? Disponível em: $<$ https://olhardigital.com.br/noticia/voce-conhece-oporto-digital/24156 $>$. Acesso em: 18 de março de 2019

OLIVEIRA, Djalma de Pinho Rebouças de Planejamento Estratégico, 22ª Ed., São Paulo: Atlas, 2006.

Porto Digital. História. Disponível em: $<$ http://www.portodigital.org/parque/historia $>$. Acesso em: 18 de março de 2019.

RAMPAZZO, Nut Leão. O significado do trabalho na indústria criativa: um estudo no Porto Digital do Recife. Recife, 2013. 74 f. Dissertação (mestrado) - UFPE, Centro de Ciências Sociais Aplicadas, Programa de Pós-graduação em Administração, 2014.

Revista Exame. Recife, O vale do Silício brasileiro. Disponível

$<$ https://exame.abril.com.br/tecnologia/recife-o-vale-dosilicio-brasileiro/>. Acesso em: 18 de março de 2019.

REZENDE, D.A. Tecnologia da informação integrada à inteligência empresarial: alinhamento estratégico e análise da prática nas organizações. São Paulo: Atlas, 2002.

Softline Group. Power BI: Como essa ferramenta pode beneficiar sua empresa? Disponível em: $<\underline{\text { https://brasil.softlinegroup.com/sobre-a- }}$

empresa/blog/power-bi-como-essa-ferramenta-podebeneficiar-a-sua-empresa-2 $>$. Acesso em: 22 de março de 2019.

SOUZA, Cesar A. de; SACCOL, Amarolinda Z. (Org.). Sistemas ERP no Brasil: (Enterprise Resource Planning): teoria e casos. São Paulo: Atlas, 2003.

\section{COPYRIGHT}

Direitos autorais: Os autores Marcelo André Esteves Barbosa Júnior, Milena Grasielle Viana Gomes, Thaiane Araújo dos Santo são os únicos responsáveis pelo material incluído no artigo. 


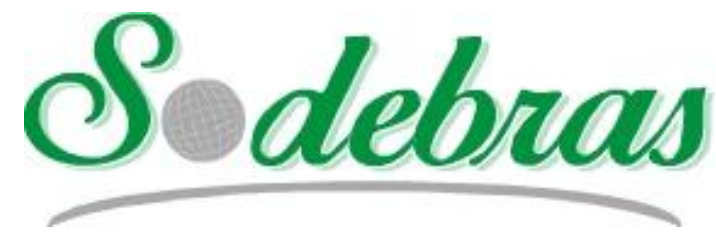

Volume $15-\mathrm{N}^{\mathrm{o}} 169$ - Janeiro / 2020

XLI International Sodebras Congress

31 de outubro a 02 de novembro de 2019 - Maceió - AL.

\title{
A CONVERSA SOLIDÁRIA PARA PENSAR UMA EDUCAÇÃO EMPREENDEDORA
}

\section{A CONVERSATION SOLIDARITY TO THINK AN ENTREPRENEURIAL EDUCATION}

\author{
GIULIANA CAVALCANTI VASCONCELOS, GABRIELA VASCONCELOS BARBOSA \\ UNIVERSIDADE FEDERAL DA PARAÍBA, CENTRO UNIVERSITÁRIO DE JOÃO PESSOA \\ giulianacv@yahoo.com.br, gabrielavasconcelosb@gmail.com
}

\begin{abstract}
Resumo - Na conjuntura atual, estamos num palco de relações econômicas, onde pequenos empreendedores apresentam diferentes estilos de organização. A educação empreendedora elenca problemas de exclusão social e econômica que exigem soluções, através da oferta de formação que favoreça ações cooperativas. Nesta proposta, buscamos apresentar reflexões que julgamos necessárias para repensar processos educativos empreendedores. Nosso objetivo é trazer o princípio da hermenêutica filosófica à baila, para subsidiar relações empreendedoras, baseadas na conversa solidária, por considerálas propulsoras de laços comunitários cooperativos. Em linhas gerais, este estudo está sob uma base teórica-metodológica hermenêutica, numa estrutura de análise do conceito de conversa solidária.
\end{abstract}

Palavras-chave: Educação Empreendedora. Conversa Solidária. Hermenêutica Filosófica.

Abstract - At the current juncture, we are on the stage of economic relations, in which small entrepreneurs present different styles of organization. The education undertaken lists problems of social and economic exclusion that solutions through the offer of training that favors cooperative actions. In this proposal, we seek to present reflexes that we deem required for entrepreneurial educational compensation processes. Our goal is to bring the principle of philosophical hermeneutics to the subsidiary entrepreneurial relations, the solidarity conversations, because it considers this driving principle of cooperative relationships. In general terms, this study is based on a hermeneutic theoretical-methodological basis, in a framework of analysis of the concept of solidarity talk.

Keywords: Entrepreneurial Education. Solidarity Conversation. Philosophical Hermeneutics.

\section{INTRODUÇÃO}

Atualmente, muitas discussões sobre a produção do conhecimento têm provocado mudanças nas posturas metodológicas de alguns pesquisadores. Estamos num palco onde pequenos empreendedores apresentam diferentes estilos de organização e demonstram simples e complexos ângulos de abordagem, frente às dificuldades econômicas. A área de estudo da educação empreendedora elenca muitos problemas de exclusão social e econômica, que exigem a impulsão de soluções, através da oferta de formação.

Como diz Andrade (2017, p. 21), "segundo a Confederação Nacional das Micro e Pequenas Empresas e dos Empreendedores Individuais - (CONAMPE) o micro empreendedor é responsável pela maior geração de emprego do país (BURKHARD, 2015)". Com isso, vemos que as possibilidades de repensar e contribuir para a melhoria das relações entre essas iniciativas, em prol de uma economia que favoreça a todos, deve ser o foco da cultura empreendedora e democrática.

Discussões, sobre a produção de conhecimentos úteis aos processos educativos, são solícitas de propostas que favoreçam ações cooperativas. Corujas intelectuais propõem modelos teóricos espetaculosos que prometem resolver qualquer problema educativo/formativo. Nesta nossa proposta, buscamos apresentar reflexões que julgamos necessárias para repensar processos educativos empreendedores.

Nosso objetivo é trazer o princípio da hermenêutica à baila, para subsidiar procedimentos empreendedores, baseados na conversa solidária, por considerá-la propulsora de laços comunitários cooperativos. Em linhas gerais, este estudo está apresentado sob uma base teórica-metodológica hermenêutica, numa estrutura de análise do conceito de conversa solidária, interpretado entre proposições de uma educação empreendedora e cooperativa.

\section{METODOLOGIA}

Nossa interpretação tem como fundamento a hermenêutica filosófica, uma disciplina que oferece instrumentos conceituais para repensar o uso do conhecimento. Nos propomos a aprender com a própria hermenêutica a "escolher possibilidades" (GADAMER, 1983, p. 59). Nossa postura é chamada por Gadamer (1983, p. 79) de "práxis", relação entre o que se deseja, os próprios princípios e a prática vivida.

Assim, a estrutura textual aqui apresentada delimita-se na interpretação da hermenêutica filosófica, posicionando-a como subsídio à análise conceitual da noção de conversa solidária, na condição de pressuposto necessário à educação empreendedora e cooperativa.

\section{DISCUSSÃO}

Para Gadamer (2002, p. 35), “o modo como vivenciamos uns aos outros é o que forma uma conversa solidária, um universo verdadeiramente hermenêutico, no 
qual não estamos encerrados como entre barreiras instransponíveis, mas para o qual estamos abertos". Uma conversa é um processo que intenta compreender o que anunciamos pela fala, por gestos e símbolos, por nós, pelo mundo e pelos demais indivíduos.

Quando pensamos numa educação empreendedora, colocamos em questão o modo como nos relacionamos, como vivenciamos uns aos outros. A disposição solidária, de cada participante desses processos, precisa ser incentivada tanto por um quanto pelo outro. Porém, essa estrutura de falas é dependente dos aspectos formativos que um e/ou o outro viveu.

$\mathrm{O}$ desafio que se coloca à educação empreendedora abrange a priorização da relação do indivíduo com o mundo e com as pessoas em geral, ensinando todos a lidarem com o inusitado e a aprenderem a tirar lições da experiência vividas. A conversa solidária pode ser um modelo de relação que fundamente inserções de uma cultura organizacional e comunitária, que tome por base a cooperação e a sustentabilidade das relações entre os participantes.

Se a conversa solidária é aquela que proporciona, a partir das intenções de cada participante, situações que buscam o entendimento, podemos entender que, para uma educação empreendedora, uma conversa hermenêutica é aquela em que seus participantes interagem, oferecem e ensinam saberes entre si.

Ensinar numa conversa solidária é uma disposição que chama a nossa atenção. Pois, o ato de ensinar implica na ação de um indivíduo sobre o outro, ao mesmo tempo em que esse outro, seja por disposições voluntárias ou não, coloca-se ou é posto a aprender tais ensinamentos.

A busca por trabalho e emprego no mundo do trabalho e do desemprego é uma preocupação que, além de atingir a todos que estão em fase de formação, deve estar entre as prioridades de nosso país. Pensamos isso, baseados na importância da realização do indivíduo a partir do potencial que cada um pode oferecer. Para nos relacionarmos em espaços que viabilizem relações de crescimento comum, o princípio que nos conduz a nos abrirmos à aprendizagem é o que possibilita a conversa solidária.

Para conversarmos, precisamos estar abertos um ao outro e vice-versa. Aquele que ensina deve estar solidário a ensinar e aquele que aprende deve estar solidário a aprender. É esse encontro de vontades que estrutura uma conversa solidária. Pois, essa solidariedade é uma escolha, uma vontade que se manifesta no mundo do trabalho e do desemprego.

Pensando assim, podemos entender que uma conversa solidária só existe na vida adulta, quando seus participantes estão em condições autônomas de usufruir do próprio, pleno e livre arbítrio de decidir, conforme as próprias vontades. Sim, podemos fazer esta afirmação. Mas, toda conversa é educativa, seja ela voluntária ou não, é uma ação mental que representa uma linguagem de entendimento do mundo, na qual, cada um pode manifestar/desenvolver/demonstrar o seu potencial.

Uma conversa é uma relação intersubjetiva, que manifesta a compreensão, que anuncia o acordo entre os falantes, que é o que a caracteriza, segundo as intenções de cada um, como solidária. Essa condição eleva os atos de conversar do estado de consciência do indivíduo de si mesmo à interação, à aprendizagem e à educação com o outro. Assim, a conversa, por si mesma, representa um processo educativo.

Uma criança conversa com o outro, outra criança ou com um adulto ou mais participantes que desta conversa participarem. Uma conversa é uma interação, um exercício da linguagem, que instrui e retroalimenta reciprocidades. Uma conversa pode ter características manipuladoras, mas também pode estar orientada pela solidariedade; pode educar sob manipulações, mas também, ao contrário, pelo bem querer de compreender o outro, pela alteridade.

Quando nos preocupamos com o mundo do trabalho, colocamos em evidência a conjuntura política e econômica de nosso país, e destacamos a necessidade de focarmos na formação que ofertamos. A conversa solidária, para pensar uma educação empreendedora, preocupa-se com o bemestar comum e com as intenções que a norteiam, e fundamenta-se no querer bem ao outro.

$\mathrm{Na}$ conjuntura atual que rege nosso país, nos processos formativos que temos, há uma grande ausência de instruções que orientem os indivíduos para gerirem as suas vidas financeiras. Exigência esta que é a que assegura a sobrevivência de cada um nas sociedades. No senso comum, ouvimos falas que valorizam a organização financeira como exigência à sustentabilidade econômica de cada um.

Se a hermenêutica filosófica, como nos propomos, pode tecer fundamentos sobre as possibilidades dos atos de conversar, ela pode assim fundamentar métodos de ensino, discursos pedagógicos e estilos de estudo empreendedores e cooperativos. Nesse sentido, os processos formativos para uma educação empreendedora representam o esforço e o contínuo exercício, nos quais indivíduos interagem, oferecem e ensinam entre si, numa verdadeira conversa solidária.

Mas, como podemos ensinar a todos a construírem uma organização financeira? Como introduzir essas instruções no cotidiano da escola? Como ofertar uma formação humanizada que coloque, entre as prioridades instrutivas, a educação empreendedora como necessária?

A economia tem vivido a realidade das migrações que favorecem as miscigenações. Esse fenômeno influencia e surge, como um condicionante que fortalece um modelo mental, chamado de meta-humano, identificado como "um processo de mutação, revelando a capacidade surpreendente para se adaptar em diferentes habitats, que o coloque em situação de perigo" (GUERREIRO, 2014 apud YEMAL, 2018, p. 17).

A sobrevivência, a orientação para a vida e a necessidade de organização individual para viver em sociedade, sob a condição de sermos uma espécie, constituem o prisma do panorama da sobrevivência humana. Isso seria ensinar sobre a nossa posição no mundo. "Todo desenvolvimento humano significa conjugar autonomias individuais, participações comunitárias e a pertença à espécie humana" (MORIN, 2001, p. 55).

O desejar ser, o querer fazer, o saber e o reunir condições para poder realizar-se estão relacionados à educação que desejamos, que é o nosso tesouro, ainda a descobrir (DELORS, 2004): aprender a ser, desenvolvendo sua personalidade e autonomia; aprender a aprender, para beneficiar-se das oportunidades educacionais; aprender a 
fazer, saber sua profissão; e aprender a conviver, compreender o outro e perceber interdependências.

É nesse panorama que a conversa solidária se entrecruza com a educação empreendedora, oferecendo uma proposta de comportamento que possa favorecer relações interpessoais promissoras. Interações promissoras são aquelas que levam seus participantes ao crescimento comum, em consonância com o bem-estar de todos, com o bem querer do outro na comunidade e na sociedade em que vive. Isso é o que podemos chamar de prosperidade.

Esse prisma alimenta o que identificamos como espírito empreendedor, um posicionamento do indivíduo que combina: "(i) introdução de um novo bem; (ii) ou de uma nova qualidade de bem; (iii) abertura de novos mercados; (iv) conquista de novas fontes de oferta e matérias-primas; (v) estabelecimento de uma nova organização que abrange as coisas novas e as novas maneiras de se fazer" (SCHUMPETER, 1982 apud BENEDICTO, 2017, p. 98)

Estamos falando de um espírito que só encontra o seu alimento na reciprocidade de uma economia honesta, que prioriza o bem-estar participativo e cooperativo, comum a todos; leva em conta a inovação, ao passo em que deposita toda essa responsabilidade no indivíduo, alimentando-o com a partilha econômica e com os bens de seguridade social; não esgota o sujeito, ao contrário, nutre-o e solidariza-o com valores morais e materiais, necessários para a vida em sociedade.

É no bojo das relações interpessoais, das conversas propositais ou involuntárias que a confiança comum se legitima. É assim que a conversa se torna solidária, por meio da confiança que os atos de fala estabelecem em acordos ou consensos. Favorecer relações interpessoais, baseadas na conversa solidária, pode significar o investimento necessário ao futuro social e econômico do nosso país.

Fazer entrepeneur, fazer empreender, fazer algo novo relacionado a mudança de uma dada realidade, na qual o indivíduo está inserido, e reconstruir verdades, sem ultrapassar a linha ética que separa o próprio largo do largo do outro, é uma mudança que deve ocorrer, melhor se for, em cooperação; isso exige o compartilhamento de ideias, a solidariedade da vontade de ser áltero, de colocar-se no lugar do outro, de querer que a comunidade em que vive prospere em valores, visando algo superior à mediocridade, à corriqueira vantagem do vis a vis; não se trata de quem vence, do lado A ou do lado B; trata-se de aprender a viver juntos, a conviver. "A habilidade empreendedora, então, torna-se preponderante para que se consiga combinar os recursos de modo a gerar os melhores produtos e serviços possíveis", para uma dada comunidade (SCARAMUSSA, 2017, p. 17).

Consensos obtidos por conversas solidárias podem desencadear, vislumbrar e representar avanços de causas sociais, ambientais e assistenciais à saúde, em lugares onde nada disso exista. A conversa solidária favorece a educação/ formação empreendedora porque envolve consenso obtido por e para atitudes criativas que valorizem o potencial dos indivíduos; envolve a capacidade de obter recursos, de organizar processos e ideias, de construção e produção de oportunidades de crescimento mútuo.
Uma conversa é solidária quando legitima e valida a solução de um problema comum; quando enfrenta desafios comuns e maximiza o potencial de cada indivíduo na confiança e no respeito entre todos. Uma conversa é solidária quando busca favorecer a cooperação através da articulação entre as pessoas, para melhorar a sua condição social, suas crises e desafios econômicos e ambientais. Esse conversar e fazer entrepeneur pode promover o bem-estar da sociedade, beneficiar comunidades, promover pessoas e incluir aquelas que estão em situação de risco social, sob o viés da emancipação econômica.

Esse conversar insere-se no interior dos incentivos de desenvolvimento da "capacidade de identificar oportunidades de negócio ou soluções de necessidades e coloca-las em prática, assumindo seus riscos" (BENEDICTO et. all., 2017, p. 24); serviria como uma força de aprendizagem colaborativa, que possa viabilizar a construção de uma inteligência social, coletiva, comum a todos, que vai distribuindo-se por toda parte, sempre em reciprocidade a todos que dela participem (LÉVY, 2000).

Podemos perceber que numa conversa solidária, até mesmo os insucessos podem tornar-se valores de impulso para novas aprendizagens, que podem ser empreendedoras. $\mathrm{O}$ insucesso pode ser visto como demonstração da necessidade de aprendizagem de novas habilidades. Um insucesso é uma jornada na qual se exige a reflexão cooperativa sobre o conhecimento, uma condição "social e psicológica, por meio da qual os empreendedores têm a oportunidade de aprender, com os próprios erros, a desenvolverem uma atitude comportamental que contribua para o crescimento comum" (DIAS e MARTENS, 2015, p. 172).

O que qualifica uma educação empreendedora são as possibilidades de conversa solidária, nas quais um indivíduo se coloca no lugar do outro, enriquecendo a si mesmo, sob o propósito de cooperar para o crescimento do outro, na contrapartida do próprio crescimento. A relação da hermenêutica com esses processos ocorre na compreensão comum do fazer dos conhecimentos, que permite a revelação da inteligência entre os indivíduos, da relação entre o que desejam, de seus princípios e de suas ocupações práticas.

Por isso, aquilo que agregamos a nossa cultura configura o imprinting que possibilita que indivíduos, em comum acordo, em conversa, pensem, racionalizem, sintam e acreditem no que lhes é ensinado. Não se trata de um indivíduo dominar o outro ou de ambos conformarem-se, com as situações descompensatórias em que vivem. Esse imprinting estaria determinado por regras de convívio comuns à comunidade. Pois, não podemos deixar de admitir que vivemos sob determinantes e condicionantes sociais. Viver a noção de liberdade, sem darmo-nos conta desses determinantes e condicionantes, seria o mesmo que adormecer numa realidade ingênua, distante de conflitos e contradições.

A aprendizagem empreendedora é isso, "um processo ancorado em práticas sociais que se iniciam antes mesmo do envolvimento com uma ação empreendedora" (VOGT e BULGACOV, 2019, p. 99). Essa aprendizagem estaria regimentada pelo princípio da solidariedade vivida, como imprinting cultural, ao longo da vida. Assim, a existência de 
uma vida empreendedora ocorre, sem enganos, sob entrelaçamentos sociais conduzidos, pela partilha inevitável de imprintings culturais.

Uma conversa solidária é aquela em que um indivíduo, em cooperação com o outro, promove o uso de informações para interpretar ações econômicas comuns e necessárias à própria comunidade. Com isso, reconhecemos a hermenêutica filosófica não como uma doutrina na qual se basearia um sistema educativo; reconhecemo-la como uma teoria com a qual ainda temos muito a aprender, porque ela mostra conceitos que podem repercutir nas projeções de práticas educativas, a exemplo, o conceito de conversa que assim, coloca a solidariedade em prática.

\section{CONCLUSÃO}

Concluímos que o princípio da hermenêutica filosófica, que eleva a noção de conversa solidária ao entendimento de que a interação com o outro e nossas relações comuns entre o que desejamos, os nossos princípios e a utilidade dos conhecimentos que produzimos, é um saber que possibilita revelar novas práticas educativas, empreendedoras e cooperativas. A conversa solidária é aquela que se coloca para articular comunidades e pessoas que empreendem economias cooperativas e sustentáveis.

Afinal, como enfatiza Andrade et. all. (2017, p. 20), “devido à crise financeira, há um crescimento do número de brasileiros que vêem no empreendedorismo uma oportunidade de garantir a renda familiar e fugir do fantasma do desemprego". Assim, o princípio da conversa solidária, como valor cultural, torna-se também um bem econômico porque impulsiona a confiança dos cidadãos uns nos outros, favorecendo a construção do laço social e democrático.

Viver uma conversa solidária significa substituir a solidão, que internaliza o sujeito no fosso que o separa do mundo circundante, pela reciprocidade mútua e pela integração; significa pensar que a vida, em sociedade e em comunidades, só pode tornar-se sustentável se basear-se em economias que permitam a participação solidária de todos, sob estruturas de articulação dos potenciais que cada um pode oferecer.

\section{REFERÊNCIAS BIBLIOGRÁFICAS}

ANDRADE. Higor. F. C. et. all. Compreensão e uso da informação contábil por microempreendedores que atuam no mercado público de São José/PE. In: Congresso XXXVIII International Sodebras Congress, 06 a 08 de junho de 2017, Fortaleza/CE. Disponível em: $<$ http://www.sodebras.com.br/edicoes/N141.pdf $>$. Acesso em: 03 out. 2019.

BENEDICTO, Samuel et. all. Alinhamento das estratégias e competências em uma instituição de ensino. In: Revista Sodebras, v. 12, $\mathrm{n}^{\mathrm{o}}$ 139, julho, 2017. Disponível em: $<$ http://www.sodebras.com.br/edicoes/N139.pdf $>$. Acesso em: 03 out. 2019.

Estratégias de apropriação indireta das inovações ecotecnológicas em universidades brasileiras. In: Revista Sodebras, v. 12, $\mathrm{n}^{\circ}$ 139, julho, 2017. Disponível em:
$<$ http://www.sodebras.com.br/edicoes/N139.pdf $>$. Acesso em: 03 out. 2019.

DELORS, Jacques (org.). Educação: um tesouro a descobrir. 9 ed. Brasília: MEC/Cortez, 2004. (Relatório para a UNESCO da Comissão Internacional sobre Educação para o Século XXI)

DIAS, T. e MARTENS, C. Competências e Aprendizagem Empreendedora no Contexto de Insucesso Empresarial: Proposição de um Modelo Conceitual. Revista Desenvolvimento em Questão, v. 14, n. 33, p. 172-202, 10 jul. 2015. Disponível em: $<$ https://www.revistas.unijui.edu.br/index.php/desenvolvime ntoemquestao/article/view/3189/4775>. Acesso em: 06 out. 2019.

GADAMER, Hans-Georg. A razão na época da ciência. Tradução Ângela Dias. Rio de Janeiro: Tempo Brasileiro, 1983. (Biblioteca Tempo Brasileiro, 72)

Verdade e método II: complementos e índice. Tradução Enio Paulo Giachini. Petrópolis: Vozes, 2002. (Coleção Pensamento Humano)

LÉVY, Pierre. Inteligência coletiva: por uma antropologia do ciberespaço. Tradução Luiz Paulo Rouanet. São Paulo; Loyola, 2000.

MORIN, Edgar. Os sete saberes necessários à educação do futuro. Tradução Catarina Eleonora F. da Silva e Jeanne Sawaya. 4 ed. São Paulo: UNESCO/Cortez, 2001.

SCARAMUSSA, Abel U. et. all. A importância dos custos de produção no desenvolvimento das estratégias: um estudo de caso na indústria de extração de rochas ornamentais. In: Revista Sodebras, v. 12, $\mathrm{n}^{\mathrm{o}}$ 156, janeiro, 2017. Disponível em: $\quad<$ http://www.sodebras.com.br/edicoes/N133.pdf $>$. Acesso em: 03 out. 2019.

VOGT, Sérgio e BULGACOV, Yara Lúcia M. História de vida de empreendedores: estratégia e método de pesquisa para estudar a aprendizagem empreendedora. In: Revista de empreendedorismo e Gestão de Pequenas Empresas Regepe, v. 8, $\mathrm{n}^{\mathrm{o}} \quad 3,2019$. Disponível em: $<$ https://doi.org/10.14211/regepe.v8i3.1299>. Acesso em: 06 out. 2019

YEMAL, José Alberto et. all. Metamorfose da filosofia 5s e seus desdobramentos no contexto brasileiro. In: Revista Sodebras, v. 13, no 156, dezembro, 2018. Disponível em: $<$ http://www.sodebras.com.br/edicoes/N156.pdf $>$. Acesso em: 03 out. 2019.

\section{COPYRIGHT}

Direitos autorais: Os autores são os únicos responsáveis pelo material incluído no artigo. 


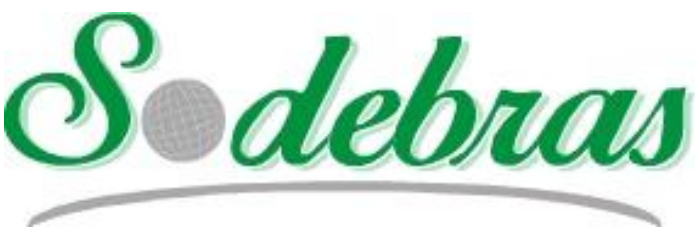

Volume $15-\mathrm{N}^{\mathrm{o}} 169$ - Janeiro / 2020

XLI International Sodebras Congress

31 de outubro a 02 de novembro de 2019 - Maceió - AL.

\title{
O POTENCIAL MÚLTIPLO DA INTELIGÊNCIA PARA O MUNDO DO TRABALHO NO SÉCULO XXI
}

\section{THE MULTIPLE POTENTIAL OF INTELLIGENCE FOR THE WORLD WORK IN THE 21ST CENTURY}

\author{
GIULIANA CAVALCANTI VASCONCELOS, GABRIELA VASCONCELOS BARBOSA \\ UNIVERSIDADE FEDERAL DA PARAÍBA, CENTRO UNIVERSITÁRIO DE JOÃO PESSOA \\ giulianacv@yahoo.com.br, gabrielavasconcelosb@gmail.com
}

\begin{abstract}
Resumo - No final da segunda década do século XXI, práticas educativas acenam para o desenvolvimento do potencial humano de saber-lidar, de forma empreendedora, com o inusitado. Esta proposta está conduzida sob o desafio de superar a definição de coeficiente da inteligência, com o objetivo de colaborar para projeções de processos educativos que promovam o desenvolvimento do potencial múltiplo da inteligência. Este estudo está apresentado sob uma base metodológica hermenêutica, numa estrutura de análise do conceito de inteligências múltiplas, que se distribui entre definições, termos e interpretações relacionadas ao mundo do trabalho. Vemos que nosso compromisso deve promover a projeção de processos educativos que possam equipar cada um, para tirar o máximo proveito das oportunidades ao seu alcance e ajudar a criar novas para aqueles que vêm depois.
\end{abstract}

Palavras-chave: Potencial Múltiplo da Inteligência. Inteligências Múltiplas. Práticas Educativas Empreendedoras.

\begin{abstract}
At the end of the second decade of the 21st century, educational practices point to the development of the human potential of know-how, in an entrepreneurial way, with the unusual.This proposal is conducted under the challenge of overcoming the definition of intelligence coefficient, with the objective of collaborating for projections of educational processes that promote the development of the multiple potential of intelligence.This study is presented on a hermeneutic methodological basis, in a framework of analysis of the concept of multiple intelligences, which is distributed among definitions, terms and interpretations related to the world of work. We see that our commitment must promote the design of educational processes that can equip each one, to take all opportunities available to them and they can help to create new ones for those who come later.
\end{abstract}

Keywords: Multiple Potential of Intelligence. Multiple intelligences. Entrepreneurial Educational Practices.

\section{INTRODUÇÃO}

Vemos que no final da segunda década do século XXI, o Brasil vive uma democracia que se move entre dois lados: A e B / esquerda e direita. Cada qual com um escudo idealista próprio, de rotas e paradas obrigatórias, que condicionam ações e determinam punições. O cidadão comum, representante da maioria da população, existe no desgaste mental de sobreviver nessa confusão social. $\mathrm{O}$ saber-fazer fica determinado pelo ideal de humano que, sob as dilacerações da própria existência, saiba sobreviver.

Práticas educativas acenam para o desenvolvimento do potencial humano de saber-lidar, de forma empreendedora, com o inusitado. A segurança do mundo do trabalho, as certezas dos saberes e a estabilidade das ideias cederam à mobilidade do melhor argumento. Conceitos e definições cedem à força de discursos, debates e interatividades.

Seguindo as perspectivas de Zhu e Cheung (2017, p. 8 ), estamos aqui para encontrar conceitos, que nos permitam vislumbrar potenciais de inteligências, que possam renovar, inovar e oferecer à economia brasileira, "at microenterprise levels, behavioral differentials that support the quality of services and products", isto é, em níveis de microempresas, diferenciais comportamentais que sustentem a qualidade dos serviços e produtos". Desejamos que, com isso, ocorra a agregação de mais valores do sujeito, em reciprocidade às comunidades que sustentam as microempresas.

Esta proposta está conduzida sob o desafio de superar a definição de coeficiente da inteligência, com o objetivo de colaborar para projeções de processos educativos que promovam o desenvolvimento do potencial múltiplo da inteligência. Em linhas gerais, este estudo está apresentado sob uma base metodológica hermenêutica, numa estrutura de análise do conceito de inteligências múltiplas, que se distribui entre definições, termos e interpretações relacionadas ao mundo do trabalho.

\section{METODOLOGIA}

Os procedimentos utilizados, para esta investigação qualitativa, tomam por base o princípio da hermenêutica, que está situado na interpretação do pesquisador. Consideramos que "somente a luz da interpretação algo se converte em fato e uma observação possui força elucidativa" (GADAMER, 2002, p. 392).

A estrutura textual apresentada consiste no esclarecimento da proposta de aplicação da teoria das inteligências múltiplas, considerando a tessitura formativa do início do século XXI. Os conceitos que fundamentam essa teoria estão delimitados pelas seguintes categorias teóricas: (1) a linguagem do cérebro, (2) a biopsicoidentidade da potência múltipla da inteligência humana e (3) as inteligências eleitas. 


\section{DISCUSSÃO}

Para a multimodalidade econômica da vida em sociedade hoje, o conceito de inteligência que se delimite como um potencial biopsicológico a ser ativado para processar informações, solucionar problemas ou criar produtos valorizados numa cultura (GARDNER, 2000), pode vir a tornar-se salutar ao mundo do trabalho. Para melhor compreendermos essa delimitação, há três aportes/categorias de sustentação teórica que precisamos considerar, apresentadas a seguir.

$\left(1^{a}\right)$ A linguagem do cérebro, pois temos achados genéticos que nos permitem identificar que o sistema nervoso possui conexões plásticas que asseguram organização e estruturação ao comportamento humano, sob programações, regularidades, regenerações e integrações próprias, em interação e sob intervenção com e do ambiente externo, mesmo que o próprio indivíduo não se dê conta disso.

Assim, para alcançar essa compreensão é preciso considerar estudos já realizados sobre:

a) o que a "decodificação do material genético da espécie humana pode revelar" (GARDNER, 1994, p. 25);

b) a manifestação da inteligência de outros animais comparada à da espécie humana;

c) descrições anatômicas de cérebros de animais mortos e de indivíduos humanos talentosos;

d) imagens do funcionamento do cérebro em ação, obtidas por tomografia computadorizada, ressonância magnética, eletroencefalograma e magnoencefalograma.

São a complexidade do mundo de conhecimentos mais a complexidade biológica do mundo natural, que nos permitem desenvolver nossa inteligência e demonstrar o que somos capazes de fazer.

Podemos saber, a partir da decodificação do material genético de um organismo, a que espécie o mesmo pertence e supor quais são as pré-disposições biológicas que tem, suas necessidades e potencialidades. Porém, quando nos referimos à identificação do potencial múltiplo da inteligência humana, ainda ignoramos o gene que assegura uma dada inteligência, dentre as que elegemos para viver em sociedade(s).

(2a) A biopsicoidentidade da potência múltipla da inteligência humana é a segunda categoria que precisamos considerar. Essa biopsicoidentidade é desenvolvida e caracterizada em conformidade com os avanços do desenvolvimento neural, do qual, sob experiências individuais e sob processos educativos que a sociedade oportuniza e valoriza, permitem surgir funções cognitivas e comportamentos novos.

Os processos educativos ocorrem dentro do mundo que produzimos. Fazemos isso, quando nos apropriamos da natureza, elaborando conhecimentos e expondo nossas potencialidades cognitivas. Produzimos tecnologias e, para nos organizarmos socialmente, estruturamos papéis sociais, realizamos interações simbólicas e reunimo-nos à nossa espécie, com linguagens diversas e com diferentes códigos.

A cultura humana é complexa, diferente de outras espécies animais. Ela reúne-se ao mundo natural e social com uma diversa rede de elementos que a condicionam. Fato esse que reforça diferenças entre a espécie humana e a aprendizagem de outras espécies.

Essa condição cultural ocorre como mediadora dos processos cognitivos humanos. Essa é uma condição social que determina nossos comportamentos, apontando caminhos a seguir. É com a cultura que novas gerações são formadas. Mesmo que a condição biológica siga uma sequência de desenvolvimento, o que o humano é e passa a ser depende de como ele relaciona-se com o mundo e dos elementos culturais que constituem essa relação. Por isso, não podemos excluir as influências culturais da maneira como cada indivíduo desenvolve o seu potencial intelectual (GARDNER, 1994).

$\left(3^{a}\right)$ A terceira categoria considerada em nossa análise é constituída pelas inteligências eleitas. Pois, como saber até onde nossa programação biológica pode nos levar é uma questão que nos inquieta e para a qual ainda não temos uma só resposta. Mas, apesar disso, vemos que nosso compromisso deve promover a projeção de processos educativos informais e escolares que nos permitam "melhor equipar cada humano, para tirar o máximo proveito das oportunidades que se encontram ao seu alcance e ajudar a criar novas para aqueles que vêm depois" (GARDNER, 1999, p. 61).

(1) A primeira inteligência que elencamos é a linguística, um potencial que revela a capacidade do indivíduo de aprender noções dos códigos linguísticos, guardá-los na memória e aplicá-los com criatividade; traduz uma competência valorizada nas sociedades modernas: ler, escrever, interpretar e aplicar palavras e frases em situações de comunicação. Mas, essa inteligência está relacionada às oportunidades que o indivíduo tem de vivenciar aprendizagens sobre a linguagem.

(2) A segunda inteligência que listamos é a matemática, um tipo de inteligência que se revela na capacidade mental de memorizar informações de representações quantitativas e aplicá-las no cotidiano, para resolver problemas. A inteligência matemática é um potencial que revela a capacidade do indivíduo de criar soluções factíveis, com base em representações numéricas.

(3) A terceira inteligência é a musical, um potencial que revela a capacidade do indivíduo de aprender sons e ritmos, de interpretá-los e conceber novos contornos melódicos, com arranjos musicais. Há evidências de que "certas áreas do hemisfério direito do cérebro são ativadas no desempenho da percepção e da produção de músicas" (GARDNER, 1995, p. 23). É como se o indivíduo tivesse "sons na cabeça" (GARDNER, 1994, p. 79).

(4) A inteligência espacial também está na lista. É uma inteligência que se traduz na percepção dos espaços. O indivíduo é capaz de executar modificações sobre percepções iniciais de espaço e de recriar aspectos mesmo na ausência do contato material. Essa inteligência permite que indivíduos desenhem, mapeiem e visualizem objetos em várias dimensões e representem imagens internas.

(5) A inteligência corporal é aquela que se revela na capacidade do indivíduo de usar o próprio corpo, com habilidades que se expressam nos movimentos; é uma competência responsável pelo controle dos movimentos 
corporais, criando representações possíveis de serem executadas pelo corpo, em espaços e situações diversas.

(6) A inteligência intrapessoal é uma inteligência que mostra aspectos introspectivos de reflexão e de autocompreensão, que se manifestam na interpretação de sentimentos e emoções, relacionando-os com linguagens que servem de base para entender e executar comportamentos. Um indivíduo que possui essa inteligência revela o interesse de conhecer a si mesmo e de aprender, com os seus erros, a mudar os próprios comportamentos, úteis à vida social. Ele "possui um modelo viável e efetivo de si mesmo" (GARDNER, 1995, p. 28).

Essa inteligência intrapessoal é viabilizadora do potencial da inteligência interpessoal, pois permite pensar sobre o que motiva o próprio sujeito a participar e a compartilhar o que aprende. Podemos considerar que essa inteligência viabiliza o que Medina e Medina (2017) entendem como exercício da comunicação empreendedora, que seria o saber-lidar com os conflitos internos e externos de uma empresa, na identificação das expectativas e no estabelecimento de relações a longo prazo como, por exemplo, daqueles que puderem ser identificados como stakeholders.

(7) A inteligência interpressoal é um potencial que revela a capacidade humana de comunicar-se, de observar e fazer distinções entre indivíduos quanto às necessidades, desejos e escolhas de cada um. Há demonstrações de aprendizagem que envolvem sentimentos de interação e colaboração.

A inteligência interpessoal é aquela que pode viabilizar a demonstração do que Araújo e Pedron (2015 apud SANTOS e PEDRON, 2019, p. 171) consideram para "liderar, motivar e capacitar membros em equipe, para assumirem papéis e responsabilidades mais formais para alavancarem a motivação e o uso das ideias geradas internamente".

(8) A naturalista é um potencial da inteligência que é demonstrado em condutas criativas, de aplicação de informações sobre condições biológicas no mundo amplo. Está relacionada à sobrevivência, até mesmo instintiva. Cientistas, agricultores e engenheiros civis são exemplos de uso da inteligência naturalista.

(9) A inteligência espiritual é demonstrada na compreensão de fenômenos que não são pura matéria ou física, mas que constituem abstrações que são valorizadas em diferentes sociedades. É um tipo de inteligência que lida com fenômenos sobrenaturais e abstratos (GARDNER, 2000).

(10) A inteligência existencial surge da capacidade humana do indivíduo de "situar-se em relação aos limites extremos do mundo como o infinito e o infinitesimal" (GARDNER, 2000, p. 78). Esse "situar" ocorre em relação à condição humana de existir e representar o mundo com significados sobre a vida, a morte, o destino do mundo, o porquê do amor e o significado da felicidade.

(11) Pensar numa inteligência moral torna-se aceitável quando passamos a interpretar o senso de justiça como uma produção de seleção natural de nossa espécie. É possível constatar, por exemplo, que ao longo de nossa evolução, lidamos com a moral como qualidade essencial a vida humana. Refletimos e elaboramos conhecimentos sobre o que é "próprio e impróprio, certo e errado, justo e injusto" (GARDNER, 2000, p. 99).

Um indivíduo que vive em ambientes escolares, nos quais recebe estímulos e motivações para desenvolver o seu potencial múltiplo da inteligência, pode tornar-se disposto a idealizar, coordenar e colocar em prática projetos, serviços, produções/produtos e negócios cooperativos. Termos esse prisma de possibilidades pode ser uma riqueza, para o alcance da estabilidade econômica de um povo.

Segundo Campos et. all. (2018, p. 17), "a chamada geração Milênio, nascidos após a década de 1980, hoje adultos com menos de 40 anos, está amadurecendo com um perfil empreendedor"; são pessoas urbanizadas, consumidoras de culturas, turismo e entretenimentos; são aqueles que, em sua maioria, aplicam seus recursos financeiros em bens não-tácitos, pois priorizam o trabalho, combinando-o com o viver.

A geração milênio usufruiu da transição que viabilizou a consolidação da internet $\mathrm{e}$, assim, vêm vivendo a aprendizagem a distância. Fenômeno esse que mudou as relações no trabalho e entre as pessoas. A aprendizagem passou a descrever-se como comportamentos mutáveis, plásticos e abertos. A cada dia, esse perfil enfrenta os dilemas conjunturais do seu país, ao mesmo tempo em que ambiciona romper com o sedentarismo, do território fixo.

Essas aspirações estão presentes em todas as classes sociais; são vontades normalizadas pelo imprinting cultural, principalmente, daquele que se apresenta nas redes sociais, sem terrenos planos, pela vontade coletiva e pelo trabalho internacionalizado. Nas redes sociais, a aprendizagem para o trabalho torna-se móvel, sem medos, avança pelo instinto de sobrevivência e pela satisfação de aprender, fortalece a imigração e a desterritorialização. Podemos dizer que essa geração Milênio é mutável, plástica e cidadã do mundo.

Com isso, vemos que as diferenças e os fossos sociais da conjuntura política e econômica do Brasil, por exemplo, estão solícitos de estratégias educacionais que estimulem, motivem, incentivem e formem microempreendedores talentosos, sem desperdiçar os seus potenciais. Para que todos possam participar da economia de forma sustentável é preciso que todos sejam orientados a buscar, em si mesmos, o que podem fazer de melhor, conforme suas vontades.

Não nos referimos às atividades freelancers do mundo do trabalho. Referimo-nos às oportunidades de desenvolvimento do sujeito que lhes permita sentir-se valorizado, dignificado e realizado com um saber-fazer que o conecte/a, de maneira cooperativa e compensatória, na superação do vis a vis. O princípio das inteligências múltiplas pode ser posto em prol da busca por reciprocidades sócioeconômicas.

Cada sujeito que empreende precisa saber mais sobre as suas capacidades e sobre as próprias inteligências. Precisamos focar no investimento daquelas inteligências que mais se manifestam e aprimorá-las. Cada microempreendedor deve investir na contínua renovação dos espaços dinâmicos em que atua. Espaços esses que são influenciados pelas necessidades dos indivíduos e de sua comunidade, pelo avanço tecnológico e pelos determinantes e condicionantes econômicos, que são mutáveis e vulneráveis (SANTOS e PEDRON, 2019, p. 160-161). 
São as habilidades, manifestadas por cada inteligência isolada ou articulada às demais inteligências, que vão oferecer maior consistência a demonstração de competências, as quais são identificadas por Xiang, Yang e Zhang (2016) como soft skills, aprendidas no cotidiano, e hard skills, obtidas na formação. Vemos assim, uma importante percepção entre o saber viver e o saber existir, e vice-versa, conforme o que podemos oferecer e desfrutar da sobrevivência em sociedade.

\section{CONCLUSÃO}

Concluímos que a inteligência representa a capacidade do humano de criar a partir do que aprendeu culturalmente, e do que desenvolveu em seu cérebro. Essa capacidade é múltipla porque pode revelar diferentes habilidades intelectuais ou competências cognitivas. A inteligência é um potencial múltiplo porque representa a potência biológica e cultural que pode multiplicar-se, dando vez ao surgimento de outras habilidades e competências. Isso é comum a qualquer humano.

As projeções de processos educativos para o mundo do trabalho dependem das competências profissionais que valorizamos. O saber-fazer que se manifesta a partir das inteligências que elegemos é resultado do quanto motivamos o indivíduo. Todo trabalho é sempre realizado por mãos que a ele são dedicadas e, por ele, tornam-se habilidosas; são mãos que "transformam, por meio de operações manuais ou de máquinas e equipamentos, os insumos em produtos acabados ou serviços prestados" (SCARAMUSSA et. all., 2017, p. 51).

Aprender a empreender, a partir das inteligências múltiplas que cada um possui, torna-se necessário para que cada um possa oferecer o seu melhor, em produtos e serviços, em prol da comunidade em que vive. Cada indivíduo é parte de um todo social e econômico e quanto mais e melhor ele entende o que sabe fazer e o aprimora, o que ele oferece a sociedade em que vive tona-se melhor.

$\mathrm{O}$ potencial múltiplo da inteligência favorece $\mathrm{o}$ convívio social porque pode alimentar estruturas econômicas solidárias e cooperativas, que permitam que cada indivíduo possa empreender o melhor de si, a partir do que lhe proporciona felicidade. Portanto, essa compreensão de inteligência permite-nos extrair o máximo do humano em reciprocidade com a sociedade.

\section{REFERÊNCIAS BIBLIOGRÁFICAS}

CAMPOS. Higor. F. C. et. all. AIRBNB: uma nova dinâmica do consumo colaborativo na atividade de turismo e hospitalidade. In: Congresso XXXIX International Sodebras Congress, 21 a 23 de maio de 2018, Santiago, Chile. Disponível em: < http://www.sodebras.com.br/edicoes/N152.pdf $>$. Acesso em: 10 out. 2019.

GADAMER, Hans-Georg. Verdade e método II: complementos e índice. Tradução Enio Paulo Giachini. Petrópolis: Vozes, 2002. (Coleção Pensamento Humano)
GARDNER, Howard. Estruturas da mente: a teoria das Inteligências múltiplas. Tradução Sandra Costa. Porto Alegre: Artes Médicas Sul, 1994.

Inteligências múltiplas: a teoria na prática. Tradução Maria Adriana Veríssimo Veronese. Porto Alegre: Artmed, 1995. (Reimpressão 2000)

Inteligência: um conceito reformulado. Tradução Adalgisa Campos da Silva. Rio de Janeiro: Objetiva, 2000.

. O verdadeiro, o belo e o bom: os princípios básicos para uma nova educação. Tradução Álvaro Cabral. Rio de Janeiro: Objetiva, 1999.

MEDINA, Rolf e MEDINA, Alicia. Gerenciando competência e aprendizado em organizações intensivas em conhecimento e intensivas em projetos. In: Revista International Journal of Management Projects in Business, v. 10, $\mathrm{n}^{\mathrm{o}} \quad 3, \quad$ 2017. Disponível em: $<$ https://doi.org/10.1108/IJMPB-04-2016-0032>. Acesso em: 13 out. 2019 .

SANTOS. Tainá Alves dos e PEDRON, Cristiane Debres. As competências do gerente de projetos de inovação: uma revisão sistemática da literatura. In: Revista Brasileira de Gestão e Inovação, v. 7, $\mathrm{n}^{\mathrm{o}}$ 1, 2019. Disponível em: $<$ http://www.ucs.br/etc/revistas/index.php/RBGI/article/vie w/6358/pdf $>$. Acesso em: 13 out. 2019.

SCARAMUSSA, Abel U. et. all. A importância dos custos de produção no desenvolvimento das estratégias: um estudo de caso na indústria de extração de rochas ornamentais. In: Revista Sodebras, v. 12, $\mathrm{n}^{\circ} 156$, janeiro, 2017. Disponível em: $\quad<$ http://www.sodebras.com.br/edicoes/N133.pdf $>$. Acesso em: 03 out. 2019.

XIANG, Chunjie; YANG, Zhonghua e ZHANG, Ling. Improving IS development teams' performance during requirement analysis in project-The perspectives from shared mental model and emotional intelligence. In Revista International Journal of Project Management, v. 34, $\mathrm{n}^{\mathrm{o}}$ 7. 2016. Disponível em: < https://doi.org/10.1016/j.ijproman.2016.06.009>. Acesso em: 13 out. 2019 .

ZHU, Liuying. \& CHEUNG, Sai On. Harvesting Competitiveness through Building Organizational Innovation Capacity. In Revista Journal of Management in Engineering, v. 33, $\mathrm{n}^{\mathrm{o}}$ 5, 2017. Disponível em: $<$ https://doi.org/10.1061/(ASCE)ME.1943-5479.0000534>. Acesso em: 13 out. 2019.

\section{COPYRIGHT}

Direitos autorais: Os autores são os únicos responsáveis pelo material incluído no artigo. 


\section{Área: Ciências Agrárias e Biológicas}

\begin{tabular}{|c|c|}
\hline $4-1$ & $\begin{array}{l}\text { HISTOPATOLOGIA DE LESÕES ORAIS DECORRENTES DE TERAPIA } \\
\text { IMUNOSSUPRESSORA RELACIONADA À TRANSPLANTE DE FÍGADO } \\
\text { HISTOPATHOLOGY OF ORAL INJURIES ARISING FROM IMMUNOSPRESSOR } \\
\text { THERAPY RELATED TO LIVER TRANSPLANTATION } \\
\text { Gabriel Ricardo Dionísio Do Nascimento; Maria Eduarda Dias Monteiro Bispo; } \\
\text { Luciana Maria Silva De Seixas Maia; Juliana Pinto De Medeiros }\end{array}$ \\
\hline $4-5$ & $\begin{array}{l}\text { GORDURA SATURADA DIETÉTICA E SISTEMA NERVOSO: REVISÃO } \\
\text { SISTEMÁTICA DA LITERATURA } \\
\text { DIETARY SATURATED FAT AND NERVOUS SYSTEM: SYSTEMATIC } \\
\text { LITERATURE REVIEW } \\
\begin{array}{l}\text { Isabel Michely Da Silva Galvão De Melo; Hericles Cleyton De Jesus Santana; } \\
\text { Jeymesson Raphael Cardoso Vieira; Luciana Maria Silva De Seixas Maia }\end{array}\end{array}$ \\
\hline 5-1 & $\begin{array}{l}\text { ASPECTOS AGRONÔMICOS EM HÍBRIDOS DE MILHO SUBMETIDOS AO } \\
\text { TRATAMENTO DE SEMENTES COM NANOPARTÍCULAS DE COBRE } \\
\text { AGRONOMIC ASPECTS IN CORN HYBRIDS SUBMITTED TO TREATMENT OF } \\
\text { COPPER NANOPARTIC } \\
\text { Cristiano Reschke Lajús; Gean Lopes Da Luz; Nédio Luiz Verdi; Luciano Luiz Silva }\end{array}$ \\
\hline 5-1 & $\begin{array}{l}\text { QUALIDADE DE SEMENTES DE MILHO APÓS TRATAMENTO COM } \\
\text { NUTRIENTES À BASE DE ZINCO E ARMAZENAMENTO } \\
\text { QUALITY OF CORN SEED AFTER TREATMENT WITH ZINC NUTRIENTS AND } \\
\text { STORAGE } \\
\text { Gean Lopes Da Luz; Cristiano Reschke Lajús; Ana Cristina Lopes; Adriana Cioato } \\
\text { Ferrazza }\end{array}$ \\
\hline $5-2$ & $\begin{array}{l}\text { TÉCNICAS DE NUCLEAÇÃO PARA RESTAURAÇÃO DE } \\
\text { DEGRADADO } \\
\text { NUCLEATION TECHNIQUES FOR RESTORATION OF DEGRADED CERRADO }\end{array}$ \\
\hline
\end{tabular}




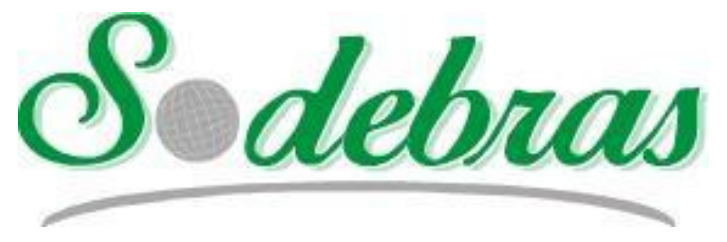

\author{
Volume 15 - No 169 - Janeiro / 2020 \\ XLI International Sodebras Congress
}

31 de outubro a 02 de novembro de 2019 - Maceió - AL.

\title{
HISTOPATOLOGIA DE LESÕES ORAIS DECORRENTES DE TERAPIA IMUNOSSUPRESSORA RELACIONADA À TRANSPLANTE DE FÍGADO
}

\author{
HISTOPATHOLOGY OF ORAL INJURIES ARISING FROM \\ IMMUNOSPRESSOR THERAPY RELATED TO LIVER TRANSPLANTATION
}

\author{
GABRIEL RICARDO DIONÍSIO DO NASCIMENTO ${ }^{1}$, MARIA EDUARDA DIAS MONTEIRO BISPO ${ }^{1}$, \\ LUCIANA MARIA SILVA DE SEIXAS MAIA ${ }^{1}$, JULIANA PINTO DE MEDEIROS ${ }^{1}$. \\ 1 - UNIVERSIDADE FEDERAL DE PERNAMBUCO (UFPE), DEPARTAMENTO DE EMBRIOLOGIA E \\ HISTOLOGIA, PROGRAMA DE PÓS-GRADUAÇÃO EM MORFOTECNOLOGIA, RECIFE, \\ PERNAMBUCO, BRASIL. \\ gabrielrdn1998@gmail.com; diasdevintage@gmail.com; lumaiabr@yahoo.com.br;jupinto2@gmail.com
}

\begin{abstract}
Resumo-Introdução: Estudos indicam que infecções orais focais podem estar relacionadas a complicações após o transplante de fígado. Objetivo: Análise histopatológica de lesões orais macroscópicas em indivíduos que foram submetidos a terapia imunossupressora por causa de transplante hepático. Método: Revisão sistemática utilizando a base de dado eletrônica: BVS, incluindo artigos publicados entre 01/2000 a 09/2019. Resultados: Devido a ação de medicamentos imunossupressores observamos que as alterações, tais como os distúrbios do crescimento, podem ser causadas por efeito colateral adverso $e$ por defesa imunológica comprometida. Conclusão: Conclui-se que as reações adversas $e$ a vulnerabilidade das defesas imunológicas são importantes fatores que propiciam a formação de injúrias em mucosa oral.
\end{abstract}

Palavras-chave: Transplante de Fígado; Boca; Patologia

Abstract-Introduction: Studies indicate focal of oral infections may be related to complications after liver transplantation. Objective: Histopathological analysis of macroscopic oral lesions in individuals who was submitted immunosuppressive therapy because of liver transplantation. Method: Systematic review using the electronic database: BVS, including articles published between 2000 to 2019. Results: Due to the action of immunosuppressive drugs we observed that changes, such as growth disorders, may be caused by adverse side effects and compromised immune defense. Conclusion: We concluded that adverse reactions and the vulnerability of immune defenses are important factors that favor the formation of oral mucosa injuries.

Keywords: Liver Transplantation; Mouth; Pathology

\section{I.INTRODUÇÃO}

A indicação do transplante hepático está reservada aos portadores de insuficiência hepática crônica terminal. Desde os primeiros transplantes de fígado, observou-se um progresso extraordinário nos resultados do procedimento devido ao aperfeiçoamento da técnica operatória, maior precisão das indicações e, principalmente, devido a uma melhor compreensão dos mecanismos imunológicos presentes no fenômeno da rejeição (CASTRO-E-SILVA, 2002).

Atualmente, a terapia padrão para a profilaxia da rejeição consiste na administração de um inibidor de calcineurina, tipicamente o Tacrolimo ou Ciclosporina (em casos de contraindicação do Tacrolimo), adicionado ou não de Micofenolato de mofetila ou Micofenolato (BRASIL, 2016). Apesar do sucesso no emprego dessa estratégia, é sabido que o paciente imunodeprimido apresenta-se vulnerável a diversas complicações, principalmente em regiões mucosas, como a cavidade oral. Assim, alguns estudos corroboram com a ideia de que focos de alterações bucais podem ter relação com complicações após o transplante de fígado (PROFIO et al., 2016). Portanto, buscamos analisar a histopatologia de lesões orais macroscópicas em indivíduos que foram imunodeprimidos por causa de transplante hepático, avaliando quais são as alterações teciduais evidenciadas.

\section{METODOLOGIA}

A pesquisa foi realizada na BVS (Biblioteca Virtual em Saúde), vinculada às bases de dados: MEDLINE (Medical Literature Analysis and Retrieval System Online), LILACS (Literatura Latino-Americana e do Caribe em Ciências da Saúde) e IBECS (Índice Bibliográfico Espanhol em Ciências da Saúde). Previamente consultamos os Descritores em Ciências da Saúde (DECs), estabelecendo assim nossas palavras chave. Assim sendo, a busca ocorreu através da consulta dos seguintes termos: "Transplante de fígado ", "Boca" e "Patologia". O período de estudo inclui artigos publicados entre janeiro de 2000 a setembro de 2019 nas línguas Portuguesa, Inglesa e Espanhola.

Os artigos identificados pela estratégia de busca foram realizados, obedecendo rigorosamente aos seguintes critérios de inclusão: texto na íntegra, tipo de estudo (clínicos e revisões sistemáticas), localização da alteração oral (sem delimitação específica). Foram excluídos do estudo: os artigos que não apresentam o contexto do transplante hepático ou o trate de forma genérica; artigos 
que não discutam sobre lesões orais; artigos que não discutam sobre imunossupressão; artigos que abordem o transplante hepático apenas como uma técnica cirúrgica; artigos publicados fora do período temporal delimitado.

\section{RESULTADOS}

De acordo com as estratégias de busca descritas anteriormente, no total, 14 artigos foram encontrados: 11 na MEDLINE, 2 no LILACS e 1 no IBECS. Através da adequação aos critérios de inclusão e exclusão, 6 artigos foram selecionados.

Após a aplicação de tais critérios, escolheu-se 3 destes artigos, os que apresentavam análise histopatológica, para que fossem comparados num quadro (Quadro 1). Nesta representação, os critérios estabelecidos foram: autor, ano e país de publicação, quantidade de pacientes, idade dos pacientes no momento do transplante de fígado, terapia imunossupressora utilizada, aspectos macroscópicos e microscópicos das lesões orais.

Os resultados deste estudo indicam que há um incipiente interesse em pesquisar sobre os aspectos histopatológicos de lesões orais decorrentes de terapia imunossupressora relacionada a transplante de fígado.

Quadro 1-Análise dos artigos incluídos na pesquisa

\begin{tabular}{|c|c|c|c|}
\hline $\begin{array}{c}\text { Autor/Ano/P } \\
\text { aís }\end{array}$ & $\begin{array}{l}\text { Saalman, } \\
\text { et al. (2010), } \\
\text { Suécia. }\end{array}$ & $\begin{array}{l}\text { Nakamura, et } \\
\text { al. (2018), } \\
\text { Brasil. }\end{array}$ & $\begin{array}{l}\text { Stawinska, } \\
\text { et al. (2015), } \\
\text { Polônia. }\end{array}$ \\
\hline $\begin{array}{l}\text { Quantidade } \\
\text { de pacientes }\end{array}$ & 7 & 1 & 1 \\
\hline $\begin{array}{c}\text { Idade dos } \\
\text { pacientes no } \\
\text { momento do } \\
\text { transplante }\end{array}$ & $\begin{array}{l}\text { Idade Média } \\
\text { de } 6 \text { meses. }\end{array}$ & 24 anos & $\begin{array}{c}1 \text { ano e } 6 \\
\text { meses }\end{array}$ \\
\hline $\begin{array}{c}\text { Terapia } \\
\text { imunossupre } \\
\text { ssora } \\
\text { utilizada }\end{array}$ & $\begin{array}{l}\text { Predniso- } \\
\text { lone e } \\
\text { Tracolimus }\end{array}$ & $\begin{array}{l}\text { Prednisone e } \\
\text { Micofeno- } \\
\text { lato de sódio }\end{array}$ & $\begin{array}{l}\text { Tracolimus } \\
\text { (Prograf) e } \\
\text { glicocorti- } \\
\text { coesteróide } \\
\text { (Encorton) }\end{array}$ \\
\hline $\begin{array}{c}\text { Lesões } \\
\text { Macroscópic } \\
\text { as }\end{array}$ & $\begin{array}{l}\text { Múltiplos } \\
\text { nódulos } \\
\text { esféricos no } \\
\text { dorso da } \\
\text { língua }\end{array}$ & $\begin{array}{c}\text { Lesões } \\
\text { ulcerativas } \\
\text { superficiais } \\
\text { bem definidas } \\
\text { cobertas por } \\
\text { fibrina com } \\
\text { bordas } \\
\text { eritematosas } \\
\text { regulares em } \\
\text { gengiva e } \\
\text { palato }\end{array}$ & $\begin{array}{c}\text { Lesões de } \\
\text { mucosa } \\
\text { exofítica na } \\
\text { língua e lesões } \\
\text { hiperplásicas } \\
\text { na mucosa } \\
\text { oral. }\end{array}$ \\
\hline $\begin{array}{c}\text { Aspectos } \\
\text { Histopatológ } \\
\text { icos }\end{array}$ & $\begin{array}{c}\text { Infiltrado } \\
\text { subepitelial } \\
\text { crônico de } \\
\text { células } \\
\text { redondas e } \\
\text { alguns } \\
\text { granulócitos } \\
\text { eosinofílico }\end{array}$ & $\begin{array}{l}\text { Fragmentos } \\
\text { de mucosa } \\
\text { escamosa com } \\
\text { infiltrado } \\
\text { inflamatório } \\
\text { histiocítico } \\
\text { intenso } \\
\text { associado a } \\
\text { estruturas } \\
\text { fúngicas. }\end{array}$ & $\begin{array}{c}\text { Polimorfismo } \\
\text { compatível } \\
\text { com Desordem } \\
\text { Linfoproli- } \\
\text { ferativa Pós } \\
\text { Transplante. }\end{array}$ \\
\hline
\end{tabular}

Volume $15-\mathrm{N}^{\circ} 169$ - Janeiro/2020.

\section{DISCUSSÃO}

$\mathrm{O}$ aumento do número de transplantes de fígado, nos últimos anos, possibilitou que mais condições relacionadas a este procedimento fossem estudadas. Apesar de existirem alguns trabalhos que buscam avaliar a saúde da cavidade oral de indivíduos após transplante hepático, observa-se que a maioria deles se utiliza apenas do exame clínico em suas considerações (HELENIUS-HIETALA, 2014). De acordo com os critérios de inclusão deste estudo, somente três dos seis artigos incluídos representam relatos de caso que contêm análise de tecidos das lesões em boca. Dessa forma, fica evidente que é necessário desenvolver estudos histopatológicos nesta área.

No início desta revisão, esperava-se que grande parte das complicações orais relacionadas aos imunossupressores fosse de etiologia infecciosa, mas observou-se que é frequente que essas lesões estejam associadas a distúrbios proliferativos. Como por exemplo, casos de hiperplasia gengival que pode ser causada por diferentes drogas, como ciclosporina, droga imunossupressora, e antagonistas do cálcio. Esses fármacos têm em comum a ação de inibir a recaptação das células de cálcio, um mecanismo considerado envolvido na patogênese do aumento gengival (DÍAZ ORTIZ, 2005).

Sabe-se ainda que outros aspectos, além da imunossupressão, são colaboradores para que ocorra injúrias orais. Em estudo produzido por Santos et al. (2018), a presença da doença foi comparada com variáveis sujeitas a possíveis fatores de risco como, por exemplo, intensidade de exposição a possíveis patógenos, fatores sociodemográficos e cuidados pós-operatórios. A partir desses levantamentos ele pode que verificar que tais fatores influenciaram significativamente no estado de saúde dos indivíduos imunodeprimidos que apresentavam candidíase.

Como limitações deste estudo, podemos relatar que a reduzida quantidade de trabalhos que enfoquem na citopatologia (Quadro 1), a inclusão de pacientes em diferentes estágios de imunossupressão e discrepância da faixa etária em que ocorreu a cirurgia, sugerem que ainda não existe como traçar algum padrão histopatológico das lesões decorrentes de imunossupressão relacionadas a transplante de fígado.

\section{CONCLUSÃO}

Diante do exposto, podemos concluir que tanto as reações adversas quanto a vulnerabilidade das defesas imunológicas são importantes fatores que propiciam a formação de injúrias em mucosa oral a nível celular, que podem apresentar distúrbios de crescimento, alterações morfofuncionais e presença de células de defesa. Principalmente quando decorrente da forte imunossupressão necessária pós-transplante hepático. 


\section{REFERÊNCIAS BIBLIOGRÁFICAS}

BRASIL. Ministério da Saúde - Secretaria de Ciência, tecnologia e Insumos Estratégicos/CONITEC - Comissão Nacional de Incorporação de Tecnologias no SUS:

Protocolo clínico e diretrizes terapêuticas imunossupressão no transplante hepático em adultos relatório de recomendação. Agosto 2016 [Internet].

CASTRO-E-SILVA JR, Orlando de et al. Transplante de fígado: indicação e sobrevida. Acta Cir. Bras, São Paulo, v. 17, supl. 3, p. 83-91, 2002.

DÍAZ ORTIZ, María Luisa et al. Estudio del estado bucodental del paciente trasplantado hepático. Medicina Oral, Patología Oral y Cirugía Bucal (Ed. impressa), v. 10, n. 1, p. 58-65, 2005.

HELENIUS-HIETALA, Jaana et al. Saúde da mucosa oral em receptores e controles de transplante de fígado. Transplante de fígado, v. 20, n. 1, p. 72-80, 2014.

KRASUSKA-SŁAWIŃSKA, E. et al. Post-Transplant Lymphoproliferative Disorder (PTLD) Manifesting in the Oral Cavity of a 13-Year-Old Liver Transplant Recipient (LTx). Annals of transplantation, v. 20, p. 478-482, 2015.

NAKAMURA, Gabriele Prospero et al. Oral ulcerative lesions in a post-liver-transplantation patient. Autopsy \& case reports, v. 9, n. 1, 2019.

PROFIO, Bruna et al. Condição bucal de hepatopatas prétransplantados e transplantados hepáticos: revisão da literatura. Braz J Periodontol- março, v. 26, n. 01, 2016.

SAALMAN, Robert et al. Lesões mucosas orais de longa data em crianças transplantadas em órgãos sólidos - uma nova entidade clínica. Transplantation, v. 89, n. 5, p. 606$611,2010$.

SANTOS, Samantha Bertoncello dos et al. Presence of Candida spp. and candidiasis in liver transplant patients. Anais brasileiros de dermatologia, v. 93, n. 3, p. 356-361, 2018.

\section{AGRADECIMENTOS}

Os autores agradecem à UFPE pelo apoio para o desenvolvimento deste trabalho.

\section{COPYRIGHT}

Os autores são os únicos responsáveis pelo material incluído no artigo. 


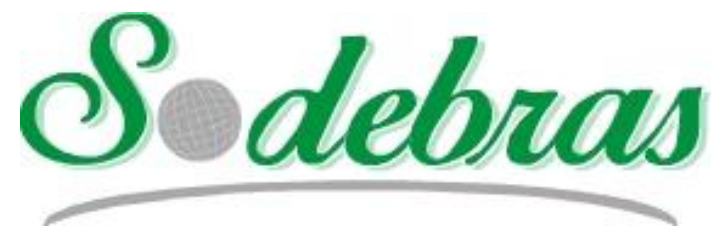

Volume 15 - $\mathrm{N}^{\mathrm{o}} 169$ - Janeiro / 2020

XLI International Sodebras Congress

31 de outubro a 02 de novembro de 2019 - Maceió - AL.

\title{
GORDURA SATURADA DIETÉTICA E SISTEMA NERVOSO: REVISÃO SISTEMÁTICA DA LITERATURA
}

\author{
DIETARY SATURATED FAT AND NERVOUS SYSTEM: SYSTEMATIC \\ LITERATURE REVIEW
}

\begin{abstract}
ISABEL MICHELY DA SILVA GALVÃO DE MELO ${ }^{1}$, HERICLES CLEYTON DE JESUS SANTANA ${ }^{1}$, JEYMESSON RAPHAEL CARDOSO VIEIRA ${ }^{1}$, LUCIANA MARIA SILVA DE SEIXAS MAIA ${ }^{1}$. 1 - UNIVERSIDADE FEDERAL DE PERNAMBUCO (UFPE), DEPARTAMENTO DE EMBRIOLOGIA E HISTOLOGIA, PROGRAMA DE PÓS-GRADUAÇÃO EM MORFOTECNOLOGIA, RECIFE, PERNAMBUCO, BRASIL.

michely.isabel@gmail.com; heriisantana@hotmail.com; jeymesson@gmail.com; lumaiabr@yahoo.com.br
\end{abstract}

\begin{abstract}
Resumo-Introdução: A gordura saturada, quando administrada de forma inadequada, pode acarretar alterações no sistema nervoso. Objetivo: Revisar as evidências na literatura sobre as alterações que a gordura saturada acomete no sistema nervoso. Método: Os dados foram obtidos de maio a setembro de 2018. Incluindo artigos originais, dos últimos 5 anos, envolvendo todas as linhagens de ratos e camundongos submetidos a uma dieta com gordura saturada. As bases de dados consultadas: SciELO, PUBMED e MEDLINE. Resultados: Os países que estudam esse tema são: Canadá, Brasil e EUA. A porcentagem de gordura variou entre $7 \%$ a $45 \%$ e as áreas do cérebro estudadas foram o hipocampo e hipotálamo. Conclusão: Uma alimentação balanceada em lipídios é fundamental para o bom funcionamento do sistema nervoso.
\end{abstract}

Palavras-chave: Gordura. Sistema nervos. Rato.

\begin{abstract}
Background: Saturated fat, when improperly administered, can cause changes in the nervous system. Objective: To review the evidence in the literature about the changes that saturated fat affects in the nervous system. Method: Data were obtained from May to September 2018. Including original articles from the last 5 years, involving all strains of rats and mice submitted to a saturated fat diet. The consulted databases: SciELO, PUBMED and MEDLINE. Results: The countries that study this theme are: Canada, Brazil and USA. The percentage of fat ranged from $7 \%$ to $45 \%$ and the brain areas studied were the hippocampus and hypothalamus. Conclusion: A balanced diet in lipids is essential for the proper functioning of the nervous system.
\end{abstract}

Keywords: Fat. Nerves system. Rats.

\section{INTRODUÇÃO}

O desenvolvimento do organismo ocorre em grande intensidade da gestação a primeira infância devido ao crescimento rápido, maturação de órgãos e sistemas replicação e diferenciação celular (MORGANE, et al., 1993). Alterações nesse período, chamado "Período crítico do desenvolvimento" pode ocasionar em efeitos persistentes, no entanto fora deste período somente induz mudanças reversíveis (REMMERS e DELEMARRE-VAN DE WAAL, 2011). Sendo assim, se torna imprescindível neste período a oferta adequada de nutrientes para a manutenção do crescimento e desenvolvimento do sistema fisiológicos (LIU, et al., 2009).

Para manter um metabolismo equilibrado, o organismo deve obter continuamente os chamados nutrientes, sendo um deles a gordura dietética, que possui uma importante função energética, promovem crescimento, auxilia na absorção e transporte de vitaminas lipossolúveis, responsável pela síntese de hormônios, sinalização intra e extracelular e fornecem ácidos graxos essenciais (WAITZBERG, 2006; MAHAN, et al., 2012).

As gorduras podem ser classificadas como saturadas, mono ou poli-insaturadas. As gorduras saturadas mais frequentemente utilizadas em nossa alimentação são: ácidos láurico, identificado no coco e no óleo de coco; ácidos mirístico, encontrado no leite e seus derivados; ácidos palmítico, cujas principais fontes são a gordura animal e o óleo de palma; ácidos esteárico, presente na gordura do cacau. Entre os monoinsaturados, o mais frequente são o ácido oleico, encontrado em abundância no azeite de oliva; e os poli-insaturados, que podem ser classificados como ômega 3 (Eicosapentaenoico, Docosahexaenóico e linolênico), ou ômega 6 (linoleico), sendo encontrados em maiores concentrações nos óleos vegetais (MARTIN, et al., 2006; FALUDI, et al., 2017; 2013).

Até pouco tempo prevalecia a crença de que o cérebro era imune aos nossos hábitos alimentares. Porém pesquisas apontam que as gorduras de boa qualidade, têm um papel importante para o bom funcionamento cerebral. As necessidades biomoleculares, muitas vezes, são supridas através da nossa alimentação (ROSA e REIS, 2017). No sistema nervoso o processo de mielinização ocorre no segundo trimestre da gestação, continua após o nascimento e se prolonga até os 25 ou 30 anos (MENDES e MELO, 2011), quando há a maturação completa dos processos mielinizantes. Quanto à composição molecular da bainha de mielina, podemos dizer que sua estrutura é rica em lipídeos, cerca de $70 \%-80 \%$ de lipídios (em peso seco) e na sua formação é altamente dependente da ingestão nutricional de alguns ácidos graxos essenciais, ômega-3 e ômega-6, pois o organismo não tem a capacidade de sintetizá-los, e devem ser obtidos através da dieta. (SIMON e NAVE, 2016). 
A gordura saturada, está inclusa na alimentação diária da maioria da população mundial, deixando o consumidor exposto a possíveis riscos que podem oferecer uma alimentação desequilibrada (MOREIRA, et al., 2014). A Abeso (2016) verificou que a gordura está associada a muitas doenças na população brasileira. Quando consumida de forma elevada, pode ocasionar doenças vasculares, doenças cardíacas, ganho excessivo de peso, danos aos neurônios e acarretar alterações no sistema nervoso (ABESO, 2016; YANG, et al., 2017), afetando a função hipotalâmica, controle homeostático do balanço energético corporal (VELLOSO, et al., 2011) permanentemente e consequentemente aumentar a suscetibilidade à obesidade (CESAR e PISANI, 2016). Diferindo do hipocampo que uma de suas principais funções são as formações e armazenamentos de memórias explícita que se refere a situações nas quais nos faz lembrar eventos específicos (BEZERRA, et al., 2017)

No entanto, a gordura presente na dieta é fundamental para o equilíbrio do sistema nervoso podendo auxiliar na prevenção de doenças psiquiátricas e neurodegenerativas, por meio de efeitos neuroprotetores envolvendo a modulação do fluxo de membrana, respostas antiinflamatórias e atividade antioxidante (ANGELISPEREIRA, et al., 2017). Diante disso, destaca-se a importância de uma alimentação equilibrada para o bom funcionamento do sistema nervoso.

Em pesquisas a utilização de animais de laboratório traz diversas vantagens, uma vez que oferece a possibilidade de controlar variáveis, sendo uma dessas a dieta, uma vez que influencia diretamente o crescimento, a capacidade de reprodução, seu estado de saúde e desenvolvimento de doenças nos animais (SANTOS et al., 2015). Nesse sentido, temos dietas comerciais e dietas purificadas que tem como função manter a saúde do animal sem influenciar no desfecho do estudo. O American Institute of Nutrition publicou em 1993, a partir de um comitê, a dieta purificada que considera quatro fases da vida: crescimento, gestação e lactação (dando origem a dieta AIN-93G) e manutenção da saúde na vida adulta (dieta AIN-93M), que são utilizadas como dieta padrão/controle em diversos estudos na nutrição experimental. Sendo elaborada com a finalidade de padronizar as pesquisas médicas em relação a alimentação ofertada a animais de grupo controle e minimizar os vieses dos experimentos que utilizam animais de laboratório em todo o mundo (REEVES, et al., 1993; SANTOS, et al., 2015).

Com base nessa explanação da literatura, notou-se que é necessário, um conhecimento das características desta gordura para melhor compreensão do seu uso na prevenção primária de patologias. Com isso, o objetivo deste estudo é revisar as evidências disponíveis na literatura sobre as possíveis alterações que as gorduras saturadas dietéticas promovem no sistema nervoso.

\section{METODOLOGIA}

Nessa revisão sistemática, os dados que a compõem foram obtidos no período de maio de 2018 a setembro de 2018. Inclui artigos originais, de estudos transversais e de coorte, prospectivos e retrospectivos, com o limite temporal dos últimos 5 anos de caráter experimental envolvendo todas as linhagens de ratos e camundongos submetidos a uma dieta composta todos os tipos de alimentos que possuem como fonte principal a gordura saturada. Foram excluídos artigos em que os animais foram submetidos à suplementação, que tiveram intervenções cirúrgicas ou farmacológicas, bem como aqueles em que os ratos tiveram alguma doença, alteração hormonal ou realizaram algum tipo de atividade física.

As bases de dados Scientific Eletronic Library Online (SciELO), Biblioteca Nacional de Medicina e Instituto Nacional de Saúde (PUBMED) e Biblioteca Nacional de Medicina - 1997-2010 (MEDLINE) foram consultadas com os seguintes descritores combinados e em inglês: "gordura saturada" e "sistema nervoso". Os resumos dos artigos selecionados foram lidos independentemente por dois autores, para inclusão ou exclusão desta revisão. Os revisores chegaram a um consenso sobre todos os itens, avaliaram os títulos e resumos de todos os estudos identificados e, em seguida, obtiveram cópias completas de todos os artigos. Dos estudos que avaliaram a associação entre a gordura saturada e o sistema nervoso foram extraídos os seguintes itens: nome do primeiro autor, ano de publicação, país em que foi realizado o estudo, linhagem e idade dos ratos, objetivo dos estudos, métodos estudados, porcentagem de caloria advindo de gordura saturada, áreas avaliadas no sistema nervoso e resultados.

A pesquisa eletrônica identificou 38.101 estudos publicados com as palavras-chave, combinadas entre elas, sendo 1 no SciELO, 37.878 no PUBMED e 222 no MEDLINE. Inicialmente, 38.091 artigos foram excluídos por não atenderem os critérios estabelecidos, apenas 10 artigos foram selecionados pelo resumo. Desses artigos 5 foram excluídos após leitura completa por se tratarem de suplementação ou de utilizar outros tipos de animais no estudo. Os 5 artigos restantes foram totalmente analisados e preencheram os critérios de inclusão estabelecidos.

\section{RESULTADOS}

Entre os 5 artigos considerados relevantes, dois artigos são do Canadá (MARIC, et al., 2014; ROBB, et al., 2017), dois são do Brasil (SOARES, et al., 2014; ANGELISPEREIRA, et al., 2017) e um do Estados Unidos da América (SCHIPPER, et al., 2013). A maioria dos artigos trabalhou com a linhagem de ratos Wistar (MARIC, et al., 2014; SOARES, et al., 2014; ANGELIS-PEREIRA, et al., 2017), exceto dois que utilizou a linhagem Sprague-Dawley (ROBB, et al., 2017) e C57B1/ 6J (SCHIPPER, et al., 2013). Dois desses artigos trabalharam com ratos acima do período de 21 dias de vida (SCHIPPER, et al., 2013; ROBB, et al., 2017), apenas 1 artigo usou ratos abaixo do período de lactação (SOARES, et al., 2014) e dois artigos não informaram a idade apenas referiam se tratar de ratos adultos (MARIC, et al., 2014; ANGELIS-PEREIRA, et al., 2017).Dentre os métodos estudados, todos os artigos analisaram a bioquímica desses animais, dois desses artigos verificaram aspectos comportamentais (SOARES, et al., 2014; ROBB, et al., 2017) e os demais observaram a eletrofisiologia, cromatografia gasosa, imunohistoquímica e medidas antropométricas (SCHIPPER, et al., 2013; ANGELIS-PEREIRA, et al., 2017; ROBB, et al., 2017).

Sendo assim, o objetivo do estudo de Angelis-Pereira, et al., (2017) analisou o teor de ácidos graxos em fontes comerciais de gordura altamente consumidas pela população 
(margarina pobre em PUFA, margarina rica em PUFA, manteiga e gordura vegetal hidrogenada) e avaliar o efeito do consumo dessas fontes no perfil lipídico do sangue e do fígado, e no perfil de ácidos graxos em tecido cerebral de ratos Wistar. O artigo de Robb, et al., (2017) determinou se uma doença materna causada pela dieta afetaria o comportamento no hipocampo da prole e se quaisquer mudanças observadas eram sexualmente dimórficas. No entanto, Maric, et al., (2014) investigou se a variação da fonte de gordura e o nível de gordura saturada na dieta potencializariam os efeitos da exposição a uma dieta com apenas moderados níveis de gordura total na periferia basal e na inflamação hipotalâmica. Os autores do artigo Soares, et al., (2014) verificaram se uma dieta materna contendo gordura de leite de cabra oferecido durante o período crítico de desenvolvimento cerebral em ratos pode interferir na maturação reflexa e ganho de peso corporal da prole. O que diferiu do estudo de Schipper, et al., (2013) que analisou se os efeitos da dieta contendo $50 \%$ de banha ofertada no período pós-natais no desenvolvimento de projeções neurais do núcleo arqueado do hipotálamo (ARH) e no núcleo paraventricular $(\mathrm{PVH})$ poderia ocasionar um aumento de leptina pós-natal.

A porcentagem de calorias advindas das gorduras saturadas, distribuídas nas dietas desses animais, foram de $45 \%, 32 \%, 12 \%, 10 \%$ e $7 \%$ (SCHIPPER, et al., 2013; MARIC, et al., 2014; SOARES, et al., 2014; ANGELISPEREIRA, et al., 2017; ROBB, et al., 2017) respectivamente. As áreas avaliadas do sistema nervoso foi o cérebro em dois artigos (SOARES, et al., 2014; ANGELIS-PEREIRA, et al., 2017), o hipotálamo nos outros dois artigos (SCHIPPER, et al., 2013; MARIC, et al., 2014) e hipocampo em um artigo (ROBB, et al., 2017). Sendo assim, apenas um artigo observou nos resultados que não houve alteração no sistema nervoso (ROBB, et al., 2017). Os demais artigos verificaram alterações na indução de inflamação central em áreas-chaves que controlam a regulação metabólica (MARIC, et al., 2014), redução de ácido docosahexaenoico (DHA) na concentração cerebral (ANGELIS-PEREIRA, et al., 2017), diminuição na densidade de projeções neurais orexígenas e anorexígenas do núcleo paraventricular (SCHIPPER, et al., 2013); e aparecimento precoce no desenvolvimento da maturação reflexa destes animais (SOARES, et al., 2014). A quadro 1 sumariza todos os nossos achados.

\section{DISCUSSÃO}

Mediante aos artigos analisados neste estudo, pôde-se ter uma visão mais ampla na literatura sobre alterações no sistema nervoso devido a ingestão desequilibrada de gordura saturada. Pois, a dieta tem um papel importante para manter o desenvolvimento e saúde dos animais (ANDRADE, et al., 2002), devendo levar em consideração as quatro diferenças na fase de vida dos ratos e camundongos, como: crescimento, gestação, lactação e manutenção. Reeves et al., (1993) recomenda utilização de dois tipos de dieta para a fase de crescimento, gestação e na lactação, empregar a dieta AIN-93G com 7\% de lipídeo das calorias totais, para a fase de manutenção do animal adulto a dieta AIN-93M com 4\% de lipídeo das calorias totais (HENRIQUES et al., 2014). Já o Conselho Nacional de Pesquisa (National Research Council - NRC) na sua última versão em 1995, orientou que as dietas devem apresentar valores entre 5 e $15 \%$ das calorias totais da dieta para animais adultos, sendo que essa quantidade é suficiente para absorção de caroteno e vitamina A pelo organismo (CRN, 1995).

No nosso estudo verificamos que o autor SCHIPPER, et al., (2013), dos Estados Unidos, utilizou 10\% de gordura saturada na dieta de ratos adultos e constatou alterações no hipocampo. Já Soares, et al., (2014), no Brasil, utilizou, cerca de $7 \%$ de gordura saturada na dieta de ratos lactentes, e observou alterações no cérebro, como o aparecimento precoce no desenvolvimento da maturação reflexa. Em contraste, ao estudo de Robb, et al., (2017), no Canadá, sendo o único estudo que avaliou o hipocampo e maior porcentagem de gordura saturada, cerca de $45 \%$ na dieta em ratos adultos, não apresentando alterações opondo-se as recomendações de Reeves et al., (1993) e da CRN (1995). Diante da variação da composição da dieta, faz-se necessário mais estudos para identificar qual equilíbrio dietético é mais adequado.

Outro ponto analisado nos estudos que compões esta revisão, foi que a maioria dos autores utilizaram ratos adultos (SCHIPPER, et al., 2013; MARIC, et al., 2014; ANGELIS-PEREIRA, et al., 2017; ROBB, et al., 2017), exceto o de Soares, et al., (2014) que utilizou ratos no período de lactação onde está ocorrendo o desenvolvimento cerebral. Quaisquer mudanças nesta fase da vida, onde é chamado de período crítico podem ocasionar alterações no desenvolvimento e na maturação levando a modificações morfológicas, bioquímicas, comportamentais tornando os indivíduos mais susceptíveis a agravos nutricionais que podem persistir na fase adulta (LUCAS, 1991; SCHWEIGERT, et al., 2009). Esta fase inicial da vida precisa ser mais amplamente investigada.

O Ácido Docosahexaenóico tem importante função no funcionamento e desenvolvimento da retina e cérebro, sendo predominante na maioria das membranas celulares (MEYER, et al., 2007). O trabalho de Angelis-Pereira et al., (2017) verificaram que ao utilizar $12 \%$ de gordura saturada na dieta observaram que houve redução na concentração de ácido Docosahexaenóico no cérebro de ratos adultos. Contudo, se está dieta fosse ofertada no período crítico da vida poderia ocasionar carência de ômega 3 reduzindo a produção de enzimas relacionadas com as funções de aprendizagem, pois o mesmo representa um terço de da estrutura de lipídeos no cérebro (MORAES e COLLA, 2006).

As diferenças entre as nossas descobertas, devem ser provavelmente devido às diferenças na composição das dietas, duração do consumo, idade ofertada a dieta, área do cérebro, estirpe e espécie dos animais. SCHIPPER, et al., (2013) que utilizou uma linhagem de camundongos transgênicos e mutantes, $\mathrm{C} 57 \mathrm{Bl} / 6 \mathrm{~J}$, que possuem alta susceptibilidade a obesidade, diabetes tipo 2 e aterosclerose induzidos pela dieta (MILLS, et al., 1993; NISHINA, et al., 1993). Diversificando dos demais estudos, onde a maior parte utilizou ratos Wistar e apenas um utilizou ratos Sprague Dawley, ambos são os mais utilizados mundialmente em pesquisas. Sendo assim, alterações no sistema nervoso a partir da ingestão elevada de gordura saturada dependem de vários fatores como em que fase da vida a dieta está sendo ofertada, frequência e a porcentagem de calorias. No entanto, estes estudos são insuficientes para 
garantir até que ponto esses parâmetros podem influenciar essas alterações.

\section{CONCLUSÃO}

Diante do exposto, recomenda-se que na alimentação diária sempre esteja presente fontes balanceadas de lipídios, visto que os mesmos estão diretamente em consonância com o desenvolvimento do sistema nervoso, além de ser um componente estrutural de grande parte do cérebro. A maioria dos trabalhos indicaram que alterações ocasionadas por ingestão de gordura saturada podem afetar o sistema nervoso de forma permanente. Desta maneira são necessários mais trabalhos para investigar fontes alternativas de lipídios que possam substituir a gordura saturada, principalmente aquelas advindas de produtos regionais. Uma vez que poucos trabalhos experimentais têm relatado as implicações deste tipo de gordura no desenvolvimento do organismo.

\section{REFERÊNCIAS BIBLIOGRÁFICAS}

MORGANE, P. J., AUSTIN-LAFRANCE, R., BRONZINO, J., TONKISS, J., DIAZ-CINTRA, S., CINTRA, L., KEMPER, T., GALLER, J. R. Prenatal malnutrition and development of the brain. Neurosci Biobehav Rev. 1993; 17(1): 91-128;

REMMERS, F., DELEMARRE-VAN DE WALL, H. A. Developmental programming of energy balance and its hypothalamic regulation. Endocrine Reviews. 2011; 32 (2): 272-311;

LIU, N., MAO, L., SUN, X., LIU, L., YAO, P., CHEN, B. The effect of health and nutrition education intervention on women's postpartum beliefs and practices: a randomized controlled trial. BMC Public Health. 2009; 9: 45;

BEYER, P. L. Ingestão: digestão, absorção, transporte e excreção de nutriente. In: MAHAN, L. K., ESCOTTSTRUMP, S., RAYMOND, J. L. Krause: alimentos, nutrição e dietoterapia. $13^{\circ}$ edição. Rio de Janeiro: Elsevier; 2012. 2-18;

WAITZBERG, D. L. Nutrição Oral, Enteral e Parenteral na Prática

Clínica. $4^{\circ}$ edição. São Paulo: Atheneu; 2006;

FALUDI, A. A., IZAR, M. C..D. O., SARAIVA, J. F. K., CHACRA, A. P. M., BIANCO, H. T., AFIUNE NETO, A., BERTOLAMI, A., PEREIRA, A. C., LOTTENBERG, A. M., SPOSITO, A. C., CHAGAS, A. C. P., CASELlA FILHO, A., SIMÃO, A. F., ALENCAR FILHO, A. C. D., CARAMELLI, B., MAGALHÃES, C. C., NEGRÃO, C. E., FERREIRA, C. E. D. S., SCHERR, C., FEIO, C. M. A., KOVACS, C., ARAÚJO, D. B. D., MAGNONI, D., CALDERARO, D., GUALANDRO, D. M., MELLO JUNIOR, E. P. D., ALEXANDRE, E. R. G., SATO, E. I., MORIGUCHI, E. H., RACHED, F. H., SANTOS, F. C. D., CESENA, F. H. Y., FONSECA, F. A. H., FONSECA, H. A. R. D., XAVIER, H. T., MOTA, I. C. P., GIULIANO, I. D. C. B., ISSA, J. S., DIAMENT, J., PESQUERO, J. B., SANTOS, J. E. D., FARIA NETO, J. R., MELO FILHO, J. X. D., KATO, J. T., TORRES, K. P., BERTOLAMI, M. C., ASSAD, M. H., FORTI, N. A., COELHO, O. R., MARANHÃO, R. C., SANTOS FILHO, R. D. D., ALVES,
R. J., CASSANI, R. L., BETTI, R. T. B., CARVALHO, T. D., MARTINEZ, T. L. D. R., GIRALDEZ, V. Z. R., SALGADO FILHO, W. Atualização da Diretriz Brasileira de Dislipidemias e Prevenção da Aterosclerose - 2017. Arq Bras Cardiol. 2017; 109(2Supl.1):1-76;

FALUDI, A. A., GELONEZE, B., SCHERR, C., KOVACS, C., TOMAZZELA, C., CARLA, C., BARRERAARELLANO, D., CINTRA, D., QUINTÃO, E., NAKANDAKARE, E. R., FONSECA, F. A. H., PIMENTEL, I., SANTOS, J. E. D.,BERTOLAMI, M. C., ROGERO, M., IZAR, M. C. D. O., NAKASATO, M., DAMASCENO, N. R. T., MARANHÃO, R., CASSANI, R. S. L.,PERIM, R., RAMOS, S. Sociedade Brasileira de Cardiologia. I Diretriz sobre o consumo de Gorduras e Saúde Cardiovascular. Arq Bras Cardiol. 2013;100(1Supl.3):1-40;

MARTIN, C. A., ALMEIDA, V. V. D., RUIZ, M. R.,VISENTAINER, J. E. L., MATSHUSHITA, M.,SOUZA, N. E. D.,VISENTAINER, J. V. Omega-3 and omega-6 polyunsaturated fatty acids: importance and occurrence in foods .Rev. Nutr. 2006; 19(6):761-770;

ROSA, T. G., REIS, F. B. D. A bainha de mielina: sua formação, composição, funções e plasticidade. ANAIS DA XI MOSTRA CIENTÍFICA DO CESUCA. 2017; 23175915;

MENDES, P. B., MELO, S. R. D. Origem e desenvolvimento da

mielina no sistema nervoso central - Um estudo de revisão. Revista Saúde e Pesquisa,Maringá. 2011; 4 (1): 93-99;

SIMONS, M., NAVE, K. A. Oligodendrocytes: Myelination and Axonal Support.

Cold Spring Harbor Perpectives in Biology. 2016; 8:a020479.

MOREIRA, R. A. D. M., SANTOS, L. C. D., MENEZES, M. C. D., LOPES, A. C. S. Eating behavior toward oil and fat consumption versus dietary fat intake. Rev. Nutr. 2014; 27(4):447-457;

Associação Brasileira para o Estudo da Obesidade e da Síndrome Metabólica Diretrizes brasileiras de obesidade/ABESO - Associação Brasileira para o Estudo da Obesidade e da Síndrome Metabólica. $4^{\mathrm{a}}$ edição. São Paulo. 2016;

YANG, W., SHE, H., ZHANG, J., SHEN, Z., ZHOU, G., HU, M. Effects of the duration of hyperlipidemia on cerebral lipids, vessels and neurons in rats. Lipids in Health and Disease. 2017; 16: 26;

VELloso, L. A., SCHWARTZ, M. W. Altered hypothalamic function in dietinduced obesity. Int J Obes. 2011; 35(12):1455 65 ;

CESAR, H. C., H. C., PISANI, L. P. Fatty-acid-mediated hypothalamic inflammation and epigenetic programming. Journal of Nutritional Biochemistry. 2017; 42: 1-6;

BEZERRA, M. G. C. E., GUSMÃO, J. E. D. L. S. D. FERMOSELI, A. F. D. O. A importância da emoção no processo de consolidação da memória e da aprendizagem. Ciências Biológicas e de Saúde Unit. 2017; 4 (2):57-68; 
ANGELIS-PEREIRA, M. C. D., BARCELOSII, M. D. F. P., PEREIRA, J. D. A. R., PEREIRA, R. C., SOUZA, R. V. D. Effect of different commercial fat sources on brain, liver and blood lipid profiles of rats in growth phase. Acta Cir Bras. 2017; 32(12):1013-1025;

SANTOS, J. C. F., AMARAL, M. S., OLIVEIRA, S. L., BARBOSA, J. P., CABRAL, C. R. JR., MELO, I. S., BUENO, N. B., FREITAS J. D., SANT'ANA, A. G., ATAÍDE, T. R. Dietary intake of AIN-93 standard diet induces fatty liver with altered hepatic fatty acid profile in Wistar rats. Nutrición Hospitalaria. 2015; 31(5):2140- 2146;

REEVES, P. G., NILESEN, F. H., FAHEY, C. J. AIN-93 Purified Diets for Laboratory Rodents: Final Report of the American Institute of Nutrition Ad Hoc Writing Committee on the Reformulation of the AIN76A Rodent Diet. Journal of Nutrition. 1993; 22 (3166): 1939- 1951;

MARIC, T., WOODSIDE, B., LUHESHI, G. N. The effects of dietary saturated fat on basal hypothalamic neuroinflammation in rats. Brain, Behavior, and Immunity. 2014; 36: 35-45;

ROBB, J. L., MESSA, I., LUI, E., YEUNG, D., THACKER, J., SATVAT, E., MIELKE, J. G. A maternal diet high in saturated fat impairs offspring hippocampal function in a sex-specific manner. Behavioural Brain Research. 2017; 326: 187-199;

SOARES, J. K., QUEIROGA, R. C., BOMFIM, M. A., PESSOA, D. C., BARBOSA, E. A., SOUZA, D. L., CABRAL-FILHO, J. E., MEDEIROS, M. C. Acceleration of reflex maturation and physical development in suckling rats: effects of a maternal diet containing lipids from goat milk. Nutr Neurosci. 2014; 17(1): 1-6;

SCHIPPER, L., BOUYER, K., OOSTING, A., SIMERLY, R. B., BEEK, E. M. V. D. Postnatal dietary fatty acid composition permanently affects the structure of hypothalamic pathways controlling energy balance in mice. Am J Clin Nutr. 2013; 98: 1395-401;

ANDRADE, A., PINTO, S. C., OLIVEIRA, R. S. D. Animais de laboratório: criação e experimentação. $1^{\circ}$ edição. Rio de Janeiro: Editora FIOCRUZ, 2002. 388 p. ISBN: 857541-015-6 Disponível em:

http://books.scielo.org/id/sfwtj/pdf/andrade-

9788575413869.pdf $<$

HENRIQUES, G. S., MARTINO, H. S. D., PELUZIO, M. D. C. G., COSTA, N. M. B. Nutrição experimental: Teoria e prática. $1^{\text {o }}$ Edição.Rio de Janeiro: Rubio, 2014.

NATIONAL RESEARCH COUNCIL Nutrient Requeriments of Laboratory Animals. Revisão da $4^{\circ}$ edição.Washington, D.C.: National Academy Press, 1995, $173 p$.

LUCAS A. Programming by early nutrition in man.Ciba Found Symp. 1991; 156:38-50.

SCHWEIGERT, I. D., SOUZA, D. O. G. D., PERRY, M. L. S. Malnutrition, central nervous system maturation and neuropsychiatric diseases. Rev. Nutr. 2009; 22(2):271-281;

MEYER, B. J., HAMMERVOLD, T., RUSTAN, A. C., HOWE, P. R.Dose-dependent effects of docosahexaenoic acid supplementation on blood lipids in statin-treated hyperlipidaemic subjects. Lipids. 2007; 42 (2):109-15;

MORAES, F. P., COLLA, L. M. Alimentos funcionais e nutracêuticos: definições, legislação e benefícios à saúde. Rev Eletr Farm. 2006; 3(2):109-22;

MILLS, E., KUHN, C. M. ,FEINGLOS, M. N., SURWIT, R. Hypertension in $\mathrm{CB} 57 \mathrm{BL} / 6 \mathrm{~J}$ mouse model of noninsulin-dependent diabetes mellitus. American Physiological Society. 1993; 264(1);

NISHINA, M. P., WANG, J., TOYOFUKU, W., KUYPERS, F. A., ISHIDA, B. Y., PAIGEN, B..Atherosclerosis And plasma and liver lipids in nine inbred strains of mice. Lipids.1993;28(7): 599-605.

\section{AGRADECIMENTOS}

Os autores agradecem ao CNPq (Conselho Nacional de Desenvolvimento Tecnológico e Científico) as bolsas de estudo concedida.

\section{COPYRIGHT}

Os autores são os únicos responsáveis pelo material incluído no artigo. 
Quadro 1- Estudos que avaliaram a gordura saturada no sistema nervoso em animais.

\begin{tabular}{|c|c|c|c|c|c|c|c|}
\hline $\begin{array}{l}\text { Autor/ Ano/ } \\
\text { País }\end{array}$ & $\begin{array}{l}\text { Linhagem } \\
\text { dos ratos }\end{array}$ & Idade & Objetivo & Métodos estudado & $\begin{array}{l}\text { \% de caloria } \\
\text { advindo de } \\
\text { gordura } \\
\text { saturada }\end{array}$ & $\begin{array}{l}\text { Áreas } \\
\text { avaliadas no } \\
\text { sistema } \\
\text { nervoso }\end{array}$ & $\begin{array}{c}\text { Resultados no sistema } \\
\text { nervoso }\end{array}$ \\
\hline $\begin{array}{l}\text { Robb, messa, lui } \\
\text { et al. (2017); } \\
\text { canadá }\end{array}$ & $\begin{array}{l}\text { Sprague- } \\
\text { dawley }\end{array}$ & 98 dias & $\begin{array}{l}\text { Determinar se uma doença materna causada pela } \\
\text { dieta afetaria o comportamento no hipocampo da } \\
\text { prole e se quaisquer mudanças observadas eram } \\
\text { sexualmente dimórficas. }\end{array}$ & $\begin{array}{l}\text { Bioquímico; } \\
\text { eletrofisiologico; } \\
\text { comportamental; } \\
\text { antropometria }\end{array}$ & $45 \%$ & Hipocampo & Não houve alterações \\
\hline $\begin{array}{l}\text { Maric, woodside, } \\
\text { luhesh et al. } \\
\text { (2014); canadá }\end{array}$ & Wistar & $\begin{array}{l}\text { Não } \\
\text { informa }\end{array}$ & $\begin{array}{l}\text { Investigar se a variação da fonte de gordura e o } \\
\text { nível de gordura saturada na dieta potencializariam } \\
\text { os efeitos da exposição a uma dieta com apenas } \\
\text { moderados níveis de gordura total na periferia } \\
\text { basal e na inflamação hipotalâmica. }\end{array}$ & Bioquímica & $32 \%$ & Hipotálamo & $\begin{array}{l}\text { Indução da inflamação } \\
\text { central em áreas-chave } \\
\text { que controlam a } \\
\text { regulação metabólica }\end{array}$ \\
\hline $\begin{array}{l}\text { Angelis-pereira, } \\
\text { barcelosii, } \\
\text { ribeiro et al. } \\
\text { (2017); brasil }\end{array}$ & Wistar & $\begin{array}{l}\text { Não } \\
\text { informa }\end{array}$ & $\begin{array}{l}\text { Analisar o teor de ácidos graxos em margarina } \\
\text { pobre em pufa, margarina rica em pufa, manteiga e } \\
\text { gordura vegetal hidrogenada e avaliar o efeito do } \\
\text { consumo dessas fontes no perfil lipídico do sangue } \\
\text { e do fígado, e no perfil de ácidos graxos em tecido } \\
\text { cerebral de ratos wistar. }\end{array}$ & $\begin{array}{l}\text { Bioquímica; } \\
\text { cromatografia } \\
\text { gasosa }\end{array}$ & $12 \%$ & Cérebro & $\begin{array}{l}\text { Reduziram a } \\
\text { concentração cerebral } \\
\text { de docosahexaenóico }\end{array}$ \\
\hline $\begin{array}{l}\text { Schipper, } \\
\text { bouyer, oosting } \\
\text { et al. (2013); usa }\end{array}$ & $\mathrm{c} 57 \mathrm{bl} / 6 \mathrm{j}$ & $\begin{array}{l}23,26 \\
31,33,35 \\
37 \text { e } 42 \\
\quad \text { dias }\end{array}$ & $\begin{array}{l}\text { Analisar se os efeitos da dieta contendo } 50 \% \text { de } \\
\text { banha ofertada no período pós-natais no } \\
\text { desenvolvimento de projeções neurais do núcleo } \\
\text { arqueado do hipotálamo e no núcleo } \\
\text { paraventricular poderia ocasionar um aumento de } \\
\text { leptina pós-natal. }\end{array}$ & $\begin{array}{c}\text { Bioquímico; } \\
\text { Imunohistoquímica }\end{array}$ & $10 \%$ & Hipotálamo & $\begin{array}{lr}\text { Diminuição } & \text { nas } \\
\text { densidades } & \text { de } \\
\text { projeções } & \text { neurais } \\
\text { orexígenas } & \text { e } \\
\text { anorexígenas para o } & \text { núcleo paraventricular }\end{array}$ \\
\hline $\begin{array}{l}\text { Soares, queiroga, } \\
\text { bomfim et al. } \\
\text { (2014); brasil }\end{array}$ & wistar & $0-21$ dias & $\begin{array}{l}\text { Verificar se uma dieta materna contendo gordura } \\
\text { de leite de cabra oferecido durante o período } \\
\text { crítico de desenvolvimento cerebral em ratos pode } \\
\text { interferir na maturação reflexa e ganho de peso } \\
\text { corporal da prole. }\end{array}$ & Comportamental & $7 \%$ & Cérebro & $\begin{array}{l}\text { Aparecimento precoce } \\
\text { no desenvolvimento da } \\
\text { maturação reflexa }\end{array}$ \\
\hline
\end{tabular}




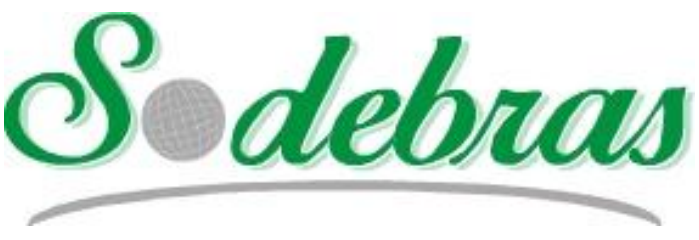

Volume 15 - $\mathrm{N}^{\mathrm{o}} 169$ - Janeiro / 2020

XLI International Sodebras Congress

31 de outubro a 02 de novembro de 2019 - Maceió - AL.

\title{
ASPECTOS AGRONÔMICOS EM HÍBRIDOS DE MILHO SUBMETIDOS AO TRATAMENTO DE SEMENTES COM NANOPARTÍCULAS DE COBRE
}

\section{AGRONOMIC ASPECTS IN CORN HYBRIDS SUBMITTED TO TREATMENT OF COPPER NANOPARTIC}

\author{
CRISTIANO RESCHKE LAJÚS ${ }^{1}$; GEAN LOPES DA LUZ ${ }^{1}$; NÉDIO LUIZ VERDI ${ }^{1}$; LUCIANO LUIZ \\ SILVA $^{1}$ \\ 1 - PROGRAMA DE PÓS-GRADUAÇÃO EM TECNOLOGIA E GESTÃO DA INOVAÇÃO, \\ UNOCHAPECÓ - CHAPECÓ/SC - BRASIL, UNOCHAPECÓ - CHAPECÓ/SC - BRASIL \\ clajus@unochapeco.edu.br; geanluz@unochapeco.edu.br; verdi@unochapeco.edu.br; \\ lucianols@unochapeco.edu.br
}

\begin{abstract}
Resumo - O estudo foi conduzido em Delineamento de Blocos Casualizados (DBC), em esquema de parcela subdividida (PSD) (5 $x$ 6), sendo que, na parcela principal foram alocados os híbridos de milho e na subparcela foram alocadas as doses de nanopartículas de $\mathrm{Cu}$ via $\mathrm{TS}$, com 3 repetições. As variáveis respostas analisadas foram: índice de vegetação da diferença normalizada, temperatura do dossel, identificação e incidência de doenças em milho, rendimento e peso hectolítrico. Os dados coletados foram submetidos à Análise de Variância (ANOVA) pelo teste $F(P \leq 0,05)$ e as diferenças entre as médias foram comparadas pelo Teste de Tukey $(P \leq 0,05)$. Os hibridos $20 A 30$ VIPTERA3 ${ }^{\circledR}$ (HB 02) e 20A20 TOP2® (HB 05) na dose de 900 mg de nanopartículas/kg de semente apresentam os melhores resultados em relação aos aspectos agronômicos analisados.
\end{abstract}

Palavras-chave: Nanotecnologia. Doenças. Rendimento.

Abstract - The study was conducted in a randomized block design $(D B C)$ in a split plot scheme (PSD) $(5 x$ 6 $)$. The maize hybrids were allocated in the main plot and the subplot the $\mathrm{Cu}$ nanoparticle doses were allocated. via TS, with 3 repetitions. The response variables analyzed were: normalized difference vegetation index, canopy temperature, identification and incidence of diseases in maize, yield and hectolitic weight. The data collected were subjected to analysis of variance (ANOVA) by the $F$ test $(P \leq 0.05)$ and the differences between the means were compared by the Tukey test $(P \leq 0.05)$. Hybrids 20430 VIPTERA3 ${ }^{\circledR}\left(\mathrm{HB}\right.$ 02) and $20 A 20 \mathrm{TOP}{ }^{\circledR}(\mathrm{HB} 05)$ at a dose of $900 \mathrm{mg}$ nanoparticles / $\mathrm{kg}$ seed presented the best results in relation to the agronomic aspects analyzed.

Keywords: Nanotechnology Diseases. Yield.

\section{INTRODUÇÃO}

O Brasil encontra-se consolidado como $3^{\circ}$ maior produtor de milho no mundo e $2^{\circ}$ maior exportador, com um consumo doméstico do cereal elevado, uma vez que é um dos principais produtores mundiais de proteína animal (CONAB, 2018).

Para o mesmo autor, nos últimos anos, a dinâmica da cadeia produtiva do milho mudou significativamente no país, visto que o grão deixou de ser apenas um produto destinado à alimentação animal, mas também uma commodity exportável, configurando-se no cenário do agronegócio brasileiro como um dos cereais mais importantes.

O milho é caracterizado por ser uma cultura com baixa população de plantas, logo a produção pode ser comprometida de forma significativa ao ser atacada por pragas e doenças durante o período de germinação das sementes e emergência das plântulas. Por isso, é extremamente importante que todas as sementes semeadas

germinem e assegurem, o número desejado de plantas no momento da colheita e o bom rendimento da lavoura (PESKE, 2013).

Para Jandrey (2014), as sementes de milho híbrido carregam um dos mais modernos pacotes tecnológicos da agricultura moderna. Isso tem provocado investimentos cada vez maiores em qualidade e proteção, pois com a introdução de eventos que incorporam características como resistência a doenças, insetos e herbicidas, ocorreu um aumento do custo inicial de implantação da lavoura, aumentando o valor agregado da semente. Além das tecnologias, o melhoramento genético tem propiciado materiais adaptados aos mais diferentes ambientes.

$\mathrm{Na}$ busca pela elevação dos níveis atuais de rendimento e redução nos custos de produção do milho no Brasil, novas tecnologias vêm sendo incorporadas aos sistemas de produção. Dentre essas, destaca-se a utilização de nanopartículas de nutrientes aplicadas via tratamento de sementes (TS), a qual é considerada uma estratégia agronômica promissora, pois garante o sucesso no estabelecimento da respectiva cultura, possibilitando às plantas maior capacidade em resistir aos estresses bióticos (ocasionados por pragas e doenças) ou abióticos (em função das condições ambientais e nutrição) durante as fases de definição dos componentes de rendimento.

Para que todo esse potencial seja expressado é necessário haver na planta um equilíbrio nutricional. $\mathrm{O}$ cobre $(\mathrm{Cu})$ é essencial para a planta completar seu ciclo, ou seja, formar sementes viáveis. O mesmo desempenha importante papel em diversos processos fisiológicos, tais como: fotossíntese, respiração, distribuição de carboidratos, 
redução e fixação do nitrogênio, e metabolismo de proteínas e das paredes celulares. Controla as relações de água na planta e a sua produção de DNA e RNA, sendo que a sua deficiência reduz a produção de sementes pelo aumento da esterilidade do pólen; está envolvido, também, nos mecanismos de resistência a doenças (TAIZ et al., 2017).

Ao longo dos últimos anos, tem sido observado um avanço de doenças, nessa cultura, como consequência do estreitamento das relações patógeno-hospedeiro-ambiente. Os principais fungos que atacam as sementes de milho são Fusarium moniliforme (Sheld.), Cephalosporium sp., Aspergillus spp. e Penicillium spp., e ocorrem em duas etapas específicas do sistema de produção: na pré-colheita (podridões fúngicas de espigas, com a formação de grãos ardidos) e na pós-colheita, durante o beneficiamento, armazenamento e transporte (grãos mofados ou embolorados) (STEFANELLO et al., 2012).

Em face do que foi visto, a nanotecnologia apresenta um largo espectro de oportunidades e possibilidades, embora seja amplamente empregada em diversas áreas do conhecimento, ainda é pouca utilizada em estudos agronômicos. Desta forma, se justifica a presente pesquisa, com o objetivo de avaliar os aspectos agronômicos em híbridos de milho submetidos ao TS com nanopartículas de $\mathrm{Cu}$.

\section{METODOLOGIA}

O estudo foi conduzido na área experimental e laboratório de Tecnologia e Produção de Sementes do Curso de Agronomia na Universidade do Oeste de Santa Catarina no município de São José do Cedro/SC, localizados a uma latitude de $26^{\circ} 28^{\prime} 43,88^{\prime}$ ' S e longitude $53^{\circ} 30^{\prime} 44.68^{\prime}$ ' Oeste, com altitude de 684 metros do nível do mar.

As condições climáticas (temperatura máxima, média e mínima e precipitação acumulada) do período experimental (Figura 1) foram obtidas no Sistema de Monitoramento Agrometeorológico (AGRITEMPO, 2019).

Figura 1 - Condições climáticas registradas durante o período experimental.

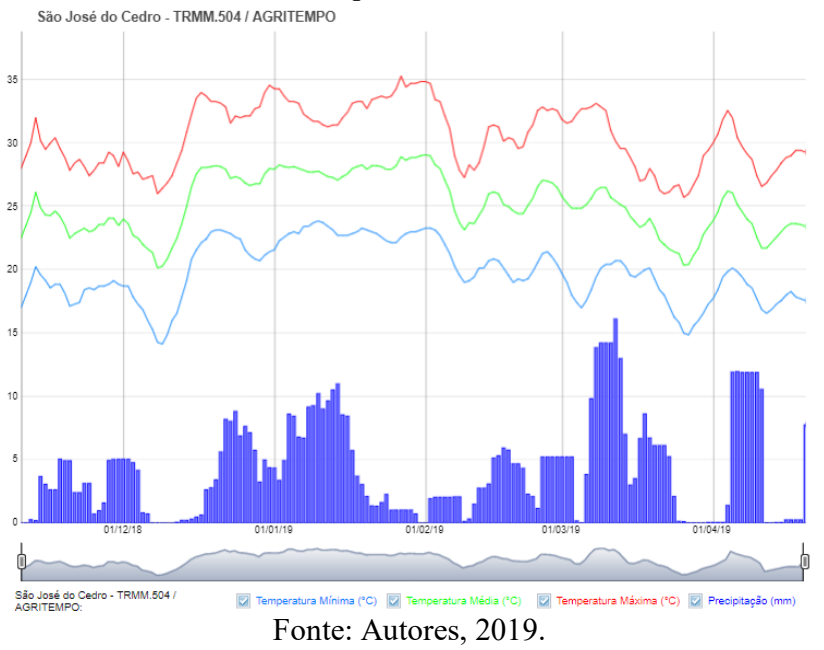

O solo da área é classificado como CAMBISSOLO Háplico (EMBRAPA, 2018).

$\mathrm{O}$ estudo foi conduzido em Delineamento de Blocos Casualizados (DBC), em esquema de parcela subdividida (PSD) $(5 \times 6)$, sendo que, na parcela principal foram alocados os híbridos de milho (H1: 22S18 TOP2®; H2: 20A30 VIPTERA $\AA$; H3: 20A80 TOP2 $\AA ; ~ H 4: ~ 22 S 18$ TOP3 ${ }^{\circledR}$ e H5: 20A20 TOP2 $\AA$ ) e na subparcela foram alocadas as doses de nanopartículas de $\mathrm{Cu}$ via TS (D1: testemunha (testemunha negativa: TN); D2: 100,00mg de nanopartículas de $\mathrm{Cu} / \mathrm{kg}$ de semente; D3: 300,00mg de nanopartículas de $\mathrm{Cu} / \mathrm{kg}$ de semente; D4: 900,00mg de nanopartículas de $\mathrm{Cu} / \mathrm{kg}$ de semente; D5: 2700,00mg de nanopartículas de $\mathrm{Cu} / \mathrm{kg}$ de semente e D6 (testemunha positiva: TP): $4,00 \mathrm{~g}$ de $\mathrm{Cu} / \mathrm{kg}$ de semente), com 3 repetições.

A implantação da cultura do milho ocorreu sobre a palhada de aveia preta (Avena strigosa Scherb), dessecada no dia 18 de outubro de 2018 com o herbicida Glyphosate (Glifosato Nortox $\mathrm{WG} \AA$ ), na dose de $2,50 \mathrm{~kg} / \mathrm{ha}$, com antecedência de 21 dias antes da semeadura. A semeadura foi realizada no dia 10 de novembro de 2018, de forma manual com auxílio de semeadora conhecida como "matraca" com a finalidade de controlar a densidade e distribuição das sementes na profundidade de 2 a $3 \mathrm{~cm}$.

Em agosto de 2018 foi realizada a amostragem de solo com trado tipo calador em três pontos aleatórios/repetição. Em cada ponto foram coletadas cinco amostras na profundidade de $00-10 \mathrm{~cm}$, totalizando 15 amostras, conforme instruções do Manual de Calagem e Adubação para os estados do Rio Grande do Sul e Santa Catarina (CQFS, 2016). A análise de solo foi realizada no Laboratório de Solos do Centro de Pesquisa para Agricultura Familiar - CEPAF, localizado no município de Chapecó/SC.

Após a interpretação dos resultados da análise de solo, foram aplicadas as recomendações conforme Manual de Calagem e Adubação para os estados do RS/SC da Comissão de Química e Fertilidade do Solo - RS/SC, referentes aos nutrientes. A fórmula utilizada foi $500 \mathrm{~kg} / \mathrm{ha}$ do adubo 09-33-12, com um adicional $90 \mathrm{~kg}$ de $\mathrm{KCl}$ a lanço na semeadura. Em relação a adubação nitrogenada, foram aplicados: $255 \mathrm{~kg}$ de $\mathrm{N} / \mathrm{ha}$, sendo $45 \mathrm{Kg} / \mathrm{ha}$ na base (10 de novembro de 2018) e $210 \mathrm{Kg}$ em cobertura nos estádios fenológicos V4 (18 de dezembro de 2018) e V8 (29 de dezembro de 2018). A fonte utilizada foi a uréia (45\% de $\mathrm{N})$. Para fósforo (P2O5) e potássio (K2O), foram aplicados $165 \mathrm{Kg} / \mathrm{ha}$ e $150 \mathrm{Kg} / \mathrm{ha}$, respectivamente, para uma expectativa de rendimento de 12 toneladas por hectare. Quanto aos teores de micronutrientes, não houve a necessidade de realizar aplicação dos mesmos, pois estavam acima das exigências da cultura do milho (CQFS, 2016). Em relação à calagem não foi necessária à correção na respectiva área experimental.

Foram utilizados 2,00ml de água destilada $(\mathrm{pH}$ de $6,2) / \mathrm{kg}$ de semente, para a realização do tratamento de sementes (TS) (homogeneização/mistura das sementes).

$\mathrm{O}$ desbaste foi realizado na emergência das plântulas. Quando a cultura se encontrava no estádio fenológico V3 (22 de novembro de 2018), foi efetuada a dessecação em pós emergência com o herbicida Glyphosate (Glifosato ${ }^{\circledR}$ ) na dose de 4,00L/ha.

Os tratamentos fitossanitários realizados foram: TS com o produto Tiametoxam (Cruiser 350 FS $®$ ) na dose de $100 \mathrm{ml} / 60.000$ sementes. Em fase de emergência visando o controle de lagartas e percevejos foi aplicado o inseticida Tiametoxam e Lambda-cialotrina (Engeo pleno ${ }^{\circledR}$ ) na dose de $200 \mathrm{ml} / \mathrm{ha}$. 
A colheita do milho foi realizada quando às plantas entraram em maturação de campo (20 de abril de 2019), segundo a metodologia proposta pelo Mapa (2009).

As análises de NDVI e temperatura do dossel foram realizadas no florescimento. Para tal, foi utilizado o leitor de reflectância GreenSeeker ${ }^{\circledR}$, em cinco plantas por parcela, posicionando o equipamento a $60 \mathrm{~cm}$ da planta, conforme metodologia proposta por Garcia (2015). A medida de temperatura do dossel foi realizada com a utilização do sensor termal infravermelho InfraPro ${ }^{\circledR}$ fabricado pela Oakton ${ }^{\circledR}$ na folha abaixo da espiga "folha bandeira", em cinco plantas por parcela (Crusiol et al., 2012).

As doenças na cultura do milho foram identificadas de acordo com Sabato e Fernandes (2014). Para a avaliação da incidência das doenças em raízes, colmos, folhas e grãos do milho, foi utilizada a nomenclatura adaptada de Sempre Sementes (2019).

Após a identificação dos fungos, foi realizada a avaliação de incidência das doenças em raízes de duas plantas de milho por parcela, no estádio V8, classificando-as da seguinte forma: (S) quando mais de $50 \%$ do sistema radicular estava afetado pela doença; (MS) quando de 25 a $50 \%$ do sistema radicular estava afetado pela doença; (MR) quando menos de $25 \%$ do sistema radicular estava afetado pela doença; (T) quando o sistema radicular não estava afetado pela doença.

Identificados os fungos, foram realizadas as avaliações de incidência das doenças em colmos de duas plantas de milho por parcela, da seguinte forma: abertos os colmos longitudinalmente ao meio e observados o terceiro entre nó da planta de baixo para cima, nos estádios V8, VT, R2, R4 e R6, classificando-os em: (S) quando mais de 50\% do terceiro entre nó do colmo estava afetada pela doença; (MS) quando de 25 a $50 \%$ do terceiro entre nó do colmo estava afetada pela doença; (MR) quando menos de $25 \%$ do terceiro entre nó do colmo estava afetada pela doença; $(\mathrm{T})$ quando o terceiro entre nó do colmo não estava afetado pela doença.

Realizada a identificação dos fungos, a avaliação de incidência das doenças em folhas de duas plantas de milho por parcela, ocorreu na última folha completamente expandida no estádio V8. A partir da bainha da folha, mediu-se $20 \mathrm{~cm}( \pm 2 \mathrm{~cm})$, coincidindo com a parte intermediária da folha. Nos estádios VT, R2, R4 e R6 a folha analisada foi a folha logo abaixo da espiga (folha bandeira), classificando-as em: (S) quando mais de 50\% da folha estava afetada pela doença; (MS) quando de 25 a 50\% da folha estava afetada pela doença; (MR) quando menos de $25 \%$ da folha estava afetada pela doença; (T) quando da folha não estava afetado pela doença.

As espigas da área útil foram colhidas manualmente, trilhadas em debulhador manual e separadas as impurezas, logo após os grãos foram submetidos à determinação da umidade, corrigidos a $13 \%$ de base úmida, efetuando-se os cálculos para estimar o rendimento em $\mathrm{kg} / \mathrm{ha}$. $\mathrm{O}$ rendimento e peso hectolítrico foram determinados conforme metodologia proposta pelo Mapa (2009).

Os dados coletados foram submetidos à Análise de Variância (ANOVA) pelo teste $\mathrm{F}(\mathrm{P} \leq 0,05)$. As diferenças entre médias foram comparadas pelo Teste de Tukey $(\mathrm{P} \leq 0,05)$.

\section{RESULTADOS}

As condições climáticas ocorridas (Figura 1) indicaram um modelo climático com grande potencial para "El Niño", na safra de milho 2018/19. Para o Brasil, o fenômeno trouxe aumento de temperatura e ocorrência de chuvas acima da média, especialmente na região Sul, refletindo diretamente na definição dos componentes de rendimento da respectiva cultura (FlOSS, 2011).

Conforme a Figura 1 foi possível constatar que as condições climáticas (temperatura e precipitação) ocorridas no respectivo experimento influenciaram nos diferentes estádios de desenvolvimento: VE (germinação x estande de plantas); V6 a V9 (definição do número de fileiras de grãos por espiga); V12 a V15 (determinação do número de grãos por fileira na espiga); VT (polinização); R1 a R5 (enchimento de grãos); R6 (maturação fisiológica) determinando diferentes comportamentos em relação às variáveis respostas qualitativas (NDVI; temperatura do dossel; identificação e incidência de doenças) e quantitativas (rendimento e peso hectolítrico), conforme os fatores híbridos de milho e doses de nanopartículas de $\mathrm{Cu} / \mathrm{kg}$ de semente.

A análise de variância revelou efeito significativo $(\mathrm{P} \leq 0,05)$ do fator híbridos em relação às variáveis respostas NDVI e temperatura do dossel (Tabela 1).

Tabela 1 - NDVI do experimento em relação ao fator híbridos (São José do Cedro, SC - safra 2018/2019).

\begin{tabular}{|c|c|c|}
\hline \multirow{2}{*}{ Híbridos de milho } & NDVI & Temperatura do dossel \\
\hline & ----------(Índice)--------- & - $\left({ }^{\circ} \mathrm{C}\right)$ \\
\hline HB 03: 20A80 $\mathrm{TOP}^{16}$ & $0,796 \mathrm{~b}$ & $28,55 \mathrm{c}$ \\
\hline HB 01: 22S18 TOP2 ${ }^{\circledR}$ & $0,814 \mathrm{ab}$ & $27,93 \mathrm{bc}$ \\
\hline HB 04: 22S18 TOP3 ${ }^{\text {B }}$ & $0,816 \mathrm{ab}$ & $27,66 \mathrm{~b}$ \\
\hline HB 02: 20A30 VIPTERA3 ${ }^{\circledast}$ & $0,816 \mathrm{ab}$ & $27,26 \mathrm{ab}$ \\
\hline HB 05: 20A20 TOP2 ${ }^{\varpi}$ & $0,821 \mathrm{a}$ & $26,71 \mathrm{a}$ \\
\hline
\end{tabular}

Médias seguidas de mesma letra não diferem significativamente entre si pelo teste de Tukey $(\mathrm{P} \leq 0,05)$.

Fonte: Autores, 2019.

A análise de variância revelou efeito significativo $(\mathrm{P} \leq 0,05)$ do fator doses de nanopartículas de $\mathrm{Cu}$ em relação às variáveis respostas NDVI e temperatura do dossel (Tabela 2).

Tabela 2 - NDVI e temperatura do dossel com testemunha positiva (4,00 $\mathrm{g} \mathrm{de} \mathrm{Cu} / \mathrm{kg}$ de semente) experimento em relação ao fator doses de nanopartículas de Cu (São José do Cedro, SC - safra 2018/2019).

\begin{tabular}{|c|c|c|}
\hline \multirow{2}{*}{$\begin{array}{l}\text { Doses de nanopartículas de } \mathrm{Cu} / \mathrm{kg} \\
\text { de semente }\end{array}$} & NDVI & Temperatura do dossel \\
\hline & 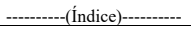 & 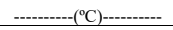 \\
\hline $0(\mathrm{TN})$ & $0,80 \mathrm{~b}$ & $28,05 \mathrm{ab}$ \\
\hline 100 & $0,81 \mathrm{ab}$ & 27,93 ab \\
\hline 300 & $0,81 \mathrm{ab}$ & $27,45 \mathrm{ab}$ \\
\hline 900 & $0,82 \mathrm{a}$ & 27,38 a \\
\hline 2700 & $0,80 \mathrm{~b}$ & $27,88 \mathrm{ab}$ \\
\hline $4 \mathrm{~g} \mathrm{de} \mathrm{Cu}(\mathrm{TP})$ & $0,79 \mathrm{~b}$ & $28,64 \mathrm{~b}$ \\
\hline
\end{tabular}

Médias seguidas de mesma letra não diferem significativamente entre si pelo teste de Tukey $(\mathrm{P} \leq 0,05)$.

Fonte: Autores, 2019.

Para a avaliação de incidência das doenças em raízes do milho, de acordo com Sabato e Fernandes (2014) foi observada a podridão de raiz (Fusarium spp.) e podridões de colmo (Fusarium spp., Pythium aphanidermatum e Macrophomina phaseolina), conforme a nomenclatura adaptada de Sempre Sementes (2019) os híbridos de milho foram classificados como moderadamente resistente (MR). 
A análise de variância revelou efeito significativo $(\mathrm{P} \leq 0,05)$ do fator híbridos em relação às variáveis respostas podridão de raiz (Fusarium spp.) e podridões de colmo (Fusarium spp., Pythium aphanidermatum e Macrophomina phaseolina) (Tabela 3).

A análise de variância revelou efeito significativo $(\mathrm{P} \leq 0,05)$ do fator estádios de desenvolvimento em relação às variáveis respostas podridão de raiz (Fusarium spp.) e podridões de colmo (Fusarium spp., Pythium aphanidermatum e Macrophomina phaseolina) (Tabela 4).

Os híbridos diferiram significativamente em relação a podridão da raiz e colmo causada pela infecção por Fusarium spp., com destaque para o híbrido HB 05: 20A20 TOP2 $\AA$ que foi o menos acometido tanto pela podridão da raiz $(0,56 \%)$, quanto pela podridão do colmo $(2,22 \%)$ (Tabela 3).

Tabela 3 - Podridão de raiz (Fusarium spp.) e podridões de colmo (Fusarium spp., Pythium aphanidermatum e Macrophomina phaseolina) do experimento em relação ao fator híbridos (São José do Cedro, SC - safra 2018/2019).

\begin{tabular}{|c|c|c|c|c|}
\hline \multirow{3}{*}{ Híbridos de milho } & Podridão de raiz & \multicolumn{3}{|c|}{ Podridões de colmo } \\
\hline & $\begin{array}{c}\begin{array}{c}\text { Fusarium } \\
\text { spp. }\end{array} \\
\end{array}$ & $\begin{array}{l}\text { Fusarium } \\
\text { spp. }\end{array}$ & $\begin{array}{c}\text { Pylhium } \\
\text { aphanidermatum }\end{array}$ & $\begin{array}{c}\text { Macrophomina } \\
\text { phaseolina }\end{array}$ \\
\hline & \multicolumn{4}{|c|}{----------(\%)---------- } \\
\hline HB 05: 20A20 TOP2 $2^{\text {Ti }}$ & $0,56 \mathrm{a}$ & $2,22 \mathrm{a}$ & $0,00 \mathrm{a}$ & $3,89 \mathrm{c}$ \\
\hline HB 03: 20A80 TOP2 ${ }^{\circledR}$ & $1,11 \mathrm{ab}$ & $2,78 \mathrm{a}$ & $0,00 \mathrm{a}$ & $3,33 \mathrm{~b}$ \\
\hline HB 02: 20A30 VIPTERA $3^{\varpi}$ & $2,22 \mathrm{ab}$ & $4,44 \mathrm{a}$ & $0,00 \mathrm{a}$ & $3,33 \mathrm{~b}$ \\
\hline HB 04: $22 \mathrm{~S} 18 \mathrm{TOP}^{\text {(8) }}$ & $278 \mathrm{~b}$ & $3,88 \mathrm{a}$ & $0,56 \mathrm{a}$ & $2,22 \mathrm{a}$ \\
\hline HB 01: $22 \mathrm{~S} 18 \mathrm{TOP}^{\circledR}$ & $5,00 \mathrm{c}$ & $6,67 \mathrm{~b}$ & $3,33 \mathrm{~b}$ & $4,44 \mathrm{c}$ \\
\hline
\end{tabular}

Médias seguidas de mesma letra não diferem significativamente entre si pelo teste de Tukey $(\mathrm{P} \leq 0,05)$.

Fonte: Autores, 2019.

A infecção por Fusarium spp. pode acometer além da raiz e colmo outras partes da planta, como a espiga, sendo uma das principais responsáveis pela incidência de grãos ardidos (RAMOS et al., 2010). Uma vez que a espiga é infectada, o fungo tende a deteriorar parte do amido dos grãos, e assim causar redução na densidade e na qualidade dos mesmos (BENTO et al., 2012). Este fato é uma provável explicação para o maior rendimento e peso do hectolitro observado para o híbrido mais resistente a podridão da raiz e do colmo causada por Fusarium spp., o HB 05: 20A20 TOP2® (Tabela 8).

As diferenças entre híbridos em relação a incidência de infecções por Fusarium spp. podem ser explicadas pela maior resistência decorrente do próprio genoma de algumas plantas, que atua limitando o crescimento fúngico e até mesmo interferindo na biossíntese de micotoxinas através da produção de metabólitos específicos (GAO et al., 2009).

Tabela 4 - Podridão de raiz (Fusarium spp.) e podridões de colmo (Fusarium spp., Pythium aphanidermatum e Macrophomina phaseolina) do experimento em relação ao fator estádios de desenvolvimento (São José do Cedro, SC - safra 2018/2019).

\begin{tabular}{ccccc}
\hline \multirow{2}{*}{ Estádios de desenvolvimento } & Podridão de raiz & \multicolumn{3}{c}{ Podridões de colmo } \\
\cline { 2 - 5 } & $\begin{array}{c}\text { Fusarium } \\
\text { spp. }\end{array}$ & $\begin{array}{c}\text { Fusarium } \\
\text { spp. }\end{array}$ & $\begin{array}{c}\text { Pylhium } \\
\text { aphanidermatum }\end{array}$ & $\begin{array}{c}\text { Macrophomina } \\
\text { phaseolina }\end{array}$ \\
\cline { 2 - 5 } & & $-\ldots,-0--(\%)---\ldots---$ & \\
\hline V8 & $11,67 \mathrm{~b}$ & $0,00 \mathrm{a}$ & $0,00 \mathrm{a}$ & $0,00 \mathrm{a}$ \\
VT & $0,00 \mathrm{a}$ & $0,00 \mathrm{a}$ & $0,00 \mathrm{a}$ & $0,55 \mathrm{a}$ \\
R2 & $0,00 \mathrm{a}$ & $1,67 \mathrm{a}$ & $0,00 \mathrm{a}$ & $3,89 \mathrm{ab}$ \\
R4 & $0,00 \mathrm{a}$ & $8,89 \mathrm{~b}$ & $1,67 \mathrm{~b}$ & $3,89 \mathrm{ab}$ \\
R6 & $0,00 \mathrm{a}$ & $9,44 \mathrm{~b}$ & $2,22 \mathrm{~b}$ & $8,89 \mathrm{~b}$ \\
\hline
\end{tabular}

Médias seguidas de mesma letra não diferem significativamente entre si pelo teste de Tukey $(\mathrm{P} \leq 0,05)$.

Fonte: Autores, 2019.
A análise de variância revelou efeito significativo $(\mathrm{P} \leq 0,05)$ do fator doses de nanopartículas de $\mathrm{Cu}$ em relação às variáveis respostas podridão de raiz (Fusarium spp.) e podridões de colmo (Fusarium spp., Pythium aphanidermatum e Macrophomina phaseolina) (Tabela 5).

Em relação às doses de nanopartículas avaliadas, a dose de $900 \mathrm{~g} / \mathrm{kg}$ de sementes foi que resultou nos menores níveis de ocorrência de podridão de raiz $(0,00 \%)$ e colmo (1,33\%) por Fusarium spp., com tendência similar para a podridão de colmo causada por Pylhium aphanidermatum $(0,00 \%)$ e Macrophomina phaseolina $(0,00 \%)$ (Tabela 5$)$.

A atividade antifúngica de nanopartículas metálicas já foi comprovada em outras culturas, como no controle in vitro do fitopatógeno Alternaria brassicicola. Neste caso as nanopartículas de prata foram capazes de inibir de forma consistente o desenvolvimento do fungo fitopatogênico e também dos esporos (CAVALCANTE, 2014). Kim (2012) também observou a inibição in vitro de várias espécies de fitopatógenos, incluindo Fusarium spp., a partir de nanopartículas de prata.

Tabela 5 - Podridão de raiz (Fusarium spp.) e podridões de colmo

(Fusarium spp., Pythium aphanidermatum e Macrophomina phaseolina) com testemunha positiva $(4,00 \mathrm{~g}$ de $\mathrm{Cu} / \mathrm{kg}$ de semente) do experimento em relação ao fator doses de nanopartículas de $\mathrm{Cu}$ (São José do Cedro, SC - safra 2018/2019).

\begin{tabular}{|c|c|c|c|c|}
\hline \multirow[b]{2}{*}{$\begin{array}{c}\text { Doses de nanopartículas de } \mathrm{Cu} / \mathrm{kg} \\
\text { de semente }\end{array}$} & Podridão de raiz & \multicolumn{3}{|c|}{ Podridões de colmo } \\
\hline & $\begin{array}{l}\text { Fusarium } \\
\text { spp. }\end{array}$ & Fusarium spp. & $\begin{array}{c}\text { Pylhium } \\
\text { aphanidermatum }\end{array}$ & $\begin{array}{l}\text { Macrophomina } \\
\text { phaseolina }\end{array}$ \\
\hline & \multicolumn{4}{|c|}{ 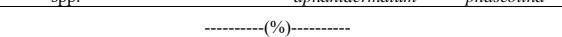 } \\
\hline $0(\mathrm{TN})$ & $4,67 \mathrm{c}$ & $5,67 \mathrm{e}$ & $2,00 \mathrm{~b}$ & $3,33 \mathrm{~cd}$ \\
\hline 100 & $3,33 \mathrm{bc}$ & $4,00 \mathrm{~d}$ & $1,33 \mathrm{ab}$ & $2,67 \mathrm{c}$ \\
\hline 300 & $2,98 \mathrm{~b}$ & $3,33 \mathrm{c}$ & $0,67 \mathrm{a}$ & $1,33 \mathrm{~b}$ \\
\hline 900 & $0,00 \mathrm{a}$ & $1,33 \mathrm{a}$ & $0,00 \mathrm{a}$ & $0,00 \mathrm{a}$ \\
\hline 2700 & $1,27 \mathrm{a}$ & $2,00 \mathrm{~b}$ & $0,00 \mathrm{a}$ & $1,33 \mathrm{~b}$ \\
\hline $4 \mathrm{~g}$ de $\mathrm{Cu}(\mathrm{TP})$ & $1,27 \mathrm{ab}$ & $4,67 \mathrm{de}$ & $0,67 \mathrm{a}$ & $4,00 \mathrm{~d}$ \\
\hline
\end{tabular}

Médias seguidas de mesma letra não diferem significativamente entre si pelo teste de Tukey $(\mathrm{P} \leq 0,05)$. Fonte: Autores, 2019.

Diversas são as formas de atuação das nanopartículas frente aos microrganismos. As nanopartículas metálicas podem interferir nos sistemas de transporte e ocasionar o acúmulo dos íons metálicos no interior das células, impedindo o metabolismo celular (SHRIVASTAVA et al., 2007), incluindo a inativação da função ribossomal e da produção de ATP, danos a estrutura do DNA e desnaturação de proteínas (SURYAWANSHI et al., 2018). Outra forma de ação dos íons metálicos é através da reação com o oxigênio produzindo espécies reativas de oxigênio capazes de danificar o material genético e a estrutura das células (SURYAWANSHI et al., 2018).

$\mathrm{O}$ aumento da resistência a fungicidas específicos, além do interesse na redução da utilização de agroquímicos de alta toxicidade, impele a busca por novos agentes capazes de controlar efetivamente estes microrganismos. Os resultados obtidos colaboram com a possibilidade de utilização de nanopartículas metálicas como uma alternativa no controle de fungos patogênicos com potencial para produção de micotoxinas, como o Fusarium spp.

$\mathrm{Na}$ indústria existem várias formas de minimizar a contaminação por micotoxinas, envolvendo métodos químicos, físicos e biológicos, porém ainda em desenvolvimento ou de baixa viabilidade econômica, fato que nos faz evidenciar a relevância tanto dos híbridos que se apresentaram mais resistentes, quanto ao tratamento de 
sementes utilizando nanopartículas de cobre, para minimizar a incidência de fungos do gênero Fusarium spp.. Ao minimizar a ocorrência destes fungos podemos obter grãos de melhor qualidade, além de reduzir a predisposição da cultura do milho à contaminação por fumonisinas, como estratégia para evitar danos à saúde dos seres humanos e dos animais.

Para a avaliação de incidência das doenças de folhas do milho, conforme Sabato e Fernandes (2014) foram observadas: ferrugem comum (Puccinia sorghi), classificada como: suscetível (S); moderadamente suscetível (MS); tolerante $(\mathrm{T})$ e moderadamente resistente (MR) e Helmintosporiose (Exserohilum turcicum) e Mancha-branca (Pantoea ananatis), as quais foram classificadas como moderadamente resistente (MR).

A análise de variância revelou efeito significativo $(\mathrm{P} \leq 0,05)$ do fator híbridos em relação às variáveis respostas ferrugem comum (Puccinia sorghi), Helmintosporiose (Exserohilum turcicum) e Mancha-branca (Pantoea ananatis) (Tabela 6).

Tabela 6 - Ferrugem comum (Puccinia sorghi), Helmintosporiose (Exserohilum turcicum) e Mancha-branca (Pantoea ananatis) do experimento em relação ao fator híbridos (São José do Cedro, SC safra 2018/2019).

\begin{tabular}{|c|c|c|c|}
\hline \multirow[t]{2}{*}{ Híbridos de milho } & Puccinia sorghi & $\begin{array}{c}\text { Exserohilum } \\
\text { turcicum }\end{array}$ & Pantoea ananatis \\
\hline & -----------(\%)---------' & 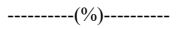 & ----------(\%)--------- \\
\hline HB 05: 20A20 TOP $2^{\circledR}$ & $47,78 \mathrm{a}$ & $9,44 \mathrm{ab}$ & $5,55 \mathrm{a}$ \\
\hline HB 03: 20A80 TOP2 ${ }^{\circledR}$ & $53,33 \mathrm{~b}$ & $6,67 \mathrm{a}$ & $10,00 \mathrm{bc}$ \\
\hline HB 02: 20A30 VIPTERA3 ${ }^{\circledR}$ & $61,67 \mathrm{~b}$ & $7,22 \mathrm{ab}$ & $10,56 \mathrm{a}$ \\
\hline HB 04: 22S18 TOP3 ${ }^{\circledast}$ & $53,88 \mathrm{ab}$ & $8,33 \mathrm{ab}$ & $9,44 \mathrm{~b}$ \\
\hline HB 01: $22 \mathrm{~S} 18 \mathrm{TOP}^{\circledR}$ & $51,67 \mathrm{~b}$ & $11,67 \mathrm{c}$ & $8,89 \mathrm{~b}$ \\
\hline
\end{tabular}

Médias seguidas de mesma letra não diferem significativamente entre si pelo teste de Tukey $(\mathrm{P} \leq 0,05)$. Fonte: Autores, 2019.

A análise de variância revelou efeito significativo $(\mathrm{P} \leq 0,05)$ do fator estádios de desenvolvimento em relação às variáveis respostas ferrugem comum (Puccinia sorghi), Helmintosporiose (Exserohilum turcicum) e Mancha-branca (Pantoea ananatis) (Tabela 7).

Tabela 7 - Ferrugem comum (Puccinia sorghi), Helmintosporiose (Exserohilum turcicum) e Mancha-branca (Pantoea ananatis) do experimento em relação ao fator estádios de desenvolvimento (São José do Cedro, SC - safra 2018/2019).

\begin{tabular}{cccc}
\hline \multirow{2}{*}{ Estádios de desenvolvimento } & Puccinia sorghi & Exserohilum turcicum & Pantoea ananatis \\
\cline { 2 - 4 } & $-------(\%)--------$ & $------(\%)-------$ & $------(\%)-------$ \\
\hline V8 & $68,89 \mathrm{~b}$ & $0,00 \mathrm{a}$ & $0,00 \mathrm{a}$ \\
VT & $93,33 \mathrm{c}$ & $3,33 \mathrm{a}$ & $11,11 \mathrm{~b}$ \\
R2 & $100,00 \mathrm{~d}$ & $13,33 \mathrm{~b}$ & $10,00 \mathrm{~b}$ \\
R4 & $2,22 \mathrm{a}$ & $11,11 \mathrm{~b}$ & $10,00 \mathrm{~b}$ \\
R6 & $0,00 \mathrm{a}$ & $15,56 \mathrm{~b}$ & $13,33 \mathrm{~b}$ \\
\hline
\end{tabular}

Médias seguidas de mesma letra não diferem significativamente entre si pelo teste de Tukey $(\mathrm{P} \leq 0,05)$. Fonte: Autores, 2019.

A análise de variância revelou efeito significativo $(\mathrm{P} \leq 0,05)$ do fator híbridos em relação às variáveis respostas rendimento e peso hectolítrico (Tabela 8).
Tabela 8 - Rendimento e peso hectolítrico do experimento em relação ao fator híbridos (São José do Cedro, SC - safra 2018/2019).

\begin{tabular}{|c|c|c|}
\hline \multirow{2}{*}{ Híbridos de milho } & Rendimento & Peso hectolítrico \\
\hline & 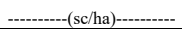 & 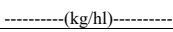 \\
\hline HB 03: 20A80 TOP2 ${ }^{\circledR}$ & $144,93 \mathrm{~d}$ & $78,63 \mathrm{~b}$ \\
\hline HB 01: $22 \mathrm{~S} 18$ TOP2 $^{\circledR}$ & $149,22 \mathrm{c}$ & $80,70 \mathrm{a}$ \\
\hline HB 04: 22S18 TOP3 ${ }^{\circledast}$ & $157,33 \mathrm{~b}$ & 81,02 a \\
\hline HB 02: 20A30 VIPTERA $3^{\mathbb{E}}$ & 159,76 a & $81,29 \mathrm{a}$ \\
\hline HB 05: 20A20 TOP2 ${ }^{\varpi}$ & $160,59 \mathrm{a}$ & $82,25 \mathrm{a}$ \\
\hline
\end{tabular}

Médias seguidas de mesma letra não diferem significativamente entre si pelo teste de Tukey $(\mathrm{P} \leq 0,05)$.

Fonte: Autores, 2019.

A análise de variância revelou efeito significativo $(\mathrm{P} \leq 0,05)$ do fator doses de nanopartículas de $\mathrm{Cu}$ em relação às variáveis respostas rendimento e peso hectolítrico (Tabela 9).

O ano agrícola de 2018/19 apresentou uma distribuição pluviométrica elevada em São José do Cedro na região Extremo Oeste Catarinense, principalmente durante o período reprodutivo da cultura (Figura 1). Nesse sentido, foi registrada nos meses de janeiro, fevereiro, março e abril uma precipitação total de $543,24 \mathrm{~mm}$. As precipitações elevadas no verão favoreceram o desenvolvimento de fungos fitopatogênicos.

Tabela 9 - Rendimento e peso hectolítrico com testemunha positiva (4,00 g de $\mathrm{Cu} / \mathrm{kg}$ de semente) experimento em relação ao fator doses de nanopartículas de $\mathrm{Cu}$ (São José do Cedro, SC - safra 2018/2019).

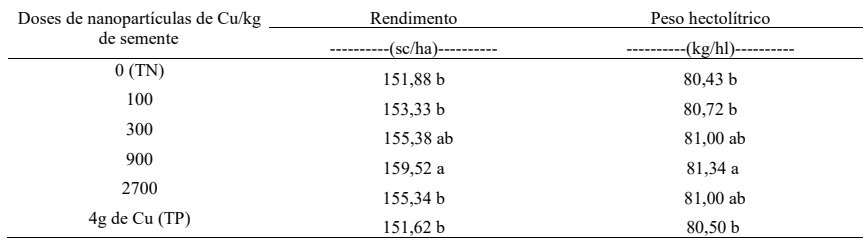

Médias seguidas de mesma letra não diferem significativamente entre si pelo teste de Tukey $(\mathrm{P} \leq 0,05)$. Fonte: Autores, 2019.

A incidência de doenças de raízes, colmos e folhas foram significativamente alteradas pelos efeitos simples dos híbridos (Tabelas 3 e 6), estádios de desenvolvimento (Tabelas 4 e 7) e doses de nanopartículas de $\mathrm{Cu} / \mathrm{kg}$ de semente (Tabelas 5 e 8), influenciando diretamente no NDVI e temperatura do dossel (Tabelas 1 e 2) e rendimento e peso hectolítrico, com destaque para os híbridos 20A30 VIPTERA3 ${ }^{\circledR}($ HB 02) e 20A20 TOP2 $₫($ HB 05) (Tabela 8) na dose de $900 \mathrm{mg}$ de nanopartículas/kg de semente (Tabela 9).

Após a floração, o fluxo de fotoassimilados dentro da planta de milho é direcionado prioritariamente ao enchimento de grãos. Quando a planta não produz fotoassimilados em quantidade suficiente para a manutenção dos tecidos, a maior demanda exercida pelos grãos por esses produtos leva os tecidos da raiz e base do colmo a senescerem precocemente, fragilizando essas regiões e tornando-as mais suscetíveis a doenças de colmo (FLOSS, 2011). Um fator importante que afeta este balanço nutricional entre os diferentes órgãos da planta de milho é o híbrido. Em um determinado ambiente, a manifestação fenotípica é o resultado da ação do genótipo sob influência do meio. Essa interação quantifica o comportamento diferenciado dos genótipos (híbridos de milho) diante das variações ambientais (GxA). Assim, a adaptabilidade 
genotípica se refere à capacidade dos genótipos (híbridos de milho) em aproveitarem vantajosamente o estímulo do ambiente, neste caso, o respectivo estímulo está relacionado com a aplicação de nanopartículas de $\mathrm{Cu}$ via $\mathrm{TS}$.

Nas Tabelas 5 e 8, doses inferiores a $900 \mathrm{mg}$ de nanopartículas de $\mathrm{Cu} / \mathrm{kg}$ de semente, provavelmente, proporcionam maiores estresses fisiológicos, como pode ser verificado na variável temperatura do dossel (indicativo de estresse) (Tabela 2), aumentando desta forma a competição por água, luz e nutrientes, reduzindo a disponibilidade de fotoassimilados para atender a demanda para enchimento do grão e manutenção das demais estruturas da planta (FLOSS, 2013), o que ocasiona alteração no transporte de elétrons da fotossíntese e fotoinibição (CAMBROLLÉ et al., 2015).

Doses maiores que $900 \mathrm{mg}$ de nanopartículas de $\mathrm{Cu} / \mathrm{kg}$ de semente, possivelmente, indicam efeito tóxico o qual está associado a danos gerados nas células vegetais devido a excesso de $\mathrm{Cu}$. Isso favorece o desenvolvimento de doenças de raízes, colmo e folhas conforme observado na presente pesquisa, visto que, nestas condições há evidências científicas que o ocorre o aumento na síntese de proteínas e enzimas envolvidas na defesa aos danos oxidativos (CAMBROLLÉ et al., 2015). Tais resultados são confirmados por Bochicchio et al. (2015), os quais citam que o estresse por $\mathrm{Cu}$ pode danificar a estrutura das raízes, o que pode reduzir a absorção de água e nutrientes minerais do solo e, assim, diminuir o crescimento das plantas. $\mathrm{Na}$ presente pesquisa, percebe-se que a dose recomenda ( $4 \mathrm{~g}$ de $\mathrm{Cu} / \mathrm{kg}$ de semente), também proporciona efeito tóxico, divergindo dos resultados encontrados por Luchese et al., (2004).

A capacidade fotossintética de cada híbrido pode influenciar de forma marcante no fracionamento dos produtos oriundos da fotossíntese durante o período de enchimento de grãos (FLOSS, 2013). Nesse sentido, os híbridos testados no presente trabalho, demonstram ser mais eficientes em termos fotossintéticos, o que também podem explicar suas menores suscetibilidades às doenças de raízes, colmo e folhas (Tabelas 3 e 6) ao longo dos diferentes estádios de desenvolvimento (Tabelas 4 e 7).

\section{CONCLUSÃO}

A incidência de doenças de raízes, colmos e folhas é significativamente alterada pelos efeitos simples dos híbridos, estádios de desenvolvimento e doses de nanopartículas de $\mathrm{Cu} / \mathrm{kg}$ de semente, influenciando diretamente no NDVI, temperatura do dossel, rendimento e peso hectolítrico, com destaque para os híbridos 20A30 VIPTERA3 $₫($ HB 02) e 20A20 TOP2 $₫($ HB 05) na dose de $900 \mathrm{mg}$ de nanopartículas/kg de semente.

\section{REFERÊNCIAS BIBLIOGRÁFICAS}

AGRITEMPO - Sistema de Monitoramento Agrometeorológico, 2019.

BENTO, F. L. et al. Ocorrência de fungos e aflatoxinas em grãos de milho. Revista do Instituto Adolfo Lutz, v. 71, n. 1, p. 44-49, 2012.

BOCHICCHIO R. et al. Root architecture and morphometric analysis of Arabidopsis thaliana grown in $\mathrm{Cd} / \mathrm{Cu} / \mathrm{Zn}$-gradient agar dishes: A new screening technique for studying plant response to metals. Plant Physiology and Biochemistry, v. 91, p. 20-27, jun. 2015.

CAMBROLLÉ, J. et al. Evaluating wild grapevine tolerance to copper toxicity. Chemosphere, v. 120, p. 171178 , feb. 2015.

CAVALCANTE, N. B. Atividade antibacteriana e antifúngica de nanopartículas de prata produzidas por Curvularia inaequalis (Shear) Boedijn. 2014. $79 \mathrm{f}$. Dissertação (Mestrado) - Curso de (mestrado em Recursos Naturais do Semiárido, Universidade Federal do Vale do São Francisco - Univasf, Petrolina, 2014.

CONAB - Companhia Nacional de Abastecimento. Perspectivas para a agropecuária/Companhia Nacional de Abastecimento, v.1 - Brasília: Conab, 2018.

CQFS - Comissão de Química e Fertilidade do Solo. Manual de calagem e adubação para os Estados de Rio Grande do Sul e de Santa Catarina. Viçosa, Sociedade Brasileira de Ciência do Solo, 2016.

CRUSIOL, L. G. T. et al. Comportamento espectral de diferentes genótipos de soja (GM para tolerância a seca e convencionais), em condição irrigada e sob estresse hídrico. In: VI Congresso brasileiro de soja. Cuiabá, 2012. Resumos... Brasília: Embrapa, 2012.

EMBRAPA - Empresa Brasileira de Pesquisa Agropecuária. Sistema Brasileiro de Classificação de Solos. 5. ed., rev. e ampl. - Brasília, DF: Embrapa, 2018.

FLOSS, E. L. Fisiologia das plantas cultivadas: o estudo do que está por trás do que se vê. Passo Fundo: Editora Universitária, 2011.

GAO, X. et al. Inactivation of the Lipoxygenase ZmLOX3 Increases Susceptibility of Maize to Aspergillus spp. Molecular plant-microbe interactions, v. 22, n. 2, p. 222231, 2009.

GARCIA, M. R. Caracterização espectro-temporal de cultivares de trigo por meio do índice de vegetação por diferença normalizada-NDVI de sensores terrestres. 2015.

JANDREY, D. B. Manejo de milho para altos rendimentos. Informativo PIONEER, 38. ed., p. 14, 2014.

KIM, S. W. et al. Antifungal Effects of Silver Nanoparticles (AgNPs) against Various Plant Pathogenic Fungi. Mycobiology, v. 40, n. 1, p. 53-58, 2012.

LUCHESE, A. V. Emergência e absorção de cobre por plantas de milho (Zea mays) em resposta ao tratamento de sementes com cobre. Ciência Rural, v. 34, n. 6, p. 1949 1952, 2004

MAPA - Ministério da Agricultura, Pecuária e Abastecimento. Regras para Análise de Sementes, p. 31, 2009.

PESKE, S. T. et al. Sementes: Fundamentos Científicos e Tecnológicos. 3. ed., Pelotas: Ed. Universitária/UFPel, p. 457, 2012.

RAMOS, A. T. M. Levantamento da micoflora presente em grãos ardidos e sementes de milho. Summa Phytopathologica, v. 36, n. 3, p. 257-259, 2010. 
SABATO, E. O.; FERNANDES, F. T. Doenças do Milho, 2014.

SEMPRE SEMENTES. Híbridos de milho, 2019.

SHRIVASTAVA, S. Characterization of enhanced antibacterial effects of novel silver nanoparticles. Nanotechnology, v. 18, p. 1-9, 2007.

STEFANELLO, J. Incidência de fungos em grãos de milho em função de diferentes épocas de aplicação foliar de fungicida. Pesquisa Agropecuária Tropical, v. 42, p. 476-481, 2012.

SURYAWANSHI, A. D. Silver nanoparticles as a new generation of antimicrobials - a review. International Research Journal of Science and Engineering, p. 202206, 2018.

TAIZ, L. et al. Fisiologia e Desenvolvimento Vegetal. Artmed, 6. ed. Porto Alegre - RS, 2017.

\section{COPYRIGHT}

Direitos autorais: $\mathrm{O}(\mathrm{s})$ autor(es) é(são) o(s) único(s) responsável(is) pelo material incluído no artigo. 


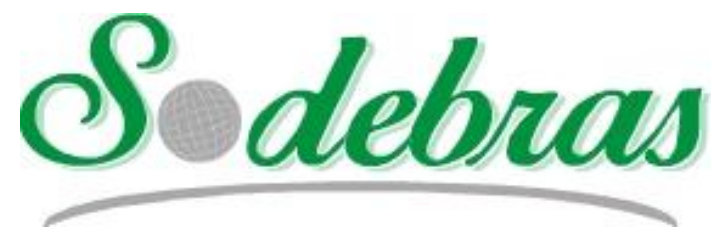

Volume 15 - $\mathrm{N}^{\mathrm{o}} 169$ - Janeiro / 2020

XLI International Sodebras Congress

31 de outubro a 02 de novembro de 2019 - Maceió - AL.

\title{
QUALIDADE DE SEMENTES DE MILHO APÓS TRATAMENTO COM NUTRIENTES À BASE DE ZINCO E ARMAZENAMENTO
}

\section{QUALITY OF CORN SEED AFTER TREATMENT WITH ZINC NUTRIENTS AND STORAGE}

\author{
GEAN LOPES DA LUZ'; CRISTIANO RESCHKE LAJÚS ${ }^{1}$; ANA CRISTINA LOPES²; ADRIANA CIOATO \\ FERRAZZA $^{1}$ \\ 1 - PROGRAMA DE PÓS-GRADUAÇÃO EM TECNOLOGIA E GESTÃO DA INOVAÇÃO, \\ UNOCHAPECÓ - CHAPECÓ/SC - BRASIL; 2 - GRADUAÇÃO EM AGRONOMIA, UNOCHAPECÓ - \\ CHAPECÓ/SC - BRASIL \\ geanluz@unochapeco.edu.br; clajus@unochapeco.edu.br; ana_cristina@unochapeco.edu.br; \\ adriferrazza@unochapeco.edu.br
}

\begin{abstract}
Resumo - O presente trabalho objetivou avaliar o efeito do tratamento de sementes de milho com nutrientes à base de zinco em relação à germinação $e$ ao vigor. $O$ delineamento experimental utilizado foi o DIC com tratamentos constituídos por três níveis do fator tratamento de sementes $(\mathrm{ZnO}(9,83 \mathrm{mg} / \mathrm{l})$; NanoZnO $(6,96 \mathrm{mg} / \mathrm{l})$ e sem zinco = água pura $)$, que foram avaliados em três níveis do fator tempo de tratamento (30; $180 \mathrm{e}$ 330 minutos) e três níveis do fator tempo de armazenamento $(0$ dias; 90 dias; 180 dias). Dos itens avaliados, a hidratação é o fator que apresenta maior efeito prejudicial sobre a germinação e vigor das sementes, pois houve redução da qualidade das sementes que passaram pelo processo de hidratação tanto quando do processo de tratamento das sementes com nutrientes quanto quando da aplicação da água pura.
\end{abstract}

Palavras-chave: Micronutrientes. Zea mays. Hidratação.

\begin{abstract}
The present work aimed to evaluate the effect of corn seed treatment with zinc-based nutrients in relation to germination and vigor. The experimental design used was the IHD with treatments consisting of three levels of the seed treatment factor $(\mathrm{ZnO}(9.83 \mathrm{mg} / \mathrm{l}) ; \mathrm{NanoZnO}(6.96 \mathrm{mg} / \mathrm{l})$ and without zinc $=$ pure water), which were evaluated in two groups. three levels of treatment time factor $(30 ; 180$ and 330 minutes) and three levels of storage time factor (0 days; 90 days; 180 days). Of the evaluated items, hydration is the factor that has the most detrimental effect on seed germination and vigor, as there was a reduction in seed quality that went through the hydration process both during the seed treatment process and when the seed application was applied. pure water.
\end{abstract}

Keywords: Micronutrients. Zea mays. Hydration.

\section{INTRODUÇÃO}

Os micronutrientes são utilizados pelas plantas em baixas concentrações, entretanto, mesmo nessas baixas concentrações, os mesmos são fundamentais para o crescimento e o desenvolvimento das plantas, podendo trazer também efeitos no armazenamento de sementes e consequentemente afetar a produtividade das culturas. Dentre os micronutrientes, o zinco é um elemento essencial para as culturas assim desempenhando papel de ativador enzimático, sendo requerido para a síntese do aminoácido triptofano, um precursor da biossíntese do AIA (ácido indolaético). Ou seja, participa de diversos ciclos bioquímicos das plantas como, defesa de patógenos, fertilidade de sementes, crescimento e fotossíntese, e em função disso, pode levar à queda ou não, da produção de grãos (KIRKBY; ROMHELD, 2007).

O solo é a principal fonte de Zinco para as plantas, porém, dentre os micronutrientes, o Zinco é o que mais frequentemente se mostra deficiente em solos brasileiros (FUNGUETTO et al., 2012). Sua disponibilidade é influenciada principalmente pelo $\mathrm{pH}$, teor de matéria orgânica, óxidos de $\mathrm{Fe}, \mathrm{Al}$ e $\mathrm{Mn}$, CTC, teor de fósforo e mineralogia das argilas também influenciam a dinâmica do Zn no solo (LÉLES et al., 2010).

A aplicação de zinco nas sementes tem a vantagem de ser um método eficaz, pois assegura a disponibilidade e absorção do nutriente nas fases iniciais de crescimento da cultura, uma vez que a plântula não absorve grandes quantidades desse elemento do solo. O tratamento de sementes permite, ainda, melhor uniformidade de distribuição do nutriente sobre as sementes, redução de perdas, menor custo de aplicação, assim nutrientes como o Zinco (Zn), que é encontrado em pequena quantidade nos solos brasileiros e tem baixa mobilidade no solo e planta, pode ser incorporado via tratamento de sementes por nanopartículas, de tal maneira a auxiliar e otimizar os resultados (TUNES et al., 2012).

A possibilidade de armazenamento das sementes tratadas com zinco abre novas perspectivas, tendo em vista a oportunidade das empresas produtoras de sementes de disponibilizarem, no mercado, sementes enriquecidas com este micronutriente, com garantia de qualidade e com o benefício de eliminar possíveis erros na condução da lavoura, pela aplicação de doses e fontes inadequadas desse micronutriente (TUNES et al., 2012).

Cabe lembrar, que o processo de deterioração é inevitável mas pode ser retardado dependendo das condições de armazenamento e das características da semente (CARDOSO, et al., 2012). Torna-se assim importante avaliar o potencial fisiológico da semente, para identificar os lotes que possuem maior probabilidade de 
apresentar o desempenho desejado em campo e/ou durante o armazenamento (MARCOS FILHO, 2015).

Sendo assim, o presente trabalho objetivou avaliar o efeito de diferentes períodos de armazenamento sobre a germinação e vigor de sementes de milho submetidas ao tratamento com nutrientes à base de zinco.

\section{METODOLOGIA}

A presente pesquisa foi desenvolvida no Laboratório de Sementes da Universidade Comunitária da Região de Chapecó - UNOCHAPECÓ, dentre o período de Maio à Novembro de 2016. Foi adotado o Delineamento Inteiramente Casualizado (DIC).

Os tratamentos empregados foram constituídos, conforme a figura 1 , por três níveis do fator tratamento de sementes ( $\mathrm{ZnO}(9,83 \mathrm{mg} / \mathrm{l})$; NanoZnO $(6,96 \mathrm{mg} / \mathrm{l})$ e sem zinco $=$ água pura), que foram avaliados em três níveis do fator tempo de tratamento $(30 ; 180$ e 330 minutos) e três níveis do fator tempo de armazenamento (0 dias; 90 dias; 180 dias). Também foi utilizado um tratamento testemunha, sem zinco e sem exposição à água, $\mathrm{O}$ qual também foi avaliado nos três níveis do fator tempo de tratamento, dessa forma, totalizando 30 tratamentos, os quais foram replicados em 4 repetições, totalizando 40 parcelas por período de armazenamento e 120 parcelas no experimento todo.

$\mathrm{O}$ tratamento das sementes foi realizado em reatores de vidro contendo soluções aquosas ultrapuras e em condições controladas de $\mathrm{pH}$, de temperatura e de velocidade de agitação em três tempos de tratamento, 30, 180, e 330 minutos. Após, foram colocadas em estufa de ventilação forçada a $25^{\circ} \mathrm{C}$ por 48 horas.

As sementes foram armazenadas por três períodos de armazenamento (0 dias; 90 dias; 180 dias) no período de maio a novembro de 2016 em câmara seca $\left(20{ }^{\circ} \mathrm{C}\right.$, e umidade relativa de $40 \%$ )

A cultura empregada no experimento foi o Milho (Zea mays L.) SCS 155 Catarina.

Determinação de Umidade: determinou-se o teor de água das sementes pertencentes a cada tratamento, pelo método da estufa a $105 \pm 3^{\circ} \mathrm{C}$, por 24 horas (BRASIL, 2009).

Teste de Germinação: as sementes tratadas com concentrações de $\mathrm{ZnO}$, NanoZnO, testemunha hidratada em água pura, em diferentes tempos, sendo avaliadas quanto ao seu desempenho de germinação após cada período de armazenamento. Os procedimentos de germinação foram realizados com 02 rolos de papel germitest com 50 sementes cada, totalizando 100 sementes por repetição, executados com quatro repetições cada, assim totalizando 400 sementes para cada tratamento. Os rolos foram amarrados com atílio de borracha e colocados de pé no interior do germinador de maneira que as radículas ficassem apontando para baixo, de acordo com os procedimentos padrões. A contagem das sementes germinadas foi desenvolvida aos sete dias após a semeadura, contabilizando a porcentagem de plântulas normais, anormais e sementes mortas (BRASIL, 2009).

Teste de Vigor - Índice de Velocidade de Germinação (IVG): Empregou-se três folhas de papel germitest umedecidos com 2,5 vezes o peso do papel seco. Em cada repetição, foram depositadas 20 sementes, com 4 repetições, totalizando 80 sementes por tratamento, sendo as mesmas semeadas sobre a linha traçada no terço superior do papel substrato, pré umedecido, no sentido longitudinal.
Os rolos foram preparados normalmente como no teste de germinação, porém fechados com saco plástico, visando manter constante a umidade dos rolos.

$\mathrm{Na}$ condução dos testes de IVG o germinador utilizado foi uma câmara vertical do tipo B.O.D. (Biochemical Oxigen Demand) contendo 2 prateleiras removíveis de arame, controle de temperatura e circulador de ar regulado a $25^{\circ} \mathrm{C}$ e ausência de luz. Após a semeadura, as sementes germinadas foram contadas diariamente conforme o padrão estabelecido de $2 \mathrm{~cm}$. Foi avaliado o seguinte parâmetro: vigor das plântulas pela velocidade de germinação.

Para redução de interferência de luz e manuseio constante das sementes no teste de germinação, o Índice de Velocidade de Germinação foi conduzido separadamente do teste de germinação (SANTOS et al, 2010).

Os dados coletados foram submetidos à análise de variância pelo teste $\mathrm{F}$ e as diferenças entre as médias foram comparadas pelo teste de Tukey $(\mathrm{P} \leq 0,05)$ para os fatores tratamento de sementes, tempo de hidratação e tempo de armazenamento

\section{RESULTADOS}

Quanto maior o período de exposição à água nos processos de tratamento das sementes, maior a umidade das sementes após o processo (Tabela 1) em uma escala que pode chegar ao dobro da umidade da testemunha nos períodos de tratamento de 330 minutos. A presença de umidade é um dos fatores principais na causa da deterioração da semente no armazenamento (PESKE et al, 2012).

Tabela 1 - Umidade (\%) das sementes de milho após os tratamentos realizados (0 dias). Chapecó (SC), 2016.

\begin{tabular}{lc}
\hline Tratamentos & Umidade (após tratamento) \\
\hline ZINCO & 23,16 \\
30 minutos & 26,84 \\
180 minutos & 28,08 \\
330 minutos & 21,22 \\
\hline NANOZINCO & 21,57 \\
30 minutos & 28,57 \\
180 minutos & \\
330 minutos & 20,75 \\
\hline TESTEMUNHA EM ÁGUA & 25,03 \\
30 minutos & 26,53 \\
180 minutos & 14,13 \\
330 minutos & 21971 . \\
\hline TESTEMUNHA &
\end{tabular}

Médias seguidas de mesma letra não diferem significativamente entre si pelo teste de Tukey $(\mathrm{P} \leq 0,05)$. Fonte: Autores, 2019.

A Análise da Variância demonstrou efeito significativo dos fatores tratamentos de semente, tempos de hidratação e tempos de armazenamento sobre a germinação das sementes Tabela 02. Também foi significativa a interação entre os tratamentos de semente e os tempos de armazenamento, sendo esta interação decomposta na Tabela 04 . 
Tabela 2 - Análise da variância da germinação de sementes de milho submetidas à diferentes tempos de armazenamento, tratamentos de semente e tempos de hidratação. Chapecó (SC), 2016.

\begin{tabular}{lcrrr}
\hline \multicolumn{1}{c}{ FV } & GL & \multicolumn{1}{c}{ SQ } & \multicolumn{1}{c}{ QM } & \multicolumn{1}{c}{ FcPr>Fc } \\
\hline ARMAZENAMENTO & 2 & 427.116 .667 & 213.558 .333 & 24.2750 .0000 \\
TRATAMENTO & 3 & 191.241 .667 & 63.747 .222 & 7.2460 .0002 \\
TEMPO HIDRATAÇ̃̃O & 3 & 314.019 .444 & 104.673 .148 & 11.8980 .0000 \\
THIDRAT*ARMAZE & 6 & 104.272 .222 & 17.378 .704 & 1.9750 .0763 \\
TRATA*ARMAZE & 6 & 132.383 .333 & 22.063 .889 & 2.5080 .0266 \\
Erro & 99 & 870.958 .333 & 8.797 .559 & \\
Total corrigido & 119 & 2.039 .991 .667 & & \\
\hline Média geral & 55.333 .333 & \multicolumn{4}{c}{ Número de observações } \\
\hline
\end{tabular}

Fonte: Autores, 2019.

De modo geral, observa-se na Tabela 03 que a hidratação das sementes a partir de 180 minutos prejudicou a germinação das sementes. $\mathrm{O}$ tratamento com 330 minutos de hidratação apresentou significativa redução da germinação quando comparado aos demais tratamentos e o tratamento com 30 minutos de hidratação não diferenciou significativamente da testemunha sem hidratação, demonstrando ser possível hidratar as sementes de milho por até 30 minutos sem redução significativa da qualidade da semente. Estes resultados estão atrelados à umidade da semente apresentada na Tabela 01, a qual destacou que a umidade se elevou quando da exposição das sementes à água de forma direta aos tempos de exposição, o que pode ter prejudicado a qualidade fisiológica das sementes que estiveram expostas por períodos maiores.

Este fato já havia sido observado também por Gomes et al. (2012), trabalhando com lotes de sementes de soja, relatando ser a alta umidade um dos principais fatores que contribuem para redução da qualidade de sementes de soja.

Tabela 3 - Germinação de sementes de milho (\%) submetidas a diferentes tempos de hidratação. Chapecó (SC), 2016.

\begin{tabular}{lcc}
\hline \multicolumn{1}{c}{ Tratamentos } & Médias & Resultados do teste \\
\hline 0 & 95.750000 & $\mathrm{c}$ \\
30 & 93.916667 & $\mathrm{bc}$ \\
180 & 92.972222 & $\mathrm{~b}$ \\
330 & 90.666667 & $\mathrm{a}$ \\
\hline
\end{tabular}

Médias seguidas de mesma letra não diferem significativamente entre si pelo teste de Tukey $(\mathrm{P} \leq 0,05)$. Fonte: Autores, 2019.

Os resultados apresentados na Tabela 04 demonstram que quando se há a pretensão da semeadura imediatamente após o tratamento das sementes, esses tratamentos proporcionam germinação das sementes de milho iguais ao da testemunha, ou seja, não prejudicam a germinação da semente imediatamente após os tratamentos.

Tabela 4 - Germinação de sementes de milho (\%), submetidas a diferentes tratamentos de sementes e tempos de armazenamento. Chapecó (SC), 2016.

\begin{tabular}{lllll}
\hline \multicolumn{5}{c}{ Tempo de armazenamento } \\
\hline Tratamentos & \multicolumn{1}{c}{$\mathbf{9 0}$} & $\mathbf{1 8 0}$ & Média* \\
\hline ZINCO & $94,75 \mathrm{Aa}$ & $89,08 \mathrm{bB}$ & $92,08 \mathrm{abA}$ & 09,97 \\
NANOZINCO & $96,00 \mathrm{aA}$ & $89,16 \mathrm{bB}$ & $90,41 \mathrm{bB}$ & 91,85 \\
ÁGUA PURA & $95,00 \mathrm{aA}$ & $92,33 \mathrm{bA}$ & $93,83 \mathrm{abA}$ & 93,72 \\
TESTEMUNHA & $96,25 \mathrm{aA}$ & $96,25 \mathrm{aA}$ & $94,75 \mathrm{aA}$ & 95,75 \\
\hline Média & 95,50 & 91,70 & 92,76 & \\
\hline
\end{tabular}

Médias seguidas de mesma letra não diferem significativamente entre si pelo teste de Tukey $(\mathrm{P} \leq 0,05)$.

Fonte: Autores, 2019.
Destaca-se (Tabela 4) que, quando expostas à água, as sementes reduzem sua germinação após armazenadas, visto as médias reduzidas aos 90 e 180 dias de armazenamento nos tratamentos com água, zinco e nanozinco, todos hidratados, em comparação à testemunha.

De maneira semelhante, Santos et al. (2008) observaram que plântulas prove $\neg$ nientes de sementes de sorgo tratadas com $\mathrm{Zn}$ e Co apresentaram maior germinação.

Ohse et al. (2012) também verificaram incremento na germinação de sementes de melancia tratadas com $0,95 \mathrm{~g} / \mathrm{kg}$ de $\mathrm{Zn}$ em sementes.

Ao comparar os tratamentos com zinco e nanozinco com o tratamento com água pura tem-se a resposta de diferença não significativa em relação ao potencial germinativo (Tabela 4), demonstrando que o efeito de depleção da germinação possivelmente ocorreu por conta da hidratação das mesmas e não pelo nutriente aplicado.

Alencar et al. (2008), trabalhando com armazenando de grãos de soja em diferentes teores de água $(11,2 ; 12,8$ e $14,8 \%$ b.u.) verificaram, que os melhores resultados foram obtidos nos menores teores de água, e que assim, sementes que apresentam os teores iniciais de água menores apresentam melhor qualidade fisiológica.

Autores como Smaniotto et al., (2014) observaram em sementes de soja, que o menor teor de água inicial, 12\% (b.u.), mantém as sementes com maior qualidade sendo recomendado para conservação do vigor das sementes de soja.

Para o armazenamento em 90 dias, temos que a testemunha não hidratada se destaca com maior germinação, e no armazenamento por 180 dias, o nanozinco apresentou a menor média, porém não diferindo do zinco e da hidratação em agua pura, isso demonstra mais uma vez que a hidratação prejudicou a germinação, uma vez que, a umidade das sementes elevou-se com a exposição à água, conforme demonstra a (Tabela 1).

Smaniotto et al., (2014), afirmam que na condução do seu trabalho com soja, houve decréscimo durante o armazenamento para todos os teores de água iniciais, e este foi mais acentuado quando passou da umidade de $11 \%$ para o teor de água maior de $14 \%$. Esta maior perda de vigor comparada às demais se deve à combinação da temperatura $\left(27^{\circ} \mathrm{C}\right)$ e ao maior teor de água ( $14 \%$ b.u.). Para o teor de água inicial de 13\% (b.u.) houve uma redução no decorrer do armazenamento chegando aos 180 dias com 94,16\% de germinação; já para o teor de água inicial de $14 \%$ (b.u.) verificou-se uma redução maior da germinação no decorrer do armazenamento com o valor de 77,3\% no final dos 180 dias de armazenamento. As sementes tendem a perder o vigor e a germinação durante o armazenamento devido a peroxidação dos lipídeos, juntamente com um alto teor de água e temperatura, ser passível de ter provocado esta maior queda na germinação comprovando que o teor de água das sementes influencia na qualidade fisiológica durante $o$ armazenamento.

A Análise da Variância demonstrou efeito significativo dos fatores tratamentos de semente, armazenamento e tempo de hidratação sobre as sementes mortas, não havendo interação entre os fatores (Tabela 05). 
Tabela 5 - Análise da variância da porcentagem de sementes mortas de milho, submetidas à diferentes tempos de armazenamento, tratamentos de semente e tempos de hidratação. Chapecó (SC), 2016.

\begin{tabular}{lcrrr}
\hline \multicolumn{1}{c}{ FV } & GL & \multicolumn{1}{c}{ SQ } & \multicolumn{1}{c}{ QM } & \multicolumn{1}{c}{$\mathbf{F c P r}>\mathbf{F c}$} \\
\hline ARMAZENAMENTO & 2 & 425.866 .667 & 212.933 .333 & 36.2730 .0000 \\
TRATAMENTO & 3 & 205.255 .556 & 68.418 .519 & 11.6550 .0000 \\
TEMPO HIDRATAÇ̃̃O & 3 & 275.922 .222 & 91.974 .074 & 15.6680 .0000 \\
THIDRAT*ARMAZE & 6 & 54.744 .444 & 9.124 .074 & 1.5540 .1686 \\
TRATA*ARMAZE & 6 & 64.911 .111 & 10.818 .519 & 1.5540 .1686 \\
Erro & 99 & 581166667 & 5.870 .370 & \\
Total corrigido & 119 & 1.607 .866 .667 & & \\
\hline Média geral & 55.333 .333 & Número de observações & \multicolumn{1}{c}{120} \\
\end{tabular}

Fonte: Autores, 2019.

Os tempos de hidratação influenciaram significativamente sobre a porcentagem de sementes mortas de milho (Tabela 6), sendo que o tempo de 330 minutos foi o que apresentou significativamente a maior porcentagem $\mathrm{e}$ as sementes não hidratadas foram as que significativamente menos morreram.

Mais uma vez, os resultados demonstram que o período de hidratação influencia diretamente a qualidade das sementes.

Tabela 6 - Porcentagem de sementes mortas de milho submetidas a diferentes tempos de hidratação. Chapecó (SC), 2016

\begin{tabular}{|c|c|c|}
\hline Tratamentos & Médias & Resultados do teste \\
\hline 0 & 2.333333 & a \\
\hline 30 & 4.694444 & b \\
\hline 180 & 5.555556 & $\mathrm{~b}$ \\
\hline 330 & 7.416667 & c \\
\hline
\end{tabular}

Médias seguidas de mesma letra não diferem significativamente entre si pelo teste de Tukey $(\mathrm{P} \leq 0,05)$

Fonte: Autores, 2019.

Cabe destacar que existem danos em sementes submetidas a embebição, pois quando submetidas de forma rápida a esse processo, não há tempo suficiente para que as membranas celulares voltem do estado gel para o cristalino líquido, o que acarreta sérios danos celulares, prejudicando de forma direta a germinação. Assim, sementes que são submetidas a estresses, como graus de hidratação e desidratação, podem ter como consequência a diminuição da capacidade metabólica até a perda total da capacidade sintética, ou seja, incapaz de cumprir sua função para manutenção dos tecidos e germinação (COSTA et al., 2008).

Em sementes de feijão, oito horas de submersão em água são descritas como suficiente para diminuir a germinação e comprometer o estabelecimento da cultura (CUSTÓDIO et al., 2009).

Quanto ao armazenamento das sementes, observa-se na Tabela 7, que, independente do período, o armazenamento aumenta a porcentagem de sementes mortas, o que é também reflexo de se armazenar sementes que passaram por processo de hidratação, as quais iniciam o processo germinativo e perdem a viabilidade após um período de tempo.

Barbosa et al. (2010) observaram perda de vigor nas sementes de soja durante os seis meses de armazenamento com temperatura de $23{ }^{\circ} \mathrm{C}$ e umidade relativa do ar de $60 \%$.

Outros pesquisadores constataram redução nos valores de primeira contagem da germinação ao longo do armazenamento utilizando sementes de crambe durante nove meses, em diferentes embalagens (Cardoso et al., 2012)

De acordo com Cunha et al. (2009), a deterioração pode intensificar-se com o prolongamento do período de armazenamento, mesmo em ambiente refrigerado.

Ficou claro que com o aumento do período de armazenamento, as sementes deterioram mais rapidamente a sua qualidade fisiológica.

Tabela 7 - Porcentagem de sementes mortas de milho submetidas a diferentes tempos de armazenamento. Chapecó (SC), 2016.

\begin{tabular}{lcc}
\hline Tratamentos & Médias & Resultados do teste \\
\hline 0 & 2.900000 & $\mathrm{a}$ \\
180 & 6.500000 & $\mathrm{~b}$ \\
90 & 7.200000 & $\mathrm{~b}$ \\
\hline
\end{tabular}

Médias seguidas de mesma letra não diferem significativamente entre si pelo teste de Tukey $(\mathrm{P} \leq 0,05)$. Fonte: Autores, 2019.

A Tabela 8 revela os efeitos significativos dos tratamentos de semente sobre a porcentagem de sementes mortas, sendo que, a testemunha (sem tratamento em meio aquoso), apresentou a menor porcentagem de sementes mortas e o tratamento com zinco apresentou a maior porcentagem de sementes mortas, não diferindo do tratamento com nanozinco. Dessa forma, percebe-se que, a hidratação das sementes influenciou também os resultados dos tratamentos, onde, claramente os tratamentos que passaram por meio aquoso apresentaram maior porcentagem de sementes mortas. Os tratamentos com nutrientes (zinco e nanozinco) podem ter provocado algum nível de salinização das sementes, o que pode ter causado o aumento porcentagem de sementes mortas após o armazenamento, aumentando a média desses tratamentos na comparação com os demais.

Portanto, estudos sobre doses do micronutriente e também fontes aplicadas às sementes de híbridos de milho revestem-se de grande importância, pois, se forem inadequadas, podem afetar o crescimento da cultura, provocando toxidez nas plântulas, com consequente diminuição da taxa de emergência, reduzindo o stand e comprometer a produção. Assim, o conhecimento do desempenho das fontes de zinco, especialmente nas formas de sulfato e óxido, na nutrição inicial de plantas de milho, especialmente com relação à eficiência nutricional, mostrase importante, sendo, os estudos incipientes no Brasil (PRADO, et al., 2007).

Tabela 8 - Porcentagem de sementes mortas de milho submetidas a diferentes fontes de tratamento. Chapecó (SC), 2016.

\begin{tabular}{lcc}
\hline Tratamentos & Médias & Resultados do teste \\
\hline TESTEMUNHA & 2.333333 & $\mathrm{a}$ \\
ÁGUA PURA & 4.861111 & $\mathrm{~b}$ \\
NANOZINCO & 6.000000 & $\mathrm{bc}$ \\
ZINCO & 6.805556 & $\mathrm{c}$ \\
\hline
\end{tabular}

Médias seguidas de mesma letra não diferem significativamente entre si pelo teste de Tukey $(\mathrm{P} \leq 0,05)$.

Fonte: Autores, 2019.

Para plântulas anormais, observa-se na Tabela 9 que a análise de variância revela efeito significativo dos fatores tempo de armazenamento e tratamentos de semente. 
Tabela 9 - Análise da variância da porcentagem de plântulas anormais de milho, submetidas à diferentes tempos de armazenamento, tratamentos de semente e tempos de hidratação.

\begin{tabular}{lccll}
\multicolumn{5}{c}{ Chapecó $(\mathrm{SC}), 2016}$. \\
\hline \multicolumn{1}{c}{ FV } & GL & \multicolumn{1}{c}{ SQ } & QM & FcPr $>$ Fc \\
\hline ARMAZENAMENTO & 2 & 15.416 .667 & 7.708 .333 & $4.1190,0191$ \\
TRATAMENTO & 3 & 17.352 .778 & 5.784 .259 & $3.0910,0305$ \\
TEMPO & 3 & 6.463 .889 & 2.154 .630 & $1.1510,3323$ \\
THIDRATA*ARMAZE & 6 & 14.861 .111 & 2.476 .852 & $1.3240,2538$ \\
TRATA*ARMAZENA & 6 & 23.638 .889 & 3.939 .815 & $2.1050,0600$ \\
Erro & 99 & 185.258 .333 & 1.871 .296 & \\
Toral Corrigido & 119 & 262.991 .667 & & \\
\hline Média geral & 16.583 .333 & Número de observações: & 120 \\
\hline
\end{tabular}

Fonte: Autores, 2019.

Na Tabela 10, observa-se que o período de armazenamento com menor número de plântulas anormais foi o de 180 dias, não diferindo da contagem logo após o tratamento das sementes, já o período de 90 dias após o armazenamento foi o que apresentou o maior número de plântulas anormais. Esse resultado não revela efeito lógico, pois aos 90 dias de armazenamento temos mais plântulas anormais do que aos 180 dias de armazenamento. A diferença mínima significativa considerada nessa análise foi de $0,72 \%$, o que, apesar de ser significativo estatisticamente, pode não ser significativo na análise laboratorial e principalmente na realidade da agricultura intensiva.

Apesar dos resultados conflitantes, é importante lembrar que o armazenamento constitui-se em uma etapa essencial na produção de sementes de alta qualidade. A semente precisa ser adequadamente armazenada, caso contrário, os esforços para o desenvolvimento do material e as técnicas culturais para a produção podem ser perdidos (GRISI; SANTOS, 2007).

Tabela 10 - Porcentagem de plântulas anormais de milho submetidas a diferentes tempos de armazenamento. Chapecó (SC),

\begin{tabular}{lcc}
\multicolumn{3}{c}{2016.} \\
\hline Tratamentos & Médias & Resultados do teste \\
\hline 180 & 1.200000 & a \\
0 & 1.700000 & ab \\
90 & 2.075000 & $\mathrm{~b}$ \\
\hline
\end{tabular}

Médias seguidas de mesma letra não diferem significativamente entre si pelo teste de Tukey $(\mathrm{P} \leq 0,05)$.

Fonte: Autores, 2019.

Apesar de a análise de variância ter revelado efeito significativo dos tratamentos de sementes sobre a porcentagem de plântulas anormais, o teste de Tukey não demonstrou essa diferença, sendo que, o mesmo considerou uma diferença mínima significativa de 1,03\%. Isso ocorre porque, mesmo o teste de Tukey sendo considerado um teste rigoroso, o teste F é mais criterioso do que o teste de Tukey (VIANA; SANTOS, et al., 2012).

Tabela 11 - Porcentagem de plântulas anormais de milho submetidas a diferentes fontes de tratamento. Chapecó (SC), 2016.

\begin{tabular}{lll}
\hline Tratamentos & Médias & Resultados do teste \\
\hline 1 & 1.250000 & a \\
3 & 1.472222 & a \\
4 & 1.916667 & a \\
2 & 2.166667 & a \\
\hline
\end{tabular}

Médias seguidas de mesma letra não diferem significativamente entre si pelo teste de Tukey $(\mathrm{P} \leq 0,05)$

Fonte: Autores, 2019.

Para o índice de velocidade de germinação, a Análise da Variância demonstrou efeito significativo dos fatores tratamentos de semente, tempos de hidratação e tempos de armazenamento sobre o índice de velocidade de germinação das sementes (Tabela 12). Também foi significativa a interação entre os tempos de armazenamento e tempos de hidratação, e tempos de armazenamento e tratamentos, ou seja, todos os fatores demonstram-se significativos.

Tabela 12 - Análise da variância do índice de velocidade de germinação de milho, submetidas à diferentes tempos de armazenamento, tratamentos de semente e tempos de hidratação. Chapecó (SC), 2016.

\begin{tabular}{|c|c|c|c|c|}
\hline FV & GL & SQ & QM & $\mathrm{Fe} \operatorname{Pr}>\mathrm{Fe}$ \\
\hline TRATAMENTO & 3 & 141.891 .163 & 47.297 .054 & $184.4670,0000$ \\
\hline TEMPOHIDRATAÇÃO & 3 & 113.101 .791 & 37.700 .597 & $147.0390,0000$ \\
\hline ARMAZENAMENTO & 2 & 129.950 .287 & 64.975 .143 & $253.4150,0000$ \\
\hline ARMAZE*TEMPOHIDRATA & 6 & 101.213 .552 & 16.868 .925 & $65.7920,0000$ \\
\hline ARMAZE*TRATA & 6 & 63.014 .747 & 10.502 .458 & $40.9620,0000$ \\
\hline Erro & 99 & 25.383 .407 & 0.256398 & \\
\hline Toral Corrigido & 119 & 574.554 .947 & & \\
\hline Média geral & 74.356 .667 & Número de obs & & 20 \\
\hline
\end{tabular}

Levando em consideração os fatores tratamento $\mathrm{x}$ tempo de armazenamento como interação, observa-se que o maior índice de velocidade de germinação se encontra com o tratamento de zinco, seguido do nanozinco que não difere da água pura, e o menor índice de velocidade de germinação pode ser visto na testemunha livre de qualquer tratamento (Tabela 13), o que já foi demonstrado por Ohse et al., (2012), onde verificaram que a aplicação entre 0,76 e 1,04 $\mathrm{g} / \mathrm{kg}$ de sementes de trigo, aumentou o vigor das mesmas. Isso então sugere a importância do tratamento com zinco no vigor das sementes e também a necessidade de adequação da dose de nanozinco para um possível efeito positivo sobre o vigor da semente, uma vez que a dose de nanozinco aplicada com base em resultados anteriores foi quase mil vezes menor do que a dose de zinco.

Tabela 13 - Índice de velocidade de germinação de sementes de milho submetidas a diferentes fontes de tratamento e tempos de armazenamento. Chapecó (SC), 2016.

\begin{tabular}{lccccl}
\hline \multicolumn{5}{c}{ Tratamentos } \\
\hline Tempo Armazenamento & Zn & NanoZn & Água & Testemunha & Média* $^{*}$ \\
\hline 0 & $11,87 \mathrm{aA}$ & $8,21 \mathrm{aB}$ & $7,56 \mathrm{aB}$ & $5,75 \mathrm{aC}$ & 8,34 \\
90 & $8,17 \mathrm{bA}$ & $6,61 \mathrm{bB}$ & $6,51 \mathrm{bB}$ & $6,08 \mathrm{aB}$ & 6,84 \\
180 & $7,08 \mathrm{cA}$ & $6,12 \mathrm{bB}$ & $6,16 \mathrm{bB}$ & $6,23 \mathrm{aB}$ & 6,39 \\
Média & 9,08 & 6,98 & 6,74 & 6,02 & \\
\hline
\end{tabular}

Médias seguidas de mesma letra não diferem significativamente entre si pelo teste de Tukey $(\mathrm{P} \leq 0,05)$. Fonte: Autores, 2019.

Já, para o fator tempo de hidratação $\mathrm{x}$ tempo de armazenamento, conclui-se que houve diferença significativa entre todos os tempos de hidratação em que as sementes foram submetidas, mostrando que conforme aumenta o tempo de hidratação, maior o vigor das sementes. Porém, as mesmas devem passar pelo menor tempo possível de armazenamento, para assim não prejudicar sua viabilidade, conforme mostra Tabela 14. 
Tabela 14 - Índice de velocidade de germinação de sementes de milho submetidas a diferentes tempos de hidratação e tempos de armazenamento. Chapecó (SC), 2016.

\begin{tabular}{|c|c|c|c|c|c|}
\hline \multicolumn{6}{|c|}{ Tempos de hidratação } \\
\hline Tempo Armazenamento & $\mathbf{0}$ & 30 & 180 & 330 & Média* \\
\hline 0 & $5,75 \mathrm{aD}$ & $7,01 \mathrm{aC}$ & $8,62 \mathrm{aB}$ & $12,01 \mathrm{aA}$ & 8,34 \\
\hline 90 & $6,08 \mathrm{aC}$ & $6,51 \mathrm{bBC}$ & $6,97 \mathrm{bB}$ & $7,81 \mathrm{bA}$ & 6,84 \\
\hline 180 & $6,23 \mathrm{aA}$ & $6,47 \mathrm{bA}$ & $6,31 \mathrm{cA}$ & $6,58 \mathrm{cA}$ & 6,39 \\
\hline Média & 6,02 & 6,66 & 7,30 & 8,80 & \\
\hline
\end{tabular}

Médias seguidas de mesma letra não diferem significativamente entre si pelo teste de Tukey $(\mathrm{P} \leq 0,05)$. Fonte: Autores, 2019.

O efeito observado sobre o tempo de hidratação pode estar relacionado com a pré-embebição das sementes durante o processo de hidratação que as mesmas sofreram, isso então refletindo em efeito benéfico na velocidade de germinação, podendo estar associado ao reparo das membranas durante a fase de hidratação Guimarães et al., (2013), efetuando trabalho em sementes de melancia, verificou, de forma semelhante ao encontrado no presente trabalho, que períodos de pré-embebição superiores a 49,80 $\mathrm{h}$ e inferiores a $134,70 \mathrm{~h}$, afetam positivamente as características quantitativas de crescimento de plântulas de melancia, aos seis e 12 dias após a semeadura.

\section{CONCLUSÃO}

Dos itens avaliados, a hidratação no processo de tratamento das sementes é o fator que apresenta maior efeito prejudicial sobre a germinação das mesmas. Esse efeito se refletiu com a redução da qualidade das sementes, que passaram pelo processo de hidratação tanto quando do processo de tratamento das sementes com nutrientes quanto quando da aplicação da água pura. Dessa forma observa-se que o processo de tratamento de sementes com nutrientes deve utilizar técnicas que evitem a hidratação das sementes devendo ser realizado o mais próximo possível da semeadura.

O zinco tem a capacidade de aumentar a velocidade de germinação das sementes de milho, sendo necessária avaliação mais criteriosa da dose de nanozinco a ser aplicada nas sementes para obtenção de tal efeito.

\section{REFERÊNCIAS BIBLIOGRÁFICAS}

ALENCAR, E. R. de. et al. Qualidade dos grãos de soja em função das condições de armazenamento. Engenharia na Agricultura, v. 16, p. 155-166, 2008.

BARBOSA, C. Z. dos R. et al. Qualidade de sementes de soja BRS Tracajá, colhidas em Roraima em função do tamanho no armazenamento. Revista Ciência Agronômica, v. 41, p. 73-80, 2010.

BRASIL. Ministério da Agricultura, Pecuária e Abastecimento. Regras para análise de sementes. Brasília: Mapa/ACS, 2009 399p.

CARDOSO, R. B.; BINOTTI, F. F. da S.; CARDOSO, E. D. Potencial fisiológico de sementes de crambe em função de embalagens e armazenamento. Pesquisa Agropecuária Tropical, v. 42, p. 272-278, 2012.

COSTA, C. J. et al. Pré- hidratação de sementes de ervilha e sua interferência na avaliação do potencial fisiológico. Revista Brasileira de Sementes, v. 30, n. 1, p. 198- 207, 2008.

CUNHA, J. P. A. R. da et al. Qualidade das sementes de soja após a colheita com dois tipos de colhedora e dois períodos de armazenamento. Ciência Rural, v. 39, p. 1420-1425, 2009.
CUSTÓDIO, C. C. et al. Water submersion of bean seeds in the vigour evaluation. Revista Brasileira de Ciências Agrarias, v. 4, n. 3, 2009.

EMPRESA BRASILEIRA DE PESQUISA AGROPECUÁRIA, Nanotecnologia na Agricultura Aumenta seu Papel Social e de Inclusão. 2006. Disponível em: $<$ http://www.embrapa.br/imprensa/noticias/2007/outubro/2aseman a/nanotecnologia-na agricultura-aumenta-seu-papel-social-e-deinclusao/>. Acesso em: 15 set. 2015.

FUNGUETTO, C. I. et al. Desempenho de sementes de arroz irrigado recobertas com zinco. Revista Brasileira de Sementes, v. 32, n. 2, p. 117-123, 2010.

GUIMARÃES, M. A. et al. Pré-embebição de sementes e seus efeitos no crescimento e desenvolvimento de plântulas de melancia. Revista Ceres, v. 6, n. 3, p. 442-446, 2013.

GRISI, P. U.; SANTOS, C. M. Influência do armazenamento, na germinação das sementes de girassol. Horizonte Científico, v. 1, n. 7, p. 14, 2007 .

GOMES, G. D. R. et al. Produção e qualidade fisiológica de sementes de soja em diferentes ambientes de cultivo. Semina, v. 33, suplemento 1, p. 2593-2604, 2012.

KIRKBY, E. A; RÖMHELD, V. Micronutrientes na fisiologia de plantas: funções, absorção e mobilidade. Informações Agronômicas, v. 118, n. 2, p. 1-24, 2007.

LÉLES, E. P. et al. Interação de doses de calcário e zinco nas características morfológicas e nos componentes de produção da mamoneira. Acta Scientiarum Agronomy, v.32, n.3, p. 501-509, 2010.

MARCOS-FILHO, J. Fisiologia de sementes de plantas cultivadas. 2.ed. Londrina: ABRATES, 2015. 660p.

OHSE, S. et al. Vigor e viabilidade de sementes de trigo tratadas com zinco. Biotemas, v. 25, n. 4, p. 49-58, 2012.

PRADO, R. M; NATALE, W.; MOURO, M. C. Fontes de zinco aplicado via semente na nutrição e crescimento inicial do milho cv. Fort. Biosci, v. 23, n. 2, p. 16-24, 2007.

PESKE, S. T. et al. Sementes: Fundamentos científicos e tecnológicos. Pelotas: Editora Universitária / UFPel, n. 3, p. 573, 2012 .

SANTOS, J. dos et al. Qualidade fisiológica de sementes de cenoura classificadas por tamanho. Ciência Rural, v. 40, n. 9 , 2010.

SANTOS, H. C. et al. Qualidade fisiológica de sementes de sorgo em resposta a adubação com zinco. Revista Caatinga, v. 21, n. 1, 2008.

SMANIOTTO, T. A. S. de et al. Qualidade Fisiológica das sementes de soja armazenadas em diferentes condições. Revista Brasileira de Engenharia Agrícola e Ambiental, v. 18, n. 4, 2014.

TUNES, L. M. de. et al. Tratamento de sementes de trigo com zinco: armazenabilidade, componentes do rendimento e teor do elemento nas sementes. Ciência Rural, v. 42, n. 7, p. 1141-1146, 2012.

VIANA D. C. et al. Estudo dos testes de comparações de médias através da análise dos valores bioquímicos de creatinina obtidos de quatro raças zebuínas. Revista de Ciências da Vida, v. 32, n. 2, p. $17-22,2012$.

\section{COPYRIGHT}

Direitos autorais: $\mathrm{O}(\mathrm{s})$ autor(es) é(são) o(s) único(s) responsável(is) pelo material incluído no artigo. 


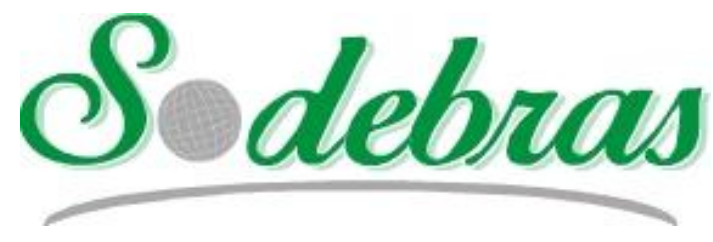

Volume 15 - $\mathrm{N}^{\mathrm{o}} 169$ - Janeiro / 2020

XLI International Sodebras Congress

31 de outubro a 02 de novembro de 2019 - Maceió - AL.

\title{
TÉCNICAS DE NUCLEAÇÃO PARA RESTAURAÇÃo DE CERRADO DEGRADADO
}

\author{
NUCLEATION TECHNIQUES FOR RESTORATION OF DEGRADED \\ CERRADO
}

\author{
GILDOMAR ALVES DOS SANTOS ${ }^{1}$; DAVID FRANCIS R. P. BURSLEM ${ }^{1}$; MILTON SERPA DE MEIRA JR ${ }^{3}$ \\ 1 - CENTRO UNIVERSITÁRIO DE MINEIROS, CURSO DE ENGENHARIA FLORESTAL; 2 - UNIVERSITY OF \\ ABERDEEN, PLANT \& SOIL SCIENCE DEPARTMENT; 3 - UNIVERSIDADE DE BRASILIA, FACULDADE DE \\ TECNOLOGIA, DEPARTAMENTO DE ENGENHARIA FLORESTAL, POST \\ gildomar@unifimes.edu.br; d.buslem@abdn.ac.uk; milton.serpa@gmail.com
}

\begin{abstract}
Resumo - O objetivo deste estudo foi identificar a adequação de três estratégias de nucleação para a promoção da sucessão em vegetação de cerrado degradada. No local foram instalados oito blocos, quatro com cerca e quatro sem cerca. Três diferentes estratégias de nucleação e um controle foram instaladas: translocação de sementes, translocação de solos, poleiros artificiais $\mathrm{e}$ o controle sem manipulação. $O$ número, a densidade $e$ a sobrevivência dos recrutas foram registrados durante um período de 24 meses. As três estratégias testadas resultaram no recrutamento de 739 indivíduos, dos quais $79,7 \%$ foram da translocação de sementes, $15,7 \%$ dos poleiros artificiais $e$ 4,6\% da translocação do solo. As plântulas apresentaram sobrevivência de $67,58 \%$ nos poleiros artificiais, $66,36 \%$ na translocação de sementes e $20,0 \%$ na translocação do solo. As estratégias aumentaram o número de plantas e de espécies.
\end{abstract}

Palavras-chave: Translocação de sementes. Translocação de Solo. Poleiros artificiais.

\begin{abstract}
The aim of this study was to identify the adequacy of three nucleation strategies for the promotion of succession in degraded cerrado vegetation. In the site were installed eight blocks, four with fence and four without fence. Three different nucleation strategies and one control were installed: seed translocation, soil translocation, artificial perches and control without any manipulation. The number, density and survival of the recruits were recorded for a 24 months period. The three tested strategies resulted in the recruitment of 739 individuals, of which $79.7 \%$ were from seed translocation, $15.7 \%$ from artificial perches and $4.6 \%$ from Soil translocation. The seedlings presented survival of $67.58 \%$ in the artificial perches, $66.36 \%$ in the seed translocation and $20.0 \%$ in soil translocation. The strategies increased the number of plants and species.
\end{abstract}

Keywords: Seed translocation. Soil translocation. Artificial Perches.

\section{INTRODUCTION}

Tropical dry forests around the world are among the most heavily exploited ecosystems and much of their natural landscapes have been used for economic purposes. These special ecosystems have become endangered (CABIN et al., 2002; GRISCOM \& ASHTON, 2011). The Brazilian cerrado is a dry forest in South America and it is one of the most threatened ecosystems on earth (MYERS et al., 2000).
The barriers that prevent succession should be understood. Many studies have focused on identifying those barriers (GUARIGUATA \& PINARD, 1998; ZIMMERMAN et al., 2000; HOLL, 2002), but very little of those research has been conducted in cerrado vegetation, where stressful climate conditions, low availability of soil nutrients, and a lack of propagule availability may play important roles in limiting forest recovery.

Depending on the amount of disturbance, sites can recover naturally without an active restoration process, although rates of recovery vary greatly (HOLL \& AIDE, 2011). Cerrado vegetation can regenerate in few decades (PILON \& DURIGAN, 2013), if the disturbance did not jeopardize the potential for recovery which depends on the existing nearby vegetation and land use history (GRISCOM \& ASHTON, 2011; HOLL \& AIDE, 2011).

In fragmented and degraded forested lands, the establishment by natural means of later successional tree species can be difficult, because most tropical tree seeds are short-lived and do not form a viable soil seed bank (GARWOOD, 1989). The establishment of forest species in degraded areas is generally dependent on the dispersal of new seeds from nearby forest remnants (CUBINA \& AIDE, 2001; HOLL et al., 2000). Shortage of tree seeds, seed and seedling predation, drought, competition with established grasses/weeds, depletion of soil nutrients, and changes in soil physical properties are also factors that could delay or slow forest recovery (CUBINA \& AIDE, 2001).

A range of interventions has been proposed to overcome these barriers to tree colonisation and survival, which include different approaches (HOLL \& AIDE, 2011; GRISCOM \& ASHTON, 2011). Those strategies vary from planting seedlings in islands forming nuclei of regeneration (HOLL et al., 2011) to other strategies collectively named Nucleation Techniques (BECHARA, 2006).

The nucleation strategy has been established by planting trees or sometimes shrubs, or by creating nuclei by transplanting soil or seeds or introducing bird perches (BECHARA et al., 2006; HOLL, 1998) or brush piles (UHL et al., 1981). Few studies using these approaches have been conducted in cerrado vegetation. Bechara (2006) used these strategies in a cerrado area located in Sao Paulo State 
(Brazil) but focused more on a Cost/Benefit analysis of this strategy.

Studies have emphasized the potential to utilize natural processes governing dispersal, establishment, resource availability and community assembly to achieve specific strategies for achieving succession and restoration of degraded lands (CORBIN \& HOLL, 2012; GRISCOM \& ASHTON, 2011). Nucleation is an approach that can facilitate succession in degraded habitats by mimicking natural processes of seed dispersal, but little is known about the success of this strategy in a hostile environment with harsh climate conditions and low soil nutrient status. A better understanding of how this nucleation strategy will contribute to natural succession in such a site is required. The goals of this study are to identify the role of three nucleation strategies in the natural succession of degraded cerrado vegetation, in terms of propagule availability, seed germination and seedling establishment, and to determine whether restoration is feasible using these strategies.

\section{METHODS}

\section{Experimental design}

Eight randomized blocks were installed in the area of Chitolina gully from where the soil was displaced after the landslide event: four blocks were fenced and four were unfenced (Figure 1). Plots located within these blocks received the following treatments: $\mathrm{T} 1$-soil translocation to monitor seedling recruitment and mortality; T2-seed translocation with a known number of seeds to monitor seedling recruitment and mortality; T3-artificial perches to monitor seedling recruitment and mortality, and; T8-control without any treatment.

Figure 1 Image of the experimental area, showing the location of the experimental plots

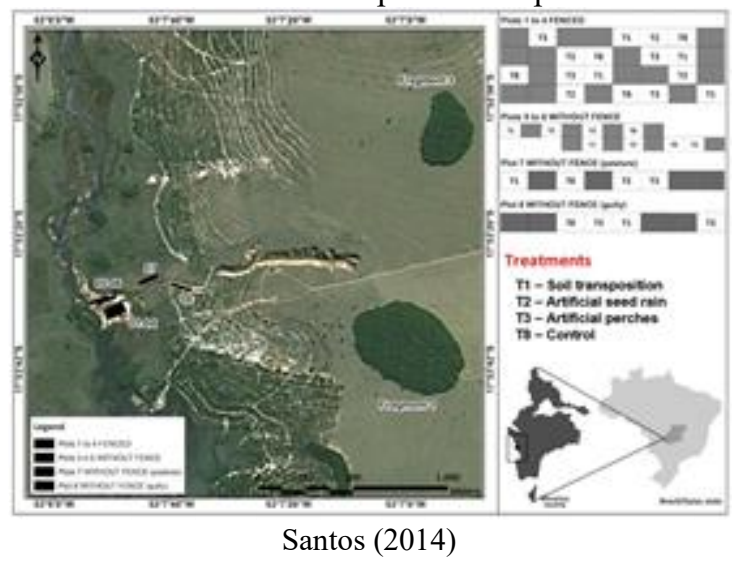

The fenced blocks were created to monitor the influence of vertebrates on seed predation and seedling herbivory. Before any intervention was applied, a survey was carried out in the area inside the blocks to identify the occurrence of any native tree seedlings.

Each block measuring $96 \times 12 \mathrm{~m}$ was divided into 8 plots and the four different nucleation treatments were applied in four sub-plots of $12 \times 12 \mathrm{~m}$ and the four other plots were used for a different researh. For logistic reasons the four fenced blocks were contiguous and a single fence was constructed around them. For analysis, the experiment was considered to possess a randomized block design with two blocks, one fenced and another unfenced, and four treatments including the control. Although this design ignores the lack of spatial dependence among blocks and fails to include replication of the fence effect, the structure of the available landscape and lack of resources prevented from mitigating these constraints by establishing multiple fenced plots. The fence to exclude vertebrates and small mammals had a mesh of $15 \mathrm{~mm}$ x $15 \mathrm{~mm}$, installed from 30 $\mathrm{cm}$ below soil surface to a height of $1.20 \mathrm{~m}$ above ground.

The treatments (soil translocation, seed translocation and artificial perches) were monitored for 24 months. The recruitment and survival of new plants were first recorded on January 24th 2007 and then every 3 months coinciding with the different seasons of the year. Every new seedling were tagged using a small plaque beside it. The final enumeration date was January 31st 2009.

\section{Soil translocation trial}

Soil samples for translocation were taken from an undisturbed forest community near to the area to be restored, as recommended by Reis et al. (2006). The forest community chosen for collecting the soil was the nearest to the experimental site (around $1300 \mathrm{~m}$ ). The floristic composition of this forest fragment was surveyed. All soil samples had the same characteristics and they were collected and transferred on the same day. Each sample was $1 \mathrm{~m}^{2}$ in area and $20 \mathrm{~cm}$ in depth (200 litres; including leaves and other surface organic material). The litter was not separated from the soil and they were mixed by the time they were put into a bag. The samples were transported in large plastic bags and placed into pre-prepared pits that were also $1 \mathrm{~m}^{2}$ in area and $20 \mathrm{~cm}$ deep. This procedure imports both soil and the dormant seeds within it.

\section{Seed translocation trial}

For the artificial seed rain treatment, seeds were taken from the 10 species that are most commonly used for restoration projects locally, and manually distributed across the plots in batches of 100 seeds of each species per plot. The species were Enterolobium contortisiliquum, Guazuma ulmifolia, Hymeneae stilbocarpa, Kielmeyera coriacea, Platymenia reticulata, Pterodon emarginatus, Rapanea gardineriana, Sclerolobium paniculatum, Tabebuia heptaphylla and Terminalia fagifolia. Seeds were made available by the Universidade de Brasilia (UnB), which collects and stores the seeds of these species on a regular basis for seedling production. The non-viable seeds were discharded and only germinable seeds were used.

The seeds were distributed manually simulating natural seed rain. All plots with this procedure received the seeds on the same day and they were randomly selected.

The artificial seed rain treatment was monitored every three months for germination and seedling survival from January 2007 to January 2009. At each census the number of recruits, number of deaths and seedling survival were recorded.

\section{Artificial perches}

The artificial perch treatment was created by installing vegetation towers in order to attract birds and bats. The perches were created using three $5 \mathrm{~m}$ lengths of bamboo installed in the centre of the plots selected for this treatment. Momordica charantia L., a weed plant found in hummocks and disturbed sites, was planted close to the pieces of 
bamboo. The recruitment and survival of the new species that germinated within the plot were monitored at the same three-month intervals as the seed rain and soil translocation approaches for a 24 month period. The species Momordica charantia $L$. did not survive in any plot, thus the perches remained bare.

\section{Data analysis}

Data analyses were carried out using R Project 3.0.2. The variables (number of recruits, number of dead individuals, density and survival) were tested for homoscedasticity using the car package (Fox \& Weisberg, 2011). Variables failing these tests were log-transformed.

The experimental design was considered to represent two blocks (with and without fence) and four treatments (three restoration strategies and a control). The treatments were replicated four times in each fenced and unfenced block. The recruitment of new plants for each species and the number of plots containing new plants of each species were recorded during the study period. In total, 86 "observations" were registered for the whole period of study (22 observations for perches, 47 for seed translocation and 17 for soil translocation), where an observation represents a plot containing at least one new recruit. The experiment was analysed by fitting an analysis of variance model with terms for block and treatment. The metrics analysed were the number of recruits, number of dead individuals, density, and survival. The significance of differences among the different strategies were examined with Tukey's Pairwise comparison tests $(\mathrm{p}<0.05)$ using the $\mathrm{R}$ package agricolae (Mendiburu, 2013).

\section{RESULTS}

Of the 8000 seeds sowed in the artificial seed rain treatment, only 589 germinated and of these seedlings, 395 survived to the end of 24 month study period. Germination varied significantly among species. Kielmeyera coriacea had the highest germination (374), followed by Platymenia reticulata (138), Hymenaea stigonocarpa (134), Sclerolobium paniculatum (101), Enterolobium sp (38), Rapanea gardineriana (8) and Pterodon emarginatus (7). The species Guazuma ulmifolia, Tabebuia heptaphyla and Terminalia fagifolia did not show any seed germination during the whole period. The control plots did not show germination of any tree species during the experiment.

In total, 739 individuals were recruited over the 24 months and from this total 589 were recruited in the artificial seed rain strategy, 116 around perches and 34 in the soil translocation strategy (Table 1). Although seeds from ten different species were sown in the artificial seed rain treatment, only seven species germinated and survived to the end of the experiment. The artificial perches recruited 12 different species and soil transposition recruited seven species. There were three species in common between perches and soil transposition strategies (one identified to family - Myrtaceae - one identified to genus - Nectandra sp. - and one unknown).
Table 1. Number of Recruits, Seedling survival and Density for different strategies during 24 months study

\begin{tabular}{|c|c|c|c|c|}
\hline Technique & Species & $\begin{array}{c}\mathbf{N} \\
\text { (un) }\end{array}$ & $\begin{array}{c}S \\
(\%)\end{array}$ & $\begin{array}{c}\mathbf{D} \\
\left(\mathbf{r} / \mathbf{m}^{2}\right)\end{array}$ \\
\hline \multirow[t]{13}{*}{ Perches } & Calypthranthes sp & 68 & 89.91 & 0.059 \\
\hline & Inga spp & 1 & 0.00 & 0.001 \\
\hline & Leguminoseae & 3 & 100.00 & 0.003 \\
\hline & Miconia sp & 5 & 100.00 & 0.004 \\
\hline & Myrtaceae & 6 & 50.00 & 0.005 \\
\hline & Nectandra sp & 15 & 93.75 & 0.013 \\
\hline & S. paniculatum & 1 & 0.00 & 0.001 \\
\hline & S. versicolor & 3 & 0.00 & 0.003 \\
\hline & Species 03 & 1 & 100.00 & 0.001 \\
\hline & Species 05 & 11 & 21.67 & 0.010 \\
\hline & Species 06 & 1 & 0.00 & 0.001 \\
\hline & Species 07 & 1 & 0.00 & 0.001 \\
\hline & Total Recruited & 116 & & \\
\hline \multirow[t]{8}{*}{ Seed Rain } & Enterolobium $s p$ & 28 & 43.45 & 0.024 \\
\hline & H. stigonocarpa & 99 & 87.55 & 0.086 \\
\hline & K. coriacea & 275 & 70.78 & 0.239 \\
\hline & P. reticulata & 102 & 37.84 & 0.089 \\
\hline & P. emarginatus & 5 & 83.33 & 0.004 \\
\hline & R. gardineriana & 6 & 80.00 & 0.005 \\
\hline & S. paniculatum & 74 & 56.08 & 0.064 \\
\hline & Total Recruited & 589 & & \\
\hline \multirow[t]{7}{*}{ Soil Trans. } & Enterolobium $s p$ & 9 & 25.00 & 0.008 \\
\hline & Myrtaceae & 13 & 33.33 & 0.011 \\
\hline & Nectandra sp & 1 & 0.00 & 0.001 \\
\hline & Species 01 & 5 & 0.00 & 0.004 \\
\hline & Species 02 & 3 & 0.00 & 0.003 \\
\hline & Species 03 & 2 & 0.00 & 0.002 \\
\hline & Species 04 & 1 & 0.00 & 0.001 \\
\hline
\end{tabular}

$\mathrm{N}$ - Number of recruits, $\mathrm{S}$ - Survival and D - Density (recruits $/ \mathrm{m}^{2}$ )

There was a significant difference between fenced and unfenced blocks, although we must treat this conclusion with caution because the fencing was not independently replicated. According to ANOVA the null hypothesis of no difference among the three restoration treatment can be rejected. The mean number of recruits differed significantly among strategies (Table 2). Tukey's pairwise comparison test showed that the artificial seed rain resulted in higher recruitment than the soil transposition and perch treatments, but that there was no difference between the latter two treatments (Table 3).

Table 2. Analysis of Variance for Number of Recruits

\begin{tabular}{lccccc}
\hline \multicolumn{6}{l}{ ANALYSIS OF VARIANCE (ANOVA) } \\
\hline V.Source & df & S. of Squares & Mean Square & F & p (same) \\
\hline Block & 1 & 1218.4 & 1218.4 & 4.71 & $0.042^{*}$ \\
Strategy & 2 & 22436.6 & 11218.3 & 43.37 & $5.3 \mathrm{E}-08^{* * *}$ \\
Residuals & 20 & 5173.0 & 258.6 & & \\
\hline
\end{tabular}

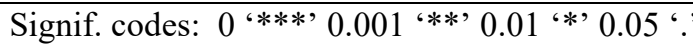


Table 3. Mean number of recruits $( \pm \mathrm{SEM})$ for strategies during the study period.

\begin{tabular}{lcc}
\hline Treatment & Means & $\begin{array}{c}\text { Tukey's pairwise } \\
\text { comparisons }\end{array}$ \\
\hline Soil Translocation & $4.25 \pm 1.37$ & $\mathrm{a}$ \\
Perches & $14.50 \pm 3.85$ & $\mathrm{a}$ \\
Seed rain & $73.63 \pm 9.87$ & $\mathrm{~b}$ \\
\hline
\end{tabular}

Treatments sharing the same letter do not differ significantly $(\mathrm{P}<0.05)$

In the artificial seed rain treatment seeds were spread out over the soil surface and could be predated by small rodents, a separate ANOVA was conducted to determine the differences among species in terms of seed germination (numbers of recruits) (Table 4).

Table 4 Analysis of variance for seed germination (number of Recruits) between blocks

\begin{tabular}{lccccc}
\hline \multicolumn{5}{l}{ ANALYSIS OF VARIANCE (ANOVA) } \\
\hline V.Source df & S.Square & M.Square & F & p(same) \\
\hline block & 1 & 248.5 & 248.51 & 6.50 & $0.013 *$ \\
species & 8432.4 & 936.93 & 24.51 & $<2 \mathrm{E}-16^{* * *}$ \\
Residuals & 69 & 2637.6 & 38.23 & \\
\hline
\end{tabular}

This analysis suggests that there was evidence of a significant difference between the fenced and unfenced blocks for the number of recruits and differences among species for this variable. A Tukey's pairwise comparison test showed that the number of recruits was higher in the fenced than in the unfenced blocks (Table 5).

Table 5. Mean number of recruits $( \pm$ SEM) for seed translocation during the study period per block.

\begin{tabular}{lcc}
\hline Treatment & Means & $\begin{array}{c}\text { Tukey's pairwise } \\
\text { Comparisons }\end{array}$ \\
\hline Fenced block & $91.25 \pm 7.30$ & $\mathrm{a}$ \\
Unfenced block & $56.00 \pm 4.20$ & $\mathrm{~b}$ \\
\hline
\end{tabular}

Same letters indicates no significant differences between groups $(\mathrm{P}<0.05)$

The highest number of recruits (seed germination) was found for Kielmeyra coriacea and the lowest was found for Pterodon emarginatus (Table 4.6). The species Terminalia fagifolia, Guazuma ulmifolia and Tabebuia heptaphylla did not germinate during the study period (Figure 2).

Figure 2 Germination rates for 10 species used in seed translocation strategy

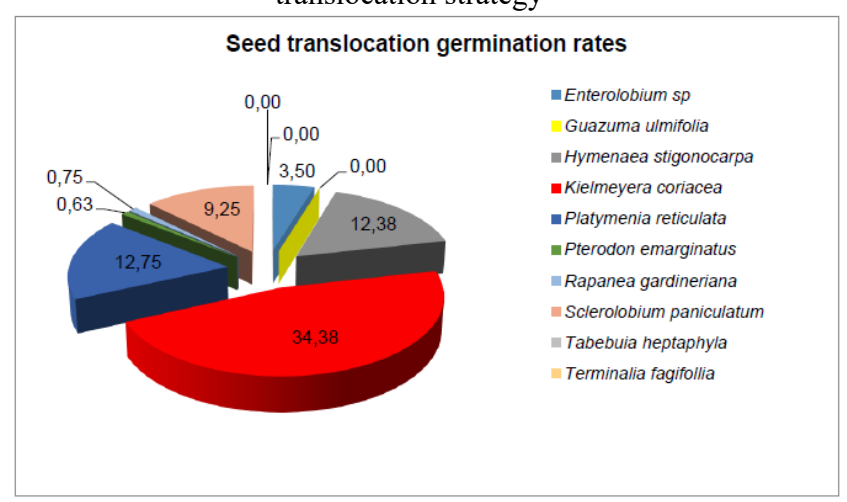

Santos, 2014
The analysis of variance comparing the number of seedlings that died between nucleation treatments showed no significant difference between fenced and unfenced blocks but a highly significant difference amongst treatments (Table 6).

Table 6 Analysis of variance for number of seedlings that died.

\begin{tabular}{lccccl}
\hline \multicolumn{6}{l}{ ANALYSIS OF VARIANCE (ANOVA) } \\
\hline V. Source & df & Sum & Mean & F & p(same) \\
& Squares & Squares & & \\
\hline block & 1 & 92.04 & 92.04 & 2.64 & 0.1196 \\
strategy & 2 & 2394.25 & 1197.13 & 4.38 & $3.4 \mathrm{E}-07 * * *$ \\
residuals & 20 & 696.33 & 34.82 & \\
\hline Signif. codes: & 0 ‘*** 0.001 '**' 0.01 '*’ 0.05 '?
\end{tabular}

Tukey's pairwise comparison test showed that mortality in the artificial seed rain treatment was significantly greater than in the other two treatments, which did not differ statistically from each other (Table 7).

Table 7 The mean number of deaths $( \pm$ SEM $)$ in the different treatments

\begin{tabular}{|c|c|c|}
\hline Treatment & Means & $\begin{array}{c}\text { Tukey's pairwise } \\
\text { comparisons }\end{array}$ \\
\hline Perches & $3.00 \pm 1.15$ & $\mathrm{a}$ \\
\hline Soil transposition & $3.13 \pm 0.99$ & $\mathrm{a}$ \\
\hline Artificial seed rain & $24.25 \pm 3.43$ & $\mathrm{~b}$ \\
\hline
\end{tabular}

Treatments sharing the same letter do not differ significantly

The analysis of variance for the density of recruits (recruits. $\mathrm{m}^{-2}$ ) showed that there were significant differences between blocks and among treatments (Table 8).

Table 8 Analysis of variance for density (Recruits. $\mathrm{m}^{-2}$ )

\begin{tabular}{lrlcrl}
\hline \multicolumn{6}{l}{ ANALYSIS OF VARIANCE (ANOVA) } \\
\hline V. Source & df & $\begin{array}{l}\text { Sum } \\
\text { square }\end{array}$ & \multicolumn{2}{c}{$\begin{array}{c}\text { Mean } \\
\text { square }\end{array}$} & p(same) \\
\hline blocks & 1 & 0.059 & 0.059 & 4.71 & $0.043^{*}$ \\
strategy & 2 & 1.082 & 0.541 & 43.37 & $5.3 \mathrm{E}-08^{* * *}$ \\
residuals & 20 & 0.250 & 0.013 & & \\
\hline
\end{tabular}

Signif. codes: 0 '***’ $0.001^{\text {'**’ }} 0.01$ '*’ 0.05 '?

The strategy that had the highest value for recruit density and was significantly different from the others was artificial seed rain, according to Tukey's pairwise comparison test (Table 9). The lowest value was observed for soil transposition, which was not significantly different from the artificial perch strategy.

Table 9 Mean recruit density $( \pm$ SEM) for strategies during the study period.

\begin{tabular}{lcc}
\hline Treatment & Means (Recruits.m ${ }^{-2}$ ) & $\begin{array}{c}\text { Tukey's pairwise } \\
\text { comparisons }\end{array}$ \\
\hline Soil transposition & $0.030 \pm 0.010$ & $\mathrm{a}$ \\
Perches & $0.101 \pm 0.027$ & $\mathrm{a}$ \\
Artificial seedrain & $0.511 \pm 0.069$ & $\mathrm{~b}$
\end{tabular}

Same letters indicates no significant differences between groups $(\mathrm{P}<0.05)$ 
The Analysis of variance for seedling survival (\%) showed that there was no significant difference between fenced and unfenced blocks. However, there was significant difference among treatments according to the ANOVA (Table 10)

Table 10 Analysis of variance for seedling survival (\%).

\begin{tabular}{lrcccl}
\hline \multicolumn{7}{l}{ ANALYSIS OF VARIANCE } & (ANOVA) & & \\
\hline V. Source & df & S. of Squares & M. Square & F & p(same) \\
\hline blocks & 1 & 40 & 40.0 & 0.064 & 0.803 \\
strategy & 2 & 11773 & 5886.3 & 9.384 & $0.001 * *$ \\
residuals & 20 & 12545 & 627.3 & &
\end{tabular}

Signif. codes: 0 ‘***’ $0.001^{\text {'**’ }} 0.01^{\text {'*’ }} 0.05$ '?

The highest value for seedling survival was found for the seed translocation treatment followed by the artificial perch treatment and the means for these two treatments were not significantly different from each other. The lowest value was found for the soil translocation treatment (Table 11).

Table 11 Mean seedling survival ( \pm SEM) for strategies during the study period.

\begin{tabular}{lcc}
\hline Treatment & Means (\%) & $\begin{array}{c}\text { Tukey's pairwise } \\
\text { comparisons }\end{array}$ \\
\hline Soil translocation & $20.00 \pm 10.37$ & $\mathrm{a}$ \\
Perches & $67.58 \pm 10.65$ & $\mathrm{~b}$ \\
Seed translocation & $66.36 \pm 1.96$ & $\mathrm{~b}$ \\
\hline
\end{tabular}

Same letters indicates no significant differences between groups $(\mathrm{P}<0.05)$.

\section{DISCUSSION}

Total seed germination (all species) was low (7.36\%) and it ranged from 0 to $34.38 \%$ among species. These results are consistent with the findings of other studies conducted in the tropics that showed similar low germination overall and high variation among species (PARROTTA et al., 1997; BONILLA-MOHENO \& HOLL, 2010). Seedlings derived from artificial seed rain treatment had survival rates varying from 37.8 to $87.6 \%$, which are comparable with the results from studies done in dry forests elsewhere (BONILLA-MOHENO \& HOLL, 2010; DOUST et al., 2008; COLE et al., 2011). Some former studies have suggested that high light and temperature conditions and low water availability in degraded sites frequently results in reduced seedling survival (CABIN et al., 2002).

Analysing seed translocation individually, there was a difference between fenced and unfenced blocks and seed may have predated in unfenced blocks. Past studies showed that burial improved germination rates of tree seeds in abandoned pastures (COLE et al., 2011) and reduced the incidence of seed predation (GARCIA-ORTH \& MARTINEZ-RAMOS, 2008) and this can be the explanation for lower number of recruits in unfenced blocks.

There was recruited 739 individuals, of which $79.7 \%$ were from the artificial seed rain, $15.7 \%$ from perches and $4.6 \%$ from soil transposition. Perches recruited 12 different species and this result is consistent with those of other studies in the tropics. Holl (1998) found 11 different species in a study using artificial perches conducted in an abandoned pasture in Costa Rica over a one year study period. McClanahan and Wolfe (1993) found 12 genera recruiting in a mining reclamation site in Florida using perches in a two-year study. In a 14 month study, Shiels and Walker (2003) found 14 species under perches located on a landslide in Puerto Rico.

Perches recruited a greater number of species than artificial seed rain ( 7 from 10 species used) and soil transposition strategies after two years of observation, which indicates that perches increase the number of species seeds dispersed into experimental sites and can improve degraded land restoration if seedlings could overcome barriers for survival (SHIELS \& WALKER, 2003; HOLL, 1998; MCCLANAHAN \& WOLF, 1993). Seedlings had a high survival rate under perches $(67.58 \%)$, but this was not significantly different from seedling survival in the artificial seed rain treatment $(66.36 \%)$. Past studies did not indicate survival rates for seedlings as seeds were collected and counted under the perches but were not left to germinate (SHIELS \& WALKER, 2003; HOLL, 1998; MCCLANAHAN \& WOLFE, 1993).

Soil translocation recruited 34 individuals from seven species. Past studies in Brazilian tropical forests have observed a greater number of seedlings recruiting from soil translocation plots than found in this study. Tres and Reis (2009) found that transplanting soil from a mixed rain forest in the south of Brazil recruited 36 species over a 12 month study period, but their methodology was quite different from the one used in this study: they took only $10 \mathrm{~cm}$ depth from $1 \mathrm{~m} 2$ of soil and separated the litter for deposition on top of the planted soil. Bechara (2006), working in cerrado vegetation in Sao Paulo state (Brazil), found that soil transposition recruited 41 individuals of 14 species in a 16 month study period, from $1 \mathrm{~m} 2$ soil collected $3-5 \mathrm{~cm}$ deep plus litter. Neto et al. (2010), working with the same methodology in abandoned pasture in Atlantic forest, found 231 individuals recruited from 22 different species. The lower results obtained in this study could be explained by the fact that we used soil from $20 \mathrm{~cm}$ depth and mixed it with the litter prior to translocation. As a result seeds stored in the litter layer may have been buried during mixing and may not have had the right conditions for germination.

Mean seedling survival was lower in the soil transposition treatment $(20.00 \%)$ than in the artificial seed rain and perch treatments $(66.36 \%$ and $67.58 \%$ respectively). This low seedling survival rate may be explained by competition with grasses that also germinated in the soil, and perhaps by pathogens imported with the soil from the forest fragment.

\section{CONCLUSION}

Nucleation strategies enhance the number of plants and species in the recovering area that are able to germinate and establish. It may be suggested that planting pioneer species as starting nuclei (BONILLA-MOHENO \& HOLL, 2010; COLE et al., 2011; ENGEL \& PARROTA, 2001; HOLL et al., 2011) and planting non-pioneer species seed after the first few years of natural succession, together with perches and soil transposition techniques could be a successful strategy to accelerate restoration.

The poor performance of the ten species used in the artificial seed rain approach highlighted the need for preliminary testing of species suitability for direct sowing under field conditions. Further studies to refine 
methodologies and apply them to different degraded landscapes are needed.

\section{REFERÊNCES}

BECHARA, F.C. Unidades demonstrativas de restauração ecológica através de técnicas nucleadoras: Floresta Estacional Semidecidual, Cerrado e Restinga. University of São Paulo, Piracicaba, 2006.

CABIN, R.J. et al. Effects of microsite, water, weeding, and direct seeding on the regeneration of native and alien species within a Hawaiian dry forest preserve. Biological conservation, v. 104, n. 2, p. 181-190, 2002.

COLE, R.J. et al. Direct seeding of late-successional trees to restore tropical montane forest. Forest Ecology and Management, v. 261, n. 10, p. 1590-1597, 2011 ..

CORBIN, J.D.; HOLL, K.D. Applied nucleation as a forest restoration strategy. Forest Ecology and Management, v. 265, p. 37-46, 2012.

CUBIÑA, A.; AIDE, T. M.. The effect of distance from forest edge on seed rain and soil seed bank in a tropical pasture 1. Biotropica, v. 33, n. 2, p. 260-267, 2001.

DOUST, S.J.; ERSKINE, P.D.; LAMB, D. Restoring rainforest species by direct seeding: tree seedling establishment and growth performance on degraded land in the wet tropics of Australia. Forest Ecology and Management, v. 256, n. 5, p. 1178-1188, 2008.

ENGEL, V.L.; PARROTTA, J.A. An evaluation of direct seeding for reforestation of degraded lands in central Sao Paulo state, Brazil. Forest Ecology and Management, v. 152 , n. $1-3$, p. $169-181,2001$..

FOX, J. \& WEISBERG. S (2011). An $\{\mathbf{R}\}$ Companion to Applied Regression, Second Edition. Thousand Oaks CA: Sage. Available http://socserv.socsci.mcmaster.ca/jfox/Books/Companion.

GARCIA-ORTH, X.; MARTÍNEZ-RAMOS, M. Seed dynamics of early and late successional tree species in tropical abandoned pastures: seed burial as a way of evading predation. Restoration Ecology, v. 16, n. 3, p. 435-443, 2008.

GARWOOD, N.C.Tropical soil seed banks: a rewiew. In LECK, M.A., PARKER, V.T. \& SIMPSON, R.L. (ed.) Ecology of soil seed banks. London: Academic Press, pp. 149-209.

GRISCOM, H.P.; ASHTON, M.S. Restoration of dry tropical forests in Central America: a review of pattern and process. Forest Ecology and Management, v. 261, n. 10, p. 1564-1579, 2011.

GUARIGUATA, M.R.; PINARD, M.A. Ecological knowledge of regeneration from seed in neotropical forest trees: implications for natural forest management. Forest ecology and management, v. 112, n. 1-2, p. 87-99, 1998.

HOLL, K.D. Do bird perching structures elevate seed rain and seedling establishment in abandoned tropical pasture?.

Restoration Ecology, v. 6, n. 3, p. 253-261, 1998.
HOLL, K.D. Effect of shrubs on tree seedling establishment in an abandoned tropical pasture. Journal of Ecology, v. 90, n. 1, p. 179-187, 2002.

HOLL, K.D.; AIDE, T. M. When and where to actively restore ecosystems?. Forest Ecology and Management, v. 261, n. 10, p. 1558-1563, 2011.

HOLL, K.D. et al. Tropical montane forest restoration in Costa Rica: overcoming barriers to dispersal and establishment. Restoration ecology, v. 8, n. 4, p. 339-349, 2000 .

HOLL, K.D. et al. Planting seedlings in tree islands versus plantations as a large-scale tropical forest restoration strategy. Restoration Ecology, v. 19, n. 4, p. 470-479, 2011.

MCCLANAHAN, T. R.; WOLFE, R. W. Accelerating forest succession in a fragmented landscape: the role of birds and perches. Conservation Biology, v. 7, n. 2, p. 279288, 1993.

MENDIBURU. F. Agricolae: Statistical Procedures for Agricultural Research. R package version 1.1-4. 2013.Available at: http://CRAN.Rproject.org/package=agricolae

MYERS, N. et al. Biodiversity hotspots for conservation priorities. Nature, v. 403, n. 6772, p. 853, 2000 .

NETO, A.M. et al. Transposition of soil seed bank as a methodology of forest restoration of abandoned pasture in Viçosa, MG. Revista Árvore, v. 34, n. 6, p. 1035-1043, 2010..

PARROTTA, J.A.; TURNBULL, J.W.; JONES, N. Catalyzing native forest regeneration on degraded tropical lands. Forest Ecology and Management, v. 99, n. 1-2, p. $1-7,1997$

PILON, N.A.L. \& DURIGAN, G. (2013) Criteria to indicate priority species for the restoration of Cerrado vegetation, Scientia Forestalis/Forest Sciences, 41(99), pp. 389-399.

SHIELS, A. B., AND WALKER, L.R. Bird perches increase forest seeds on Puerto Rican landslides, Restoration Ecology, 11(4), pp. 457-465. 2003.

UHL, C.et al. Early plant succession after cutting and burning in the upper Rio Negro region of the Amazon basin. The Journal of Ecology, p. 631-649, 1981.

ZIMMERMAN, J.K.; PASCARELLA, J.B.; AIDE, T. M. Barriers to forest regeneration in an abandoned pasture in Puerto Rico. Restoration ecology, v. 8, n. 4, p. 350360,2000 .

\section{ACKNOWLEDGEMENTS}

The authors wish to thanks the European Union Community (Alban Programme), Centro Universitário de Mineiros and University of Aberdeen for supporting the research.

\section{COPYRIGHT}

The authors are the only ones responsible for the material included in the article. 


\section{Área: Ciências Exatas e Engenharias}

\begin{tabular}{|c|c|}
\hline $1-3$ & $\begin{array}{l}\text { ALGORITMO PARA OTIMIZAR HEURÍSTICO COMPLEXO ENTRE AS TAREFAS } \\
\text { ALGORITHM TO SIMPLIFY HEURISTIC OF COMPLEX PROCESSES BETWEEN } \\
\text { TASKS } \\
\text { Koichi Sanoki; Bráulio Alturas; Isabel Machado Alexandre }\end{array}$ \\
\hline $1-3$ & $\begin{array}{l}\text { CONSTRUINDO MOSAICOS COM O GEOGEBRA: EXPERIMENTAÇÕES E } \\
\text { APRENDIZAGENS } \\
\text { BUILDING MOSAICS AS A GEOGEBRA: EXPERIMENTATION AND LEARNING } \\
\text { Náyra Milla Da Silva Santos; Joilma Silva Carneiro }\end{array}$ \\
\hline $1-3$ & $\begin{array}{l}\text { LINGUAGEM DO PARADIGMA ORIENTADO A } \\
\text { COMPARATIVOS VIA SIMULADOR DE TRÁFEGO } \\
\text { NOTIFICATION ORIENTED PARADIGM } \quad \text { LANGUAGE: } \\
\text { THROUGH TRAFFIC SIMULATOR } \\
\text { Fabio Negrini; Leonardo Faix Pordeus; Robson Ribeiro Linhares; Jean Marcelo } \\
\text { Simão }\end{array}$ \\
\hline $1-3$ & $\begin{array}{l}\text { PARÂMETROS CRÍTICOS NA AVALIAÇÃO GEOMÉTRICA DE VIAS DE } \\
\text { TRANSPORTE DE MINA A CÉU ABERTO: UMA ABORDAGEM MULTIVARIADA } \\
\text { CRITICAL PARAMETERS IN THE GEOMETRIC ASSESSMENT OF OPEN PIT } \\
\text { MINE HAUL ROADS: A MULTIVARIATE APPROACH } \\
\text { Navarro Torres, V.F; Silveira, L.G.C; Cunha, F.P.; Ayres, J. }\end{array}$ \\
\hline $1-3$ & $\begin{array}{l}\text { UMA ABORDAGEM TEÓRICA E PRÁTICA EM UM PROTOCOLO PARA IOT } \\
\text { A THEORETICAL AND PRACTICAL APPROACH TO AN IOT PROTOCOL } \\
\text { Nepomuceno, César; Chen, Daniel; Lopes, Diego; Albuquerque, Jesus; Neves, } \\
\text { Nayra; Soares, André; Valenzuela, Walter }\end{array}$ \\
\hline $1-3$ & $\begin{array}{l}\text { REDES BAYESIANAS APLICADAS A PRIORIZAÇÃO DE TESTE DE } \\
\text { SOFTWARE NA ABORDAGEM AADSP } \\
\text { BAYESIAN NETWORKS APPLIED TO SOFTWARE TEST PRIORIZATION } \\
\text { Vitor Souza Silva Santana; Antonio Carlos Santos Souza }\end{array}$ \\
\hline $1-3$ & $\begin{array}{l}\text { SMDCIC - SISTEMA PARA MONITORAMENTO DE DATA CENTERS BASEADO } \\
\text { NA INTERNET DAS COISAS } \\
\text { SMDCIC - SYSTEM OF DATA CENTER MONITORING IOT-BASED } \\
\text { Carlos Alicio Andrade Carvalho; Márcio Macedo; Antonio Carlos Dos Santos Souza }\end{array}$ \\
\hline $1-6$ & $\begin{array}{l}\text { CÉLULA SOLAR PRODUZIDA COM CORANTE EXTRAÍDO DA CAPSICUM } \\
\text { ANNUUM } \\
\text { PRODUCTION SOLAR CELL WITH DYE EXTRACTED FROM CAPSICUM } \\
\text { ANNUUM } \\
\text { Julianno Pizzano Ayoub; Gideã T. Tractz; Everson P. Banczek; Luana E. N. } \\
\text { Korocoski; Paulo R. P. Rodrigues }\end{array}$ \\
\hline
\end{tabular}




\begin{tabular}{|c|c|}
\hline $1-6$ & $\begin{array}{l}\text { CONTAMINAÇÃO DE RECURSOS HÍDRICOS DA AMAZÔNIA: ESTUDO DE } \\
\text { CASO NA REPRESA DE TUCURUÍ - PA } \\
\text { CONTAMINATION OF AMAZON WATER RESOURCES: A CASE STUDY IN } \\
\text { TUCURUÍ DAM } \\
\text { Simone De Fátima Pinheiro Pereira; Davis Castro Dos Santos; Cléber Silva E Silva; } \\
\text { Erivan Sousa Cruz }\end{array}$ \\
\hline $1-6$ & $\begin{array}{l}\text { HISTÓRIA EM QUADRINHOS COMO INSTRUMENTO NA EDUCAÇÃO } \\
\text { AMBIENTAL EM REGIÃO IMPACTADA POR AGROTÓXICO } \\
\text { COMICS AS AN INSTRUMENT IN ENVIRONMENTAL EDUCATION IN REGION } \\
\text { IMPACTED BY PESTICIDE } \\
\text { Simone De Fátima Pinheiro Pereira; Janilce Lirne Da Silva; Cléber Silva E Silva; } \\
\text { Erivan Sousa Cruz }\end{array}$ \\
\hline $1-6$ & $\begin{array}{l}\text { INFLUÊNCIA DA PREPARAÇÃO DO CORANTE N719 EM CÉLULAS SOLARES } \\
\text { DE TIO2: UMA ANÁLISE ELETROQUÍMICA } \\
\text { N719 DYE PREPARATION INFLUENCE IN TIO2 SOLAR CELLS: AN } \\
\text { ELECTROCHEMICAL ANALYSE } \\
\text { Julianno P. Ayoub; Gideã T. Tractz; Everson P. Banczek; Paulo R. P. Rodrigues }\end{array}$ \\
\hline 3-1 & $\begin{array}{l}\text { PLANO DE ADEQUAÇÃO DAS ESTRUTURAS FÍSICAS DE CALÇADAS DO } \\
\text { CENTRO DE SÃO MIGUEL DOS CAMPOS - AL } \\
\text { ADEQUACY PLAN FOR THE PHYSICAL STRUCTURES OF THE SIDEWALKES } \\
\text { FRON SÃO MIGUEL DOS CAMPOS DOWNTOWN } \\
\text { Talita Maria Gomes De Morais; Bruna Dos Santos; Geovânia Dos Santos Almeida }\end{array}$ \\
\hline 3-4 & $\begin{array}{l}\text { ESTUDO SOBRE TECNOLOGIAS EM VEÍCULOS ELÉTRICOS: UM REVIEW } \\
\text { STUDY ON TECHNOLOGIES IN ELECTRIC VEHICLES: A REVIEW } \\
\text { Felipe Venturini Cavali; Teófilo Miguel De Souza }\end{array}$ \\
\hline 3-4 & $\begin{array}{l}\text { IMPLEMENTAÇÃO DE UM SISTEMA DE SENSORIAMENTO ULTRASSÔNICO } \\
\text { PARA APLICAÇÕES EM IOT NO CONTEXTO DE SMART CITIES } \\
\text { IMPLEMENTATION OF AN ULTRASONIC SENSING SYSTEM FOR IOT } \\
\text { APPLICATIONS IN THE SMART CITIES CONTEXT } \\
\text { Coelho, Vinícius; Almeida, Thiago; Pereira, Luis; Santos, Italo; Dinardi, Phellipe; } \\
\text { Vermehren, Victor; Valenzuela, Walter }\end{array}$ \\
\hline 3-5 & $\begin{array}{l}\text { CONTROLE DE VIBRAÇÕES EM LAVRA DE MINAS PRÓXIMO A ZONAS } \\
\text { URBANAS } \\
\text { MINING VIBRATION CONTROL NEAR URBAN ZONES } \\
\text { Leonardo Chaves; Fabiano Ferreira; Leandro Silveira; Vidal Torres }\end{array}$ \\
\hline 3-5 & $\begin{array}{l}\text { REUTILIZAÇÃO DE AREIA DE FUNDIÇÃO ATRAVÉS DA REGENERAÇÃO } \\
\text { MECÂNICA: ESTUDO DE CASO EM UMA FUNDIÇÃO LOCALIZADA EM } \\
\text { PERNAMBUCO } \\
\text { REUSE OF FOUNDRY SAND THROUGH MECHANICAL REGENERATION: } \\
\text { CASE OF A PERNAMBUCO FOUNDRY COMPANY } \\
\text { Thiago H. B. Santana; Guilherme G. S; Ivan B. M. Picchi; Tiago F. A. Santos }\end{array}$ \\
\hline
\end{tabular}




\begin{tabular}{|c|l|}
\hline $3-5$ & $\begin{array}{l}\text { SISTEMA TERMICO ASISTIDO DE SECADO DE CAFÉ } \\
\text { COFFEE DRYING ASSISTED THERMAL SYSTEM } \\
\text { Mauricio Hernandez Sarabia; Liliana Delgadillo }\end{array}$ \\
\hline $3-6$ & $\begin{array}{l}\text { A REALIDADE DO TRABALHADOR RURAL EXPOSTO AOS AGROTÓXICOS } \\
\text { THE REALITY OF THE RURAL WORKER EXPOSED TO THE AGROCHEMICALS } \\
\text { JésSica Priscila Da Silva Lima; Talita Maria Gomes De Morais }\end{array}$ \\
\hline $3-8$ & $\begin{array}{l}\text { O PROCESSO DECISÓRIO: A SISTEMATIZAÇÃO DO PROCESSO DECISÓRIO } \\
\text { PARA TOMADAS DE DECISÃO MULTICRITÉRIO THE DECISION-MAKING } \\
\text { PROCESS: THE SYSTEMATIZATION OF THE DECISION-MAKING PROCESS } \\
\text { FOR MULTIRITHERARY DECISION-MAKING } \\
\text { ManOel MesSias Domingos Da Silva; LesSO Benedito Dos Santos }\end{array}$ \\
\hline
\end{tabular}




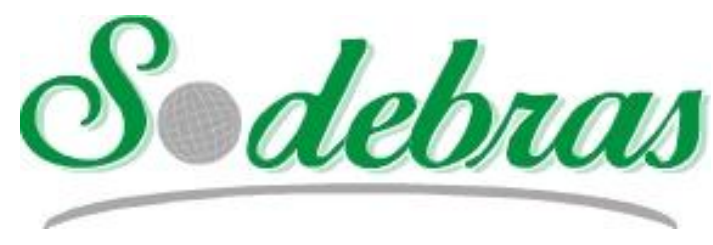

Volume $15-\mathrm{N}^{\mathrm{o}} 169$ - Janeiro / 2020

XLI International Sodebras Congress

31 de outubro a 02 de novembro de 2019 - Maceió - AL

\title{
ALGORITMO PARA OTIMIZAR HEURÍSTICO COMPLEXO ENTRE AS TAREFAS ALGORITHM TO SIMPLIFY HEURISTIC OF COMPLEX PROCESSES BETWEEN TASKS
}

\author{
KOICHI SANOKI; BRÁULIO ALTURAS; ISABEL MACHADO ALEXANDRE \\ INSTITUTO UNIVERSITÁRIO DE LISBOA; \\ koichi_sanoki@iscte-iul.pt;braulio.alturas@iscte-iul.pt;isabel.alexandre@iscte-iul.pt
}

\begin{abstract}
Resumo - Este artigo descreve o algoritmo que otimiza o heurístico complexo de relacionamentos entre tarefas. Essas tarefas são as lógicas computacionais de interação nas aquisições, tratamentos, e disponibilizações de informações. As informações dos dados básicos adquiridos são armazenadas $e$ organizadas em um grupo agregado com indexação para acesso em determinada ordenação que permite relacioná-las com outros grupos de mesma natureza de mídias. A metodologia para a otimização baseia-se na geração de uma indexação única, de tal maneira que os dados se alinhem em uma única forma hierárquica, ou na forma natural da aquisição dos mesmos. Com a composição em uma única indexação o algoritmo descreve a ordem em que as informações são dispostas. Dessa maneira, tais informações são manuseadas por um processo ágil e simplificado em comparação com uma lógica convencional complexa. A escolha de um tipo de heurística, a forma de ordenação da indexação, e o relacionamento entre as tarefas, são a essência para a obtenção do menor percurso no para o acesso $e$ o tratamento de dados. Processo que, pautado nessa indexação, agiliza a disponibilização da informação.
\end{abstract}

Palavras-chave: Algoritmo Computacional. Heurística. Lógica alternativa. Indexação. Agilização.

\begin{abstract}
This article describes the algorithm that optimizes the complex heuristic of relationships between tasks. These tasks are the computational logics of interaction in the acquisition, treatment, and availability of information. The informations of the basic data acquired is stored and organized in an aggregated group with indexing for access in a given ordering that allows it to be related to other groups of the same nature of media. The methodology for optimization is based on the generation of a single index, in such a way that the data are aligned in a single hierarchical form, or in the natural form of the acquisition of the same ones. With the composition in a single indexing, the algorithm describes the order in which the information is arranged. In this way, such information is handled by an agile and simplified process compared to a complex conventional logic. The choice of a heuristic type, the indexing ordering form, and the relationship between the tasks, are the essence to obtain the smallest path in the data access and processing. That process, based on this indexation, expedites the availability of information.
\end{abstract}

Keywords: Computational Algorithm. Heuristic. Alternative Logic. Indexing.

\section{INTRODUÇÃO}

O propósito deste artigo é descrever um algoritmo otimizado para o heurístico complexo:

\begin{abstract}
"O método heurístico pressupõe a formulação e a estruturação, de um sistema de ação adequado para cada problema a investigar, o qual é construído durante o próprio processo de investigação.” (W. C. de A. Pereira, 1979).
\end{abstract}

Com a divisão em várias tarefas simples (N. Facci; C. H. Marroni; L. B. Facci, 2004) e com a utilização do mapa trapezoidal no projeto de mecanização de processos, obterse-á:

- A análise de um processo manual identificado com uma tarefa de início e final, procurando as funções e as rotinas, e buscando o ponto comum entre essas rotinas. Assim, pode-se ver que existem pontos que estão fora do processo, agilizando então o mesmo;

- A compreensão de que uma vez não entendidas as análises de processos, é gerada uma outra rotina para contornar esse obstáculo. Este projeto mostra que ao invés de contornar esse obstáculo, deve-se achar o espaço livre entre as rotinas;

- A utilização do modelo de Davis (1989) da Figura 2, com seus cinco construtos (Utilidade Percebida - UP; Facilidade de Uso Percebida - FUP; Atitude para Uso - AU; Intenção Comportamental de Uso - IC; e Uso Real - UR) como linha de base para verificar as relações entre as variáveis do modelo, com a aplicação do Mapa Trapezoidal, que no fundo é a Atitude para Uso - AU, e altera sensivelmente o item Facilidade de Uso Percebida - FUP. Portanto essa é a inovação deste projeto em relação aos convencionais.

A proposta é que esta pesquisa seja descritiva e exploratória para abordar como o processo de mecanização aceita a colocação de uma metodologia alternativa onde os projetos eram desenvolvidos de forma tradicional.

Neste tema, segundo Kermen e outros (1976), na tarefa entre o início e o término, pode-se construir uma estrutura de dados chamada de "mapa trapezoidal", que quando utilizada é encontrado o caminho das tarefas sem restrições ou obstáculos que impeçam sua livre execução, e sem que tenha-se que recorrer a alternativas de "ajustes". 


\section{METODOLOGIA}

Inicialmente, visa-se analisar a utilidade das metodologias quantitativa, qualitativa, e da aplicação do Modelo de Aceitação de Tecnologias, de Davis (1985, 1993), e Davis, Bagozzi e Warshaw (1989), uma vez que este projeto tem como finalidade sua utilização em desenvolvimentos de projetos de mecanização que envolvem as áreas que desenvolvem processos de tarefas de forma virtual. "Davis argumenta que usuários formam tendências motivacionais logo depois de serem expostos a um novo sistema ou projetos e suas respectivas potencialidades. Seria também possível verificar consequências comportamentais como tendências de aceitação ou não. $\mathrm{O}$ processo de teste da aceitação consiste em breve demonstração de novos sistemas, utilizando o próprio sistema, ou recursos multimídia de apresentação, seguido da aplicação de uma medida para verificar a motivação para o uso do sistema no trabalho (DAVIS, 1986)".

Figura 1 - Modelo de Aceitação da Tecnologia (TAM).

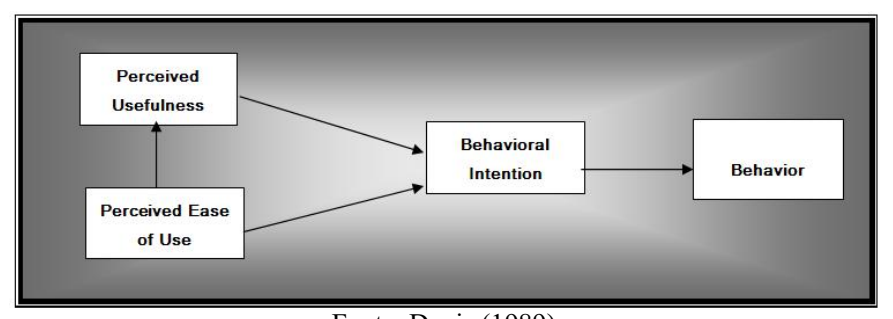

Fonte: Davis (1989).

Essa é a visão geral do Modelo de Aceitação da Tecnologia (TAM), para descrever o processo motivacional entre a tecnologia e o comportamento do usuário. Uma versão mais recente do TAM foi apresentada por Davis, Bagozzi e Warshaw (1989), que aplicaram o modelo em dois estudos, o primeiro desenvolvido a partir de um sistema em uso, e o segundo sobre um sistema que ainda viria a ser utilizado. As medidas de Utilidade Percebida e de Facilidade de Uso Percebida foram refinadas e simplificadas, resultando em dois blocos de seis questões cada, com margem de confiabilidade para Utilidade Percebida de 0,98, e para Facilidade de Uso Percebida, de 0,94 (DAVIS; BAGOZZI; WARSHAW, 1989). Sua estrutura é apresentada na Figura 2.

"No TAM, variáveis externas referem-se às características de sistemas, como menus, ícones e interfaces, ou seja, a tecnologia em si, sobre a qual se está investigando a aceitação. A Utilidade Percebida é compreendida como a possibilidade de conceber vantagem ao desempenho de determinada atividade. A percepção de Facilidade de Uso refere-se à ideia da necessidade de pouco ou nenhum esforço para utilizar determinado sistema" (DAVIS, 1989). Atitude para Uso é o "[...] grau individual de avaliação que vai influenciar a intenção de comportamento" (FISHBEIN; AJZEN, 1975, p. 216). Intenção Comportamental é "[...] uma probabilidade subjetiva individual que determina $o$ comportamento" (FISHBEIN; AJZEN, 1975, p. 288). Portanto, o uso real é uma função de avaliação da frequência de uso, no caso de sistemas já disponibilizados, ou intenção de uso futuro, no caso do desenho de novos sistemas (DAVIS, 1989, p. 989)".
Figura 2 - Modelo de Aceitação de Tecnologia.

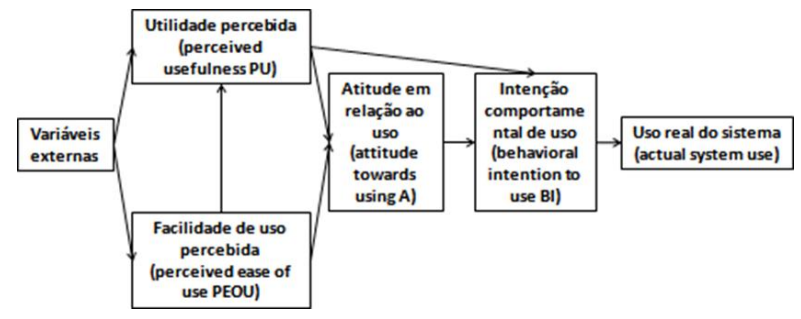

Fonte: Davis, Bagozzi e Warshaw (1989).

Davis, Bagozzi e Warshaw (1989) aplicaram o modelo em dois estudos, o primeiro desenvolvido a partir de um sistema em uso e o segundo sobre um sistema que ainda viria a ser utilizado. As medidas de Utilidade Percebida e de Facilidade de Uso Percebida foram refinadas e simplificadas, resultando em dois blocos de seis questões cada, com margem de confiabilidade para Utilidade Percebida de 0,98, e para Facilidade de Uso Percebida, de 0,94 (DAVIS; BAGOZZI; WARSHAW, 1989).

Utilizaram, pois, o modelo de Davis (1989) com seus cinco construtos (Utilidade Percebida - UP; Facilidade de Uso Percebida - FUP; Atitude para Uso - AU; Intenção Comportamental de Uso - IC e Uso Real - UR) como linha de base para verificar as relações entre as variáveis do modelo.

A proposta de Kedem e outros é dividir a tarefa entre o início e o término em um trapézio, para calcular este percurso sem obstáculos entre os dois pontos, o que é possível com essa estrutura. Considerando que uma tarefa "S" qualquer no processo de mecanização com início e final, que não se cruzam, e seja "R" uma caixa de funções de todo o processo contidas na tarefa $\mathrm{S}$, então, o mapa trapezoidal $\mathrm{T}(\mathrm{S})$ é obtido traçando-se duas linhas verticais a partir de todos os pontos extremos das funções, uma para cima e outra para baixo, parando em um outra tarefa de S, ou quando tocar em uma das arestas da função R.

O importante é clarificar em que consiste o mapa trapezoidal, visando a compreensão da relação entre o uso do computador (em estudos recentes usado em sentido lato para o uso das tecnologias) por parte dos utilizadores, e o conjunto de variáveis que viabilizavam a aceitação da tecnologia por parte desses mesmos utilizadores.

Esse mapa visa a compreensão da Facilidade de Uso Percebida pelo utilizador, assim como a Utilidade Percebida da tecnologia, relacionando tais conceitos entre si, com a intenção de gerar comportamento, e de fazer uso do sistema e das referidas variáveis externas. A figura 3, mostrando o mapa trapezoidal, foi feita a partir do artigo retirado da fonte $<\mathrm{http}$ //upload.wikimedia.org/wikipedia/

en/4/43/Trapezoidal_decomposition.png $>$, que não se encontra mais disponível. 
Figura 3 - Mapa trapezoidal.

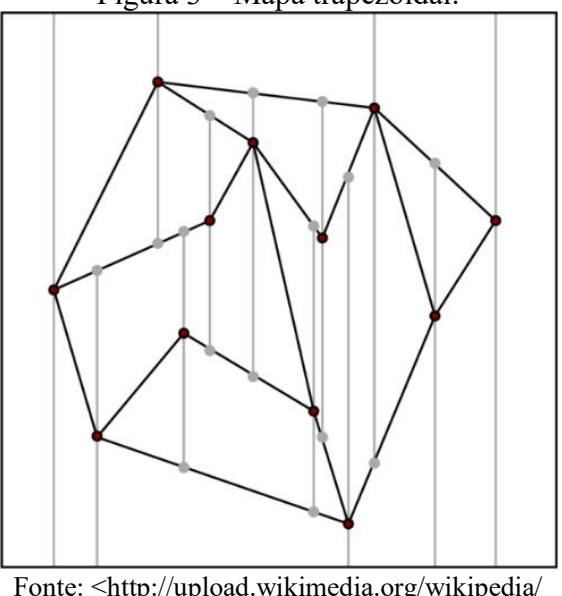

en/4/43/Trapezoidal_decomposition.png $>$.

\section{RESULTADOS}

Com o mapa trapezoidal obtém-se a representação das tarefas de início e final sem obstáculos, e utiliza-se trapézios que se encontram dentro de polígonos:

\section{1 - Variáveis externas}

Para calcular o percurso entre o início "s" e o término " $t$ " nesse polígono "P", basta traçar uma linha reta entre os dois pontos, que estão contidos no trapézio, ou seja, fazendo uma analogia, é como se uma tarefa desse processo estivesse na mesma função.

Agora, caso os pontos estejam em trapézios diferentes, não basta traçar uma linha reta, pois algumas vezes é necessário construir grafos de caminhos livres, fazendo curvas para entrar em determinados trapézios, ou seja, fazendo outra analogia, é como se uma função de uma tarefa utilizasse uma função de outra tarefa, exatamente onde se faria uso de uma terceira função, o que muitas vezes não é feito nessas buscas de "arestas" entre as funções de outras tarefas.

\section{2 - Utilidade Percebida}

Com esse grafo montado, basta adicionar uma aresta de "s" ao vértice que se encontra no meio do trapézio onde o mesmo "s" está contido, e adicionar uma aresta " $t$ " ao vértice do seu trapézio, buscando a largura ou o algoritmo de DIJKSTRA para achar um caminho possível de "s" a " $t$ ", ou seja, é buscar uma função que muitas vezes não está nos vértices e nem nas arestas, mas sim na largura que pode consistir exatamente na disposição das arestas e vértices de acordo com a disposição das funções dentro das tarefas.

\section{3 - Caminhos mínimos}

De acordo com os autores Natan e Carlos Eduardo, há de se encontrar o caminho de menor distância euclidiana.

Neste sentido, pode-se enunciar o seguinte lema:

\section{- Lema 1}

Qualquer caminho mínimo entre dois pontos "s" e " $\mathrm{t}$ ", entre os polígonos em "P", é um caminho polígamo onde seus vértices são dos polígonos em "P". Analogamente pode-se dizer que entre as funções de uma tarefa " $P$ " e o local onde as rotinas são os vértices, então as rotinas da tarefa.

\section{- Prova}

Supondo que o caminho "C" não seja um poligonal, e seja mínimo, sendo que em obstáculos poligonais existe um vértice "P" em "C" que está contido no espaço livre, e que existe um "E" tal, que o disco "D" com centro "P" e raio "E" esteja totalmente contido em um espaço livre, logo os dois pontos onde o caminho cruza com "D" e conecta-se com eles através de uma linha reta ao invés de passar por "P", é a heurística de um caminho de comprimento menor que " $\mathrm{C}$ ", pois qualquer caminho de extensão mínima tem que ser localmente mínimo também. Dessa forma conclui-se que o caminho tem que ser poligonal e tem que excluir a possibilidade de haver pontos contidos no espaço livre. Colocar essa forma em processo mecanizado é dizer que nas tarefas inicial e final existe uma função com uma rotina "P" que está fora do processo da tarefa conhecida, e esse relacionamento está em "D", tornando assim o caminho "lógico" de relacionamento diferente do conhecido pelas rotinas através das funções que diminuem o caminho para a codificação computacional.

\section{4- Grafo de visibilidade de " $P$ "}

Chamado de Gvis $\left(\mathrm{P}^{*}\right)$, o grafo de visibilidade de "P", onde seus vértices são os dos polígonos em $\mathrm{PU}\{\mathrm{s}, \mathrm{t}\}=\mathrm{P} *$, e onde " $s$ " e " $t$ " são os pontos entre os quais se quer a menor distância.

Por definição, os arcos em Gvis( $\left.\mathrm{P}^{*}\right)$ são entre vértices, que agora incluem "s" e " $t$ ", onde há um caminho em linha reta entre eles, e onde não haja colisão com obstáculos, assim o menor caminho entre " $\mathrm{s}$ " $\mathrm{e}$ " $\mathrm{t}$ " consiste em arcos neste grafo, com o uso do seguinte algoritmo para que se encontre o menor caminho:

\section{OAlgoritmo SHORTESTPATH $(P, s, t)$;}

oEntrada: um conjunto "P" de polígonos e dois pontos " $\mathrm{s}$ " e " $\mathrm{t}$ " localizados em algum espaço livre;

oSaída: O menor caminho sem colisão entre "s" e "t";

$\circ G(v i s) \leftarrow$ VISIBILITY GRAPH(P U $\{s, t\})$

oQualquer ij pertence $G($ vis $)$, custo (i, j) $\leftarrow$ a distância euclidiana do segmento ij.

oUso do algoritmo de Dijkstra para calcular o caminho mais curto entre "s" e " $\mathrm{t}$ ".

\section{CONCLUSÃO}

A técnica utilizada nesta pesquisa está de acordo com a divisão em várias tarefas simples e com a utilização do mapa trapezoidal no projeto de mecanização de processos, identificado com uma tarefa de início e final, determinando as funções e as rotinas, e obtendo o ponto comum entre essas rotinas.

A compreensão de que uma vez não entendidas as análises de processos, é gerada uma outra rotina para 
contornar esse obstáculo mostrando que ao invés de contornar esse obstáculo, acha-se o espaço livre entre as rotinas.

\section{REFERÊNCIAS BIBLIOGRÁFICAS}

D. Rozoff. Heuristic - The Accounting Review, 39(3), 768769. 1964. Disponível em

$<$ http://www.jstor.org/stable/242477>.

E. K. Burke; M. Gendreau; M. Hyde; G. Kendall; G. Ochoa; E. Özcan \& R. Qu (2013). Hyper-heuristics: a survey of the state of the art, Journal of the Operational Research Society, 64:12, 1695-1724, DOI:10.1057/jors.2013.71. Disponível em

$<$ https://www.jstor.org/journal/joperresesoci?refreqid=excel sior\%3Af0d13f36775f8a16c737b5dce4e1cb75>.

F. D. Davis. Perceived usefulness, perceived ease of use and user acepptance of information technology. Mis Quarterly, v. 13, n. 3, p. 319-340, 1989.

F. D. Davis, R. P. Bagozzi, P. R. Warshaw. User Acceptance of Computer Technology: A Comparison of Two Theoretical Models. Management Science, v. 35, n. 8, p. 982-1003, 1989.

J. Leung. A New Graph-Theoretic Heuristic for Facility Layout. Management Science, 38(4), 594-605. 1992. Disponível em $<$ http://www.jstor.org/stable/2632437>.

J. O'Rourke. Computational Geometry in C (Cambridge Tracts in Theoretical Computer Science) ISBN 10: 0521640105 ISBN 13: 9780521640107 Publisher: Cambridge University Press, 1998.

K. Kedem; R. Livne; J. Pach; M. Sharir. On the union of Jordan regions and collision-free translation motion amdst polygonal obstacles, Discrete Comput. Geom. 1 (1986), 5971.

K. Kedem; M. Sharir, An e-cient algorithm for planning collision-free translation motion of convex polygon object in 2-dimensional space amidst polygonal obstacles. Proceedings of the 1st Annual Symp. Comp. Geom. (1985), 7580.

K. Mulmuley. Computational Geometry: An Introduction Through Randomized Algorithms. The University of Chicago. 1993.

K. Sheibani. A fuzzy greedy heuristic for permutation flowshop scheduling. The Journal of the Operational Research Society, 61(5), 813-818. 2010. Disponível em $<$ http://www.jstor.org/stable/40608242>.

M. de Berg; M. van Kreveld; M. Overmars; O. Schwarzkopf, Computacional Geometry: Algorithms and applications, ISBN 978-3-540-77974-2, New York, 2008.

M. Fishbei; I. Ajzen. Belief, attitude, intention, and behavior: an introduction to theory and research. Boston (MA): Addison-Wesley, 1975.
M. Libicki; L. Ablon; T. Webb. A Heuristic Cybersecurity Model. In The Defender's Dilemma: Charting a Course Toward Cybersecurity (pp. 61-98). Santa Monica, (2015). Calif:: RAND Corporation. Disponível em $<$ http://www.jstor.org/stable/10.7249/j.ctt15r3x78.13>.

M. Nagano; J. Moccellin. A High Quality. Solution Constructive Heuristic for Flow Shop Sequencing. The Journal of the Operational Research Society, 53(12), 13741379. 2002. Disponível em $<$ http://www.jstor.org/stable/822727>.

N. Facci; C. H. Marroni; L. B. Facci. Análise do relacionamento sistêmico entre o processo decisório e o Sistema de Informação Gerencial: Um Estudo de Caso em Frigorífico. Revista Cesumar, v. 9, n. 1. 2004.

N. C. Lima; C. E. Ferreira. Algoritmos e estrutura de dados para problemas de deslocamento no plano. IV Simpósio de Iniciação Científica e Jornadas de Iniciação Científica. Rio de Janeiro, 2008.

R. Zamani; L. Y. Shue. Solving Project Scheduling Problems with a Heuristic Learning Algorithm. The Journal of the Operational Research Society, 49(7), 709-716. 1998. doi:10.2307/3010241.

U. Aickelin; A. Clark. Guest Editorial: Heuristic optimisation. The Journal of the Operational Research Society, 62(2), 251-252. 2011. Disponível em $<$ http://www.jstor.org/stable/41058898>.

W. C. de A, Pereira. O método heurístico em pesquisa. Journal Sul-Americano Medicina 1, n.1. p. 21-27, 1979.

\section{COPYRIGHT}

Direitos autorais: $\mathrm{O}(\mathrm{s})$ autor(es) é(são) o(s) único(s) responsável(is) pelo material incluído no artigo. 


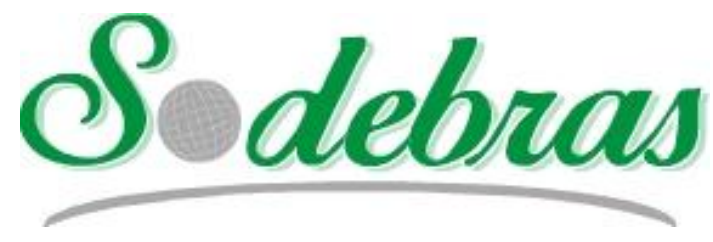

Volume $15-\mathrm{N}^{\mathrm{o}} 169$ - Janeiro / 2020

XLI International Sodebras Congress

31 de outubro a 02 de novembro de 2019 - Maceió - AL.

\title{
CONSTRUINDO MOSAICOS COM O GEOGEBRA: EXPERIMENTAÇÕES E APRENDIZAGENS
}

\author{
BUILDING MOSAICS AS A GEOGEBRA: EXPERIMENTATION AND \\ LEARNING
}

\author{
NÁYRA MILLA DA SILVA SANTOS ${ }^{1}$; JOILMA SILVA CARNEIRO ${ }^{2}$; \\ 1 - COLÉGIO ESTADULA POLIVALENTE DE CONCEIÇÃO DO COITÉ; 2 - UNIVERSIDADE \\ ESTADUAL DE FEIRA DE SANTANA (UEFS); \\ nayrinhamilla@yahoo.com.br; joilma.carneiro@hotmail.com
}

\begin{abstract}
Resumo - Este artigo tem o objetivo de apresentar o estudo dos mosaicos com aplicações para o ensino básico dando direcionalidade à aprendizagem matemática. Esse estudo tornase ainda mais entusiasmante, quando fazemos o uso da Geometria Dinâmica, por isso construímos os mosaicos utilizando o GeoGebra. Mosaico é um padrão que cobre inteiramente o plano sem superposição das figuras, nem espaços vazios entre elas, podendo ser estudado também a partir das operações de simetria que os deixam invariantes. Iniciamos o artigo com a parte histórica para em seguida fazer um tratamento matemático para os mosaicos. Ao final apresentamos um tutorial para construção de um mosaico no GeoGebra.
\end{abstract}

Palavras-chave: Mosaico. GeoGebra. Ensino Básico.

\begin{abstract}
The purpose of this article is to present the study of mosaics with applications for basic education, providing directionality to mathematics learning. This study becomes even more exciting when we use Dynamic Geometry; therefore, we may build the mosaics by applying the GeoGebra. Mosaic is a pattern that completely covers the plane without overlapping figures, or the emptiness among them. It can also be studied from the symmetry operations that leave them invariant. We initiated the article with a historical part in order to give a mathematical treatment for mosaics. At the end, we presented a tutorial about how to build a mosaic in GeoGebra.
\end{abstract}

Keywords: Mosaic. GeoGebra. Basic Education.

\section{INTRODUÇÃO}

Presentes no cotidiano, nas mais variadas formas (esculturas, casas, roupas, etc.), os mosaicos tornam-se atraentes não só pela sua beleza, como também pelo desafio dessa arte milenar em encaixar cada peça, independentemente do material, para montar o padrão, cobrir o plano e deixá-los ainda mais interessantes.

Os Mosaicos são produzidos desde a antiguidade. Não há consenso quanto à data em que esta arte surgiu. Em cada cultura o mosaico teve seu lugar. No Brasil foram introduzidos pelos portugueses, que receberam esse legado dos mouros e ampliaram suas técnicas.

O primeiro a tratar matematicamente os mosaicos foi Joanes Kepler (1997) em seu livro A Harmonia do Mundo publicado em 1619. Nesta obra, ele pontuou detalhes para pavimentar o plano com polígonos regulares ou não, sem sobreposições. Esses polígonos se encontram em um ponto, sendo a soma dos ângulos nesse ponto igual a quatro ângulos retos.

Para construir o mosaico é preciso definir uma célula primitiva, a partir da qual, através de transformações no plano, pavimenta-se a mesma. Um mosaico tem dois vetores linearmente independentes ao longo dos quais pode ser transformado sem mudança e ser classificado segundo tais transformações. Neste artigo, nos limitamos a tratar dos mosaicos para o Ensino Básico.

O estudo dos mosaicos sob o olhar da matemática é recente. O livro Tilings and Patterns de Branko Grünbaum e G. C. Sheppard é a indicação mais completa para simpatizantes do tema. Os polígonos são elementos de um mosaico, mas nem todo conjunto de polígonos pavimenta o plano. Os avanços na tecnologia contribuíram para novas formas de construção dos mosaicos através da Geometria Dinâmica. Um instrumento importante para a construção dos mosaicos é o GeoGebra, um software gratuito. Com o passar dos anos, os recursos tecnológicos tendem a se tornarem mais acessíveis em um contexto em que cada dia há mais expansão tecnológica. Assim, muitas escolas já dispõem de laboratório de informática, que viabiliza esta construção e contribui também para o ensino da Geometria na medida em que a manipulação na tela do computador pode motivar a participação dos alunos.

Assim, apresentaremos na próxima seção, como resultados deste trabalho, um tratamento matemático aos mosaicos, ilustrando com exemplos construídos por essas autoras no GeoGebra. Na seção seguinte apresentaremos a metodologia utilizada, sistematizando um tutorial para a utilização do GeoGebra, a fim de contribuir com a difusão dessa ferramenta para o ensino de matemática no nível básico.

\section{RESULTADOS}

Nos últimos anos, foram descobertos um conjunto finito de ladrilhos com os quais se faz uma quantidade infinita de mosaicos aperiódicos. Um polígono que atrai a atenção dos estudiosos sobre o tema é o pentágono. Com os pentágonos regulares não podemos pavimentar o plano, porém, com alguns irregulares sim. Atualmente só 15 tipos de pentágonos irregulares pavimentam o plano. O $15^{\circ}$ foi descoberto em 2015, por uma equipe de professores da 
Universidade de Washington, em Bathell, Estados Unidos. Segundo Bellos (2017), a equipe contou com: Casey Mann, Jennifer McLoud - Mann e David Von Derau. Os dois primeiros são professores associados, o último um aluno recém-formado da mesma universidade. Quando Michaël Rao, um matemático do CNRS (Centro Nacional de Pesquisa Científica da França) e da École Normale Supérieure de Lyon, soube da descoberta de Mann e sua equipe, decidiu fazer uma pesquisa exaustiva que completaria a classificação dos pentágonos convexos em mosaicos. Segundo Wolchover (2017), no final de seu algoritmo Rao determinou que apenas os 15 tipos de pentágonos descobertos podem pavimentar o plano.

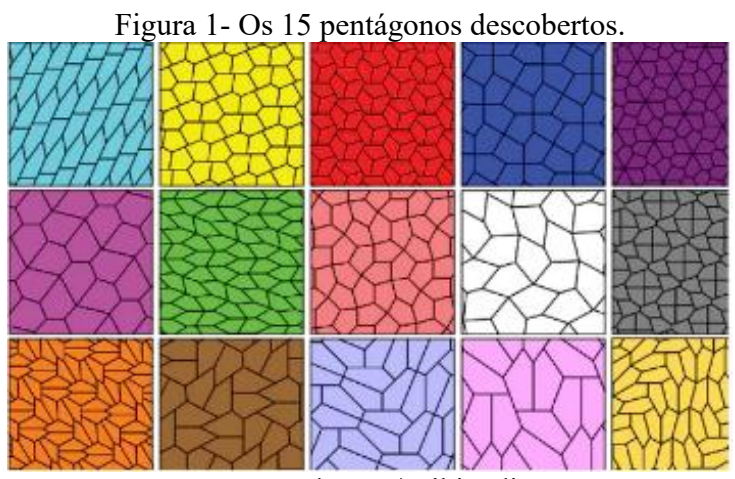

Fonte: Ed Pegg/Wikipedia.

Matematicamente falando, segundo Rousseau (2015), um mosaico é um padrão que pode se repetir para preencher o plano e é periódico ao longo de duas direções linearmente independentes (correspondentes a dois vetores linearmente independentes no plano, ou seja, não paralelos).

Um mosaico tem dois vetores linearmente independentes $t_{1}$ e $t_{2}$, ao longo dos quais pode ser transladado sem mudança. Em outras palavras, é um padrão que cobre inteiramente o plano, sem superposição das figuras, nem espaços vazios entre elas.

Os polígonos são elementos de um mosaico, mas nem todo conjunto de polígonos preenche totalmente o plano. Segundo Barbosa (1993), se o polígono é regular e tem $n$ lados, seu ângulo externo $e=\frac{360^{\circ}}{n}$ e o ângulo interno atende à seguinte condição: $i+e=180^{\circ}$. Supondo que $k$ desses polígonos se ajustem ao redor de um ponto, temos que: $k . i=360^{\circ}$, como $i+e=180^{\circ}$ e $e=\frac{360^{\circ}}{n}$, temos $k=\frac{2 n}{n-2}$. Se um ou dois polígonos ao redor de um ponto forem posicionados, não se conseguirá preencher todo o plano, daí $k \geq 3$ e $n \leq 6$.

Os mosaicos formados por um tipo só de polígono regular são chamados de mosaicos regulares.

Figura 2 - Mosaicos $(4,4,4,4)$

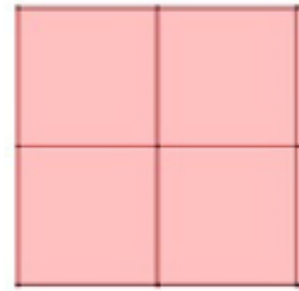

Fonte: Santos e Carneiro, 2019.
Figura 3 - Mosaicos $(3,3,3,3,3,3)$

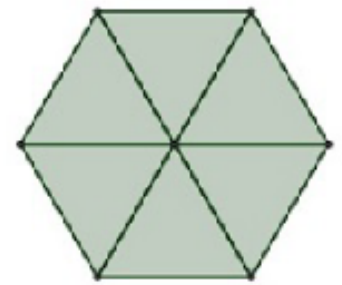

Fonte: Santos e Carneiro, 2019

Figura 4 - Mosaico $(6,6,60)$

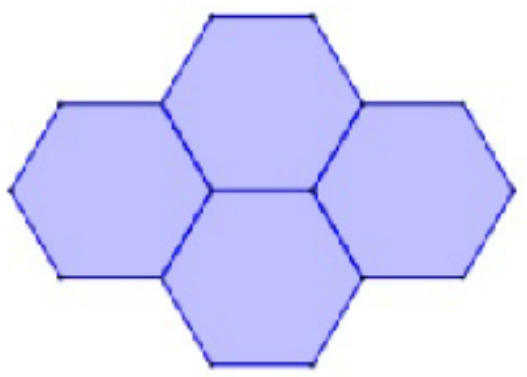

Fonte: Santos e Carneiro, 2019.

Há também os mosaicos Arquimedianos ou semirregulares. São aqueles formados por polígonos regulares, não necessariamente iguais. Existem oito tipos de mosaicos semirregulares no plano euclidiano.

Figura 5 - Mosaico $(3,12,12)$

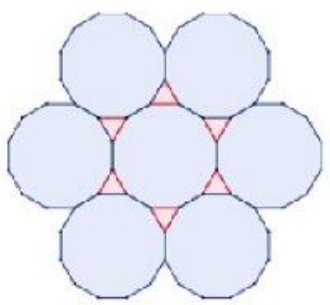

Fonte: Santos e Carneiro, 2019

Figura 6 - Mosaico $(4,8,8)$

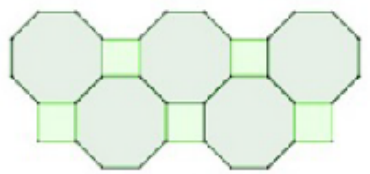

Fonte: Santos e Carneiro, 2019

Figura 7- Mosaico $(4,6,12)$

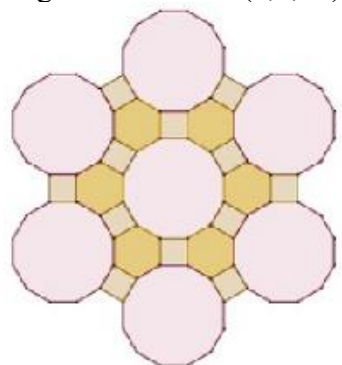

Fonte: Santos e Carneiro, 2019 
Figura 8 - Mosaico $(3,4,6,4)$

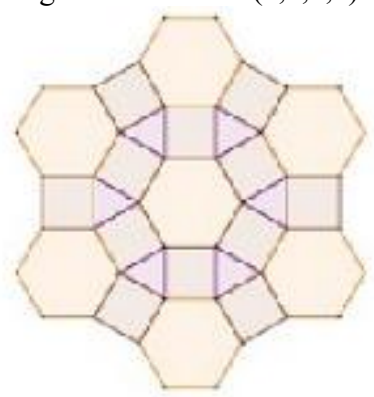

Fonte: Santos e Carneiro, 2019.

Figura 9 - Mosaico(3,6,3,6)

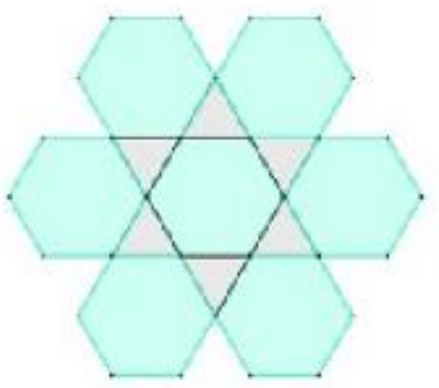

Fonte: Santos e Carneiro, 2019.

Figura 10 - Mosaico $(3,3,4,3,4)$

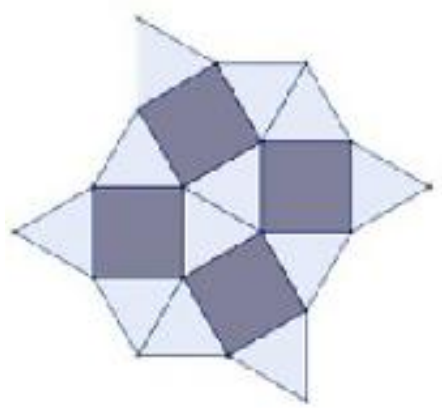

Fonte: Santos e Carneiro, 2019.

Figura 11 - Mosaico(3,3,3,4,4)

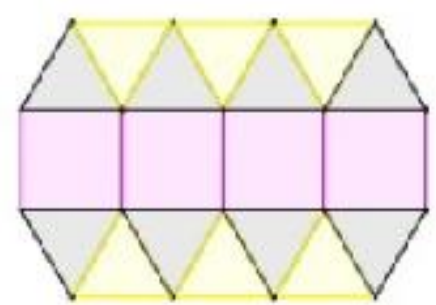

Fonte: Santos e Carneiro, 2019.

Figura 12 - Mosaico(3,3,3,3,6)

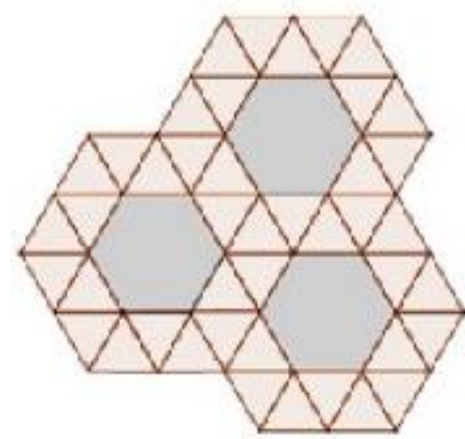

Fonte: Santos e Carneiro, 2019.
Seja $T: \mathbb{R}^{2} \rightarrow \mathbb{R}^{2}$, tal que $u=\left(x_{1}, y_{1}\right), v=\left(x_{2}, y_{2}\right)$ $\in \mathbb{R}^{2}$ e $\alpha \in \mathbb{R}$, uma transformação linear no plano é uma correspondência que associa a cada vetor $v \in \mathbb{R}^{2}$ um vetor $T(v) \in \mathbb{R}^{2}$, de modo que valham as seguintes relações:

- $\quad T(u+v)=T(u)+T(v)$

- $T(\alpha u)=\alpha T(u)$

A translação, determinada pelo vetor $v$, é a transformação que leva cada ponto $\mathrm{P}$ do plano no ponto $T_{V}(P)=P+\nu$. Quando o grupo de simetria de um mosaico não tem pelo menos duas translações não paralelas, eles são considerados não periódicos ou aperiódicos. Por muitos anos, acreditou-se que esse fato seria impossível. Um exemplo de mosaico aperiódico são os mosaicos de Penrose. São chamados assim, pois, foram descobertos pelo físico inglês Roger Penrose em 1974, GARDNER (1990), trata desses mosaicos.

Figura 13 - Mosaico de Penrose

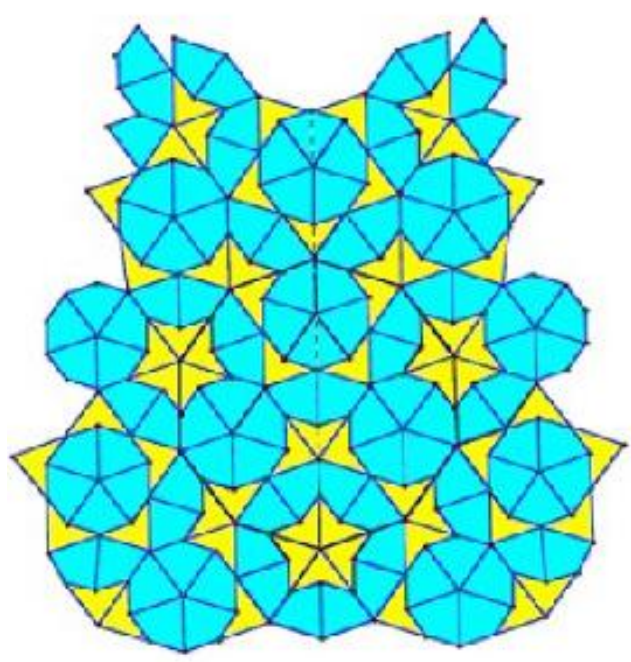

Fonte: Sallun, 2017

\section{METODOLOGIA}

Neste artigo, além de uma revisão bibliográfica, utilizamos um instrumento importante para a construção dos mosaicos: o GeoGebra.

O GeoGebra é um software gratuito de matemática dinâmica, idealizado por Markus Salzburgo, Salzburgo, Áustria. Pode ser baixado do site oficial www.geogebra.org e instalado em computadores, aparelhos celulares e tablets com sistemas operacionais diversos.

A maioria dos mosaicos deste artigo foram construídos no GeoGebra. Quando mosaicos são construídos lida-se quase que simultaneamente com álgebra e geometria. $\mathrm{O}$ GeoGebra facilita esse processo além de torná-lo prazeroso descobrindo propriedades envolvidas nas manipulações das figuras na tela do computador. Segue abaixo o tutorial para construção de um mosaico, lembrando que para cada construção métodos diferentes são utilizados.

Tutorial

Passo 1: Construa o reticulado e identifique a célula primitiva. 


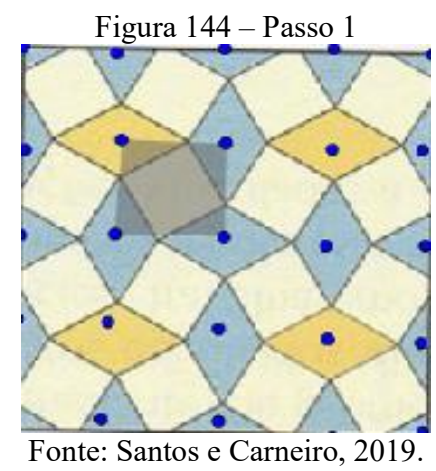

Passo 2: Construa a célula primitiva e verifique quais transformações são usadas para montar o nosso motivo. A célula primitiva é formada por 4 triângulos e 1 quadrado. Construa um triângulo retângulo; Sobre a hipotenusa do triângulo retângulo construa o quadrado; Construa triângulos retângulos sobre os lados do quadrado, sendo que, cada lado do quadrado será a hipotenusa do triângulo.

Passo 3: Na janela de álgebra, clique com o botão direito sobre um polígono e selecione a opção propriedades. $\mathrm{Na}$ janela de preferências, selecione os pontos e desative a opção exibir rótulo. Faça os mesmos para os polígonos e segmentos.

Passo 4: Ainda na janela de preferências, clique sobre o nome do polígono na aba cor e escolha uma. $\mathrm{O}$ tom da cor é dado selecionado na opção transparência.

Figura 15 - Passo 4

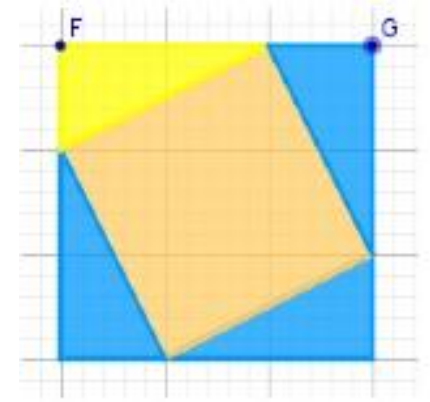

Fonte: Santos e Carneiro, 2019.

Passo 5: Selecione a opção rotação em torno de um ponto e rotacione cada polígono em torno do ponto $\mathrm{F}$, clicando sobre o polígono depois no ponto, pelo ângulo de $180^{\circ}$ no sentido anti-horário.

Passo 6: Selecione a opção reta, em seguida clique sobre os pontos $\mathrm{F}$ e G.

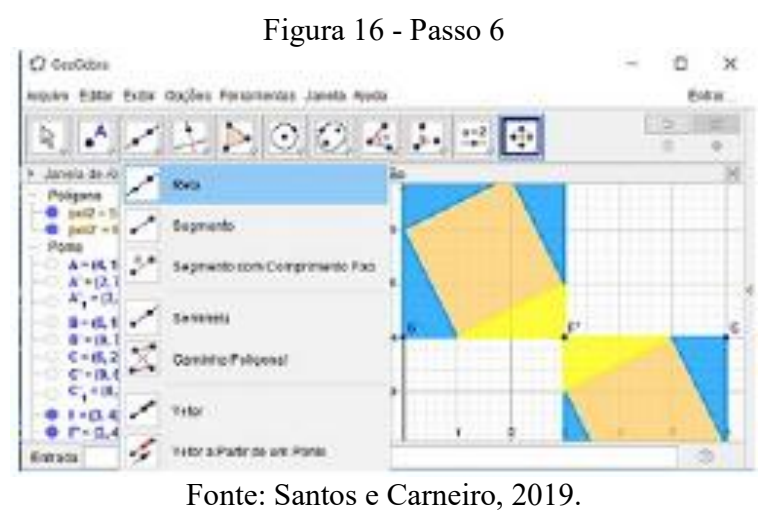

Passo 7: Selecione a opção reflexão em relação a uma reta, que fica no mesmo ícone da rotação em torno de um ponto, em seguida clique sobre o polígono e depois sobre a reta. Repita o procedimento para cada polígono.

Figura 17 - Passo 7

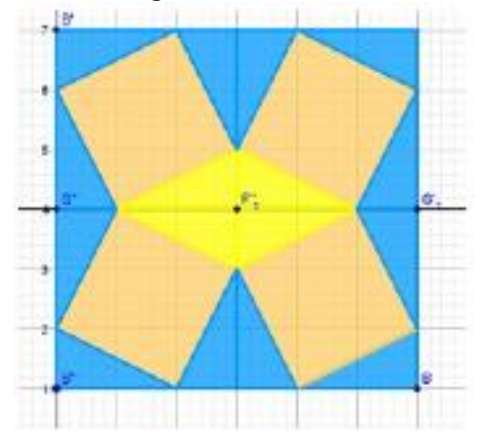

Fonte: Santos e Carneiro, 2019

Passo 8: Depois de construir o motivo, selecione a opção vetor, e clique nos pontos B0 e B00, depois nos pontos B00 e B, construindo os vetores $\mathrm{u}$ e v, respectivamente.

Passo 9: Selecione a opção translação por um vetor, clique em um polígono e depois no vetor u. Repita o procedimento para todos os polígonos.

Passo 10: Mesmo procedimento do passo 9, porém, translade cada polígono pelo vetor $\mathrm{v}$.

Passo 11: $\mathrm{Na}$ janela de álgebra, clique sobre o ponto relacionado a cada vetor, ocultando os mesmos.

Passo 12: Na janela de álgebra, clique com o botão direito sobre um ponto e selecionar a opção propriedades. Em seguida, selecione todos os pontos, desmarque a opção exibir objetos. Faça o mesmo processo para os segmentos, desmarcando a opção exibir objetos. Seguidos os passos, o mosaico estará construído. 


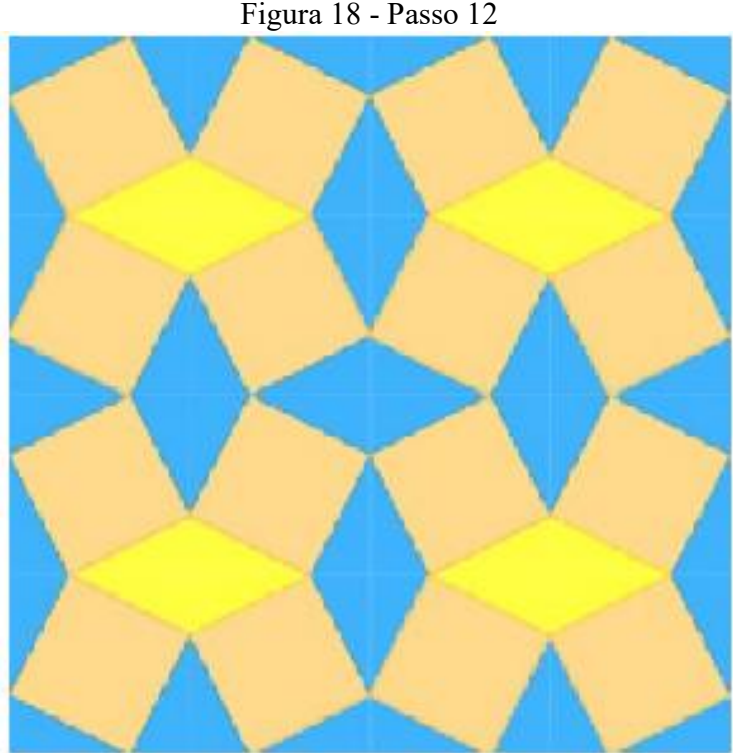

Fonte: Santos e Carneiro, 2019.

\section{CONCLUSÃO}

Neste artigo apresentamos um breve estudo sobre os mosaicos, sob o olhar da matemática, culminando em um tutorial para construção dos mesmos utilizando o GeoGebra.

As tecnologias educacionais nos permitem desenvolver atividades investigativas, baseadas em construções e transformando o fazer matemático dos estudantes. Segundo Gardanidis et al. (2014), as descobertas de padrões ou singularidades entre representações de objetos matemáticos propulsiona a produção de sentidos matemáticos.

A representação dos objetos matemáticos através dos mosaicos dá direcionalidade à aprendizagem matemática. A sua construção através do GeoGebra, permite que essa aprendizagem aconteça a partir de experimentações com tecnologia. Permite que o aluno visualize, crie e experimente objetos geométricos. Desta forma, permite aos alunos descobrirem propriedades envolvidas nas manipulações das figuras na tela do computador, tornando a aprendizagem mais significativa.

Diante de tais estudos, percebemos o quão vasto são os mosaicos e a gama de possibilidades para conexões com as mais variadas áreas da matemática em todos os níveis de ensino. Nos limitamos ao ensino básico. Um estudo voltado ao ensino superior requer uma abordagem matemática mais elaborada.

\section{REFERÊNCIAS BIBLIOGRÁFICAS}

BARBOSA, Ruy Madsen. Descobrindo Padrões em Mosaicos. São Paulo: Atual, 1993.

BELLOS, Alex. Attack on the pentagon results in Discovery of new mathematical tile. Disponível em $:<$ http://www.theguardian.com/science/alexs-adventures-innumberland/2015/aug/10/attack-on-the-pentagon-results-indiscovery-of-new-mathematical-tile $>$. Acesso em: 04 jan. 2017.

GADANIDIS, George; BORBA, Marcelo Carvalho e SILVA, Ricardo S. Rodrigues. Fases das tecnologias digitais em Educação Matemática: Sala de aula e internet em movimento. Autêntica Editora, 2014.

GARDNER, Martin. Mosaicos de Penrose y Escotillas Cifradas. Barcelona: Editorial Labor, 1990.

GRÜNBAUM, Branko; G. C., Shephard. Tilings and Patterns. New York: Freeman \& Co, 1987.

KEPLER, Johannes. The Harmony of the World. Vol. 209. Translated into English with an introduction and Notes by: E. J. Aiton, A.M. Duncan e J. V. Field. By the American Philosophical Society, 1997.

ROUSSEAU, Christiane e SAINT-AUBIN, Yvan. Matemática e atualidade. Vol. 1. Rio de Janeiro: SBM, 2015.

SALLUN, Elvia Mureb. Ladrilhamentos. Disponível em: $<$ http://www.ime.usp.br/matematica/textos/ladrilhamentos.p df/>. Acesso em: 20 jan.2017.

WOLCHOVER, Natalie. Pentagon Tiling Proof Solves Century - Old Math Problem. Disponível em: $<$ http:// https://www.quantamagazine.org/pentagon-tiling-proofsolves-century-old-math-problem-20170711/>. Acesso em: 09 out. 2019.

\section{COPYRIGHT}

Direitos autorais: As autoras Náyra Milla da Silva Santos e Joilma Silva Carneiro, são as únicas responsáveis pelo material incluído no artigo. 


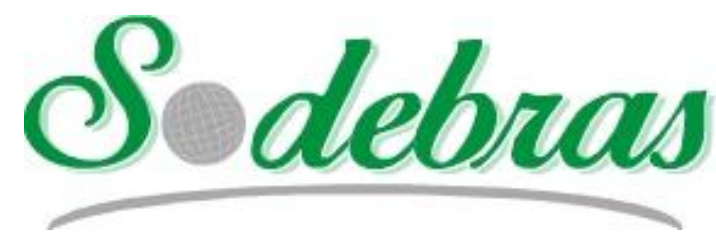

Volume $15-\mathrm{N}^{\mathrm{o}} 169$ - Janeiro / 2020

XLI International Sodebras Congress

31 de outubro a 02 de novembro de 2019 - Maceió - AL.

\title{
LINGUAGEM DO PARADIGMA ORIENTADO A NOTIFICAÇÕES: COMPARATIVOS VIA SIMULADOR DE TRÁFEGO
}

\section{NOTIFICATION ORIENTED PARADIGM LANGUAGE: COMPARISONS THROUGH TRAFFIC SIMULATOR}

\section{FABIO NEGRINI ${ }^{1}$; LEONARDO FAIX PORDEUS ${ }^{1}$; ROBSON RIBEIRO LINHARES ${ }^{1}$; JEAN MARCELO $\mathrm{SIMÃO}^{1}$}

\author{
1 - UNIVERSIDADE TECNOLÓGICA FEDERAL DO PARANÁ \\ negrini@alunos.utfpr.edu.br; leonardopordeus@alunos.utfpr.edu.br; linhares@utfpr.edu.br; \\ jeansimao@utfpr.edu.br
}

\begin{abstract}
Resumo - O Paradigma Orientado a Notificações (PON) é um novo paradigma de desenvolvimento de sistemas que vem se mostrando eficiente $e$ aplicável a diversas áreas, tanto em software quando em hardware. $O$ PON é composto de pequenas entidades computacionais que se comunicam por meio de notificações, o que leva a não redundância de processamento $e$ desacoplamento das mesmas. A mais recente materialização do PON é a linguagem LingPON. Este artigo apresenta um comparativo de desempenho de processamento, baseado no problema de controle de tráfego, entre um sistema feito em LingPON, com outros dois sistemas equivalentes feitos com programação imperativa (PI). Um deles feito em Programação Orientada a Objetos (POO) e outro em Programação Reativa (PR). Nos resultados se observa um desempenho computacional do LingPON próximo de POO e superior a PR, demonstrando a potencial viabilidade do LingPON em termos de desempenho.
\end{abstract}

Palavras-chave: Linguagem de Programação. Paradigma Orientado a Notificações. Comparativos.

\begin{abstract}
The Notification Oriented Paradigm (NOP) is a new paradigm for system development that has been shown to be efficient and applicable to many areas, such as software and hardware. NOP is composed of small computational entities that communicate through notifications, which leads to nonredundancy of processing and decoupling of them. The latest materialization of PON is the LingPON language. This paper presents a performance comparison, based on a traffic control problem, between a system made in LingPON, with two other equivalent systems made with imperative programming (IP). One of them done in Object Oriented Programming (OOP) and the other in Reactive Programming (RP). The results show a computational performance of LingPON close to OOP and higher than RP, demonstrating the potential viability of LingPON in terms of performance.
\end{abstract}

Keywords: Programming Language. Notification Oriented Paradigm. Comparative.

\section{INTRODUÇÃO}

Os sistemas computacionais têm exigido soluções de softwares que apresentem melhor desempenho, com métodos e ferramentas que tornem o processo de seu desenvolvimento cada vez mais produtivo e eficiente (BORKAR e CHIEN, 2011). Neste âmbito, uma técnica alternativa de desenvolvimento de software é o chamado Paradigma Orientado a Notificações (PON).

O PON é, em suma, uma nova abordagem para o desenvolvimento de sistemas computacionais. O PON tende a apresentar melhor desempenho, permitir maior nível de abstração e proporciona facilidades para o desacoplamento de entidades, o que facilita paralelismo/distribuição em comparação com sistemas baseados em subparadigmas tradicionais. Dentre os subparadigmas usuais, salienta-se a Programação Procedimental e a Programação Orientada a Objetos (POO) do Paradigma Imperativo (PI), assim como os Sistemas baseados em Regras (SBR) do paradigma declarativo (PD) (VAN ROY, 2009). Estes subparadigmas apresentam deficiências com relação a redundâncias estruturais/temporais e forte acoplamento entre suas entidades, diminuindo assim o desempenho e gerando maior dificuldade de paralelização e distribuição (SIMÃO e STADZISZ, 2009) (ASANOVIć, BODIK, et al., 2006).

$\mathrm{O}$ diferencial do PON em relação as soluções usuais como POO e SBR reside em suas entidades factoexecucionais (i.e., entidades com atributos e métodos) e lógico-causais (i.e., entidades de regras com condições e ações). Todas estas entidades colaboram por meio de notificações pontuais e precisas, portanto não acoplantes e não redundantes, as quais constituem um eficiente mecanismo de inferência colaborativo que surge automaticamente a partir de sistemas descritos de forma orientada a regras (SIMÃO e STADZISZ, 2009).

Para avaliar a eficiência do PON no tocante a desempenho, neste artigo são apresentados os experimentos e resultados de comparações entre um dado software implementado em PI, primeiro na forma de Programação Orientada a Objetos (POO) (STROUSTRUP, 2013) e depois, particularmente, na forma de programação reativa (PR) (REACTIVEX, 2017), com uma implementação equivalente feita em PON. Tais comparações são efetuadas por meio da análise de tempo de execução da implementação de um software de Controle de Trânsito Automatizado (CTA) sobre um simulador de trânsito chamado CTA Simulator.

Neste software, mais precisamente, os módulos responsáveis pelo controle são implementados tanto em PI 
Figura 1. Colaboração por notificações das entidades do PON

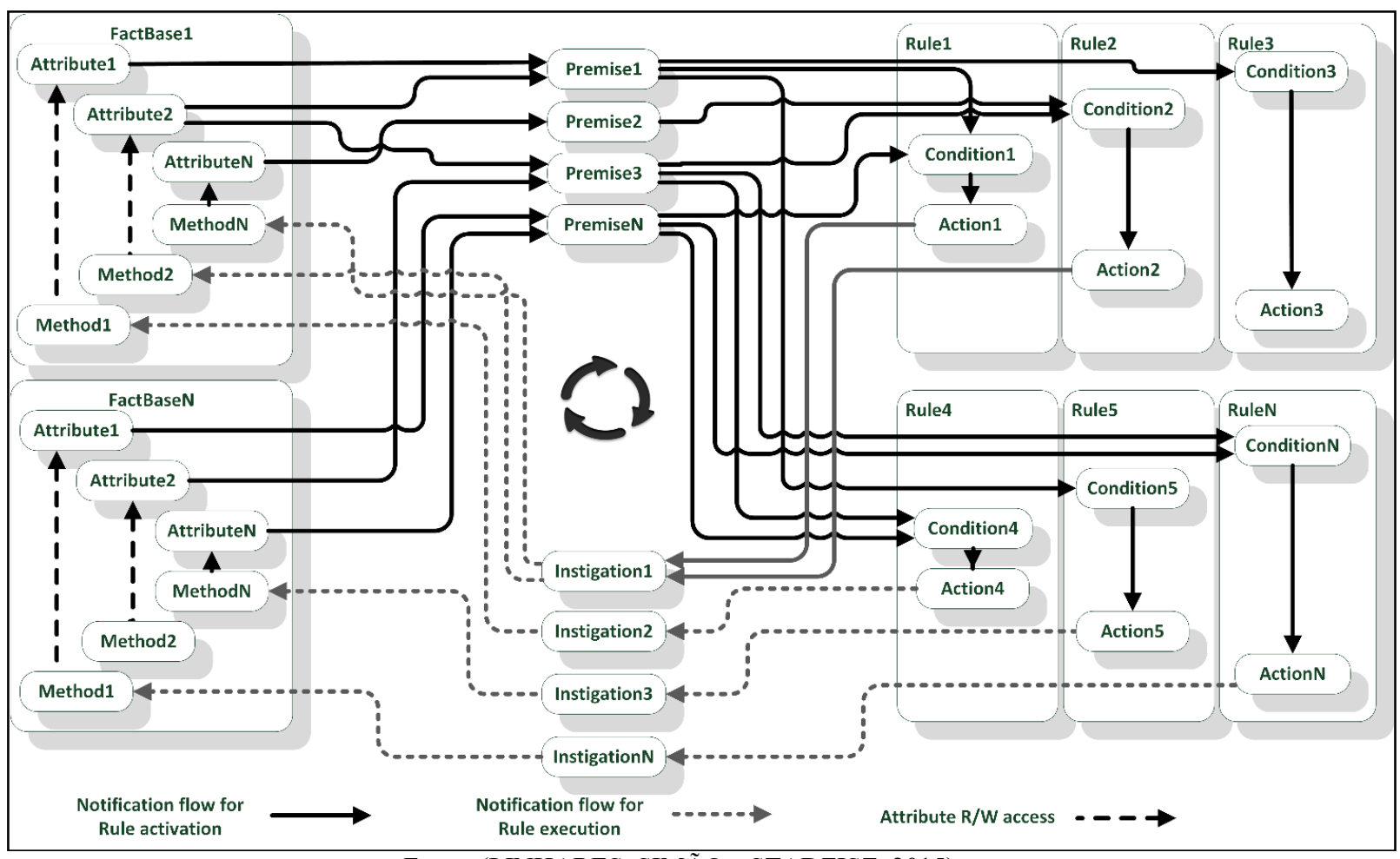

Fonte: (LINHARES, SIMÃO e STADZISZ, 2015)

$\mathrm{C}++$ (POO $\mathrm{C}++$ usual e $\mathrm{PR} \mathrm{C}++$ multithread) quanto em uma linguagem própria do PON, chamada de LingPON. Isto permite uma comparação de desempenho com POO em uma aplicação com maior número de regras que a feita em (RONSZCKA, BELMONTE, et al., 2011) e a comparação de desempenho de LingPON (e mesmo PON) com a programação reativa

\section{PARADIGMA ORIENTADO A NOTIFICAÇÕES (PON)}

O PON foi proposto como um novo paradigma de desenvolvimento de software, que apresenta algumas vantagens quando comparado aos paradigmas tradicionais, mais especificamente, o Paradigma Imperativo (PI) e o Paradigma Declarativo (PD). Tais vantagens dizem respeito ao seu modelo de execução por notificações e mesmo à forma de expressão de suas entidades lógico-causais e factoexecucionais.

As vantagens são constituídas, em suma, por uma maior facilidade na concepção de sistemas que apresentem paralelismo ou distribuição (RONSZCKA, BANASZEWSKI, et al., 2015) (BELMONTE, LINHARES, et al., 2016) (RONSZCKA, FERREIRA, et al., 2017), bem como da redução ou mesmo eliminação de alguns dos problemas clássicos de software PI e PD, tais como redundâncias de execução e acoplamento excessivo entre entidades computacionais, sem perder as vantagens da programação lógico-declarativa em alto nível (RONSZCKA, FERREIRA, et al., 2017).

Em termos de expressão, PON pode ser utilizado na forma de um sistema orientado a regras. Estruturalmente, entretanto, o software PON é representado na forma de entidades, estas nomeadas de Elementos da Base de Fatos (FBE - Fact Base Element) e as Regras (Rules) conforme apresentado em forma de diagrama na Figura 1. As entidades $F B E$ são utilizadas para representar objetos do mundo (real ou abstrato) em um sistema computacional, por meio de estados (atributos) e serviços (métodos).

Os elementos Rules, por sua vez, definem o cálculo lógico-causal a ser efetuado sobre os estados dos FBEs, controlando a execução dos seus serviços. A colaboração entre estes elementos ocorre por meio de notificações diretas e pontuais, que é um processo de inferência essencialmente distinto dos processos de busca utilizados em SBR do PD, e mais diferente ainda da maneira de se programar PI, orientado a laços de repetição.

Nos FBEs, os estados (atributos) são representados por meio de instâncias do tipo Attribute, enquanto os serviços dessas entidades (métodos) são representados por meio de instâncias do tipo Method. O elemento Rule é composto por uma condição, representada pela instância do tipo Condition, e uma ação, representada pela instância do tipo Action.

Cada Condition efetua um cálculo relacional ou causal sobre o valor de uma ou duas premissas, representadas por instâncias do tipo Premise. Estas são responsáveis por efetuar o cálculo lógico-causal sobre os valores dos Attributes de um FBE. Cada Action, por sua vez, faz referência a uma ou mais instâncias do tipo Instigation, por meio das quais é capaz de disparar Methods de FBEs.

Ainda na Figura 1 é possível observar as relações de envio e recebimento de notificação de um software PON. As quatro linhas em negrito representam o fluxo de notificações para a ativação das Rules (cálculo lógico-causal), ao passo que as linhas mais claras representam o fluxo para a execução das Rules (cálculo factual).

Do ponto de vista dinâmico, cada vez que o valor de um Attribute (i.e., atSemaphoreState) é modificado, o próprio Attribute notifica as entidades Premise que dependem do seu valor. Cada uma destas Premises, por sua vez, tem seu valor lógico reavaliado por meio do cálculo lógico que a define, o qual opera sobre o novo valor do Attribute que a 
notificou e também sobre um segundo valor. Este segundo valor pode ser o valor de outro Attribute previamente notificado. No exemplo da Figura 2, foi utilizado um valor constante 35 .

Figura 2. Exemplo de Rule para controle independente

\begin{tabular}{|l|}
\hline Rule rlHorizontalTrafficLightGreen \\
\begin{tabular}{|l|l|}
\hline Condition & \multirow{2}{*}{ Premises } \\
FBE Semaphore_NOP Attribute atSeconds = 2 AND & \\
\hline FBE Semaphore_NOP Attribute atSemaphoreState $=35$ & Instigations \\
\hline \begin{tabular}{|l}
\hline Action \\
Instigate FBE Semaphore_NOP mtHorizontalTrafficlightGreen
\end{tabular} \\
\hline
\end{tabular} \\
\hline
\end{tabular}

Fonte: (Autores, 2019)

Cada Premise cujo resultado lógico tenha sido alterado notifica um conjunto de entidades Conditions que dela dependem. Assim, cada uma destas Conditions também tem seu estado lógico reavaliado de acordo com o novo valor notificado e demais valores lógicos das Premises nela armazenados.

Ainda no exemplo da Figura 2, se o Attribute atSeconds ou o Attribute atSemaphoreState forem alterados, a Premise correspondente será notificada para fazer sua avaliação lógica. Se o resultado alterar seu estado lógico, esta Premise notificará a Condition definida para a Rule rlHorizontalTrafficLightGreen, enviando o seu novo valor lógico. A Condition, em seguida, recalculará o seu valor lógico a partir da operação lógica AND definida.

Se o valor lógico da entidade Condition é calculado como verdadeiro, esta aprova a execução da sua respectiva Rule. Com isso, a entidade Action agregada a esta Rule notifica as Instigations às quais está conectada. As Instigations, por sua vez, disparam os Methods correspondentes, que podem ser executados sequencialmente e/ou de forma concorrente. A execução dos Methods gera o processamento facto-execucional que atualiza Attributes dos FBEs, reiniciando o ciclo.

Inicialmente, para o desenvolvimento de softwares fazendo uso do PON, foram elaborados frameworks em $\mathrm{C}++$, permitindo a criação de softwares PON, implementando o mecanismo de orientação a notificações na linguagem $\mathrm{C}++$. Subsequentemente, surgiram frameworks similares em C\# e Java. Nos testes feitos usando esses frameworks, os resultados de testes de desempenho em média, foram razoáveis quando comparados ao $\mathrm{POO} \mathrm{C}++$ tradicional e muito bons quando comparados com RBS Clips Rete (RONSZCKA, BANASZEWSKI, et al., 2015). Também houve uso de framework $\mathrm{PON} \mathrm{C}++$ para programação multicore com balanço fino, bem como um recente framework PON em Elixir, sendo os resultados apropriados graças inclusive a propriedades de desacoplamento do PON (BELMONTE, LINHARES, et al., 2016) (NEGRINI, RONSZCKA, et al., 2019).

Outrossim, visando inclusive melhorar o desempenho esperado do PON, atualmente há o desenvolvimento de uma linguagem de programação chamada LingPON, a qual permite geração de códigos específicos $\mathrm{C}$ e/ou $\mathrm{C}++$ seguindo os conceitos do PON, com tempos de resposta melhores que as materializações em framework (RONSZCKA, FERREIRA, et al., 2017).

Outras pesquisas também exploraram a aplicação do PON em hardware digital (PON-HD) com uso de lógica reconfigurável. No PON-HD cada implementação se constitui em um circuito em FPGA implicitamente e altamente paralelo (KERSCHBAUMER, LINHARES, et al., 2017) (SIMÃO, LINHARES, et al., 2012).

Apoiado na propriedade do PON-HD, foi proposta a aplicação em lógica reconfigurável de um coprocessador PON (CoPON). Com isso, alcançou-se uma solução híbrida na qual o processamento factual-execucional da aplicação é executada em um núcleo von Neumann e o processamento lógico-causal via propagação de notificações é executada no CoPON (PETERS, 2012).

Ainda, uma arquitetura computacional inteira foi desenvolvida de acordo com o modelo do PON, sendo denominada Notification-Oriented Computer Architecture (NOCA) (LINHARES, SIMÃO e STADZISZ, 2015) (LINHARES, 2015). Por fim, associada à arquitetura, há também um simulador chamado NOCASim que permite, dentre outros, testar sua escalabilidade da NOCA (PORDEUS, 2017).

\section{METODOLOGIA}

Nesta seção são apresentados os objetivos e características o software CTA Simulator, que será utilizado para avaliação do PON em termos de LingPON, frente ao POO e PR do PI. Em tempo, a especificação detalhada do CTA foi elaborada por outrem e encontra-se em (RENAUX, LINHARES, et al., 2015).

Os objetivos do projeto CTA Simulator são desenvolver estratégias de controle de semáforos, simular regiões de tráfego em uma área urbana, comparar o desempenho das estratégias e comparar a complexidade quando as estratégias de controles forem implementadas em paradigmas diferentes, como o PI e o PON.

\section{1 - Simulador}

O simulador representa elementos do mundo real, como veículos, ruas, pistas, quadras, sinaleiros, sensores e cruzamentos em uma região de simulação matricial composta por dez ruas verticais e 10 ruas horizontais de mão única, formando uma matriz $10 \times 10$ com um total de 100 interseções.

Cada interseção da região simulada é composta por dois sinaleiros, um em cada rua, que têm os mesmos estados de um sinaleiro do mundo real: verde, amarelo e vermelho. Para a aplicação, a união de um sinaleiro para a rua vertical e outro para a rua horizontal é chamada de semáforo.

Em todas as quadras são instalados sensores que monitoram a quantidade de veículos que estão parados em um sinal vermelho. Esses sensores apresentam três estados em função da taxa de ocupação da rua: $F E W$ (menor que $60 \%$ ), MANY (entre $60 \%$ e $99 \%$ ) e FULL $(100 \%)$. Todos os detalhes do simulador estão disponíveis em (RENAUX, LINHARES, et al., 2015). 
Figura 3. Exemplo de FBE e Rule para estratégia controle independente

\begin{tabular}{|c|c|}
\hline $\begin{array}{l}\text { fbe Semaphore_NOP } \\
\text { attributes } \\
\text { integer atSeconds } 0 \\
\text { integer atSemaphoreState } 5 \\
\text { end_attributes } \\
\text { methods } \\
\text { method mtResetTimer(atSeconds = 0) } \\
\text { method mtHorizontalTrafficLightGREEN(atSemaphoreState = ) } \\
\text { method mtHorizontalTrafficLightYELLOW(atSemaphoreState = 1) } \\
\text { method mtHorizontalTrafficLightRED }(\text { atSemaphoreState = 2) } \\
\text { method mtVerticalTrafficLightGREEN(atSemaphoreState = 3) } \\
\text { method mtVerticalTrafficLightYELLOW(atSemaphoreState = 4) } \\
\text { method mtVerticalTrafficLightRED (atSemaphoreState = 5) } \\
\text { end_methods } \\
\text { end_fbe }\end{array}$ & $\begin{array}{l}\text { rule rlHorizontalTrafficLightGreen } \\
\text { condition } \\
\text { subcondition sbHorizontalTrafficLightGreen } \\
\text { premise imp prSeconds semaphore_NOP.atSeconds == } 2 \text { and } \\
\text { premise prSemaphoreState semaphore_NOP.atSemaphoreState == } 5 \\
\text { end_subcondition } \\
\text { end_condition } \\
\text { action } \\
\text { instigation inHTLG semaphore_NOP.mtHorizontalTrafficLightGREEN(); } \\
\text { end_action } \\
\text { end_rule }\end{array}$ \\
\hline
\end{tabular}

Fonte: (Autores, 2019)

A arquitetura de software referente ao CTA foi dividida em dois módulos: um módulo de simulação e outro de controle de estratégias, de forma que seja possível implementar o controle dos semáforos em paradigmas de programação diferentes. Para o desenvolvimento do simulador, foi utilizada a linguagem $\mathrm{C}++$ com o ambiente de desenvolvimento Visual Studio 2017 Professional. As estratégias de controle, no tocante a este trabalho, foram desenvolvidas em PI ( $\mathrm{C}++\mathrm{POO}$ usual e $\mathrm{C}++\mathrm{POO} / \mathrm{PR}$ via threads), com a mesma linguagem do simulador, e em PON por meio da geração de código em LingPON para $\mathrm{C}$ e $\mathrm{C}++$ específico e orientado a notificações.

\section{2 - Estratégias de controle}

Para o simulador CTA, foram levantadas três alternativas de estratégia de controle de semáforos: controle independente, controle baseado em congestionamento e controle baseado em tráfego facilitado.

$\mathrm{Na}$ estratégia de controle independente (CI), cada semáforo possui tempos fixos para cada estado do sinaleiro, não sendo considerados os sensores de quantidade de veículos e tempos de semáforos vizinhos.

$\mathrm{Na}$ estratégia de controle baseada em congestionamento (CBCL), são avaliados o tempo de cada semáforo e o estado referente à quantidade de veículos parados. Se o sensor detecta que a porcentagem de veículos parados está entre $60 \%$ até $100 \%$ e o tempo do sinaleiro em vermelho é menor do que 24 segundos, então o tempo total do sinaleiro no estado vermelho é ajustado para 30 segundos. Caso o sensor detecte que a taxa de ocupação está entre $60 \%$ e $100 \%$ e o tempo do semáforo vermelho está entre 25 segundos e 39 segundos, o sinaleiro oposto se altera imediatamente para o estado amarelo e o tempo restante do sinaleiro no estado vermelho é ajustado para 6 segundos. Se o sensor detectar que a ocupação está entre $60 \%$ e $100 \%$, e o tempo do sinaleiro em vermelho for maior do que 39 segundos, não é realizada nenhuma alteração no tempo do sinaleiro.

$\mathrm{Na}$ estratégia de controle baseada em tráfego facilitado (CBTF), para cada semáforo, uma de suas direções (vertical ou horizontal) possui um flag identificando que esta deve ter o tráfego facilitado. Neste método de controle, cada semáforo conhece o estado do semáforo posterior na direção do tráfego facilitado. Aqui também há todos os controles de congestionamento descritos na estratégia CBCL. Desta forma, quando o semáforo é acelerado para mudança de sinal em função de veículos parados, este também notifica o próximo semáforo que deverá acelerar a passagem para verde antecipando o aumento de veículos que virá com a abertura acelerada do semáforo. Desta forma, há então uma sincronização das aberturas em uma onda verde. Esta estratégia representa uma maior complexidade, além de obrigar uma integração entre os semáforos criando assim um maior conjunto de objetos no processo de análise de decisão.

\section{3 - Desenvolvimento de Estratégias de controle}

Os experimentos realizados tiveram como objetivo analisar o desempenho das estratégias de controle implementadas em PON, comparadas às implementações em PI (POO e PR) afim de fazer um comparativo à luz da eficiência da primeira em relação às demais. Para isso, foram desenvolvidas as três estratégias em ambos os paradigmas, sendo que, para o PI foi utilizada a abordagem clássica orientada a objetos e, subsequentemente, também a PR. Conforme descrito na Seção 3.2, cada implementação ocupou-se de inferir apenas na estratégia de controle. Desta forma, foi possível garantir um ambiente equivalente, portanto comparável, para todas as implementações. A seguir serão detalhados os aspectos mais importantes de cada implementação apresentada neste artigo.

Desenvolvimento POO/PI. Para a aplicação das estratégias de controle em POO/PI C++, a lógica foi implementada por meio de estruturas de decisão if-else aninhadas. Nas aplicações, as três estratégias se distinguiram pela complexidade e número de variáveis de controle consideradas em cada proposta de solução, para resolução das regras de mudança de estados dos sinaleiros que representam cada estratégia de controle conforme descritas em (RENAUX, LINHARES, et al., 2015).

Desenvolvimento de Programação Reativa. A programação reativa (PR) foi incorporada por propor uma forma de desenvolvimento com um viés muito próximo do PON, pois esta facilita o desenvolvimento declarativo de aplicativos orientados a eventos, permitindo que os desenvolvedores expressem programas em termos de "o que fazer" e deixe a linguagem gerenciar "quando fazer" (BAINOMUGISHA, CARRETON, et al., 2013). Para este desenvolvimento foi feito uso de componentes disponibilizados pelo projeto ReactiveX (REACTIVEX, 2017) que cria tarefas (threads) assíncronas. No entanto, o projeto herdou exatamente as mesmas regras lógicas de implementação da programação imperativa (PI). Desta forma, o processo se diferencia por distribuir em diferentes tarefas as mesmas etapas implementadas em POO. 
Desenvolvimento em PON. Para fazer a aplicação das estratégias de controle descritas na Seção 3.2 em PON, foram codificadas as regras em aplicações específicas LingPON (RONSZCKA, FERREIRA, et al., 2017) que, por sua vez, foram compiladas para $\mathrm{C}++$ com código específico e orientado a notificações. Esta implementação gerou as classes específicas derivadas da classe Semaphore presente no simulador. Desta forma, cada estratégia gerou uma classe derivada de Semaphore que foi incorporada ao projeto. Para implementação da estratégia CI através de LingPON, os atributos foram descritos em $F B E$ conforme apresentado na Figura 3. Por sua vez, cada transição de estado do sinaleiro foi traduzida para uma regra (Rule) que também pode ser vista na Figura 3. Foram criadas no total seis regras, cada uma delas possui duas Premises, o estado e o tempo do semáforo.

$\mathrm{Na}$ implementação da estratégia $\mathrm{CBCL}$ o $F B E$ Semaphore_NOP_CBCL contém os mesmos Attributes do FBE Semaphore_NOP e foram adicionados Attributes dos sensores de congestionamento para os sinaleiros horizontais e verticais, além dos métodos que alteram seus estados.

No desenvolvimento desta estratégia foi necessário criar novas Rules para implementação do controle baseado em congestionamento em PON, sendo dezoito o total de Rules implementadas e oito dessas Rules possuem avaliações de congestionamento através dos sensores.

Para aplicação da estratégia CBTF, de maneira análoga às suas antecessoras, foram implementadas vinte e três Rules, que avaliam o tempo, o estado atual, sensor de congestionamento e a flag de tráfego facilitado de cada semáforo. O FBE Semaphore_NOP_CBTF contém os mesmos Attributes da FBE Semaphore_NOP_CBCL e foram adicionados Attributes de identificação de tráfego facilitado e de reconhecimento que a onda verde precisa ser propagada. Este segundo Attribute é utilizado na comunicação entre um semáforo e seu sucessor na sequência da rua.

Como resultante do desenvolvimento desta estratégia, foi criado um total de vinte e duas novas Rules. Sendo que oito dessas Rules possuem avaliações de congestionamento através dos sensores e quatro possuem avaliações de propagação de onda observando sua condição de onda verde e a notificação pelo semáforo anterior.

\section{RESULTADOS}

Para executar os experimentos foi utilizado um notebook com processador core i5 - 4210U $1.70 \mathrm{GHz}$ e $6 \mathrm{~GB}$ de memória RAM, com sistema operacional Windows 10 Pro. Para análise dos experimentos de desempenho, a aplicação foi executada alterando o número de ciclos de simulação: 100, 200, 500, 1000, 1500 e 2000, na qual cada ciclo representa 1 segundo do semáforo.

A Tabela 1 e a Figura 4 apresentam os resultados dos experimentos executados, que correspondem ao tempo de execução em milissegundos das duas estratégias implementadas, alterando o número de ciclos. Para maior assertividade de valores, foi utilizado o menor valor acumulado de tempo de execução da estratégia em um universo de cinco repetições.
Tabela 1. Resultados do experimento em milissegundos

\begin{tabular}{|l|c|c|c|c|c|c|}
\hline Strategy & $\mathbf{1 0 0}$ & $\mathbf{2 0 0}$ & $\mathbf{5 0 0}$ & $\mathbf{1 0 0 0}$ & $\mathbf{1 5 0 0}$ & $\mathbf{2 0 0 0}$ \\
\hline Independent POO & 18190 & 31122 & 60330 & 105776 & 162869 & 203745 \\
\hline Independent PON & 20108 & 34006 & 66012 & 116871 & 179978 & 224451 \\
\hline Independent PR & 22702 & 41005 & 77014 & 139006 & 211092 & 266121 \\
\hline CBCL POO & 23214 & 33599 & 73207 & 141390 & 206444 & 265619 \\
\hline CBCL PON & 25868 & 37041 & 81020 & 155129 & 229112 & 297212 \\
\hline CBCL PR & 32614 & 44090 & 94532 & 189019 & 267381 & 344981 \\
\hline CBTF POO & 26483 & 37180 & 77409 & 141104 & 213560 & 390205 \\
\hline CBTF PON & 30108 & 40980 & 86439 & 155659 & 235456 & 430212 \\
\hline CBTF PR & 37065 & 48989 & 98080 & 190212 & 285091 & 508121 \\
\hline \multicolumn{7}{|c|}{ Fonte: (Autores, 2019) }
\end{tabular}

A partir dos dados da Tabela 1 e da Figura 4 observouse que a implementação em PON teve desempenho ligeiramente inferior quando comparado ao da implementação em POO e desempenho superior em comparação à implementação em PR. Tendo em vista a facilidade da composição das Rules derivada da programação lógica, a nova técnica trazida pelo PON se apresenta bastante promissora. Isto se dá inclusive porque os resultados são efetivamente próximos da implementação em POO. Ademais, o LingPON está sendo evoluído em termos de seu compilador, sendo que os tempos de processamento estão melhorando à luz de experimentos posteriores aos experimentos aqui apresentados.

Figura 4. Gráfico dos resultados do experimento em milissegundos

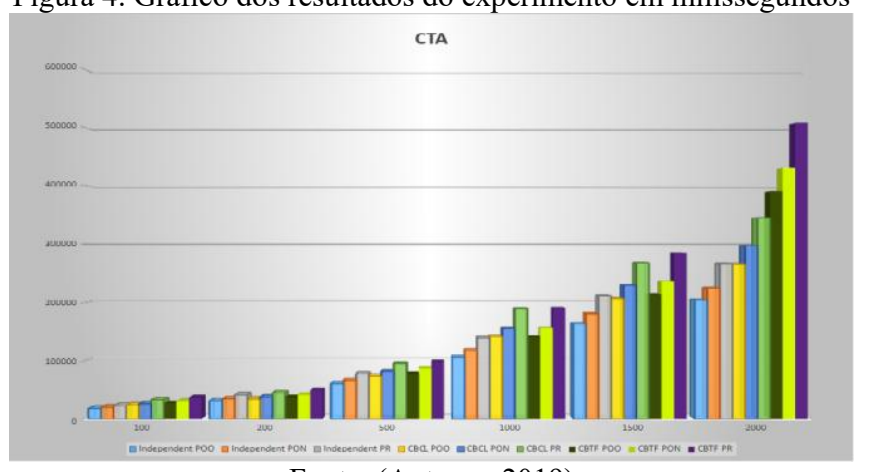

Fonte: (Autores, 2019)

Em todo caso, não é usual uma abordagem orientada a regras ter tempo de desempenho similar ao imperativo, sendo geralmente o tempo daquela, dezenas de vezes maior (VAN ROY, 2009). Neste sentido, na sua materialização antiga chamada de framework $\mathrm{PON} \mathrm{C}++1.0$ já foi comparado com o RBS Clips Rete compilado e apresentou melhores resultados, sendo o Rete a melhor máquina de inferência industrial utilizada (RONSZCKA, BANASZEWSKI, et al., 2015). Em suma, nos experimentos passados, o PON obteve melhores resultados da ordem de seis vezes em relação a sua implementação em framework (antiga e computacionalmente mais custosa, por usar estruturas de dados em C++ STL) (RONSZCKA, BANASZEWSKI, et al., 2015).

\section{CONCLUSÃO}

O PON apresenta uma alternativa para o desenvolvimento e execução de softwares em comparação aos paradigmas tradicionais. Este novo paradigma se propõe a resolver problemas tais como redundâncias estruturais e temporais, bem como o forte acoplamento entre as suas entidades, visando facilitar o desenvolvimento e execução de softwares paralelos e distribuídos.

Este trabalho apresentou o desenvolvimento de uma aplicação para a comparação de desempenho entre software 
desenvolvido em PON via a LingPON (1.0) e software desenvolvido em PI (POO e PR) via $\mathrm{C}++$. Apesar de resultados de desempenho ainda ligeiramente inferiores em relação ao POO, a avaliação dos resultados permite elaborar conclusões a respeito do potencial desta nova técnica, visto que o PON possui menor complexidade de desenvolvimento tendo em vista sua facilidade de declarações lógico causais herdada da programação orientada a regras (RONSZCKA, FERREIRA, et al., 2017).

Quando realizados os experimentos, comparando a implementação da aplicação CTA Simulator em ambos os paradigmas, a implementação em POO se demonstrou ligeiramente mais eficiente em relação à implementação equivalente em PON, ficando esta cerca de 10,5\% em média mais lento que POO no teste de 2000 ciclos e 9,5\% em média mais lento nos testes de 100 ciclos. Na comparação com $\mathrm{PR}$, o PON foi mais rápido cerca de $17 \%$ em média no teste de 2000 ciclos e $25 \%$ em média mais rápida nos testes de 100 ciclos.

Entretanto, a tecnologia LingPON utilizada foi ainda prototipal, sendo que está em curso o desenvolvimento de tecnologias mais maduras, que explore as propriedades do PON de maneira mais apropriada. Assim, há a tendência desses tempos de processamento diminuírem uma vez que tecnologia de compilador pertinentes explorem o potencial do PON e ao mesmo tempo o compilador em si amadureça (RONSZCKA, 2019).

Ainda, com relação à complexidade de desenvolvimento, no PON as Rules do sistema podem ser visualizadas de maneira mais natural, pois o nível de abstração das Rules é maior, quando comparado às abstrações das mesmas transições desenvolvidas em linguagem imperativa. Isto se constitui em uma consequência natural da herança da programação lógicodeclarativa aplicada no PON, i.e., a orientação à regras.

$\mathrm{O}$ uso da linguagem LingPON é promissor, à luz dos seus resultados atuais e de materializações outras do PON para multicore e para hardware, que já permitem a execução concorrente/paralela de maneira implícita (NEGRINI, RONSZCKA, et al., 2019). Neste sentido, com o avanço no estado da técnica do LingPON, como otimizações do compilador, inclusão de estruturas de dados e garantias de determinismo, será possível gerar código de maneira mais eficiente, em maior nível de abstração e supostamente menor tempo de desenvolvimento para plataformas distintas, incluso as paralelas (RONSZCKA, 2019).

\section{REFERÊNCIAS BIBLIOGRÁFICAS}

ASANOVIć, K. et al. The Landscape of Parallel Computing Research: A View from Berkeley. [S.1.]: EECS Department, University of California, Berkeley, 2006.

BAINOMUGISHA, E. et al. A Survey on Reactive Programming. ACM Comput. Surv., New York, NY, USA, v. 45, n. 4, p. 52:1 -52:34, Agosto 2013.

BELMONTE, D. L. et al. A new Method for Dynamic Balancing of Workload and Scalability in Multicore Systems. IEEE Latin America Transactions, p. 3335-3344, 2016. ISSN 1548-0992.

BORKAR, S.; CHIEN, A. A. The Future of Microprocessors. Communications of the ACM, 2011. 67-77.

KERSCHBAUMER, R. et al. Notification-Oriented Paradigm to Implement Digital Hardware. Journal of Circuits, Systems and Computers, nov. 2017.
LINHARES, R. R. Contribuição para o desenvolvimento de uma arquitetura de computação própria ao paradigma orientado a notificações. Curitiba: CPGEI, UTFPR, 2015. Tese de doutorado.

LINHARES, R. R.; SIMÃO, J. M.; STADZISZ, P. C. NOCA - A Notification-Oriented Computer Architecture. IEEE Latin America Transactions, v. 13, p. 1593-1604, 2015. ISSN 15480992.

NEGRINI, F. et al. NOPL-Erlang: Programação multicore transparente em linguagem de alto nível. V Escola Regional de Alto Desempenho do Rio de Janeiro (ERAD-RJ 2019), Rio de Janeiro, Setembro 2019.

PETERS, E. Co-processor to Speed up of Application developed under the Notification Oriented Paradigm. CPGEI-UTFPR. Curitiba, Brasil. 2012.

PORDEUS, L. F. Simulação de uma arquitetura de computação própria ao paradigma orientado a notificações. Curitiba: CPGEI-UTFPR, 2017. Dissertação de mestrado.

REACTIVEX. Reactive Extensions for C++. Reactive Extensions for $\mathbf{C + +}$, 2017. Disponivel em: <https://github.com/ReactiveExtensions/RxCpp>. Acesso em: 01 mar. 2017.

RENAUX, D. P. B. et al. CTA CONOPS. CTA CONOPS, 2015. Disponivel em: $<$ http://www.dainf.ct.utfpr.edu.br/ douglas/CTA_CONOPS.pdf $>$. Acesso em: 01 mar. 2017.

RONSZCKA, A. F. Método para a criação de linguagens de programação e compiladores para o paradigma orientado a notificações em plataformas distintas. Curitiba: CPGEI-UTFPR, 2019. Tese de doutorado.

RONSZCKA, A. F. et al. Qualitative and quantitative comparisons between Object Oriented Paradigm and Notification Oriented Paradigm based on play simulator. III Internacional Congress of Computationm and Telecomunications (Congreso Internacional de Computación y Telecomunicaciones COMTEL, Lima, Peru, 2011.

RONSZCKA, A. F. et al. Notification-Oriented and Rete Network Inference: A Comparative Study. IEEE International Conference On Systems, Man and Cybernetics Conference, Hong-Kong, China, Outubro 2015

RONSZCKA, A. F. et al. Notification-Oriented Programming Language and Compiler. 2017 VII Brazilian Symposium on Computing Systems Engineering (SBESC), 2017. 125-131.

SIMÃO, J. M. et al. Paradigma Orientado a Notificações em Hardware Digital. BR 102012026429 3, 2012. Patent pending submitted to INPI/Brazil in 2012 and UTFPR Innovation Agency (2012). INPI Provisory Number: BR 1020120264293.

SIMÃO, J. M.; STADZISZ, P. C. Inference Based on Notifications: A Holonic Metamodel Applied to Control Issues. IEEE Transactions on Systems, Man, and Cybernetics - Part A: Systems and Humans, v. 39, p. 238-250, Jan 2009. ISSN $1083-4427$

STROUSTRUP, B. The C ++ Programming. 4th. ed. [S.1.]: Addison-Welsey, 2013. 1346 p. ISBN 9780321563842.

VAN ROY, P. Programming Paradigms for Dummies: What Every Programmer Should Know. [S.1.]: New Computational Paradigms for Computer Music, 2009.

\section{AGRADECIMENTOS}

Agradecimentos a Douglas P. B. Renaux et al pela especificação do CTA e à equipe de pesquisa do PON. 


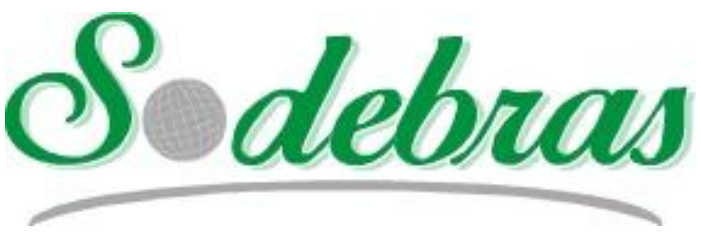

Volume 15 - $\mathrm{N}^{\mathrm{o}} 169$ - Janeiro / 2020

XLI International Sodebras Congress

31 de outubro a 02 de novembro de 2019 - Maceió - AL.

\title{
PARÂMETROS CRÍTICOS NA AVALIAÇÃO GEOMÉTRICA DE VIAS DE TRANSPORTE DE MINA A CÉU ABERTO: UMA ABORDAGEM MULTIVARIADA

\author{
CRITICAL PARAMETERS IN THE GEOMETRIC ASSESSMENT OF OPEN PIT \\ MINE HAUL ROADS: A MULTIVARIATE APPROACH
}

\author{
NAVARRO TORRES, V.F ${ }^{1}$; SILVEIRA, L.G.C ${ }^{1,2}$; CUNHA, F.P. ${ }^{3}$. AYRES, J ${ }^{3}$. \\ 1 - INSTITUTO TECNOLÓGICO VALE; 2 - UNIVERSIDADE FEDERAL DE OURO PRETO; 3 - VALE \\ S.A. \\ vidal.torres@itv.org; leandro.silveira@itv.org; fernando.cunha@vale.com; jane.ayres@vale.com
}

\begin{abstract}
Resumo -São vários os parâmetros que devem ser levados em consideração durante o desenvolvimento dos trechos, contudo observa-se que boa parte do conhecimento aplicado é empírico. Procurando identificar o impacto dos parâmetros geométricos de vias de transporte, utilizou-se de estatística multivariada para analisar e avaliar a correlação das variáveis e quais são de fato significativas na velocidade dos caminhões fora de estrada, afetando diretamente a produtividade das operações. Para coleta de dados utilizou-se informações de rotas de transporte de um complexo minerador, localizado no Quadrilátero Ferrífero. Como resultado observou-se que o grade e o raio de curvatura são os parâmetros geométricos de maior relevância, sendo determinantes quanto a produtividade do transporte no circuito, negligencia-los pode afetar diretamente o custo operacional.
\end{abstract}

Palavras-chave: Vias de transporte. Parâmetros geométricos. Estatística multivariada.

\begin{abstract}
There are several parameters that must be taken into account during the development of the sections, however, it is observed that much of the applied knowledge is empirical. In order to identify the impact of the geometric parameters of the haul roads, multivariate statistics was used to analyze and evaluate the correlation of the variables and which are indeed significant in the speed of off-highway trucks, directly affecting the productivity of operations. For data collection information of haul routes of a mining complex, located in the Quadrilatero Ferrifero were used. As a result, it was observed that the grid and the radius of curvature are the most relevant geometric parameters, being determinants as the haul productivity in the circuit, neglecting them can directly affect the operational cost.
\end{abstract}

Keywords: Haul roads. Geometric parameters. Multivariate statistics.

\section{INTRODUÇÃO}

A atividade mineradora é composta por vários seguimentos e processos que em conjunto determinam a capacidade produtiva do sistema. Em uma operação de lavra a céu aberto convencional o desenvolvimento de vias de transporte é fundamental para sua viabilização, contudo sua importância ainda é tratada de maneira discreta. Para Thompson (2015) a rede rodoviária de transporte é um item crítico e vital no processo produtivo e o baixo desempenho de uma via de transporte impactará imediatamente nos custos das operações, bem como na segurança e longevidade dos caminhões e seus componentes.
Basicamente para se projetar uma estrada mineira são considerados alguns parâmetros de projeto geométrico, tais como: largura, raio de curvatura e inclinação de rampa (SOUZA et al., 2012).

A falta de padronização e o desenvolvimento tácito destas vias de transporte faz com que não tenhamos como determinar a relevância dos itens geométricos adotados durante seu planejamento, haja visto que sua característica pode afetar diretamente a velocidade do caminhão e assim o tempo de viagem. Este, é o termo utilizado na mineração para determinar o tempo de percurso de um veículo de sua origem ao destino, incluindo seu retorno. Já que os aspectos geométricos das estradas de mina podem influenciar na performance dos equipamentos de transporte, sobretudo no tempo de viagem dos caminhões fora de estrada, e assim consequentemente na produtividade, o presente estudo busca, mediante estatística multivariada, ponderar o impacto parâmetro geométrico no tempo de trajeto dos caminhões fora de estrada e assim na produtividade dos mesmos.

A Estatística Multivariada pode ser compreendida como o conjunto de métodos estatísticos utilizados em ocasiões onde se tem um grande número de variáveis medidas simultaneamente em cada elemento da amostra. $\mathrm{Na}$ mineração as técnicas de estatística multivariadas encontram amplo campo de aplicação, uma vez que os trabalhos envolvem um grande número de parâmetros medidos ao mesmo tempo e que, em geral, tem correlação entre si (MINGOTI, 2013).

Inicialmente, no que diz respeito à aplicação da técnica de componentes principais na mineração e em áreas correlatas, o maior campo de aplicação era na prospecção geoquímica, que tinham como objetivo interpretar as relações mineralógicas e aprofundar o conhecimento geológico da área. Nesse contexto, destacam-se os trabalhos de McCammon (1975), Guillaume (1977), Le Maître (1982) e Andriotti et al. (1989). Já Bernardi et al. (2001) fizeram o uso da técnica para avaliar o impacto ambiental da emissão de um efluente no Rio Paraíba do Sul. O autor destacou a importância da técnica para identificação das variáveis mais influentes na qualidade da água.

Gomes (2005) utilizou a técnica juntamente com a geoestatística para interpretar a distribuição espacial de elementos-traço nos sólidos em suspensão no Alto do Rio 
Madeira e afluentes. O estudo foi apoiado no levantamento hidrogeoquímico realizado na região.

Shang et al. (2010) utilizaram a técnica de análise das componentes principais juntamente com as redes neurais artificiais para classificar e interpretar eventos microssísmicos e detonações em uma pedreira na China. Foram registrados vinte e dois parâmetros a partir de mil e seiscentos eventos, envolvendo variáveis tais como: energias de ondas $\mathrm{P}$ e $\mathrm{S}$, tempo total dos registros sísmicos, queda de tensões estática dentre outras avaliadas. A técnica das componentes principais foi eficaz em reduzir o número de dimensões do conjunto de dados, no qual foram mantidas as dez primeiras componentes, conservando $88 \%$ da variabialidade do sistema.

Pandey, Agrawal e Singh (2012) também aplicaram a técnica de análise das componentes principais para avaliar os principais poluentes atmosféricos em uma mina de carvão na Índia. Os loadings das três primeiras componentes que foram mantidas por apresentarem autovalores maior que um e representar cerca de $79 \%$ da variância total acumulada. Tais componentes permitiram identificar a fonte dos componentes, tais como: $\mathrm{Cu}, \mathrm{Ni}, \mathrm{PM}$ 1, PM 2,5, PM 10, $\mathrm{SO} 2$, que apresentaram altos loadings na primeira componente foram indicadas como lavra de carvão. SO2, PM 10, PM 2.5 foram interpretados como queima de carvão e o $\mathrm{SO} 2, \mathrm{Ni}$ e $\mathrm{Cu}$ como fogos ativos na mina.

Santos (2016) fez o uso da técnica juntamente com a análise discriminante para prever a condição de estabilidade de taludes de mina. O autor utilizou um banco de dados fornecido por Naghadehi et al. (2013) que apresentava 84 taludes coletados em diferentes locais do mundo com 18 variáveis relacionadas a parâmetros geomecânicos e características dos taludes, e uma variável qualitativa relacionada às condições de estabilidade dos taludes. $\mathrm{O}$ estudo mostrou, mediante o score plot das primeiras componentes mostrando que quando a componente assume valores positivos o talude apresenta condição estável, caso contrário instável. Dessa forma, foi possível interpretar que a primeira componente responde pela estabilidade dos taludes do banco de dados.

Nesse sentido, o presente estudo utiliza da análise das componentes principais para quantificar a influência de parâmetros geométricos de vias de transporte na velocidade de caminhões fora de estrada em uma mina do Quadrilátero Ferrífero.

\section{METODOLOGIA}

Três aspectos foram fundamentais a serem avaliados:

- Seleção de unidades amostrais (mina/trajeto) para os estudos;

- Compilação das informações de modo que seja possível demonstrar a relevância do objeto de estudo.

Posteriormente, foi selecionado o banco de dados, que expressa a velocidade provável dos caminhões fora de estrada da marca Caterpillar, modelos: 793 C (maior payload e maior potência), $789 \mathrm{D}$ e $777 \mathrm{G}$ (menor payload e menor potência), por trajetos principais nas minas $\mathrm{X}$ e $\mathrm{Y}$ do complexo minerador em estudo, considerando um período de 12 meses corridos entre os anos de 2016 e 2017 . Tal base de dados estima a velocidade do caminhão vazio e carregado por trecho, considerando os seguintes parâmetros geométricos:
- Grade;

- Raio de curvatura (somente nas curvas, onde foram identificadas curvas mais acentuadas);

- Superelevação (somente nas curvas mais acentuadas);

- Largura da estrada (constante no banco de dados);

- Resistência ao rolamento (estimada empiricamente a partir do grade).

Foram selecionados seis trajetos do complexo minerador, sendo três para mina $\mathrm{X}$ e três para mina $\mathrm{Y}$. Os mesmos foram selecionados com base em sua relevância em termos de distância e massa/hora trabalhada de transporte. Estes trechos representam caminhos com alto fluxo de caminhões e impacto direto na estratégia operacional das minas. Neste sentido tais rotas possuem amostra representativa e robustez de parâmetros para aplicação da técnica de estatística multivariada: análise das componentes principais com o intuito de verificar a influência dos parâmetros geométricos na velocidade e assim no tempo de viagem. Mais ainda, foi selecionado o modelo de caminhão CAT 793 C para análise, pois neste complexo minerador dispõe-se de uma frota composta por cinquenta e três CAT 793 C, sete CAT 789 D e dois CAT 777 G em operação. Dessa forma, a escolha pelo CAT 793 C é mais representativa.

Para a aplicação da técnica das componentes principais, foram considerados os dados de:

- velocidade;

- grade;

- resistência ao rolamento;

- raio de curvatura;

Devido ao fato da base de dados mapear apenas os raios de curvatura mais fechados, foi adotado o procedimento do cálculo do raio de curvatura por trecho baseado no cálculo do raio para uma circunferência definida por três pontos, conforme equações (1), (2) e (3) e assim obter mais dados, requisito para a análise multivariada.

$$
\begin{aligned}
& x=\left(x_{1}^{2}+y_{1}^{2}\right) \cdot\left(y_{2}-y_{3}\right)+\left(x_{2}^{2}+y_{2}^{2}\right) \cdot\left(y_{3}-y_{1}\right)+\left(x_{3}{ }^{2}+y_{3}{ }^{2}\right) \cdot\left(y_{1}-\right. \\
& \left.y_{2}\right) / 2\left(x_{1}\left(y_{2}-y_{3}\right)-y_{1}\left(x_{2}-x_{3}\right)+x_{2} y_{3}-x_{3} y_{2}\right) \\
& x=\left(x_{1}^{2}+y_{1}^{2}\right) \cdot\left(x_{3}-x_{2}\right)+\left(\quad x_{2}{ }^{2}+y_{2}{ }^{2}\right) \cdot\left(x_{1}-x_{3}\right)+\left(x_{3}{ }^{2}+y_{3}{ }^{2}\right) \cdot\left(x_{2}-\right. \\
& \left.x_{1}\right) / 2\left(x_{1}\left(y_{2}-y_{3}\right)-y_{1}\left(x_{2}-x_{3}\right)+x_{2} y_{3}-x_{3} y_{2}\right) \\
& r=\left(\left(x-x_{1}\right)^{2}+\left(y-y_{1}\right)^{2}\right)^{1 / 2}
\end{aligned}
$$

Onde:

$x$ e $y$ : coordenadas do centro da circunferência definida por três pontos;

$x_{1}, y_{1}, x_{2}$ e $y_{2}$ : coordenadas dos pontos anterior e sucessor ao ponto central onde define-se o raio da circunferência, respectivamente;

$r$ : raio de curvatura.

As rotas atribuídas neste estudo na Mina $\mathrm{X}$ foram:

- Rota A;

- Rota B;

- Rota C

Já para a Mina $\mathrm{Y}$ foram: 
- Rota D;

- Rota E;

- Rota F

A largura de estrada e a superelevação não foram incluídas na análise visto foi verificado que as minas não apresentavam problemas de grandes variações de largura de pistas principais, acessos e a superelevação ser registrada apenas nas curvas mais acentuadas. Tais rotas são mostradas nas Figuras 1 e 2.

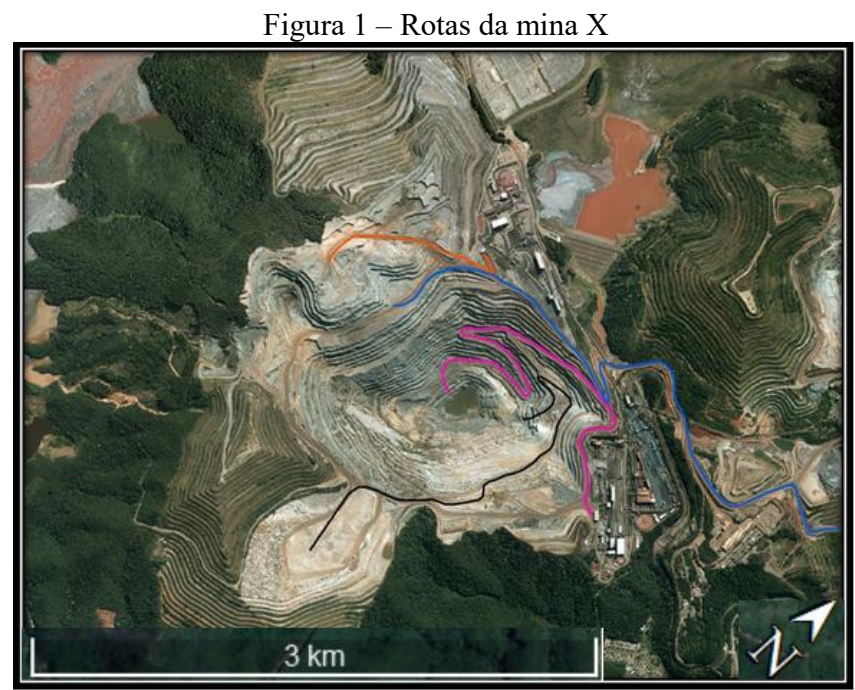

Fonte: Autores, 2019.

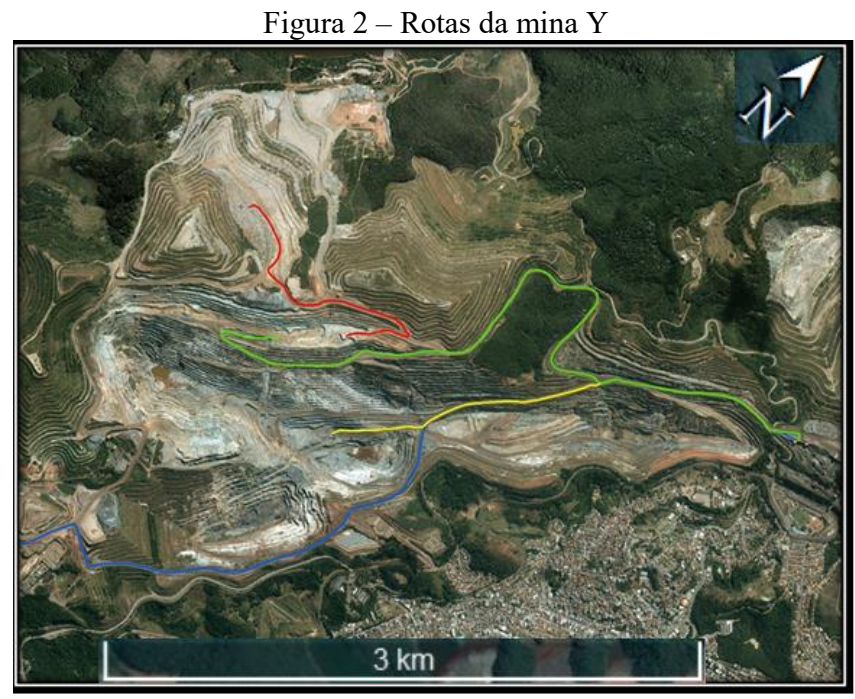

Fonte: Autores, 2019.

\section{RESULTADOS}

A fim de verificar a influência dos parâmetros geométricos na velocidade do caminhão $793 \mathrm{C}$, maior frota do complexo minerador e assim no tempo de viagem na rota A foi realizada a técnica das componentes principais. Primeiramente foi realizada a técnica de detecção de outliers multivariada, a chamada Distância de Mahalanobis. Identificados os valores anômalos, estes foram removidos e novamente verificados como mostra a Figura 3. Como nenhum dos valores ultrapassou o limite superior de 3,129, logo não há mais outliers.
Feito isso, partiu-se para o procedimento das análises das componentes principais como mostra o resultado do software MiniTAB na Figura 4.

Observa-se que somente a primeira componente explica $61,2 \%$ de toda a variabilidade do sistema, já somente a segunda explica $24,8 \%$ da variabilidade e quando juntas correspondem a $86,1 \%$ da variabilidade total do conjunto de dados. Então, para a escolha do número de componentes principais a serem consideradas nas análises aplicou-se o critério de conservar as componentes com variâncias iguais ou maiores que um segundo scree-plot (Figura 5). Logo manteve-se as duas primeiras componentes como mostram as equações (4) e (5).

Figura 3 - Identificação de outliers pela Distância de Mahalanobis.

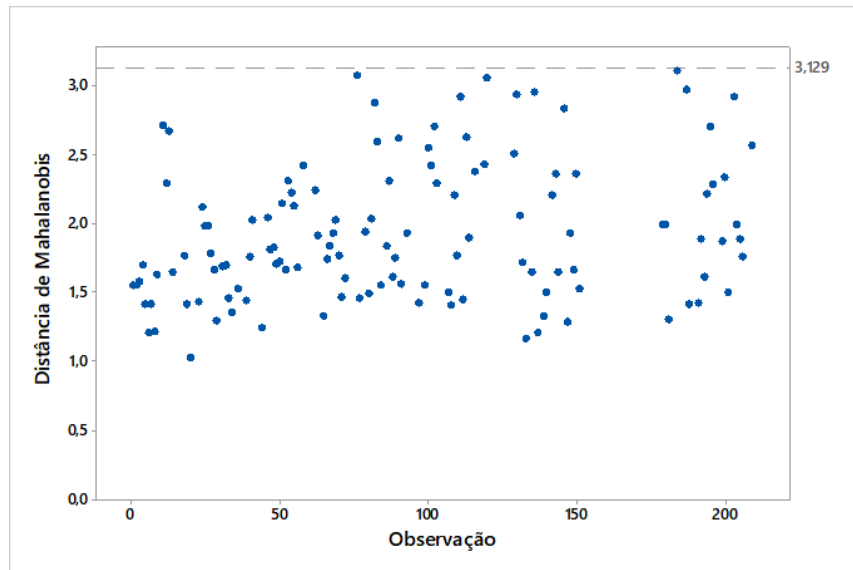

Fonte: Autores, 2019.

Figura 4 - Output do software MiniTAB para análise das componentes principais.

Eigenanalysis of the Correlation Matrix 125 cases used, 84 cases contain missing values

$\begin{array}{lrrrr}\text { Eigenvalue } & 2,4493 & 0,9932 & 0,5202 & 0,0374 \\ \text { Proportion } & 0,612 & 0,248 & 0,130 & 0,009 \\ \text { Cumulative } & 0,612 & 0,861 & 0,991 & 1,000\end{array}$

$\begin{array}{lrrrr}\text { Variable } & \text { PC1 } & \text { PC2 } & \text { PC3 } & \text { PC4 } \\ \text { vel_ida_793 } & 0,571 & 0,020 & 0,602 & 0,558 \\ \text { grade_ida_793 } & 0,522 & 0,064 & -0,790 & 0,315 \\ \text { RR_ida_793 } & -0,629 & -0,042 & -0,113 & 0,768 \\ \text { RC_ida } & 0,071 & -0,997 & -0,034 & -0,001\end{array}$

Fonte: Autores, 2019.

Figura 5 - Scree-plot das componentes principais

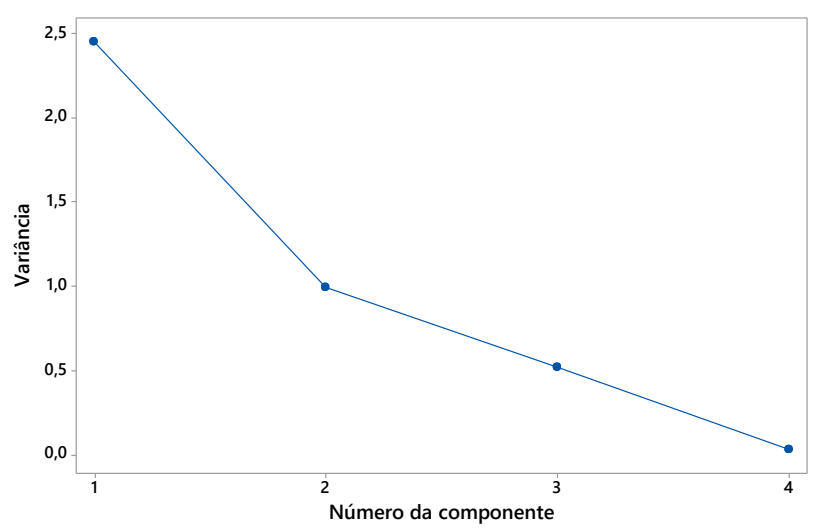

Fonte: Autores, 2019. 
$\mathrm{Y}_{1}=0,571 \mathrm{~V}+0,522 G-0,629 R R+0,071 R C$

$\mathrm{Y}_{2}=0,020 \mathrm{~V}+0,064 G-0,042 R R-0,997 R C$

Onde:

$V$ : é a velocidade do caminhão $793 \mathrm{C}(\mathrm{km} / \mathrm{h})$;

$G$ : é o grade da via (\%)

$R R$ : é a resistência ao rolamento da via (\%);

$R C$ : é o raio de curvatura $(\mathrm{m})$;

Visto que o perfil do trajeto estudado é predominantemente um declive, a primeira componente principal refere-se a um comparativo da resistência ao rolamento com a velocidade e o grade. À medida que a resistência ao rolamento aumenta, a velocidade tende a diminuir e visto que o perfil predominantemente do trajeto estudado é um declive, à medida que o grade diminui, isto é, aumenta-se a declividade, uma menor resistência ao rolamento poderá estar atuando ali. O raio de curvatura apresenta um peso (loading) menor nessa componente em comparação às outras variáveis, logo não apresenta muita relevância nesta comparação.

Já a segunda componente pode ser interpretada como a influência do raio de curvatura e da resistência ao rolamento na velocidade e no grade. Cabe aqui ressaltar a maior relevância do raio de curvatura, dado seu alto loading em relação às demais variáveis. Dessa forma, essa componente assume um significado da influência de baixos valores de raio de curvatura em curvas na velocidade, isto é, na prática, curvas muito fechadas apresentam impacto de redução na velocidade de caminhões, visto que a velocidade assume baixos loadings. O grade apresenta relação inversa ao raio de curvatura, no entanto isto está mais ligado ao fato do perfil predominante de declive do trajeto, que uma diminuição do grade representa uma tendência a maior velocidade e também a uma menor resistência ao rolamento.

Adicionalmente a análise das componentes principais, verifica-se na base de dados coletada uma grande redução da velocidade nos trechos do trajeto A onde estão registradas as curvas mais fechadas (Tabela 1).

Tabela 1 - Redução da velocidade nos raios de curvatura registrados na base de dados original.

\begin{tabular}{llllll}
\hline $\begin{array}{l}\text { Raio } \\
\text { curvatura(m) }\end{array}$ & Ponto & $\mathbf{1}^{\mathbf{a}}$ & $\mathbf{2}^{\mathbf{a}}$ & $\mathbf{3}^{\mathbf{a}}$ & $\mathbf{4}^{\mathbf{a}}$ \\
& curva & curva & curva & curva \\
\hline \multirow{3}{*}{30} & Antecessor & 28,3 & 34,8 & 16,3 & 18,6 \\
& Curva & 20,5 & 18,5 & 10,7 & 10,6 \\
& Sucessor & 29,9 & 34,8 & 34,8 & 14,7 \\
\hline
\end{tabular}

Dessa forma, como já esperado pela análise das componentes principais, o raio de curvatura é um dos principais parâmetros geométricos influenciadores da velocidade e assim no tempo de viagem dos caminhões fora de estrada no complexo minerador

A Tabela 2 mostra um resumo comparativo entre os parâmetros geométricos mais relevantes no tempo de viagem para os trajetos estudados segundo as análises de componentes principais realizadas, com base nos pesos (loadings) que cada variável assumiu nas componentes principais.
Tabela 2 - Valores obtidos durante os testes.

\begin{tabular}{cc}
\hline Trajeto & Parâmetro mais relevante \\
\hline A & Raio de curvatura \\
B & Grade e raio de curvatura \\
C & Grade \\
D & Grade e raio de curvatura \\
E & - \\
F & Grade \\
G & Raio de curvatura \\
\hline
\end{tabular}

A resistência ao rolamento, apesar de não ser um parâmetro essencialmente geométrico, assumiu alta influência na velocidade dos caminhões, logo, deve ser dada uma atenção especial aos materiais construtivos das vias do complexo minerador

No trajeto E os parâmetros geométricos mais relevantes não puderam ser identificados devido à quantidade de outliers e à impossibilidade de tratá-los segundo os métodos estatísticos de estatística básica e multivariada.

\section{CONCLUSÃO}

Foi possível identificar os itens geométricos mais relevantes em relação as rotas estudadas. Estes apresentaram o grade e os raios de curvaturas como itens de grande impacto no tempo de viagem. Vale ressaltar que apesar do grade ser considerado o fator de maior relevância entre os planejadores durante o desenvolvimento das vias, o estudo mostrou que o raio de curvatura tem alto impacto, principalmente no trecho mais longo.

Sugere-se com este resultado um estudo maior quanto a resistência ao rolamento, bem como a gestão de informação das rotas, desenvolvendo uma base de dados mais consistente e robusta para estudos futuros. Foi observado durante a pesquisa uma abstenção de controle de parâmetros de infraestrutura, área esta responsável pela manutenção e construção das vias no âmbito operacional, tal falta reduz a quantidade de números de referência e eventual comparativo de eficiência.

Uma avaliação mais detalhada ou adequação do grade e raios de curvaturas podem ser indicados para as equipes de planejamento de mina concomitante a de operação, já que estes indicaram fatores geométricos de real relevância nos trechos quanto ao impacto no tempo de viagem. Manipular estes itens em função de estratégias operacionais ou gargalos em detrimento da velocidade de transporte devem ser repensados, pois tais aspectos influenciam diretamente não só a capacidade produtiva das minas, como a utilização correta dos ativos e sua preservação, evitando desgastes desnecessários de pneus, combustíveis e vida útil.

O resultado deste trabalho não deve ser generalizado para todas as organizações, pois sabe-se que existem vários fatores que podem interferir no processo produtivo. Questões como o porte da empresa, potencial das minas e estratégias de mercados são itens que promovem diferença na elaboração do planejamento de lavra. Esta pesquisa sugere que empresas que atuem com movimentação de massa através de transporte rodoviários busquem a melhoria contínua do processo em todas suas instâncias, principalmente no que tange a construção de vias, aderindoo como requisito tão importante quanto a determinação de portes de equipamentos entre outros. 


\section{REFERÊNCIAS BIBLIOGRÁFICAS}

ANDRIOTTI, J. L. S. Análise de componentes principais: BERNARDI, J. V. E. FOWLER, H. G. LANDIM, P. M. B. Um estudo de impacto ambiental utilizando análises estatísticas espacial e multivariada. Holos Environment, Rio Claro, v. 1, n. 2, p.162-172, 16 out. 2001. Anual.

CATERPILLAR INC. Manual de Produção. 32 ed. Peoria, E.U.A.,2007.

CRUZ, C. D. Aplicação de algumas técnicas multivariadas no melhoramento de plantas. Tese (Doutorado em Genética e Melhoramento de Plantas) Escola Superior de Agricultura "Luiz de Queiroz", Universidade de São Paulo, Piracicaba.1990, 188p.

GOMES, J. P. de O. Aplicação da análise de componentes principais e geoestatística no estudo hidrogeoquímico de elementos-traço nos sólidos em suspensão do alto rio madeira. 2005. 87 f. TCC (Graduação) - Curso de Ciências Biológicas, Departamento de Biologia, Universidade Federal de Rondônia, Porto Velho, 2005.

GUILLAUME, A. Introduction à la Géologie Quantitative. Masson, Paris, 1977, cap. 6, 200 p.

HOLMAN, P. J. Caterpillar mechanical drive offhighway trucks. Proc. Int. Symp. on Off-Highway Haulage in Surface Mines. Balkema, Rotterdam, 1989.

JESUS, L. Dimensionamento de equipamentos de mina e custos operacionais. 1 ed. São Paulo: Baraúna, 2013.

KAISER, H. F. The varimax criterion for analytic rotation in fator analysis. Psychometrika, 23, p. 187-200, 1958.

KAUFMAN W.W.; AULT J.C. Design of surface mining haulage roads - a manual. U.S. Department of Interior, Bureau of Mines, Information Circular 8758, 1977.

LE MAÎTRE, R. W. Numerical Petrology. Elsevier Sci. Pub., 1982, cap 7 e 8, $281 \mathrm{p}$

LÓPEZ JIMENO, C.; LÓPEZ JIMENO, E.; GARCÍA BERMUDEZ; HERNANDO DEGEA. Manual de transporte con volquetes $y$ diseño de pistas mineras. Universidad Politécnica de Madrid, Espanha. 2014.

McCAMMON, R. B. Concepts in Geostatistics. SpringerVerlag, Nova York, 1975, 168 p.

MINGOTI, S. A. Análise de dados através de métodos de estatística multivariada: uma abordagem aplicada. 2.ed. Belo Horizonte: UFMG, 2013. 297 p.

MINITAB INC Minitab 17: Getting Started with Minitab 17. 2017. Tutorial. Disponível em: $<$ https://www.minitab.com/uploadedFiles/Documents/gettin g-started/Minitab17_GettingStarted-en.pdf $>$. Acesso em: 04 de junho de 2017.

OLIVEIRA FILHO, W. L.; FERNANDES G.; VAM HAM, G. H. J.; RODRIGUES, C. A.; MASETTI, L.; COSTA, W. Manual de drenagem em minas de minério de ferro. Ouro Preto, 2010

PANDEY, B.; AGRAWAL, M.; SINGH, S. Assessment of air pollution around coal mining area: Emphasizing on spatial distributions, seasonal variations and heavy metals, using cluster and principal component analysis. Atmospheric Pollution Research. 79-86 p. 2012.

REIS, M. S. Classificação e diagnóstico das estradas de mina de lavra a céu aberto de minério de ferro dentro do quadrilátero ferrífero. Dissertação de mestrado, PPGEM/UFOP, 2014.

SHANG, X.; LI, X.; MORÁLES-ESTEBÁN, A.; CHEN, G. Improving microseismic event and quarry blast classification using Artificial Neural Networks based on Principal Component Analysis. Soil Dynamics and Earthquake Engineering. 142-149p.

TANNANT D. D.; REGENSBURG B. Guidelines for mine haul road design. University of British Columbia Okanagan. 2001.

THOMPSON, R. J. Principles of mine haul road design and construction. 2015.

TORRES, V. Dimensionamento de frota. Material de Curso, Ouro Preto, 2016.

SANTOS, A. E. Predição da condição de estabilidade de taludes de mina por meio de estatística multivariada. (Dissertação de Mestrado em Engenharia Mineral). Programa de Pós-Graduação em Engenharia Mineral. Universidade Federal de Ouro Preto. 2016. 93 p.

SOUSA L. M. L S. Dimensionamento estrutural de estradas de mina a céu aberto. Revista da Escola de Minas 65(2), 2012.

\section{AGRADECIMENTOS}

Os autores gostariam de agradecer ao Instituto Tecnológico Vale e à Vale S.A por apoiarem e financiarem a realização deste estudo.

\section{COPYRIGHT}

Direitos autorais: Os autores são os únicos responsáveis pelo material incluído no artigo. 


\title{
UMA ABORDAGEM TEÓRICA E PRÁTICA EM UM PROTOCOLO PARA IOT
}

\section{A THEORETICAL AND PRACTICAL APPROACH TO AN IOT PROTOCOL}

\author{
NEPOMUCENO, CÉSAR; CHEN, DANIEL; LOPES, DIEGO; ALBUQUERQUE, JESUS; NEVES, \\ NAYRA; SOARES, ANDRÉ; VALENZUELA, WALTER \\ UNIVERSIDADE DO ESTADO DO AMAZONAS \\ camn.lic@uea.edu.br;dac.eng17@uea.edu.br;diml.eng@uea.edu.br; jda.eng17@uea.edu.br; \\ ngn.eng16@uea.edu.br; alsoares@uea.edu.br; wvalenzuela@uea.edu.br
}

\begin{abstract}
Resumo - O protocolo de mensagem MQTT possibilita a interconexão de dados e interações em tempo real entre sistemas, softwares $e$ máquinas que desempenham um papel importante em aplicações em Indústria 4.0 e Internet das Coisas (IoT). Esse trabalho realizou uma análise qualitativa de caráter descritivo dos conceitos e arquitetura do MQTT. Como resultado da análise das características dos brokers, foi possível determinar o Mosquitto como melhor opção para uma aplicação no cenário proposto para esse estudo. Em experimentos, o protocolo apresentou um bom desempenho, com um rápido tempo de resposta, praticidade de aplicação e opções de qualidade de serviço (QoS). Logo, concluímos que o protocolo é adequado para aplicativos que usam dispositivos IoT para análise em tempo real, monitoramento, manutenção preventiva, entre outros usos.
\end{abstract}

Palavras-chave: MQTT. Internet das coisas . Indústria 4.0 .

Summary - The MQTT message protocol turns possible the interconnection data and real-time interactions between systems, software, and machines that play an important role in applications in Industry 4.0 and Internet of Things (IoT). This work conducted a qualitative analysis of the descriptive character of the concepts and architecture of the MQTT. As a result of the analysis of the characteristics of the brokers, it was possible to determine the mosquito as best option for an application in the proposed scenario for this study. In experiments, the protocol showed good performance, with a fast response time, application practicality and quality of service (QoS) options. In essence, it can be affirmed that the protocol is suitable for applications that use IoT devices for real-time analysis, monitoring, preventive maintenance, among others uses.

Keywords: MQTT. Internet of Things . Industry 4.0.

\section{INTRODUÇÃO}

Há dois séculos a Inglaterra iniciou a mecanização de seus processos de fabricação ao utilizar o carvão como fonte de energia que gradativamente substituiu os métodos artesanais de fabricação por maquinários movidos a vapor. Tal troca gerou consequências sociais e econômicas que revolucionaram os métodos de produção e as relações sociais (SILVA et al, 2018).

A segunda fase da revolução industrial intensificou o desenvolvimento dos processos industriais, pois foi impulsionado por inovações técnicas ao utilizar o petróleo, aço e eletricidade. Nesse período ocorreram avanços nos meios de transportes e o surgimento de linhas de montagens com esteiras rolantes a partir de um novo modelo de produção em massa. Além disso, foi possível avançar em diversos campos da comunicação e da eletricidade que mais tarde, já na metade do século XX desencadeou a terceira revolução industrial (SILVA et al, 2018).

Esse período foi marcado pelo uso de semicondutores provocando avanços significativos de automação e robótico nas linhas de produção. Também houve criação de novos computadores e softwares que associados desenvolveram a internet, otimizaram os métodos de comunicação e de telefonia móvel. As novas tecnologias desenvolvidas, nessa fase, possibilitaram que as informações fossem transmitidas cada vez mais rápido e estimularam a interação entre as pessoas do mundo todo de modo que tudo estivesse conectado (SAKURAI \& ZUCHI).

Hoje, Tessarini (2018) define a quarta fase da industrialização como Indústria 4.0 em que novas tecnologias permitem a comunicação, integração e controle de informações por meio de sistemas cibernético-físico atrelado a internet das coisas, IoT. Isso permite que quaisquer objetos tanto fabris como do dia a dia possam estar conectados à rede mundial de computadores.

Em virtude disso estima-se que nos próximos anos haverá mais coisas do que pessoas interagindo na web (Cisco IBSG, 2011).É necessário que tais coisas sejam de baixo custo, o que implica baixa capacidade de processamento, armazenamento e comunicação (TORRES et al., 2016). Por isso também é necessário que os protocolos de comunicação possuam simples codificação, baixa latência e baixo consumo de energia e para isso alguns protocolos foram criados com essas características para essa finalidade.

Nesse estudo o protocolo MQTT (Message Queuing Telemetry Transport [MQTT Version 3.1.1 2014] será abordado de forma teórica e prática partir de uma análise qualitativa de sua arquitetura e funcionamento para aplicações com sistemas IoT.

\section{REFERÊNCIA TEÓRICA}

\section{1 - Protocolos}

Protocolo, de acordo com a definição de dicionário (Dicionário Aurélio, 2010), é uma "reunião de regras que regulam os atos públicos", mas já em um contexto de comunicação, protocolo é um conjunto de regras, parâmetros, sintaxe e informações que serão usados como 
padrão para a troca de dados. O protocolo de comunicação serve para que haja uma comunicação entre duas ou mais entidades.

$\mathrm{Na}$ computação moderna, o uso destes protocolos é essencial para que haja comunicação entre os dispositivos eletrônicos. Por exemplo, existe o protocolo MQTT, que é largamente usado para a comunicação entre dispositivos, ele tem como vantagens suas regras e sintaxe simples, permitindo usá-lo em equipamentos menos poderosos, como sensores e microcontroladores.

\section{2 - Indústria 4.0.}

Idealizada originalmente na Alemanha, a Indústria 4.0 traz o conceito de interconectividade da linha de produção ao usar ferramentas como o sensoriamento e a conexão sem fio, em essência, ela apoia e estimula a automação, troca de informações e o uso de conceitos computacionais.

Assim como as outras revoluções industriais, esta nova indústria emergente tem como objetivo atingir um nível mais elevado de eficiência produtiva, para isso, ele usa os conceitos de tecnologia moderna para digitalizar, otimizar, customizar e adaptar as máquinas, diminuindo a necessidade de interação humana e enfatizando a autonomia desses equipamentos. (Lu, Y., 2017)

Para estimular essa nova indústria, nove aspectos serão usados: Big data e sua análise, robótica autônoma, simulações digitais de produtos, integração digital do sistema de produção, integração de internet, segurança cibernética, armazenamento "em nuvem", monitoramento preciso e realidade aumentada. (Vaidya, S., Ambad, 2018)

\section{3 - IoT (Internet of things).}

IoT é uma interconexão entre máquinas e dispositivos que compartilham dados através da internet, permitindo uma vigorosa comunicação de dispositivo-dispositivo e humanodispositivo. Esse último possibilita inúmeras ferramentas disponíveis às pessoas, de certa forma, esta é umas das ideias das cidades inteligentes.

\section{METODOLOGIA}

\section{1 - Conceito}

O protocolo MQTT (Messaging Queue Telemetry Transport) foi criado por Dr. Andy Stanford, da International Business Machine Corporation (IBM) e Arlen Nipper, da Arcom (agora Eurotech) em 1999. Segundo MQTT official web page (2019), é um protocolo de mensagens publicador / assinante, extremamente simples e leve, projetado para dispositivos com restrições, baixa largura de banda, alta latência ou redes não confiáveis. Seus princípios básicos são: minimizar a largura de banda de rede e os requisitos de dispositivo, tais princípios fazem com que seja propício o seu uso em "Machine-to-Machine" (M2M) e "Internet of Things" (IoT).

\section{2 - Modelo de comunicação}

O protocolo MQTT permite comunicação assíncrona entre cliente e servidor (chamado de broker), segundo PERALTA et al. (2016) este protocolo permite transmitir mensagens de um cliente (publicador) para um ou vários clientes (assinantes), que chegam até o broker e este se encarrega de encaminhar as mensagens para os assinantes.
A figura 1 representa o modelo de comunicação utilizado pelo MQTT.

De acordo com AL-FUQAHA et al. (2015), o MQTT possui três componentes básicos: o assinante, o publicador e o broker. Cada dispositivo que se interessa em um determinado tópico, deve assiná-lo para que o broker possa informar quando publicadores publicarem mensagens neste tópico. O broker também verifica a autorização dos publicadores e assinantes.

\section{Figura 1 - Modelo de Comunicação Utilizado pelo MQTT}

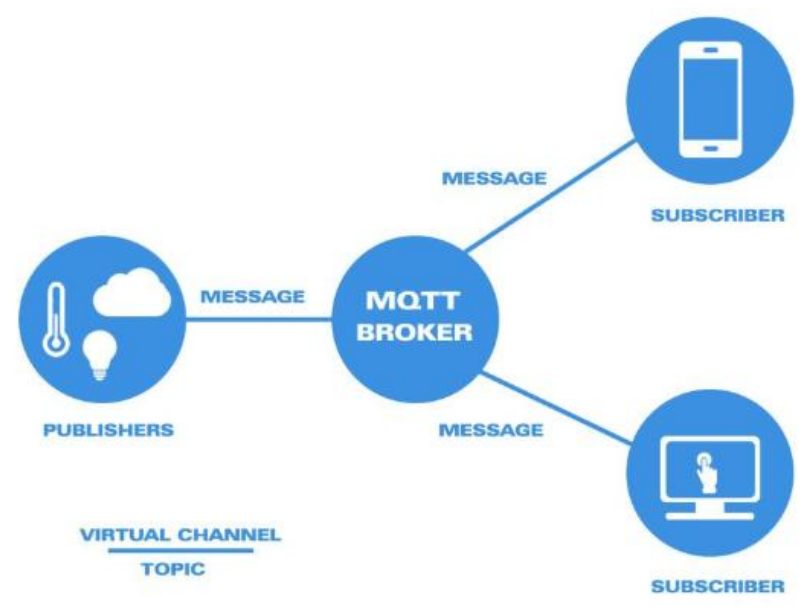

Fonte: Novus, 2019

\section{3 - Mensagens}

As mensagens do protocolo possuem um cabeçalho fixo composto por dois bytes, o primeiro indica o tipo de mensagem e alguns flags que são: entrega duplicada (DUP), qualidade de serviço (QoS) e RETAIN. Segundo MARTINS, ZEM (2016), DUP é ativado quando há tentativa de reenvio de mensagens (PUBLISH, PUBREL, SUBSCRIBE ou UNSUBSCRIBE) que tenham QoS maior que zero, oflag QoS indica o nível de garantia de entrega de uma mensagem PUBLISH e o RETAIN indica se uma mensagem PUBLISH deve permanecer no broker após ter sido entregue a todos os assinantes. $O$ cabeçalho fixo também possui bytes para representar a quantidade total de bytes que a mensagem contém. A figura 2 apresenta o modelo de mensagem do MQTT.

Figura 2 - Formato da mensagem MQTT

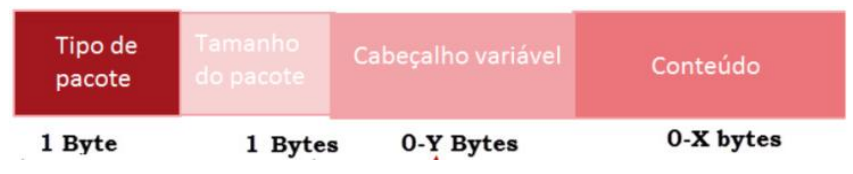

Fonte: Steve's Internet Guide, 2019

Algumas mensagens possuem um cabeçalho variável e o próprio conteúdo da mensagem, chamado de payload. $\mathrm{O}$ quadro 1 apresenta com mais detalhes as mensagens do protocolo. 
Quadro 1 - Descrição das mensagens MQTT

\begin{tabular}{|c|c|c|c|c|}
\hline Nome & Descrição & & Fluxo & \\
\hline CONNECT & $\begin{array}{l}\text { Solicitação do cliente para se } \\
\text { conectar ao servidor }\end{array}$ & Cliente & $\longrightarrow$ & Servidor \\
\hline CONNACK & $\begin{array}{l}\text { Reconhecimento do } \\
\text { CONNECT }\end{array}$ & Servidor & & Cliente \\
\hline PUBLISH & $\begin{array}{l}\text { Publica uma mensagem em } \\
\text { um tópico }\end{array}$ & $\begin{array}{l}\text { Cliente } \\
\text { Servidor }\end{array}$ & $\stackrel{\text { ou }}{\longrightarrow}$ & $\begin{array}{l}\text { Servidor } \\
\text { Cliente }\end{array}$ \\
\hline PUBACK & $\begin{array}{c}\text { Reconhecimento de um } \\
\text { PUBLISH }\end{array}$ & $\begin{array}{l}\text { Cliente } \\
\text { Servidor }\end{array}$ & $\stackrel{\text { ou }}{\longrightarrow}$ & $\begin{array}{l}\text { Servidor } \\
\text { Cliente }\end{array}$ \\
\hline PUBREL & $\begin{array}{c}\text { Reconhecimento de um } \\
\text { PUBACK }\end{array}$ & $\begin{array}{l}\text { Cliente } \\
\text { Servidor }\end{array}$ & $\stackrel{\text { ou }}{\longrightarrow}$ & $\begin{array}{l}\text { Servidor } \\
\text { Cliente }\end{array}$ \\
\hline PUBCOMP & $\begin{array}{c}\text { Reconhecimento de um } \\
\text { PUBREL }\end{array}$ & $\begin{array}{l}\text { Cliente } \\
\text { Servidor }\end{array}$ & ou & $\begin{array}{l}\text { Servidor } \\
\text { Cliente }\end{array}$ \\
\hline SUBSCRIBE & Solicitação de assinatura & Cliente & & Servidor \\
\hline SUBACK & $\begin{array}{l}\text { Reconhecimento de um } \\
\text { SUBSCRIBE }\end{array}$ & Servidor & $\Rightarrow$ & Cliente \\
\hline UNSUBSCRIBE & $\begin{array}{c}\text { Cancelamento de uma } \\
\text { assinatura }\end{array}$ & Cliente & & Servidor \\
\hline UNSUBACK & $\begin{array}{l}\text { Reconhecimento de um } \\
\text { UNSUBSCRIBE }\end{array}$ & Servidor & & Cliente \\
\hline PINGREQ & Pedido PING & Cliente & - & Servidor \\
\hline PINGRESP & Resposta PING & Servidor & - & - Cliente \\
\hline DISCONNECT & Solicitação de desconexão & Cliente & $\longrightarrow$ & Servidor \\
\hline
\end{tabular}

Fonte: Os autores

No âmbito dos projetos em IoT, os protocolos de comunicação desempenham papéis de alta importância. Dentre os disponíveis, o protocolo MQTT, que tem alcançado altos números de adesão, proporciona uma estrutura bastante completa para as aplicações. Para elucidar a compatibilidade do MQTT com as aplicações IoT basta citar as principais características do protocolo:

- Simples configuração: É possível fazer configurações com linhas de comando de baixa complexidade, sem a perda de padronização.

- Comunicação bidirecional: Qualquer integrante de uma rede com MQTT pode desempenhar o papel de receptor e/ou de fornecedor de informação.

Modelo Publisher/Subscriber: As informações são enviadas na estrutura de tópicos, assim o receptor não recebe informações que não sejam úteis para seu funcionamento.

- Assíncrono: O sistema utilizado permite um funcionamento em que o fornecedor de informações não necessita de confirmações para funcionar.

- $\quad$ Segurança: O protocolo MQTT permite a utilização de ferramentas para a segurança da rede, como por exemplo designar dados de login e senha para cada cliente conectado à rede. Em adicional, os brokers que são parte do protocolo podem utilizar ferramentas de criptografia.

- Baixo consumo de energia, conforme apresentado no quadro 2.

Quadro 2 - Consumo de energia dos protocolos https e MQTT com SSL

\begin{tabular}{|c|c|c|c|c|}
\hline & \multicolumn{2}{|c|}{$3 \mathrm{G}$} & \multicolumn{2}{c|}{ Wifi } \\
\cline { 2 - 5 } & HTTPS & MQTT with SSL & HTTPS & MQTT with SSL \\
\hline \% Battery/Message & 0.01709 & $\mathbf{0 . 0 0 0 1 0}$ & 0.00095 & $\mathbf{0 . 0 0 0 0 2}$ \\
\hline Messages/Hour & 1708 & $\mathbf{1 6 0 2 7 8}$ & 3628 & $\mathbf{2 6 3 3 1 4}$ \\
\hline $\begin{array}{c}\text { Messages } \\
\text { Received per 1024 } \\
\text { Sent Messages }\end{array}$ & 240 & 1024 & 524 & 1024 \\
\hline
\end{tabular}

Volume $15-\mathrm{N}^{\mathrm{o}} 169$ - Janeiro/2020.
- Bom desempenho em áreas com problemas de transmissão

Em destaque também, além das informações apresentadas anteriormente, é preciso fazer um estudo sobre brokers disponíveis para utilização em uma rede com MQTT, visto que a escolha correta viabiliza o bom funcionamento do projeto. Existem atualmente vinte e dois brokers disponíveis, mas para uma comparação simples serão apresentados aqui quatro exemplos: ActiveMQ (Classic e Artemis), Mosca, Mosquitto, Ponte, conforme o quadro 3 .

Quadro 3 - Comparação dos brokers.

\begin{tabular}{|c|c|c|c|c|}
\hline & 8 AC & $\begin{array}{c}\text { mosch } \\
\text { mose }\end{array}$ & $\underset{\text { mos uilto }}{((()))}$ & \\
\hline Multiprotocolo & Sim & Não & Não & Sim \\
\hline Linguagem & Java & JavaScript & $C$ & JavaScript \\
\hline Versão MQTT & 3.1 .1 & 3.1 e 3.1 .1 & $5.0,3.1$ e 3.1 .1 & 3.1 .1 \\
\hline $\begin{array}{c}\text { Estado de } \\
\text { Implementaçăo }\end{array}$ & $\begin{array}{c}\text { Em andamento } \\
\text { (Artemis) }\end{array}$ & Estável & Estável & Em andamento \\
\hline Extras & $\begin{array}{l}\text { Suporte à STOMP, } \\
\text { AMQP e OpenWire }\end{array}$ & $\begin{array}{l}\text { Pode ser usado como } \\
\text { autônomo ou } \\
\text { embarcado }\end{array}$ & $\begin{array}{c}\text { Biblioteca em C para a } \\
\text { implementação dos } \\
\text { clientes } \\
\end{array}$ & $\begin{array}{c}\text { Realiza ponte } \\
\text { (interligação) entre HTTP, } \\
\text { MQTT e CoAP }\end{array}$ \\
\hline Criador & Apache & Mateo Collina & Eclipse & Eclipse \\
\hline
\end{tabular}

Fonte: Os autores

Com a análise dos parâmetros apresentados, o broker Mosquitto foi escolhido para a aplicação a ser desenvolvida, pois sua linguagem de implementação é amplamente usada com microcontroladores. É relevante destacar alguns pontos em relação aos brokers apresentados:

- $\quad \mathrm{Na}$ versão atual, apesar de estável, o broker Ponte ainda apresenta features em estado de implementação, como por exemplo seus módulos de segurança.

- O ActiveMQ Artemis encontra-se em processo de adaptação aos moldes de implementação da Apache, em especial à versão ActiveMQ 5.

- O broker Mosca é estável, porém limitado. Sua implementação é mantida pela comunidade, sendo o broker utilizado como base para outros projetos.

- Mosquitto foi o único dentre os quatro a apresentar suporte para três versões do MQTT. A biblioteca em C oferecida pelo Mosquitto também é um ponto forte na escolha, facilitando a implementação de clientes.

\section{RESULTADOS}

Nessa etapa foi criado um possível cenário prático associado à indústria: o publisher Sensor01 seria o sensor instalado em uma máquina medindo a sua temperatura externa constantemente, ou seja, a medição da temperatura ambiente; o subscriber Leitura01 seria o dispositivo que recebe as leituras para controle da temperatura. Como a etapa foi uma simulação, ambos os clientes juntamente com o broker estão rodando na mesma máquina no terminal Prompt de Comando com Windows 10.

A segunda etapa também utiliza o Mosquitto broker e Mosquitto clientes no terminal, porém com a adição de um novo cliente. Desta vez, dentro do cenário de testes na indústria, este seria o cliente controlado por um técnico que poderia publicar informações e receber também, todas essas 
funcionalidades sendo utilizadas pelo seu smartphone. Este cliente novo está sendo executado em um smartphone com sistema operacional Android.

\subsection{Rede com broker e cliente na mesma máquina}

Primeiramente, dentro do Prompt de Comando, o Mosquitto Broker foi iniciado utilizando o comando mosquitto -v -p 1884 (-v inicia o broker com as configurações padrões; -p escolhe a porta do broker). As linhas imprimidas posteriormente mostram algumas informações do broker.

\section{Figura 3 - Broker no terminal iniciado}

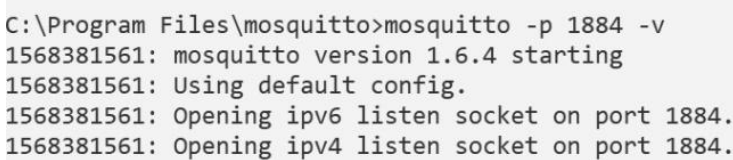

\section{Fonte: Os autores}

Em seguida, já em outra instância do terminal do Windows 10, foi iniciado um cliente como subscriber do broker em um tópico novo chamado de temperatura com QoS 2 e o ID como Leitura01 representando o dispositivo que monitora a temperatura na máquina industrial. $\mathrm{O}$ comando utilizado foi mosquitto_sub -h localhost -p 1884 -t temperatura -i Sensor01 -q 2 (-h configura o host do broker; -t é o tópico; -i configura o ID do Cliente e o -q configura o QoS).

Figura 4 - Subscriber inscrito no tópico "temperatura"

C:|Program Files/mosquittosmosquitto_sub -h localhost -p 1884 -t temperatura -i Leitura01 -q 2

\section{Fonte: Os autores}

A figura 5 mostra o broker recebendo a requisição do subscriber com o seu ID, tópico e a configuração de QoS.

Figura 5 - Broker recebendo uma inscrição

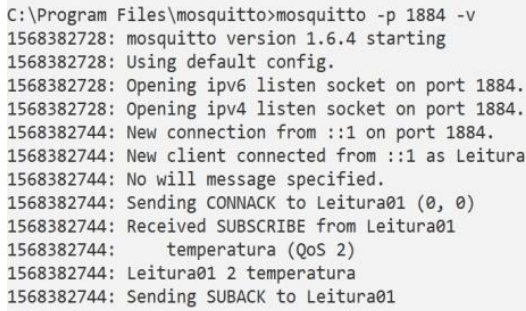

Fonte: Os autores

A próxima etapa é iniciar o publisher no broker e no mesmo tópico do Cliente Leitura01 para posteriormente enviar mensagens. Este cliente representa, dentro do cenário prático, o sensor instalado na parte externa da máquina industrial. Uma terceira instância do Prompt de Comando foi iniciado e o seguinte comando foi utilizado: mosquitto_pub -h localhost -p 1884 -t tempetatura -i Sensor01 -m 14 graus -q 2 (-m é usado para as mensagens).
Figura 6 - Publisher enviando mensagem

C:|Program Files\mosquitto>mosquitto_pub - $h$ localhost -p 1884 -t temperatura -i Sensor01 -m "14 graus" -q 2

C: \Program Files\mosquitto〉

Fonte: Os autores

A Figura 7 mostra o broker recebendo a requisição do Cliente publisher com Id Sensor01, QoS 2 e que uma mensagem deve ser enviada para o subscriber Leitura01.

Figura 7 - Broker recebendo uma inscrição

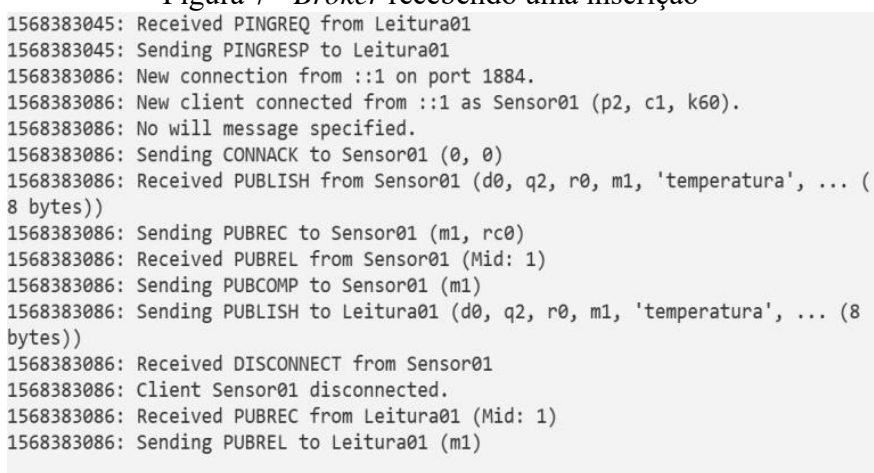

Fonte: Os autores

Por fim, o subscriber recebe a mensagem "14 graus". Essa leitura está representando a temperatura ambiente onde a máquina industrial está operando. A Figura 8 mostra esse evento.

Figura 8 - Subscriber recebendo uma mensagem

C: Program Files/mosquitto>mosquitto sub -h localhost -p 1884 -t temperatura -i Leitura01 - 92 14 graus

Fonte: Os autores

\subsection{Rede Mosquitto com cliente em mobile}

Nesse experimento foi utilizado um smartphone com Android conectado na mesma rede LAN do broker e dos clientes simulando o cliente no qual o técnico está sob controle tanto de subscriber quanto de publisher. O aplicativo mobile utilizado foi o MQTT Dashboard. A Figura 9 mostra a requisição do cliente pelo celular no broker.

Figura 9 - Broker recebendo uma inscrição de cliente 1568384455: New client connected from ::1 as Leitura01 (p2, c1, k60). 1568384455: No will message specified.

1568384455: Sending CONNACK to Leitura $1(\theta, \theta)$

1568384455: Client Leitura 01 already connected, closing old connection. 1568384455: New client connected from ::1 as Leitura01 (p2, c1, k60). 1568384455: No will message specified.

1568384455: Sending CONNACK to Leiturae1 $(\theta, \theta)$

1568384455: Socket error on client <unknown>, disconnecting.

1568384455: New client connected from 192.168.1.119 as LeituraCelular15683881075 $76(\mathrm{p} 2, \mathrm{c} 1, \mathrm{k} 60)$

1568384455: No will message specified.

1568384455: Sending CONNACK to LeituraCelular1568388107576 $(\theta, \theta)$

1568384455: Received SUBSCRIBE from Leitura01

1568384455: temperatura (QOS 2)

1568384455: Leitura01 2 temperatura

1568384455: Sending SUBACK to Leitura01

Fonte: Os autores

As telas da Figura 10 fazem a demonstração, respectivamente, de um cliente em um smartphone 
recebendo uma mensagem no tópico temperatura e em seguida publicando uma informação no mesmo tópico.

Figura 10 - Cliente no celular recebendo mensagem

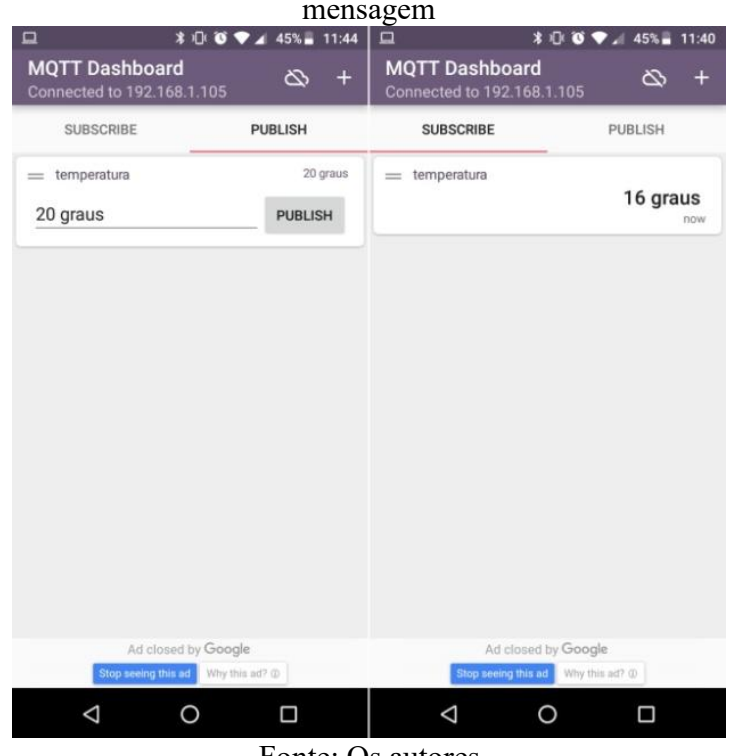

Fonte: Os autores

A Figura 11 mostra o subscriber de ID Leitura01 recebendo a mensagem. Dentro do cenário hipotético no qual a máquina industrial está operando, foi possível perceber uma alteração de temperatura no ambiente externo agora captada pelo técnico e enviada para o dispositivo de controle.

Figura 11 - Subscriber no computador recebendo mensagem

C: |Program Files/mosquittormosquitto_sub -h localhost -p 1884 -t temperatura -i Leitura01 - 92

20 graus

Fonte: Os autores

\section{CONCLUSÃO}

Pela Metodologia acerca do MQTT apresentada, notou-se que o mesmo atende a algumas características tanto de Indústria 4.0 quando de IoT. Visto que o protocolo mencionado possui simples sintaxe e regras de envio e recebimento de mensagens, pode então ser empregado em dispositivos de baixo consumo. Nas comparações entre os brokers, o Mosquitto foi o escolhido por apresentar melhores resultados dentre as características analisadas..

Para exemplificar a facilidade do MQTT, foi realizado um experimento com a implementação do Mosquitto. Um cenário hipotético que ilustre o conceito de Indústria 4.0 foi idealizado: uma máquina industrial está em pleno curso enquanto um sensor representando o cliente mensura a temperatura ambiente no qual ela está sujeita; outro dispositivo cliente é responsável pelo e controle da temperatura, então ele recebe os dados do sensor toma decisões a partir disso; um técnico conectado na rede do protocolo MQTT como cliente pelo seu smartphone pode enviar temperatura mensuradas e receber as leituras do sensor, podendo também tomar decisões.
Pelos resultados obtidos, observamos a praticidade de implementação de protocolo MQTT através de um estudo de caso com o broker Mosquitto em um cenário industrial moderno no qual se necessita de rapidez nas trocas de mensagens e a utilização de dispositivos de baixo consumo, ideal para o conceito de Indústria 4.0.

\section{REFERÊNCIAS BIBLIOGRÁFICAS}

A. B. B. Torres, A. R. Rocha, and J. Neuman De Souza, "Análise de Desempenho de Brokers MQTT em Sistema de Baixo Custo," An. do XXXVI Congr. da Soc. Bras. Comput., no. Julho, pp. 2804-2815, 2016.

Ala Al-Fuqaha, Senior Member, IEEE, et al. Internet of Things: A Survey on Enabling Technologies, Protocols, and Applications. IEEE COMMUNICATION SURVEYS \& TUTORIALS, VOL. 17, NO. 4, FOURTH QUARTER 2015

Camero, A., \& Alba, E. (2019). Smart City and information technology: A review. Cities, 93(April), 84 94. https://doi.org/10.1016/j.cities.2019.04.014

CARUSO, José Mário. Controle de Velocidade de um MIT Tracionando um Veículo Elétrico. Taubaté, 2007.

Dicionário Aurélio da Língua Portuguesa - $8^{\text {a }}$ Ed. 2010

ERBER, Pietro. "Gasolina e Tomada": o carro elétrico está perto. Rio de Janeiro: Revista do Empresário da ACRJ, maio/junho, 2010.

EVANS, Dave. THE INTERNET OF THINGS: How the Next Evolution of the Internet Is Changing Everything. Cisco Internet Business Solutions Group (IBSG), 2011.

FRÉ, Paulo; MARCELINO, Márcio Abud; ADAMI, José Feliciano. Sensor Kelvin para detecção de Tensão. Revista Sodebras [on line]. v. 10, n.117, Set./2015, p. 147-152. ISSN 1809-3957. Disponível em: $<$ http://www.sodebras.com.br/edicoes/N117.pdf $>$. Acesso em 04 out. 2015 .

Fong, Ming: Powering the Internet of Things with MQTT. Disponível em: https://www.automation.com . Acesso em 10 set 2019.

Lu, Y. (2017). Industry 4.0: A survey on technologies, applications and open research issues. Journal of Industrial Information Integration, 6, 1-10. https://doi.org/10.1016/j.jii.2017.04.005

MARTINS, Ismael, ZEM, José. ESTUDO DOS PROTOCOLOS DE COMUNICAÇÃO MQTT E COAP PARA APLICAÇÕES MACHINE-TO-MACHINE E INTERNET DAS COISAS 2015

\section{MQTT official webpage. [Online]. Available: http://mqtt.org/faq. Acessado em 11/09/2019}

MUNDO EDUCAÇÃO. Figura 2. Disponível em: http://mundoeducacao.bol.uol.com.br/geografia/tiposgraficos.htm. Acesso em 26 jan 2016.

Nord, J. H., Koohang, A., \& Paliszkiewicz, J. (2019). The Internet of Things: Review and theoretical framework. Expert Systems with Applications, 133, 97-108. https://doi.org/10.1016/j.eswa.2019.05.014 
Novus, Artigo: Modelo Cliente-Servidor do Modbus TCP e Publish-Subscribe do MQTT: quando utilizar cada um deles e quais suas vantagens e desvantagens?. Disponível em: https://www.novus.com.br/site/default.asp?TroncoID $=0536$ $63 \&$ SecaoID $=0 \&$ SubsecaoID $=0 \&$ Template $=. . /$ artigosnoticia s/user_exibir.asp \&ID $=618088 \&$ idioma $=55$. Acesso em 30 set $20 \overline{19}$.

PACHECO, Marco Aurélio C. Algoritmos Genéticos:

Princípios e Aplicações. Disponível em: http://www.ica.ele.puc-rio.br/Downloads/38/CE-ApostilaComp-Evol.pdf. Acesso em 04 dez 2010.

PERALTA, Goiuri, et al. Fog Computing Based Efficient IoT Scheme for the Industry 4.0. Espanha: IK4-Ikerlan Technology Research Centre, Information and Communication Technologies Area, 2016.

SAKURAI, R.; ZUCHI, J. D. AS REVOLUÇÕES INDUSTRIAIS ATÉ A INDÚSTRIA 4.0. Revista Interface Tecnológica, v. 15, n. 2, p. 480-491, 30 dez. 2018.

SILVA, Elcio B; SCOTON, Maria; DIAS, Eduardo M; PEREIRA, Sérgio. AUTOMAÇÃO E SOCIEDADE: quarta revolução industrial, um olhar para o Brasil. Brasport, 2018.

Steve's Internet Guide. Understanding the MQTT Protocol Packet Strutucture. Disponível em: http://www.stevesinternet-guide.com/mqtt-protocol-messages-overview/.

Acesso em 30 set 2019

Team, I. (n.d.). 5 Areas Where The IoT Is Having The Most Business Impact. Retrieved September 12, 2019, from Forbes Insights website: https://www.forbes.com/sites/insights-hitachi/

2017/12/18/dont- get- caught- unprepared- when- it- comesto- iot- security/ \#74e9c7f4d800

Torres, A. B. B., Rocha, A. R., and de Souza, J. N. ANÁLISE DE DESEMPENHO DE BROKERS MQTT EM SISTEMA DE BAIXO CUSTO. In Anais do XXXVI congresso da sociedade brasileira de computação, 2016.

Vaidya, S., Ambad, P., \& Bhosle, S. (2018). Industry 4.0 A Glimpse. Procedia Manufacturing, 20, 233-238. https://doi.org/10.1016/j.promfg.2018.02.034

\section{AGRADECIMENTOS}

Este trabalho conta com o apoio da Samsung Eletrônica da Amazônia Ltda. através da Lei de Informática, AGIN Agência de Inovação da UEA e FUEA - Fundação Universitas de Estudos Amazônicos.

\section{COPYRIGHT}

Direitos autorais: Os autores são os únicos responsáveis pelo material incluído no artigo. 


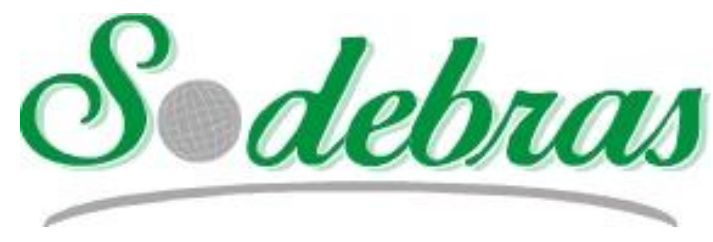

Volume 15 - $\mathrm{N}^{\mathrm{o}} 169$ - Janeiro / 2020

XLI International Sodebras Congress

31 de outubro a 02 de novembro de 2019 - Maceió - AL.

\title{
REDES BAYESIANAS APLICADAS A PRIORIZAÇÃO DE TESTE DE SOFTWARE NA ABORDAGEM AADSP
}

\section{BAYESIAN NETWORKS APPLIED TO SOFTWARE TEST PRIORIZATION}

\author{
VITOR SOUZA SILVA SANTANA ${ }^{1}$; ANTONIO CARLOS SANTOS SOUZA ${ }^{1}$ \\ 1 - INSTITUTO FEDERAL DE EDUCAÇÃO, CIÊNCIA E TECNOLOGIA DA BAHIA \\ vitorsouzasantana@gmail.com; acsantossouza@gmail.com
}

\begin{abstract}
Resumo - O presente trabalho visa apresentar o uso de Redes Bayesianas para a priorização de casos de teste em projetos de software. Além da priorização, o estudo propõe o gerenciamento dos defeitos que surgirem durante os lançamentos do projeto. Consequentemente, apontar o status de cada caso de testes executado. Com a aplicação da ferramenta, espera-se reduzir o tempo gasto na escolha e execução de casos de teste de um projeto de software.
\end{abstract}

Palavras-chave: Redes Bayesianas, Priorização de Casos de Testes, Otimização em Engenharia de Software, Otimização em Teste de Software, AADSP

\begin{abstract}
The present work aims to present a tool in development that use Bayesian Networks for the prioritization of test cases in a software project. With the tool it will be possible, besides the prioritization, to be made the management of the bugs that arose during the releases of the project. With the application of the tool, it is expected to reduce the time spent choosing and executing test cases of a software project.
\end{abstract}

Keywords: Bayesian Networks, Test Case Prioritization, Software Engineering Optimization, Software Test Optimization, AADSP

\section{INTRODUÇÃO}

$\mathrm{O}$ aumento da presença de softwares no cotidiano faz com que cada vez mais a interação entre usuários e dispositivos computacionais se expanda. A interação também faz com que sejam descobertas novas necessidades de sistemas (SANTANA, 2016). A demanda por novos softwares faz com que o mercado de desenvolvimento de sistemas eleve o grau de competitividade. Além disso, é um dos diferenciais na hora de se destacar da concorrência seja através da entrega de produtos de maior grau de qualidade possível (QUINTELLA, ALMEIDA, 2006).

Diante desse mercado competitivo, as indústrias de software estão em busca de métodos e processos que façam com que a produtividade dos seus projetos aumente (SANTANA, 2016). Dentro de um projeto é importante que seja entregue o que o cliente pediu, mas, tão importante quanto, é entregar um software confiável e com a menor quantidade de erros possível (CALDAS, PITANGUEIRA, 2012).

A verificação da qualidade de um software desenvolvido é medida através de testes. Existem variados tipos de testes que visam verificar a confiabilidade do sistema como um todo, não somente a parte funcional do produto (LUZ, 2012). Por exemplo, há testes que tem como objetivo verificar o quanto de estresse o sistema pode receber, ou o quanto de carga que ele suporta (LUZ, 2012).

Só que testar um software é um processo custoso e demorado. As vezes os testes selecionados não conseguem cobrir totalmente a funcionalidade, resultando em erros que chegam ao cliente final. Esses erros podem causar consequências desastrosas, como prejuízos financeiros ou de reputação, podendo até chegar a danos a integridade física das pessoas (SANTANA, 2016).

Para tentar minimizar este problema, o presente trabalho apresenta o uso de redes bayesianas para priorização de testes de software, permitindo o gerenciamento do módulo de teste dos projetos de softwares de uma empresa. Além disso, foi utilizada a AADSP (SOUZA, 2018), Adaptive Approach for Deployment of Software Process, que é uma abordagem adaptativa para implantação de processo de software criada pelo grupo de pesquisa do IFBA LABRASOFT (LABRASOFT, 2016).

Foi criada para tanto a ferramenta T-AADSP Test, que permite a entrega de partes dos requisitos em Sprints com os respectivos desenvolvedores que atuaram nesse requisito. Uma Sprint delimita os requisitos que foram alterados e os casos de testes executados em um momento de tempo.

$\mathrm{O}$ sistema tem um módulo para cadastro e gerenciamento de bugs encontrados no sistema e outro para o cadastro dos casos de testes. O sistema permitirá o cadastro de desenvolvedores e os seus níveis de maturidade, juntamente com uma nota atrelada ao seu desempenho com o passar das entregas de funcionalidades.

Para realizar a priorização dos casos de teste, foi desenvolvido um algoritmo de Redes Bayesianas para calcular o risco de bugs de um módulo. Serão utilizados dados reais de projetos em andamento e concluídos, de diferentes portes e em diferentes fases de desenvolvimento, para o treinamento do algoritmo de Rede Bayesiana. É esperado que o resultado da predição tenha um alto índice de acerto nas escolhas dos casos de teste para. Assim, a sua aplicação em projetos de desenvolvimento reais ajudará a equipe de testes a reduzir o tempo gasto na escolha dos casos de testes mais prioritários. Isto é, os casos de testes que têm mais chances de capturarem erros, reduzindo, consequentemente, o custo da etapa de testes (CALDAS, PITANGUEIRA, 2013). 
A Rede Bayesiana proposta nesse trabalho e implementada dentro do T-AADSP Test foi primeiramente modelada no Netica. O Netica é um software feito pela Norsys Software que permite a criação de Redes Bayesianas através de interface gráfica. A representação gráfica da Rede Bayesiana pode ser vista na figura 1 .
- ChanceDeImpactoNoRequisito: A probabilidade desse nó é dada através dos nós pais AlteraçõesRequisito e MediaNivelDesenvolvedor. Ele indicará se a chance de impacto no requisito é alta, média ou baixa a partir dos resultados dos seus nós pais.

Figura 1 - Exemplo de Rede Bayesiana

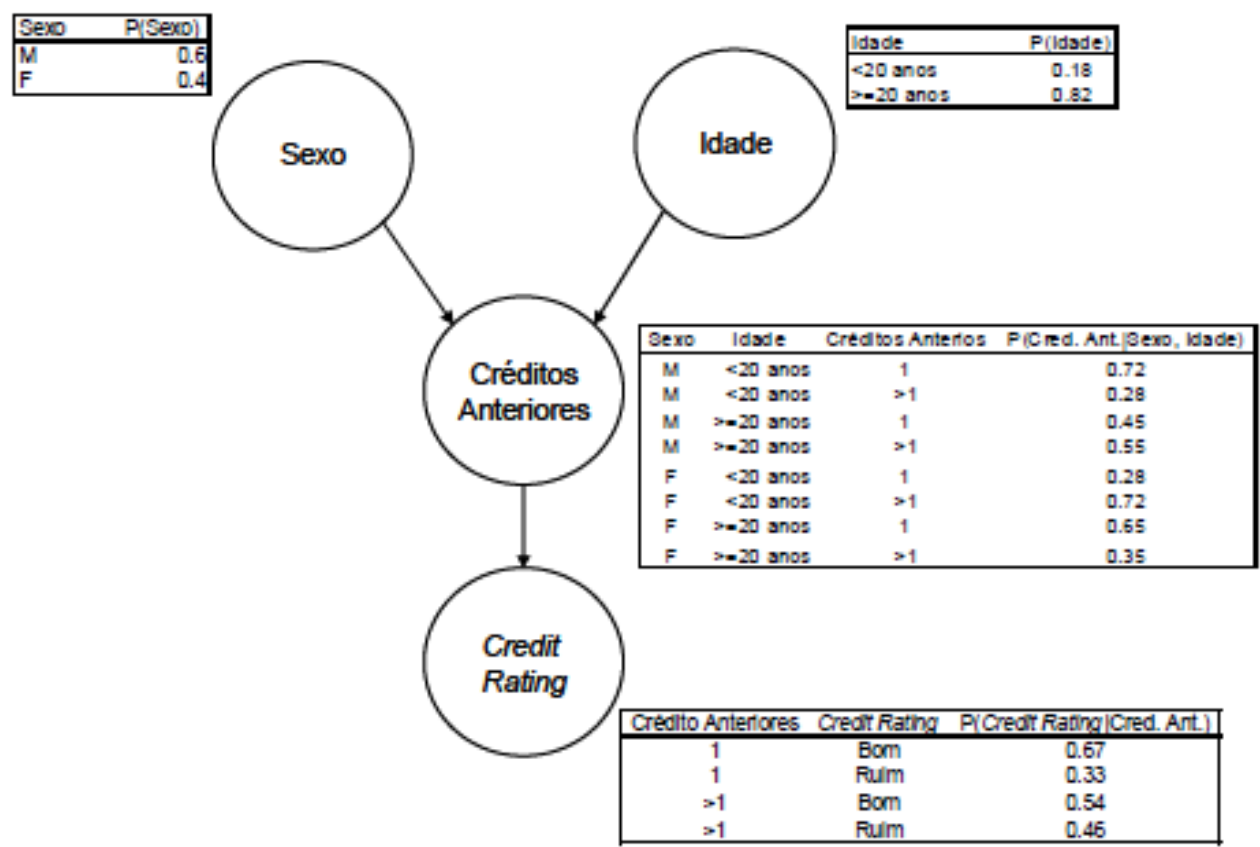

Fonte: SANTANA, 2010

De certo modo, pode-se dizer que a Rede Bayesiana principal tem outras duas redes embutidas, onde uma irá predizer a hierarquia gerencial do requisito e a outra irá predizer a chance de um requisito ter bugs. Juntas, essas redes priorizam o requisito decidindo se, mesmo com uma alta chance de bugs, a sua execução é importante dentro da hierarquia dos projetos de software.

\section{ESTRUTURA DA REDE BAYESIANA}

Os nós da Rede que são responsáveis por calcular a chance de bugs em um requisito são:

- AlteraçõesRequisito: Será fornecido quando o usuário vincular um requisito a Sprint que está em andamento. $\mathrm{O}$ usuário informará qual foi o impacto que as novas funcionalidades e/ou as correções de bugs causaram no requisito.

- MediaNivelDesenvolvedor: A entrada desse nó será feita a partir da nota dos desenvolvedores que atuaram no requisito. Caso somente um desenvolvedor tenha atuado no requisito, somente a nota dele será utilizada; caso mais de um desenvolvedor tenha atuado, a média das notas dos desenvolvedores será dada como entrada.
Se, por exemplo, a alteração foi de alta proporção e o desenvolvedor é muito confiável, diz-se que a chance de impacto nas funcionalidades do requisito e alta, mas não tão alta devido a qualificação do desenvolvedor. Mas se a nota do desenvolvedor for menor, a criticidade de bugs no requisito será maior e por consequência, sua chance vai ser mais alta.

- PorctCoberExecTestesRelAnt: Esse nó indicará a o nível de cobertura de testes que uma sprint anterior teve. O cálculo da porcentagem se dará através do número de todos os casos de testes executados com sucesso pelo número total de casos de testes existentes daquele requisito.

Se a porcentagem da cobertura for menor que $40 \%$, a cobertura será considerada mínima; se a porcentagem estiver entre $40 \%$ e $69 \%$, a cobertura será definidacomo sendo média. Acima de 70, a cobertura será considerada alta. 


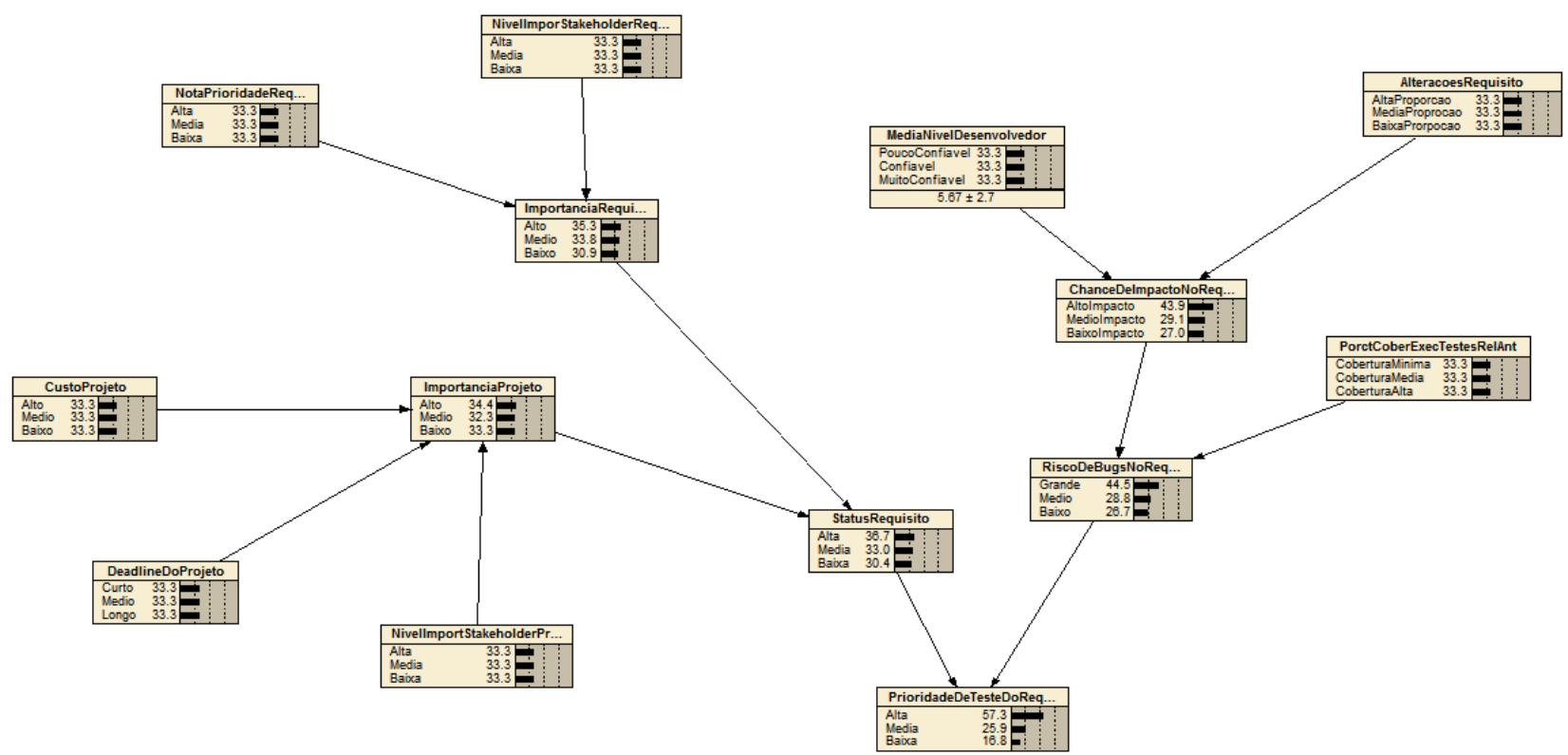

Fonte: elaboração própria dos autores, 2019.

- RiscoDeBugsNoRequisito: A probabilidade desse nó é dada através dos nós ChanceDeImpactoNoRequisito e PorctCoberExecTestesRelAnt, e definirá a probabilidade de encontrar bugs no requisito.

- NivelImporStakeholderRequisito: Do mesmo jeito que um projeto tem um stakeholder vinculado, um requisito também tem um stakeholder vinculado. Um requisito tem prioridade sobre outro se a nota de prioridade do stakeholder vinculado também for maior.

- NotaPrioridadeRequisito: Esse nó é representado pela nota do requisito. Define o quão importante um requisito é para um projeto de software.

- ImportanciaRequisito: O nó é resultado dos nós NivelImporStakeholderRequisito NotaPrioridadeRequisito. Ele indica o quão importante é o requisito frente a outros requisitos.

- CustoProjeto: O custo do projeto é fornecido pelo usuário quando um projeto é cadastrado. A depender da empresa, ela pode ter vários projetos de pequeno, médio, e grande porte, e o custo desses projetos também são diferentes entre si.

- DeadlineDoProjeto: A Deadline (prazo de entrega) do projeto indica quando o projeto será entregue ao cliente.

- NivelImportStakeholderProjeto: Dentro do sistema, cada stakeholder tem uma nota de prioridade vinculado a ele. Um stakeholder pode estar vinculado a um ou mais projetos dentro do sistema. Um projeto tem prioridade sobre o outro se a nota de prioridade do stakeholder vinculado a ele for maior.
- ImportanciaProjeto: O nó é resultado dos três nós DeadlineDoProjeto,

NivelImportStakeholderProjeto e CustoProjeto. Ele determina a hierarquia do projeto frente a outros projetos.

- StatusRequisito: A probabilidade desse nó é dada pelo resultados dos nós ImportanciaRequisito e ImportanciaProjeto. Esse nó indica qual irá ser o a prioridade de teste do requisito levando em conta questões gerenciais, como custo, nivel de importância dos stakeholders e prazo de entrega.

- PrioridadeDeTesteDoRequisito: O nó final da Rede Bayesiana, que vai definir qual vai ser a prioridade de teste do requisito dentre todos os outros. A probabilidade desse nó é resultado

\section{METODOLOGIA}

Para realizar o processo de avaliação da ferramenta, o primeiro passo realizado foi calibrar/treinar a rede bayesiana. Para isso, foram usados três cenários sintéticos, com dois requisitos cada.

Como o objetivo da rede bayesiana na ferramenta é auxiliar a solução de conflitos acerca da prioridade de teste dos requisitos de vários projetos reais, foi realizado a avaliação com trinta requisitos de três projetos reais da empresa Computação Brasil. Para a predição, foram extraídos oito requisitos de um projeto de cartão combustível, oito do primeiro projeto e dois do segundo projeto de uma empresa pública de visualização de dados.

Os requisitos, os dados dos desenvolvedores e dos stakeholders foram cadastrados em conjunto com os casos de testes de cada requisito selecionado. Com isso, foi possível gerar a sugestão de ordem de execução dos testes dos requisitos utilizando todos os dados reais.

\section{RESULTADOS}

O cenário 1 tem as seguintes características: 


\begin{tabular}{|l|l|l|}
\hline Tabela & Requisito A & Requisito B \\
\hline Participação de desenvolvedores & Confiável $(5,0)$ & Muito confiavel $(8,3)$ \\
\hline Cobertura de testes anteriores & Baixa $(30 \%)$ & Média (45\%) \\
\hline Impacto das alterações realizadas & Alto $(80 \%)$ & Médio (50\%) \\
\hline $\begin{array}{l}\text { Nível de importância do requisito } \\
\text { para o stakeholder }\end{array}$ & Alto (9.0) & Médio (5.0) \\
\hline $\begin{array}{l}\text { Nível de importância do requisito } \\
\text { para o projeto }\end{array}$ & Alto (10.0) & Média (6.0) \\
\hline $\begin{array}{l}\text { Nível de importância do stakehol- } \\
\text { der para o projeto }\end{array}$ & Alto (8.0) & Alta (8.0) \\
\hline Valor do projeto & Médio (R\$45.000,00) & Baixo (R\$15.000,00) \\
\hline Prazo de entrega & Curto (dois meses) & Curto (2 meses e meio) \\
\hline
\end{tabular}

Após a entrada na rede, temos as seguintes probabilidades para cada requisito:

- Requisito A: (Alta: 73.8\%, Média: 18.7\%, Baixo: $7.48 \%$ )

- Requisito B: (Alta: 44.1\%, Média: 36.9\%, Baixo: $18.9 \%$

Como pode-se ver, os dois requisitos saíram com prioridade alta, mas o requisito A tem uma importância muitíssimo mais relevante do que o requisito B. Avaliando as entradas que calculam o risco de erros do requisito, notase que o Requisito A tende muito mais a ter bugs devido ao alto impacto da alteração que sofreu na Sprint atual (80\%), e também os desenvolvedores responsáveis por essa alteração serem medianos, sendo reconhecidos apenas como confiáveis. Ao mesmo tempo, avalia-se que o requisito $\mathrm{B}$ não teve uma alteração tão impactante do que o Requisito A, e os desenvolvedores responsáveis por essas alterações são considerados muito confiáveis, o que dá uma margem de confiança grande de que o que foi desenvolvido não terá tantos erros.

Além disso, no requisito $\mathrm{A}$, a cobertura dos testes anteriores cobriu apenas $30 \%$ da funcionalidade, enquanto no requisito $\mathrm{B}$ esse nível de cobertura conseguiu cobrir metade da funcionalidade. Isso significa dizer que tem muito mais chances de um bug não detectado na Sprint anterior do requisito A ter passado e continuado na Sprint atual do que a Sprint B.

Dos dados de importância do requisito, nota-se que o requisito A é um requisito muito importante tanto para seu projeto, quanto para os stakeholders, enquanto o requisito $\mathrm{B}$ fica no meio termo: seus stakeholders tem importância mediana e a sua importância no projeto é de nível médio.

Entretanto, nota-se que o projeto do requisito B é um projeto muito mais prioritário do que o do requisito $\mathrm{A}$, visto que o mesmo tem uma data de entrega curtíssima, e os stakeholders que cuidam desse projeto são muito importantes. No requisito A o projeto também tem stakeholders muitíssimos importantes, mas é considerado de média importância devido a não ter uma data de entrega tão curta, apesar do seu custo médio, comparado com o custo baixo do projeto do requisito $\mathrm{A}$.

Em resumo, podemos definir que, apesar de não ter um risco imediato de bugs, a importância alta do requisito $\mathrm{B}$ deve-se muito mais a condição que seu projeto está, com prazo curto e stakeholders de níveis altos. Apesar de estar em um projeto consideravelmente de importância média, o requisito $\mathrm{A}$ tem chances muito altas de bugs devido ao impacto sofrido durante as alterações.

Agora, o cenário 2 está configurado com as seguintes características:

\begin{tabular}{|l|l|l|}
\hline Tabela & Requisito C & Requisito D \\
\hline Participação de desenvolvedores & Confiável (6.0) & Confiável (5.0) \\
\hline Cobertura de testes anteriores & Média (55\%) & Média (45\%) \\
\hline Impacto das alteraçes realizadas & Médio (65\%) & Baixo (35\%) \\
\hline $\begin{array}{l}\text { Nivel de importância do requisito } \\
\text { para o stakeholder }\end{array}$ & Médio (6.0) & Médio (5.0) \\
\hline $\begin{array}{l}\text { Nivel de importância do requisito } \\
\text { para o projeto }\end{array}$ & Médio (6.0) & Baixo (2.0) \\
\hline $\begin{array}{l}\text { Nivel de importância do stakehol-- } \\
\text { der para o projeto }\end{array}$ & Médio (5.0) & Alto (8.0) \\
\hline Valor do projeto & Médio (R\$50.000,00) & Médio (R\$65.000,00) \\
\hline Prazo de entrega & Curto (3 meses e meio) & Médio (4 meses) \\
\hline
\end{tabular}

Comparando os dois requisitos, nota-se que eles são classificados como sendo de requisito de média prioridade de teste, só que o requisito $\mathrm{C}$ tem uma probabilidade maior com relação ao requisito D. Analisando os dados de entrada, percebe-se que o requisito $\mathrm{D}$ tem um risco menor de ter erros do que o requisito $\mathrm{C}$ porque as alterações sofridas no requisito $\mathrm{D}$ foram de muito menos impacto. Os dois foram alterados por desenvolvedores confiáveis e tiveram uma cobertura média de testes anteriores.

A importância do requisito $\mathrm{C}$ é média, porque a sua nota de importância dentro do projeto é considerada média, assim como a importância dos stakeholders vinculados a ele. Já o requisito $\mathrm{D}$ tem uma importância mais baixa porque a sua nota de prioridade dentro do seu próprio projeto é baixa.

Sobre o projeto, verifica-se que o requisito $\mathrm{C}$ está em um projeto considerado de média importância por causa do seu custo médio e o fato de que os stakeholders desse projeto também serem de média importância. Apesar de estar classificado como médio, o seu prazo de entrega é curto, que lhe dá também uma probabilidade consideravelmente alta. O projeto do requisito $\mathrm{D}$ também é classificado como médio porque tanto o seu custo quanto o seu prazo de entrega são médios, mas o que eleva um pouco a sua probabilidade de ser alto é a alta importância que os stakeholders participantes do projeto tem.

\begin{tabular}{|l|l|l|}
\hline Tabela & Requisito E & Requisito F \\
\hline Participaçōo de desenvolvedores & Muito Confiável (9.0) & Muito Confiável (8.0) \\
\hline Cobertura de testes anteriores & Alta (86\%) & Alta (75\%) \\
\hline Impacto das alteraçêes realizadas & Médio (65\%) & Baixo (35\%) \\
\hline $\begin{array}{l}\text { Nivel de importância do requisito } \\
\text { para o stakeholder }\end{array}$ & Médio (5.0) & Baixo (3.0) \\
\hline $\begin{array}{l}\text { Nivel de importância do requisito } \\
\text { para o projeto }\end{array}$ & Médio (5.0) & Baixo (2.0) \\
\hline $\begin{array}{l}\text { Nivel de importância do stakehol- } \\
\text { der para o projeto }\end{array}$ & Baixo (2.0) & Alto (8.0) \\
\hline Valor do projeto & Médio (R\$15.000,00) & Médio (R\$55.000,00) \\
\hline Prazo de entrega & Longo (7 meses e meio) & Médio (5 meses e meio) \\
\hline
\end{tabular}

Já o cenário 3 foi configurado dessa forma:

Os dois requisitos estão classificados como tendo prioridade baixa, mas nota-se que o requisito $\mathrm{F}$ tem uma probabilidade baixa maior que o requisito E. Essa diferença se dá primeiramente pelo risco que os dois apresentam de apresentar erros: enquanto o requisito $\mathrm{E}$ tem um risco um pouco mais elevado devido a alteração nele ter sido de médio impacto, o requisito $\mathrm{F}$ teve alteração de baixo impacto, o que significa que existe uma chance baixa de bugs surgirem. Os dois requisitos foram alterados por desenvolvedores muito confiáveis e tiveram cobertura alta nos testes anteriores

$\mathrm{O}$ requisito $\mathrm{F}$ tem uma importância muito menor que o requisito $\mathrm{E}$ porque, mesmo os dois tendo nota de importância baixa, os stakeholders do requisito E são de média importância, e os do requisito $\mathrm{F}$ são de baixa importância. Ao analisar os projetos dos dois requisitos, nota-se uma situação contrária ao que se viu anteriormente: o projeto do requisito $\mathrm{F}$ tem uma importância maior em 
relação com o do requisito E devido ao seu prazo de entrega curto; o custo dos dois projetos são considerados médios e os stakeholders são considerados de baixa importância.

Utilizando os dados reais, a predição dos requisitos foram feitos em três Sprints separadas. Dessas três Sprints, foram retirados os cinco requisitos mais prioritários dentro do projeto.

- Sprint 1: A primeira Sprint teve como entrada trinta requisitos dos três projetos diferentes e, da saída, foram extraídos os seguintes requisitos:

\begin{tabular}{|l|l|l|l|l|l|}
\hline & $\begin{array}{l}\text { Atualizar } \\
\text { Visitante }\end{array}$ & {$[$ SDV024] } & $\begin{array}{l}\text { Consulta } \\
\text { compras } \\
\text { beneficia- } \\
\text { rio }\end{array}$ & $\begin{array}{l}\text { Controle } \\
\text { de Acesso }\end{array}$ & $\begin{array}{l}\text { Cadastro } \\
\text { benefi- } \\
\text { ciários } \\
\text { lote }\end{array}$ \\
\hline $\begin{array}{l}\text { Nivel de impacto } \\
\text { de alteraçōes }\end{array}$ & Média & Alta & Alta & Alta & Alta \\
\hline $\begin{array}{l}\text { Nivel dos desen- } \\
\text { volvedores }\end{array}$ & $\begin{array}{l}\text { Pouco con- } \\
\text { fiável }\end{array}$ & Confiavel & Confiavel & $\begin{array}{l}\text { Muito Con- } \\
\text { fiavel }\end{array}$ & $\begin{array}{l}\text { Muito Con- } \\
\text { fiavel }\end{array}$ \\
\hline $\begin{array}{l}\text { Porcentagem de } \\
\text { cobertura dos } \\
\text { testes anteriores }\end{array}$ & Mínima & Minima & Minima & Minima & $\begin{array}{l}\text { Cobertura } \\
\text { Minima }\end{array}$ \\
\hline $\begin{array}{l}\text { Nivel de impor- } \\
\text { tância do stakehol- } \\
\text { der para o reçui- } \\
\text { sito }\end{array}$ & Alta & Alta & Alta & Alta & Alta \\
\hline $\begin{array}{l}\text { Nota de priori- } \\
\text { dade do requisito }\end{array}$ & Alta & Alta & Alta & Alta & Alta \\
\hline $\begin{array}{l}\text { Nivel de impor- } \\
\text { tância do stakehol- } \\
\text { der para o projeto }\end{array}$ & Média & Media & Alta & Média & Alta \\
\hline Custo do projeto & Alto & Baixo & Médio & Alto & Médio \\
\hline Prazo de entrega & Médio & Curto & Longo & Médio & Longo \\
\hline $\begin{array}{l}\text { PRIORIDADE } \\
\text { ALTA }\end{array}$ & $74 \%$ & $72 \%$ & $72 \%$ & $72 \%$ & 69 \\
\hline $\begin{array}{l}\text { PRIORIDADE } \\
\text { MÉDIA }\end{array}$ & $19 \%$ & $18 \%$ & $18 \%$ & $21 \%$ & 21 \\
\hline $\begin{array}{l}\text { PRIORIDADE } \\
\text { BAIXA }\end{array}$ & $7 \%$ & $9 \%$ & $9 \%$ & $8 \%$ & 11 \\
\hline
\end{tabular}

- $\quad$ Sprint 2: Depois de indicar o status dos casos de testes de cada requisito e finalizada a Sprint 1, foi iniciada uma nova Sprint. Os seguintes requisitos foram escolhidos:

\begin{tabular}{|l|l|l|l|l|l|}
\hline & Login & $\begin{array}{l}\text { Consultar } \\
\text { SCILici- } \\
\text { tacao }\end{array}$ & $\begin{array}{l}\text { Cadastrar } \\
\text { Conse- } \\
\text { lheiro }\end{array}$ & $\begin{array}{l}\text { Atualizar } \\
\text { Conse- } \\
\text { lheiro }\end{array}$ & $\begin{array}{l}\text { Editar } \\
\text { convenio }\end{array}$ \\
\hline $\begin{array}{l}\text { Nivel de impacto } \\
\text { de alteraçes }\end{array}$ & Alta & Alta & Média & Média & Média \\
\hline $\begin{array}{l}\text { Nível dos desen- } \\
\text { volvedores }\end{array}$ & Confiável & $\begin{array}{l}\text { Pouco Con- } \\
\text { fiável }\end{array}$ & Confiável & Confiável & $\begin{array}{l}\text { Muito Con- } \\
\text { fiável }\end{array}$ \\
\hline $\begin{array}{l}\text { Porcentagem de } \\
\text { cobertura dos } \\
\text { testes anteriores }\end{array}$ & Alta & Média & Média & Média & Média \\
\hline $\begin{array}{l}\text { Nivel de impor- } \\
\text { tância do stakehol- } \\
\text { der para o requi- } \\
\text { sito }\end{array}$ & Alta & Baixa & Alta & Alta & Alta \\
\hline $\begin{array}{l}\text { Nota de priori- } \\
\text { dade do requisito }\end{array}$ & Alta & Media & Alta & Alta & Alta \\
\hline $\begin{array}{l}\text { Nivel de impor- } \\
\text { tância do stakehol- } \\
\text { der para o projeto }\end{array}$ & Alta & Média & Média & Média & Alta \\
\hline Custo do projeto & Médio & Alto & Alta & Alta & Médio \\
\hline Prazo de entrega & Longo & Médio & Média & Media & Longo \\
\hline \hline $\begin{array}{l}\text { PRIORIDADE } \\
\text { ALTA }\end{array}$ & $60 \%$ & $55 \%$ & $55 \%$ & $55 \%$ & $54 \%$ \\
\hline $\begin{array}{l}\text { PRIORIDADE } \\
\text { MÉDIA }\end{array}$ & $26 \%$ & $30 \%$ & $34 \%$ & $34 \%$ & $31 \%$ \\
\hline $\begin{array}{l}\text { PRIORIDADE } \\
\text { BAIXA }\end{array}$ & $14 \%$ & $15 \%$ & $11 \%$ & $11 \%$ & $15 \%$ \\
\hline
\end{tabular}

- Sprint 3: Depois de indicar os requisitos mais críticos da Sprint 2, indicar o status dos testes e finalizar a Sprint 2, foi gerado mais uma nova Sprint. O resultado da priorização da Sprint 3 foi:

\begin{tabular}{|l|l|l|l|l|l|}
\hline & $\begin{array}{l}\text { Consultar } \\
\text { Convenio }\end{array}$ & $\begin{array}{l}\text { MovimentosCadastrar } \\
\text { por co- } \\
\text { merciante }\end{array}$ & $\begin{array}{l}\text { endereco } \\
\text { adm }\end{array}$ & SDV004] & $\begin{array}{l}\text { Bloquear } \\
\text { Cartao }\end{array}$ \\
\hline $\begin{array}{l}\text { Nivel de impacto } \\
\text { de alteraçōes }\end{array}$ & Alta & Média & Alta & Alta & Baixa \\
\hline $\begin{array}{l}\text { Nivel dos desen- } \\
\text { volvedores }\end{array}$ & Confiavel & Confiável & $\begin{array}{l}\text { Muito Con- } \\
\text { fiável }\end{array}$ & $\begin{array}{l}\text { Muito Con- } \\
\text { fiável }\end{array}$ & $\begin{array}{l}\text { Muito Con- } \\
\text { fiável }\end{array}$ \\
\hline $\begin{array}{l}\text { Porcentagem de } \\
\text { cobertura dos } \\
\text { testes anteriores }\end{array}$ & Alta & Alta & Média & Média & Média \\
\hline $\begin{array}{l}\text { Nivel de impor- } \\
\text { tância do stakehol- } \\
\text { der para o requi- } \\
\text { sito }\end{array}$ & Alta & Alta & Alta & Alta & Alta \\
\hline $\begin{array}{l}\text { Nota de priori- } \\
\text { dade do requisito }\end{array}$ & Média & Alta & Baixa & Baixa & Alta \\
\hline $\begin{array}{l}\text { Nivel de impor- } \\
\text { tância do stakehol- } \\
\text { der para o projeto }\end{array}$ & Alta & Alta & Alta & Média & Alta \\
\hline Custo do projeto & Médio & Média & Médio & Baixo & Médio \\
\hline Prazo de entrega & Longo & Longo & Longo & Curto & Longo \\
\hline \hline $\begin{array}{l}\text { PRIORIDADE } \\
\text { ALTA }\end{array}$ & $50 \%$ & $49 \%$ & $48 \%$ & $48 \%$ & $47 \%$ \\
\hline $\begin{array}{l}\text { PRIORIDADE } \\
\text { MÉDIA }\end{array}$ & $30 \%$ & $34 \%$ & $29 \%$ & $29 \%$ & $35 \%$ \\
\hline $\begin{array}{l}\text { PRIORIDADE } \\
\text { BAIXA }\end{array}$ & $20 \%$ & $17 \%$ & $22 \%$ & $22 \%$ & $18 \%$ \\
\hline
\end{tabular}

\section{V.CONCLUSÃO}

Este trabalho apresentou o uso das Redes Bayesiana integradas na ferramenta T-AADSP para definir a prioridade dos casos de testes e gerenciar todo o processo de testes de acordo com a Abordagem Adaptativa para implantação de Processo de Software (AADSP). Durante o estudo do tema com a pesquisa da fundamentação teórica, análise dos documentos de testes obtidos para a avaliação, treino da rede e contato com pessoas da área, percebeu-se que a priorização dos casos de teste de requisito é de uma importância muito grande. As empresas de software querem e precisam gerenciar melhor a etapa de testes dos seus projetos, sobretudo de empresas de pequeno e médio porte, que não contam com muito investimento de tempo e de pessoas.

Como trabalhos futuros, podem ser desenvolvidos módulos para a integração de outras gerências presentes no AADSP (como Gerência de projetos, Gerência de requisitos e modelagem, Gerência de configuração e mudanças, Gerência de colaboradores e Gerência de Reutilização). Esses novos módulos irão aprimorar a ferramenta tornandoa mais completa.

Tal esforço permitirá que todos os requisitos propostos pela AADSP para um projeto se software sejam atendidos. Também, outros tipos de algoritmos para fazer estimativa dos casos de testes podem ser aplicados, como a utilização de Redes Neurais, Classificador Bayesiano ou Algoritmos Genéticos.

\section{REFERÊNCIAS BIBLIOGRÁFICAS}

CALDAS, Lorena; PITANGUEIRA, Antônio. T-suite: Uma ferramenta para seleção ótima de casos de teste manuais para regressão. Instituto Federal de Educação, Ciência e Tecnologia da Bahia - IFBA, 2012.

CALDAS, Lorena, PITANGUEIRA, Antônio. Uma ferramenta para selecionar casos de testes manuais de forma ótima. 10th International Conference on Information Systems and Technology Management - CONTECSI. Março, 2013.

LABRASOFT - Grupo de Pesquisa Laboratório de Desenvolvimento de Software. AADSP Guia de implementação - Geral: Fundamentação para 
implantação da abordagem adaptativa para implantação de processo de software. Salvador, 2016.

LUZ, Vielimir Silva. Uma abordagem para automação de testes de aceitação utilizando selenium, testng e tabelas fit. Departamento de Computação e Automação do Centro de Tecnologia da Universidade Federal do Rio Grande do Norte. Dezembro, 2012.

QUINTELLA, Heitor Luiz Murat de Meirelles; ALMEIDA, José Luiz Iannibelli de. Fábrica de software: análise do impacto na competitividade. p. 13. 2006.

SANTANA, Rafael. Eta - easy test automation: uma ferramenta para automação de testes funcionais web baseada em selenium webdriver e testng. Instituto Federal de Educação, Ciência e Tecnologia da Bahia - IFBA, 2016.

SOUZA, Anderson Luiz Ara-. Redes bayesianas: Uma introdução aplicada a credit scoring. Universidade Federal de São Carlos - UFSCar, 2010.

SOUZA, Antonio Carlos; DIAS, Caio; MACEDO, Márcio. AADSP: Gerência de Requisitos. 1. ed. Sao Paulo: Editora Ixtlan, 2018.

\section{COPYRIGHT}

Direitos autorais: Os autores são os únicos responsáveis pelo material incluído no artigo. 


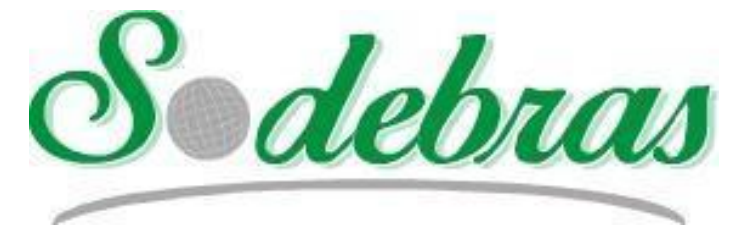

Volume 15 - $\mathrm{N}^{\mathrm{o}} 169$ - Janeiro / 2020

XLI International Sodebras Congress

31 de outubro a 02 de novembro de 2019 - Maceió - AL.

\title{
SMDCIC - SISTEMA PARA MONITORAMENTO DE DATA CENTERS BASEADO NA INTERNET DAS COISAS
}

\author{
SMDCIC - SYSTEM OF DATA CENTER MONITORING IOT-BASED
CARLOS ALICIO ANDRADE CARVALHO'; MÁRCIO MACEDO; ANTONIO CARLOS DOS SANTOS SOUZA $^{1}$ \\ 1 - INSTITUTO FEDERAL DA BAHIA; 2 - UNIVERSIDADE FEDERAL DA BAHIA \\ carlosalicio.developer@gmail.com; marciocfmacedo@hotmail.com; acsantossouza@gmail.com
}

\begin{abstract}
Resumo - A Internet of Things (IoT) ou Internet das Coisas está mudando a forma com que o mundo se conecta e troca informações. Ao passo que essa transformação acontece, novas tecnologias e processos surgem, abrindo um leque de possibilidades para o seu uso. Uma aplicação possível é no ambiente de Data Centers, componente essencial para o desenvolvimento da computação como um todo e principalmente a área de IoT. $O$ presente trabalho descreve os passos executados para a construção de uma solução para o monitoramento do ambiente de data centers valendo-se dos conceitos e tecnologias desenvolvidas nos últimos anos com base na internet das coisas.
\end{abstract}

Palavras-chave: Internet das coisas. IoT. Monitoramento. Data centers.

\begin{abstract}
Internet of Things - IoT is changing the way the world connects and exchanges information. As this transformation takes place, new technologies and processes emerge, opening a range of possibilities for IoT use. One possible application is in data center environment, an essential component for the development of computing as a whole and especially in the area of IoT. This paper describes the steps taken to build a solution for monitoring data center environment using the concepts and technologies developed in recent years based on Internet of Things.
\end{abstract}

Keywords: Internet of things. IoT. Monitoring. Data centers.

\section{INTRODUÇÃO}

Um Data Center pode ser definido como um ambiente no qual estão equipamentos que armazenam informações essenciais para o negócio de uma organização. $\mathrm{O}$ aumento da demanda de produção e consumo de informação advindos da elevação do uso de dispositivos conectados, faz parte do cenário, em que os Data Centers são de extrema relevância (MARIN, 2011).

Assim, o monitoramento de data centers é um fator importante a ser considerado, pois a disponibilidade dos dados e da informação é fundamental para o negócio no qual estão inseridos. No que se diz respeito ao monitoramento do ambiente de data centers, aspectos devem ser considerados, pois uma simples mudança de temperatura pode acarretar em danos aos equipamentos, levando a interrupções de disponibilidade do sistema, o que pode resultar em perdas para a organização (DILLY; MENDES, 2015). Fatores como o alto custo e a complexidade de implantação de um sistema para monitorar o ambiente em data centers justifica a adoção de novas tecnologias, a fím de solucionar essa questão (COLE, 2012).

Outra área da computação que cresceu com amplo destaque é a de IoT (Internet of Things ou Internet das Coisas). Com o desenvolvimento da IoT, nos últimos anos, surgiram várias tecnologias que possibilitaram a conexão e comunicação dos mais diversos tipos de dispositivos na rede (internet). Isso expandiu a gama de possíveis aplicações desenvolvidas, principalmente nas áreas de automação, monitoramento e utilização de sensores (ATZORI; IERA; MORABITO, 2010; PIYARE, 2013).

Tendo como base o cenário descrito acima, o presente trabalho descreve os passos executados para a construção da solução batizada como SMDCIC - Sistema para Monitoramento de Data Centers baseado na Internet das Coisas. O principal objetivo do SMDCIC é o uso dos novos conceitos e tecnologias da área de IoT para desenvolver uma solução que permita, de forma prática, a implantação de um sistema de monitoramento e acompanhamento do ambiente de um data center, atentando-se a aspectos como baixo custo, fácil escalonamento, simples implantação e acompanhamento remoto pelo usuário.

\section{METODOLOGIA}

O Sistema para Monitoramento de Data Centers baseado na Internet das Coisas - SMDCIC, é uma solução que mescla software e hardware a fim de disponibilizar, de forma online, informações do data center. Nesta seção é apresentado o processo de construção do sistema, detalhando os elementos e ferramentas utilizados.

\section{$2.1-$ Requisitos}

O primeiro passo para a construção do sistema foi estabelecer o escopo da aplicação, definindo os seguintes pontos monitorados de acordo com a norma ANSI/TIA-942:

Temperatura - Monitorar a temperatura do ambiente é importante, porque os equipamentos de um data center, durante seu funcionamento, geram muito calor. Um valor de temperatura elevado pode causar sobreaquecimento dos servidores e consequentemente desligamento ou até mesmo danos irreversíveis ao mesmo. 
Umidade - A alta umidade na sala do data center pode provocar condensação de água nos servidores, já a baixa umidade pode gerar curtos dentro dos servidores devido a geração de carga eletrostática.

Fumaça - A presença de fumaça no ambiente é um indicativo de incêndio, por isso também deve ser monitorada.

Corrente da rede elétrica - Monitorar a corrente elétrica se faz necessário, uma vez que oscilações e interrompimento de energia podem causar o desligamento e reinicialização dos servidores.

Espaço em disco rígido - Esse ponto é importante para detectar se o espaço disponível está próximo do limite e poder realizar medidas de escalonamento. Outro aspecto é prevenir possíveis perdas devido a falhas ao tentar salvar informações.

Status do link de dados - O monitoramento do link é importante para não comprometer a disponibilidade dos serviços agindo rapidamente caso o mesmo fique offline.

Também foram definidos os elementos que não estão diretamente ligados ao monitoramento, mas são de suma importância para o propósito do sistema (requisitos nãofuncionais). Nesse sentido temos:

Escalabilidade - Deve ser possível aumentar ou diminuir o número de componentes sem causar impactos ao sistema.

Heterogeneidade - O sistema deve ser capaz de lidar com componentes que distinguem nos seguintes aspectos: Sistema operacional, Hardware ou linguagem de programação. Em outras palavras, o SMDCIC pode ter componentes codificados na linguagem Python sendo executado em um servidor Linux, componentes codificados em C\# executados em um desktop Windows ou mesmo componentes escritos em Java executados em um dispositivo mobile Android.

\section{2 - Arquitetura}

Após a definição dos requisitos foi desenvolvida a arquitetura prescritiva do sistema. Para lidar com as questões de escalabilidade e heterogeneidade do SMDCIC adotou-se como referência o estilo arquitetural Event-Based, que baseia-se em invocação implícita (LUCKHAM; VERA, 1995).

O protocolo utilizado para a comunicação interna foi o MQTT, já para comunicação para a comunicação externa foi utilizado o HTTP. Como pode ser visto na figura 1 , o sistema é composto pelos seguintes elementos: Message Broker, Cliente, Banco de Dados, App mobile.

Figura 1 - Arquitetura SMDCIC.

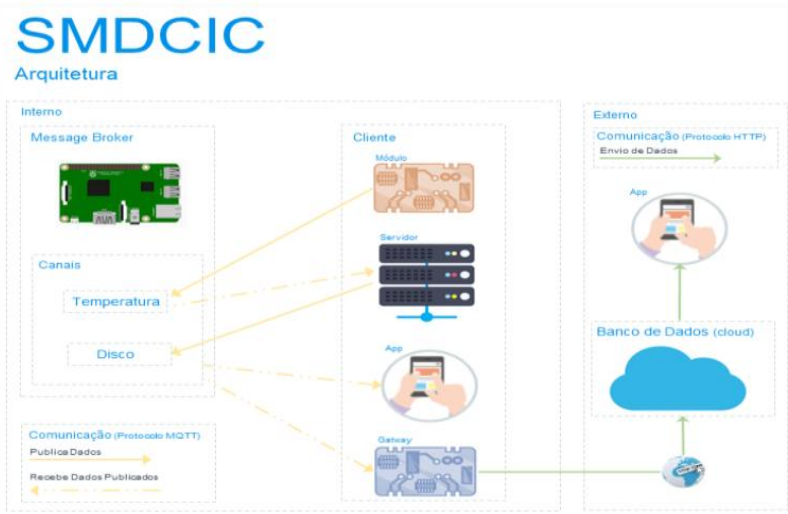

Fonte: Autores, 2019.
Clientes - Elemento da arquitetura é responsável por publicar dados, receber dados publicados ou efetuar as duas atividades concomitantemente. Publicadores enviam suas mensagens para canais (ou tópico), enquanto assinantes recebem as mensagens dos canais que estão inscritos.

Message Broker - É o conector responsável por receber as mensagens, criar os canais e enviar as mensagens recebidas para os clientes assinantes dos canais.

Banco de dados - Outro componente da arquitetura é o banco de dados na nuvem, que armazena todos os dados coletados e publicados e os disponibilizam a aplicações externas. A persistência dos dados é feita através de um cliente assinante de todos os canais providos pelo Message Broker.

App Mobile (externo) - Esse componente consulta as informações do banco de dados e as exibem em seu dashboard.

\section{3 - Modelagem}

A modelagem do sistema foi feita usando a UML Linguagem de Modelagem Unificada (do inglês, Unified Modeling Language), através da qual foram elaborados os diagramas de caso de uso do sistema.

As figuras 2, 3 e 4 ilustram os diagramas de caso de uso em que as ações são desempenhadas por máquinas, já a figura 5 representa as ações do usuário através dos apps mobiles interno e externo.

Figura 2 - Caso de Uso SMDCIC (Clientes).

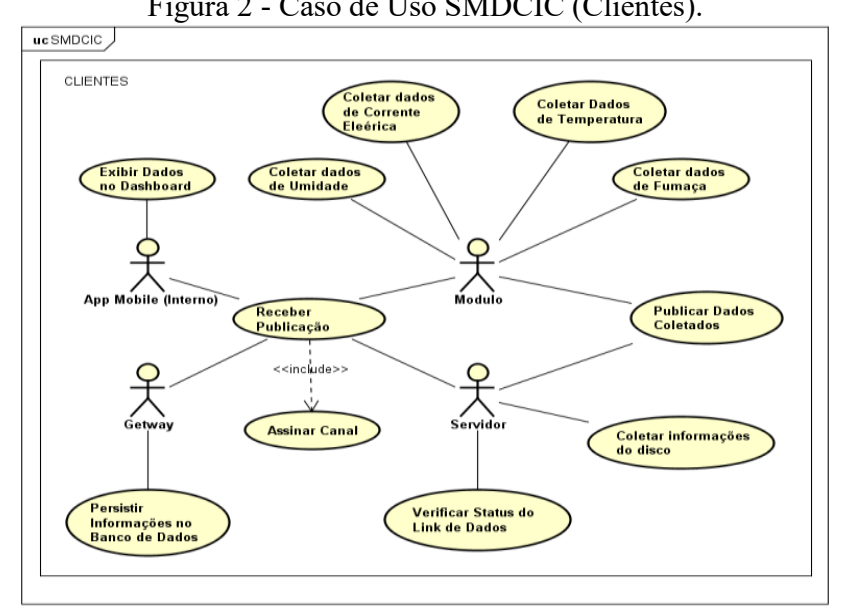

Fonte: Autores, 2019.

Figura 3 - Caso de Uso SMDCIC (App Externo).

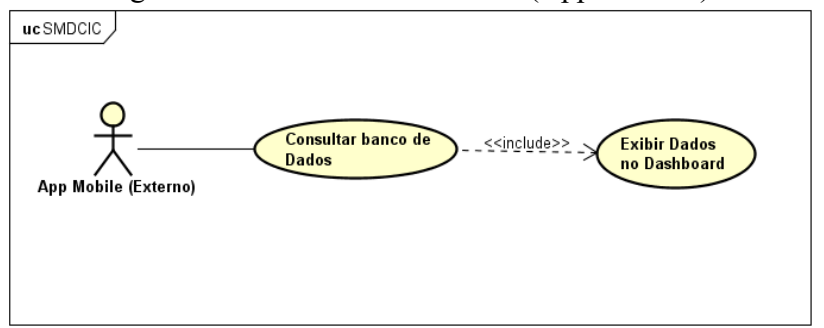

Fonte: Autores, 2019. 
Figura 4 - Caso de Uso SMDCIC (Message Broker).

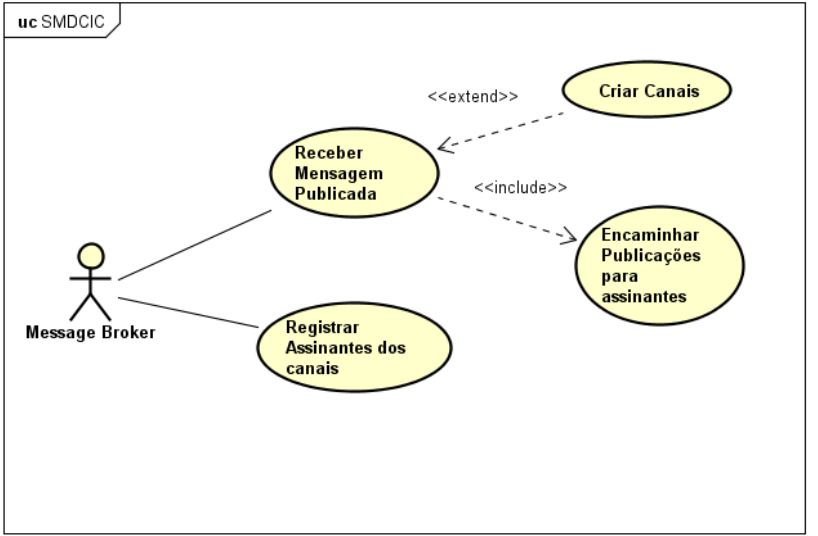

Fonte: Autores, 2019.

Figura 5 - Caso de Uso SMDCIC (Usuário).

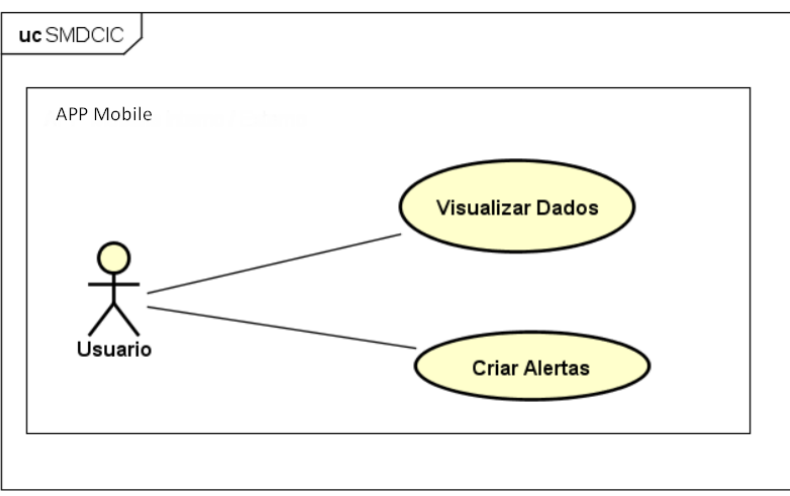

Fonte: Autores, 2019.

\section{4 - Ferramentas}

Nesta subseção estão detalhadas as ferramentas, tanto de hardware quanto de software, utilizadas para a implementação e implantação do SMDCIC.

\section{Hardware}

Sensor DH11 - Realiza a leitura de temperaturas entre 0 a 50 Celsius, através de um termistor do tipo NTC, e a leitura da umidade entre 20 a $90 \backslash \%$, através de um sensor do tipo HR202. O circuito interno do DH11 captura as informações do ambiente e as enviam para um microcontrolador (DAN-AO; FEI, 2013).

Sensor Gás MQ-2 - Detecta a concentração no ar de fumaça e gás inflamável, tais como GLP, Metano, Propano, Butano, Hidrogênio, Álcool, Gás Natural entre outros. A sensibilidade pode ser ajustada via potenciômetro (NOGRALES, 2014).

Sensor SCT-013 20A - É um sensor não invasivo capaz de medir corrente até 20A (SUPRIANTO; SUBAGYO, 2017). O sensor trabalhou em temperaturas entre -25 a $70^{\circ} \mathrm{C}$, com um corrente de entrada entre $0-20 \mathrm{~A}$ e sinal de saída de $1 \mathrm{~V}$ (tensão).

Protoboard - É uma ferramenta para prototipagem que permite a montagem de circuitos eletrônicos sem a necessidade de solda. Fabricada em plástico $\mathrm{ABS}$ não propaga chamas.

Jumpers - Usado em conjunto com protoboard, são uma ótima ferramenta de auxílio a prototipação.

NodeMCU - é uma placa de desenvolvimento que combina, em um mesmo PCB, o chip ESP8266, uma interface usb-serial e um regulador de tensão 3.3V. Pode ser programada usando a IDE do Arduino, ainda possui 11 pinos $\mathrm{I} / \mathrm{O}$, conversor analogio-digital, antena embutida e um conector micro-usb. O NodeMCU ainda suporta upgrade remoto de firmware e dimensões de 49 × 25,5 x $7 \mathrm{~mm}$.

Raspberry PI 3 - É um microcomputador completo com dimensões, aproximadas, de um cartão de crédito. A versão PI 3 conta com processador Broadcom Quad Core BCM2837 de 64 bits e clock de $1.2 \mathrm{GHz}, 1 \mathrm{G}$ de memória RAM, além de adaptadores Wi-fi e Bluetooth 4.1 integrados. Os componentes apresentados foram utilizados para a confecção dos Clientes e Message Broker. A figura 6 mostra os itens utilizados na construção dos componentes.

Figura 6 - Itens utilizados na construção dos componentes.

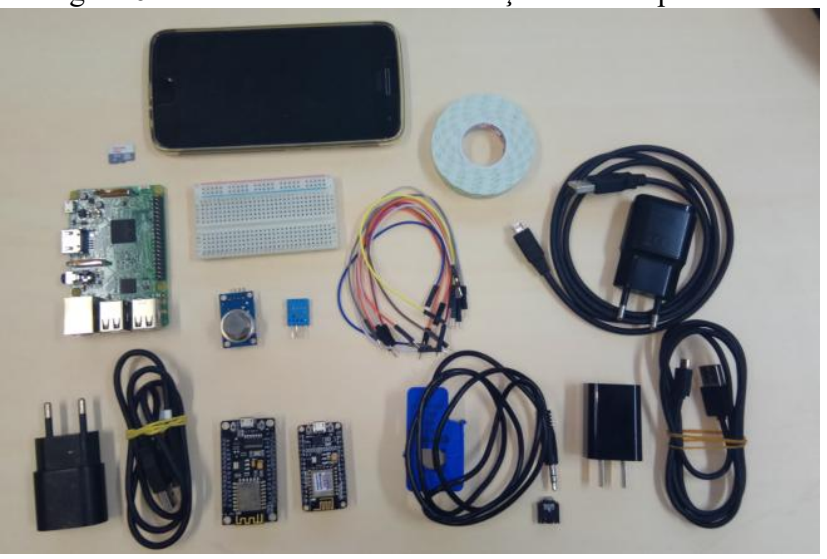

Fonte: Autores, 2019.

\section{Software}

Arduino IDE - é um software usado para escrever e gravar programas (firmwares) nas placas Arduino. Uma de suas principais características é a possibilidade de estender funcionalidades através de bibliotecas. O Arduíno IDE foi usado para programação das placas NodeMCU, através das bibliotecas disponíveis para o esp8266 (OLIVEIRA, 2017).

Android Studio - é o ambiente de desenvolvimento, oficial fornecido pela Google, para dispositivos Android. A ferramenta foi usada no desenvolvimento dos APPs mobiles.

PyCharm - é uma ferramenta para a programação em Python e foi usada para a desenvolvimento do cliente que coleta as informações do servidor.

Eclipse Mosquitto - é um broker de código aberto mantido pela iot.elipse.org que implementa o protocolo MQTT nas versões 3.1 e 3.1.1. O mosquitto foi utilizado no gerenciamento dos eventos de envio e recebimento de mensagens pelo Message Broker.

Raspbian - é um dos sistemas operacionais disponíveis para a instalação no Raspberry PI 3. Ele é baseado no Debian e foi utilizado como servidor MQTT.

\section{5 - Funcionamento}

O SMDCIC integra quatro tipos de elementos, Message Broker, Cliente, Banco de dados e App Mobile externo. Segue o detalhamento do funcionamento de cada um deles.

Clientes - A função dos Clientes é coletar dados e publicá-los através do envio de mensagens, categorizadas por canais, ao Message Broker. Existem quatro tipos de clientes: Módulo, Servidor, Gateway e App mobile.

Módulos - O hardware de um módulo é composto pelo conjunto de sensor e placa NodeMCU montados em 
uma protoboard e interligados com jumpers. Cada placa NodeMCU de um módulo recebe o firmware específico responsável por ler as informações capturadas pelo sensor de forma a conectar-se com o Message Broker e enviar os dados. O firmware também pode ser configurado, se for o caso, para assinar canais de interesse e receber as mensagens publicadas nesses canais. Para escrever os firmwares e gravá-los no NodeMCU foi utilizada a IDE Arduino (OLIVEIRA, 2017).

Gateway - O Gateway é composto só por uma placa NodeMCU, pois seu papel se resume em apenas persistir os dados coletados pelos demais clientes no banco de dados. Para isso, firmware do Gateway está programado para se conectar ao Message Broker e assinar todos os canais existentes assim todas as mensagens publicadas são recebidas por ele. Periodicamente o Gateway se conecta do banco de dados e faz a persistência do mesmos. Também foi utilizado o Arduino IDE para desenvolver e gravar o firmware.

Servidor - Como uma das funcionalidades do SMDCIC é monitorar informações lógicas do data center, foi desenvolvida em Python uma aplicação para os servidores que fazer a coleta periódica dos dados de disco e rede. Para aquisição dos dados foi utilizado o módulo subprocess do Python, que possibilita a execução de comandos shell através da aplicação, assim periodicamente as informações são coletadas e publicadas. Aplicação dos servidores também conta com a implementação de um cliente MQTT responsável por se conectar ao Message Broker, publicar e receber mensagens. A aplicação do servidor foi desenvolvida utilizando a ferramenta Pycharm.

App Mobile (interno) - O App mobile interno, consiste em um aplicativo que se conecta ao Message Broker e pode assinar canais para receber publicações ou publicar mensagens. Como App mobile interno foi utilizado o IoT MQTT Dashboard (NGHIA TH), um app para a plataforma Android que implementa o protocolo MQTT e pode ser instalado em tablets ou smartphones.

Message Broker - O Message Broker é um conector que implementa um servidor MQTT para receber as mensagens publicadas e as despacham para os clientes assinantes dos canais. Vale ressaltar que o conector não armazena nenhuma mensagem, apenas verifica quais clientes estão inscritos no canal da mensagem publicada e encaminha a mesma para os respectivos assinantes. Em termos de hardware o Message Broker é composto de um Raspberry PI 3 rodando como sistema operacional Resbian. O servidor MQTT utilizado foi o Mosquitto.

Banco de dados - Para armazenamento das informações foi utilizado o Firebase, que é um banco de dados não relacional na nuvem (cloud) mantido pela empresa Google. As mensagens são armazenadas no Firebase organizadas por canal, ID do sensor, valor e data.

App Mobile (externo) - O funcionamento do App mobile externo é similar ao interno exceto que não possui um cliente MQTT, pois obtém os dados através de consulta ao banco de dados Firebase. Outra característica do app externo é a possibilidade criação de alertas pelo usuário. Para desenvolver o aplicativo foi utilizado o Android Studio e a linguagem de programação Java.

Comunicação - No ambiente do data center a comunicação é feita através de rede interna utilizando o protocolo MQTT (COSTA, 2018). Já para a comunicação externa entre o Gateway, Firebase e App mobile, é feita pela internet através do http. Toda a comunicação é feita por $W i$ $F i$, exceto o servidor que utiliza conexão cabeada ethernet.

As publicações seguem o seguinte padrão: canal/ID do sensor/valor. $\mathrm{Na}$ figura 7 é mostrado o esquema de funcionamento do SMDCIC.

Figura 7 - Funcionamento do SMDCIC.

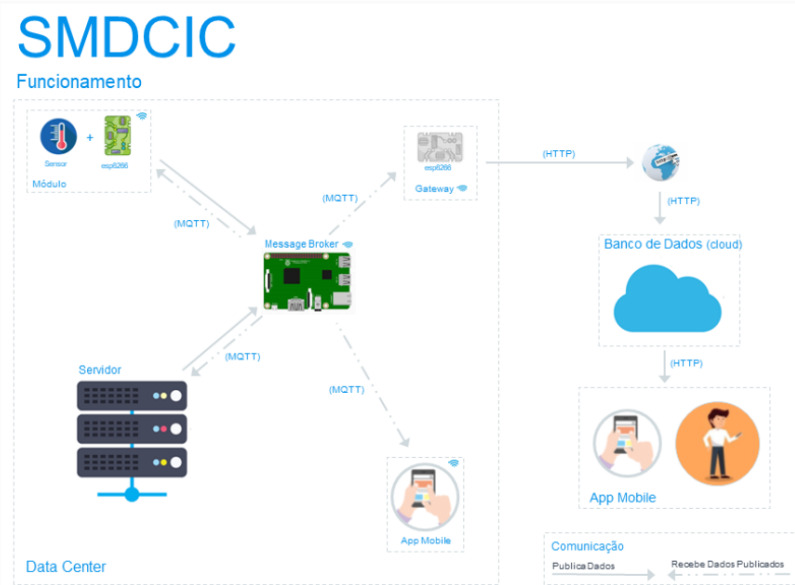

Fonte: Autores, 2019.

\section{6 - Implantação}

Nesta seção, são apresentados os resultados obtidos com o SMDCIC. Para isso o sistema foi utilizado para monitorar um data center mantido pela empresa Computação Brasil, que também disponibilizou um servidor para testes.

\section{Hardware}

No ambiente físico do data center foram implantados três componentes sendo um Message Broker, um Módulo e um Gateway. Com os três componentes se comunicam através de $W i$ - $f i$ eles podem ser posicionados em qualquer local do ambiente, porém é importante alocá-los em pontos estratégico de monitoramento. Da figura 8 à 10 são exibidas as imagens da alocação de alguns componentes no data center.

Figura 8 - Posicionamento do módulo sensor no data center.

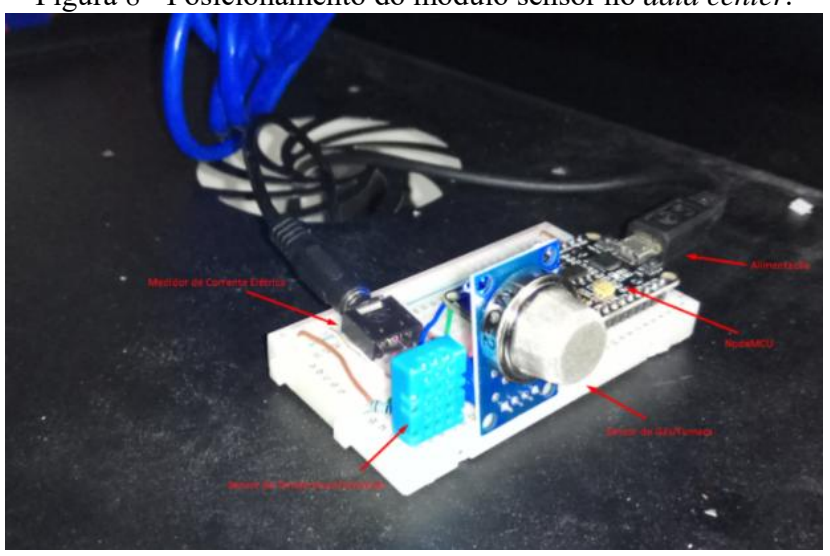

Fonte: Autores, 2019. 
Figura 9 - Posicionamento do sensor SCT-013 20A.

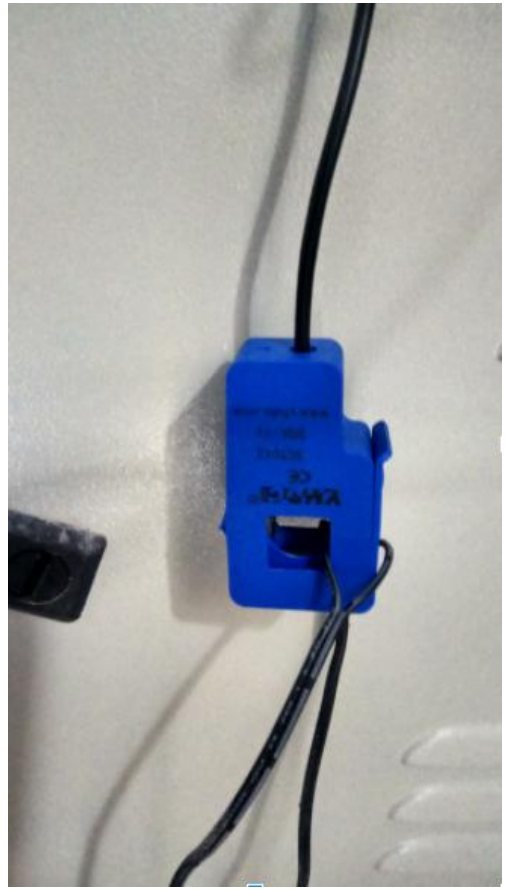

Fonte: Autores, 2019

Figura 10 - A esquerda Message Broker, no meio App Mobile (interno) e a direita módulo sensor.

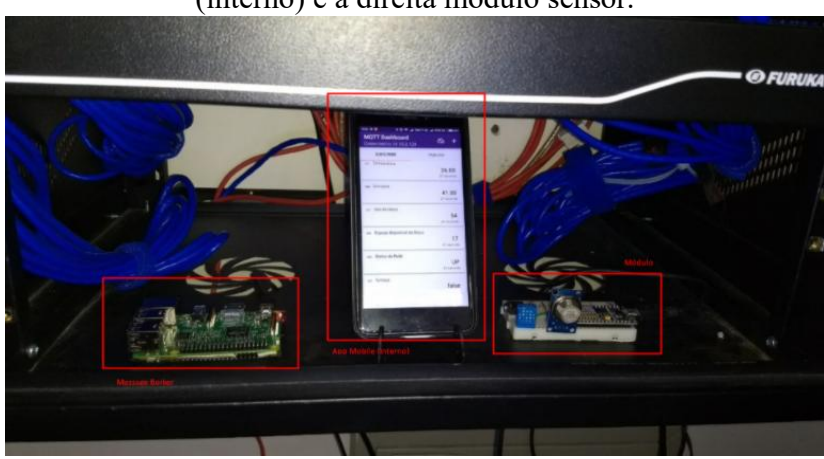

Fonte: Autores, 2019.

\section{Software}

Também foi instalado um cliente no servidor para a coleta das informações de disco e status do link de dados.

Para exibição interna dos dados monitorados foi instalado o IoT MQTT Dashboard em um aparelho Android, que recebe os dados enviados diretamente pelo Message Broker.

Os dados persistidos no banco de dados são visualizados pelo usuário através do App Mobile externo desenvolvido.

\section{RESULTADOS}

Um dos principais pontos verificados foi a escalabilidade assim a cada passo da implantação foram coletados os resultados do monitoramento.

Primeiramente foi instalado o cliente no servidor a fim de coletar os dados lógicos do sistema. Nesse momento os sensores de ambientes ainda não tinham sido colocados no data center. Posteriormente foram incorporados os sensores de umidade, temperatura, fumaça e rede elétrica, como mostra a figura 11 .
Figura 11 - Inclusão das medições de temperatura e umidade fumaça e rede elétrica

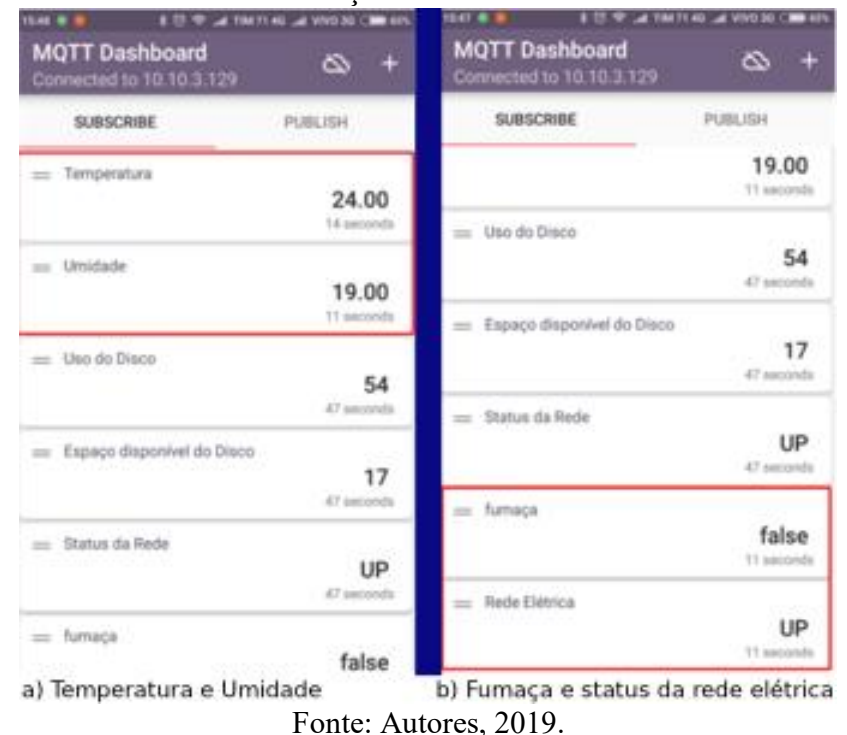

Como esperado a adição de novos elementos ao sistema não causou impactos aos que já haviam sido implantados, assim ao incorporar mais pontos de monitoramento não foi preciso reiniciar o sistema, apenas configurar a exibição no cliente Mobile.

Durante o processo de acompanhamento do SMDCIC foram feitas algumas simulações a fim de verificar os dados coletados pelo sistema.

\section{1 - Umidade / Temperatura}

Foram feitas algumas alterações de temperatura através do controlador do ar condicionado e observadas as leituras capturadas pelo SMDCIC. A figura 12 mostra a variação de temperatura e umidade em telas diferentes.

Figura 12 - Dados da temperatura e umidade.

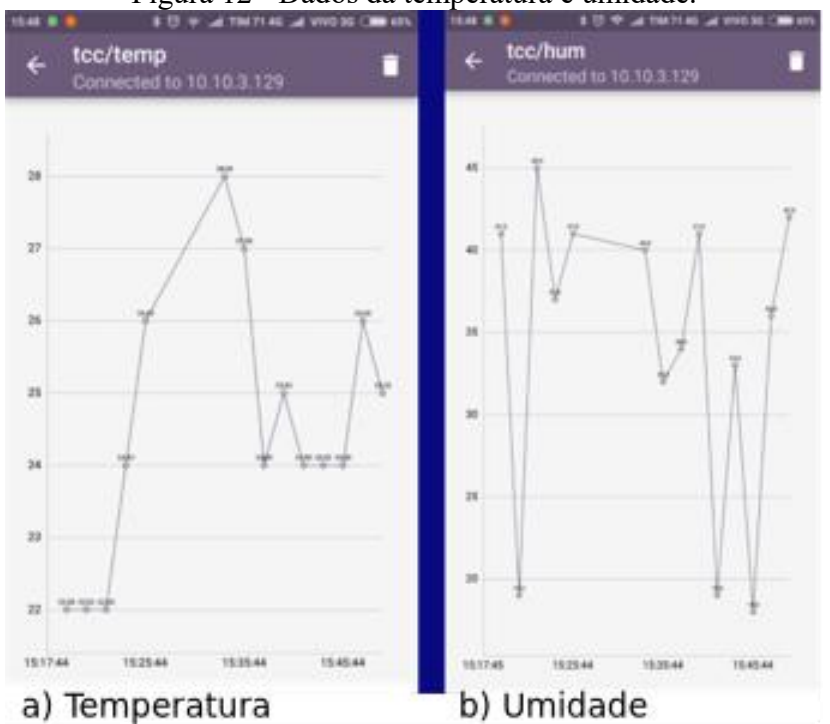

Fonte: Autores, 2019.

\section{2 - Rede Elétrica}

Para testes do monitoramento da rede elétrica, com o módulo devidamente instalado, o sensor SCT-013 foi periodicamente conectado e desconectado, a fim de simular a interrupção da corrente elétrica. 


\section{3 - Uso do Disco}

Foram copiados e removidos alguns arquivos do disco do servidor. A figura 13 representa as informações de variação do espaço usado do disco (GB) durante os testes.

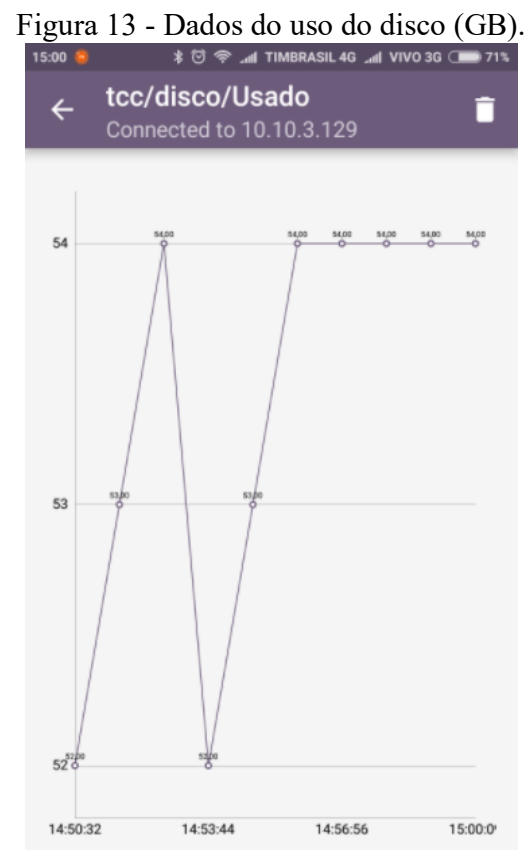

Fonte: Autores, 2019.

\section{4 - Link de Dados}

O teste do link de dados foi feito bloqueando o acesso a rede externa pelo servidor, assim o teste de ping realizado pelo cliente instalado resulta em falha, publicando uma mensagem de status "down" da rede. Os resultados podem ser vistos na figura 14. Também foram disparados alertas de notificação ao usuário durante os testes pelo App Mobile externo.

Figura 14 - Dados de monitoramento do status da rede.

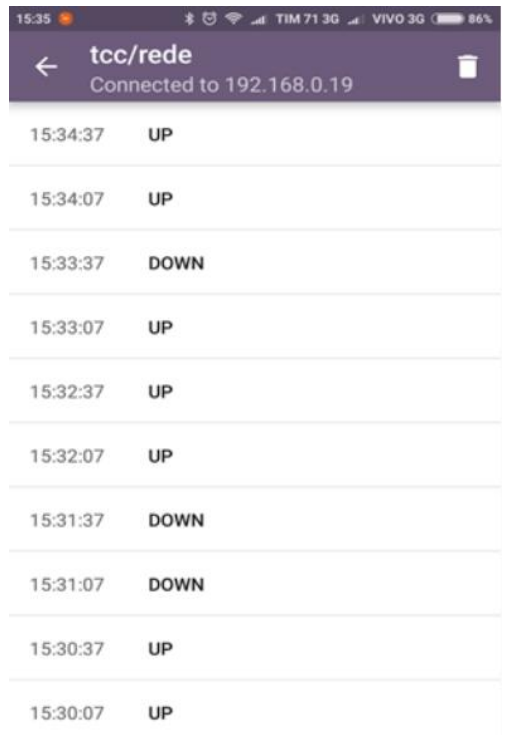

Fonte: Autores, 2019.

\section{CONCLUSÃO}

O desenvolvimento da área de $I o T$ traz com ela novas tecnologias que podem ser aplicadas nos mais diversos fins. Um exemplo de aplicabilidade é em data centers, pois devido ao grau de importância para a organização no qual estão inseridos é fundamental o seu monitoramento.
O presente trabalho apresentou o SMDCIC uma ferramenta composta por hardwares e softwares para o monitoramento de data centers. A motivação foi desenvolver uma solução que aplique os novos conceitos e tecnologias da área de IoT no contexto dos data centers, realizando o monitoramento do ambiente físico e dos servidores. As principais características do sistema são escalabilidade e facilidade de implantação, pois possibilita a adição de novos elementos para monitoramento sem a necessidade de parar o sistema.

\section{REFERÊNCIAS BIBLIOGRÁFICAS}

ANSI/TIA-942. Telecommunications industry association. about data centers. Disponível em: https://manuais.iessanclemente.net/images/9/9f/Tia942.pdf. Acesso em 11/07/2019.

AZEVEDO, Rodolfo Jardim de. Uma arquitetura para execução de código comprimido em sistemas dedicados. 2002.

ATZORI, Luigi; IERA, Antonio; MORABITO, Giacomo. The internet of things: A survey. Computer networks, v. 54, n. 15, p. 2787-2805, 2010.

COLE, Dave. Data center infrastructure management. Data Center Knowledge, 2012.

COSTA, Guilherme Rocha da. Monitoramento de variáveis ambientais para um data center. Sorocaba-SP, 2018.

DAN-AO, H. A. N.; FEI, W. A. N. G. Research application of the digital temperature and humidity sensor DHT11 [J]. Electronic Design Engineering, v. 13, 2013.

NOGRALES, H. Abdul Hadi. Low cost internet based wireless sensor network for air pollution monitoring using zigbee module. In: 2014 Fourth International Conference on Digital Information and Communication Technology and its Applications (DICTAP). IEEE, 2014. p. 310-314.

DILLY, Rosiene Oliveira; MENDES, Luiz Felipe Carvalho. Aplicação em Tempo Real de Monitoramento de Umidade e Temperatura Utilizando Arduino. Caderno de Estudos em Sistemas de Informação, v. 2, n. 1, 2015.

LUCKHAM, David C.. ; VERA, James. An event-based architecture definition language. IEEE transactions on Software Engineering, v. 21, n. 9, p. 717-734, 1995.

NGHIA TH. IoT MQTT Dashboard. Aplicativo disponível em:https://play.google.com/store/apps/details?id=com.thn.iotmqttd ashboard\&hl=pt BR. Acesso em 13 jul. 2019.

OLIVEIRA, Sérgio de. Internet das coisas com ESP8266, Arduino e Raspberry PI. Novatec Editora, 2017.

PIYARE, Rajeev. Internet of things: ubiquitous home control and monitoring system using android based smart phone. International journal of Internet of Things, v. 2, n. 1, p. 5-11, 2013.

SUPRIANTO, Bambang; SUBAGYO, Lucky Aggazi. Control system of current flow 3-phase unbalanced based on Arduino Uno. International Journal of Engineering and Applied Sciences, v. 4, n. 9, 2017

\section{COPYRIGHT}

Direitos autorais: $\mathrm{O}(\mathrm{s})$ autor(es) é(são) o(s) único(s) responsável(is) pelo material incluído no artigo. 


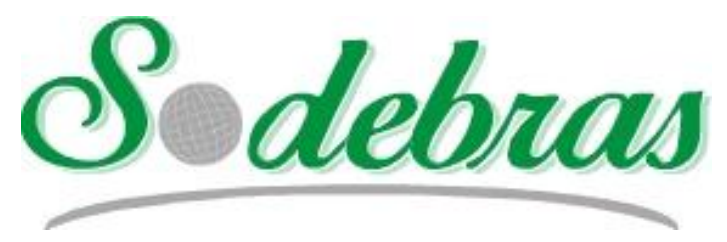

Volume 15 - $\mathrm{N}^{\mathrm{o}} 169$ - Janeiro / 2020

XLI International Sodebras Congress

31 de outubro a 02 de novembro de 2019 - Maceió - AL.

\title{
CÉLULA SOLAR PRODUZIDA COM CORANTE EXTRAÍDO DA CAPSICUM ANNUUM
}

\section{PRODUCTION SOLAR CELL WITH DYE EXTRACTED FROM CAPSICUM ANNUUM}

\author{
JULIANNO PIZZANO AYOUB ${ }^{1}$; GIDEÃ T. TRACTZ ${ }^{1}$; EVERSON P. BANCZEK ${ }^{1}$; LUANA E. N. \\ KOROCOSKI $^{1}$; PAULO R. P. RODRIGUES ${ }^{1}$ \\ 1 - UNIVERSIDADE ESTADUAL DO CENTRO OESTE \\ juliannopa@hotmail.com;gide.tractz@hotmail.com; \\ edopradobanczek@yahoo.com.br;luanaesteche@yahoo.com.br;prprodrigues@gmail.com
}

\begin{abstract}
Resumo - O uso do efeito fotovoltaico para conversão de energia solar em elétrica é uma alternativa para diminuir a emissão de gases poluentes. As células solares sensibilizadas por corante (CSSC) utiliza um óxido semicondutor, e um fotossensibilizador, que absorve energia e ejeta elétrons, fornecendo corrente elétrica. Este trabalho tem como objetivo produzir e caracterizar uma célula solar de $\mathrm{TiO}_{2}$ sensibilizada com o corante extraído da páprica. As técnicas de caracterização empregadas foram a Espectroscopia no UV-VIS, medidas do potencial de circuito aberto em função do tempo (Eca), medidas de fotocronoamperometria $(j-t)$ e curvas de densidade de corrente em função do potencial $(j-E)$.
\end{abstract}

Palavras-chave: Sustentabilidade. Energia Renovável. Células de Gratzel.

\begin{abstract}
The use of photovoltaic solar energy for solar energy conversion is an alternative to reduce the emission of polluting gases. The Dye Sensitized Solar Cell, a methodology that has been studied, uses a semiconductor oxide and a photosensitizer, which absorb energy and ejects electrons, receive electric current. extracted from paprika. The characterization techniques used are: UV-VIS spectroscopy, measurements of open motion potential as a function of time (Eca), photochromoamperometry measurements $(j-t)$ and curves of current density as a function of potential $(j-E)$.
\end{abstract}

Keywords: Sustainability. Renewable energy. Gratzel cells.

\section{INTRODUÇÃO}

As reservas mundiais de combustíveis fosseis, não acompanham a crescente demanda mundial, além desse tipo de energia estar associado a problemas ambientais (COSTA, 2011).

Novas alternativas energéticas vem sendo estudadas, entre elas a energia solar (PAURUSSULO, 2013). As células solares, através do efeito fotovoltaico, são capazes de transformar energia solar em corrente elétrica, entre várias classes de dispositivos que vem sendo desenvolvidos, tem-se as CSSC, células solares sensibilizadas por corante (GRATZEL, 2001)

$\mathrm{Na}$ produção de uma CSSC o corante, que atua como fotossensibilizador é impregnado na superfície de um óxido semicondutor. A corrente elétrica é gerada, quando há incidência de luz solar no dispositivo, permitindo que elétrons do corante sejam ejetados para uma banda de maior energia, e posteriormente à banda de condução do semincondutor. (GRATZEL,2003)

Os corantes mais utilizados nesses sistemas, possuem elevado custo, tornando atrativa a pesquisa por novos fotossensibilizadores, como os corantes extraídos de produtos naturais. (PATROCINIO,2010)

Nos corantes naturais, os principais compostos responsáveis pela transferência de carga, são, antocianina, betalaína, clorofila, e carotenoides, esse último, encontrado em produtos como, cenoura, tomate e páprica. (GÓMEZORTÍZ et al., 2010; HERNANDEZ-MARTINEZ et al., 2011; KURZ et al.,2008;)

Este trabalho tem como objetivo produzir e caracterizar eletroquimicamente a célula solar de $\mathrm{TiO}_{2}$ com corante extraído da páprica.

\section{METODOLOGIA}

Dióxido de titânio $\left(\mathrm{TiO}_{2}\right)$ foi utilizado na preparação do fotoânodo, depositado via Doctor Blading em um substrato condutor FTO (óxido de estanho dopado com flúor) calcinadas a $450^{\circ} \mathrm{C}$ durante 30 minutos. (TRACTZ et al.,2018)

A solução do corante foi extraído de 10 gramas de páprica em $60 \mathrm{~mL}$ de etanol $70 \%$ e o tempo de impregnação utilizado foi de 24 horas garantindo a adsorção do corante no óxido. (TRACTZ et al.,2018). Como contra eletrodo foi utilizada a platina eletrodepositada sobre o FTO e a o par redox $\mathrm{I}_{3}{ }^{-} / 3 \mathrm{I}^{-}$como intermediador de cargas. (GRATZEL,2003)

A célula foi montada em formato sanduíche com anodo e catodo com área de $0,2 \mathrm{~cm}^{2}$, unidos pela presença do eletrólito, como mostra a Figura 1. 
Figura 1 - Célula com o corante extraído da páprica, montada em formato sanduiche

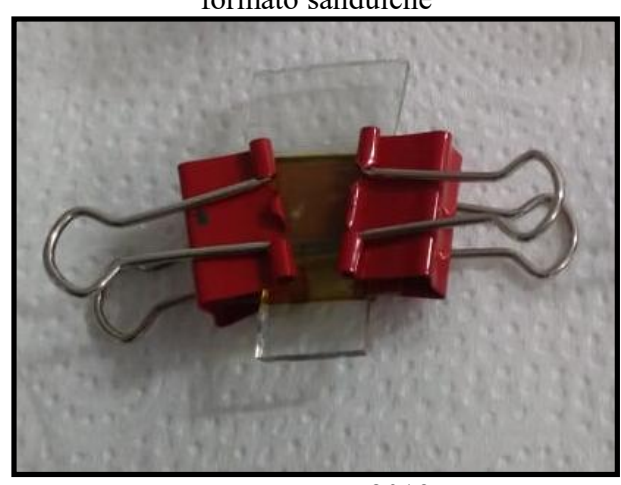

Fonte: Autor, 2019

Para determinar a região de absorção do corante no espectro eletromagnético foram realizadas medidas, em um espectrofotômetro UV-VIS $320 \mathrm{G}$ Gehaka, com feixe duplo a $25^{\circ} \mathrm{C}$, numa faixa de varredura de $400 \mathrm{~nm}$ a $800 \mathrm{~nm}$.

As medidas eletroquímicas foram obtidas em um potenciostato Zhenium Zahner ${ }^{\circledR}$, com sistema de simulação solar Lot Oriel LS0106 controlado por um potenciostato auxiliar Xpot, com lâmpada de xenônio e diâmetro do feixe de $25 \mathrm{~nm}$, e intensidade solar de $100 \mathrm{~mW} \mathrm{~cm}^{-2}$, com espectro solar padrão de AM 1.5G. (TRACTZ et al.,2018)

\section{RESULTADOS}

A região de absorção do corante no espectro, é mostrada na Figura 2.

Figura 2 - Espectro UV-VIS para o corante da páprica extraído em solução etanoica.

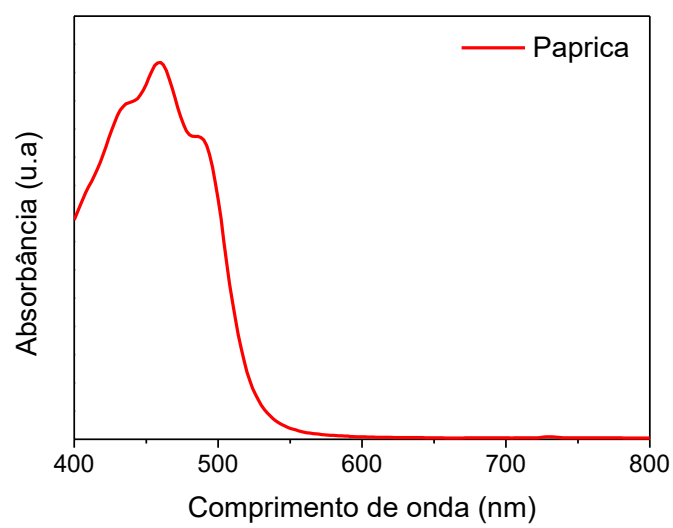

Nota-se no espectro da Figura 2 que o corante extraído da páprica possui um pico de absorção na região próxima a $470 \mathrm{~nm}$, característica dos carotenóides presentes (CHANWITHEESUK et al.,2005; SÁNCHEZ-MORENO et al.,2006).

Percebe-se que há a limitação do corante analisado quanto a absorção na região do infravermelho, quando comparado aos corantes comerciais sintéticos, capazes de absorver nessa região. Porém, sua disponibilidade e custo relativamente baixo torna o uso de corante naturais viável (GUIMARÃES et al., 2008; PATROCINIO et al.,2010)

Na Figura 3 é apresentada a curva de potencial de circuito aberto em função do tempo.
Figura 3 - Potencial de circuito aberto em relação ao tempo para a célula solar com corante da páprica

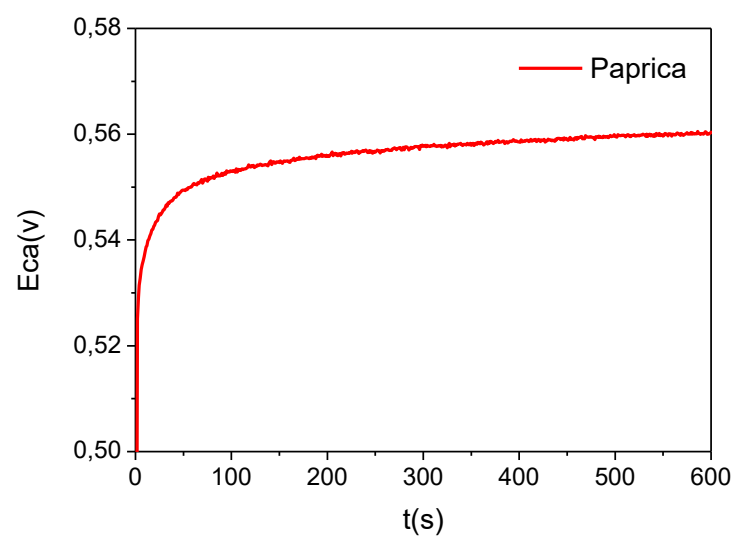

Verifica-se na Figura 3 que o sistema possui pequenas variações dos potenciais em relação ao tempo, devido a intensidade luminosa, sendo que quando a temperatura se estabiliza, o potencial também é estabilizado. (BERGINC et al.,2007)

Como os valores de potencial de circuito aberto estão relacionados aos efeitos de recombinação na célula, e quanto menor o valor, maiores são as perdas, a célula montada apresenta maior dificuldade em converter energia solar em eletricidade, quando comparada as células solares de Gratzel, que foram as primeiras desenvolvidas, e apresentam um potencial de aproximadamente $700 \mathrm{mV}$ (AYOUB et al.,2018; VIOMAR et al.,2016)

$\mathrm{Na}$ Figura 4 é apresentado o resultado da fotocronoamperometria.

Figura 4 - Fotocronoamperometria para a célula solar com corante da páprica sob iluminação de $100 \mathrm{~mW} \mathrm{~cm}{ }^{-2}$

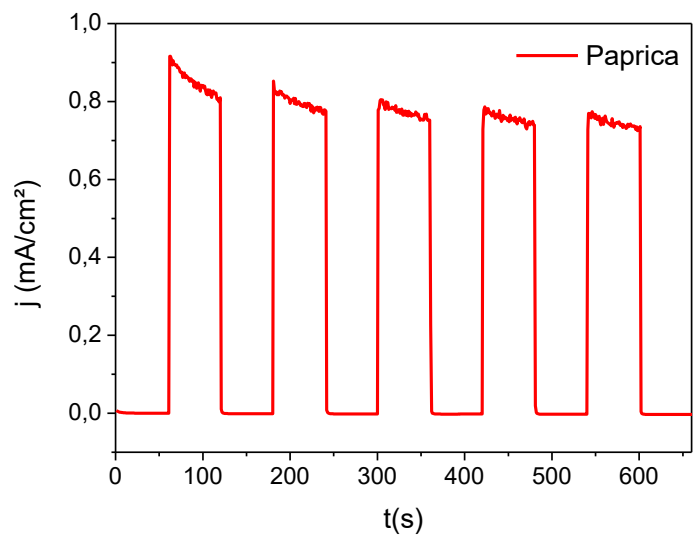

Analisando as curvas fotocronoamperometricas, da Figura 4 verifica-se que a célula produzida foi fotossensível, pois ao inserir luz no dispositivo houve um aumento da corrente $\left(\mathrm{j}=0,92 \mathrm{~mA} \cdot \mathrm{cm}^{-2}\right)$ e quando a lâmpada foi desligada a corrente produzida foi nula.

Também apresentou um tempo de carga e descarga, visto que com a incidência de luz o aumento da corrente foi instantâneo, e quando a lâmpada foi desligada, o valor da corrente foi nulo. (TRACTZ et al.,2018). Na Figura 5 encontra-se a curva de densidade de corrente em função do potencial, que foram usadas para cálculo da eficiência em conversão energética, através da Equação 1 e apresentados na Tabela 1. (HAGFELDT et al.,2010) 


\section{$\eta=\underline{\text { Jcc.Eca.FF. } 100 \%} \quad$ ( Equação1) \\ Pin}

Onde $\eta$ representa a eficiência energética, Jcc a corrente de curto circuito, Eca o potencial de circuito aberto, FF o fator de preenchimento e Pin a potência incidente.

Figura 5-Curva de densidade de corrente em função do potencial para a célula solar com corante da páprica sob iluminação de $100 \mathrm{~mW} \cdot \mathrm{cm}^{-2}$

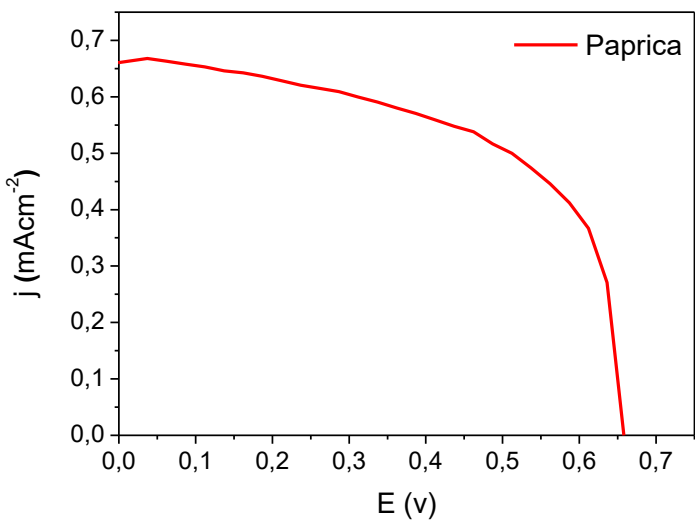

Tabela 1 - Parâmetros fotoeletroquímicos para a célula solar com o corante da páprica

\begin{tabular}{|c|c|c|c|c|}
\hline Corante & $\begin{array}{c}\mathbf{J c c}(\mathbf{m A} \\
\left.\mathbf{c m}^{-2}\right)\end{array}$ & $\mathbf{F F}$ & $\mathbf{E c a}(\mathbf{v})$ & $\mathbf{\eta}(\%)$ \\
\hline Páprica & $0,668 \pm$ & $0,582 \pm$ & $0,658 \pm$ & $0,256 \pm$ \\
& 0,090 & 0,094 & 0,068 & 0,028 \\
\hline
\end{tabular}

$\mathrm{O}$ valor de $\mathrm{FF}=0,582$ encontrado nesse sistema, é adequado, visto que se aproxima dos valores obtidos com corantes artificiais usados comercialmente (VIOMAR et al.,2016)

Também a Tabela 1 apresenta a eficiência do aproveitamento de energia com $\rceil=0,256 \%$, valor próximo aos encontrados para células solares produzidas com corantes naturais (KUMARA et al.,2017)

\section{CONCLUSÃO}

É possível utilizar produtos naturais, como o corante extraído da páprica, para a fabricação de células solares sensibilizadas por corante.

O dispositivo foi fotossensível, com um excelente tempo de carga/descarga, apresentando uma densidade de fotocorrente próxima de $\mathrm{j}=0,92 \mathrm{~mA} \cdot \mathrm{cm}^{-2}$.

\section{REFERÊNCIAS BIBLIOGRÁFICAS}

AYOUB, J. P.; TRACTZ, G. T.; BANCZEK, E.; RODRIGUES, P. R. P. Em busca da sustentabilidade: célula solar produzida com corante extraído da Morus Nigra. Sodebras. V.14, Mar/ 2019.

BERGINC, M; KRASOVEC, U, O; JANKOVEC, M; TOPIC, M. The effect of temperature on the performance of dye sensitized solar cells based on a propyl-methyl- imidazolium iodide electrolyte. Solar energy materials and solar cells. 91, 821-828. 2007.

CHANWITHEESUK,A.;

TEERAWUTGULRAG,A.; RAKRIAYATAM, N. Screening of antioxidant activity and antioxidant compounds of some edible plants of Thailand. Food Chemistry, London, 92, 491, 2005

COSTA, S. V. Construção de Células Solares Sensibilizadas por Corante a partir de Nanoestruturas de ZnO obtidas por Método Hidrotermal. 2011. 124f. Dissertação (Mestrado em energia) - Universidade Federal do ABC, Santo André, 2011.

GÓMEZ-ORTÍZ, N. M.; VÁZQUEZ-MALDONADO, I. A.; PÉREZ-ESPADAS, A. R.; MENA-REJÓN, G. J.; AZAMAR-BARRIOS, J. A.; OSKAM, G.; Sol. Energy Mater. Sol. Cells 2010 , 94, 40.

GUIMARAES, R. R; PARUSSULO, A. L. A; MATIAS, T. A; TOMA, H. E; ARAKI, K. Electrostatic blocking barrier as an effective strategy to inhibit electron recombination in DSSCs. Eletrochimica Acta 2008, 255, 20

GRATZEL, M. Dye sensitized solar cells. Journal of photochemistry and photobiology C: Photochemistry Reviews. V. 4, Jul./2003, pg 145-153.

GRATZEL, M. Photoelectrochemical Cells. Nature, V. 414, p. 338-345, 2001.

HAGFELDT, A; BOSCHLOO, G; SUN, L; KLOO, L; PETTERSON, Henrike. Dye Sensitized solar cells. Chemistry reviews. V. 110, 2010, pg 6595-6663.

HERNANDEZ-MARTINEZ， A. R.; ESTEVEZ, M.; VARGAS, S.; QUINTANILLA, F.; RODRIGUEZ, R.; Int. J. Mol. Sci.2011 , 12, 5565 .

KUMARA, N. T. R. N; LIM, A; LIM, C. M; PETRA, M. I; EKANAYAKE, P. Recent progress and utilization of natural pigments in dye sensitized solar cells. A review. Renewable and Sustainable Energy Reviews. 78. 301317. 2017.

KURZ, C.; CARLE, R.; SCHIEBER, A. HPLC-DADMSn characterisation of carotenoids from apricots and pumpkins for the evaluation of fruit product authenticity. Food Chemistry, London, v. 110, p. 522-530, 2008.

PATROCINIO, A. O. T; ILHA, N. Y. M. Em busca da sustentabilidade: Células solares sensibilizadas por extratos naturais. Química nova. V.33, n. 03, Fev./2010, pg 574578.

PAURUSSULO, A. L. A. Conceitos supramoleculares e morfologia interfacial em células solares de $\mathrm{TiO}_{2}$. Tese de Doutorado, São Paulo, 2013.

SÁNCHEZ-MORENO， C.; PLAZA,L .;ANCOS， B.; CANO,M.P. Nutritional characterization of commercial traditional pasteurized tomato juices:carotenoids, vitamin $\mathrm{C}$ and radical-scavenging capacity.Food Chemistry, London, 98, 794, 2006.

TRACTZ, G. T.; MAIA, G. A. R.; DIAS, B. V.; BANCZEK, E.; MOLINARES, M. A.; CUNHA, M. T.; RODRIGUES, P. R. P.; Influence of deposition methodology and heating treatment on dye sensitized solar 
cell with natural extract. Orbital: The electronic journal of chemistry. V.10, n. 03, pg. 204-210, 2018.

TRACTZ, G. T.; MAIA, G. A. R.; DIAS, B. V.; IGNACHEWSKI, F.; Rodrigues, P.R.P.; Avaliação da adsorção e estudo eletroquímico de células solares sensibilizadas com corante do Hibisco. Química Nova, v.41, pg. 512-518, 2018.

TRACTZ, G.T.; VIOMAR, A.; MATHEUS, A. P. C.; MAIA, G. A. R.; BANCZEK, E.; CUNHA, M. T.; RODRIGUES, P. R. P. Produção de célula solar com corante natural extraído da Acacia Decurrens. Sodebras. V.13, Mar/ 2018.

VIOMAR, A.; MAIA, G. A. R; SCREMIN, F. R; KHALIL, N. M; CUNHA, M. T; ANTUNES, A. C; RODRIGUES, P. R. P. Influencia do método de obtenção de partículas de $\mathrm{Nb} 2 \mathrm{O} 5$ empregadas em células solares sensibilizadas por corante composta de $\mathrm{TiO}_{2} / \mathrm{Nb}_{2} \mathrm{O}_{5}$. Revista Virtual de Química, v. 8, 2016, pg 889-900.

\section{AGRADECIMENTOS}

O presente trabalho foi realizado com o apoio da coordenação de aperfeiçoamento de pessoal de nível superior-Brasil (Capes) código de financiamento 001. Os autores agradecem a FAU/UNICENTRO pelo apoio financeiro, e também ao CNPq, FINEP, Fundação Araucária e SETI/UGF.

\section{COPYRIGHT}

Direitos autorais: Os autores são os únicos responsáveis pelo material incluído no artigo. 


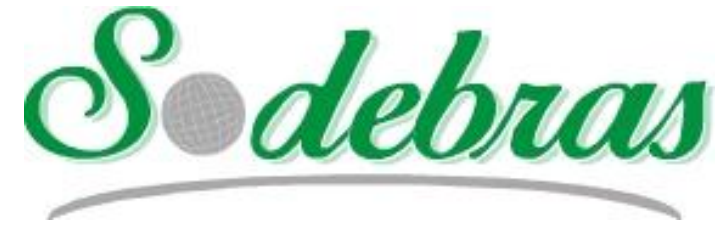

Volume 15 - $\mathrm{N}^{\mathrm{o}} 169$ - Janeiro / 2020

XLI International Sodebras Congress

31 de outubro a 02 de novembro de 2019 - Maceió - AL.

\title{
CONTAMINAÇÃO DE RECURSOS HÍDRICOS DA AMAZÔNIA: ESTUDO DE CASO NA REPRESA DE TUCURUÍ -PA
}

\author{
CONTAMINATION OF AMAZON WATER RESOURCES: A CASE STUDY IN \\ TUCURUÍ DAM
}

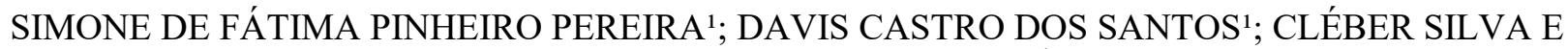 \\ SILVA $^{2}$; ERIVAN SOUSA CRUZ ${ }^{1}$ \\ 1 - LABORATÓRIO DE QUIIMICA ANALÍTICA E AMBIENTAL DA UNIVERSIDADE FEDERAL DO \\ PARÁ; 2 - INSTITUTO FEDERAL DE EDUCAÇÃO CAMPUS BELÉM \\ simonefp@ufpa.br; davisquimica@gmail.com; cleber.silva@ifpa.edu.br; erivansc@ufpa.br
}

\begin{abstract}
Resumo - A represa de Tucuruí localiza-se no rio Tocantins, no estado do Pará e próximo a este empreendimento existe uma grande exploração minerária tornando o reservatório de Tucuruí o depositário dos metais lançados no ambiente. $O$ objetivo do estudo foi avaliar a qualidade da água através da avaliação da presença de metais traço. A análise dos metais foi feito através da espectrometria de emissão ótica com plasma indutivamente acoplado (ICP-OES). Dos elementos analisados ( $\mathrm{Al}, \mathrm{Ba}, \mathrm{Cu}, \mathrm{Fe}$, $\mathrm{Mg}, \mathrm{Mn}, \mathrm{Sr}$ e Ti), apenas o alumínio (Min. = <LD; Max. = $584,19 \mu \mathrm{g} / \mathrm{L}$ ) com média de 248,65 $\mu \mathrm{g} / \mathrm{L}$ e o ferro (Min. $=223,94$ $\mu g / L ;$ Max. $=2186 \mu g / L)$ com média de 538,68 $\mu \mathrm{g} / \mathrm{L}$ apresentaram concentração acima do máximo permitido pela resolução 357/05 do CONAMA.
\end{abstract}

Palavras-chave: Rio Tocantins, Reservatório de Tucuruí, Metais tóxicos.

\begin{abstract}
The Tucurui dam is located in the Tocantins river, in the Para state and near this venture there is a great mining exploration, making the Tucurui reservoir the depository of the metals released in the environment. The objective of the study was to evaluate the water quality by evaluating the presence of trace metals. The metals analysis was done using inductively coupled plasma optical emission spectrometry (ICPOES). From the analyzed elements ( $\mathrm{Al}, \mathrm{Ba}, \mathrm{Cu}, \mathrm{Fe}, \mathrm{Mg}, \mathrm{Mn}, \mathrm{Sr}$ and $\mathrm{Ti})$, only aluminum $($ Min. $=\langle L D ;$ Max. $=584,19 \mu \mathrm{g} / L)$ with a mean of $248.65 \mu \mathrm{g} / \mathrm{L}$ and iron $(\mathrm{Min}=223.94 \mu \mathrm{g} / \mathrm{L}, \mathrm{Max}=2186 \mu \mathrm{g} / \mathrm{L})$ with a mean of $538.68 \mu \mathrm{g} / \mathrm{L}$ presented concentration above the maximum allowed by resolution 357/05 of CONAMA.
\end{abstract}

Keywords: Tocantins river, Tucuruí reservoir, Toxic metals.

\section{INTRODUÇÃO}

Os rios da Amazônia têm sofrido, ao longo dos anos, influência antrópica principalmente pela exploração mineral e implantação de grandes projetos como as hidrelétricas.

$\mathrm{O}$ rio Tocantins é um dos principais afluentes do rio Amazonas. Os últimos $360 \mathrm{~km}$ do Tocantins apresentam o trecho do lago de Tucuruí, encobrindo antigos desníveis que ali existiam, seguindo pelo trecho até a foz, com declividade insignificante, sofrendo, inclusive, a influência das marés.

A partir da construção da Usina Hidrelétrica de Tucuruí, desencadearam na região alterações significativas quanto os aspectos ambientais e socioeconômicos. Muitos estudos têm sido realizados desde o enchimento do reservatório de Tucuruí, com o objetivo de verificar os possíveis impactos e modificações na antiga calha do rio Tocantins ao ser transformado em reservatório artificial, como também as consequências sobre a diversidade biológica e aspectos químicos do rio.

A construção de barragens traz grandes alterações ao meio ambiente e o estudo destas alterações tem grande importância na avaliação da qualidade da água consumida pela população do entorno da represa (FEARNSIDE, 2016).

Pesquisas mostram que a inundação altera o equilíbrio dos elementos e dos compostos do solo, resultando em importantes mudanças químicas, físicas, biológicas e mineralógicas, das quais a mais significativa é possivelmente o decréscimo no potencial eletroquímico de elétrons ou potencial redox (LIMA et al., 2004). Sem esquecer que outras alterações são importantes como o aumento de $\mathrm{pH}$ em solos ácidos e decréscimo nos solos alcalinos, mudanças na condutividade elétrica, na força iônica e na sorção e dessorção de íons (SANTOS, 2003).

De modo geral, os teores mais elevados de elementos tóxicos em solução são observados nos horizontes superficiais, certamente em decorrência da presença de formas menos estáveis e do maior conteúdo de matéria orgânica nesses horizontes (SALOMONS \& FÖRSTNER, 1984). A magnitude dessas alterações depende de características do solo com $\mathrm{pH}$ inicial, teores de ferro e de manganês, além do conteúdo de matéria orgânica, etc. O potencial redox, portanto influencia no estado de oxidação dos elementos no sistema aquoso e, representa uma medida quantitativa da tendência de um dado sistema oxidar ou reduzir substâncias ou elementos suscetíveis a esses fenômenos. Em um sistema natural raramente é alcançado o equilíbrio entre oxidação e redução, em razão da contínua adição de elétrons (BAST et al., 1991).

Os elementos tóxicos entram no ambiente aquático de forma natural (deposição atmosférica, erosão e os processos intempéries que atingem a matriz geológica), ou a partir de fontes antropogênicas. Os metais pesados surgem nas águas naturais devido à mineração e eliminação de resíduos diversos, aos lançamentos de efluentes industriais tais como os gerados em indústrias extrativistas de metais, indústrias de tintas e pigmentos e, especialmente, as galvanoplastias, que se espalham em grande número nas periferias das grandes cidades (CLARCK, 2000). 
A contaminação de seres humanos por poluentes orgânicos e inorgânicos, associados a sistemas aquáticos, ocorre principalmente devido ao consumo de água e pescado contaminado; este último é capaz de concentrar os elementos tóxicos em até 105 vezes as concentrações observadas no meio ambiente (OLIVEIRA, 2008).

Os elementos tóxicos, dependendo da forma química e de sua concentração podem assumir características bastante nocivas ao ambiente aquático, pois se localizam no grupo das substâncias não biodegradáveis e bioacumulativas, o que tem motivado o interesse em acompanhar a evolução da concentração destes poluentes nos ambientes e conhecer melhor suas formas realmente biodisponíveis e especiações que oferecem risco ao sistema ecológico (BLASCO et al., 2000).

Para Ellis (2003), quando há contaminantes dissolvidos nas águas superficiais, o transporte destes pode ser governado pela rápida mudança das características físicas e químicas que ocorrem no meio ambiente. Dessa forma, a avaliação e controle da poluição ambiental torna-se um problema, ao passo que a liberação de elementos tóxicos em grandes quantidades nos rios pode ser causada tanto por meio natural quanto através de processos de industrialização.

$\mathrm{Na}$ área de Tucuruí, o enriquecimento dos elementos químicos pode estar relacionado principalmente com a interação dos processos de intemperismo que acometem o ambiente geoquímico e posterior transporte desses elementos para toda a biota (SIQUEIRA, 2001).

\section{METODOLOGIA}

O reservatório da Usina Hidrelétrica de Tucuruí (UHE de Tucuruí) está localizado no sudeste do Estado do Pará, na microrregião de Tucuruí, no baixo Rio Tocantins, a 7,5 km a montante da cidade de Tucuruí, a $300 \mathrm{~km}$ em linha reta da cidade de Belém (Figura 1). Sua posição geográfica é definida pelas coordenadas $03^{\circ} 45^{\prime}$ de latitude sul e $49^{\circ} 41^{\prime}$ de longitude oeste. A área de influência do reservatório à montante compreende integral ou parcialmente aos municípios de Tucuruí, Novo Repartimento e Itupiranga - na margem esquerda, a Breu Branco, Goianésia do Pará, Jacundá e Nova Ipixuna - na margem direita, totalizando uma área de aproximadamente $25.750 \quad \mathrm{~km}^{2}$ (ELETRONORTE, 2001).

Para a avaliação ambiental da qualidade da água superficial do reservatório da Usina Hidrelétrica de Tucuruí, partiu-se da coleta de amostras d'água provenientes de vários pontos a montante do reservatório localizados no sudeste do Estado do Pará, no Baixo Tocantins e a 7,5 km a montante da cidade de Tucuruí, no final do período chuvoso (mês maio) onde o Reservatório da UHE de Tucuruí apresentava-se "cheio".

A área onde o estudo foi realizado é ocupada por residências e pequenos comércios. A população possui padrão de renda de baixa a muito baixa. Em algumas residências verifica-se a prática de cultura de subsistência como pequenas hortas, criação de animais (aves e porcos), venda de peixe, castanha-do-pará e açaí.

Foram pré-selecionadas estações de monitoramento no reservatório da Usina Hidrelétrica de Tucuruí, objetivando representar as diferenças existentes no ambiente de estudo, como à entrada da água do rio, o ponto de mistura do rio com o lago e o reservatório em si.

Figura 1 - Reservatório da Usina Hidrelétrica de Tucuruí

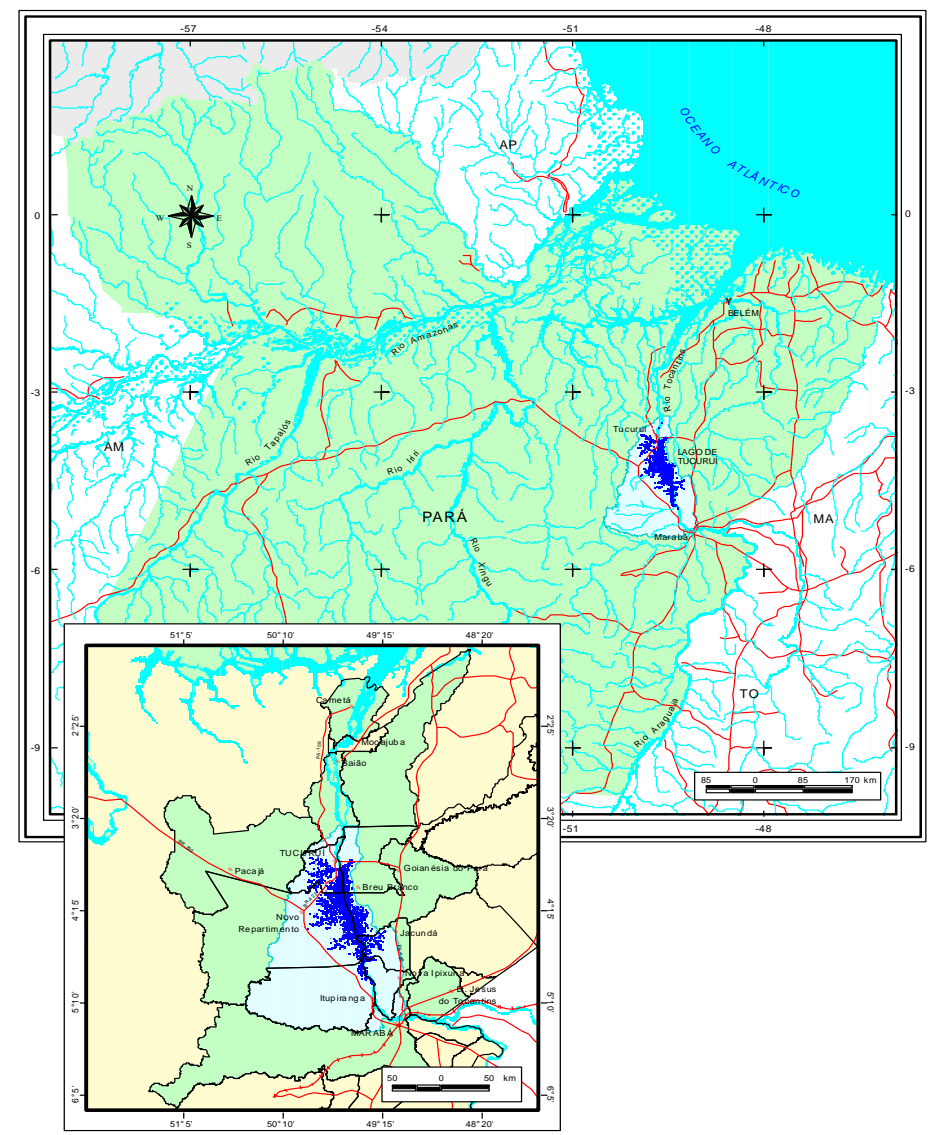

Fonte: ELETRONORTE, 2001.

As estações de monitoramento da Eletronorte e que foram utilizadas neste estudo estão situadas ao longo do reservatório da UHE de Tucuruí como mostrado na Tabela 1

Tabela 1 - Estações de amostragem e coordenadas geográficas.

\begin{tabular}{clcc}
\hline \multirow{2}{*}{ Siglas } & \multicolumn{1}{c}{ Estações } & \multicolumn{2}{c}{ Coordenadas } \\
\cline { 3 - 4 } & & $\begin{array}{c}\text { W } \\
\text { (Longitude) }\end{array}$ & $\begin{array}{c}\text { S } \\
\text { (Latitude) }\end{array}$ \\
\hline C1 & Caraipé 1 & $49^{\circ} 42^{\prime} 35.62^{\prime \prime}$ & $3^{\circ} 50^{\prime} 9.49^{\prime \prime}$ \\
C2 & Caraipé2 & $49^{\circ} 48^{\prime} 39.98^{\prime \prime}$ & $3^{\circ} 51^{\prime} 48.32^{\prime \prime}$ \\
M1 & Montante 1 & $49^{\circ} 37^{\prime} 52.51^{\prime \prime}$ & $3^{\circ} 51^{\prime} 47.08^{\prime \prime}$ \\
MBB & M. Breu Branco & $49^{\circ} 33^{\prime} 51.45^{\prime \prime}$ & $3^{\circ} 47^{\prime} 22.50^{\prime \prime}$ \\
MB & M. Belauto & $49^{\circ} 27^{\prime} 56.88^{\prime \prime}$ & $4^{\circ} 13^{\prime} 54.29^{\prime \prime}$ \\
MP & M. Pucuruí & $4^{\circ} 46^{\prime} 7.52^{\prime \prime}$ & $4^{\circ} 21^{\prime} 19.33^{\prime \prime}$ \\
M3 & Montante3 & $49^{\circ} 30^{\prime} 22.38^{\prime \prime}$ & $4^{\circ} 24^{\prime} 27.52^{\prime \prime}$ \\
MR & M. Repartimento & $49^{\circ} 41^{\prime} 51.75^{\prime \prime}$ & $4^{\circ} 13^{\prime} 1.38^{\prime \prime}$ \\
B1 & Base 1 & $49^{\circ} 38^{\prime} 57.73^{\prime \prime}$ & $4^{\circ} 5^{\prime} 26.81^{\prime \prime}$ \\
MI & M. Ipixuna & $49^{\circ} 24^{\prime} 31.67^{\prime \prime}$ & $4^{\circ} 29^{\prime} 36.57^{\prime \prime}$ \\
MJV & M. J. Velho & $49^{\circ} 26^{\prime} 31.60^{\prime \prime}$ & $4^{\circ} 33^{\prime} 7.07^{\prime \prime}$ \\
ML & M. Lontra & $49^{\circ} 31^{\prime} 42.05^{\prime \prime}$ & $4^{\circ} 29^{\prime} 53.81^{\prime \prime}$ \\
JT & Jusante Tucuruí & $49^{\circ} 39^{\prime} 40.94^{\prime \prime}$ & $3^{\circ} 47^{\prime} 14.17^{\prime \prime}$ \\
NP & Nazaré dos Patos & $49^{\circ} 36^{\prime} 38.96^{\prime \prime}$ & $3^{\circ} 26^{\prime} 48.97^{\prime \prime}$ \\
\hline
\end{tabular}

M.=Montante

As amostras foram coletadas com equipamento apropriado em três profundidades (superfície, intermediária e fundo) no período de maior pluviosidade (período chuvoso 
mês Maio) e condicionadas em frascos devidamente descontaminados, mantidas em refrigeração a $4^{\circ} \mathrm{C}$ e preservadas segundo recomendação da CETESB (1988). As amostras foram coletadas em duplicata.

No Laboratório montado no próprio reservatório, as amostras foram filtradas em membrana de $0,45 \mu \mathrm{m}$ de porosidade de modo a quantificar somente o material dissolvido sem adicionar ácido (elementos solúveis) e encaminhadas para o Laboratório de Química Analítica e Ambiental (LAQUANAM) da UFPA, onde foram efetuadas as análises dos elementos traço usando a espectrometria de emissão ótica com plasma indutivamente acoplado (ICPOES).

A otimização dos instrumentos utilizados foi realizada através da confecção de curvas analíticas visando a determinação do coeficiente angular (a) e linear (b), e coeficiente de correlação (r) além do cálculo dos limites de detecção (LD) através da análise de 15 brancos (3S) e cálculo do limite de quantificação (LQ).

Todas as curvas se mostraram lineares com coeficientes de correlação acima de 0,9900. Os resultados para o limite de detecção e limite de quantificação mostraram que a técnicas do ICP-OES pode ser usada na determinação de elementos em amostras de água, onde os mesmos se encontram em baixas concentrações.

O estudo da exatidão foi realizado com a análise do material padrão de referência de água de rio (SRM 1640 NIST) onde os elementos analisados se encontram em concentrações próximas às encontradas nas amostras analisadas neste estudo e através da análise de padrão multielementar.

Para a realização da avaliação da qualidade das águas do reservatório de Tucuruí para os elementos tóxicos nos pontos de amostragem, durante o período chuvoso, foi utilizado como parâmetro comparativo a Legislação Federal do CONAMA Resolução No 357/2005, e, para aqueles, que tal resolução não cita, utilizou-se alguns estudos realizados na área.

\section{RESULTADOS}

\section{1 - Alumínio}

O Al foi detectado com altos valores na maioria dos pontos de amostragem (Figura 2), sendo o seu valor mínimo de $2,07 \mu \mathrm{g} / \mathrm{L}$ na camada de fundo da estação $\mathrm{C}$ 1, enquanto que o valor máximo de $584 \mu \mathrm{g} / \mathrm{L}$ da camada intermediaria da estação MI. A média dos teores detectados nas estações foi de 248,69 $\mu \mathrm{g} / \mathrm{L}$. Assim, nem todas as concentrações estão em conformidade com a Resolução no 357/2005 do CONAMA (linha vermelha tracejada), que determina valor máximo de $100 \mu \mathrm{g} / \mathrm{L}$ de Al para águas de classe II, necessitando de um estudo mais apurado quanto a sua origem.

A concentração de alumínio em águas naturais é normalmente pequena, cerca de $10^{-6} \mathrm{mg} / \mathrm{L}$ a um $\mathrm{pH}$ igual a 5 , se o valor do $\mathrm{pH}$ reduzir a concentração de alumínio aumenta. Portanto, o alumínio é mais solúvel em rios e lagos ligeiramente ácidos do que naqueles em que os valores de $\mathrm{pH}$ não caem abaixo de 6 e 7 . De fato o $\mathrm{Al}^{3+}+$, é usualmente o cátion principal em águas cujo $\mathrm{pH}$ é menor que 4,5,

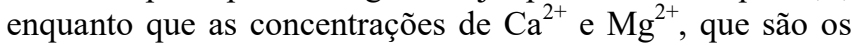
cátions dominantes têm valores de $\mathrm{pH}$ superiores a 4,5 (BAIRD, 1999).
O alumínio é produzido e consumido em grandes quantidades em muitas nações, sendo o Brasil um grande produtor. É o principal constituinte de um grande número de componentes atmosféricos, particularmente de poeira derivada de solos e partículas originadas da combustão de carvão. Em áreas urbanas, a concentração de alumínio na poeira das ruas varia de 3,7 a 11,6 $\mu \mathrm{g} / \mathrm{kg}$ (WHO, 1997).

Figura 2 - Variação de $\mathrm{Al}(\mu \mathrm{g} / \mathrm{L})$ no reservatório de Tucuruí.

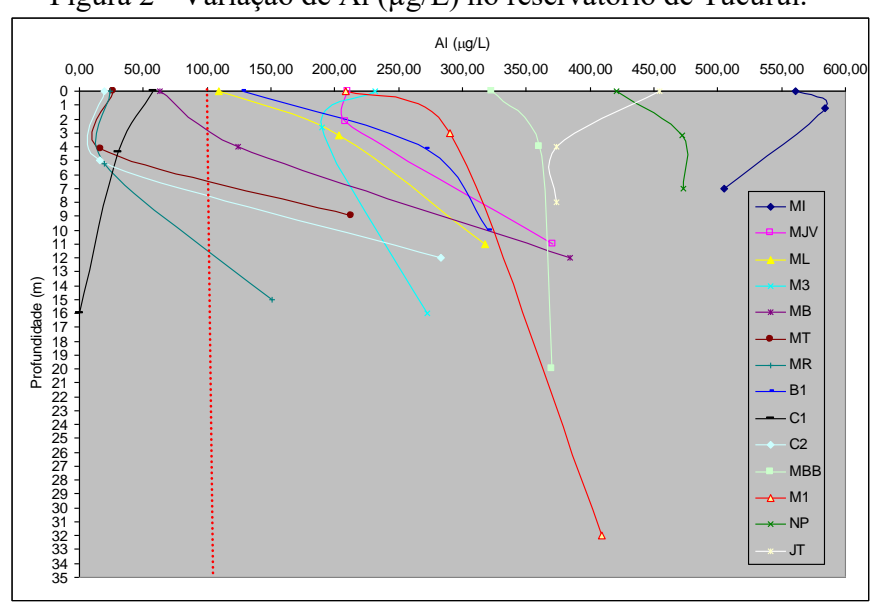

Fonte: Próprios autores, 2019.

Na água, o alumínio é complexado e influenciado pelo $\mathrm{pH}$, temperatura e a presença de fluoretos, sulfatos, matéria orgânica e outros ligantes. A solubilidade é baixa em $\mathrm{pH}$ entre 5,5 e 6,0. O alumínio deve apresentar maiores concentrações em profundidade, onde o $\mathrm{pH}$ é menor e pode ocorrer anaerobiose. Se a estratificação, e consequente anaerobiose, não for muito forte, o teor de alumínio diminui no corpo de água como um todo, à medida que se distancia a estação das chuvas. $\mathrm{O}$ aumento da concentração de alumínio está associado com o período de chuvas e, portanto, com a alta turbidez (PEREIRA et al., 2007).

Pensa-se que o principal efeito prejudicial das águas ácidas sobre os peixes é causado pelo alumínio, pois após ser solubilizado do solo, ele existe na água ácida como íon livre, e se precipita como hidróxido na forma de coloide quando entra em contato com as brânquias, menos ácidas dos peixes. O gel impede a absorção normal do oxigênio dissolvido na água, sufocando o peixe. Quando o $\mathrm{pH}$ do solo cai abaixo de 4,2 o alumínio lixiviado de solo e rochas, torna-se particularmente disponível (BAIRD, 1999).

A principal via de exposição humana não ocupacional é pela ingestão de alimentos e água. Não há indicação de carcinogenicidade para o alumínio. A osteomalacia é observada em humanos expostos ao alumínio. Há considerável evidência que o alumínio é neurotóxico. Em experimentos com animais, porém há uma grande variação desse efeito, dependendo da espécie analisada. O acúmulo de alumínio no homem tem sido associado ao aumento de casos de demência senil do tipo Alzheimer (WHO, 1997).

\section{2 - Bário}

O bário foi detectado com valores baixos em todos os pontos de amostragem (Figura 3) sendo seu valor mínimo de $14,20 \mu \mathrm{g} / \mathrm{L}$ na camada intermediária da estação JT, enquanto que o valor máximo de $51,39 \mu \mathrm{g} / \mathrm{L}$ da camada intermediária na estação MT, a média dos teores detectados foi de 32,29 $\mu \mathrm{g} / \mathrm{L}$. Portanto, todas as concentrações de Bário 
encontradas neste estudo, estão em conformidade com a Resolução $n^{\circ} 357 / 2005$ do CONAMA que estabelece a concentração máxima de bário em $700 \mu \mathrm{g} / \mathrm{L}$.

Figura 3 - Variação de $\mathrm{Ba}(\mu \mathrm{g} / \mathrm{L})$ no reservatório de Tucuruí.

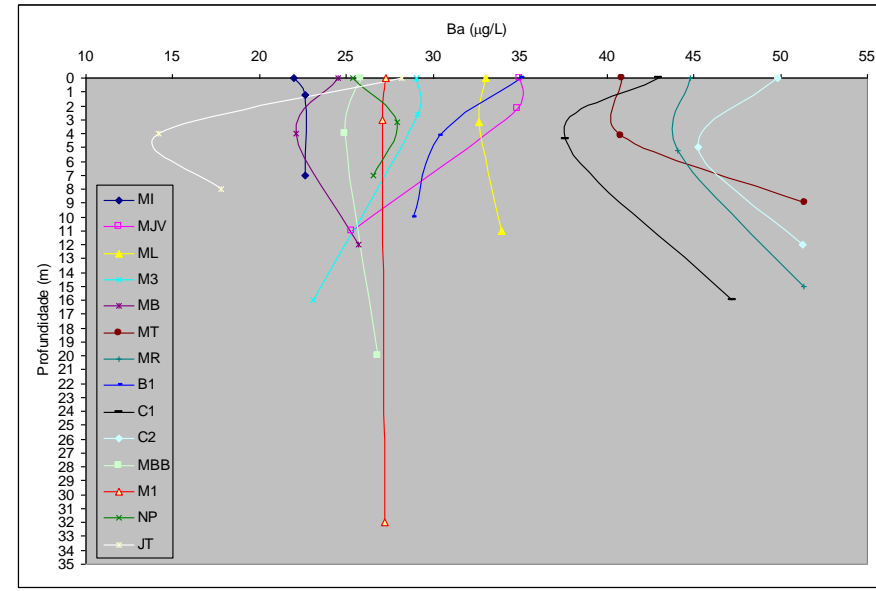

Fonte: Próprios autores, 2019.

O elemento bário pode ocorrer naturalmente na água, na forma de carbonatos em algumas fontes minerais e provenientes das atividades industriais e da extração da bauxita. Não possui efeito cumulativo, sendo que a dose fatal para o homem é considerada de 550 a $600 \mathrm{mg}$ (OLIVEIRA, 2008).

O Ba é um elemento geoquimicamente pouco móvel. O teor médio é de $595 \mathrm{mg} / \mathrm{kg}$ em rochas ígneas. As baixas concentrações de $\mathrm{Ba}^{2+}$ nas águas superficiais são consequência da pouca solubilidade do sulfato de $\mathrm{Ba}$ (barita) e pelo fato deste elemento ser facilmente adsorvido pelos hidróxidos e óxidos metálicos (PEREIRA et al., 2007).

\section{3 - Cobre}

A maioria das concentrações de cobre deu resultados $<$ LD. Somente nas estações C1 e C2 as concentrações de cobre não se apresentaram em conformidade com a legislação do CONAMA estando acima do limite de $9 \mu \mathrm{g} / \mathrm{L}$ (Figura 4).

Figura 4 - Variação de $\mathrm{Cu}(\mu \mathrm{g} / \mathrm{L})$ no reservatório de Tucuruí.

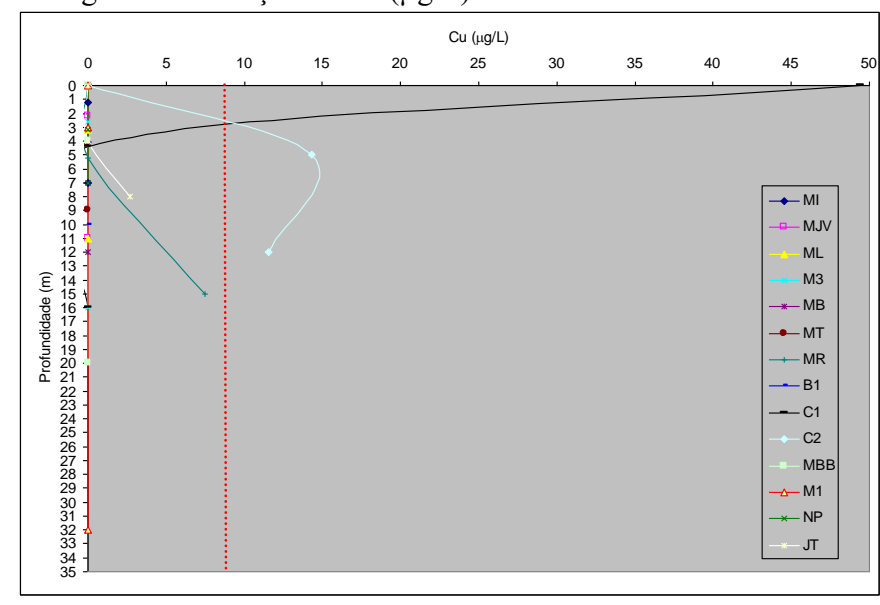

Fonte: Próprios autores, 2019

O cobre apresentou uma variação de 49,45 $\mu \mathrm{g} / \mathrm{L}$ na camada superficial da estação $\mathrm{C} 1$, e concentração mínima $<$ LD na camada de fundo da estação M1 com média de 2,04 $\mu \mathrm{g} / \mathrm{L}$. A concentração média de cobre encontrada neste trabalho está em desacordo ao apresentado por Pereira et al. (2007) que encontrou uma média de $0,2 \mu \mathrm{g} / \mathrm{L}$ no rio Tocantins.

A exposição excessiva ao cobre pode danificar o fígado e os rins. A doença de Wilson é um distúrbio hereditário (genético) no qual o cobre se acumula no fígado. Os sintomas de toxicidade hepática (icterícia, inchaço, dor) geralmente não aparecem até a adolescência (WHO, 1998).

\section{4 - Ferro}

O ferro foi detectado com altos valores em vários pontos de amostragem (Figura 5) sendo o valor mínimo de 223,94 $\mu \mathrm{g} / \mathrm{L}$ na camada intermediária da estação $\mathrm{C} 1$, enquanto que o valor máximo de $2186 \mu \mathrm{g} / \mathrm{L}$ da camada de fundo da estação C2, e a média foi de $538,66 \mu \mathrm{g} / \mathrm{L}$. Portanto a maioria das concentrações de ferro não está em conformidade com a legislação do CONAMA Resolução $n^{\circ}$ $357 / 2005$ que determina o valor máximo de $300 \mu \mathrm{g} / \mathrm{L}$.

Figura 5 - Variação de Fe $(\mu \mathrm{g} / \mathrm{L})$ no reservatório de Tucuruí.

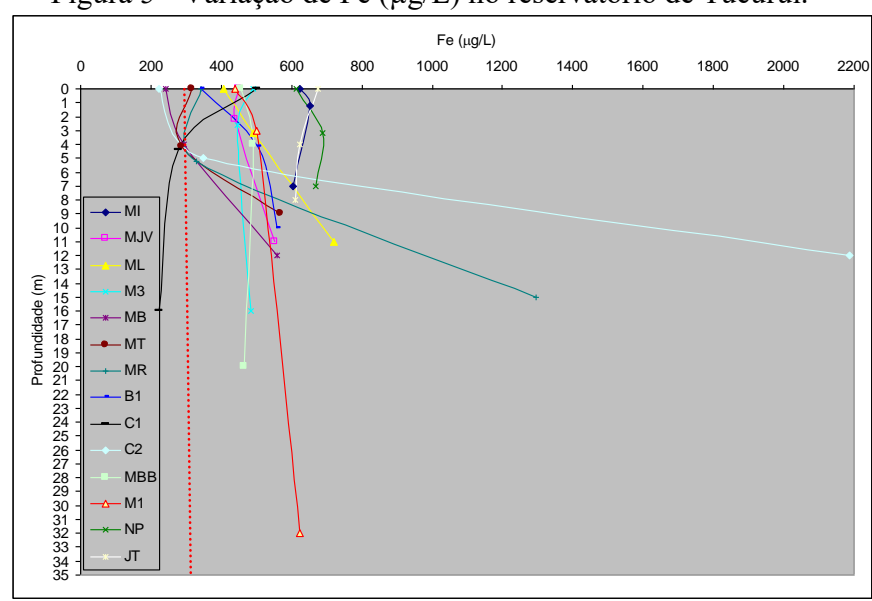

Fonte: Próprios autores, 2019.

O Fe não é o cátion principal nas águas superficiais continentais, mas é normalmente estudado em rios, lagos e reservatórios por se constituir no micronutriente essencial aos seres vivos, como também possui o ciclo biogeoquímico interferente a outros nutrientes, principalmente, do fósforo (MIRANDA et al., 2009).

A predominância de cada forma depende do $\mathrm{pH}$, por exemplo, com um $\mathrm{pH}$ maior que 4,8 a solubilidade do íon $\mathrm{Fe}^{3+}$ é inferior a $10 \mu \mathrm{g} / \mathrm{L}$. Além disso, sua concentração é baixa (até zero) em águas oxigenadas excepcionalmente, o $\mathrm{Fe}$ na forma de $\mathrm{Fe}(\mathrm{OH})_{3}$ constitui coloides muito pequenos em ambientes oxidantes, porém em águas reduzidas (baixas concentrações de oxigênio) apresentam teores de $\mathrm{Fe}$ geralmente entre 1.000 e $10.000 \mu \mathrm{g} / \mathrm{L}$. A solubilidade do $\mathrm{Fe}$ também depende das concentrações de $\mathrm{SO}_{4}{ }^{2-}$ e $\mathrm{CO}_{2}$ presentes no sistema aquático (SIQUEIRA, 2001).

\section{5 - Manganês}

O manganês foi detectado com valores baixos em todos os pontos de amostragem (Figura 6), sendo o seu valor mínimo $2,24 \mu \mathrm{g} / \mathrm{L}$ na camada intermediária da estação MT, enquanto que o valor máximo foi de $8,36 \mu \mathrm{g} / \mathrm{L}$ na camada superficial da estação JT e a média foi de 4,06 $\mu \mathrm{g} / \mathrm{L}$. Estando em conformidade com a legislação do CONAMA 
357/05 que permite até $100 \mu \mathrm{g} / \mathrm{L}$ de $\mathrm{Mn}$ em água de rio classe II.

Figura 6. Variação de $\mathrm{Mn}(\mu \mathrm{g} / \mathrm{L})$ no reservatório de Tucuruí.

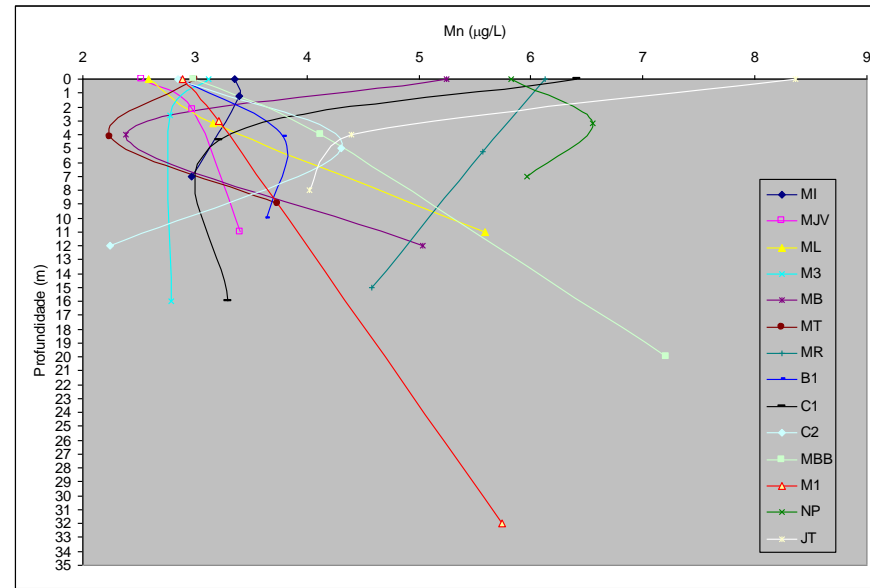

Fonte: Próprios autores, 2019

O comportamento do $\mathrm{Mn}$ nas águas é muito semelhante ao do $\mathrm{Fe}$ em seus aspectos os mais diversos, apresentando-se em concentrações variando de 2,2 a 230 $\mu \mathrm{g} / \mathrm{L}$ em águas de rios amazônicos (PEREIRA et al., 2007). As principais fontes antropogênicas deste elemento são: a indústria do aço, a fabricação de ligas metálicas e baterias, a indústria de tintas, vernizes, fogos de artifícios e fertilizantes, entre outras (ATSDR, 2000).

\section{6 - Magnésio}

O magnésio foi detectado com valores baixos em todos os pontos de amostragem (Figura 7), sendo o valor mínimo de $720,70 \mu \mathrm{g} / \mathrm{L}$ na camada intermediária da estação JT, enquanto que o valor máximo foi de $1711 \mu \mathrm{g} / \mathrm{L}$ na camada superficial da estação C1 e a média de $1145 \mu \mathrm{g} / \mathrm{L}$.

Figura 7 - Variação de $\mathrm{Mg}(\mu \mathrm{g} / \mathrm{L})$ no reservatório de Tucuruí.

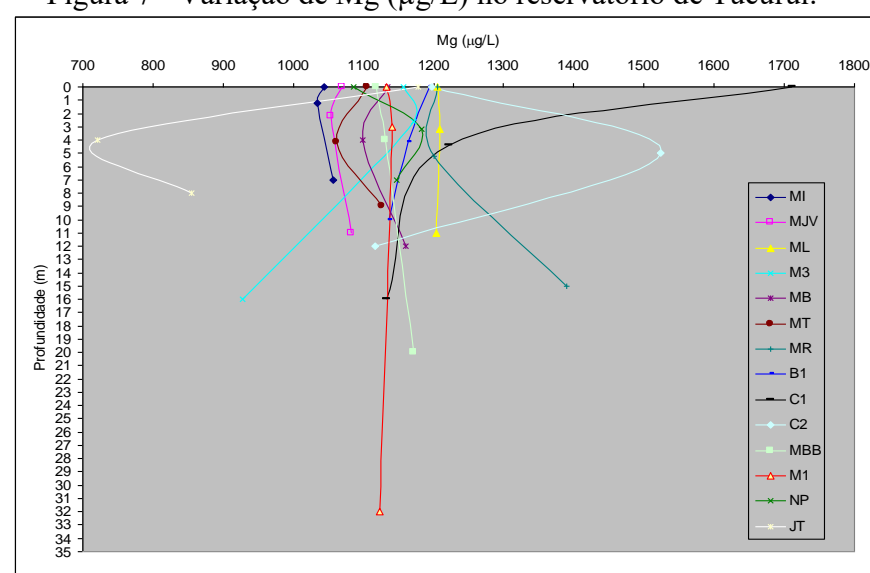

Fonte: Próprios autores, 2019.

As concentrações de magnésio encontradas estão de acordo com valores encontrados por Pereira et al. (2007) que mostram um intervalo de magnésio variando de 1300,6 $\mu \mathrm{g} / \mathrm{L}$ a $2095,3 \mu \mathrm{g} / \mathrm{L}$ com média de $1592,1 \mu \mathrm{g} / \mathrm{L}$ no rio Tocantins.

$\mathrm{O}$ íon magnésio tem tendência a formar complexos iônicos tais como $\mathrm{Mg}\left(\mathrm{H}_{2} \mathrm{O}\right)^{2+}$ e $\mathrm{Mg} \mathrm{OH}^{+}$, mas é geralmente apresentado na forma de $\mathrm{Mg}^{2+}$. Em águas naturais, as concentrações mais frequentes são inferiores a $40 \mathrm{mg}$ de
$\mathrm{Mg}^{2+} / \mathrm{L}$, concentrações mais elevadas aparecem geralmente vinculadas a uma salinidade maior da água (FENZL, 1986). O íon magnésio é procedente principalmente da dissolução do carbonato de magnésio - provenientes das águas calcárias não poluídas Esse íon é facilmente adsorvido em argila (BAIRD, 1999).

\section{7 - Estrôncio}

O estrôncio (Figura 8) apresentou concentração máxima de 34,02 $\mu \mathrm{g} / \mathrm{L}$ na camada de fundo da estação MR e concentração mínima de $14,05 \mu \mathrm{g} / \mathrm{L}$ na camada intermediária da estação JT com média foi de $22,49 \mu \mathrm{g} / \mathrm{L}$. As concentrações encontradas de estrôncio estão de acordo aos apresentados por Pereira et al. (2007) com um intervalo de $21 \mu \mathrm{g} / \mathrm{L}$ a $52,5 \mu \mathrm{g} / \mathrm{L}$ e média de $30,6 \mu \mathrm{g} / \mathrm{L}$ no rio Tocantins.

Figura 8 - Variação de $\operatorname{Sr}(\mu \mathrm{g} / \mathrm{L})$ no reservatório de Tucuruí.

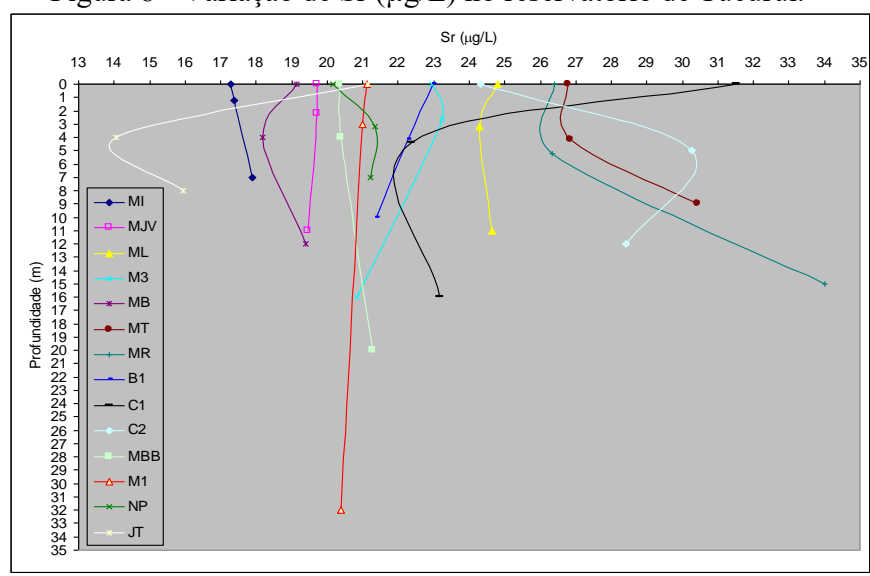

Fonte: Próprios autores, 2019

O estrôncio se acumula em alto grau nos ossos e, em altas concentrações, pode interferir seriamente no processo normal de desenvolvimento. Alguns estudos associam o raquitismo à presença de estrôncio na infância (ATSDR, 2004).

\section{8 - Titânio}

O titânio (Figura 9) apresentou concentração máxima de $24,01 \mu \mathrm{g} / \mathrm{L}$ na camada intermediária da estação MI e a concentração mínima de $6,14 \mu \mathrm{g} / \mathrm{L}$ na camada de fundo da estação $\mathrm{C} 1$ e a média foi de $12,74 \mu \mathrm{g} / \mathrm{L}$.

Figura 9 - Variação de Ti ( $\mu \mathrm{g} / \mathrm{L})$ no reservatório de Tucuruí

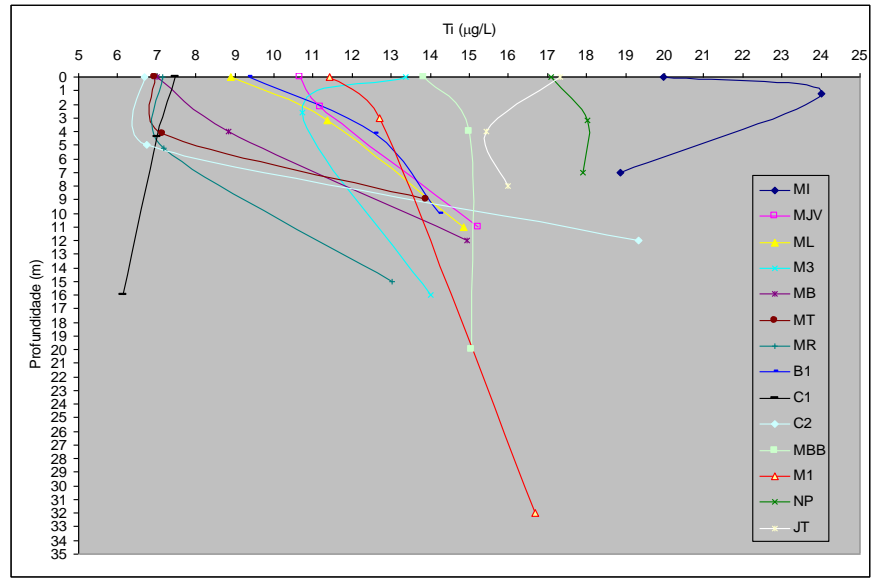

Fonte: Próprios autores, 2019. 
A concentração média de titânio encontrada neste estudo esteve em concordância com a reportada por Linnik e Zhezherya (2015) que variou de $<\mathrm{LD}$ a $68,7 \mu \mathrm{g} / \mathrm{L}$. Segundo os mesmos autores a taxa de titânio dissolvido em corpos hídricos depende do conteúdo da matéria suspensa e da sua natureza, em águas do rio, a forma dissolvida é a dominante.

A toxicidade aguda do titânio está relacionada à lesão no fígado e rins após a administração oral. Os exames de biodistribuição também mostraram acúmulo predominante do elemento no fígado, rim, baço e pulmões. (WHO, 1982).

\section{CONCLUSÃO}

Os metais solúveis $\mathrm{Ba}, \mathrm{Mn}, \mathrm{Mg}, \mathrm{Sr}$ e Ti apresentaram teores dentro dos padrões permitidos. Al e Fe apresentaram teores acima daqueles estabelecidos pela legislação vigente, demonstrando a necessidade de monitoramento desses elementos no meio ambiente e em suas fontes poluidoras. $\mathrm{O}$ $\mathrm{Cu}$ apresentou valores altos em apenas duas estações amostrais, apresentando resultado anômalo que precisa de estudos complementares para ser esclarecido.

\section{REFERÊNCIAS BIBLIOGRÁFICAS}

ATSDR - Agency for Toxic Substances and Disease Registry. Toxicological Profile for Manganese. Atlanta, GA. September, 556p. 2000.

ATSDR - Agency for Toxic Substances and Disease Registry. Toxicological Profile for Strontium. Atlanta, GA. April, 445p. 2004.

BAIRD, C. Environmental Chemistry. 2a ed., W. H. Freeman and Company, New York, 557 p. 1999.

BAST, A.; HAENEN, G. R. M. M.; DOELMAN, C. J. A. Oxidants and antioxidants: state of the art. The American Journal of Medicine., v. 91, p. 135, 1991.

BLASCO, J.; SÁENZ, V.; GÓMEZ-PANA, A. Heavy metal fluxes at the sediment-water interface of three coastal ecosystems from South-west of Iberian Peninsula. The Science of the Total Environment, v. 247, p.189-199, 2000.

CETESB. Companhia de Tecnologia de Saneamento Ambiental. Normalização Técnica. São Paulo. L5.102, 1988.

CLARKE, S. C.; JACKSON, A. P.; NEFF, J. Development of a risk assessment methodology for evaluating potential impacts associated with contaminated mud disposal in the marine environment. Chemosphere, v. 41, p. 69-76, 2000.

CONAMA. Resolução do Conselho Nacional do Meio Ambiente, $\mathrm{n}^{\mathrm{o}} 357$ de 17 de março de 2005, p. 9-24, 2005.

ELETRONORTE, UHE Tucuruí etapa final - unidades 13 a 23: projeto executivo - plano de ações ambientais. Estudos ambientais associados à elevação do nível d'água do reservatório até a cota 74. Caracterização ambiental. vol 1. Consórcio Engevix - Themag. Relatório: TUC-E-MAG-8000354-RE-R.0B, dez 2001.

ELLIS, P. A.; RIVETT, M. O.; MACKAY, R. Geophysical Research Abstracts, 5, 12,063. Environment. 2ed. Berlin: Springer-Verlag. New York, 486p. 2003.
FEARNSIDE, P.M., Environmental and social impacts of hydroelectric dams in Brazilian Amazonia: implications for the aluminum industry. World Dev. v. 7, p. 48-65, 2016.

FENZL, N. Introdução a Hidrogeoquímica. Universidade Federal do Pará. 189 p. 1986.

LIMA, J. E. F. W. et al. Diagnóstico do fluxo de sedimentos em suspensão na Bacia Araguaia-Tocantins. Planaltina, DF: Embrapa Cerrados, Brasília, DF: ANEEL/ANA, 2004.

LINNIK, P. N.; ZHEZHERYA, V. A. Titanium in Natural Surface Waters: The Content and Coexisting. Forms Russian Journal of General Chemistry, v. 85, no. 13, p. 2908-2920, 2015.

MIRANDA, R. G.; PEREIRA, S. F. P.; OLIVEIRA, G. R.; ALVES, D. T. V. Qualidade dos recursos hídricos da Amazônia - Rio Tapajós: avaliação de caso em relação aos elementos químicos e parâmetros físico-químicos. Revista Ambiente \& Água, v. 4, p.75-92, 2009.

OLIVEIRA, G. R. F. Estudo dos teores e da bioacumulação de metais traço em tecido de peixes capturados no reservatório da hidrelétrica de Tucuruí-PA. Dissertação (Mestrado em Química) Universidade Federal do Pará, Belém, 125p. 2008.

PEREIRA, S. F. P.; LIMA, M. A.; FREITAS, K. H.; MESCOUTO, C. S.; SARAIVA, A. F. Estudo químico ambiental do rio Murucupi - Barcarena, PA, Brasil, área impactada pela produção de alumínio. Revista Ambi-Água, Taubaté, v. 2, n 3, p. 62-82, 2007.

SALOMONS, W. \& FÖRSTNER, U. Metals in Hidrocycle. Berlin, Springer-Verlag, 349 p. 1984.

SANTOS, M. J. M. Aspectos limnoquímicos do reservatório da usina hidrelétrica de Tucuruí (PA): uma avaliação temporal entre 1986 a 2001. Dissertação (Mestrado em Geoquímica e Petrologia). Belém: Centro de Geociências/Universidade Federal do Pará UFPA, 122p. 2003.

SIQUEIRA, G. W.; DUCATTI, G. M.; BRAGA, E. S. Avaliação de metais pesados $(\mathrm{Pb}, \mathrm{Cr}, \mathrm{Cu}, \mathrm{Fe})$ no sistema estuarino de Santos/São Vicente e Baía de Santos (São Paulo/Brasil). Anais do IX Congresso Latino Americano sobre Ciencia del Mar. Colômbia, (CD-ROM), 2001.

WHO World Health Organization. Aluminium. Environmental Health Criteria 194, Geneva, 111p. 1997.

WHO World Health Organization. Copper. Environmental Health Criteria 200, Geneva, 357p. 1998.

WHO World Health Organization. Titanium. Environmental Health Criteria 24, Geneva, 50p. 1982.

\section{AGRADECIMENTOS}

A ANEEL pelo financiamento do projeto, a ELETRONORTE pelo apoio.

\section{COPYRIGHT}

Direitos autorais: Os autores são os únicos responsáveis pelo material incluído no artigo. 


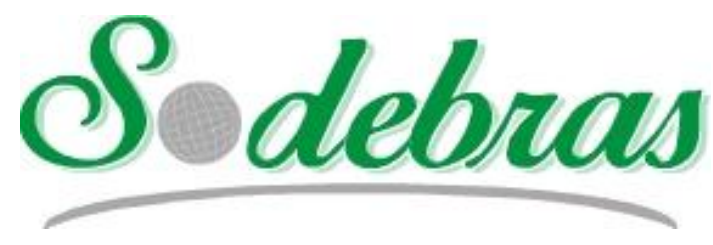

Volume 15 - $\mathrm{N}^{\mathrm{o}} 169$ - Janeiro / 2020

XLI International Sodebras Congress

31 de outubro a 02 de novembro de 2019 - Maceió - AL.

\title{
HISTÓRIA EM QUADRINHOS COMO INSTRUMENTO NA EDUCAÇÃO AMBIENTAL EM REGIÃO IMPACTADA POR AGROTÓXICO
}

\author{
COMICS AS AN INSTRUMENT IN ENVIRONMENTAL EDUCATION IN \\ REGION IMPACTED BY PESTICIDE
}

\author{
SIMONE DE FÁTIMA PINHEIRO PEREIRA ${ }^{1}$; JANILCE LIRNE DA SILVA ${ }^{1}$; CLÉBER SILVA E SILVA²; \\ ERIVAN SOUSA CRUZ
}

\author{
1 - LABORATÓRIO DE QUÍMICA ANALÍTICA E AMBIENTAL DA UNIVERSIDADE FEDERAL DO \\ PARÁ CAMPUS BELÉM; 2 - INSTITUTO FEDERAL DE EDUCAÇÃO CAMPUS BELÉM \\ simonefp@ufpa.br; janilcels2019@gmail.com; cleber.silva@ifpa.edu.br; rivansc@ufpa.br
}

\begin{abstract}
Resumo - Os diferentes impactos causados pelo homem ao meio ambiente são um problema que tem merecido a atenção da comunidade cientifica. Um desses impactos é o uso indiscriminado de agrotóxicos. $O$ consumo de agrotóxicos por agricultores na região de Itaituba-PA vem contaminando os alimentos que abastecem os mercados locais. Com base nessas informações e nas bibliografias existentes sobre o assunto foram realizados levantamentos sobre as técnicas de cultivo e o uso dos agrotóxicos por parte dos agricultores. Com essas informações, foi proposta como medida preventiva a confecção de uma revista em quadrinhos que aborda os principais efeitos dos agrotóxicos no meio ambiente, alternativas ecologicamente corretas, etc. A revista foi introduzida nas escolas de ensino fundamental $e$ médio e para os agricultores, assim como a realização de palestras.
\end{abstract}

Palavras-chave: Meio ambiente. Preservação ambiental. Contaminação por pesticidas.

\begin{abstract}
The different impacts caused by man to the environment are a problem that has deserved the attention of the scientific community. One such impact is the indiscriminate use of pesticides. The consumption of agrochemicals by farmers in the region of Itaituba-PA has been contaminating the food supplying local markets. Based on this information and in the existing bibliographies on the subject were realized surveys on the techniques of cultivation and the use of pesticides by the planters. With this information, it was proposed as a preventive measure the making of a comic book that addresses the main effects of pesticides on the environment, ecologically correct alternatives, etc. The comics were introduced in primary and secondary schools and for farmers, as well as lectures.
\end{abstract}

Keywords: Environment. Environmental preservation. Contamination by pesticides.

\section{INTRODUÇÃO}

A região Norte possui uma inigualável riqueza natural que vem sendo explorada exaustivamente, principalmente com a extração madeireira e com a agricultura, gerando assim renda e proporcionando geração de empregos na região. No município de Itaituba, noroeste do estado do Pará, a agricultura vem se destacando principalmente com a produção de arroz e horticultura na zona urbana e rural do município, sendo que, a maior parte dos alimentos (verduras, frutas e legumes) é consumida na própria região.

A Amazônia detém a maior bacia hidrográfica do mundo e o rio Tapajós é um de seus principais afluentes. As águas límpidas do rio escondem os contaminantes orgânicos e inorgânicos como os agrotóxicos e o mercúrio que são lançados em suas águas indiscriminadamente. A falta de fiscalização, de esclarecimento e de trabalhos científicos que identifiquem o problema contribui para agravar ainda mais o quadro.

No Brasil, o consumo de agrotóxicos encontra-se em franca expansão. O país é responsável pelo consumo de cerca de $50 \%$ da quantidade de agrotóxicos utilizados na América Latina, em 2010/2011 o consumo foi de $936 \mathrm{mil}$ toneladas, movimentando US\$ 8,5 bilhões entre dez empresas que controlam $75 \%$ deste mercado no país (ANVISA, 2013).

Os despejos de substâncias tóxicas estão relacionados com a proteção dada pelos agricultores às colheitas para melhor produção de alimentos, usando indiscriminadamente fertilizantes e agrotóxicos (praguicidas, fungicidas, herbicidas) nas lavouras (BUDZINSKI E COUDERCHET, 2018). O uso de agrotóxicos é apenas uma das tantas substâncias químicas que prejudicam o nosso planeta no combate de pragas nas lavouras. A princípio, o homem não mais se preocuparia com suas plantações invadidas, todavia, com o decorrer do tempo, as consequências poderão ocasionar um desequilíbrio ecológico. A complexidade desse processo de transformação de um planeta, não apenas crescentemente ameaçado, mas também diretamente afetado pelos riscos socioambientais e seus danos, é cada vez mais notório. A concepção "sociedade de risco", de Beck (1992), amplia a compreensão de um cenário marcado por nova lógica de destruição dos riscos. Uma praga nunca aparece gratuitamente, ela vem sempre proveniente de um desequilíbrio ecológico grave (LAMBERT, 1997). Como consequência tem-se águas e solos poluídos. Quando ocorrer chuvas haverá lixiviação do solo, sendo este poluído, envenenará a cadeia alimentar aquática e por fim, o próprio homem. Segundo o mesmo autor "o combate exclusivo à praga é combater a febre sem tratar a infecção", ou seja, o homem usa praguicidas para acabar com as pragas, mas 
acaba fazendo mal a si mesmo. Por isso que "é preciso plantar com consciência, para colher bons resultados, produzindo alimentos saudáveis e de forma econômica" (MACHARIA, 2015).

Os agricultores da região utilizam na sua maioria, os agrotóxicos, sem, no entanto, conhecer os produtos químicos que fazem parte da sua composição. Como consequência, observa-se que não há qualquer cuidado na manipulação destes produtos. Há de se ressaltar que, a maioria destes produtos tem como base compostos orgânicos e inorgânicos, como os organoclorados, e que são altamente prejudiciais à saúde humana podendo ocasionar sérias doenças e levar a morte (CARVALHO, 2017). Além dos agrotóxicos, outra prática comum entre os agricultores da área de Itaituba é a queimada da floresta. O fogo usado para limpar o terreno mata os microrganismos que ajudam tanto na decomposição da matéria orgânica quanto no sistema de poros e aração da terra (como é o caso das minhocas). O solo fica desgastado, ou seja, improdutivo. Há também, o uso indiscriminado dos fertilizantes, que a primeira vista é inofensiva ao meio ambiente, mas acaba por gerar uma infinidade de problemas aos ecossistemas, principalmente ao meio hídrico, onde a presença do excesso de fosfatos, nitratos e outros fertilizantes usados na agricultura causam o fenômeno da eutrofização dos rios e lagos, contaminando as águas com algas venenosas, tornando-a imprópria para o consumo.

Entendendo a gravidade da utilização dos agrotóxicos, foi necessária a criação de uma estratégia usando a educação ambiental para tentar solucionar os problemas encontrados na natureza e, consequentemente, produzindo alimentos mais saudáveis. "Uma vez que se toma consciência do problema, torna-se necessário buscar soluções" (ROPKE, 1990).

A prática de uma "agricultura sem agrotóxico" através de uma agricultura alternativa consiste na utilização de produtos naturais como, chás à base de coentro, fumo etc., visando à produção de alimentos saudáveis juntamente com a proteção do meio ambiente e da saúde do homem. Estas alternativas foram as principais justificativas para o desenvolvimento deste trabalho.

O objetivo principal deste trabalho foi promover a educação ambiental através do uso de história em quadrinhos em uma comunidade de agricultores do município de Itaituba que fazem uso de produtos químicos nas lavouras sem o conhecimento dos reais perigos e impactos que estes produtos causam ao meio ambiente e à saúde. Através do conhecimento da química do solo, da agricultura alternativa, do perigo do uso de pesticidas e do excesso de fertilizantes nas plantações, tentou-se conscientizar o agricultor que o uso do produto químico é como um círculo vicioso, que acaba colocando em risco todo o meio ambiente. Assim como, incentivar e dar subsídios para o trabalho com a agricultura alternativa e promover o envolvimento da comunidade em geral (pais, alunos, professores, etc.) para que estes tenham conhecimento sobre o que é o agrotóxico usado na lavoura e quais as consequências para a saúde e meio ambiente.

\section{METODOLOGIA}

A área a ser estudada foi à sede do município de Itaituba (Figura 1), nos bairros da periferia da cidade, onde há plantações de hortaliças que suprem as necessidades da população. Os agricultores vendem seus produtos aos supermercados e em feiras livres. Calcula-se que exista cerca de dezoito hortas de grande porte no município.

Foram elaboradas atividades como a confecção de cartazes, oficinas, revistas em quadrinhos, hortas modelos, reuniões com engenheiros agrônomos abertas a comunidade, realização de palestras nas comunidades agrícolas e nas escolas aos alunos de $5^{\circ}$ a $8^{\circ}$ séries (temas variados relacionados com o assunto em questão). Foi traçado o perfil dos hábitos da população em estudo (agricultores), além de identificar possíveis fontes de contaminação e sintomatologia das doenças provocadas pelo envenenamento por defensivos agrícolas.

Os questionários foram elaborados para os agricultores, filhos de agricultores estudantes e para professores. Os gráficos com as respostas do questionário foram elaborados no Excel.

A revista elaborada retrata uma história em quadrinhos cujo objetivo é mostrar os efeitos impactantes que o agrotóxico traz não só as pragas, mas também ao ser humano e a outros seres vivos que não degradam as lavouras (pássaros e borboletas), percebendo o mal que o agrotóxico causa ao homem. O personagem principal "seu Tião" procura alternativas para manter a sua safra sem o uso de agrotóxicos, adotando assim uma prática saudável e segura para todos. A revista foi confeccionada utilizando o programa gráfico Paint Shop Pro 9.0 e outros programas de edição. O objetivo do uso desta ferramenta principalmente junto aos filhos dos agricultores foi criar na criança uma consciência desde a infância dos malefícios do uso dos pesticidas e também mostrar que existem alternativas.

As oficinas sobre educação ambiental foram realizadas na escola em regime de convênio de ensino básico Maranata, abrangendo alunos da escola, produtores envolvidos no estudo e a comunidade de Itaituba.

Figura 1 - Localização do local de estudo - do município de Itaituba - PA

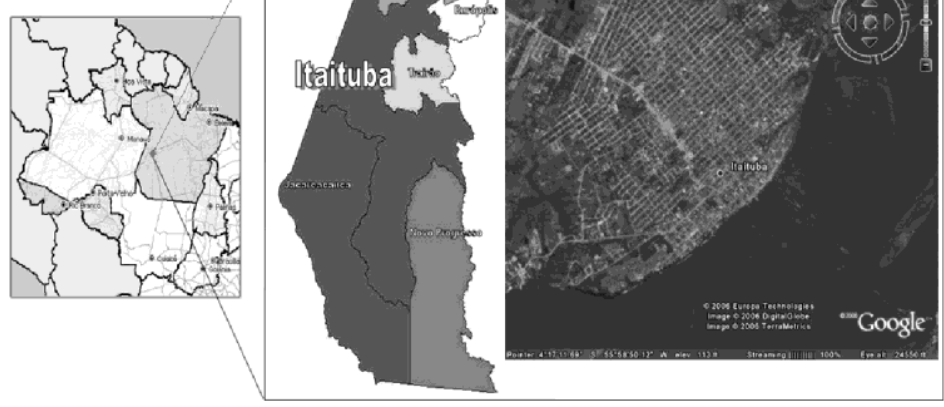

Fonte: Adaptado pelos autores do Google Earth e IBGE, 2019.

\section{RESULTADOS}

\section{1 - Resultados da aplicação do questionário de sondagem}

Os resultados obtidos com a primeira parte da pesquisa (aplicação de um questionário de sondagem junto aos agricultores) revelaram que a maioria dos agricultores em atividade em Itaituba são homens $(80 \%)$ e $20 \%$ são mulheres. Com o aumento do número de mulheres na agricultura, teme-se que, em idade reprodutiva, estas mulheres possam contaminar os fetos que podem nascer com deformidades em decorrência dos pesticidas utilizados 
na atividade agrícola, a grande maioria (93\%) consome água de poço, somente $2 \%$ dos entrevistados consomem água da rede pública. $\mathrm{O}$ grande número de entrevistados que consome água de poço estaria mais exposto a se contaminar com os agrotóxicos usados na lavoura, pois, a água da chuva e da irrigação lixivia as plantações e o solo fazendo com que os pesticidas, através do escoamento superficial, cheguem aos rios da região e outra parte percole no solo contaminando o lençol freático local. Vale ressaltar que estes poços são abertos muito próximos às plantações e residências causando sérios problemas na saúde dos agricultores, $98 \%$ utilizam agrotóxicos em suas plantações, os principais agrotóxicos utilizados são titânio, ectávio, polissur, sepec, thobel, folidol, randap, tordo, vodomil, entre outros (Figura 2). A maioria dessas hortas fica perto de casas residenciais e de escolas, sendo que as pessoas não tem ideia do perigo que tais substâncias causam, a desinformação é muito grande para que tenham consciência do problema. É muito comum observar os agricultores utilizando o pesticida sem qualquer equipamento de segurança (Figura 3).

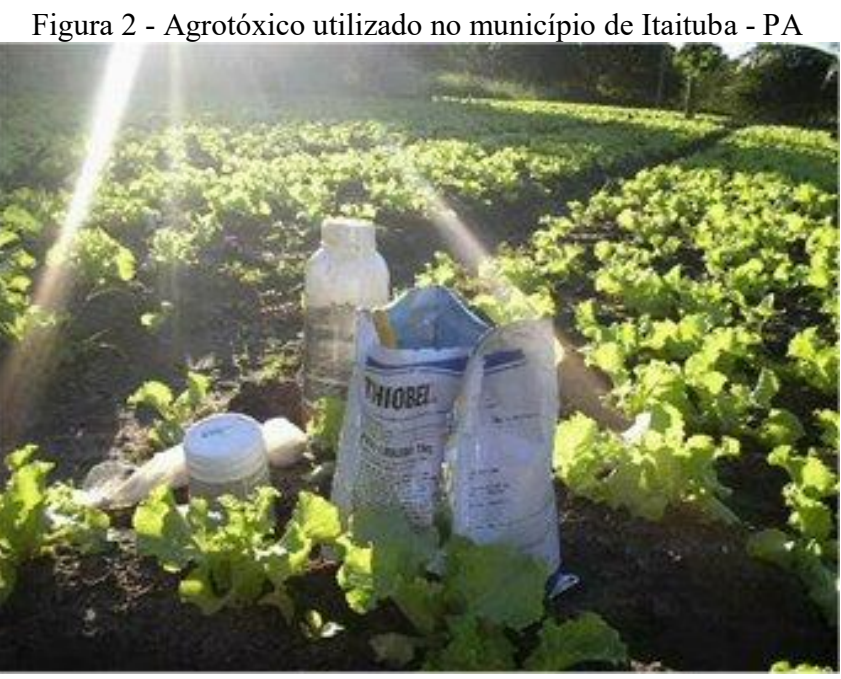

Fonte: Próprios autores, 2019.

Figura 3 - Aplicação de agrotóxico no município de Itaituba - PA

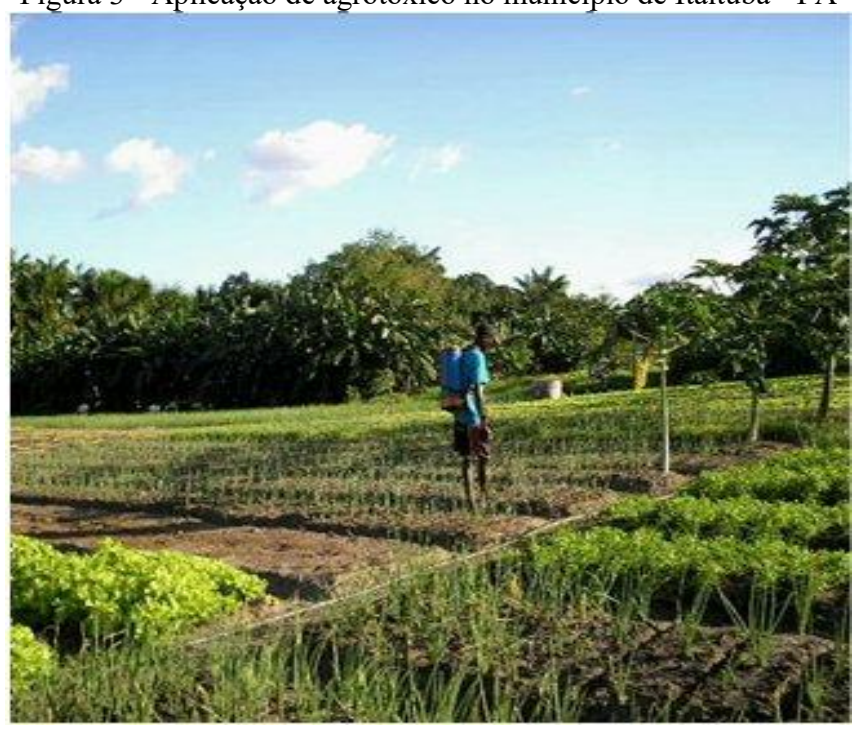

Fonte: Próprios autores, 2019.

Referente aos hábitos alimentares $45 \quad \% \quad$ dos entrevistados consomem cereais como arroz e feijão (Figura
4). Diferente do que se imaginava, já que Itaituba se localiza as margens de um grande rio (rio Tapajós), $25 \%$ dos entrevistados consome carne vermelha e $11 \%$ consome carne de peixe, mesmo vivendo em uma cidade com fartura deste produto. Este fato permite concluir que existe um risco menor de contaminação na população que prefere consumir carne vermelha, pois, o peixe através do fenômeno da bioacumulação pode contaminar o homem se estiver em um rio com problemas de contaminação por pesticidas e outros produtos tóxicos.

Figura 4 - Hábitos alimentares

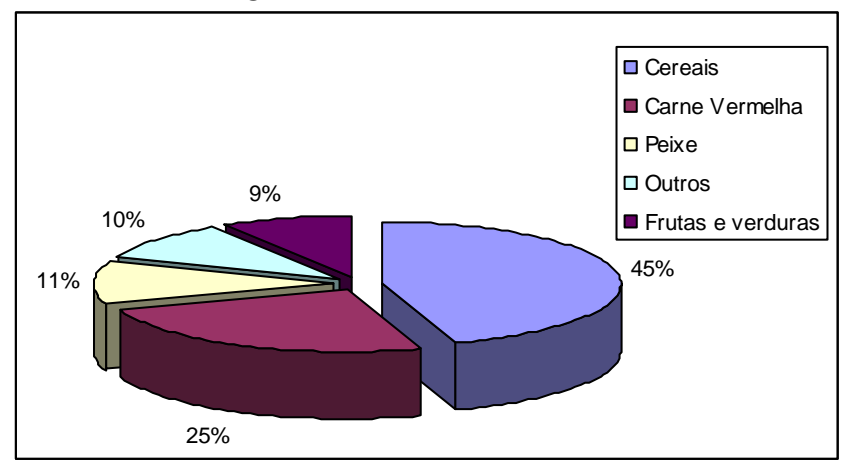

Fonte: Próprios autores, 2019.

Alguns hábitos podem potencializar os efeitos das substâncias tóxicas no organismo humano, o hábito de fumar, por exemplo, traz malefícios a saúde, pois ao fumar o indivíduo coloca para dentro de seu organismo substâncias altamente danosas ao ser humano que juntamente com os pesticidas acabam por agravar o estado de saúde dessas pessoas. Em se tratando do consumo destes produtos a maioria dos agricultores (45\%) fuma, também faz uso de bebida alcoólica (10\%) e medicamentos (11\%). $34 \%$ dos entrevistados não fazem uso de nenhum dos produtos citados (Figura 5).

Figura 5 - Consumo de outros produtos

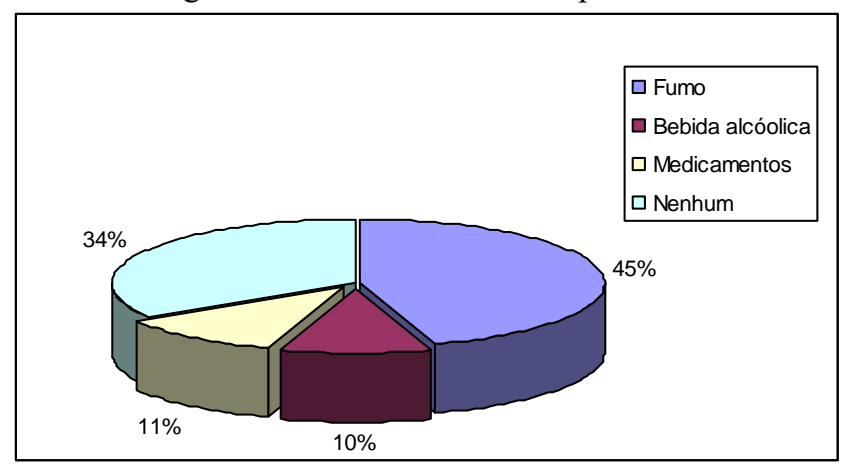

Fonte: Próprios autores, 2019.

Informações sobre o contato com produtos químicos em atividades de riscos, $80 \%$ sobrevivem somente da agricultura à maioria dos produtores de horticultura do município trabalham em não apenas uma, mas em várias hortas para ver se dá pra suprir as suas necessidades, $10 \%$ sobrevivem da criação de galinhas, porém, dizem que o que dão para as galinhas são apenas rações e $10 \%$ sobrevivem de serrarias que por sinal algumas ficam dentro de hortas.

Referente à sintomatologia constatou-se que existem problemas no trato respiratório, como a falta de ar de vez em quando chegando a $10 \%$ das pesquisas, outros chegam a ter 
problemas circulatórios com dores nas pernas, hipertensão arterial, chegando a $30 \%$ da pesquisa feita, alguns possuíam dores de cabeça muito forte devido à exposição excessiva ao sol, contato com o agrotóxico alguns dizem que o odor causa muita dor de cabeça ou que muitas vezes é ocasionado o problema de enxaqueca chegando a $40 \%$, outros causam tonturas e mal estar durante a aplicação do agrotóxico chegando a um percentual de $20 \%$ da pesquisa feita.

Os resultados obtidos com relação aos alunos referentes à oficina ambiental mostraram que $85 \%$ dos alunos participaram da oficina ambiental dando sua parcela de colaboração nas pesquisas, confeccionando cartazes, elaborando atrações etc. $15 \%$ dos alunos desinteressaram-se pela oficina e disseram que era perda de tempo.

No que se refere aos professores de outras áreas foi muito difícil o convencimento, não houve apoio entre os mesmos, até porque eles não têm o domínio do conteúdo de educação ambiental e eles não sabem sequer o significado de tal palavra. Pensando equivocadamente que falar do meio ambiente só cabe ao professor de ciências, não houve interação nenhuma entre o professor de ciências com os professores de outras áreas. $90 \%$ dos professores disseram trabalhar com carga horária pesada, e por isso trabalham em várias escolas, sendo assim a realidade é verdadeira e por isso não têm tempo para se dedicar a uma só escola. $5 \%$ alegaram trabalhar demais em salas de aula e por isso não trabalham hora-extra, só trabalham hora aula que é determinada em seu contrato e muitos precisam de descanso para ir para outra escola. $5 \%$ não se interessaram pelo problema e disseram que pouco se importavam com os alunos e que todo o trabalho feito é pura perda de tempo e que ninguém conscientiza ninguém.

\section{2 - Aplicação da revista em quadrinhos}

$\mathrm{Na}$ segunda parte da pesquisa foi utilizada a revista em quadrinhos como instrumento de educação ambiental junto aos agricultores e junto às crianças da comunidade onde a maioria era oriunda de família de agricultores.

Após a palestra e após a distribuição da revista em quadrinhos com a história Uma agricultura sem agrotóxicos (Figura 6), onde é relatado o caso de um agricultor que após a aplicação de agrotóxico sem o devido uso dos equipamentos de proteção individual (EPI) (Figura 7), sofre um problema sério de saúde e após a sua recuperação vai procurar alternativas a agricultura orgânica, foi possível constatar que houve a sensibilização dos ouvintes inclusive com pedido de mais revistas para a distribuição a parentes, amigos e vizinhos agricultores que não puderam comparecer a palestra.

O que pode ser constatado após as palestras e nas conversas com os participantes foi que os pesticidas usados na lavoura podem ter tido influência sobre alguns dos problemas de saúde da população avaliada, constatada pelos sintomas verificados no questionário aplicado aos agricultores. Muitos proprietários de hortas trocam seus trabalhadores periodicamente porque eles passam muito mal e que por isso é necessário afastar essas pessoas. Nas entrevistas informais são comuns às declarações, em relação a aplicação dos agrotóxicos, que estes produtos só são usados por extrema necessidade, e que sua condição de saúde já é muito precária e que se pudessem não usariam este tipo de produto. Muitos falam que uma horta de grande porte não funciona apenas com a agricultura alternativa, se tivesse um meio de controle biológico que acabasse com as pragas e doenças em curto prazo, aí sim eles adotariam esse meio de agricultura alternativa sem agrotóxico.

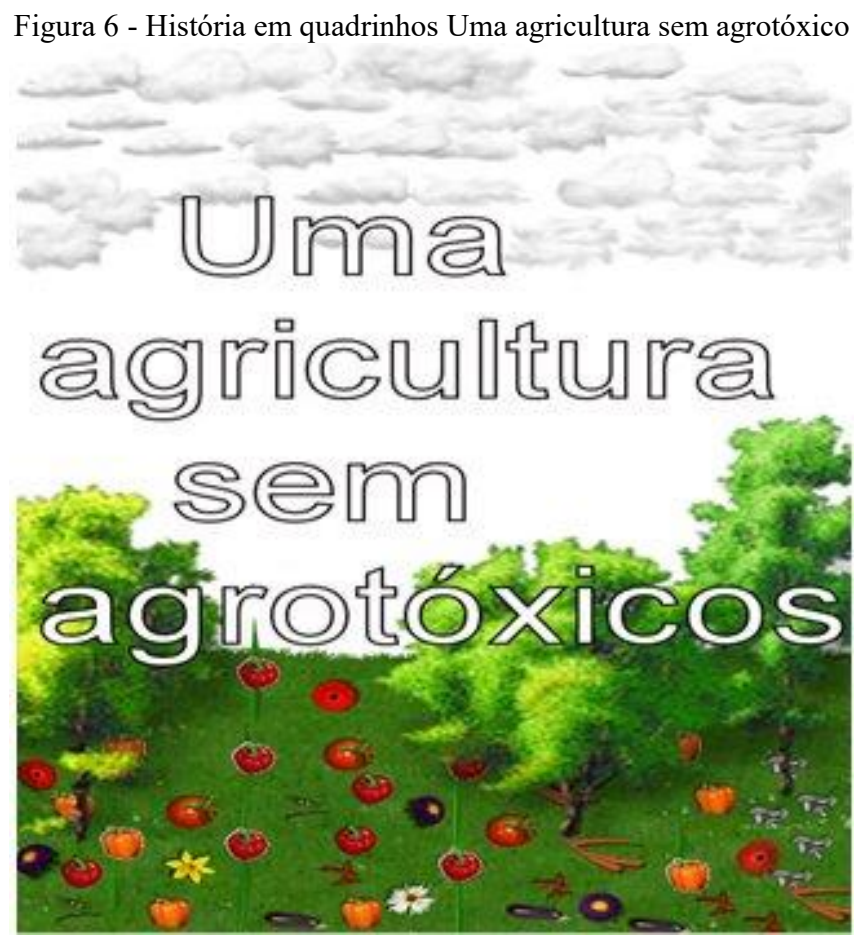

Fonte: Próprios autores, 2019.

Figura 7 - Prática dos agricultores que não usam EPI, relatada na História em quadrinhos

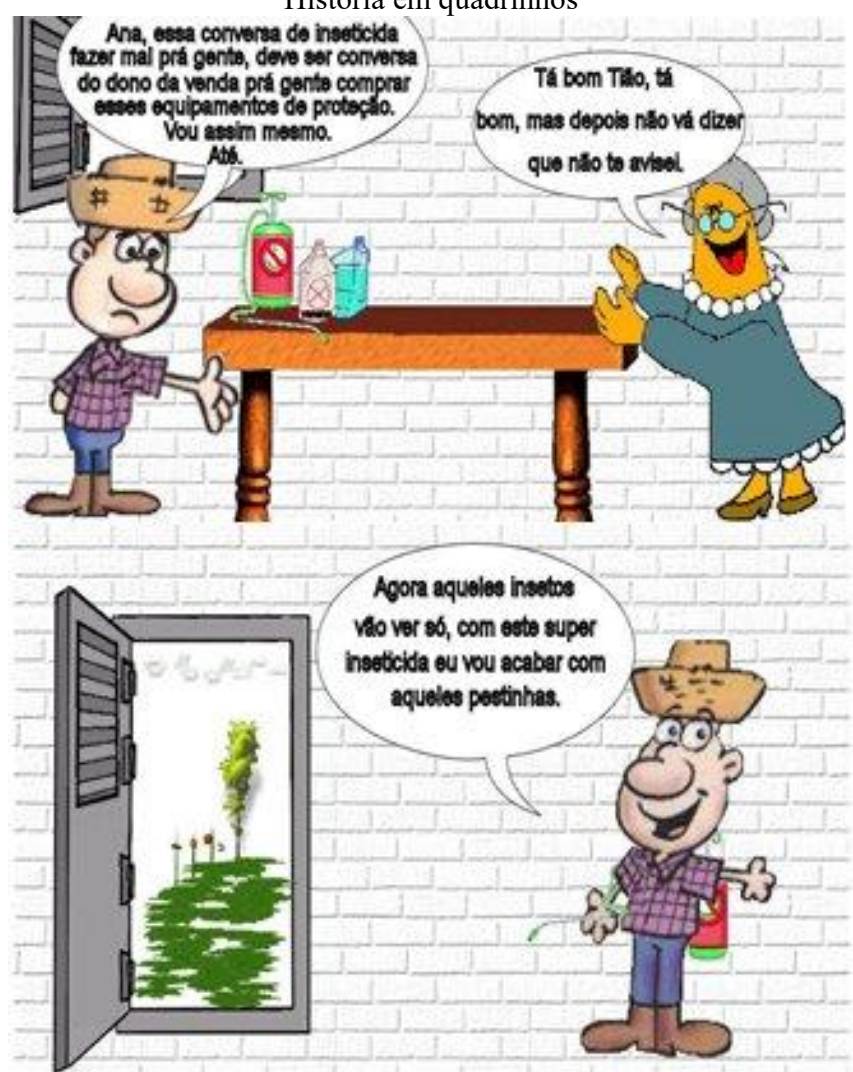

Fonte: Próprios autores, 2019.

Nas entrevistas junto à comunidade constatou-se que existem alternativas encontradas na mesma. Como: a pimenta longa que o chá de suas folhas fornece um ótimo inseticida, coentro, arruda, e principalmente as sementes do 
NIM indiano que pisadas as suas sementes no pilão, e misturada com água dá um ótimo inseticida e também fungicida. Os agricultores que estavam ouvindo a palestra não sabiam dos benefícios que principalmente o NIM fazia para as suas plantações tanto que foram entregues mais de 100 litros de sementes para os agricultores (o litro na linguagem do agricultor é equivalente a uma lata de óleo de cozinha cheio).

Muitas vezes o agricultor prefere utilizar o agrotóxico devido a eficiência dos produtos em relação as pragas da lavoura é uma prática que sai muito mais cara que as receitas caseiras. $\mathrm{O}$ agricultor da zona rural utiliza menos o agrotóxico por falta de recursos. O que os agricultores da zona urbana falam é que os comerciantes dos seus produtos não esperam tanto tempo para que eles possam praticar uma agricultura orgânica e como nessa prática o período de produção é maior, ele acabaria tendo prejuízo. Um produtor da zona urbana afirmou que em uma horta de grande porte a prática da agricultura alternativa não funcionaria e por isso é difícil manter as culturas livres de pragas usando os chás e alternativas.

Os produtores das hortaliças já se acostumaram em não ter tanto trabalho mesmo que isso vá refletir na parte financeira, pois não supre as necessidades básicas para a sua sobrevivência, como o vestir, calçar, alimentar-se somente com a produção de hortas, pois o dinheiro que é adquirido na mesma serve para comprar cada vez mais agrotóxico. Uma vez que é aplicado o agrotóxico na horta o agricultor fala que dá tempo para ser feito outras atividades e dizem que "tempo é dinheiro". O que mais chamou a atenção foi ver um pimentão branco de tanto agrotóxico, a população está cada vez mais se contaminando.

Também foi possível, através da revista, mostrar que existem algumas práticas alternativas aos agrotóxicos, que na história acontece após a recuperação do personagem após sua contaminação com agrotóxico (Figuras 8 e 9). Neste momento da história um vizinho descreve algumas das práticas alternativas para alguns dos problemas citados com o uso dos defensivos agrícolas. Essas práticas já são do conhecimento de alguns agricultores e têm sido usadas com muito sucesso. Todas essas receitas são biodegradáveis e não causam danos à saúde das pessoas, animais e vegetais. Sendo produtos naturais estas fórmulas só devem ser praticadas em último caso quando não foi possível fazer o controle com outras práticas que não seja a pulverização.

Figura 8 - Métodos alternativos, relatados na História em quadrinhos

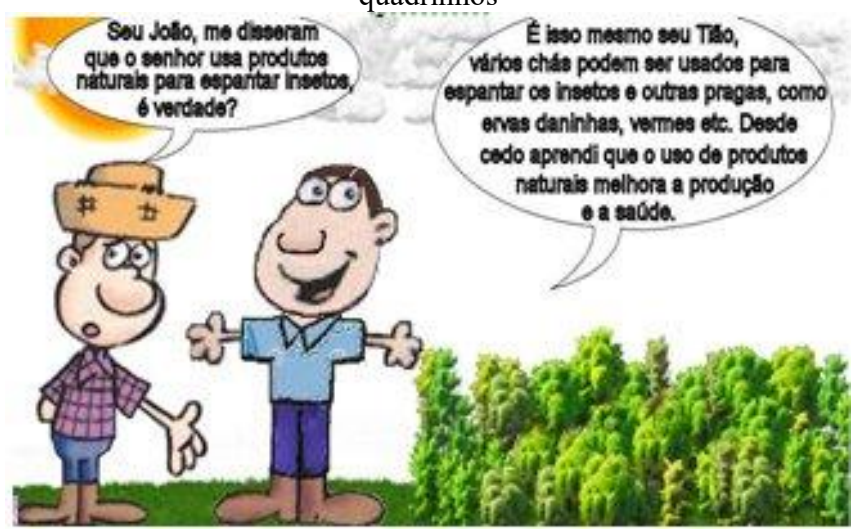

Fonte: Próprios autores, 2019.
Figura 9 - Chás e outros Métodos alternativos, relatados na História em quadrinhos

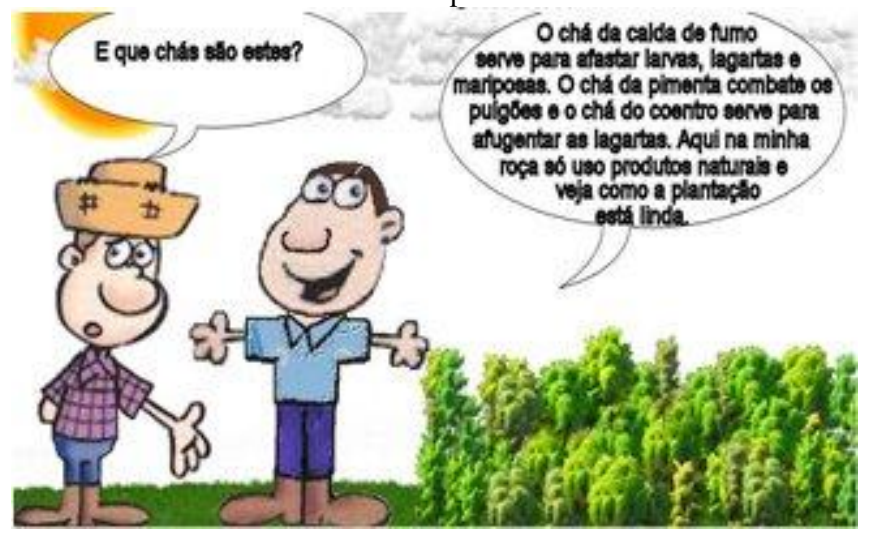

Fonte: Próprios autores, 2019.

Além da história em quadrinhos, nas palestras apresentadas foram relatadas algumas práticas utilizadas no combate às pragas e que não utilizam produtos químicos como a armadilha luminosa, que é uma prática utilizada para capturar insetos com hábitos noturnos. Muitas brocas e lagartas são provenientes de insetos que fazem a postura dos ovos durante a noite. Com a armadilha luminosa podemos capturar grande parte destes insetos, que são atraídos pela luminosidade da lâmpada. Em alguns casos a armadilha mostrou uma eficiência de 60 a $80 \%$. As armadilhas podem ser lâmpadas fluorescentes (encontradas para comprar) ou de lâmpadas comuns, podendo ser construídas na propriedade. Experiências mostraram que a armadilha deve ser colocada ao lado da cultura a ser protegida e não no meio. Se a plantação for grande usar mais armadilhas (ex: 1 armadilha/2.000 pés de tomate). A lâmpada deve ficar a uma altura de $1,20 \mathrm{~m}$ a 3,50 $\mathrm{m}$ e deve ter as paletas ao lado para ajudar na captura dos insetos. Logo abaixo da lâmpada pode ser colocada uma bacia contendo óleo queimado visando a captura definitiva e extermínio do inseto. As armadilhas são fixadas em postes e penduradas entre 1,2 e 3,5 metros de altura, de acordo com o tipo de cultura. $\mathrm{Na}$ figura 10 está mostrado o esquema de uma dessas armadilhas.

Figura 10 - A lâmpada letal

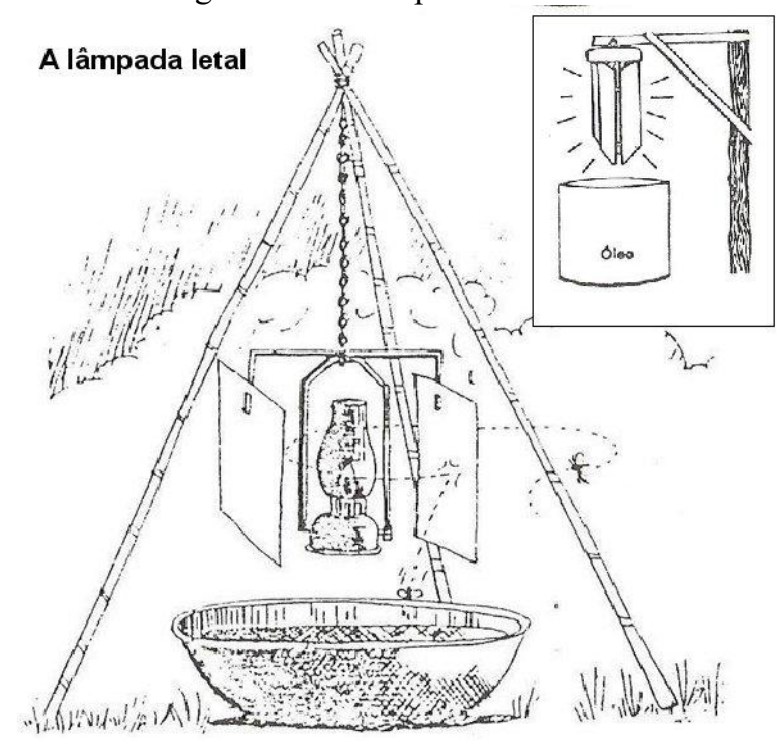


Para formigas cortadeiras de mudas frutíferas, usam-se pequenos cones feitos de câmara de ar velha, plástico, papelão parafinado ou outro material que preste para este fim. Corta-se um disco de aproximadamente $12 \mathrm{~cm}$ de diâmetro. No centro faz-se um furo mais ou menos do diâmetro dos caules das mudas na altura de aproximadamente $30 \mathrm{~cm}$ do solo. Corta-se o anel assim formado de modo a poder sobrepor as duas partes e formar um cone. Assenta-se o cone com a base para baixo.

Segundo o que foi apurado junto à secretaria de agricultura do município de Itaituba essa questão do agrotóxico ainda é um problema que terá que ser resolvido, porém no tempo certo, agora a maior preocupação é desenvolver projetos para o desenvolvimento sustentável para o município e que em relação aos impactos ambientais causados pelos agrotóxicos, no momento atual estão preocupados em fazer uma mobilização por parte dos agricultores, consumidores e donos de lojas agroindustriais que poderiam, por exemplo, vender o agrotóxico somente com a receita dada por um técnico agrícola e orientar sobre o destino das embalagens e outras medidas visando a minimização do problema, ou seja, seria um trabalho a longo prazo que teria que contar com a ajuda de toda a comunidade.

\section{CONCLUSÃO}

Este trabalho possibilitou aprofundar a questão dos agrotóxicos usados nas lavouras de Itaituba, que reflete o que acontece na Amazônia. Fazer educação ambiental requer um grande desafio, principalmente em áreas distantes dos centros de conhecimento. Existe também um grande obstáculo em reunir os agricultores e promover palestras, já que muitos alegam falta de tempo que os impedem de participarem de projetos sociais. É bem mais fácil ir até as comunidades e falar com os agricultores da zona rural que os da zona urbana. Mas tendo superado todos esses obstáculos foi possível transmitir a mensagem, principalmente a alguns alunos e agricultores, usando como exemplo os alimentos que eles estão consumindo.

Trabalhar com os alunos requer uma atenção especial, principalmente em fazer com que eles assimilem o conteúdo que está sendo abordado. O que foi mais satisfatório neste trabalho foi à interação mantida até hoje, a amizade, o respeito de ambas as partes, mesmo com aqueles alunos mais indisciplinados foi possível fazê-los trabalhar e se interessarem pelo assunto usando principalmente a história em quadrinhos desenvolvida para esta finalidade.

\section{REFERÊNCIAS BIBLIOGRÁFICAS}

ANVISA - Agência Nacional de Vigilância Sanitária. Programa de Análise de Resíduos de Agrotóxicos em Alimentos (PARA). Relatório de Atividades de 2011 e 2012. Brasília: Agência Nacional de Vigilância Sanitária; 2013.

BECK, U. Risk society. London: Sage Publications, 1992, $272 \mathrm{p}$

BUDZINSKI, H.; COUDERCHET, M. Environmental and human health issues related to pesticides: from usage and environmental fate to impact. Environmental Science and Pollution Research, 25:14277-14279, 2018.
CARVAlHO, F. P. Pesticides, environment, and food safety. Food and Energy Security 6(2):48-6, 2017.

JACOBI, P. Educação Ambiental, Cidadania e Sustentabilidade. Cadernos de pesquisa, 118:189-205, 2003.

LAMBERT, M. Agricultura e meio ambiente. Editora Scipione, 4 edição, SP, 1997, 48p.

LEFF, E. Saber ambiental. sustentabilidade, racionalidade, complexidade, poder. Petrópolis, RJ, Vozes/PNUMA, 2001, 343p.

MACHARIA, I. Pesticides and Health in Vegetable Production in Kenya. BioMed Research International, 110,2015

ROPKE, E. Alternativas para uma agricultura sem veneno, projeto Guandu 1a edição, 1990, 112 p.

\section{AGRADECIMENTOS}

Ao colegiado do Curso de Licenciatura de Ciências Naturais do Instituto de Ciências Exatas e Naturais da UFPA pela publicação das revistas em quadrinhos, ao Laboratório de Química Analítica e AmbientalLAQUANAM e a população do município de Itaituba-PA .

\section{COPYRIGHT}

Direitos autorais: Os autores são os únicos responsáveis pelo material incluído no artigo. 


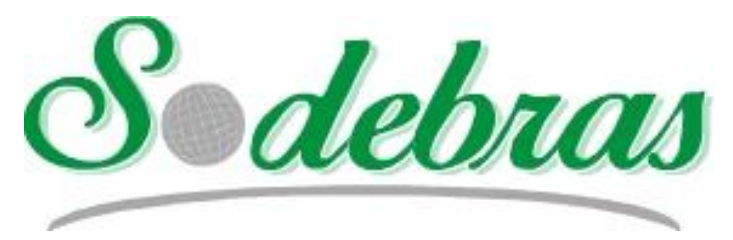

Volume 15 - $\mathrm{N}^{\mathrm{o}} 169$ - Janeiro / 2020

XLI International Sodebras Congress

31 de outubro a 02 de novembro de 2019 - Maceió - AL.

\title{
INFLUÊNCIA DA PREPARAÇÃO DO CORANTE N719 EM CÉLULAS SOLARES DE TiO 2 : UMA ANÁLISE ELETROQUÍMICA
}

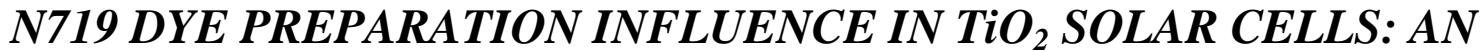 ELECTROCHEMICAL ANALYSE}

\author{
JULIANNO P. AYOUB ${ }^{1}$; GIDEÃ T. TRACTZ ${ }^{1}$; EVERSON P. BANCZEK ${ }^{1}$; PAULO R. P. RODRIGUES ${ }^{1}$ \\ 1 - UNIVERSIDADE ESTADUAL DO CENTRO OESTE \\ juliannopa@hotmail.com; gide.tractz@hotmail.com; edopradobanczek@yahoo.com.br; \\ prprodrigues@gmail.com
}

\begin{abstract}
Resumo - Devido ao crescimento populacional e a necessidade de demanda energética, as células solares são dispositivos promissores para suprir esta demanda. Dentre esses sistemas, os sensibilizados por corante (CSSC) apresentam baixo custo de produção e boa eficiência em conversão de energia. A escolha da solução para preparação do corante é de suma importância para garantir uma fotoinjeção de elétrons eficiente. Este trabalho tem como objetivo analisar eletroquimicamente uma CSSC de $\mathrm{TiO}_{2}$ com corante $N 719$ em etanol e terc-butanol:acetonitrila. As técnicas utilizadas foram: fotocronoamperometria, curvas $j x E$, espectroscopia de impedância eletroquímica, espectroscopia de fotovoltagem com intensidade modulada e extração de carga. Os resultados mostraram que a célula com terc-butanol:acetonitrila apresentou melhores parâmetros fotovoltaicos com Eca= 0,825 $V ; j=6,97 \mathrm{~mA} \mathrm{~cm}^{2} ; \mathrm{FF}=0,659 ; \eta=3,79 \%$ e $Q=944 \mu \mathrm{C} \mathrm{cm}^{-2}$. No entanto com menor tempo de recombinação e maior tempo de coleta que o etanol com N719 como solução do corante $(\mathrm{Tc}=53,02 \mathrm{~ms} e \operatorname{Tr}=\mathbf{0 , 1 0 3 s})$.
\end{abstract}

Palavras-chave: eletroquímica. IMVS. Espectroscopia de impedância eletroquímica. célula de gratzel.

\begin{abstract}
Due to population growth and the need for energy demand, solar cells are promising devices to meet this demand. In these systems, dye sensitized solar cells (DSSC), present low cost production and good photoconversion energy efficiency. Chosing the solution to dye preparation it is essential to efficiency electrons injection. This work aims to produce a $\mathrm{TiO}_{2}$ solar cell using ethanol and terc-buthanol:acetonitrile as solutions in N719 dye. The techniques used were: Photochronoamperometry, curves $j-V$, electrochemical impedance spectroscopy, intensity modulated photovoltage spectroscopy and charge extraction. The results shown tercbuthanol:acetonitrile dye presented better photovoltaic parameters with Voc $=0,825 \mathrm{~V}, j=6,97 \mathrm{~mA} \mathrm{~cm}^{-2}, \mathrm{FF}=0,659$, $\eta=3,79 \%$ and $Q=944 \mu \mathrm{C} \mathrm{cm}^{-2}$. However, with low recombination time and higher collection time than ethanol as dye N719 solution ( $T c=53,02 \mathrm{~ms}$ e $T r=0,103 \mathrm{~s}$ ).
\end{abstract}

Keywords: electrochemistry. IMVS. Eletrochemical impedance spectroscopy. gratzel cell.

\section{INTRODUÇÃO}

A alta demanda energética mundial, oriunda do crescimento populacional conduz a pesquisa e o desenvolvimento de novas metodologias de conversão energética. Atrelado aos problemas ambientais, rotas alternativas e sustentáveis são bastante promissoras para suprir o consumo de energia e entre essas, pode-se citar as célula fotovoltaica (Sonai et al., 2015).

A célula solar ou fotovoltaica é o dispositivo capaz de converter energia solar em energia elétrica, devido ao efeito fotovoltaico. Dentre as classes de sistemas solares desenvolvidos e comercializados, os de terceira geração vêm apresentando grande foco de estudo, devido a boa eficiência e baixo custo de produção (Vitoreti et al., 2017).

As células solares sensibilizadas por corante (CSSC) são sistemas produzidos pela junção de um óxido semicondutor e um corante fotossensível. Quando a luz solar incide no sistema, elétrons do corante são ejetados para a banda de condução do óxido semicondutor, que por sua vez percorrem o circuito externo, até encontrarem o contra eletrodo (Tractz et al., 2019). O corante oxidado é reduzido pelo uso de um eletrólito, propiciando assim um fluxo de injeção e consequentemente a formação de uma corrente elétrica (Alwani et al., 2016).

Os corantes mais utilizados são sintéticos, em grande parte baseados em rutênio, que formam moléculas de alto coeficiente de extinção molar e alta capacidade de ancoragem na superfície do óxido semicondutor. O corante (isotiocianato) bis (2,2'-bipiridil-4,4' dicarboxilato) rutênio (II), comercializado como N719 foi primeiramente utilizado por Gratzel e ainda apresenta destaque devido a sua alta performance fotoeletroquímica (Gratzel 2001) (Tractz et al., 2018).

Soluções desses organometálicos para posterior impregnação ao óxido semicondutor necessitam ser estudadas, pois influenciam nas propriedades dos mesmos e consequentemente na eficiência/propriedades dos sistemas solares. Esse trabalho tem como objetivo verificar as propriedades de células solares de $\mathrm{TiO}_{2}$ produzidas pela metodologia Pechini, em soluções de corante preparadas com etanol 99,5 \% e mistura 50:50 (v/v) terc-butanol: acetonitrila.

\section{PROCEDIMENTOS}

$\mathrm{TiO}_{2}$ foi produzido pela metodologia Pechini, utilizando isopropóxido de titânio, ácido cítrico e etileno glicol, como demonstrado por Ribeiro e colaboradores, na proporção 2:1 ácido cítrico: cátion metálico (Ribeiro et al., 
2012). A pasta de $\mathrm{TiO}_{2}$ foi produzida com a mistura de $3 \mathrm{~g}$ de $\mathrm{TiO}_{2}, 0,1 \mathrm{~mL}$ de acetil acetona, $0,1 \mathrm{~mL}$ de Triton $\mathrm{X}, 1$ $\mathrm{mL}$ de polietileno glicol e $4 \mathrm{~mL}$ de água deionizada. A deposição foi realizada em FTO (óxido de estanho dopado com flúor) por Doctor Blading e sinterizada a $450{ }^{\circ} \mathrm{C}$ por 30 minutos (Tractz et al., 2019).

Após a produção dos filmes, a impregnação foi realizada em solução de N719 com Etanol 99,5 \% e mistura de terc-butanol e acetonitrila $(50: 50 \mathrm{v} / \mathrm{v})$. As células foram montadas em formato sanduíche do anodo e do catodo (platina eletrodepositada via voltametria cíclica), com a intermediação de cargas realizada por $\mathrm{I}^{-} / \mathrm{I}_{3}{ }^{-}$, em uma área ativa de $0,2 \mathrm{~cm}^{2}$.

As medidas eletroquímicas empregadas foram: fotocronoamperometria, densidade de corrente em função do potencial (j-E), Espectroscopia de Impedância Eletroquímica (EIE), Espectroscopia de fotovoltagem com intensidade modulada (IMVS) e extração de carga em um potenciostato Zahnner, modelo Zennium Eleteochemical Workstation acoplado a uma lâmpada de Xenônio com um espectro solar padrão de AM 1.5G.

\section{RESULTADOS}

Na Figura 1 é mostrado o a fotocronoamperometria para os sistemas estudados.

Figura 1 - Curvas fotocronoamperometricas para os sistemas com etanol e terc-butanol:acetonitrila

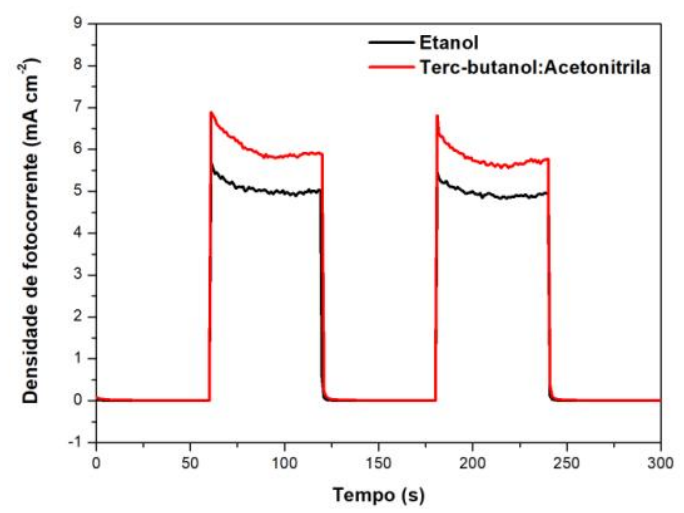

Nota-se na Figura 1 altos valores de densidade de corrente para ambos os sistemas, com $\mathrm{j}=7 \mathrm{~mA} \mathrm{~cm}$ para a célula com terc-butanol: acetonitrila e $\mathrm{j}=6 \mathrm{~mA} \mathrm{~cm}^{-2}$ para a célula com etanol. Verifica-se também que apesar das altas correntes geradas nos sistemas, há processos difusionais que acabam criando um "vale de energia", sugerido devido a concentração do eletrólito, que por sua vez não consegue regenerar o corante com a mesma velocidade em que os elétrons são fotoejetados (Dias et al., 2018).

Percebe-se também que as mesmas apresentam alta fotossensibilidade, pois quando a luz solar incide no sistema há um aumento de corrente, e quando a luz é retirada do dispositivo, a corrente se aproxima a zero.

Na Figura 2 é apresentado as curvas de densidade de corrente em função do potencial, que permitem o cálculo da eficiência em conversão de energia, empregando-se a Equação 1, onde $\eta$ equivale a eficiência de fotoconversão, jcc a densidade de corrente, FF, o fator de preenchimento, Pin a potência incidente e Eca o potencial de circuito aberto (Larsson et al., 2019).
$\eta=\frac{E_{c c} J_{c c} F F}{P_{\text {in }}} \cdot 100 \%$

Figura 2 - Curvas da densidade de corrente (j) em função do do potencial $(\mathrm{V})$ para os sistemas produzidos com etanol e tercbutanol:acetonitrila

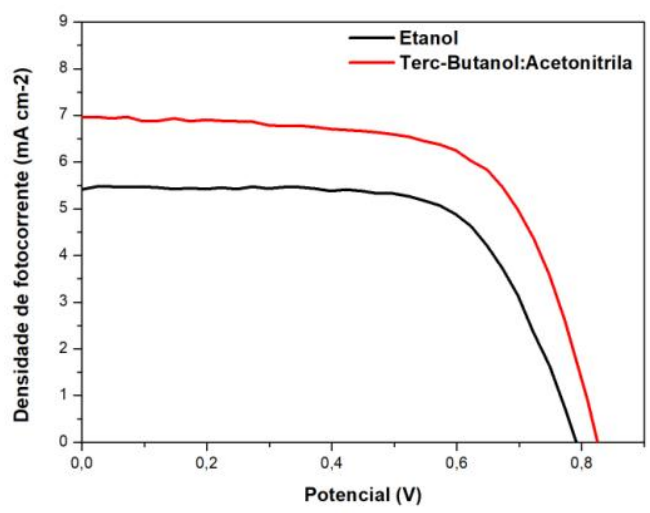

Empregando-se a Equação 1, pode-se obter os parâmetros fotovoltaicos dos sistemas analisados que encontram-se na Tabela 1 .

Tabela 1 - Parâmetros fotovoltaicos obtidos para a célula solar produzida com corante natural

\begin{tabular}{ccccc}
\hline Corante & $\begin{array}{c}\mathbf{J}_{\mathbf{C C}}(\mathbf{m A} \mathbf{A} \\
\left.\mathbf{c m}^{-\mathbf{2}}\right)\end{array}$ & $\mathbf{E}_{\mathbf{C A}}(\mathbf{V})$ & $\mathbf{F F}$ & $\mathbf{\eta}(\%)$ \\
Etanol & 5,48 & 0,791 & 0,675 & 2,92 \\
Terc- & 6,97 & 0,825 & 0,659 & 3,79 \\
Butanol: & & & & \\
Acetonitrila & & & & \\
\hline
\end{tabular}

Nota-se na Tabela 1 que as células solares apresentaram eficiências de $2,92 \%$ e 3,79\% para corantes com soluções e etanol e terc-butanol:acetonitrila respectivamente. Com relação aos potenciais, excelentes resultados foram encontrados, pois a primeira célula desenvolvida por Gratzel não atingiu esse patamares de energia (Gratzel 2001). Esse resultado, sugere que o nível de Fermi das partículas de $\mathrm{TiO}_{2}$ sintetizadas encontram-se deslocadas para valores energéticos mais altos, que conduzem consequentemente a um elevado Eca (Hagfeldt et al., 2010).

Com relação ao fator de preenchimento, quando este aproxima-se de 1, próximo a idealidade o dispositivo se encontra. Os valores aqui obtidos também são promissores quanto comparados as células padrões de $\mathrm{TiO}_{2}$ e corante. No entanto podem ser potencializadas devido a uma montagem mais eficiente do sistema, que conduz também a melhores parâmetros fotovoltaicos (Tractz et al., 2019).

A corrente do sistema apresentou menores valores quando comparado as células desenvolvidas por Gratzel $\left(\sim 10 \mathrm{~mA} \mathrm{~cm}^{-2}\right)$. Isto pode estar relacionado a uma série de fatores como tamanho das partículas produzidas, tempo de sinterização, tempo de impregnação entre outros, que não são o foco deste trabalho (Hagfeldt et al., 2010).

Quando comparado os parâmetros dos sistemas estudados de maneira geral, o produzido com tercbutanol:acetonitrila é mais eficiente para geração de sistemas fotovoltaicos. Isto comprova que esta solução, quando comparada ao etanol, pode gerar um corante mais eficiente na fotoinjeção de elétrons. Segundo Hagfeldt e 
colaboradores, corantes que apresentam maior eficiência em conversão de energia apresentam elevado coeficiente de extinção e são capazes de se ancorarem na superfície do óxido com maior facilidade e geometria adequada, fatores estes mais efetivos quando usa-se corante com tercbutanol:acetonitrila (Hagfeldt et al. 2010).

Na Figura 3, encontram-se o diagrama de Nyquist para os sistemas estudados obtidos pela técnica de espectroscopia de impedância eletroquímica.

Figura 3 - Diagrama de Nyquist para os sistemas estudados com etanol e terc-butanol:acetonitrila.

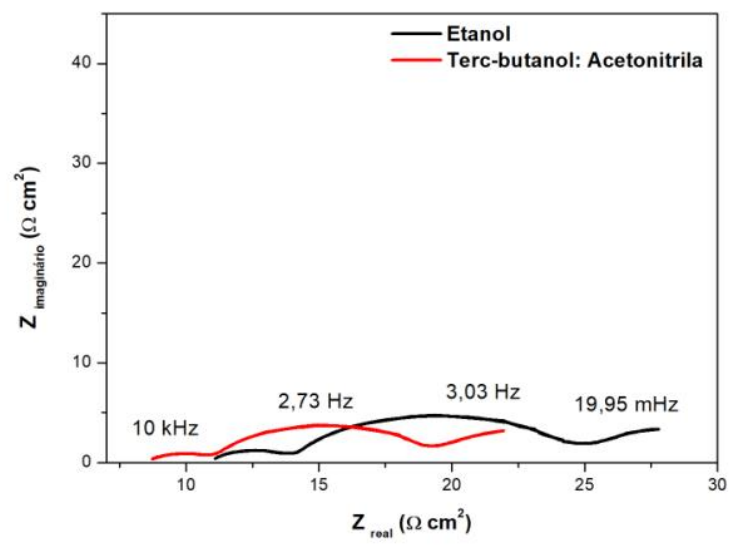

Verifica-se que a célula com etanol possui maior resistência a passagem de corrente, pois apresenta um arco capacitivo de maior impedância. Os três semicírculos nos diagramas são relacionados aos processos a alta, intermediária e baixa frequência (esquerda-direita), que como demonstrado por Guimarães e colaboradores correspondem respectivamente as reações no contra eletrodo, no óxido semicondutor e aos processos difusionais (Guimarães et al. 2016). É possível realizar o ajuste da impedância obtida de uma CSSC, como demonstrado por Bisquert e colaboradores, a um circuito elétrico (Figura 4), que fornece alguns parâmetros químicos essências, como a $\mathrm{Rr}$ e $\mathrm{C} \mu$, que equivale e resistência de recombinação e a capacitância química respectivamente (Bisquert and Fabregat-Santiago, 2010).

Figura 4 - Circuito elétrico utilizado para o ajuste da impedância dos sistemas estudados

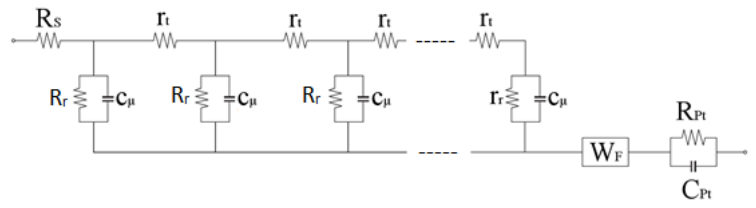

Os resultados obtidos para os sistemas com etanol e Terc-butanol:acetonitrila encontram-se dispostos na Tabela 2 , sendo que o tempo de coleta do elétron $\mathrm{T}_{\mathrm{c}}$ (tempo que o elétron leva para chegar a banda de condução de óxido semicondutor), foi calculado empregando-se a Equação 2 (Guimarães et al., 2016).

$\mathrm{Tc}=R_{\gamma} C_{\mu}$
Tabela 2 - Parâmetros fotovoltaicos obtidos para a célula solar produzida com corante natural

\begin{tabular}{cccc}
\hline Solução & $\mathbf{R}_{\text {rec }}(\boldsymbol{\Omega})$ & $\mathbf{C}_{\mathbf{u}}(\mathbf{m F})$ & $\mathbf{T}_{\mathbf{c}} \mathbf{( m s )}$ \\
Etanol & 44,87 & 1,169 & 52,45 \\
Terc-Butanol: & 34,41 & 1,541 & 53,02 \\
Acetonitrila & & & \\
\hline
\end{tabular}

Verifica-se na Tabela 2 que a velocidade de coleta de elétrons no óxido semicondutor foi mais rápida para a célula produzida com corante em meio etanoico. No entanto, para uma análise mais completa, o $\mathrm{T}_{\mathrm{r}}$ necessita ser encontrado, que equivale ao tempo que o elétron demora para se recombinar com o corante oxidado, impedindo assim a formação de um fluxo de corrente. Este tempo foi obtido empregando-se a Equação 3 e utilizando a técnica de IMVS, realizada em condição de potencial de circuito abero $(j=0)$ onde não há fluxo de corrente na célula e assume-se que todos os elétrons estão se recombinando. Onde $f_{\text {min }}$ corresponde a frequência no ponto mínimo (Tractz et al., 2019).

$$
\operatorname{Tr}=\frac{1}{2 \pi f_{\min }}
$$

Figura 5 - IMVS para as células estudadas.

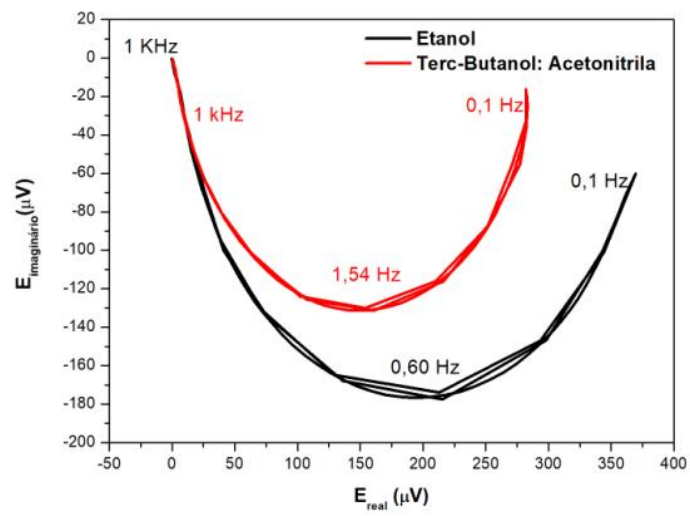

Os tempos de recombinação obtidos encontram-se disponíveis na Tabela 3.

Tabela 3 - Tempos de recombinação obtidos pela técnica de IMVS para os sistemas estudados

\begin{tabular}{ccc}
\hline Solução & $\mathbf{f}_{\min }$ & $\mathbf{T}_{\mathbf{r}}(\mathbf{s})$ \\
Etanol & 0,60 & 0,265 \\
Terc-Butanol: & 1,54 & 0,103 \\
Acetonitrila & & \\
\hline
\end{tabular}

Sabe-se que quanto maior o tempo de recombinação melhor para o sistema, pois leva-se mais tempo para que o elétron sofra a recombinação com o eletrólito oxidado. Para o corante com etanol as melhores condições foram obtidas, tanto para Tc quanto para $\operatorname{Tr}$ equivalentes a $52,45 \mathrm{~ms}$ e $0,265 \mathrm{~s}$ respectivamente, comprovando que as células produzidas com corante em meio etanoico é capaz de ejetar os elétrons em um tempo menor, e propiciar uma recombinação de cargas mais lenta quando comparada a solução de terc-butanol:acetonitrila (Hagfeldt et al., 2010). No entanto estes valores foram discrepantes com os parâmetros fotovoltaicos obtidos (Tabela 1), por isso a célula foi iluminada e após foi condicionada a curto circuito, 
podendo assim pela corrente obtida nessa condição, realizar o cálculo da extração de carga em ambos os sistemas que encontram-se na Tabela 4.

Tabela 4 - Cargas extraídas para os sistemas fotovoltaicos estudados.

\begin{tabular}{cc} 
Solução & $\mathbf{Q}\left(\boldsymbol{\mu} \mathbf{C ~ c m}^{-2}\right)$ \\
Etanol & 937 \\
Terc-Butanol: Acetonitrila & 944 \\
\hline
\end{tabular}

Apesar das células com etanol apresentarem um Tc e Tr efetivo, as mesmas fornecem menos elétrons que as células com terc-butanol:acetonitrila, na ordem de $7 \mu \mathrm{C}$ por $\mathrm{cm}^{2}$. Como $1 \mathrm{C}$ equivale a $1 \mathrm{~mol}$ de elétrons e cada mol equivale a $6,02 \cdot 10^{23}$ elétrons, é possível calcular que a célula de maior carga extraída, apresenta cerca de $4,2.10^{18}$ elétrons a mais por $\mathrm{cm}^{2}$ que a célula com corante em meio etanoico, comprovando o alto valor de corrente e potencial obtido, pelas curvas j-E (Figura 2) (Viomar, 2019).

\section{CONCLUSÃO}

Células solares de $\mathrm{TiO}_{2}$ sintetizadas pelo método Pechini e impregnadas em corantes em soluções etanoicas apresentam tempos de coleta menores e tempos de recombinação de cargas maiores quando comparadas ao uso do corante em meio de terc-butanol:acetonitrila.

$\mathrm{O}$ uso do terc-butanol:acetonitrila propicia maior quantidade de carga extraída, quando comparada ao uso do etanol na solução do corante, levando a maiores parâmetros fotovoltaicos, equivalentes a $\mathrm{Eca}=0,825 \mathrm{~V} \mathrm{jcc}=6,97 \mathrm{~mA}$ $\mathrm{cm}^{-2}, \mathrm{FF}=0,659 \eta=3,79 \%$.

\section{REFERÊNCIAS BIBLIOGRÁFICAS}

ALWANI, M. A. M; MOHAMAD, A. B; LUDIN, N. A; KHADUN, A. A. H; SOPIAN, K. Dye sensitized solar cells: Development, structure, operation principles, electron kinects, characterization, synthesis materials and natural photosensitizers. Renewable and sustainable energy reviews. V, 65, 2016, pg 183-213.

BISQUERT, J.; FABREGAT-SANTIAGO, F. Impedance spectroscopy: A general introduction and application to dyesensitized solar cells. Dye-Sensitized Solar Cell, p. 457$555,2010$.

DIAS, B. V.; TRACTZ, G. T.; VIOMAR, A.; et al. Photoelectrochemical Behavior of the Cell FTO/TiO2/ZrO2/N719 Obtained from the Pechini and Precipitation of Cerium Oxide Methods. Journal of Electronic Materials, v. 47, n. 9, 2018.

GRATZEL, M. Photoelectrochemical Cells. Nature, v. 414, n. October 1960, 2001.

GUIMARÃES, R. R.; PARUSSUlO, A. L. A.; TOMA, H. E.; ARAKI, K. Enlightening the synergic effect of anatase/rutile mixtures in solar cells. Electrochimica Acta, v. 188, p. 523-528, 2016.

HAGFELDT, A.; BOSCHLOO, G.; SUN, L.; KLOO, L.; PETTERSSON, H. 2010 ChemReview, p. 6595-6663,
2010.

LARSSON, L. F. G.; TRACTZ, G. T.; MAIA, G. A. R.; et al. Comparative Study of $\mathrm{TiO} 2$ and $\mathrm{ZnO}$ application in hybrid solar cells using copolymer P3OT/P3HT. Quim. Nova, v. 42, n. 3, p. 283-288, 2019.

RIBEIRO, P. C.; COSTA, A. C. F. DE M. DA; KIMINAMI, R. H. G. A.; SASAKI, J. M.; LIRA, H. L. Synthesis of $\mathrm{TiO} 2$ by the pechini method and photocatalytic degradation of methyl red. Materials Research, v. 16, n. 2, p. $468-472,2012$.

SONAI, G. G.; JUNIOR, M. A. M.; NUNES, J. H. B.; MEGIATTO, J. D.; NOGUEIRA, A. F. CÉlULAS SOLARES SENSIBILIZADAS POR CORANTES NATURAIS: UM EXPERIMENTO INTRODUTÓRIO SOBRE ENERGIA RENOVÁVEL PARA ALUNOS DE GRADUAÇÃO. Quimica Nova, v. 38, n. 10, p. 1357-1365, 2015.

TRACTZ, G. T.; MAIA, G. A. R.; DIAS, B. V.; et al. Study of $\mathrm{TiO} 2$ in hybrid solar cells with natural dyes. Revista Virtual de Quimica, v. 10, n. 4, 2018.

TRACTZ, G. T.; VIOMAR, A.; DIAS, B. V.; et al. Recombination study of dye sensitized solar cells with natural extracts. Journal of the Brazilian Chemical Society, v. 30, n. 2, 2019.

VIOMAR, A. Aplicação do $\mathrm{Nb}_{2} \mathrm{O}_{5}$ em células solares de TiO2. Tese de doutorado. Universidade Estdual do Centro Oeste, 2019.

VITORETI, A. B. F.; VAZ, R.; PENA, A. D. L.; et al. Artigo Aplicação de Dióxido de Titânio em Células Solares Aplicação de Dióxido de Titânio em Células Solares. Revista Virtual de Química. , v. 9, n. 4, 2017.

\section{AGRADECIMENTOS}

O presente trabalho foi realizado com o apoio da coordenação de aperfeiçoamento de pessoal de nível superior-Brasil (Capes) código de financiamento 001. Os autores agradecem a FAU/UNICENTRO pelo apoio financeiro, e também ao CNPq, FINEP, Fundação Araucária e SETI/UGF.

\section{COPYRIGHT}

Direitos autorais: Os autores são os únicos responsáveis pelo material incluído no artigo. 


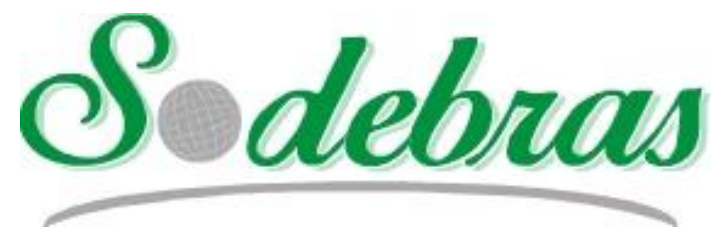

Volume $15-\mathrm{N}^{\mathrm{o}} 169$ - janeiro / 2020

XLI International Sodebras Congress

31 de outubro a 02 de novembro de 2019 - Maceió - AL.

\title{
PLANO DE ADEQUAÇÃO DAS ESTRUTURAS FÍSICAS DE CALÇADAS DO CENTRO DE SÃO MIGUEL DOS CAMPOS - AL
}

\section{ADEQUACY PLAN FOR THE PHYSICAL STRUCTURES OF THE SIDEWALKES FRON SÃO MIGUEL DOS CAMPOS DOWNTOWN}

\author{
TALITA MARIA GOMES DE MORAIS ${ }^{1}$; BRUNA DOS SANTOS ${ }^{1}$; GEOVÂNIA DOS SANTOS \\ ALMEIDA $^{1}$ \\ 1 - INSTITUTO FEDERAL DE ALAGOAS (IFAL) - CAMPUS SÃO MIGUEL DOS CAMPOS \\ talita.morais@ifal.edu.br; brunads999@gmail.com; geovania125@outlook.com
}

\begin{abstract}
Resumo - Devido à dificuldade de locomoção dos pedestres no centro de São Miguel dos Campos-AL, este estudo objetivou desenvolver um modelo de adequação das estruturas físicas de circulação de pedestres no centro de São Miguel dos Campos, através de levantamento das áreas de calçadas que são transitáveis e bloqueadas para os pedestres. Com a utilização do software autocad foi realizado o mapeamento do centro da cidade, indicando os pontos acessíveis e bloqueados. $O$ mapeamento identificou 19 pontos permanentes de falta de acessibilidade ou descontinuidade do deslocamento e três pontos temporários. Após o mapeamento, foram realizados estudos de viabilidade e elaboração de um Plano de Adequação das Estruturas Físicas de Calçadas do Centro de São Miguel dos Campos - AL. Além disso, foi possível constatar que o local estudado não está de acordo com o que preconiza a ABNT NBR 9050.
\end{abstract}

Palavras-chave: Mobilidade. Acessibilidade. Urbana.

Abstract - Due to the difficulty of pedestrian movement in the center of São Miguel dos Campos - AL, this study aimed to develop a model of adequacy of the physical structures of pedestrian circulation in the center of São Miguel dos Campos, by surveying the areas of sidewalks that are passable. and blocked for pedestrians. Using the autocad software, the city center was mapped, indicating the accessible and blocked points. The mapping identified 19 permanent points of displacement accessibility or discontinuity and three temporary points. After the mapping, feasibility studies and elaboration of a Plan of Adequacy of the Sidewalk Physical Structures of the Center of. In addition, it was possible to verify that the studied site is not in accordance with what ABNT NBR 9050 recommends.

Keywords: Mobility. Accessibility. Urban.

\section{INTRODUÇÃO}

A presente pesquisa abordará a dificuldade da mobilidade e de acessibilidade no centro de São Miguel dos Campos. De acordo com a Norma Brasileira Regulamentadora (NBR) da Associação Brasileira de Normas Técnicas (ABNT) de número 9050, acessibilidade é a possibilidade de alcance, percepção e entendimento para a utilização com segurança e autonomia de edificações, espaço, mobiliário, equipamento urbano e elementos (BRASIL, 2004, p. 40).

O planejamento de uma cidade deve estar voltado ao direito do cidadão desde o momento que deseja sair de sua casa até alcançar o destino pretendido, de maneira que este possa se transportar, com autonomia, num ambiente urbano seguro e adequado às possibilidades motoras e sensoriais de todos, garantindo assim a acessibilidade.

Segundo Baptista (2003), entende-se que as estruturas de circulação, assim com os demais âmbitos, devem ser acessíveis a todos e que, para isso, a tarefa de locomover-se deve ser realizada com conforto e segurança. Não se trata de propor soluções de acesso exclusivamente para pessoas com necessidades especiais e sim para todo um universo de pessoas.

Nas áreas de livre circulação, a calçada é o elemento mais seguro utilizado pelo pedestre. Pelo Código de Trânsito Brasileiro (BRASIL, 1997), calçada é:

\begin{abstract}
"a parte da via, normalmente segregada e em nível diferente, não destinada à circulação de veículos, reservada ao trânsito de pedestres e, quando possível, à implantação de mobiliário urbano, sinalização, vegetação e outros fins" (BRASIL, 1997).
\end{abstract}

Para tornar o espaço público mais acessível é necessário eliminar ao longo das calçadas os obstáculos físicos, naturais ou de comunicação, que existem e impedem ou dificultam a livre circulação das pessoas.

As pessoas possuem necessidades diferentes que variam conforme a idade, estatura, condição de saúde, dentre outros. As barreiras arquitetônicas e urbanísticas (árvores, floreiras dentre outros) e alguns obstáculos como barracas, tapumes, entulhos, lixo, buracos e desníveis, podem fazer do ato de caminhar pela cidade um transtorno e, muitas vezes, dificultam o deslocamento de pessoas, impedindo o uso da estrutura urbana.

Com a população total estimada em 2015 de 60539 habitantes (IBGE, 2010) e com o quarto maior Produto Interno Bruto (PIB) per captado do Estado de Alagoas, São Miguel dos Campos é referência regional de crescimento econômico e tem como principais fontes de renda as agroindústrias que produzem açúcar e etanol, a extração de petróleo e gás natural e fabricação de cimento. A economia fortalecida faz a circulação de pessoas na região do comércio da cidade se intensificar em determinados períodos do ano, o que torna mais grave a falta de mobilidade. 
Desta forma, foi feito um levantamento das áreas de calçadas que estão temporariamente ou permanentemente bloqueadas no centro de São Miguel dos Campos e com base no levantamento, foi elaborado um modelo de readequação das calçadas do centro da cidade.

\section{METODOLOGIA}

Para a realização deste estudo, inicialmente foi realizada a pesquisa bibliográfica sobre o tema utilizando as plataformas de pesquisas. Foram pesquisados estudos com, no máximo, cinco anos de publicação, que continham as palavras chaves "mobilidade", "acessibilidade" e "urbana".

Em seguida foi definida a área a ser pesquisada levando em consideração as ruas com maiores fluxos de pedestres e com conexões com os principais meios de locomoção urbana.

Foi elaborado o mapa da área a ser estudada utilizando o software Autocad com a representação das ruas e das estruturas físicas de calçadas. Logo após, foi realizado o levantamento dos pontos de bloqueios e pontos transitáveis utilizando cores.

Os pontos de circulação permanentemente bloqueados por estruturas fixas que impedem o deslocamento de pedestres ou de cadeirantes, como batentes, barracas de venda de ambulantes, buracos, postes, calçadas estreitas, caladas com inclinação, entre outas barreiras físicas, foram indicadas neste estudo na cor vermelha.

Amarela foi utilizada para indicar pontos de circulação com barreiras temporárias, como entulho de obras, tapumes, placas de divulgação de produtos ou serviços e demais barreiras que são removíveis e que indicam a interdição temporária da via.

Em verde estão os pontos de livre circulação de pessoas com e sem dificuldades de locomoção. São os trechos que permitem o acesso e deslocamento pela calçada de pessoas que tenham alguma dificuldade de locomoção.

Foi elaborado o Plano de Adequação das Estruturas Físicas de Calçadas do Centro de São Miguel dos Campos AL.

\section{RESULTADOS}

A execução deste trabalho exigiu das pesquisadoras ampliação dos conceitos de mobilidade e acessibilidade. Foi preciso quebrar o paradigma de que acessibilidade e mobilidade são termos voltados apenas para pessoas com deficiência física que empeça a locomoção.

A calçada ideal deve promover a acessibilidade a todas as pessoas, ter largura adequada à circulação de, pelo menos, duas pessoas ladeadas e permitir fluidez do deslocamento.

Para garantir a fluidez do deslocamento, o ideal é que o piso das calçadas seja liso e antiderrapante, mesmo quando molhado, quase horizontal, com declividade transversal para escoamento de águas pluviais de não mais de 3\%. Não devem existir obstáculos dentro do espaço livre ocupado pelos pedestres (ABNT NBR 9050, 2004).

Para garantir a segurança dos pedestres, além do escoamento correto da água da chuva por meio de inclinação de $3 \%$, as calçadas não podem conter estruturas que favoreçam quedas ou tropeços, como buracos, tijolos ou peças de revestimento soltas.

A Norma Brasileira Regulamentadora $n^{\circ} 9050$ (BRASIL, 2004) estabelece parâmetros mínimos de calçadas com faixa livre, faixa de circulação e faixa de acesso. Segundo esta normatização, o conceito de Faixa Livre é área do passeio ou calçada destinada exclusivamente à circulação de pedestres (ABNT NBR 9050, 2004).

Foi considerado neste trabalho o conceito de Faixa de Serviço que é a área destinada à colocação de árvores, rampas de acesso para veículos ou portadores de deficiências, poste de iluminação, sinalização de trânsito e mobiliário urbano como bancos, floreiras, telefones, caixa de correio e lixeiras (ABNT NBR 9050, 2004).

E ainda, de acordo com NBR 9050, considera-se Faixa de acesso:

\begin{abstract}
“Área em frente a imóvel ou terreno, onde pode estar a vegetação, rampas, toldos, propaganda e mobiliário móvel como mesas de bar e floreiras, desde que não impeçam o acesso aos imóveis. É, portanto, uma faixa de apoio à sua propriedade." (ABNT NBR 9050, 2004)
\end{abstract}

Há quase vinte anos a acessibilidade passou a ser item de atenção do poder público, mediante Decreto n ${ }^{\circ} 5.296 / 04$, que regulamenta as Leis $n^{\circ} 10.048 / 00$ e $n^{\circ} 10.098 / 00$. Este instrumento legal critérios básicos para a promoção da acessibilidade das pessoas portadoras de deficiência ou com mobilidade reduzida e ainda, estabelece normas para realização de adequações em obras públicas, visando que os espaços de circulação de pessoas atendam às necessidades especiais de todos os dos usuários.

O instrumento legal estabelece na Forma da Lei, adequações locais públicos novos ou já existentes:
"Capítulo IV.
Da Acessibilidade nos Edifícios Públicos ou de Uso Coletivo.
Art. 11. A construção, ampliação ou reforma de edifícios públicos ou privados destinados ao uso coletivo deverão ser executadas de modo que sejam ou se tornem acessíveis às pessoas portadoras de deficiência ou com mobilidade reduzida." (BRASIL, 2000).

E Ainda, em 2 de dezembro de 2004, o Decreto Federal $n^{\circ} 5.296$, institui regulamentos e obrigações para as diversas esferas de governo, garantindo a acessibilidade aos portadores de deficiência física em edificações de uso público e no deslocamento em vias de circulação públicas. Segundo Vila Nova (2014), o decreto diz entre seus artigos:

\footnotetext{
“a) o planejamento e a urbanização das vias públicas, dos parques e dos demais espaços de uso público deverão ser concebidos e executados de forma a torná-los acessíveis para as pessoas portadoras de deficiência ou com mobilidade reduzida;

b) as vias públicas, os parques e os demais espaços de uso públicos existentes, assim como as respectivas instalações de serviços e mobiliários urbanos deverão ser adaptados, obedecendo-se ordem de prioridade que vise à maior eficiência das modificações, no sentido de promover mais ampla acessibilidade às pessoas portadoras de deficiência ou com mobilidade reduzida;
} 
c) o projeto e o traçado dos elementos de urbanização públicos e privados de uso comunitário, nestes compreendidos os itinerários e as passagens de pedestres, os percursos de entrada e de saída de veículos, as escadas e rampas, deverão observar os parâmetros estabelecidos pelas normas técnicas de acessibilidade da Associação Brasileira de Normas Técnicas (ABNT);" (VILA NOVA, 2014).

Segundo o Decreto Federal no 5.296 (BRASIL, 2004), o proprietário do estabelecimento ou lote é responsável pela área de passeio em frente ao seu estabelecimento, devendo manter em perfeito estado de conservação, segurança e acessibilidade.

A elaboração do mapa de acessibilidade do centro de São Miguel dos Campos (Figura 01) nos permitiu chegar a estes dados:

A região estudada apresenta 19 pontos permanentes de falta de acessibilidade ou descontinuidade do deslocamento;

Existem atualmente três pontos temporários de falta de acesso ou descontinuidade do deslocamento.

Foi elaborado o Plano de Adequação das Estruturas Físicas de Calçadas do Centro de São Miguel dos Campos $\mathrm{AL}$ que indica as formas de reestruturação para adequação das estruturas das calçadas.

Figura 01: Mapeamento da mobilidade no centro de São Miguel

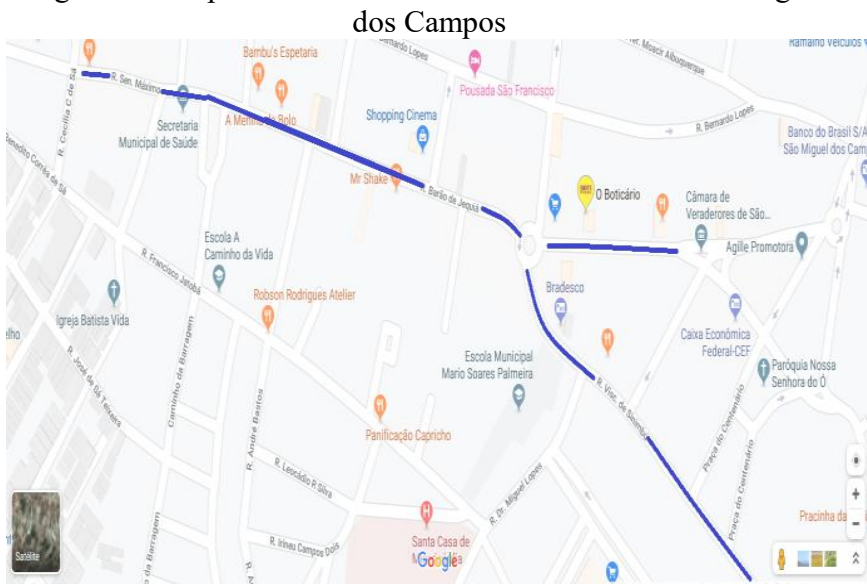

Fonte: autoras, 2019.

As figuras 02 até 06 , apresentadas a seguir, registram alguns dos pontos de bloqueio permanentes e bloqueios temporários encontrados durante a realização da pesquisa, no Centro de São Miguel dos Campos - AL, Brasil.

Figura 02 - Ponto de bloqueio permanente. Barraca impedindo o deslocamento das pessoas na Rua Senador Máximo, calçada da Escola Estadual Ana Lins.

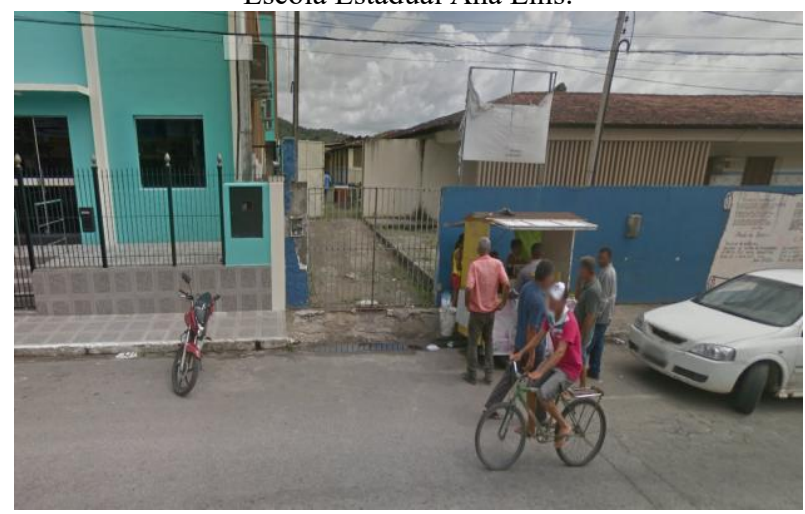

Fonte: Autoras, 2019.
Figura 03 - Ponto de bloqueio permanente. Rampa com inclinação inadequada para cadeirantes na Rua Senador Máximo, na calçada

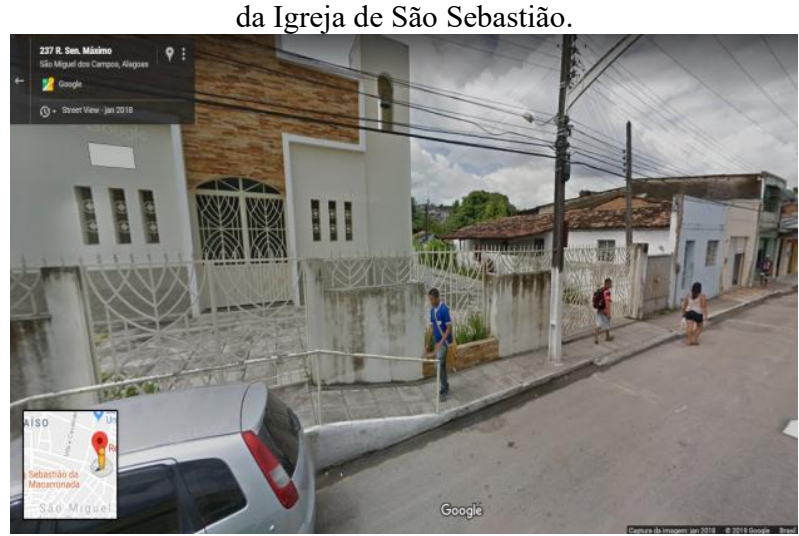

Fonte: Google, 2019.

Figura 04 - Ponto de bloqueio temporário. Obra de reforma de facada de loja Rua Barão de Jequiá, sentido Centro - Escola Ana Lins, lado direito.

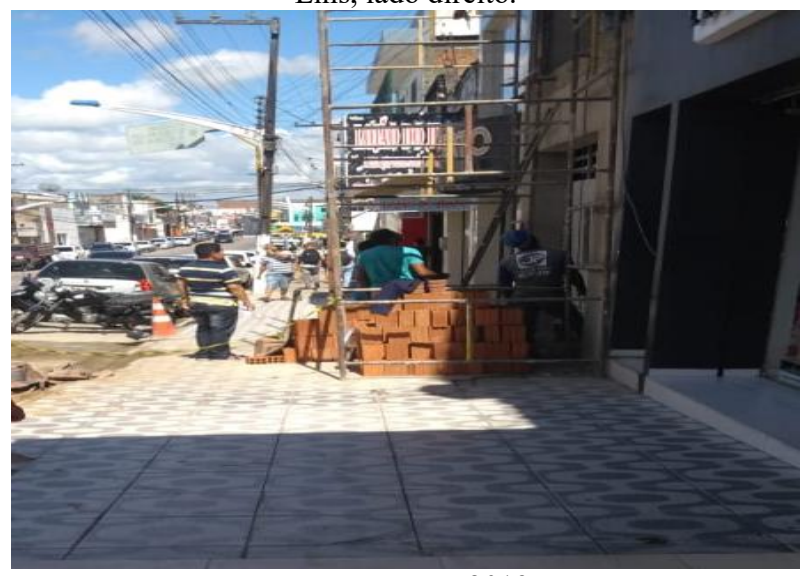

Fonte: autoras, 2019.

Figura 05 - Ponto de bloqueio permanente. Barraca impedindo o deslocamento das pessoas na Rua Senador Máximo, calçada da Escola Estadual Ana Lins.

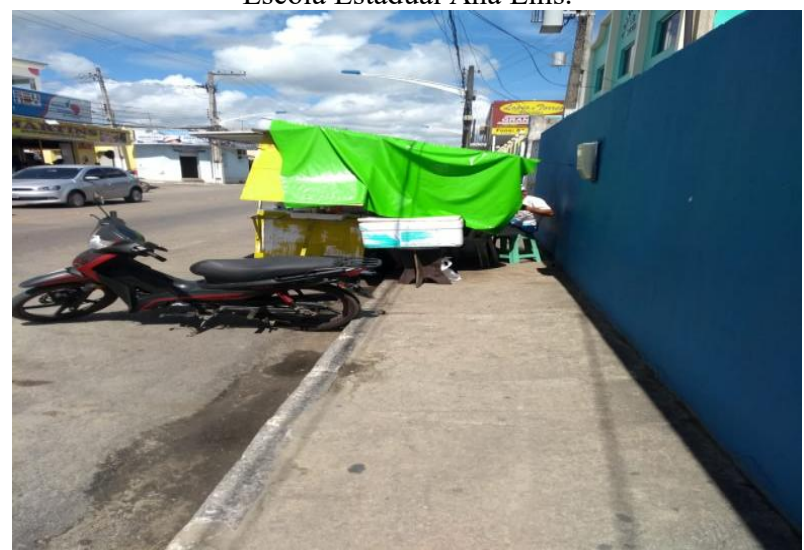

Fonte: Autoras, 2019. 
Figura 06 - Ponto de bloqueio permanente. Barraca impedindo o deslocamento das pessoas.

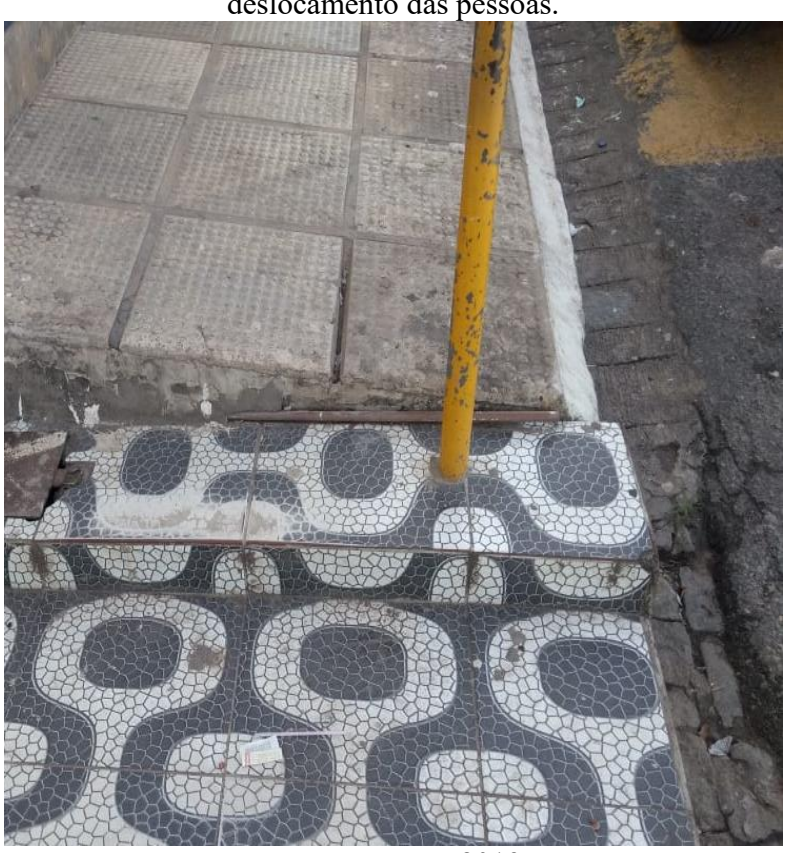

Fonte: Autoras, 2019.

\section{CONCLUSÃO}

Promover a acessibilidade significa possibilitar a completa mobilidade dos usuários, independente das suas limitações físicas. Neste aspecto, todos devem ser contemplados.

O centro da cidade de São Miguel dos Campos possui pontos permanentes de bloqueio da mobilidade e de falta de acesso para as pessoas que transitam na região delimitada no estudo.

O local pesquisado, apesar de apresentar uma área de circulação de pedestres, em comprimento, maior do que a área permanentemente bloqueada, não se enquadra nos preceitos de acessibilidade preconizados pelas Normas Brasileiras Regulamentadoras nem se enquadra no que determina as Leis $\mathrm{n}^{\circ} 10.048 / 00$ e $\mathrm{n}^{\circ} 10.098 / 00$.

No tocante à largura das calçadas, formas de acesso e segurança do pedestre, o local pesquisado não se enquadra à ABNT NBR 9050.

Recomenda-se a adequação das estruturas das calçadas da área estudada, de acordo com as dimensões determinadas pela ABNT NBR 9050. Calçadas, passeios e vias exclusivas de pedestres devem incorporar faixa livre com largura mínima de $1,20 \mathrm{~m}$, possuir superfície regular, firme, contínua e antiderrapante sob qualquer condição. Ser contínua, sem qualquer emenda, reparo ou fissura. Portanto, em qualquer intervenção o piso deve ser reparado em toda a sua largura. Recomenda-se as dimensões da faixa de serviço maiores do que $75 \mathrm{~cm}$.

O Plano de Adequação das Estruturas Físicas de Calçadas do Centro de São Miguel dos Campos - AL aponta as soluções para adequação dos pontos de bloqueio permanentes e orientações para adequação dos pontos de bloqueios temporários.

\section{REFERÊNCIAS BIBLIOGRÁFICAS}

ASSOCIAÇÃO BRASILEIRA DE NORMAS TÉCNICAS. NBR 9050: Acessibilidade a edificações, mobiliário, espaços e equipamentos urbanos. $2^{\mathrm{a}}$ edição. Rio de Janeiro, 2004.

BAPTISTA, A. H. N. Procedimentos metodológicos para a avaliação da acessibilidade de estruturas de circulação de pedestre com vistas ao projeto de "antropovias". 2003, 142p. Dissertação (mestrado em Engenharia de Produção) Universidade Federal de Pernambuco. Recife, 2003.

BRASIL. Lei LEI No 9.503, DE 23 DE SETEMBRO DE 1997. Institui o Código Nacional de Trânsito. Presidência da República, Casa Civil, Brasília, DF, 1997.

BRASIL. LEI N $\mathrm{N}^{\mathrm{O}}$ 10.098, DE 19 DE DEZEMBRO DE 2000. Estabelece normas gerais e critérios básicos para a promoção da acessibilidade das pessoas portadoras de deficiência ou com mobilidade reduzida, e dá outras providências. Presidência da República Casa Civil, Brasília, DF, 2000.

IBGE - Instituto Brasileiro de Geografia e Estatística. Censo Demográfico 2010: Resultados da Amostra - Trabalho. São Miguel dos Campos: 2010. Disponível em: $<$ http://www.cidades.ibge.gov.br/xtras/temas.php?lang=\&co dmun $=270860 \&$ idtema $=107 \&$ sea44rch=alagoas|sao-migueldos-campos|censo-demografico-2010:-resultados-da-mostratrabalho-->. Arquivo consultado em: 23 de setembro de 2019.

VILA NOVA, Flávio. Cartilha de acessibilidade urbana:Um caminho para todos. Tribunal de Contas do Estado de Pernambuco. 2 ${ }^{\mathrm{a}}$ Edição, Recife, 2014.

\section{AGRADECIMENTOS}

Agradecemos ao Campus São Miguel dos Campos do Instituto Federal de Alagoas (Ifal Campus São Miguel dos Campos) pelo fomento da pesquisa que culminou com este trabalho.

\section{COPYRIGHT}

Direitos autorais: As autoras são as únicas responsáveis pelo material incluído no artigo. 


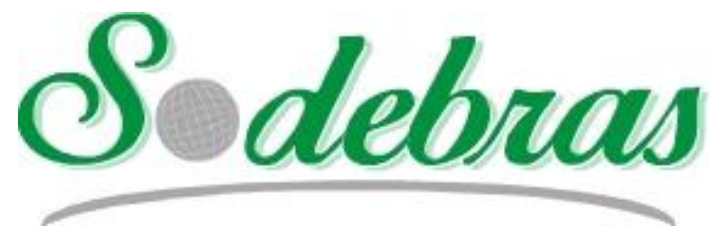

Volume 15 - $\mathrm{N}^{\mathrm{o}} 169$ - Janeiro / 2020

XLI International Sodebras Congress

31de outubro a 02 de setembro de 2019 - Maceió - AL.

\title{
ESTUDO SOBRE TECNOLOGIAS EM VEÍCULOS ELÉTRICOS: UM REVIEW
}

\section{STUDY ON TECHNOLOGIES IN ELECTRIC VEHICLES: A REVIEW}

\author{
FELIPE VENTURINI CAVALI ${ }^{1}$; TEÓFILO MIGUEL DE SOUZA ${ }^{1}$. \\ 1 - UNESP GUARATINGUETÁ - INSTITUTO DE MOBILIDADE ELÉTRICA \\ cavali.felipe.fvc@gmail.com;teofilo.souza@unesp.br
}

\begin{abstract}
Resumo - Desde 1992, na conferencia chamada de Rio-92, no Rio de Janeiro, tem-se apresentado os efeitos negativos da emissão de gases poluentes na atmosfera. Sabendo que os veículos movidos a motores a combustão interna são os principais poluentes, as medidas foram tomadas para minimizar a poluição e os veículos elétricos passaram a ser a solução. Este trabalho visa analisar os principais sistemas de um veículo elétrico, suas configurações e desafios de desempenho.
\end{abstract}

Palavras-chave: Veículos elétricos . Veículos Híbridos. Sustentabilidade.

\begin{abstract}
Since 1992, at a conference called Rio-92, in Rio de Janeiro, has been discussed the negative effects of polluting gases in the atmosphere. Knowing that the internal combustion engine (ICE) based vehicle are the main pollutants measures has been taken to minimize the effects. At this point, the electrical vehicles $(E V)$ were commercially attractive again.This work aims analyze the main systems on electrical vehicles, their configurations and challenges for better performance.
\end{abstract}

Keywords: Electrical Vehicles . Hybrid Vehicles . Sustainability.

\section{INTRODUÇÃO}

Os veículos elétricos e os veículos híbridos não são conceitos novos da mobilidade elétrica. O primeiro veículo elétrico, um triciclo, foi utilizado em 1834, construído por Thomas Devenport (CHAU e WONG, 2002). Em 1903, $20 \%$ da frota de automóveis de Nova York era composta por veículos elétricos (BARAN e LEGEY, 2010).

Porém, esses veículos perderam representatividade comercial ainda no início do século XX. São citados como motivos principais para diminuir o uso: a descoberta de grandes reservas de petróleo no Texas e a invenção do motor a combustão interna, em 1885, por Benz, tornando economicamente viável a utilização deste combustível para a mobilidade; o sistema de produção em série de automóveis, desenvolvido por Henry Ford, diminuindo o preço dos veículos com motores a combustão; a baixa eficiência das baterias e das estruturas de distribuição de energia elétrica (BARAN e LEGEY, 2010).

Em meados da década de 1970, a população começou a se conscientizar com os efeitos negativos do desenvolvimento desenfreado da referida tecnologia, entre elas a emissão de gases poluentes na atmosfera.

Em 1992, numa conferência denominada Rio-92, no Rio de Janeiro, começaram as discussões sobre emissão de gases poluentes. Assim, foram estabelecidas metas para melhorar a condição de vida no planeta, entre elas, redução de riscos para a saúde decorrentes da poluição e a promoção do desenvolvimento sustentável (MINISTERIO DO MEIO AMBIENTE).

Com o objetivo de alcançar tais metas, os conceitos de sobre veículos foram amplamente discutidos. No artigo de Chan e Chau (1997), observou-se que a substituição de veículo com motor a combustão interna por um veículo a motor elétrico pode diminuir a emissão de gases poluentes, como os gases orgânicos sem metano (NMOG) em $98 \%$, óxidos de nitrogênio $\left(\mathrm{NO}_{\mathrm{x}}\right)$ em $92 \%$ e monóxido de carbono (CO) em até $99 \%$.

A União Europeia já vem adotando medidas políticas para garantir o desenvolvimento sustentável no continente. Para isso, o White Paper da comissão europeia propõe que até $2030,80 \%$ da frota de veículos urbanos sejam movidos a eletricidade e até 2050 toda a frota já seja formada por veículos elétricos (EUR COMISSION, 2011).

Sendo assim, o uso de veículos elétricos e híbridos apresentam uma promissora vantagem para o mundo.

Assim, este artigo visa analisar os principais sistemas de um veículo elétrico, suas configurações e desafios de desempenho.

\section{FUNDAMENTOS}

Para uma melhor compreensão do artigo, toma-se como definição de veículo elétrico todo veículo movido a propulsão elétrica, incluindo veículos elétricos a bateria (BEVs) e veículos híbridos (HEVs) utilizando motores a combustão interna e motores elétricos ou motores elétricos e células combustível (CHAN, 2002).

\section{A. CONFIGURAÇÕES DOS BEVs e HEVs:}

Os BEVs e HEVs possuem diferenças em suas configurações. Há essas diferenças pois BEVs possuem apenas conexões via cabos entre seus módulos, as ligações mecânicas acontecem apenas nas rodas, além de que, diferentes baterias e motores requerem diferentes disposições. O maior critério para utilização dessas configurações, segundo CHAN (2002), estão na ampacidade, desempenho, peso e custo.

$\mathrm{Na}$ Figura 1 é apresentada algumas das principais configurações dos BEVs. 
Figura 1 - Principais modelos de configurações dos BEVs
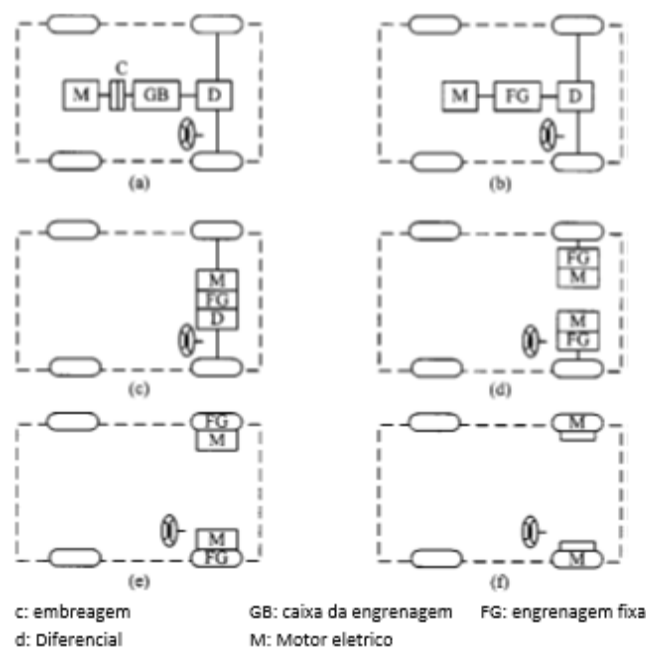

Fonte: Adaptado Chan e Chau (2002)

A Figura 1(a) mostra uma alternativa que adota uma formação longitudinal parecida com os ICEV. Consiste em diferencial, caixa de engrenagem, embreagem e motor. Com a embreagem e caixa de engrenagens o motorista consegue controlar a taxa de torque e velocidade que aciona as rodas. Essa montagem é mais utilizada em veículos MCI convertidos em EV.

Visando diminuir peso e tamanho da estrutura, foi substituída a embreagem e a caixa de engrenagens por engrenagens fixas, na Figura 1(b).

Na Figura 1(c) mostra um projeto similar a Figura 1(b) porém com seus módulos na transversal do carro. Este modo é o mais utilizado por veículos modernos.

Uma outra forma de obter a característica do diferencial é retirando o eixo mecânico e incluindo dois motores nas rodas fazendo com que esses operem em diferentes velocidades, assim como mostrado na Figura 1(d)

Visando diminuir as transmissões mecânicas foi proposta a configuração da Figura 1(e). Nessa disposição, as engrenagens fixas são empregadas para reduzir a velocidade do motor para a velocidade de roda desejada.

$\mathrm{Na}$ Figura 1(f) retirou-se totalmente qualquer tipo de ligação mecânica. Para isso é utilizado um motor diretamente ligado a roda. O controle do motor é o que controla a velocidade da roda e assim a velocidade do veículo.

Os veículos híbridos são definidos como todo veículo que possui o sistema de propulsão utilizando duas ou mais fontes de energia, conversores e fontes de energia.

Os maiores desafios na configuração dos HEVs são dadas pelo gerenciamento das múltipla fontes de energia, já que, diferentes fontes necessitam diferentes configurações.

Sendo assim, nos HEVs são necessárias a utilização tanto de conexões mecânicas como elétricas.

As principais configurações dos HEVs são apresentadas na Figura 2.

A Figura 2(a) apresenta o sistema híbrido em série. Este é o modelo mais simples dos HEV. A saída do motor mecânico é ligado a um gerador que transforma a energia mecânica em elétrica. Essa energia é passada para uma bateria, da bateria é passada para o motor elétrico que aciona a roda. Nesta montagem tem uma baixa eficiência dos HEV e como possui três dispositivos para propulsão (motor, motor elétrico e gerador) apresentam um alto custo de produção.

Figura 2 - Principais modelos de configuração dos HEVs
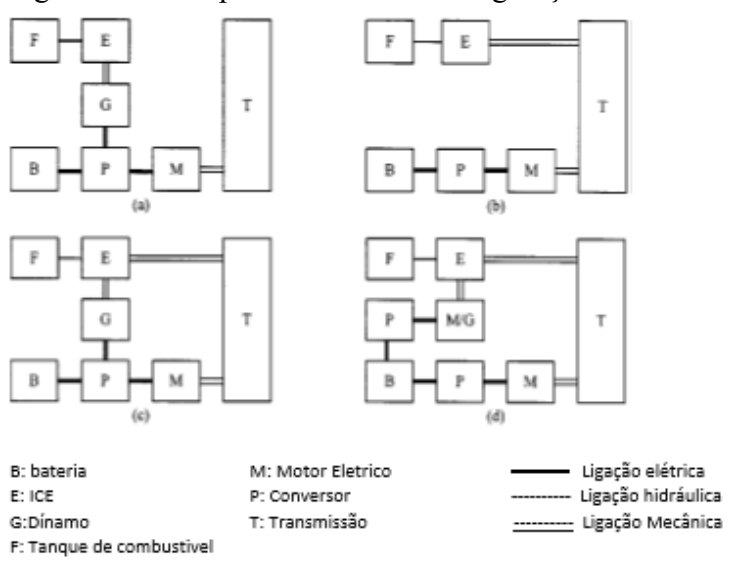

Fonte: Adaptado Chan e Chau (2002)

A Figura 2(b) apresenta o sistema híbrido paralelo. Neste sistema, o ICE e o motor elétrico distribuem energia para as rodas. Os dois são conectados a transmissão. $\mathrm{O}$ motor a combustão interna deve ser assistido eletricamente para diminuir a emissão de poluentes e o consumo de combustível. Este modelo possui uma melhor eficiência que o anterior e necessita de um ICE e motor elétrico menores.

A Figura 2(c) apresenta o sistema híbrido sérieparalelo. Este modelo é a fusão dos modelos anteriores, apenas envolvendo uma ligação mecânica adicional. Com essa configuração o ICE consegue tanto gerar energia para recarregar a bateria como gerar energia para movimentar o veículo. Essa configuração apresenta uma melhor eficiência porém a produção é mais complexa e cara. Segundo Chau (2002), esses são os modelos mais utilizados nos HEVs.

A Figura 2(d) é o sistema híbrido complexo. Esta configuração é semelhante com a série-paralelo mas a diferença principal é o sentido bidirecional da energia no motor elétrico. Com isso, pode estabelecer diferentes modos de operação, principalmente utilizando os três sistemas de propulsão constituído pelos dois motores elétricos e ICE. Esse sistema apresenta alta complexidade e custo.

\section{B. SISTEMA DE PROPULSÃO ELÉTRICA}

Este sistema é o coração dos EVs. O sistema de propulsão serve para transferir a energia elétrica das fontes (baterias, ultra capacitor ou células combustíveis) para as rodas, por meio do motor elétrico (EM) como mostrado na Figura 3.

Figura 3 - Sistema de propulsão de um veículo elétrico

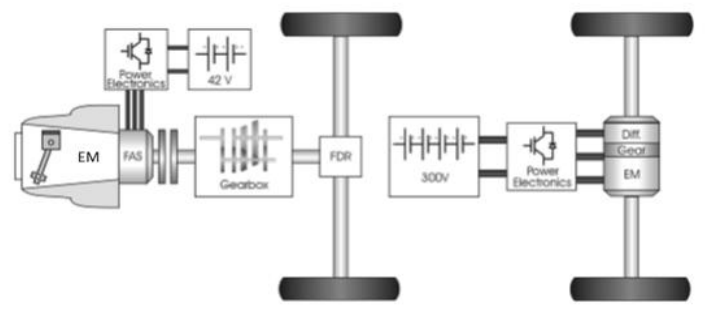

Fonte: Adaptado BĂLŢĂŢANU e FLOREA (2013)

Esta estrutura é formada por componentes elétricos como motor, conversor e controle, e por componentes mecânicas, transmissão e rodas. 
Segundo CHAN e CHAU (1997), o motor é a parte mais importante desse sistema pois é ele quem efetivamente transforma a energia elétrica em energia mecânica para o veículo.

Existem mais de 100 tipos de motores elétricos aplicados em EVs (DE SANTIAGO, 2012), porém os mais comercializados e com melhores desempenhos são quatro: (a) Motores de Corrente Continua (DC); (b) Motores de Indução (IM); (c) Motores de Ímãs Permanentes (PM); Motores de Relutância Alternada (SRM). A Figura 4 mostra esses modelos de motores.

Figura 4 - Os quatro principais tipos de motores elétricos. (a) DC; (b) IM; (c) PM; (d) SRM.

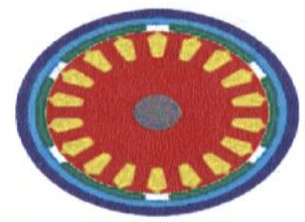

(a)

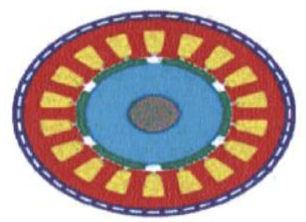

(c)

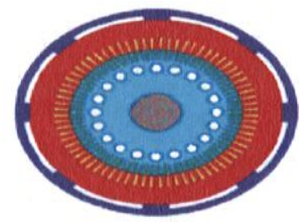

(b)

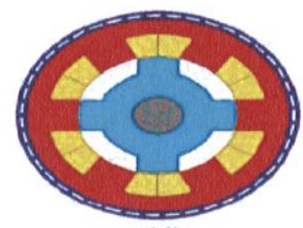

(d)
Fonte: Hashemnia e Asaei (2008)

A Figura 4(a) apresenta os motores DC. Eles tem seu funcionamento baseado no princípio da indução gerando corrente alternada que quando conectado a um comutador a saída se torna continua. Tal dispositivo também exerce a função de um inversor fazendo com que a tecnologia envolvida nesse motor se torne mais barata e simples. Esses motores apresentam controle e funcionamento simples e por ter uma tecnologia bem estabelecida e seu custo é baixo. Entretanto apresentam baixa eficiência, baixa densidade de energia e altas taxas de manutenção, umas vez que o comutador deve ser constantemente substituído por outro (DE SANTIAGO, 2012).

A Figura 4(b) mostra os IMs e seguem o mesmo princípio dos motores $\mathrm{DC}$, porém não necessitam de comutador. Uma outra diferença é que os IMs utilizam bobinas defasadas no espaço alimentadas por corrente alternada defasada no tempo. O modo de operação do motor de indução faz com que a frequência do campo girante seja maior que a frequência da rotação gerada. Esse efeito tem o nome de "escorrega-mento". Por isso este motor é chamado de motor assíncrono.

Os IMs apresentam tecnologia bem estabelecida, fácil montagem e necessitam de pouca manutenção, pois apresenta poucas peças móveis. Possuem, também, um bom desempenho, porém não tanto quanto os motores PM, já que, além do escorregamento, apresentam grandes perdas ôhmicas nos fios.

A Figura 4(c) mostra os motores PM, Eles são basicamente, motores de indução no qual as bobinas do rotor foram substituídas por imãs, como pode ser visto no trabalho de Almeida (2010). Desse modo, não é necessário o consumo de energia elétrica para criar um campo sobre o qual o princípio da indução poderá agir.

Os ímãs são os principais elementos deste motor. $\mathrm{O}$ torque e potência gerada pelo motor são dependentes dos materiais utilizados nos ímãs. Para se obter um melhor desempenho é necessário que o ímã apresente uma alta indução residual $(\mathrm{Br})$ e altos valores de força coercitiva (Hc), pois o produto desses parâmetros determina a densidade máxima de energia do ímã.

Nesta configuração, as perdas ôhmicas são menores, a relação massa e o volume do motor diminuem e não existe escorregamento e possuem ótimo desempenho. Além disso, os motores PM possuem baixa necessidade de manutenção, alta densidade energética e alta flexibilidade de configuração.

Em contrapartida, os motores PM possuem uma perda chamada cogging torque que é definido como a tendência natural de alinhamento dos pólos. Trabalhos como de Almeida (2010) e Bianchi (2002) apresentam diferentes metodologias para a diminuição da ação desta perda.

Comparado com os outros motores, os PMs possuem uma tecnologia relativamente recente e portanto apresentam altos preços.

A Figura 4(d) apresenta o motor de relutância alternada. Ele possui saliências em seu rotor e estator e funciona de modo que sempre tenha saliências não alinhadas.

O torque é produzido a partir da tendência de alinhamento dos polos causada um campo elétrico produzido a partir de uma excitação. Assim, o rotor se move para uma posição onde a relutância é minimizada.

Esse motor não apresenta imãs ou enrolamentos em seu rotor. Desta forma, apresentam menores massas e volumes, bem como poucas perdas ôhmicas.

Devido a suas características, SRM são mais baratos que os motores PM, possuem controles mais simples e são robustos. Entretanto possuem baixa densidade energética, não são tão eficientes, sofrem interferência eletromagnéticas, apresentam alta vibração radial e produzem ruídos altos.

Segundo Li et al. (2019), os SRM quando utilizados em altas velocidades apresentam windage loss que representa a resistência do ar ao movimento do motor, diminuindo seu desempenho.

\section{SISTEMA DE FORNECIMENTO DE ENERGIA:}

Este sistema é uma necessidade básica do EV. É ele que libera a corrente elétrica para ser transformada em energia mecânica pelo motor. É constituído por fontes de energia, unidade de gestão de energia e unidade de carga.

O desenvolvimento das fontes de energia elétrica são um desafio crucial para a evolução dos EVs, principalmente pelo fato destas serem caras e por serem um limitante na autonomia desses veículos.

A energia elétrica é usualmente proveniente da energia química das baterias, das células combustíveis, das flywheels e dos ultracapacitores.

Os parâmetros utilizados para a comparação das fontes de energia são a densidade de energia, a densidade de potência, o ciclo de vida, o custo por $\mathrm{kW}$, o volume e a segurança (ANDWARI et al., 2017).

As baterias são conjuntos de células que transformam a energia química em energia elétrica e vice-versa. Para obter a tensão necessária para a aplicação conecta-se múlti-plas células em serie ou paralelo (DIVYA e ØSTERGAARD, 2008). O armazenamento de energia vem da diferença da energia livre entre os componentes químicos nos estados carregados e descarregados. 
A estrutura convencional de uma bateria é formada por eletrodo positivo, eletrodo negativo, eletrólito e separador, conforme a Figura 5.

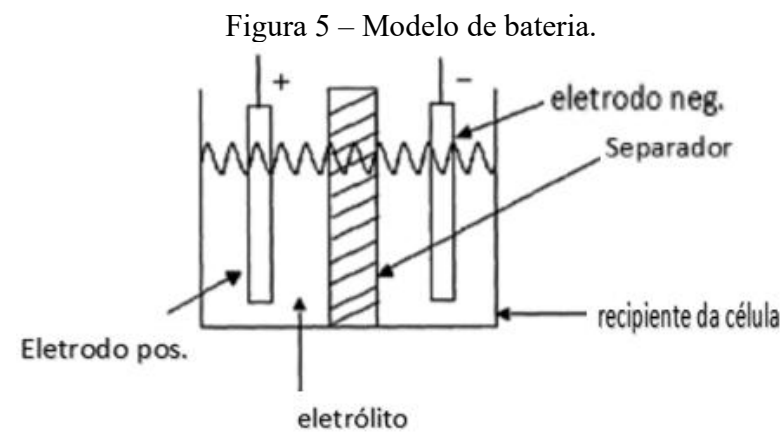

Fonte: Adaptado de Husain (2011)

Como podem ser visto em Husain (2011), existem inúmeras tecnologias para se fazer baterias. Porém, as aplicadas em mobilidade elétrica são a chumbo- ácido, a níquel - hidreto metálico, a lítio- íon, a de cloreto de sódio e níquel (ANDWARI, 2017).

As baterias de chumbo ácido apresenta tecnologia madura, ou seja, com poucas chances de aperfeiçoamento. Como são pouco eficientes são mais utilizadas em EVs pequenos para uso urbano. Para seu funcionamento, possuem chumbo esponjoso como cátodo e óxido de chumbo como ânodo, ambos mergulhados em ácido sulfúrico. Para a geração de energia elétrica os elétrons são consumidos no eletrodo positivo provindos do eletrodo negativo. A corrente elétrica sai do eletrodo positivo em direção ao motor. Essas baterias apresentam como vantagens baixo custo de produção, fácil acesso aos materiais de confecção, fácil fabricação e características eletromecânicas favoráveis (HUSAIN, 2011). Como características negativas aos seu uso, apresentam baixo tempo de vida útil, densidade de energia e de potências baixas, peso relativamente alto e não permitem taxas de descarregamento acima de $20 \%$ de sua capacidade de armazenamento (KHALIGH, 2010).

As baterias de níquel hidreto metálico (Ni-MH) são sucessores das baterias de níquel hidrogênio e já são utilizadas em HEVs. Para essa configuração, o eletrodo positivo é o hidróxido de níquel enquanto o negativo é o uma liga metálica de vanádio, titânio e níquel. O eletrólito é uma solução alcalina. A geração de energia para o motor se dá a partir de uma reação com o hidróxido de níquel com a água, gerando como subproduto hidroxila. A hidroxila reage com a liga metálica acoplando mais um átomo de hidrogênio à sua composição e liberando um elétron, dessa forma cria corrente elétrica. Essa bateria apresentam componentes inofensivos ao meio ambiente, opera de forma segura em altas tensões, possuem vida útil alta, tolerante a usos acima de seu ponto de operação ótimo e são recicláveis (KHALIGH, 2010). Elas possuem altos custos quando comparada a bateria de chumbo-ácido, taxas de auto descarga altas e baixa eficiência de célula (HUSAIN, 2011).

As baterias de lítio íon (Li-Íon) são consideradas as mais promissoras. O lítio apresenta o maior potencial eletroquímico e a menor massa equivalente. Nessa célula, o cátodo é constituído de cobaltado de lítio $\left(\mathrm{LiCoO}_{2}\right)$, o ânodo é formado por lítio intercalado com carbono na forma de grafite $\left(\mathrm{Li}_{\mathrm{x}} \mathrm{C}\right)$. O eletrólito é constituído de sal de lítio e solventes orgânicos. Para a geração de corrente, os íons de lítio são liberados pelo eletrodo negativo e reagem com o eletrodo positivo. Essas baterias apresentam alta potência específica, alta energia específica, bom desempenho em altas temperaturas, baixa taxas de auto descarga. Elas possuem baixo efeito de memora, baixa massa e são recicláveis. (ZUBI et al., 2011). Elas necessitam de um circuito de proteção para manter estabilidade tornando-as mais caras.

As baterias de cloreto de sódio e níquel $(\mathrm{NaNiCl}$ ou ZEBRA - zero emission batteries research activity) são uma alternativa para as baterias de lítio. Para seu funcionamento apresentam cátodos de cloreto de níquel $\left(\mathrm{NiCl}_{2}\right)$, ânodos de sódio fundido, eletrólito de cloro-alumínio de sódio $\left(\mathrm{NaAlCl}_{4}\right)$ e uma camada de beta-alumina para melhorar o contato iônico entre eletrodo positivo e eletrólito. Para gerar energia o cloreto de níquel reage com o sódio dissolvido no eletrólito, gerando como produto níquel e cloreto de sódio $(\mathrm{NaCl})$ e energia em forma de corrente elétrica. Esta reação ocorre em altas temperaturas. Como características, possuem alta densidade de energia, baixo custo de produção, vida útil longa, baixo efeito memoria e são robustas e seguras porém apresentam altas taxas de auto descarga (TIE e TAN, 2013).

A células combustível (FC) é um sistema de armazenamento que converte energia química do combustível em elétrica. A diferença principal entre ela e a bateria é o modo de fornecimento de energia. $\mathrm{Na} \mathrm{FC,} \mathrm{o} \mathrm{combustível} \mathrm{e}$ a matéria oxidante são demandadas externamente en-quanto nas baterias essas partes são integradas. As FCs podem oferecer rendimentos de 40 a 85\% (HANNAN et al., 2017). Os FCs possuem cátodos e ânodos como a bateria. Porém, seu ânodo são os combustíveis e são substâncias líquidas ou gasosos. As partes dos cátodos são apenas gasosas e usualmente são ar ou $\mathrm{O}_{2}$.

As células de hidrogênio são as mais populares e disponíveis no mercado. Nessa configuração o hidrogênio gasoso $\mathrm{H}_{2}$ reage com o oxigênio produzindo energia. Essa reação pode ser revertida utilizando água e eletricidade.

$\mathrm{O}$ funcionamento requer que $\mathrm{o}_{2}$ seja injetado na célula, ao relar numa superfície catalizadora se transforma em hidrogênio e elétron. Os íons de hidrogênio passam pelo eletrólito e reagem com o oxigênio do outro eletrodo formando água. Simultaneamente elétrons se movem no circuito externo passando pelo motor.

A Figura 6 apresenta um esquema de funcionamento da célula combustível em descarga, gerando energia.

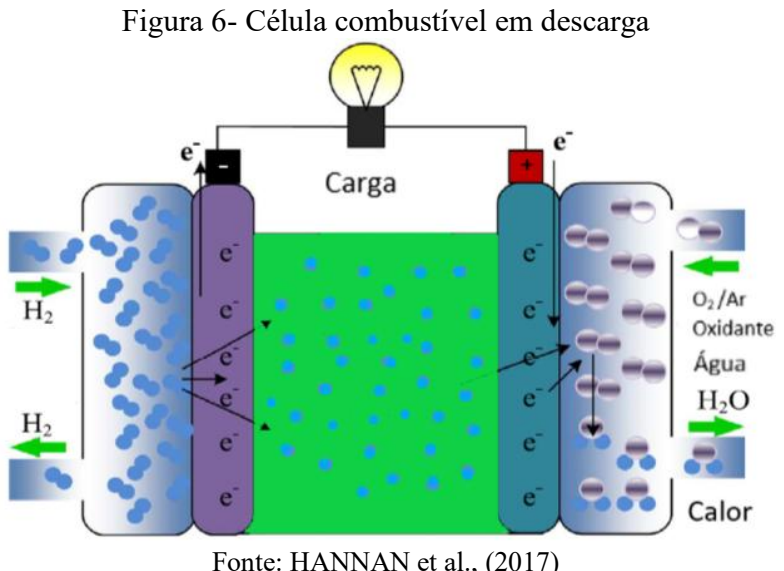

Fonte: HANNAN et al., (2017) 
Existem cinco modos de produção de células combustíveis que utilizam hidrogênio: as células combustíveis de ácido fosfórico (PAFC), as células combustíveis com eletrólito alcalino (AFC), as células combustíveis de oxido solido (SOFC), as células combustíveis de carbonato derretido (MCFC) e as células combustíveis de polímero solido (SPFC) (CHAU e CHAN, 1999).

A Tabela 1 apresenta a comparação de eficiência, temperatura de operação, vida útil e densidade de potência de cada uma das formas de FC.

Tabela 1 - Comparação das diferentes formas de confecção de células combustíveis de hidrogênio

\begin{tabular}{|c|c|c|c|c|c|}
\hline & PAFC & AFC & MCFC & SOFC & SPFC \\
\hline Eficiência do combustivel (\%) & $40-45$ & $40-50$ & $45-50$ & $45-50$ & $30-40$ \\
\hline Densidade de Potência kW/m² & $2,0-2,5$ & $2,0-3,0$ & $1,0-2,0$ & $2,4-3,0$ & $3,5-6,0$ \\
\hline Temperatura de Trabalho (으) & $18-210$ & $60-80$ & $600-700$ & $900-1000$ & $50-100$ \\
\hline Vida Útil (kh) & $>40$ & $>10$ & $>40$ & $>40$ & $>40$ \\
\hline
\end{tabular}

Fonte: Adaptado de Chau e Chan, 1999.

As FCs fazem a conversão de energia de forma direta, sem combustão. Não possuem partes móveis, portanto é silencioso, produzem zero ou quase zero emissões de poluentes, são confiáveis e duráveis (KHALIGH e LI, 2010) (EMADI, LEE e RAJASHEKARA, 2008).

Os flywheels são considerados baterias eletromecânicas, pois convertem energia elétrica, proveniente de uma máquina elétrica, em energia mecânica em uma massa rotora. São descarregados em subidas e em momentos de aceleração para aumentar a dirigibilidade do veículo e descarregados em descidas ou desaceleração (FU, 2010). Essa forma de energia dificilmente serão utilizadas em veículos elétricos porque necessitam equipamentos extras de proteção contra falhas e transmissão de energia para a tração do veículo (EHSANI, 2005) (HUSAIN, 2011). As flywheels possui características positivas como alta energia especifica, alta potência especifica, vida útil longa, alta eficiência energética, taxas de recarga rápida e não são poluentes.

Os ultracapacitores (UC) tem estruturas similares aos capacitores normais, porém com a capacidade de armazenamento de energia até vinte vezes maior (TIE e TAN, 2013). Para funcionarem são colocados dois bastões de carbono, que funcionam como eletrodos, separados entre eles por um dielétrico, imerso em solução de ácido sulfúrico. Como as cargas positivas e negativas são separadas fisicamente, quando se aplica um potencial, o eletrodo positivo atrai íons negativos do eletrólito e o eletrodo negativo atrai íons positivos. Os UCs apresentam alta densidade de potência e baixa densidade de energia. Não necessitam de manutenção, possuem longo ciclos de vida e são resistentes a variação de temperatura (KHALIGH e LI, 2010).

Segundo Ehsani (2005), é muito difícil utilizar o UC sozinho. Como os UCs e baterias possuem características complementares pode-se formar combinações para melhorar a eficiência do sistema.

Segundo o estudo de Choi (2012) as combinações podem ser feitas da seguintes formas: Apenas UC conectado em conversor $\mathrm{dc} / \mathrm{dc}$ : apresenta bateria conectada diretamente no terminal do inversor enquanto o ultracapacitor está conectado no conversor. Como a bateria está no inversor a tensão do terminal do inversor é mantida constante, quando uma potência adicional é necessária ou absorvida (recharging breaks) a bateria pode ser extremamente danificada. Apenas bateria conectada no conversor dc/dc: Nessa configuração a bateria é conectada no conversor e o UC no inversor. Dessa forma o UC age como uma buffer contra potências extras. Como resultado a bateria é protegida e o fluxo de energia é controlado efetivamente. Conexão cascateada em bateria e SC usando conversor: Neste caso o UC é conectado ao terminal do inversor por meio de um conversor e a bateria conectada ao terminal do $\mathrm{SC}$ através de um segundo conversor. O conversor entre o $\mathrm{UC}$ e o inversor garante um alcance maior de trabalho para o ultracapacitor. Porém, este mesmo conversor necessita de uma potência muito alta para a operação. Bateria e UC conectados em paralelo: apresenta a bateria e UC conectados cada um a um conversor e os dois conectados ao mesmo inversor. Esta topologia garante bom desempenho especialmente para o controle de fluxo de corrente. Além de ser tolerante a erros e pode operar com falhas em qualquer um dos dispositivos. Em contrapartida, tal metodologia de construção é cara quando comparada com as outras.

\section{SISTEMAS DE RECARGA:}

Os sistemas de recarga refere-se aos diferentes processos de reposição de energia nos veículos elétricos. Os EVs tem um carregador interno que transforma a energia elétrica recebida em uma energia adequada ao sistema de armazenamento do veículo.

Com esse objetivo são explicitados quatro estratégias de carregamento: "Dumb Charging"; Multitarefa; "Smart Charging" e "Smart Charging V2G" (LIMA, 2012).

O "Dumb Charging” consiste no carregamento de uma bateria de forma convencional, não controlada, ligada a rede com taxa continua e constante de carga até que atinja seu máximo ou haja interrupção do utilizador.

A estratégia multitarefa estimula o utilizador a fazer a recarga de seus veículos em momentos de baixa da tarifa energética. Dessa forma, o sistema de distribuição de energia elétrica seria menos afetada por picos energéticos.

O "Smart Grid” é um carregamento controlado por um dispositivo externo à rede. Ao controlar a taxa de energia para a bateria permite que a rede seja menos danificada e ainda diminui custos tanto para a companhia de distribuição como para o utilizador.

O "Smart Gridi V2G" junta o conceito de Smart Grid com a possibilidade do veículo enviar energia para a rede elétrica. Dessa forma, tanto o proprietário do veículo quanto a concessionaria de energia seriam beneficiadas. Porém, tal estratégia exigiria muito fluxo da energia da bateria, provocando desgaste. Assim, seria necessário uma otimização no ciclo de vida das baterias para se utilizar o processo.

Um sistema auxiliar de recuperação de energia é a frenagem regenerativa (RB). O RB consegue recuperar significativas quantidades de energia para os HEVs e EVs. Tal sistema transforma a energia cinética ou potencial de massa do carro em energia elétrica (EHSANI, 2010). A complexidade do mecanismo está na dificuldade de distribuir a força igualmente nas rodas e a recuperação de energia pela fricção das rodas.

Segundo Tie (2013) existem 4 modos de se armazenar a energia recuperada a partir da frenagem regenerativas em EVs e HEVs. Na primeira, a energia elétrica gerada é armazenada diretamente no sistema de armazenamento. $\mathrm{Na}$ segunda os motores hidráulicos conseguem armazenar 
pequenas quantidades de energia através de ar comprimido. $\mathrm{Na}$ terceira pode-se armazenar energia em flywheel como energia rotativa. Na última armazena-se energia como energia potencial através de materiais elásticos. Para todos esses sistemas é necessário um processo de controle de energia com o propósito de garantir a melhor eficiência dos EVs e HEVs (KUMAR, 2017). O controle de energia é realizado por processos que utilizam logica difusa ou redes neurais com dados obtidos a partir de sensores ligados a todos os sistemas dos EVs.

\section{COMPARAÇÕES}

Para uma compreensão mais detalhada dos fundamentos, as tabelas e gráficos serão mostrados para a comparação dos diferentes tipos de EVs, dos sistemas de propulsão e dos sistemas de fontes de fornecimento de energia. Na Tabela 2 são apresentados os diferentes tipos de veículos elétricos que são produzidos e suas características.

Tabela 2 - Características dos diferentes tipos de EVs

\begin{tabular}{|c|c|c|c|}
\hline Tipos de EVs & BEVS & HEVs & FCEVs \\
\hline Propulsão & - Motores elétricos & $\begin{array}{l}\text { - Motores elétricos } \\
\text { - Motores a combustão interna }\end{array}$ & - Motores Elétricos \\
\hline Sistema de Energia & $\begin{array}{l}\text { - Bateria } \\
\text { - Ultracapacitor }\end{array}$ & $\begin{array}{l}\text { - Bateria } \\
\text { - Ultracapacitor } \\
\text { - Unidade de geração de ICE }\end{array}$ & - Célula combustivel \\
\hline $\begin{array}{l}\text { Energia e } \\
\text { Infraestrutura }\end{array}$ & • Conexão à rede & $\begin{array}{l}\text { - Postos de Gasolina } \\
\text { - Conexão a rede }\end{array}$ & $\begin{array}{l}\text { - Hidrogênio } \\
\text { - Metano e Gasolina } \\
\text { - Etanol }\end{array}$ \\
\hline Características & $\begin{array}{l}\text { - Emissão Zero } \\
\text { - Independência do petróleo } \\
\text { - } 100 \text {-200 km de alcance } \\
\text { - Alto custo inicial }\end{array}$ & $\begin{array}{l}\text { - Emissão baixa } \\
\text { - Alcance de direção alto } \\
\text { - Dependência do Petróleo } \\
\text { - Complexo }\end{array}$ & $\begin{array}{l}\text { - Zero emissão ou baixa } \\
\text { - Alta eficiência } \\
\text { - Independência de Petróleo } \\
\text { - Alcance de direção bom } \\
\text { - Alto custo inicial }\end{array}$ \\
\hline Maiores desafios & $\begin{array}{l}\text { - Baterias e gerenciamento } \\
\text { - Propulsores de desempenho } \\
\text { - Estações de carga }\end{array}$ & $\begin{array}{l}\text { - Gerenciamento de múltiplas energias } \\
\text { - Dependente do ciclo de direção } \\
\text { - Tamanho da bateria }\end{array}$ & $\begin{array}{l}\text { - Custo da célula } \\
\text { - Processador de combustivel } \\
\text { - Sistema de combustivel }\end{array}$ \\
\hline & Fonte: ad & aptado Chan 2002 & \\
\hline
\end{tabular}

De acordo com a Tabela 2 os maiores desafios dos EVs são os sistemas fornecimento de energia e sistemas de propulsão.

$\mathrm{Na}$ questão dos motores características como eficiência, volume, intimidade tecnológica, confiança, custo e facilidade do controle determinam a utilização do tipo do motor. A tabela 3 mostra uma comparação entre as eficiências dos motores.

Tabela 3- Valores do rendimento dos motores e as eletrônicas envolvidas

\begin{tabular}{|l|c|c|c|}
\hline \multicolumn{4}{|c|}{ Eficiência \% } \\
\hline & Motor & Eletrônica & Ambos \\
\hline PM & 97 & 93 & 90 \\
\hline SRM & 94 & 90 & 85 \\
\hline IM & 90 & 93 & 84 \\
\hline DC & 80 & 98 & 78 \\
\hline
\end{tabular}

Fonte: Adaptado de Hashemnia e Asaei (2008)

A Tabela 3 mostra a relação geral dos motores. Foram atribuídas notas de 3 a 5 para as características mais importantes de forma relativa para a escolha dos motores. Assim, os motores que obterem o melhor desempenho nos itens citados receberão 5 e os piores 3 .

Em relação a massa e volume serão dadas notas máximas para os que possuírem menores dimensões, já que massa e volume são características limitantes dos motores.
Tabela 4- Relação geral dos motores elétricos

\begin{tabular}{|c|r|r|r|r|}
\hline Tipos de motores & \multirow{2}{*}{ DC } & \multirow{2}{*}{ IM } & PM & \multirow{2}{*}{ SRM } \\
\cline { 1 - 3 } Caracteristicas & 3 & 3,5 & 5 & 3,5 \\
\cline { 1 - 3 } Eficiência & 3 & 4 & 5 & 4 \\
Densidade De Energia & 5 & 5 & 3,5 & 4 \\
Controle & 3 & 5 & 5 & 4 \\
Confiabilidade & 5 & 5 & 4 & 4 \\
Maturidade Tecnologica & 3 & 4 & 4,5 & 5 \\
\hline Massa & 4 & 5 & 3 & 4 \\
\hline Custo & 26 & 31,5 & 30 & 28,5 \\
\hline \hline Total & & & & \\
\hline
\end{tabular}

Fonte: Adaptado de Hashemia e Aseai (2008)

Através da Tabela 4, nota-se que o motor de indução recebe as melhores notas, o que explica esse motor ser o mais utilizado tanto em veículos como em processos industriais.

Ao mesmo tempo, o motor PM e SRM recebem notas altas e muito próximas ao IM, mostrando que esses, uma vez que atingirem maturidade tecnológica podem ser substitutos ao motor de indução.

No caso dos motores de imãs permanentes, que já apresentam melhor eficiência que os IM, necessita apenas de uma redução de custo e melhorias técnicas de controle para substituir os motores de indução.

Os motores de relutância alternada também parecem ser bons substitutos aos IMs, porém, não conseguem atingir o mesmo desempenho dos motores PM.

$\mathrm{Na}$ questão dos sistema de fornecimento, características como pico de potência e energias especifica das diferentes fontes podem ser verificadas na Figura 7.

Figura 7 - Características das diferentes fontes de energias dos EVs

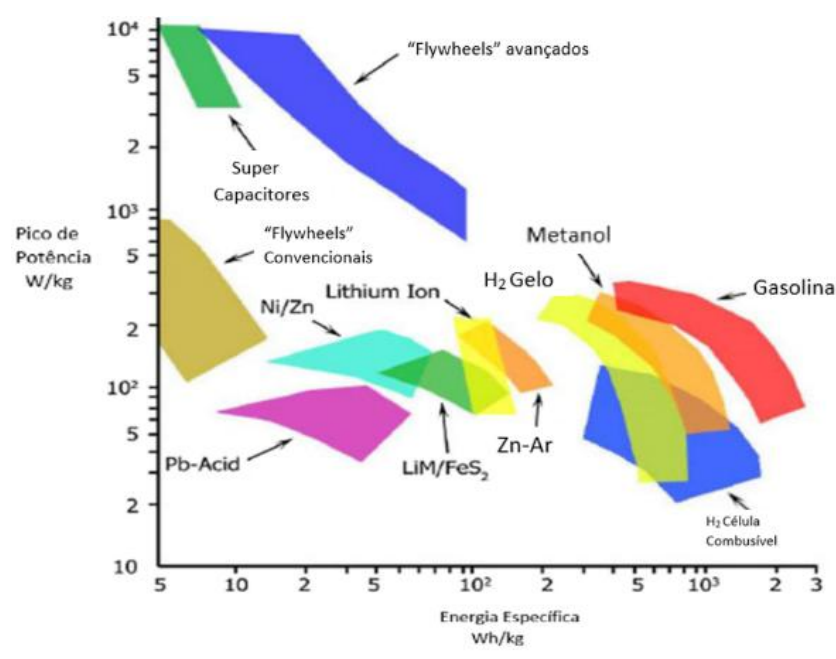

Fonte: Adaptado de Amirante (2017)

As características não são suficientes para se comparar todas as fontes. Amirante (2017) apresenta informações sobre eficiência, tempo de descarga e vida útil das fontes. Ele define eficiência como a relação entre a carga máxima apresentada e a carga necessária para atingir o estado máximo. Assim é possível notar que FCs apresentam rendimnto de $87 \%$; Os flywheels de $90 \%$ e as baterias de $97 \%$.

Sobre tempo de descarga, ultracapacitores e flywheels apresentam baixo tempo de descarga, menores que uma 
hora. As baterias apresentam até dez horas de descargas e células combustíveis mais de dez horas.

Em relação ao tempo de vida, as células combustíveis e os ultracapacitores conseguem atingir aos 40 anos, as baterias chegam aos 28 anos e flywheels aos 20 anos.

\section{PERSPECTIVAS}

Como os principais desafios dos EVs e HEVs são o aumento da autonomia e gestão de energia, os estudos mais importantes para o aumento do desempenhos destes veículos são sobre motor e fontes de armazenamento de energia.

Como mostrado na Tabela 4, os motores de imãs permanentes e de relutância alternada poderão substituir os motores de indução.

No caso dos motores PM, é necessária a diminuição de custos, diminuição de perdas por ripple torque e ainda aumento em seu desempenho.

No trabalho de Zhu et al. (2019) é mostrado como a diferentes disposições do imã no rotor do motor pode acarretar em um aumento de desempenho.

No artigo de Almeida (2010), consegue-se compreender como construir um motor PM com preço final menor e com uma menor ação de ripple torque ao substituir as bobinas do rotor de um IM por ímãs colocados em um certo ângulo.

Outras formas de se baratear o custo destes motores é desenvolvendo a tecnologia utilizada nos imãs. Como nos artigos de Alijani (2019) e Herzer (2013) que mostram a produção de diferentes tipos de ligas magnéticas em fase de estudo.

Além disso, deve ser estudada a viabilidade dos imãs nos motores PM. O estudo de Grunditz (2018), mostra três diferentes tipos de imãs e suas influências no desempenho, custo, perdas e impacto ambiental.

No caso do SRM, Li (2019) estuda como aumentar a densidade de energia neste motor utilizando materiais com saturação magnética maior e alterações no projeto do motor. Esse motor apresenta grande oscilação em seu torque e tem estudos com modelos de controle para melhorar o projeto com o material magnético e o aumento de eficiência(Ding, 2019).

As fontes de armazenamento de energia são grandes desafios para os EVs. Estes determinam a autonomia que que os terão os EVs. Existem baterias em fase experimental que apresentam um melhor desempenho. Entre elas estão as baterias de Litio-Enxofre (Li-S), Litio-Ar (Li-air) e ZincoAr (Zn-air).

As baterias Li-S apresentam alta densidade de energia e aparentemente baixo custo devido ao preço do enxofre ser menor (YONG et al., 2015).

As baterias Zn-Air também se apresentam como um possível alternativa no futuro já que apresentam densidade de energia maiores do que as baseadas em lítio. Elas possuem baixas densidades de potência e pequena vida útil. Estudos como os de Li et al. (2018) mostram processos construtivos para aumentar a densidade de potência dessa bateria.

As baterias de Li-Air ainda estão em estágio de protótipo, sua densidade de energia teórica é alta e capaz de igualar-se com os preços comparados ao da gasolina. No artigo de Girishkumar (2010) foram apresentados os diferentes processos de fabricação, as reações e os desafios para a montagem dessa bateria que estão relacionados a instabilidade elétrica (GIRISHKIMAR, 2010).

\section{V.CONCLUSÕES}

Há muitas possibilidades de construção dos EVs. As combinações de diferentes processos, motores, baterias e estruturas podem ser feitas para adequar-se as necessidades do usuário. Os melhoramento constantes são feitos para promover a melhoraria de cada sistema e obtendo um aumento de desempenho em todos os aspectos dos veículos.

Mesmo com toda tecnologia em ação sobre os EVs, a sua disponibilização no mercado é pequena, por conta da infraestrutura de geração de energia não estar preparada para receber uma grande demanda.

Para promover sua utilização, políticas públicas devem ser adotadas e pequenos passos tomados para que a tecnologia de mobilidade elétrica entre com sucesso em nossa sociedade, como evidenciado no white papper da comissão européia.

\section{REFERÊNCIAS BIBLIOGRÁFICAS}

ALIJANI, F.; REIHANIAN, M.; GHEISARI, K.: "Study on phase formation in magnetic FeCoNiMnV high entropy alloy produced by mechanical alloying" Journal of Alloys and Compounds. v.773, 2019

ALMEIDA J. L. C. N. "Analytical method for the design of the skewed permanent magnet machines of high performance". IEEE International Symposium on Industrial Electronics, p. 1210-1217, 2010.

AMIRANTE, R.; CASSONE, E.; DISTASO, E.; TAMBURRANO, P. "Overview on recente developments in energy storage: Mechanical, electromechanical and hydrogen technologies." Energy Conversion and Management. v.132, 2017

ANDWARI, M. A.; PESIRIDIS, A.; RAJOO, S.; BOTAS, R. M.; ESFAHANIAN, V. "A review of Battery Electric vehicle technology and readiness levels" Renewable and Sustainable Energy Reviews. v.78, 2017.

BARAN, R.; LEGEY, L. F. L. "Veículos elétricos: história e perspectiva no Brasil". XIII Congresso Brasileiro de Energia, 2010.

BĂLŢĂŢANU, A.; FLOREA, L. M. "Comparison of electric motors used for electric vehicles propulsion" International Conference Of Scientific Paper Afases, 2013.

BIANCHI, N.; BOLOGNANI, S. S. "Design techniques for reducing the cogging torque in surface-mounted PM motors". IEEE Transactions on Industrial Applications, v. 38, p. 1259-1265, 2002.

CHAN, C. C.; CHAU, K. T. "An Overview of Power Electronics in Electric Vehicles," IEEE Transactions on Industrial Electronics, v. 44, n. 1, 1997.

CHAN, C. C.; "The State of the Art of Electrical and Hybrid Vehicles", Proceedings of the IEEE. v. 90, n. 2, 2002.

CHAU, K. T.; WONG, Y. S.; CHAN, C. C. "An overview of energy sources for electrical vehicles" Energy Conversion and Management. v. 40, 1999.

CHAU, K. T; WONG, Y. S. "Overview of power management in hybrid eletric vehicles", Energy Conversion and Management. v. 43, 2002. 
CHOI, M. E; KIM, S. W; SEO, S. W. "Energy Management Optimization in a Battery/Supercapacitor Hybrid Energy Storage System" IEEE Transactions on Smart Grid. v.3, n. $1,2012$.

DE SANTIAGO et al.: "electrical motor drivelines in commercial all-electric vehicles: a review", IEEE Transactions on Vehicular Technology, v. 61, n. 2, 2012.

DING W.; LIU G.; LI P. "A Hybrid Control Strategy of Hybrid-Excitation Switched Reluctance Motor for Torque Ripple Reduction and Constant Power Extension", IEEE Transactions on Industry Applications, 2019.

DIVYA, C.; ØSTERGAARD, J. "Battery energy storage technology for power systems - An overview" Electric Power Systems Research. v.79, 2008.

EHSANI, M.; GAO, Y.; GAY, S. E.; EMADI, A; "Modern Electric, Hybrid Electric, and Fuel Cell Vehicles: Fundamentals, Theory, and Design" BOCA RATON: CRC PRESS. 2005.

EMADI, A.; LEE, Y. J.; RAJASHEKARA, K. "Power electronics and motor drives in electric, hybrid electric and plug-in hybrid electric vehicles" IEEE Transactions on Industrial Electronics. v. 55, n. 6, 2008.

EUR. COMMISSION, "White Paper: Roadmap to a Single European Transport Area-Towards a Competitive and Resource Efficient Transport System”, 2011.

FU, X. “A Novel Design for Flywheel Battery of Electric Vehicles" International Conference on Intelligent System Design and Engineering Application.

GIRISHKUMAR, G. et al. "Lithium-Air battery: Pomise and Challenges" The Journal of Physical Chemistry Letters. 2010.

GRUNDITZ. E. A. et al. "Three traction motors with different magnet materials - influence on cost, losses, vehicle performance, energy use and environmental impact" Thirteenth International Conference on Ecological Vehicles and Renewable Energies. 2018

HANNAN, M. A.; HOQUE, M. M.; MOHAMED, A.; AYOB, A. "Review of energy storage systems for electric vehicle applications: Issues and challenges". Renewable and Sustainable Energy Reviews. v. 69, 2017.

HASHEMNIA, N.; ASAEI B.: "Comparative Study of Using Different Electric Motors in the Electric Vehicles", International Conference on Electrical Machines, 2008.

HERZER, G; "Modern soft magnets: Amorphous and nanocrystalline materials" Acta Materialia. v.61 2013

HUSAIN, I. "Electric and hybrid vehicles design fundamentals” BOCA RATON: CRC PRESS, 2011.

KHALIGH, A. LI, Z. "Battery, Ultracapacitor, Fuel Cell, and Hybrid Energy Storage Systems for Electric, Hybrid Electric, Fuel Cell, and Plug-In Hybrid Electric Vehicles: State of the Art" IEEE Transactions On Vehicular Techinology, v. 59, n.6, 2010

KUMAR; M. S.; REVANKAR, S. T.; "Development scheme and key technology of na electric vehicle: $\mathrm{Na}$ overview" Renewable and Sustainable Energy Reviews. v.70, 2017.
KOSTENCO, M. P.; PIOTROVISK, L. M. "Maquinas Elétricas I". Editora: Editorial Mir Moscu, 1975.

LI S.; ZHANG S.; HABETLER G. T.; HARLEY R. G. "Modeling, Design Optimization and Applications of Switched Reluctance Machines - A Review" IEEE Transactions on Industry Applications, 2019.

LI Y. J et al. "Multiscale structural engineering of Ni-Doped $\mathrm{CoO}$ nanosheets for Zinc-Air batteries with high power density" Advanced Materials. 2018

LIMA, N. M. D; "Comparação de Estratégias de Carregamento de Veículos Elétricos" Dissertação De Mestrado Integrado Em Engenharia Electrotécnica E De Computadores Major Energia” 2012

MINISTÉRIO DO MEIO AMBIENTE, "Sumário do Documento Agenda 21". 1992. Disponível em: http://www.mma.gov.br/responsabilidade-

socioambiental/agenda-21/agenda-21-global/item/600.html, acesso em 05 fev 2019.

TIE, S. F.; TAN, C. W. "A review od energy sources and energy management system in electric vehicles" Renewable and Susteinable Energy Reviews. v. 20, 2013.

YONG, J. Y.; RAMACHANDAMURTHY, V. K.; TAN, K. M.; MITHULANANTHAN, N.: "A review on the state-ofthe-art technologies of electric vehicle, its impacts and prospects" Renewable and Sustainable Energy Reviews. v.49, 2015

ZHU, X.; et al. "Comprehensive Sensitivity Analysis and Multiobjective Optimization Research of Permanent Magnet Flux-Intensifying Motors" IEEE transactions on industrial electronics, v. 66, n. 4, 2019.

ZUBI, G.; LÓPES, R. D.; CARVALHO, M.; PASAOGLU, G. "The lithium-ion battery: State of the art and future perspectives" Renewable and Sustainable Energy Reviews. v. 89, 2018.

\section{COPYRIGHT}

Direitos autorais: $\mathrm{O}(\mathrm{s})$ autor(es) é(são) o(s) único(s) responsável(is) pelo material incluído no artigo. 


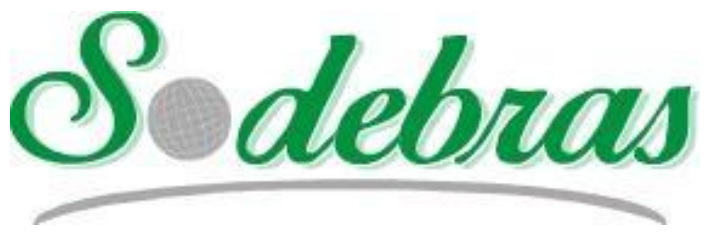

Volume $15-\mathrm{N}^{\mathrm{o}} 169$ - janeiro / 2020

XLI International Sodebras Congress

31 de outubro a 02 de novembro de 2019 - Maceió - AL.

\title{
IMPLEMENTAÇÃO DE UM SISTEMA DE SENSORIAMENTO ULTRASSÔNICO PARA APLICAÇÕES EM IOT NO CONTEXTO DE SMART CITIES
}

\section{IMPLEMENTATION OF AN ULTRASONIC SENSING SYSTEM FOR IOT APPLICATIONS IN THE SMART CITIES CONTEXT}

\author{
COELHO, VINÍCIUS; ALMEIDA, THIAGO; PEREIRA, LUIS; SANTOS, ITALO; DINARDI, PHELLIPE; \\ VERMEHREN, VICTOR; VALENZUELA, WALTER \\ UNIVERSIDADE DO ESTADO DO AMAZONAS \\ vtc.eng17@uea.edu.br; tga.eng@uea.edu.br; lembpr.eng16@uea.edu.br; idss.eng16@uea.edu.br; \\ ptd.eng16@uea.edu.br;vvalenzuela@uea.edu.br;wvalenzuela@uea.edu.br
}

\begin{abstract}
Resumo - A evolução de tecnologias de baixo custo direcionouse a desenvolver dispositivos e sistemas inovadores com inúmeras aplicabilidades, devido ao alto grau de integração que permite monitorar, gerenciar e controlar informações remotamente através de dispositivos interconectados em tempo real. Sendo assim, este artigo propõe-se a descrever um estudo de caso, em um contentor de resíduo comum, em que foram instalados um medidor de nível $e$ um sensor combinado de temperatura $e$ umidade. Em seguida, coletou-se uma quantidade finita de valores brutos da distância mensurada pelos sensores ultrassônicos e, alternadamente, quantidade semelhante à anterior, porem, corrigida em função da temperatura ambiente. Verificou-se que àquele no qual houve correção matemática dos dados extraídos garantiu maior confiabilidade à funcionalidade dos sensores ultrassônicos, podendo possibilitar, dessa forma, a agregação dos sensores ultrassônicos e de temperatura a demais dispositivos IOT (internet of Things) no contexto de Smart Cities.
\end{abstract}

Palavras-chave: Medição de nível. Medição de temperatura. Internet das coisas. Contêiner inteligente.

\begin{abstract}
The evolution of low-cost technologies has led to the development of innovative devices and systems with numerous applications, due to the high degree of integration that allows you to remotely monitor, manage and control information through real-time interconnected devices. Therefore, this paper proposes to describe a case study, in a common waste container, in which a level meter and a temperature and humidity sensor were installed. Then, a finite amount of gross distance values measured by the ultrasonic sensors was collected and, alternately, similar amount to the previous one, but corrected for the ambient temperature. It was found that the one in which there was mathematical correction of the extracted data guaranteed greater reliability to the functionality of ultrasonic sensors, thus enabling the aggregation of ultrasonic and temperature sensors to other IOT (internet of things) devices in the context of Smart Cities.
\end{abstract}

Keywords: Level measurement.. Temperature measurement. IoT. Smart container.

\section{INTRODUÇÃO}

A revolução tecnológica tem evoluído em um grande ritmo nas últimas décadas, sendo atribuída a população mundial como uma importante ferramenta de auxílio no processo de desenvolvimento e mudanças das sociedades, tornando-se quase indispensável. Tais desenvolvimentos e mudanças em uma sociedade só podem ser compreendidas quando busca-se entender além das mudanças ocorridas no comportamento da sociedade, mas também na evolução da tecnologia (Kohn and Moraes; 2007).

Com a evolução tecnológica atual, é possível ter um fácil acesso a informação e interação com uma ampla variedade de dispositivos, como, por exemplo, eletrodomésticos em geral, sensoriamento remoto, entre outras tecnologias. No entanto, tal evolução junto com a infinita variedade de dispositivos existentes torna a identificação de soluções capazes de suprir as necessidades em todos os cenários existentes necessária para possíveis aplicações. Desse modo, a dificuldade de identificação de soluções prováveis levou a realização da prática dos sistemas de IoT no desenvolvimento de várias aplicações para fornecer novos serviços a cidadãos, empresas e administrações públicas (Zanella, et al., 2014).

Neste contexto, segundo Zanella et al. (2014), a IoT (Internet of Things) é definida como um paradigma de comunicação atual, em curto tempo, que permite a integração de quaisquer objetos da vida cotidiana que possam estar conectados à Internet, sendo estes objetos equipados com microcontroladores, transceptores de comunicação digital e protocolos, que irão torná-los correspondentes em comunicar com outros objetos e com usuários, fazendo com que decisões importantes sejam tomadas.

Por esta razão, acrescer tecnologia aos meios de comunicação e administração de grandes sociedades é de fundamental importância para o desenvolvimento e evolução das mesmas e a IoT é um meio para realizar-se a conexão tanto entre máquinas e dispositivos, quanto dispositivo e homem por meio da Internet, permitindo uma vasta comunicação e, por fim, possibilitando inúmeras ferramentas disponíveis para à sociedade.

\section{REFERÊNCIA TEÓRICA}

$2.1 \quad$ Iot em cidades inteligentes 
Atualmente, as cidades têm como desafio questões relacionadas à segurança, transporte, sustentabilidade, desenvolvimento econômico, inclusão social, infraestrutura, habitação etc. Neste cenário o advento de novas tecnologias da informação e comunicação, que possuem sigla TiCs, veem possibilitando participações dos cidadãos, de forma democrática, na dinâmica de inovação das cidades (Capdevila \& Zarlenga, 2015). Assim, a tecnologia e suas aplicações devem ser vistas sob uma perspectiva holística, descentralizada, integradora e participativa, visando a melhoria da percepção e relação das pessoas com o seu ambiente.

A internet das coisas, em inglês Internet of Things IoT, é um paradigma de comunicação atual que antevê, em curto tempo, a integração de objetos da vida cotidiana equipados com microcontroladores, transceptores de comunicação digital e protocolos, que irão torná-los correspondentes em comunicar com outros objetos e com usuários, tornando-se parte integrante da Internet assim permitindo que decisões sejam tomadas (Zanella et al., 2014). As cidades já estão incorporando tecnologia na prestação dos serviços urbanos com tendências e perspectivas nas áreas de inteligência e escala urbana, verticalidade/integração, plataformas de gestão de cidades, fontes de informação com a internet das coisas e o cidadão conectado (Cunha, 2016).

A densidade de estudos sobre sistemas aplicados a Smart Cities e IoT possuem maior representatividade, $60 \%$ entre os trabalhos mais citados na temática, em países europeus e na América do Norte, ambientes de clima temperado que não sofrem influências de medições nos sensores com alta umidade e temperatura (Rizzon, 2017).

\subsection{Gerenciamento de resíduo sólidos urbanos}

O gerenciamento negligenciado dos RSU, além de provocar gastos financeiros significativos, pode provocar graves danos ao meio ambiente, comprometendo a saúde e o bem-estar da população. A quantidade de lixo gerado no Amazonas é de $0,936 \mathrm{~kg} / \mathrm{hab} /$ dia de RSU (ABRELPE/IBGE 2016) e os gastos financeiros relacionados ao gerenciamento de RSU - no Brasil, em média, os serviços de limpeza demandam de $7 \%$ a $15 \%$ do orçamento dos municípios, dos quais $50 \%$ são dedicados à coleta e transporte. Segundo a Secretaria Municipal de Limpeza Urbana (Semulsp), no infográfico elaborado em 08/02/2019, Manaus, nos 63 bairros, geram em média por dia 2.400 toneladas de RSU doméstico (SEMULSP, 2019).

As pesquisas sobre a aplicação da IOT no tratamento e disposição de resíduos domésticos usando as tecnologias relacionadas à IOT resultam em problemas técnicos, como baixo consumo de energia, baixo custo, miniaturização de sensores sem fio e coordenação de padrões técnicos (Wang, 2014). Os contentores inteligentes são ambientes com alta umidade, elevada temperatura e com presença de gases que influenciam e interferem na medição dos sensores alterando as leituras e inviabilizando os contentores inteligentes.

Os diversos estudo sobre gerenciamento de resíduos sólidos urbanos buscam integrar sensores nos contentores de lixo para que a temática seja inserida em um contexto inteligente tal como a proposta de contêineres inteligentes de lixo que evitam o transbordo e emissão de odor desagradável otimizando o gerenciamento de recolhimento (Chen, 2018); estrutura em IoT de coleta de lixo automatizado com identificação, localização e processamento de coleta identificando os fatores chaves de impacto dos resíduos sólidos urbanos (Lokuliyana, 2017); proficiência no acumulo de resíduos com escopo da IoT desenvolvendo dia-a-dia técnicas de campo do sistema de controle de resíduos (Al-Masri, 2018).

\subsection{Aplicações de IoT em sensoriamento nas cidades inteligentes.}

A Internet das Coisas (Internet of Things) está presente em quaisquer atividades diárias da atual sociedade humana, desde aplicações em parques fabris/industriais (particular) a serviços relacionadas ao transporte público, segurança pública/privada, iluminação pública e até monitoramento da qualidade do serviço de abastecimento de água. Devido aos avanços da tecnológicos da $I o T$, os municípios estão se tornando cada vez mais conectados, visando aumentar a eficiência dos serviços ofertados, reduzindo custos e, principalmente, dispêndio com recursos. Sendo assim, a nível exemplificativo, tem-se a empresa Lumca Lighting, da cidade de Quebec, que opera na iluminação inteligente da cidade. Esta companhia desenvolveu uma solução abrangente de iluminação denominada Lumca Smart Pole, que incorpora um roteador robusto de classe empresarial Digi WR44R com energia, conectividade, sensores e outros recursos inteligentes, todos configurados e gerenciados através do Digi Remote Manager $\AA$, um software centralizado plataforma com uma interface gráfica do usuário.

\subsection{Sensor Ultrassônico HC-SRO4}

Segundo o fabricante (ELEC Freaks, 2019), o sensor ultrassônico HC-SR04, que possui quatro (4) pinos cujas denominações são Vcc, Trigger, Echo e Ground, utiliza sonar para determinar distâncias de $2 \mathrm{~cm}$ a $400 \mathrm{~cm}$ de um objeto, com detecção de faixa sem contato com alta precisão, de $3 \mathrm{~mm}$, e estabilidade nas leituras. Este sensor tem módulos que incluem transmissores ultrassônicos, receptor e circuito de controle, sendo que o transmissor ultrassônico transmite uma onda ultrassônica, esta viaja à velocidade do som no ar, quando é objetada por qualquer material, é refletida de volta para o sensor pelo módulo receptor ultrassônico. A distância entre o sensor e o objeto é dada pela Equação a seguir:

$$
D=\frac{V \times \Delta T}{2}
$$

Em que $D$ : distância entre o sensor e o objeto;

$V$ : é a velocidade do som;

$\Delta T$ : é o tempo entre emissão e recepção do som.

Segundo (NUSSENZVEIG, 2002), som se classifica como uma onda mecânica que se propaga longitudinalmente em meios materiais. O cientista inglês Isaac Newton foi o primeiro a definir uma equação da velocidade do som semelhante à mais moderna, porém, desconsiderou dois fatores: temperatura e densidade do ar. Desta forma, foi somente em 1816 que Pierre-Simon Laplace deduziu a equação (2) da velocidade do som em função da temperatura. 


$$
V=V_{0} \sqrt{\frac{T}{T_{0}}}
$$

Em que $V$ : velocidade do som;

$V_{0}$ : velocidade do som a $0{ }^{\circ} \mathrm{C}$;

$T$ : temperatura em Kelvin e

$T_{0}$ : temperatura em Kelvin equivalente a $0{ }^{\circ} \mathrm{C}$.

Transformando a temperatura de Kelvin $(K)$ para Graus Celsius $\left({ }^{\circ} \mathrm{C}\right)$, obtém-se a Equação 3.

$$
V=331,45 \sqrt{\frac{\left(T_{C}+273,15\right)}{273,15}}
$$

Em que $V$ : velocidade do som.

$T_{C:}$ temperatura em graus Celsius.

\section{II.5 Sensor de Temperatura e Umidade AM2302 DHT22}

Conforme (AOSONG, 2019), o sensor digital de temperatura e umidade AM2302 DHT22 tem uma faixa medição de temperatura de $-40 \mathrm{a}+125^{\circ} \mathrm{C}$ com precisão de \pm $0,5{ }^{\circ} \mathrm{C}$. Além disso, o sensor DHT22 possui uma faixa de medição de umidade de 0 a $100 \%$ com precisão de $2-5 \%$ assim como uma taxa de amostragem de $0,5 \mathrm{~Hz}$ ou uma leitura a cada dois segundos. Ademais, o DHT22 funciona com uma tensão de operação de 3 a $5 \mathrm{~V}$, sendo a corrente máxima usada na medição de $2,5 \mathrm{~mA}$.

Internamente, o sensor DHT22 tem três elementos intrínsecos: um sensor de umidade, um sensor de temperatura NTC (ou termistor) e um circuito interno na parte traseira do sensor. Para medir a umidade, utiliza-se o sensor de umidade, que possui dois eletrodos com um substrato de retenção (geralmente um sal ou polímero plástico conduto) de umidade entre eles. Os íons são liberados pelo substrato quando o vapor de água é absorvido por ele, o que aumenta a condutividade entre os eletrodos. A mudança na resistência entre os dois eletrodos é proporcional à umidade relativa. Uma umidade relativa mais alta diminui a resistência entre os eletrodos, enquanto uma umidade relativa mais baixa aumenta a resistência entre os eletrodos. Essa mutabilidade na resistência é medida e processada pelo circuito interno, permitindo a viabilidade da leitura dos dados por um microcontrolador.

\section{METODOLOGIA}

O estudo foi desenvolvido no Laboratório INOVATEC, localizado na Universidade do Estado do Amazonas (Manaus - AM). O ambiente de teste para o ensaio foi o interior de um contentor de lixo de 700L.

Foram realizados 3 dias de coleta de amostra, expondo o contentor utilizado à temperatura ambiente e suas variações naturais.

Para realizar a calibração sensores ultrassônicos utilizados para medir a distância da tampa superior ao fundo no interior do contentor de lixo utilizado para o ensaio, utilizou-se a equação (3) para efetuar a correção da velocidade do som com base na temperatura medida no interior do contentor.

Para a averiguação da confiabilidade de tal correção foi desenvolvido um protótipo que consiste em duas partes: hardware e software.

A parte de hardware envolveu dois sensores ultrassônicos HCSR-04 e um sensor de temperatura DHT22, ambos ligados ao microcontrolador STM32F103C8T6. Todos os sensores citados foram acoplados à parte inferior da tampa do contentor utilizado, de forma que ambos os sensores se encontravam à mesma distância em linha reta em ao fundo do contentor. A disposição dos componentes do protótipo pode ser observada na figura 1 .

Figura 1 - Disposição dos componentes do protótipo no contentor

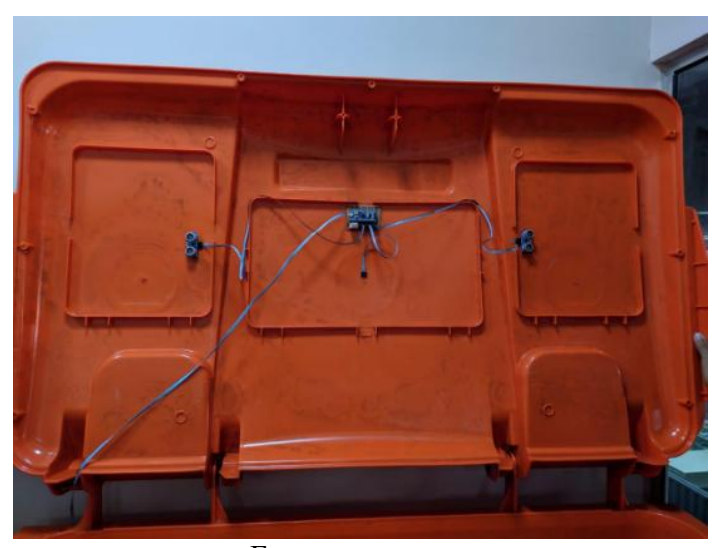

Fonte: os autores.

$\mathrm{Na}$ parte de software foi desenvolvido um algoritmo que realizou a leitura dos valores de distância dos sensores ultrassônicos e a medição de temperatura do sensor DHT22. Para correção inicial dos valores brutos obtidos e descarte de valores absurdos, prejudiciais aos resultados do experimento, realizou-se a moda de cada 100 amostras obtidas de temperatura e distâncias, e os resultados desta operação foram utilizados como temperatura ambiente e distâncias medidas a cada ciclo de leitura. Uma das distâncias medidas foi corrigida com a equação (3), e a outra mantida sem correção.

\section{RESULTADOS}

A partir do experimento realizado com os sensores dentro do contentor de lixo foram obtidos três resultados diferentes, Tabela 1, o primeiro correspondente à temperatura no interior do contentor, o segundo a distância medida pelo sensor ultrassônico sem a correção da velocidade do som em relação à temperatura e o terceiro, a distância com a velocidade do som corrigida. O experimento resultou na coleta de 13 mil amostras a partir das quais foi possível gerar os gráficos da Figura 2.

Tabela 1 - Valores obtidos durante os testes.

\begin{tabular}{ccc}
\hline Temperatura $\left({ }^{\circ} \mathbf{C}\right)$ & Distância $(\mathbf{c m})$ & Distância corrigida $(\mathbf{c m})$ \\
\hline 25,20 & 90,21 & 89,98 \\
25,20 & 90,21 & 90,36 \\
25,20 & 90,65 & 90,34 \\
25,20 & 90,24 & 89,96 \\
25,20 & 89,35 & 90,38 \\
\hline
\end{tabular}


A variação de temperatura no espaço amostral mostrado no gráfico foi de aproximadamente $5^{\circ} \mathrm{C}$, com o mínimo de $23,2^{\circ} \mathrm{C}$ e o máximo de $28,2^{\circ} \mathrm{C}$, essa variação foi fundamental para a validação do experimento.

No gráfico, pode-se observar o comportamento da distância capturada sem a correção da qual se tratava o experimento. Esta curva se mostrou instável, principalmente quando houve mudanças relevantes no valor da temperatura do ambiente, demonstrando notadamente a proporcionalidade inversa entre temperatura e distância para o método de medição ultrassônico.

Em paralelo é possível analisar o resultado obtido para a distância com o ajuste de temperatura, evidenciando que a precisão dessas leituras foi maior, visto que o comportamento do gráfico é quase linear.

Para validação do resultado obtido, foram calculados o desvio padrão e o erro para os dois casos, o resultado é mostrado na Tabela 2 .

Tabela 2 - Valores obtidos durante os testes.

\begin{tabular}{ccc}
\hline Circuito & Desvio Padrão & Erro \\
\hline Com correção & $0,4687 \mathrm{~cm}$ & $+0,36 \mathrm{~cm}$ \\
Sem correção & $0,6667 \mathrm{~cm}$ & $-0,63 \mathrm{~cm}$ \\
\hline
\end{tabular}

Figura 2 - Resultados das medições, sem e com correção.
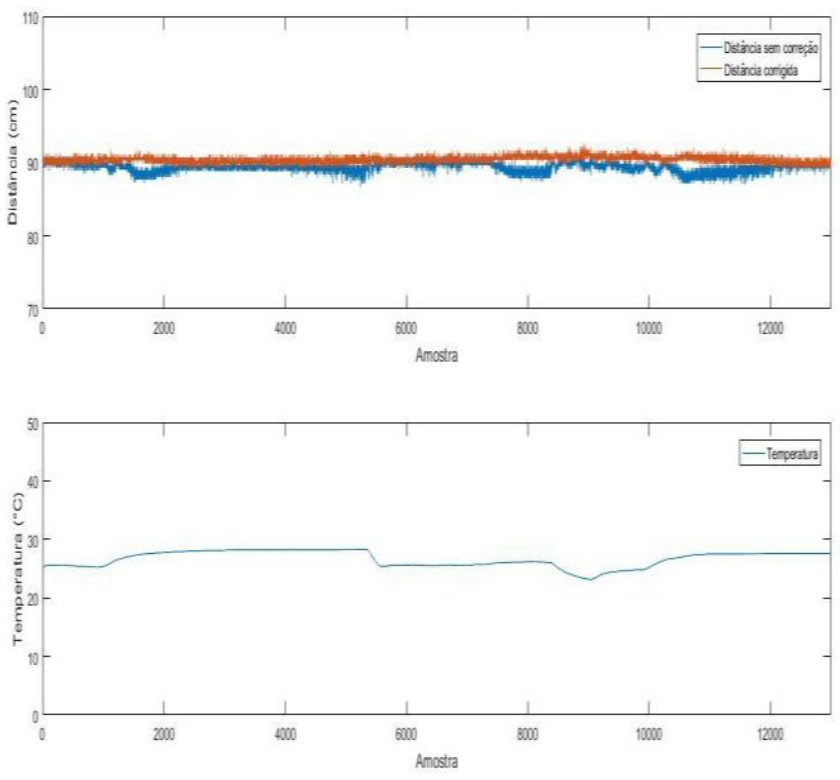

Fonte: Os autores

Como é possível observar, o erro total de medição no circuito sem correção é aproximadamente o dobro do erro com a correção por temperatura, o que reflete as variações observadas no gráfico da figura (2).

Em paralelo é possível analisar o resultado obtido para a distância com o ajuste de temperatura, evidenciando que a precisão dessas leituras foi maior, visto que o comportamento do gráfico é quase linear.

\section{CONCLUSÕES}

O presente artigo mostrou a implementação de um cenário de teste em um contentor de lixo comum com a inserção de um sensor ultrassônico (HC-SR04) e outro sensor de umidade e temperatura (DHT22). A inclusão tanto das etapas de cálculo quanto da etapa de testes fez com que gerasse uma melhor credibilidade no processo na sua operação. Foi constatado que a variação da temperatura, de fato, possui uma relevância nos resultados da velocidade da onda sonora feitas durante os processos de teste real, correspondente a medição de nível de resíduo existente dentro do contentor.

Assim, essa análise de dados presentes nos coletores de resíduos sólidos espalhadas pela cidade de Manaus reduz os gastos financeiros, os danos ao meio ambiente e relaciona com a Smart City, que busca de forma geral, a inovação nas cidades. É preciso também que ocorra uma difusão em pesquisas sobre a aplicação da IoT no tratamento e disposição de resíduos.

Deste modo, esse artigo foi de grande importância para a referência cientifica, pois, as medições da distância sem correção da velocidade do som versus medição da distância com correção da velocidade do som obtiveram os resultados esperados.

Para trabalhos futuros do projeto em questão, podemos citar sistemas que podem ser desenvolvidos para a integração com a transferência de dados analisados nos caminhões de lixo, fazendo a integralização de todo o sistema com a cidade.

\section{REFERÊNCIAS BIBLIOGRÁFICAS}

ABRELPE/IBGE, Panorama de Resíduos Sólidos no Brasil - ABRELPA 2016

Al-Masri, E. et all. Recycle.io: An IoT-Enabled Framework for Urban Waste Management - IEEE 2018, International Conference on Big Data (Big Data)

AOSONG, Temperature and humidity module DHT11 Product Manual - AOSONG Datasheets, 2019

CAPDEVILA, J., \& Zarlenga, M. I. (2015). Smart city or smart citizens? The Barcelona case. Journal of Strategy and Management, 8(3), 266-282. Retirado em de outubro de 2019 do site https://www.researchgate.net/publication/277180909 Smart _City_or_smart_citizens_The_Barcelona_case

CARUSO, José Mário. Controle de Velocidade de um MIT Tracionando um Veículo Elétrico. Taubaté, 2007.

CHEN, W. et all. A Smart IoT System for Waste Management - IEEE 2018, 1st International Cognitive Cities Conference (IC3)

CUNHA, M. A. Smart cities: transformação digital de cidades - São Paulo : Programa Gestão Pública e Cidadania - PGPC, 2016

ELEC Freaks. Ultrasonic Ranging Module HC SR04 - ELEC Freaks, 2019

ERBER, Pietro. "Gasolina e Tomada": o carro elétrico está perto. Rio de Janeiro: Revista do Empresário da ACRJ, maio/junho, 2010. 
FRÉ, Paulo; MARCELINO, Márcio Abud; ADAMI, José Feliciano. Sensor Kelvin para detecção de Tensão. Revista Sodebras [on line]. v. 10, n.117, set./2015, p. 147-152. ISSN 1809-3957. Disponível em: $<$ http://www.sodebras.com.br/edicoes/N117.pdf $>$. Acesso em 04 out. 2015.

LOKULIYANA, S. et all. IGOE IoT Framework for waste collection optimization - IEEE 2017, 6th National Conference on Tevhnology and management (NCTM)

MUNDO EDUCAÇÃO. Figura 2. Disponível em: http://mundoeducacao.bol.uol.com.br/geografia/tiposgraficos.htm. Acesso em 26 jan 2016.

NUSSENZVEIG, H. M. Curso de física básica, Volume 1 Blucher, $5^{\text {a }}$ Edição 2002.

PACHECO, Marco Aurélio C. Algoritmos Genéticos: Princípios e Aplicações. Disponível em: http://www.ica.ele.puc-rio.br/Downloads/38/CE-ApostilaComp-Evol.pdf. Acesso em $04 \mathrm{dez} 2010$.

RIZZON, F. et all. SMART CITY: UM CONCEITO EM CONSTRUÇÃO. Revista Metropolitana de Sustentabilidade Volume 7, número 3 (Set./Dez.2017) ISSN: 2318-3233

SEMULSP - Secretaria Municipal de Limpeza Pública. Relatório de atividades da SEMULSP, janeira a dezembro de 2018 - SEMULSP/Prefeitura de Manaus, 2019.

WANG, J. Y. et all. Research on application of IoT in domestic waste treatment and disposal - IEEE 2014, 11th World Congress on Intelligent Control and Automation.

ZANELLA, A., Bui, N., \& Castellani, A. (2014). Internet of things for smart cities. Ieee Internet Of Things Journal, 1(1), 22-32. Retirado 01 de Outubro de 2019 do site http://ieeexplore.ieee.org/document/6740844/authors

\section{AGRADECIMENTOS}

Este trabalho conta com o apoio da Samsung Eletrônica da Amazônia Ltda. e AGIN - Agência de Inovação da UEA.

\section{COPYRIGHT}

Direitos autorais: $\mathrm{O}(\mathrm{s})$ autor(es) é(são) o(s) único(s) responsável(is) pelo material incluído no artigo. 


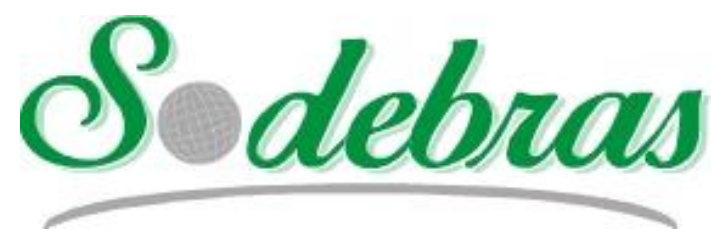

Volume 15 - $\mathrm{N}^{\mathrm{o}} 169$ - Janeiro / 2020

XLI International Sodebras Congress

31 de outubro a 02 de novembro de 2019 - Maceió - AL.

\title{
CONTROLE DE VIBRAÇÕES EM LAVRA DE MINAS PRÓXIMO A ZONAS URBANAS
}

\section{MINING VIBRATION CONTROL NEAR URBAN ZONES}

\author{
LEONARDO CHAVES $^{1}$; FABIANO FERREIRA ${ }^{1}$; LEANDRO SILVEIRA $^{1}$; VIDAL TORRES ${ }^{1}$ \\ 1 - INSTITUTO TECNOLÓGICO VALE - MINERAÇÃO \\ leonardo.chaves@itv.org; fabiano.ferreira@pq.itv.org; leandro.silveira@itv.org; vidal.torres@itv.org
}

\begin{abstract}
Resumo - O desmonte de rochas com explosivos, necessário para fragmentar e possibilitar o carregamento da rocha, é uma operação essencial em lavra de minas a céu aberto que pode resultar em efeitos indesejáveis, como as vibrações de partículas do terreno. O controle de vibrações é fundamental para operações localizadas próximas a centros urbanos, pois as vibrações podem danificar edificações e causar incômodo humano. Este trabalho apresenta um estudo de caso real conduzido em uma mina de ferro de grande porte para a determinação da lei de atenuação das vibrações. Os resultados mostraram parâmetros estatísticos aceitáveis, com índice de determinação de 0,858 e a regressão foi validada com testes de significância estatística e novas medidas. A previsão do nível de vibrações resultante na comunidade constitui uma importante ferramenta de controle de qualidade da operação de desmonte de rochas.
\end{abstract}

Palavras-chave: Vibrações. Desmonte de rochas. Sismografia.

Abstract - The rock blasting operation, although necessary for fragment and allow the material loading, is essential for open pit mining and may result in undesirable effects, such as ground vibration. The vibration control is fundamental to mining enterprises located near urban centers since the vibration may cause damage to buildings and human discomfort. This work presents a real case study conducted in a large-scale iron ore mine to determine the local attenuation law. The results have shown acceptable statistics parameters with the determination index of 0.858 and the regression was validated with statistical tests and using new measurements. The blast-induced ground vibration velocity prediction in the community is an important tool for quality control of rock blasting operations.

Keywords: Ground vibration. Rock blasting. Seismography.

\section{INTRODUÇÃO}

O desmonte de rochas com explosivos é atividade usual no dia-a-dia de uma mina e tem como objetivo desmontar e fragmentar a rocha para possibilitar o carregamento do material. Segundo Gama (1998), apenas 5 a $15 \%$ da energia do explosivo é efetivamente utilizada para fragmentação da rocha, portanto, a maior parte da energia liberada se dissipa na forma de efeitos colaterais. Dentre os diversos efeitos indesejáveis do desmonte, as vibrações do terreno podem causar danos a edificações e incômodo a comunidades vizinhas à mina.

Existem diferentes maneiras descritas na literatura científica para se prever o nível de vibrações decorrentes de uma detonação planejada. Dentre os principais métodos de previsão de vibrações, destacam-se: modelos matemáticos empíricos ou leis de atenuação (ATTEWELL; FARMER, 1973; WISS, 1981; TORRES et al., 2018a) que correlacionam parâmetros como carga máxima por espera e distância com a vibração resultante; o método conhecido por assinatura de onda (ANDERSON, 2008; BERNARD, 2012; BERNARD; GAGNON, 2014), que simula a interação de ondas provenientes de diferentes furos detonados; e a utilização de métodos de inteligência artificial como as redes neurais artificiais (KHANDELWAL; SINGH, 2009; MONJEZI; GHAFURIKALAJAHI; BAHRAMI, 2011; TORRES et al., 2018b), que permitem envolver um maior número de variáveis de entrada. Assim, a estimativa do nível vibratório em pontos de interesse permite a adoção de medidas para reduzir este nível e minimizar seus efeitos negativos.

Este trabalho apresenta um estudo de caso real em uma mina de ferro de grande porte em que foi realizado uma campanha de monitoramento de vibrações, o processamento estatístico dos dados, a determinação da lei de atenuação das vibrações para o local e a determinação de cargas máximas admissíveis por espera para se respeitar limites de vibração pré-determinados.

\section{METODOLOGIA}

A metodologia aplicada neste trabalho é constituída de cinco etapas principais, conforme detalhado a seguir e ilustrado pela Figura 1:

1) Monitoramento de vibrações decorrentes de desmontes de rochas com explosivos em pontos internos na mina, na comunidade e na região entre mina e comunidade. Para o monitoramento, foram utilizados 20 sismógrafos da marca GEOSONICS $®$, modelo SSU 3000 EZ+. No total, foram monitorados 10 desmontes, resultando em um total de 158 eventos válidos registrados. As cargas máximas detonadas por espera nos desmontes monitorados variaram entre 800 e 2100 $\mathrm{kg}$, e as distâncias de monitoramento variaram de 53 a 1955 m. A Tabela 1 apresenta as informações de cargas e distâncias mínimas e máximas de monitoramento para cada desmonte monitorado. 
Figura 1 - Metodologia utilizada para obtenção da lei de atenuação, previsão e controle das vibrações.

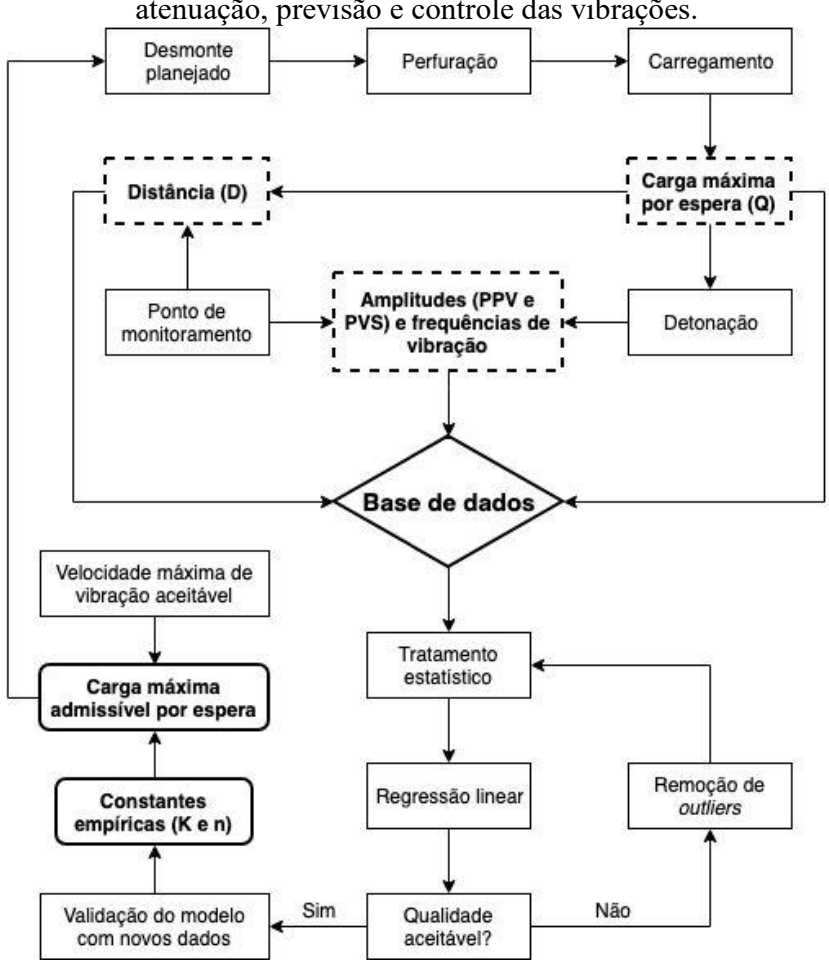

Fonte: Autores, 2019.

Tabela 1 - Dados de cargas e distâncias de monitoramento para os desmontes monitorados.

\begin{tabular}{ccc}
\hline Desmonte & Q $(\mathbf{k g})$ & Distância $(\mathbf{m})$ \\
\hline 1 & 1250 & $376-1694$ \\
2 & 2000 & $52-1827$ \\
3 & 1500 & $384-1845$ \\
4 & 1750 & $492-1955$ \\
5 & 1000 & $391-1704$ \\
6 & 1400 & $101-1622$ \\
7 & 1600 & $321-1608$ \\
8 & 1350 & $312-1424$ \\
9 & 800 & $598-1649$ \\
10 & 2100 & $240-1313$ \\
\hline
\end{tabular}

2) Elaboração do banco de dados com as informações de carga máxima detonada por espera, distância entre $\mathrm{o}$ local de detonação e $\mathrm{o}$ ponto de monitoramento, velocidades de vibração máximas medidas em cada componente ortogonal (PPV), frequências de vibração dominantes em cada componente ortogonal e velocidade máxima instantânea medida (PVS).

3) Tratamento estatístico dos dados e regressão linear através do método dos mínimos quadrados para a determinação da lei de atenuação local. $\mathrm{O}$ modelo utilizado, indicado por Jimeno, Jimeno e Bermudez (2017), relaciona a velocidade de vibração (v) com a distância escalonada segundo a equação (1):

$V=K^{*}\left(D / Q^{0,5}\right)^{n}$

Em que $\mathrm{K}$ e $\mathrm{n}$ são constantes empíricas obtidas na regressão, D é a distância entre o local de detonação e o ponto de monitoramento, e Q é a carga máxima detonada por espera. Para a execução dos cálculos, a equação foi linearizada através da aplicação de logaritmos nos dois termos da equação (1), resultando na equação (2).

$$
\log (V)=\log (K)+n * \log \left(D / Q^{0,5}\right)
$$

Para a execução dos cálculos, o PVS foi utilizado por ser considerado mais significativo que o PPV. Nesta etapa também foi determinada a equação da reta superior do intervalo de predição para $95 \%$ de confiança através da equação (3). O limite superior do intervalo de predição pode ser usado como uma estimativa mais conservadora para se respeitar os limites legais de vibração.

$$
I P_{\text {sup }}=\hat{y}+t_{n-2} *^{*} *\left(1+1 / n+\left(x-x_{\text {médio }}\right)^{2} /\left((n-1) *^{2}{ }_{x}\right)^{0,5}\right.
$$

Em que $I P_{\text {sup }}$ é o valor calculado para o logaritmo da velocidade de vibração correspondente à reta superior do intervalo de predição no ponto $x, \hat{y}$ é o valor previsto pelo modelo determinado pela regressão para o logaritmo da velocidade de vibração, $t_{n-2}$ é o valor da tabela $t$ de Student para $95 \%$ de confiança, $n$ é o número de eventos registrados, $s$ é o desvio padrão dos resíduos da regressão, $x_{\text {médio }}$ é a média aritmética dos logaritmos das distâncias escalonadas e $s_{x}$ é o desvio padrão dos valores de logaritmos das distâncias escalonadas.

4) Validação do modelo obtido para a lei de atenuação das vibrações através de testes estatísticos e com a utilização de novos dados. Do banco de dados inicial com 158 eventos, foram extraídos aleatoriamente 32 eventos (20\%), que não foram utilizados na etapa de regressão, para serem utilizadas na validação do modelo.

5) Cálculo da carga máxima por espera admissível para se respeitar a velocidade máxima de vibração aceitável no ponto de interesse através da equação (4):

$$
Q_{\text {máx }}=D^{2 *}\left(K / v_{\text {Lim }}\right)^{(2 / n)}
$$

Em que $Q_{\text {máx }}$ é a carga máxima por espera admissível para se respeitar a velocidade de vibração limite no ponto de interesse $\left(v_{\text {Lim }}\right)$.

\section{CARACTERÍSTICAS GEOLÓGICAS E GEOMECÂNICAS LOCAIS}

A mina de ferro em estudo apresenta rochas provenientes de diferentes litologias em sua composição, incluindo itabiritos compactos, friáveis, dolomíticos, goetíticos e manganesíferos, hematitas friáveis e goetíticas, rochas intrusivas, filitos, quartzitos, xistos e rochas do Grupo Piracicaba.

Com relação à classificação geomecânica, o maciço rochoso presente na mina é classificado entre as classes III, IV e $\mathrm{V}$ segundo a classificação proposta por Bieniawski (1989), além de um tipo de saprolito, classificado como uma classe especial de solo estruturado mais resistente. A seguir, 
uma breve apresentação de cada classe geomecânica encontrada na mina (TORRES et al., 2018a):

- Classe especial: ocorrem nas porções leste e oeste da mina e ocupam a maior parte da área. Essa classe é composta por litotipos de baixa coesão do Grupo Piracicaba e xistos do Supergrupo Rio das Velhas.

- Classe V: composta por rochas de qualidade geotécnica muito baixa, de baixa resistência, completamente alteradas e fraturadas. Compreende itabiritos compactos e xistos do Supergrupo Rio das Velhas e é encontrada nas porções oeste e sul da mina.

- Classe IV: presente na porção oeste da mina, compreende rochas de baixa qualidade geotécnica alteradas e muito fraturadas. É composta apenas por xistos do Supergrupo Rio das Velhas.

- Classe III: é encontrada na porção central e setentrional da mina, e é composta por maciços rochosos de qualidade geotécnica média, com média a alta resistência. O litotipo mais comum são os itabiritos compactos, mas também é composto por itabiritos dolomíticos e xistos em menores quantidades.

\section{RESULTADOS}

Os registros de velocidades de vibração, frequências dominantes, carga máxima por espera e distâncias foram utilizados para a criação do banco de dados utilizado neste estudo. As frequências de vibração registradas se enquadraram quase totalmente no intervalo entre 4 e $10 \mathrm{~Hz}$ para todos os eventos. As velocidades de vibração registradas variaram entre 0,19 e $74,93 \mathrm{~mm} / \mathrm{s}$.

\section{1 - Regressão linear}

O banco de dados com 126 eventos foi utilizado para se obter a lei de atenuação das vibrações através do procedimento de regressão linear. A análise dos dados levou à remoção de cinco eventos considerados anômalos ou outliers e o restante dos dados foi utilizado para a regressão linear. Após a análise de regressão, também foi calculada a reta superior do intervalo de predição para $95 \%$ de confiança através da equação (3) apresentada anteriormente. $\mathrm{O}$ resultado da regressão é apresentado pela equação (5) e pelo gráfico da Figura 2, que também mostra a reta superior do intervalo de predição com sua respectiva equação (6):

$$
\begin{aligned}
& V=96,66 *\left(D / Q^{0,5}\right)^{-1,484} \\
& V=235,5 *\left(D / Q^{0,5}\right)^{-1,484}
\end{aligned}
$$

Os parâmetros da análise de regressão para a função linearizada são apresentados na Tabela 2.
Figura 2 - Resultado da regressão linear com a reta superior do

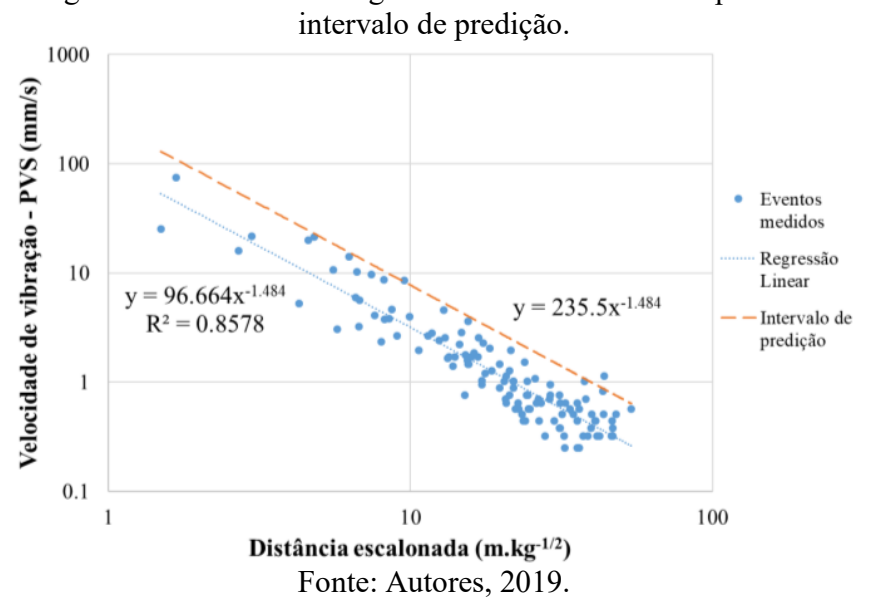

Tabela 2 - Parâmetros resultantes da regressão.

\begin{tabular}{ccc}
\hline & Coeficientes & Desvio padrão \\
\hline $\mathbf{K}$ & 1,985265 & 0,072151 \\
$\mathbf{n}$ & $-1,483645$ & 0,055377 \\
\hline
\end{tabular}

\section{2 - Teste de validação}

Para testar a significância da lei de atenuação determinada por regressão linear, foram realizados os testes $\mathrm{P}$ e T. Os valores obtidos nos respectivos testes são apresentados na Tabela 3 .

Tabela 3 - Testes de significância da regressão.

\begin{tabular}{lll}
\hline & Valor-P & Teste-T \\
\hline $\mathbf{K}$ & $2,03 \times 10^{-53}$ & 27,5154 \\
$\mathbf{n}$ & $3,13 \times 10^{-52}$ & 26,7917 \\
\hline
\end{tabular}

Como os valores-p resultantes foram inferiores ao nível de significância adotado de 0,05 , a hipótese nula foi rejeitada e a hipótese de que o modelo obtido contribui significativamente para explicar a variação de PVS com a distância escalonada foi aceita. De forma similar, como o valor obtido para o teste-T foi superior ao valor da distribuição T $(1,98)$ para o nível de significância utilizado, este teste também indica a rejeição da hipótese nula e a aceitação de que a regressão é significante para explicar as variações da velocidade de vibração em função da distância escalonada.

A qualidade das previsões através da lei de atenuação das equações também foi testada com os 32 eventos sorteados inicialmente que não fizeram parte do banco de dados utilizado para a regressão. A Figura 3 mostra o gráfico de PVS em função da distância escalonada com os eventos utilizados na validação e as retas de regressão e do intervalo de predição.

O gráfico mostra que a lei de atenuação determinada representa satisfatoriamente os novos eventos utilizados para a validação. A Figura 3 também mostra que praticamente todos os novos eventos ficaram abaixo da linha do intervalo superior de predição, exceto um único evento, ou $3,125 \%$ dos dados utilizados para a validação. Assim, a linha superior do intervalo de predição representa um limite conservador e confiável para o planejamento de desmontes em que é necessário controlar vibrações até um certo limite. 


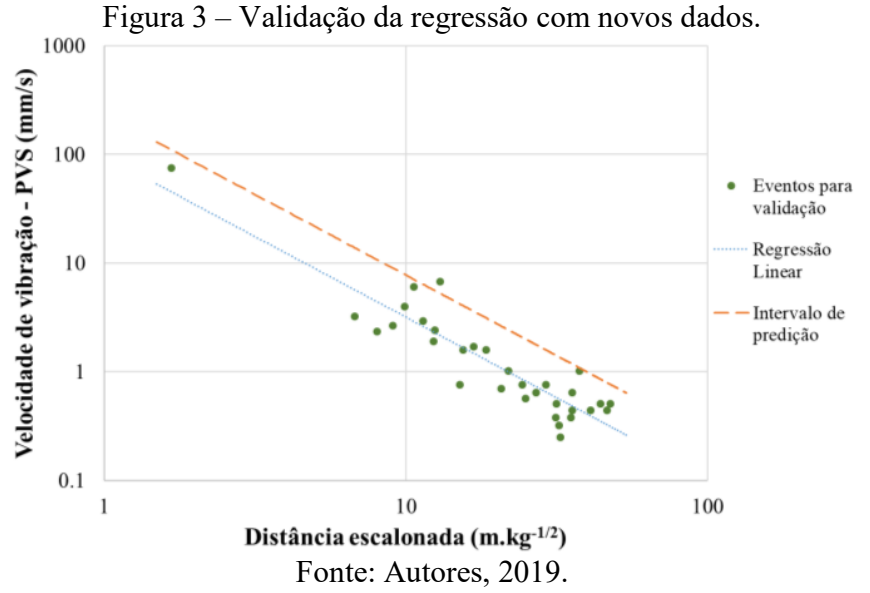

\section{3 - Carga máxima admissível por espera}

No Brasil, assim como em diversos outros países do mundo, existem normas técnicas para regulamentar o nível vibratório do terreno resultante das atividades que utilizam explosivos. Em geral, as normas técnicas estipulam valores limites para as velocidades máximas de vibração em função da frequência dominante visando preservar edificações existentes nas proximidades dos empreendimentos ou evitar incômodo à população vizinha. Algumas normas ainda classificam as edificações de acordo com sua sensibilidade às vibrações para estipular velocidades limites diferentes para cada categoria, visando preservar as estruturas destas edificações, como é o caso das normas britânica BS 7385-2 (BSI, 1993) e portuguesa NP 2074 (IPQ, 2015). A norma brasileira, NBR 9653 (ABNT, 2018), define valores de vibração limite em função da frequência dominante de vibração visando preservar as edificações. Estes valores limite devem ser respeitados nos limites do empreendimento.

Embora a norma brasileira tenha vigência legal na localidade do empreendimento em que ocorreu o estudo, foi utilizada a norma portuguesa para o cálculo da carga máxima admissível por espera, uma vez que esta norma é mais rigorosa e inclui frequência e tipo de estrutura na definição da velocidade limite. Na comunidade vizinha à mina, são encontradas estruturas predominantemente classificadas como comuns segundo a norma portuguesa, e como as frequências de vibração dominantes registradas ficaram entre 4 e $10 \mathrm{~Hz}$, a velocidade de vibração máxima considerada foi de $3,0 \mathrm{~mm} / \mathrm{s}$.

O cálculo da carga máxima admissível deve levar em consideração a menor distância entre o local do desmonte e o limite do empreendimento. Para o caso em estudo, foi utilizada a distância mínima entre os limites da cava final planejada e a comunidade vizinha, que é de cerca de $500 \mathrm{~m}$. As aplicações da equação (4) para esta distância, utilizando o limite de vibração de $3,0 \mathrm{~mm} / \mathrm{s}$ e os coeficientes das equações da lei de atenuação (equação 5) e da reta superior do intervalo de predição (equação 6) resultaram nas cargas máximas admissíveis por espera apresentadas na Tabela 4.

Tabela 4 - Cargas máximas admissíveis.

Lei de atenuação Intervalo de predição

$\mathbf{Q}_{\text {Máx }}$
$2316 \mathrm{~kg}$ $697 \mathrm{~kg}$
A carga máxima admissível por espera calculada através dos coeficientes da lei de atenuação das vibrações indica que, nas condições utilizadas para o cálculo, o número de furos detonados por espera deve ser limitado. Se houver a necessidade de um controle mais rigoroso, a reta superior do intervalo de predição pode ser usada para determinar a carga máxima admissível. Nesse caso, a carga máxima determinada indica a necessidade de maior precisão nos tempos de detonação dos furos, sendo recomendado o uso de sistema de iniciação eletrônica e detonação furo a furo.

\section{CONCLUSÃO}

A metodologia apresentou resultados satisfatórios para a previsão e controle de velocidades de vibração resultantes de desmontes de rochas com explosivos, sendo o coeficiente de determinação para a lei de atenuação de 0,858. O procedimento de regressão linear, utilizado para a determinação da lei de atenuação das vibrações para a localidade em estudo, apresentou resultados aceitáveis segundo os testes estatísticos realizados, teste-P e teste-T. A equação determinada foi, portanto, considerada significante para explicar as variações da velocidade de vibração em função da distância escalonada.

O limite superior do intervalo de predição também foi testado com novos dados que não foram utilizados na regressão, e apenas um evento dos 32 novos, ou 3,125\% dos novos eventos, resultou acima do limite do intervalo de predição. A reta do limite superior do intervalo de predição foi considerada uma boa referência para quando se necessita de um controle rígido da velocidade de vibração.

O cálculo da carga máxima admissível por espera permite adequar o planejamento do desmonte aos limites desejáveis ou legais. Com base na distância mínima prevista entre os limites da cava final e a comunidade, a carga máxima admissível por espera calculada com os coeficientes da lei de atenuação apresentou valores que indicam a necessidade de limitar a quantidade de furos detonados por espera para se respeitar o limite de vibração selecionado. Já a carga máxima admissível por espera calculada com os coeficientes da reta superior do intervalo de predição indica a necessidade de detonação furo a furo, sendo recomendada a utilização de detonadores eletrônicos para maior precisão dos tempos de disparo e consequentemente maior controle da carga máxima detonada por espera.

\section{REFERÊNCIAS BIBLIOGRÁFICAS}

ABNT - ASSOCIAÇÃO BRASILEIRA DE NORMAS TÉCNICAS. NBR 9653: Guia para avaliação dos efeitos provocados pelo uso de explosivos nas minerações em áreas urbanas. Rio de Janeiro, 2018.

ANDERSON, D.A. Signature hole blast vibration control Twenty years hence and beyond. Em: Proceedings of the $34^{\text {th }}$ Annual Conference on Explosives and Blasting Technique. Anais... International Society of Explosives Engineers. Cleveland, Ohio. p. 27-38, 2008. 
ATTEWELL, P. B.; FARMER, I. W. Attenuation of ground vibrations from pile driving. Ground Engineering, v. 3, p. 26-29, 1973.

BERNARD, T. The truth about signature hole method. Em: Proceedings of the $38^{\text {th }}$ Annual Conference on Explosives and Blasting Technique. Anais... International Society of Explosives Engineers. Cleveland, Ohio. p. 345-355, 2012.

BERNARD, T.; GAGNON, G. Blasting 1 million tons, 205 meters from a town. Journal of Explosives Engineering, v. 31, n. 4, p. 26-36, 2014.

BIENIAWSKI, Z.T. Engineering rock mass classifications. John Wiley and Sons, 1989.

BSI - British Standards Institution. BS 7385-2: Evaluation and measurement for vibration in buildings - Part 2: Guide to damage levels from groundborne vibration. Londres, 1993.

GAMA, C. D. Ruídos e vibrações ligados à utilização dos explosivos e equipamentos. Em: $1^{\circ}$ Seminário de Auditorias Ambientais Internas. Anais... Divisão de Minas e Pedreiras do Instituto Geológico e Mineiro de Portugal. 1998.

IPQ - INSTITUTO PORTUGUÊS DA QUALIDADE. NP 2074: Avaliação da influência de vibrações impulsivas em estruturas. Caparica, 9 p. 2015.

JIMENO, C.L.; JIMENO, E.L.; BERMUDEZ, P.G. Manual de Perforación, Explosivos y Voladuras. Madrid: Universidad Politécnica de Madrid. ISBN 978-84-96140-608. 2017.

KHANDELWAL, M.; SINGH, T. N. Prediction of blastinduced ground vibration using artificial neural network. International Journal of Rock Mechanics \& Mining Sciences, v. 46, p. 1214-1222, 2009.

MONJEZI, M.; GHAFURIKALAJAHI, M.; BAHRAMI, A. Prediction of blast-induced ground vibration using artificial neural networks. Tunnelling and Underground Space Technology, v. 26, p. 46-50, 2011.

TORRES, V.F.N.; REIS, J.A.; LUIZ, P.L.; COSTA, J.H.R.; CHAVES, L.S. Neural network applied to blasting vibration control near communities in a large-scale iron ore mine. Em: Proceedings of the $27^{\text {th }}$ International Symposium on Mine Planning and Equipment Selection - MPES 2018. Anais... Santiago, Chile. p. 81-91, 2018b.

TORRES, V.F.N.; SILVEIRA, L.; LOPES, P.; LIMA, H. Assessing and controlling of bench blasting-induced vibrations to minimize impacts to a neighboring community. Journal of Cleaner Production, v. 187, p. 514-524, $2018 \mathrm{a}$.

WISS, J.F. Construction vibrations: State-of-the-Art. ASCE Journal of Geotechnical Engineering, v. 10, n. GT2, 1981.

\section{AGRADECIMENTOS}

Os autores agradecem ao Instituto Tecnológico Vale Mineração e à Vale S.A. pelo apoio e financiamento do projeto de pesquisa que resultou neste estudo.

\section{COPYRIGHT}

Direitos autorais: Os autores são os únicos responsáveis pelo material incluído no artigo. 


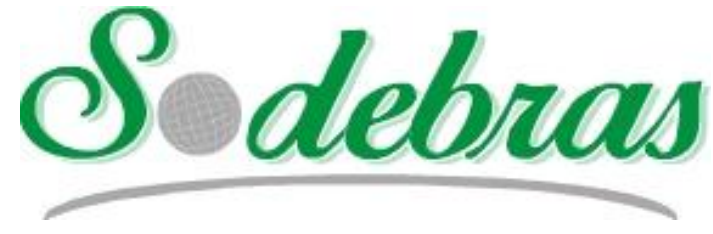

Volume 15 - $\mathrm{N}^{\mathrm{o}} 169$ - Janeiro / 2020

XLI International Sodebras Congress

31 de outubro a 02 de novembro de 2019 - Maceió - AL.

\title{
REUTILIZAÇÃO DE AREIA DE FUNDIÇÃO ATRAVÉS DA REGENERAÇÃO MECÂNICA: ESTUDO DE CASO EM UMA FUNDIÇÃO LOCALIZADA EM PERNAMBUCO
}

\section{REUSE OF FOUNDRY SAND THROUGH MECHANICAL REGENERATION: CASE OF A PERNAMBUCO FOUNDRY COMPANY}

\author{
THIAGO H. B. SANTANA ${ }^{1}$; GUILHERME G. S $^{1}$; IVAN B. M. PICCHI ${ }^{1}$; TIAGO F. A. SANTOS ${ }^{1}$ \\ ${ }^{1}$ - DEPARTAMENTO DE ENGENHARIA MECÂNICA, UNIVERSIDADE FEDERAL DE \\ PERNAMBUCO, AV. DA ARQUITETURA, S/N, CIDADE UNIVERSITÁRIA 50740-550 - RECIFE /PE - \\ BRASIL \\ tenbezerra@yahoo.com.br; guilherme.gadelhasousa@ufpe.br; tiago.felipe@ufpe.br
}

\begin{abstract}
Resumo - O trabalho atual apresenta um estudo de caso de uma fundição localizada em Pernambuco, na qual foi feito um estudo da viabilidade e emprego da reutilização de areia de fundidos proveniente de regeneração mecânica. Após a etapa de regeneração, as amostras foram testadas de acordo com as suas propriedades físico-químicas (umidade, pH, temperatura, porcentagem de finos e densidade). Após estes testes, observou-se que a areia regenerada apresenta potencial para a reutilização na linha de produção no interior do processo de fundição. Alguns defeitos em produtos fundidos devido a utilização de areia regenerada estão associados a uma elevada quantidade de aglomerante. Optou-se então pela adição de óxido de ferro no processo de regeneração da areia, resultando em uma produção de fundidos com poucos defeitos e a possibilidade de se empregar a areia regenerada em larga escala na linha de produção.
\end{abstract}

Palavras-chave: Areia de fundição. Regeneração mecânica. Reutilização de insumos de fabricação.

\begin{abstract}
The present work presents a case study of a foundry located in Pernambuco, where it was made a study of the viability and use of sand reuse of castings from mechanical regeneration. After the regeneration step, the samples were tested according to their physicochemical properties (humidity, $\mathrm{pH}$, temperature, fines percentage and density). After these tests, it was observed that the regenerated sand has potential for reuse in the production line along the casting process. Some defects in casting products due to the use of regenerated sand are associated with a high amount of binder. We then opted for the addition of iron oxide in the sand regeneration process, resulting in a production of melts with few defects and the possibility of using large scale regenerated sand in the production line.
\end{abstract}

Keywords: Foundry sand. Mechanical regeneration. Reusing production inputs.

\section{INTRODUÇÃO}

Há uma crescente preocupação a respeito dos riscos e potenciais danos ambientais que a indústria metal mecânica origina. Em especial, a indústria de fundição contribui amplamente para a poluição do ar e solo, devido a utilização de consumíveis em pó e pouca reutilização destes (XIANG et al., 2019). Ao mesmo tempo, indústria de fundição contribui ativamente com a reciclagem de materiais, reutilizando o metal descartado pela sociedade - considerada sucata - como principal matéria prima para produção de seus produtos finais, não sendo necessária a extração do minério das respectivas minas e eliminando os custos com energia para extração e industrialização desse minério (BHARDWAJ \& KUMAR, 2017).

Um dos principais consumíveis, e com alto potencial de reutilização, é a areia, utilizada na confecção dos moldes (SITHOLE, NYEMBWE, \& OLUBAMBI, 2018). O objetivo da realização deste estudo é demonstrar e viabilizar a reutilização da areia no processo de confecção de moldes através do processo de regeneração mecânica, em uma fundição localizada em Pernambuco.

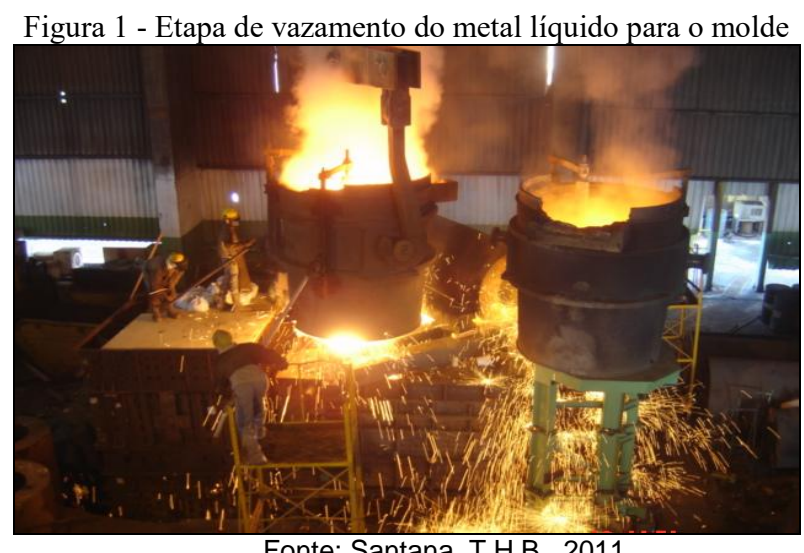

Fonte: Santana, T.H.B., 2011

A areia utilizada no processo de fundição é classificada em dois grupos: Areias a verde, utilizando argila como aglomerante natural e Areias ligadas quimicamente, com adição de material químico como aglomerante e um catalisador para o processo de secagem (BUSCHOW, 2001).

Após o processo de fundição, a areia utilizada para moldagem das peças apresenta, no segundo caso, resíduos de tinta, aglomerante e partículas metálicas. Uma das 
possibilidades de reutilização desta areia, segundo Siddique \& Cachim, (2018), é submeter as indústrias de construção. Outras opções seriam a regeneração desta, fazendo com que areia possa ser reinserida no processo produtivo

\section{METODOLOGIA}

A areia proveniente da desmoldagem das peças fundidas e machos foi inserida no circuito de regeneração mecânica e transportada, conforme esquema da Figura 2.

Figura 2 - Etapas de regeneração mecânica da areia.

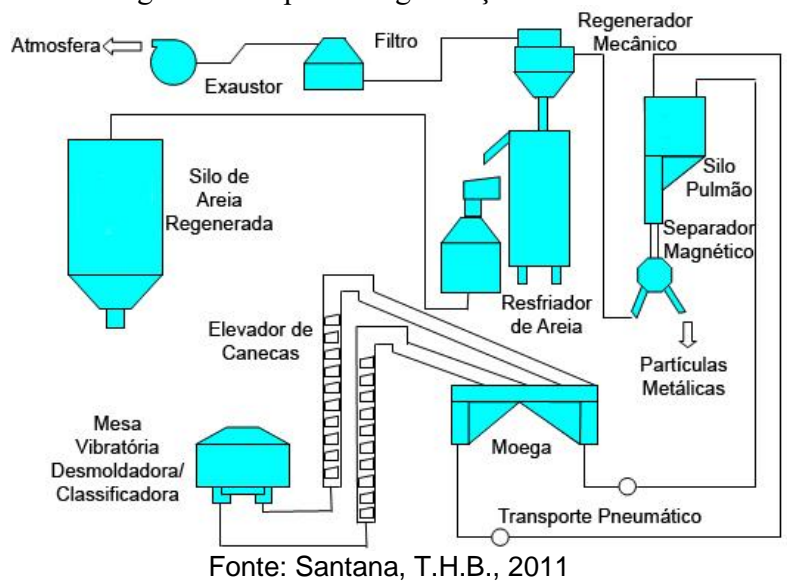

O processo de regeneração é necessário para a reutilização da areia, constituído de diversas etapas. A areia é transportada pneumaticamente até o silo pulmão, responsável pelo armazenamento da areia a ser regenerada, a qual alimentará o separador magnético. O separador magnético tem como principal finalidade reter as partículas metálicas contidas na areia para em seguida descartá-las, continuando para o conjunto regenerador. Ao entrar no conjunto regenerador a areia é projetada contra uma parede cilíndrica, fabricada com material de alta resistência à abrasão. O conjunto regenerador separa, por gravidade, a areia do ar impregnado de partículas em suspensão, chamado de finos. A areia é transportada pneumaticamente até um ciclone, onde acontece a suspensão dos finos. Os grãos mais densos são depositados num vaso resfriador por ação da gravidade. Em temperatura ambiente, a areia é despejada em uma moega e conduzida, por um transportador pneumático, até $\mathrm{o}$ reservatório de areia fria. $\mathrm{O}$ beneficiamento da areia está concluído e o próximo passo é misturá-la ao aglomerante em quantidades previamente definidas.

Três amostras de areia regenerada e areia beneficiada foram analisadas por técnicas de caracterização físicoquímicas e, posteriormente, comparadas. Também foram realizados testes de umidade, densidade, $\mathrm{pH}$, temperatura e porcentagem de finos. Foram produzidas um total de 6 peças utilizando cada tipo de areia.

\section{RESULTADOS}

A partir da metodologia utilizada acima, os resultados obtidos foram discutidos em duas seções, a seguir:

\section{1 - Característica da areia regenerada.}

A tabela 1 fornece valores médios de algumas características encontradas para a areia regenerada e beneficiada, tais como umidade percentual, densidade $\left(\mathrm{kg} / \mathrm{m}^{3}\right), \mathrm{pH}$, temperatura e porcentagem de finos. Houve uma pequena diminuição do $\mathrm{pH}$ e umidade, devido à mistura do aglomerante e do catalisador com a areia, realizada na preparação da mistura durante a confecção dos moldes. Esta pequena variação de $\mathrm{pH}$ e umidade são aceitáveis. O aumento de densidade pode ser atribuído a fenômenos de mecanosíntese atuantes nos processos de aglomeração do grão (KHAN, 2018).

Tabela 1 - Propriedades físico-químicas

\begin{tabular}{cccccc}
\hline Areia & Ph & Umid. & Dens. & Tempe. & Finos \\
\hline Regenerada & 6,48 & $0,06 \%$ & $\begin{array}{c}1,55 \\
\mathrm{~kg} / \mathrm{m}^{3}\end{array}$ & $23^{\circ} \mathrm{C}$ & $5,85 \%$ \\
$\begin{array}{c}\text { Beneficiada } \\
\text { (verde) }\end{array}$ & 6,77 & $0,05 \%$ & $\begin{array}{c}1,43 \\
\mathrm{~kg} / \mathrm{m}^{3}\end{array}$ & $23^{\circ} \mathrm{C}$ & $1,25 \%$
\end{tabular}

Em muitos casos, a areia regenerada utilizada para manufatura dos moldes não alterou a qualidade das peças fundidas. Durante o processo produtivo observou-se que areia regenerada teve comportamento similar a areia nova. $\mathrm{O}$ elevado percentual de finos leva à necessidade ocasional de utilização de resina. Isto pode ser o responsável pela presença de alguns defeitos característicos, tais como porosidade e formação de bolhas nos fundidos (CAMPBELL, 2015).

\section{2 - Testes com areia regenerada.}

Recomendou-se uma segunda produção monitorada das 6 peças fundidas anteriores utilizando a areia regenerada, adicionando-se óxido de ferro $(\mathrm{FeO})$ com objetivo de aumentar a resistência à tração a quente, em todas as peças produzidas, para assim se observar todas as possibilidades de utilização da areia regenerada e reduzir os defeitos encontrados nos fundidos. A Figura 3 ilustra alguns defeitos superficiais que foram encontrados ao final da etapa de desmoldagem. Foi verificado que a areia regenerada adicionada de óxido de ferro apresentou resultados similares à areia nova, no que se refere ao tempo cura, moldabilidade e acabamento dos moldes durante o processo de remoção do modelo.

Figura 3 - Defeitos superficiais provenientes do processo de fusão.

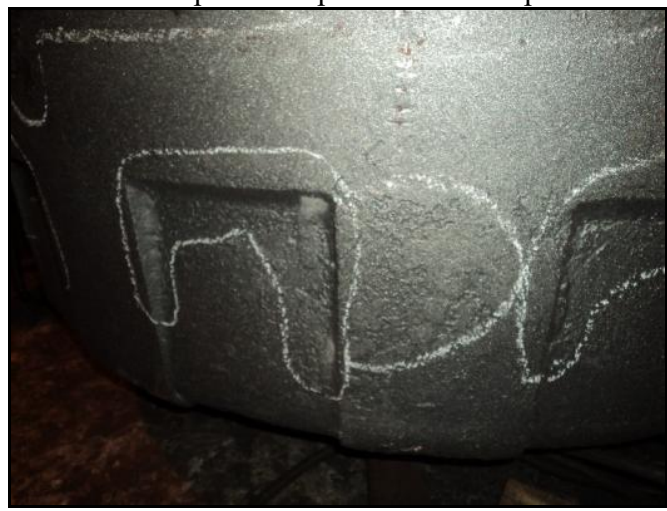

Fonte: Santana, T.H.B., 2011

A areia regenerada utilizada nesta etapa não alterou a qualidade do molde. Durante o processo produtivo observou-se que a areia regenerada atendeu todos os requisitos do processo de fabricação. 


\section{CONCLUSÃO}

Observa-se que a regeneração mecânica de areia de fundição pode proporcionar soluções que reflitam numa diminuição considerável de produção de resíduos sólidos e de redução de custo de fabricação de fundidos. Como resultado da primeira produção monitorada, usando $100 \%$ da areia regenerada, observou-se que a camada de areia que entra em contato com o metal causou alguns defeitos superficiais na peça em função do excesso de resina na areia regenerada, que pode ter ocasionado um acúmulo de gases provocando assim essa falha de acabamento. Para reduzir, ou até eliminar, os defeitos ocasionados pela areia regenerada um teste foi feito, com areia regenerada adicionada de óxido de ferro $(\mathrm{FeO})$ para aumentar a resistência à tração a quente. Resultados satisfatórios foram obtidos com relação à obtenção de produtos fundidos. Neste trabalho foi evidenciado que a regeneração mecânica pode fornecer vantagens às empresas da área de fundição através da redução de custos, minimizando os impactos ambientais e mitigando problemas de alocação e destino final da areia.

\section{REFERÊNCIAS BIBLIOGRÁFICAS}

BHARDWAJ, B.; KUMAR, P. Waste foundry sand in concrete: A review. Construction and Building Materials, v. 156, p. 661-674, dez. 2017.

BUSCHOW, K. H. J. (ED.). Encyclopedia of materials: science and technology. Amsterdam; New York: Elsevier, 2001.

CAMPBELL, J. Complete casting handbook: metal casting processes, techniques and design. 2nd edition ed. Amsterdam: Butterworth-Heinemann, 2015.

KHAN, M. M. et al. Reclamation of used green sand in small scale foundries. Journal of Materials Processing Technology, v. 255, p. 559-569, maio 2018.

SANTANA, T. H. B. Reutilização da Areia de Fundição Através da Regeneração Mecânica. Monografia (Bacharelado em Engenharia Mecânica) - Recife: Universidade de Pernambuco, 2011.

SIDDIQUE, R.; CACHIM, P. (EDS.). Waste and supplementary cementitious materials in concrete: characterization, properties and applications. Duxford, UK Cambridge, MA Kidlington, UK: WP Woodhead Publishing, an imprint of Elsevier, 2018.

SITHOLE, C.; NYEMBWE, K.; OLUBAMBI, P. Process knowledge for improving quality in sand casting foundries: A literature review. Procedia Manufacturing, v. 35, p. 356-360, 2019.

XIANG, R. et al. The potential usage of waste foundry sand from investment casting in refractory industry. Journal of Cleaner Production, v. 211, p. 1322-1327, fev. 2019.

\section{AGRADECIMENTOS}

Os autores gostariam de agradecer ao CNPq, CAPES e FACEPE; à empresa de fundição, localizada em Pernambuco, pela oportunidade de estudo de caso.

\section{COPYRIGHT}

Direitos autorais: $\mathrm{O}(\mathrm{s})$ autor(es) é(são) o(s) único(s) responsável(is) pelo material incluído no artigo. 


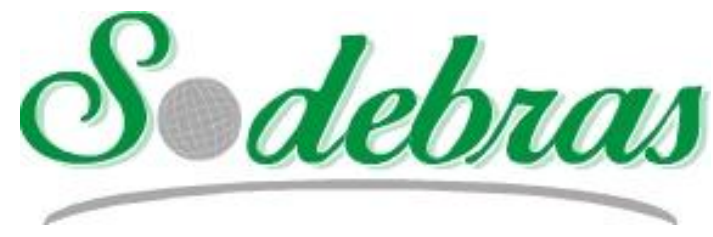

Volume 15 - $\mathrm{N}^{\mathrm{o}} 169$ - Janeiro / 2020

XLI International Sodebras Congress

31 de outubro a 02 de novembro de 2019 - Maceió - AL.

\title{
SISTEMA TERMICO ASISTIDO DE SECADO DE CAFÉ
}

\author{
COFFEE DRYING ASSISTED THERMAL SYSTEM
}

\author{
MAURICIO HERNANDEZ SARABIA1 ${ }^{1,}$ LILIANA DELGADILLO ${ }^{1}$. \\ 1 -UNIVERSIDAD DE IBAGUÉ - COLÔMBIA; GRUPO INVESTIGACIÓN GMAE \\ mauricio.hernandez@unibague.edu.co; liliana.delgadillo@unibague.edu.co
}

\begin{abstract}
Resumen - El beneficio del café es un proceso de poscosecha que genera residuos altamente contaminantes, con contenido de materia orgánica que se pueden convertir en biogás, a través de un proceso de digestión anaeróbico dentro de un biodigestor y luego aprovechar este biogás en diferentes usos energéticos. En este trabajo se plantea el diseño de un sistema asistido de secado de biogás, que consta de un biodigestor, quemador de biogás, un intercambio de calor de flujo cruzado y un sistema de control para aprovechar el biogás producido en el secado de café.
\end{abstract}

Palabras Calves: Biodigestor; Beneficio de café; Biogás; Secado de Café.

\begin{abstract}
The benefit of coffee is a post-harvest process that generates highly polluting waste, which contains organic material that can be converted into biogas, through an anaerobic digestion process within a biodigester and to provide this biogas in different energy uses. In this work is planted the design of a biogas assisted drying system. The system consisting of a biodigester, biogas burner, cross flow heat exchange and a control system to supply the biogas as energy for the drying green coffee process.
\end{abstract}

Keywords: Biodigestor; Coffee post-harvest; Biogas; Coffee dried process

\section{INTRODUCCION}

El sistema de secado de café soportado con biogás, busca aprovechar los residuos orgánicos generados en el proceso de beneficio del café más los residuos orgánicos generados en la actividad diaria de la finca, como residuos de comida, aguas residuales domésticas, estiércol de ganado, estiércol de cerdo y demás material orgánico que se generé, para producir biogás el cual energéticamente se utilizará para el secado de café pergamino.

Todo el material orgánico recolectado será alimentado a un biodigestor que mediante el proceso de digestión anaerobia se encargara de hacer la conversión de los residuos orgánicos a Biogás. Este biogás generado tendrá un componente de Metano estimado entre el 50 y $80 \%$ (Valencia \& Zambrano, 2010), con lo que se pretende generar energía renovable, limpia que puede ser utilizada en el proceso de secado de café, para suministrar energía de soporte al secado solar.

Para aprovechar la energía, es necesario tener un quemador donde se realice la combustión del Metano presente en el biogás y se genere energía que será transportada por los gases de combustión, hacia un intercambiador de tubos de flujo cruzado, que tiene como Volume 15 - No 169 - Janeiro/2020 objetivo realizar la transferencia de energía al aire que será utilizado en el secado de café. El sistema de secado asistido por biogás, como se ha denominado a este tipo de sistema es diseño del grupo de investigación GMAE de la Universidad de Ibagué, basado en la experiencia que se tiene en la investigación de digestión anaerobia y producción de biogás de diferentes residuos orgánicos agroindustriales.

El biogás, puede ser una solución a la falta de acceso a servicios energéticos modernos, la pobreza, el cambio climático y los problemas relacionados con la fertilidad del suelo. Se trata de una fuente de energía simple y económica que no es difícil de gestionar y de fácil mantenimiento. (Wamars \& Oppenoorth, 2014)

Un factor adicional, pero que tiene gran relevancia, es que con el biodigestor se va a tratar la materia orgánica que como residuos se genera en el beneficio de café, evitando que esta se vierta sin ningún tipo de tratamiento a las fuentes hídricas generando contaminación y degradación de las mismas. En Colombia generalmente el beneficio del café se hace de forma húmeda y la contaminación generada por el procesamiento de una arroba de café pergamino seco $(12,5$ $\mathrm{kg}$ ), equivalen a la contaminación generada por 100 habitantes/día (Zuluaga \& Zambrano, 1993)

\section{METODOLOGIA}

La metodología utilizada se dividió en dos partes: la primera fue exploratoria y descriptiva, tomando como base una amplia bibliografía sobre la producción de biogás a partir de diferentes tipos de residuos generados en las fincas cafeteras y entendiendo el proceso de digestión anaerobia para la conversión de estos residuos en biogás y el estudio del funcionamiento de los diferentes tipos de bioreactores existentes. La segunda parte se realizo un propuesta técnica de diseño de un sistema térmico asistido, que utilice el biogás generado por la digestión anaerobia de los residuos orgánicos, para calentar aire, que posteriormente se inyectará a un secador solar parabólico. El sistema se denomina asistido porque es energía adicional al secado solar. Con este suministro se pretende tener tempos de secado estable, independiente de la temperatura ambiente y radiación solar. El excedente de biogás producido, se utilizará directamente en la cocción de alimentos em cada una de las fincas cafeteras.

\section{RESULTADOS y DISCUSION}

Em la figura 1, podemos observar el sistema térmico asistido para secado de café, el cual consta de: un 
biodigestor tipo Taiwan de $4 \mathrm{~m}^{3}$ de membrana de PVC, un intercambiador de flujo cruzado de un solo paso de 20 tubos de acero de $3 / 4$ " de $50 \mathrm{~cm}$ de largo, un ventilador centrifugo de $0.5 \mathrm{hp} \mathrm{de} 4$ " y un sistema de control automático que consta de termocupla tipo $\mathrm{j}$ y variador de frecuencia acoplado al motor del ventilador. En la figura 1 se puede observar un esquema del sistema térmico asistido.

Figura 1: Esquema sistema térmico asistido

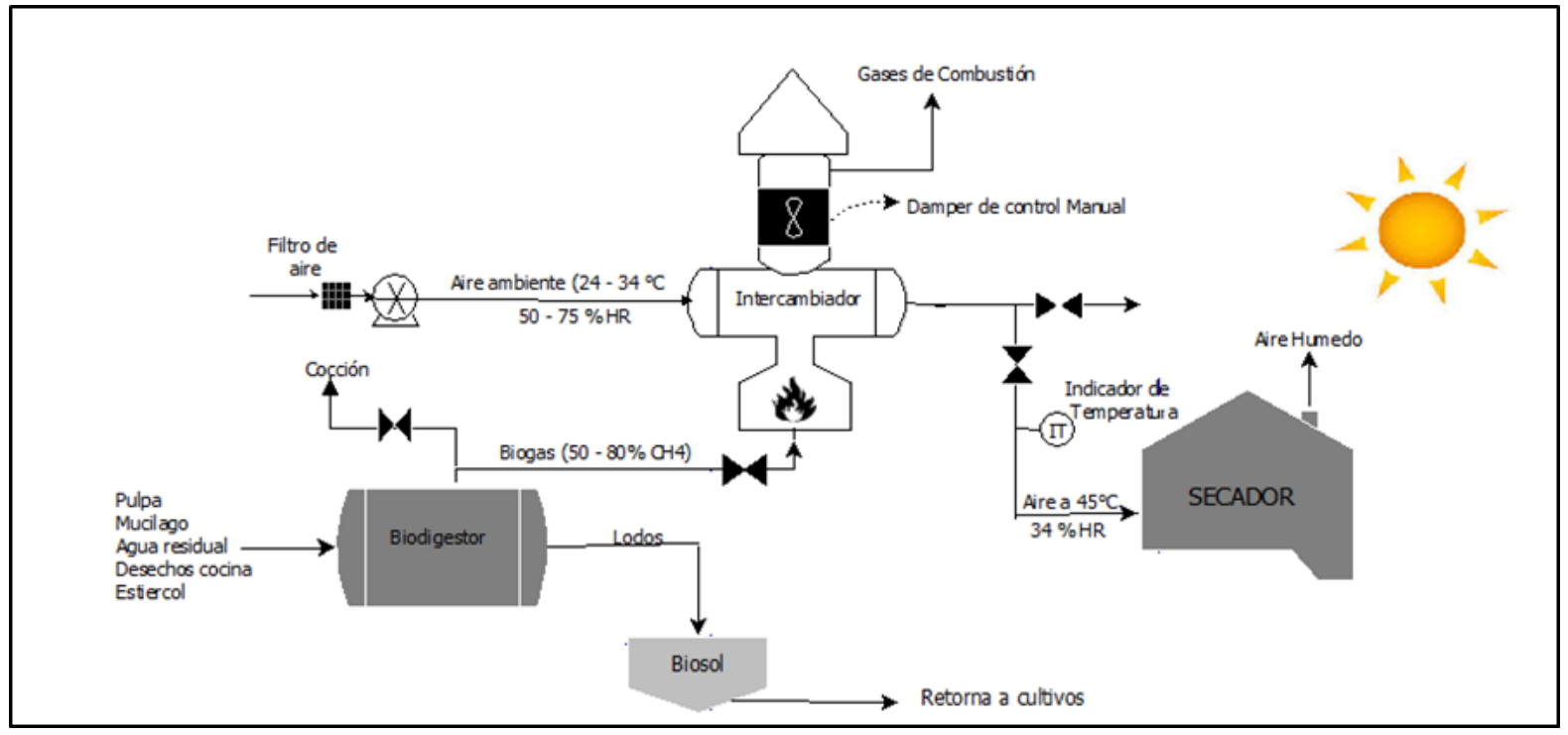

Fuente: Autores

Con el sistema se es pera disminuir el tempo de secado actual, que em promedio para $125 \mathrm{~kg}$ de café está em 144 horas em promedio a 18 horas. De esta forma se puede mantener una producción estable y controlar los defectos em taza que se pueden generar por un secado deficiente.

Teniendo como base de cálculo, el dato de $1000 \mathrm{~kg}$ de café cereza por día, entregado por la federación de cafeteros sede Ibagué, como la cantidad pico, que se puede producir en una finca cafetera del sur del Tolima con área sembrada entre 3 a 5 hectáreas; se producen $436 \mathrm{~kg}$ de pulpa y $149 \mathrm{~kg}$ de mucilago por día, de acuerdo con los reportes realizados por los investigadores de Cenicafe. (Valencia \& Zambrano, 2010). La cantidad de biogás y de energía que se puede obtener para el proceso se estima en $6,2 \mathrm{kw}$, con lo cual es suficiente para la producción de $480 \mathrm{~kg} /$ día de café pergamino seco.

Figura 2: Balance de masa y energía sistema asistido para café

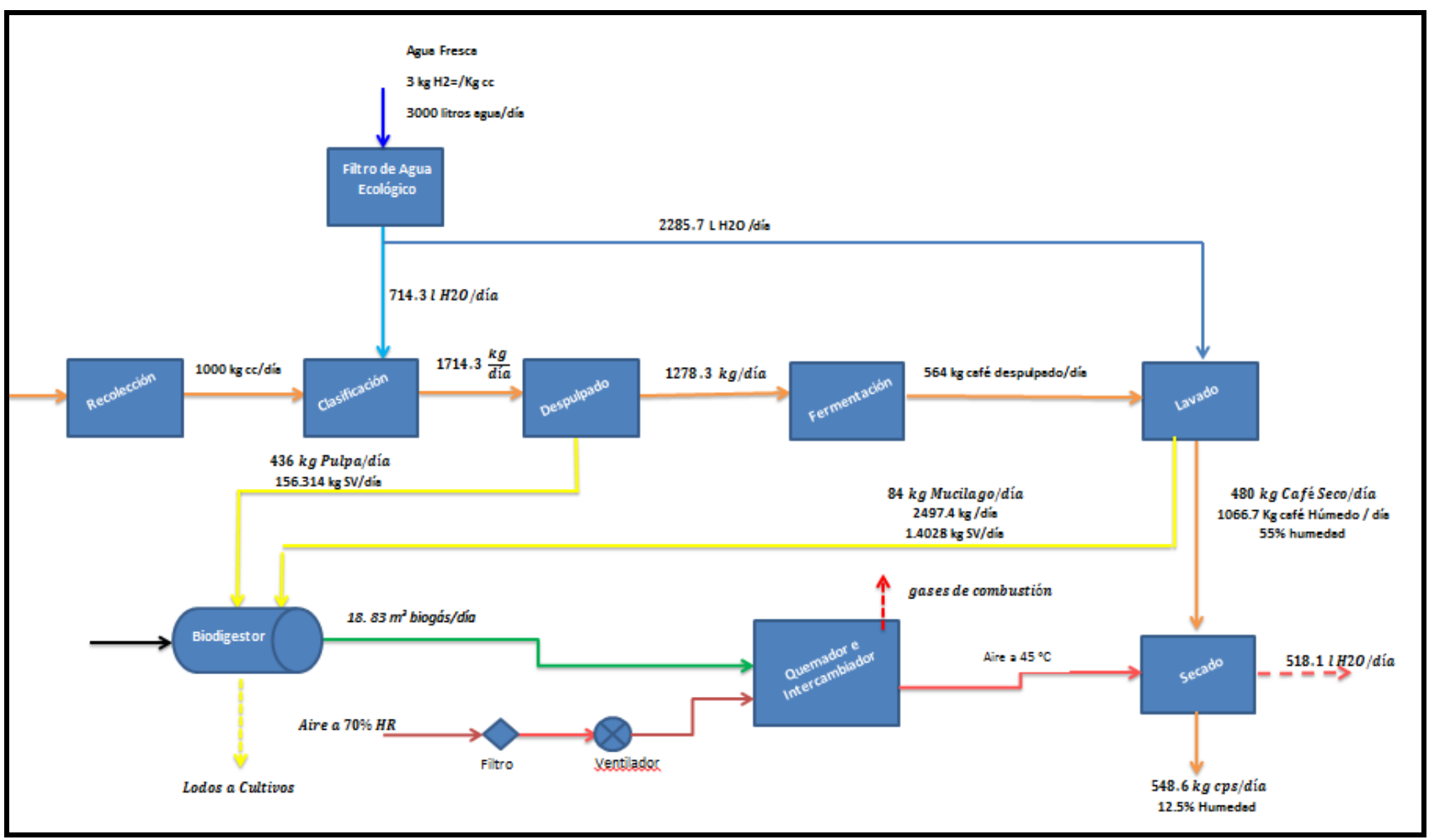

Fuente: Autores 
Con la cantidad de materia orgánica de $585 \mathrm{~kg} /$ día generada en el proceso de beneficio de café cereza, se realizó el dimensionamiento del biodigestor tipo Taiwan, teniendo en cuenta las recomendaciones dadas por (Valencia \& Zambrano 2010; Martí, 2019; Fajardo 2015; Guardo 2012; Olaya \& Gonzalez, 2010; Zambrano, etal. 2010). tabla 1.

Las características del biodigestor se presentan en la

Tabla 1: Características del biodigestor

\begin{tabular}{|l|l|}
\hline $\begin{array}{l}\text { Material: Geo membrana } \\
\text { en PVC } 1005\end{array}$ & $\begin{array}{l}\text { 1. Geo membrana } \\
\text { 2. Entrada de material } \\
\text { Diámetro: } 0.8 \mathrm{~m}\end{array}$ \\
\hline Longitud: $8 \mathrm{~m}$ & \\
\hline Volumen Total: $4 \mathrm{~m}^{3}$ & \\
\hline $\begin{array}{l}\text { Tiempo de retención: } 35 \\
\text { días }\end{array}$ & \\
\hline Válvula salida PVC $1 / 2 "$ & \multirow{2}{*}{ (2) } \\
\hline Energía generada: $6.2 \mathrm{kw}$ & \\
\hline
\end{tabular}

Fuente: Autor

El Quemador de biogás, tiene como función realizar la combustión del biogás, tiene una entrada de aire en la parte inferior y se mezcla con el biogás que ingresa por la boquilla. Los gases de combustión generados transportarán la energía que luego es transferido por intermedio de un intercambiador de coraza y tubos al aire que ingresará al secador. Tiene en la parte superior una chimenea con un sistema de dámper, para controlar el tiempo de residencia de los gases y por lo tanto la temperatura del aire de secado (Max. $45^{\circ} \mathrm{C}$ ). Es un sistema manual, de fácil operación, diseñado por el grupo de investigación GMAE de la Universidad de Ibagué. Las características principales se relacionan en la tabla 2.

Tabla 2: Características del quemador - intercambiador

\begin{tabular}{|l|l|}
\hline \multicolumn{1}{|c|}{ Ítem } & \multicolumn{1}{|c|}{ Descripción } \\
\hline Motor eléctrico & $0.75 \mathrm{HP}-110 \mathrm{vca}$ 3600 rpm \\
\hline Ventilador & Centrifugo de 4 “ \\
\hline $\begin{array}{l}\text { Chimenea en acero al } \\
\text { carbono de 4" }\end{array}$ & $\begin{array}{l}\text { Diámetro 4",Largo 50 cm, } \\
\text { acero al carbono Sch. 40 }\end{array}$ \\
\hline Coraza del intercambiador & $\begin{array}{l}8 \text { Pulgadas Schedule 40, Un } \\
\text { solo paso }\end{array}$ \\
\hline Tubos de acero al carbono & $\begin{array}{l}20 \text { tubos de 50 cm x 3/4” } \\
\text { Schedule 40 }\end{array}$ \\
\hline $\begin{array}{l}\text { Salida en Tubería de } \\
\text { Acero al carbono }\end{array}$ & 1 de diámetro, sch 40 \\
\hline Filtro de aire tipo fieltro & Área 40x40 cm, \\
\hline
\end{tabular}
Fuente: Autor

Los materiales, son resistentes y de bajo costo, siendo accequibles por los caficultores de la región, el modulo completo instalado de acuerdo con análisis de precios unitarios, teniendo en cuenta la instalación está en US \$ 1370 .

El biogás producido puede ser utilizado para secado de café y se deja la opción de cunado no se esté secando café, pueda ser utilizado para cocción, con lo cual se reduce el

Volume 15 - No 169 - Janeiro/2020 consumo de leña, teniendo en cuenta que $1 \mathrm{~m} 3$ de biogás, puede reemplazar $1.304 \mathrm{~kg}$ de madera (Martí 2019).

Además se tiene que se genera un subproducto de la salida del biodigestor, que son los lodos digeridos que salen en forma líquido y que se denomina Biol, el cual puede utilizarse para mejorar la fertilidad del suelo, su estructura y el rendimiento en los cultivos. (Wamars \& Oppenoorth, 2014).

\section{CONCLUSIONES}

La producción de energía renovable a partir de residuos orgánicos de las fincas cafeteras es una solución energética para estabilizar el proceso de secado y mejorar la calidad del café colombiano. Esta solución además de aportar energía, disminuye el impacto ambiental de las fincas cafeteras por el vertimiento directo de los residuos generados en el proceso del café, en las fuentes hídricas cercanas.

La solución planteada es de fácil instalación, costo accequible y fácil mantenimiento y operación, lo cual lo hace una excelente solución energética para los caficultores dela región del Tolima. Además produce un subproducto denominado Biol, el cual tiene aplicación como fertilizante y mejorador de suelos.

\section{REFERENCIAS BIBLIOGRÁFICAS}

GUARDO, P., Yans. Estudio de la digestión anaerobia en dos fases para el tratamiento de aguas residuales de despulpe del beneficio húmedo del café. Tesis Doctoral. Universidad politécnica de Madrid, Escuela Técnica superior de Ingenieros Agrónomos. 2012.

FAJARDO, M., Sandra. Obtención de biogás a partir de la pulpa de café y estiércol de res. Revista Universidad de Guayaquil. No 121. 2015

MARTI, H., Jaime. Biodigestores tubulares, Gua de diseño y manual de operación. Redbiolac, Ecuador. ISBN 978-9942-36276-6. 2019.

OLAYA, A.; Gonzalez L. Fundamentos para el diseño de biodigestores. Bogotá: Universidad Nacional de Colombia - Sede Palmira. 2010.

VALENCIA, N.; Zambrano, D. Los subproductos del café: fuente de energia renovable. Cenicafe, Avances técnicos, 1-8. 2010

WAMARS, L., Oppenoorth, H. El Biol: El fertilizante supremo. Estudios sobre el Biol y sus resultados. ISBN 978-90-70435-10-3. 2014.

ZAMBRANO, D., Rodriguez, N., Orozco, A., \& Lopez, U. Evaluación de un reactor metanogénico tipo filtro anaeróbico de flujo ascendente para tratar aguas mieles del café. Cenicafé, $66(1)$, $32-45.2010$

ZULUAGA, J. Zambrano, D. Manejo del agua en el proceso de beneficio húmedo del café para el control de la contaminación. Avances técnicos Cenicafe No 187, 1993.

\section{AGRADECIMENTOS}

Gobernación del Tolima por apoyar en el financiamiento del proyecto código BPIN 2016000100049 Innovación de procesos a nivel de poscosecha para la incorporación de valor agregado en la diferenciación de cafés especiales del Tolima, convenio especial de cooperación No 1874-2018. A la Universidad de Ibagué por el apoyo financiero, técnico y administrativo proyecto Código 18-487-ESP. 


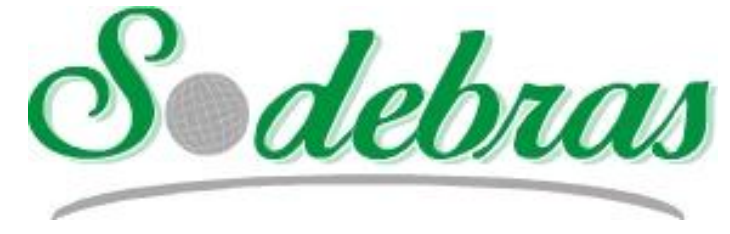

Volume 15 - $\mathrm{N}^{\mathrm{o}} 169$ - Janeiro / 2020

XLI International Sodebras Congress

31 de outubro a 02 de novembro de 2019 - Maceió - AL.

\title{
A REALIDADE DO TRABALHADOR RURAL EXPOSTO AOS AGROTÓXICOS
}

\section{THE REALITY OF THE RURAL WORKER EXPOSED TO THE AGROCHEMICALS}

\author{
JÉSSICA PRISCILA DA SILVA LIMA ${ }^{1}$; TALITA MARIA GOMES DE MORAIS ${ }^{1}$ \\ INSTITUTO FEDERAL DE ALAGOAS ${ }^{1}$ \\ jessicapriscilalima@hotmail.com; talitamgm@hotmail.com
}

\begin{abstract}
Resumo - Os agrotóxicos estão presentes na rotina de inúmeros produtores e trabalhadores rurais. Pela ótica de pesquisadores, estima-se que mais de 25 milhões de trabalhadores são afetados pelos agrotóxicos anualmente. Objetiva-se verificar as ações de segurança e saúde ocupacional voltadas para os trabalhadores rurais que lidam com agrotóxicos. Trata-se de uma revisão de literatura, realizada entre março e maio de 2019. Em determinado estudo, $100 \%$ dos trabalhadores informaram não haver o fornecimento de EPI. Em Alagoas, a área de maior risco de intoxicação por agrotóxicos foi o ambiente de trabalho, $96 \%$ em 2014, e 248 notificações de intoxicação entre 2010 e 2015. É fundamental o reforço $e$ a efetividade das medidas de prevenção, de fiscalização, de conscientização, assim como, a intensificação da vigilância em saúde ocupacional, em virtude do expressivo número de intoxicação por agrotóxicos no ambiente de trabalho.
\end{abstract}

Palavras-chave: Agrotóxico. Exposição ocupacional. Riscos químicos. Segurança do trabalho. Trabalhador rural.

\begin{abstract}
The agrochemicals are present in the routine of numerous producers and rural workers. From the perspective of researchers, it is estimated that more than 25 million workers are affected by pesticides annually. The objective is to verify occupational health and safety actions for rural workers dealing with pesticides. This is a literature review carried out between March and May 2019. In Alagoas, the area at greatest risk of pesticide poisoning was the work environment, $96 \%$ in 2014, and 248 notifications of admission between 2010 and 2015. It is fundamental to reinforce measures of prevention, control, awareness, as well as an intensification of surveillance in occupational health, due to the significant number of intoxications by pesticides in the work environment.
\end{abstract}

Keywords: Agrotoxic. Occupational exposure. Chemical hazards. Workplace safety. Rural worker.

\section{INTRODUÇÃO}

No período de modernização da agricultura e, principalmente, a partir de 1975 com o surgimento do Plano Nacional de Desenvolvimento (PND), houve uma intensa expansão da produção e do uso de agrotóxicos, situação de aumento gradativo no Brasil. Os agrotóxicos estão presentes na rotina de inúmeros produtores e trabalhadores rurais (BEGNINI \& TAVEIRA, 2014).

Devido aos inúmeros problemas que ocorrem no meio agrícola, os produtores passaram a adotar medidas de controle através do uso de agrotóxicos, porém, a utilização correta e racional nem sempre é a realidade (LEITE et al., 2016).
$\mathrm{O}$ alto investimento em produtos agroquímicos tem ocasionado o aumento de produtividade favorecendo os setores econômicos, em contrapartida, tem provocado uma série de prejuízos à saúde dos trabalhadores. Pela ótica de pesquisadores, estima-se que mais de 25 milhões de trabalhadores são afetados por agrotóxicos anualmente (MORIN \& STUMM, 2018; SILVA et al., 2014).

A toxicidade é uma característica própria dos agrotóxicos que pode provocar sérios danos à saúde, variando de acordo com o seu princípio ativo, a dose absorvida, o tipo de exposição e os aspectos individuais de cada pessoa que esteja exposta aos agentes químicos oriundos desses produtos (BRASIL, 2016).

É imprescindível um aperfeiçoamento nos setores de saúde e de segurança do trabalho voltado para a realidade do trabalhador rural exposto a agrotóxicos, onde se detecta elevados números de intoxicação, subnotificações e ações inseguras no ambiente de trabalho, especialmente, relacionadas ao inadequado uso de Equipamento de Proteção Individual. (VIERO et al., 2016).

A partir de uma revisão sistemática, este estudo objetivou verificar as ações de segurança e saúde ocupacional voltadas para os trabalhadores rurais que lidam com agrotóxicos.

\section{METODOLOGIA}

O presente estudo trata-se de uma revisão de literatura, norteada pela seguinte pergunta: quais as ações de segurança e saúde ocupacional voltadas para os trabalhadores rurais que lidam com agrotóxicos? Diante dessa problemática foi realizada a busca nas bases de dados Biblioteca Virtual em Saúde (BVS), Literatura Latino-americana e do Caribe em Ciências da Saúde (LILACS), Scientific Electronic Library Online (SCIELO) e Google Acadêmico, no período de março a maio de 2019, utilizando os seguintes termos: segurança do trabalho e agrotóxicos, agrotóxicos e trabalhador rural, agrotóxicos e EPI, condições de trabalho e pesticidas, exposição ocupacional aos agrotóxicos, doenças ocupacionais e agrotóxicos.

A partir da leitura do tema e do resumo das publicações encontradas, foram selecionadas apenas as de idioma português, indexadas no período de 2014 a 2019 e que estivessem em concordância com o objetivo deste estudo. Houve a necessidade de também incluir outro tipo de material, como: lei federal, decreto e normas regulamentadoras. Foram excluídos dissertações, cartilhas, 
artigos duplicados, outros tipos de revisão e artigos que não apresentaram dados relevantes.

De acordo com os critérios, foram selecionadas 81 publicações, mas apenas 32 entraram para este estudo, sendo: 26 artigos científicos, 2 produções bibliográficas, 2 normas regulamentadoras, 1 Lei Federal e 1 Decreto.

\section{RESULTADOS}

Durante este estudo, foi possível perceber que vários fatores podem contribuir para o agravamento da exposição dos trabalhadores aos agrotóxicos, como por exemplo, a falta de conhecimento sobre estes produtos ou sobre a maneira correta de utilizá-lo.

\subsection{O Conhecimento dos Trabalhadores sobre os Agrotóxicos}

Grande parte dos trabalhadores que lidam com agrotóxicos desconhecem os riscos dessas substâncias químicas, e a baixa escolaridade bastante expressiva nessa classe de trabalhadores, torna-se um fator agravante (MANZOLI, IGUTI \& MONTEIRO, 2018; SANTANA et al., 2016).

No estudo de Miorin et al. (2016), os trabalhadores relataram que os agrotóxicos beneficiam o cultivo, mas admitiram que prejudicam o meio ambiente, a saúde dos trabalhadores e dos consumidores, e os tratam como veneno. Além disso, declararam que é a forma encontrada para controlar pragas e não perder produtividade. Em Leite $e t$ al. (2016) também foi observado que os trabalhadores demonstraram falta de conhecimento sobre outros métodos de controle.

Viero et al. (2016) constataram que existe ainda o conformismo por parte dos trabalhadores em achar que os riscos são naturais do agronegócio e que são incapazes de agir de outra forma perante essas condições de trabalho, ou seja, que nada podem fazer.

A seguir, no Quadro 1, constam os percentuais encontrados de trabalhadores que possuíam algum tipo de conhecimento sobre os agrotóxicos.

Quadro 1 - Estudos relacionados aos trabalhadores e o conhecimento sobre agrotóxicos.

\begin{tabular}{|l|l|}
\hline \multicolumn{1}{|c|}{ Autor/Ano } & \multicolumn{3}{|c|}{$\begin{array}{c}\text { Trabalhadores e o conhecimento } \\
\text { sobre agrotóxicos }\end{array}$} \\
\hline $\begin{array}{l}\text { Tokarski, França \& } \\
\text { Lacerda (2019) }\end{array}$ & $\begin{array}{l}51,6 \% \text { tiveram orientações preventivas } \\
\text { sobre agrotóxicos. }\end{array}$ \\
\hline Castro et al. (2018) & $\begin{array}{l}82,05 \% \text { desconheciam a classificação } \\
\text { toxicológica dos agrotóxicos. }\end{array}$ \\
\hline Pedro et al. (2018) & $\begin{array}{l}50 \% \text { desconheciam os impactos } \\
\text { socioambientais ocasionados pelos } \\
\text { agroquímicos. }\end{array}$ \\
\hline Silva et al. (2017) & $\begin{array}{l}90,28 \% \text { sabiam sobre os danos que os } \\
\text { agrotóxicos podem causar à saúde. }\end{array}$ \\
\hline $\begin{array}{l}\text { Santana et al. } \\
\text { (2016) }\end{array}$ & $\begin{array}{l}94,1 \% \text { reconheciam os riscos dos } \\
\text { agrotóxicos à saúde. }\end{array}$ \\
\hline Silva et al. (2014) & $\begin{array}{l}79 \% \text { não tiveram informações sobre } \\
\text { agrotóxicos. }\end{array}$ \\
\hline
\end{tabular}

Fonte: Elaborado pelas autoras (2019)

\subsection{A Variedade de Agrotóxicos nas Atividades Agrícolas}

No que tange à variedade de agrotóxicos utilizados, Pignati, Oliveira \& Silva (2014) constataram o uso de mais de um tipo de agrotóxico, e o cultivo simultâneo de várias lavouras resultava em múltipla exposição dos trabalhadores, dos moradores próximos e do meio ambiente, ameaçando a saúde humana e ambiental.
Abreu \& Alonzo (2016) viram que nas 81 propriedades pesquisadas, eram utilizados 127 tipos de agrotóxicos com variação de 54 grupos químicos distintos, sendo $40 \%$ de classe I (extremamento tóxico) e de classe II (altamente tóxico). Já Cezar-Vaz et al. (2016) em pesquisa com 331 trabalhadores rurais, constataram que $52,20 \%$ utilizavam produtos com classificação medianamente tóxico: acefato e deltrametrina, e 35,84\% utilizavam com classificação pouco tóxico: glifosato.

De acordo com o relato de caso de um trabalhador rural estudado por Neto, Andrade \& Felden (2018), ele fazia uso de 3 diferentes tipos de agrotóxicos: deltametrina, pendimetalina e metalaxil-M. Semelhante ao estudo de Viero et al. (2016), onde todos os trabalhadores rurais também utilizavam mais de uma classe de pesticida: herbicida, fungicida e inseticida. Já Maia et al. (2018) verificaram através de notificações que os agrotóxicos mais utilizados pelos trabalhadores da agropecuária em Alagoas e que motivaram casos de intoxicação entre os anos 2010 e 2015, foram: $64,32 \%$ herbicidas e $30,81 \%$ inseticidas.

\subsection{A Utilização de Agrotóxicos pelos Trabalhadores Rurais}

$\mathrm{O}$ uso descontrolado de agrotóxicos oferece grandes riscos ao meio ambiente e atinge negativamente a saúde pública, visto que há o aumento de casos de intoxicações por exposição ocupacional e de custos com tratamento (CARDOSO et al., 2017)

Percebe-se que existe um estímulo financeiro aos agricultores para que sejam utilizados variados agrotóxicos no plantio, ocasionando o uso desenfreado e aumentando as chances de danos aos trabalhadores, aos consumidores e aos indivíduos que residem próximo às áreas de aplicação (MANZOLI, IGUTI \& MONTEIRO, 2018).

$\mathrm{O}$ controle químico deve ser realizado com base em conhecimentos importantes, como: monitoramento do surgimento de pragas e possíveis doenças; decisão de aplicação ou não; definição do produto que será utilizado; tecnologia envolvida na aplicação; uso de EPI e de outras ações de segurança do trabalho; descarte correto das embalagens e resíduos, para que se atenuem os riscos de contaminação do meio ambiente e intoxicação dos trabalhadores (LEITE et al., 2016).

\subsection{Aquisição, Transporte, Armazenamento e Aplicação de Agrotóxicos}

No estudo de Pedro et al. (2018), 87,5\% dos produtores adquiriram os produtos auxiliados por uma assistência técnica. Em Santana et al. (2016), 87,4\% compravam em casas comerciais de agropecuária e $92 \%$ declararam nunca ter utilizado receituário agronômico, alguns relataram não saber do que se tratava. Silva et al. (2014) relataram que existe uma preocupação quanto ao fato de muitos locais venderem agrotóxicos de forma descontrolada e sem visitas técnicas.

Segundo a lei federal 7.802 de 1989 , em seu artigo 13 , a venda de agrotóxicos e afins só pode ocorrer por meio de receituário próprio, prescrito por profissional legalmente habilitado, exceto em casos excepcionais (BRASIL, 1989).

No que se refere ao armazenamento dos agrotóxicos, somente o estudo de Pedro et al. (2018) mostrou dados quantitativos, onde apenas $45,8 \%$ das propriedades possuíam local adequado para guardar os produtos.

É importante atentar-se à temperatura do local de armazenamento. Altas temperaturas podem elevar a pressão 
interna da embalagem, danificando-as e aumentando os riscos de intoxicação ao manuseá-las e ao absorver gases e vapores que podem escapar das embalagens que apresentarem rupturas (SILVA et al., 2014).

Já com relação ao transporte, na pesquisa de Abreu \& Alonzo (2016) notou-se que devido às características socioeconômicas dos agricultores, as medidas de segurança não eram obedecidas, visto que os agricultores não as conheciam. Os autores reforçam que, segundo as normas de segurança, o transporte de agrotóxicos deve ser feito de forma exclusiva e em caminhonete ou caminhões devidamente adaptados com equipamentos que possibilite o transporte seguro.

Tratando-se da aplicação, no estudo de Silva et al. (2014), 40\% aplicavam agrotóxicos uma vez por semana. $18 \%$, duas vezes por semana. Quantidade superior às recomendações. Já em Pedro et al. (2018), 50\% dos produtos eram aplicados de forma correta e controlada, com anotações das áreas ou glébas tratadas, data de aplicação, quantidade utilizada, e nome do aplicador. Em Cezar-Vaz et al. (2016), 47,4\% dos trabalhadores aplicavam e 52,6\% auxiliavam na aplicação.

Os participantes da pesquisa de Viero et al. (2016) aplicavam os agrotóxicos pelos métodos de pulverização aérea e mecânica através de trator. Diferente do estudo de Sitoe, M., Moiane e Sitoe, C. (2017), onde 90\% utilizavam pulverizadores costais para a aplicação.

\subsection{Exposição Ocupacional aos Agrotóxicos}

A exposição aos agrotóxicos é caracterizada como um importante problema no âmbito da saúde pública. Até mesmo os que não trabalham diretamente com esses produtos podem estar expostos aos riscos químicos (BRASIL, 2016; CASTRO et al., 2018).

De acordo com a Norma Regulamentadora NR-31, os trabalhadores que manipulam agrotóxicos e afins, são os de exposição direta, em quaisquer ações, como no armazenamento, transporte, preparo, aplicação, descarte, limpeza de equipamentos e vestimentas de segurança. Os de exposição indireta não os manipulam, porém, executam atividades laborais em áreas próximas dos locais de aplicação ou em áreas recém-tratadas (BRASIL, 2005).

Sobre os agricultores estudados por Silva et al. (2014), $83 \%$ utilizavam os fitossanitários há mais de cinco anos e grande parte já utilizavam há décadas, com o risco de efeito cumulativo. Os próprios produtores realizavam a preparação da calda e diluição dos agrotóxicos, geralmente, feitos de forma incorreta, com baixas ou altas concentrações, produzida próximo de lavouras e de águas utilizadas na irrigação. E 34\% reutilizavam a calda várias vezes em uma mesma plantação para que não houvesse sobra, aumentando as chances de intoxicação.

Em Ribeiro \& Silva (2018), 70\% dos trabalhadores expostos aos agrotóxicos, trabalhavam mais de 40 horas por semana. De acordo com a pesquisa de Murakami et al. (2017), a jornada de trabalho dos fumicultores era prolongada e intensa nas fases de secagem do fumo e confecção de "bonecas" das folhas. Possuíam contato direto com vários agrotóxicos de nível alto de toxicidade, em repetidas vezes e, praticamente, em todas as etapas do cultivo, ou seja, da semeadura até o desenvolvimento completo da planta. Os trabalhadores ainda manipulavam agrotóxicos de alta toxicidade em equipamento costal e sem o auxílio técnico.
Em Manzoli, Iguti \& Monteiro (2018), ao relacionar as variáveis "saúde" e "contato com agrotóxicos", $60 \%$ dos trabalhadores com funções de exposição aos agrotóxicos, declararam estar com a saúde pior ou um pouco pior, comparados aos não expostos.

\subsection{O Uso de Equipamento de Proteção Individual}

Segundo a Norma Regulamentadora NR-6, subitem 6.1, Equipamento de Proteção Individual (EPI) é o dispositivo ou produto utilizado individualmente pelo trabalhador, que visa protegê-lo dos riscos ocupacionais totalmente incompatíveis com a segurança e saúde do trabalho. A utilização dos EPI é primordial para contribuir na prevenção de acidentes, desconfortos, intoxicações por agrotóxicos (BRASIL, 1978; PIGNATI, OLIVEIRA \& SILVA, 2014).

Pignati, Oliveira \& Silva (2014), revelaram um dado preocupante de seu estudo, onde $100 \%$ dos trabalhadores informaram que nenhuma contratante fornecia EPI, em um dos relatos, o trabalhador informou que aquisição e o uso de EPI só acontecia se fosse por conta própria.

Viero et al. (2016) perceberam um descaso para a utilização de EPI. Alguns trabalhadores declararam que na etapa de pulverização não é necessário utilizar, pois acreditavam estar protegidos pela cabine do trator, ou seja, havia uma ingenuidade numa situação de maior exposição aos riscos de intoxicação pelos agroquímicos

Em Silva et al. (2017), 83,33\% dos trabalhadores relataram a falta de uso de EPI devido ao incômodo que causam. Silva et al. (2014) disseram sobre a própria pesquisa que, não houve confirmação de que os EPI estavam adequados para as atividades laborais e para a variação de clima da região. Complementam que os trabalhadores justificaram a falta de uso pelo desconforto, dificuldade de mobilidade e elevação da temperatura.

Segundo Veiga, Almeida \& Duarte (2016), os EPI que são projetados para evitar o contato do trabalhador com o ambiente ou com atividades com agrotóxicos, dificultam a troca térmica, interferindo a termorregulação do corpo. Afirmaram que grande parte dos EPI utilizados nas atividades agrícolas não são desenvolvidos para este tipo de trabalho, pois na realidade são desenvolvidos para a indústria e adaptados na agricultura

O Quadro 2 explicita a utilização dos EPI por parte dos trabalhadores rurais, de acordo com a compilação dos estudos desta revisão.

Quadro 2 - A utilização de EPI pelos trabalhadores envolvidos com agrotóxicos.

\begin{tabular}{|c|c|}
\hline Autor/Ano & \% Uso do EPI \\
\hline $\begin{array}{l}\text { Tokarski, } \\
\text { França \& } \\
\text { Lacerda (2019) }\end{array}$ & $\begin{array}{l}41,4 \% \text { relataram usar luvas, } 34,5 \% \\
\text { camisa de manga longa, } 31 \% \text { roupas } \\
\text { descartáveis. }\end{array}$ \\
\hline $\begin{array}{lll}\text { Castro et al. } \\
(2018)\end{array}$ & $\begin{array}{l}74,36 \% \text { reconheceram a importância do } \\
\text { uso do EPI, mas apenas } 38,46 \% \text { faziam } \\
\text { uso. }\end{array}$ \\
\hline $\begin{array}{l}\text { Manzoli, Iguti } \\
\& \quad \text { Monteiro } \\
(2018)\end{array}$ & $56,6 \%$ disseram utilizar EPI. \\
\hline $\begin{array}{lr}\text { Neto, } & \text { Andrade } \\
\& & \text { Felden } \\
(2018) & \\
\end{array}$ & $\begin{array}{l}\text { O agricultor alegou utilizar durante a } \\
\text { aplicação: máscara, óculos de proteção e } \\
\text { macacão. }\end{array}$ \\
\hline $\begin{array}{lll}\text { Pedro } & \text { et } & \text { al. } \\
(2018) & & \end{array}$ & $\begin{array}{l}79,2 \% \text { afirmaram usar EPI, porém, } \\
63,7 \% \text { não seguiam os procedimentos de } \\
\text { segurança para vesti-los e retirá-los. }\end{array}$ \\
\hline
\end{tabular}




\begin{tabular}{|c|c|}
\hline & uso \\
\hline $\begin{array}{lll}\text { Silva } & \text { et } & \text { al. } \\
(2017) & & \end{array}$ & $\begin{array}{l}\text { Somente } 38,89 \% \text { usavam todos os EPI } \\
\text { recomendados. }\end{array}$ \\
\hline $\begin{array}{lr}\text { Sitoe, } & \text { M., } \\
\text { Moiane } & \& \\
\text { Sitoe, } & \text { C. } \\
(2017) & \end{array}$ & $\begin{array}{l}\text { Nenhum trabalhador utilizava todos os } \\
\text { EPI. } 87,5 \% \text { dos que disseram usar EPI, } \\
\text { prevaleceu o uso de botas de borracha e } \\
\text { luvas. }\end{array}$ \\
\hline $\begin{array}{l}\text { Abreu } \& \\
\text { Alonzo (2016) }\end{array}$ & \begin{tabular}{llll|} 
Utilização & durante & preparação & de \\
agrotóxicos: & $56,8 \%$ & sempre, $19,8 \%$ & âs \\
vezes e $23,5 \%$ & nunca utilizavam. & \\
Utilização & durante a aplicação & de \\
agrotóxicos: & $88,2 \%$ não utilizavam todos \\
os EPIs, apenas $11,8 \%$ usavam de forma \\
integral.
\end{tabular} \\
\hline $\begin{array}{l}\text { rgnin et al. } \\
\text { 16) }\end{array}$ & \\
\hline $\begin{array}{l}\text { Cezar-Vaz et al. } \\
\text { (2016) }\end{array}$ & $\begin{array}{l}\text { 16,6\% usavam máscara com respirador. } \\
\text { Alguns trabalhadores utilizavam jaleco e } \\
\text { calça hidrorrepelente, viseira facial, boné } \\
\text { árabe, bota impermeável, capacete e } \\
\text { máscara. }\end{array}$ \\
\hline $\begin{array}{l}\text { Leite et } \quad \text { al. } \\
(2016)\end{array}$ & $\begin{array}{l}\text { Apenas } 38,2 \% \text { relataram utilizar todos os } \\
\text { EPIs e } 41 \% \text { utilizavam luvas, botas, } \\
\text { macacão e máscara. }\end{array}$ \\
\hline $\begin{array}{l}\text { Santana et al. } \\
(2016)\end{array}$ & \begin{tabular}{|lrrr}
$56,8 \%$ não utilizavam & EPIs, & $43,2 \%$ \\
usavam apenas alguns, & $23,5 \%$ & usavam \\
principalmente luvas & e & $32,5 \%$ \\
principalmente máscaras. & & \\
\end{tabular} \\
\hline $\begin{array}{l}\text { Pignati, } \\
\text { Oliveira } \quad \& \\
\text { Silva }(2014)\end{array}$ & $\begin{array}{l}90 \% \text { relataram usar botas sempre. } 10 \% \\
\text { luvas sempre. Nenhum utilizava máscara } \\
\text { sempre, mas } 40 \% \text { as utilizam às vezes. }\end{array}$ \\
\hline $\begin{array}{lll}\text { Silva } & \text { et } & \text { al. } \\
(2014) & & \end{array}$ & $\begin{array}{l}62 \% \text { disseram não usar EPI pelo } \\
\text { desconforto e alto custo. } 32 \% \text { utilizavam } \\
\text { de acordo com a situação econômica do } \\
\text { momento, utilizando apenas alguns itens, } \\
\text { geralmente, em péssimas condições de } \\
\text { uso. }\end{array}$ \\
\hline
\end{tabular}

Fonte: Elaborado pelas autoras (2019)

\subsection{As Embalagens de Agrotóxicos}

É uma realidade o descontrole e falta de fiscalização em relação ao descarte de embalagens vazias de agrotóxicos e o ato de enterrá-las é totalmente condenado, visto que os resíduos das embalagens representam grande ameaça ao meio ambiente, podendo contaminar o solo e através das chuvas serem conduzidos para águas superficiais e subterrâneas (CARNEIRO et al., 2015).

No Quadro 3 encontram-se os estudos com o percentual de trabalhadores e suas respectivas ações com as embalagens vazias de agrotóxicos.

Quadro 3 - Ações dos trabalhadores com as embalagens vazias de agrotóxicos.

\begin{tabular}{|c|c|}
\hline Autor/Ano & \% Destino das embalagens vazias \\
\hline $\begin{array}{l}\text { Castro et al. } \\
\text { (2018) }\end{array}$ & $77,78 \%$ jogavam no lixo comum. \\
\hline $\begin{array}{l}\text { Pedro et al. } \\
(2018)\end{array}$ & $\begin{array}{l}62,5 \% \text { devolviam para os locais indicados no } \\
\text { receituário agronômico. }\end{array}$ \\
\hline $\begin{array}{l}\text { Sousa et al. } \\
(2018)\end{array}$ & $50 \%$ devolviam e $16 \%$ reutilizavam. \\
\hline $\begin{array}{l}\text { Sitoe, M., } \\
\text { Moiane e Sitoe, } \\
\text { C. (2017) }\end{array}$ & $\begin{array}{l}60 \% \text { queimavam, } 22 \% \text { enterravam e } 17,5 \% \\
\text { jogavam no meio ambiente. }\end{array}$ \\
\hline
\end{tabular}

\begin{tabular}{|lrr|l|l|}
\hline $\begin{array}{l}\text { Leite } \\
(2016)\end{array}$ & al. & $\begin{array}{l}78,9 \% \text { lavavam e devolviam, } \\
\text { no campo e 9,7\% queimavam }\end{array}$ \\
\hline $\begin{array}{l}\text { Viero et } \\
(2016)\end{array}$ & al. & $\begin{array}{l}100 \% \text { devolviam para as emam } \\
\text { fornecedoras. }\end{array}$ \\
\hline $\begin{array}{l}\text { Silva et } \\
(2014)\end{array}$ & al. & $\begin{array}{l}58 \% \text { queimavam e } \\
\text { córregos. }\end{array}$ \\
\hline
\end{tabular}

Fonte: Elaborado pelas autoras (2019)

Silva et al. (2014) ressalta que a lixiviação dos resíduos de agrotóxicos, oriundos das embalagens jogadas no solo causam grandes impactos ao meio ambiente. Ainda esclarece que além das embalagens vazias que são prejudiciais para o meio ambiente, também existem outras situações de risco, como: a calda que sobra, a água utilizada para limpeza dos EPI, além de agrotóxicos vencidos ou com fórmulas que fogem das especificações.

De acordo com a Lei Federal 7.802 de 1989, artigo $6^{\circ} \mathrm{e}$ parágrafo $2^{\circ}$, os usuários de agrotóxicos deverão devolver as embalagens para os estabelecimentos comerciais onde foram adquiridos, no prazo máximo de um ano da compra ou se o órgão responsável autorizar um prazo maior (BRASIL, 1989).

\subsection{Manifestações Clínicas pelo Uso de Agrotóxicos}

No contexto do ambiente de trabalho e trabalhadores, é preciso estabelecer nexo causal entre a geração de saúde/doença e atividades laborais, neste caso, entre o trabalhador agrícola e a utilização de agrotóxicos em seu ambiente de trabalho. A exposição aos agrotóxicos tem forte potencial de acometer o trabalhador física e psiquicamente (CEZAR-VAZ et al. 2016; MORIN \& STUMM, 2018).

Segundo a pesquisa de Maia et al. (2018), no estado de Alagoas, a área de maior risco de intoxicação foi o ambiente de trabalho, $96 \%$ em 2014. Somente quatro por cento das intoxicações ocorreram nas residências, considerando que os trabalhadores ao final do expediente, geralmente, voltavam para casa com partículas dos resíduos de agrotóxicos em suas vestimentas.

Tokarski, França \& Lacerda (2019) constataram nexo causal entre tonturas e o uso de defensivos agrícolas, entre a dificuldade de compreensão da fala e o uso de agrotóxicos e entre o zumbido e o tempo de serviço. E no estudo de Kos $e t$ al. (2014), verificou-se que os trabalhadores expostos aos agrotóxicos tiveram maior prevalência de alterações auditivas em comparação ao grupo controle.

No Quadro 4 pode-se identificar estudos com dados de trabalhadores rurais que tiveram sintomas de intoxicação por agrotóxicos e outros danos.

Quadro 4 - Compilação de dados de manifestações clínicas relacionadas ao uso de agrotóxicos.

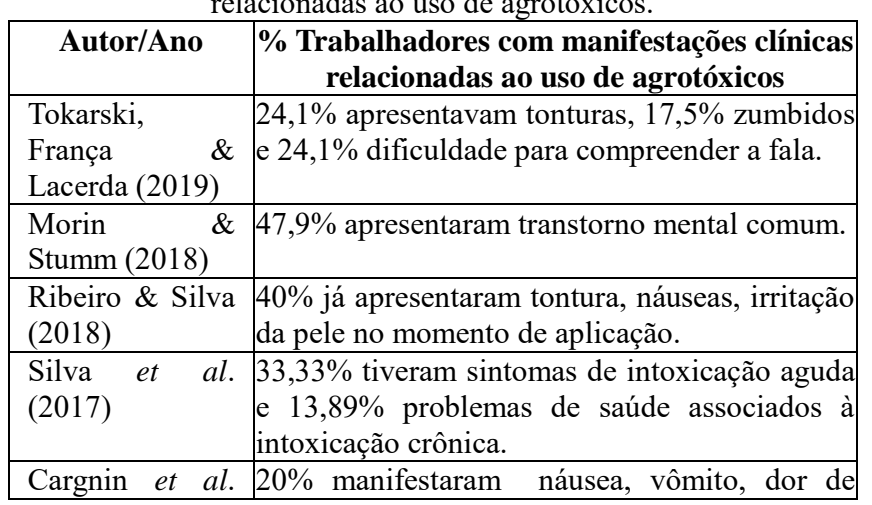

Volume $15-\mathrm{N}^{\circ} 169$ - Janeiro/2020. 


\begin{tabular}{|c|c|}
\hline (2016) & cabeça, tontura. \\
\hline $\begin{array}{l}\text { Cezar-Vaz et al. } \\
\text { (2016) }\end{array}$ & $\begin{array}{l}62,2 \% \text { apresentaram algum tipo de transtorno } \\
\text { mental } 49,8 \% \text { distúrbios circulatórios, } 45 \% \\
\text { dermatológicos, } 41 \% \text { respiratórios e } 36,2 \% \\
\text { gástricos. }\end{array}$ \\
\hline $\begin{array}{lll}\text { Santana } & \text { et } & \text { al. } \\
(2016) & & \end{array}$ & $\begin{array}{l}15 \% \text { apresentaram cefaleia, náusea, tontura, } \\
\text { irritação na pele, perda de apetite. }\end{array}$ \\
\hline $\begin{array}{lll}\text { Kos et } \quad \text { al. } \\
(2014)\end{array}$ & $\begin{array}{l}62,85 \% \text { apresentaram perda auditiva na área da } \\
\text { fala e } 71,42 \% \text { na área das frequências agudas. }\end{array}$ \\
\hline
\end{tabular}

Os agrotóxicos agrícolas possibilitam vários casos de intoxicações, além disso, é deduzido que existem muitas subnotificações e que a falta de registros pode estar associada às características do trabalhador rural, à falta de cumprimento das recomendações dos órgãos competentes e à precariedade das fiscalizações (BEGNINI \& TAVEIRA, 2014).

A intoxicação aguda ocorre pelo surgimento repentino dos sintomas. A intoxicação subaguda ocorre quando a exposição é pequena ou moderada a agrotóxicos muito tóxicos. Já a intoxicação crônica é caracterizada pela exposição a longo prazo e os sintomas aparecem tardiamente (SILVA et al., 2014).

Foram registradas 248 notificações de intoxicação por agrotóxicos no estado de Alagoas no período de 2010 a 2015. A maioria causada por agrotóxicos agrícolas, ocupando $74,6 \%$ dos casos notificados. Apesar das várias formas de exposição aos agrotóxicos, a pulverização foi a ação de risco que prevaleceu, onde $76,75 \%$ dos casos de intoxicação ocorreram dessa forma (MAIA et al., 2018).

Ainda de acordo com o estudo de Maia et al. (2018), entre 12 municípios alagoanos avaliados, 90,27\% dos casos registrados de intoxicações por agrotóxicos agrícolas, ocorreram na cidade de Igreja Nova, entre os anos de 2011 e 2015.

É importante compreender a associação entre o uso de agrotóxicos e o surgimento de patologias, de caráter psicológico e/ou físico, no âmbito da segurança e saúde do trabalho para que haja intervenções de forma que reduza a probabilidade de danos ao trabalhador e o controle dos agravos à saúde que, consequentemente, diminuirá os gastos com os acidentes de trabalho (NETO, ANDRADE \& FELDEN, 2018).

\subsection{Fiscalização das Atividades desenvolvidas com Agrotóxicos}

No artigo 70 do Decreto 4.074 de 2002, que regulamenta a Lei 7.802/1989, os agrotóxicos, seus componentes e afins, são alvos de inspeção e fiscalização, assim como, sua produção, manipulação, exportação, transporte, armazenamento, comercialização, utilização, os rótulos e a rota final de suas sobras, resíduos e embalagens (BRASIL, 2002).

Alguns gestores estaduais relataram para Neto, Lacaz \& Pignati (2014) que existe uma complexidade para desenvolver ações de monitoramento sobre o uso de agrotóxicos, dado que os gestores municipais e a sociedade desconsideram os riscos provenientes desses produtos, o que os tornam omissos quanto às ações de controle. Afirmaram ainda que é necessário reforçar aos técnicos, o conhecimento científico sobre riscos ocupacionais os quais os trabalhadores estão expostos.

Em Ribeiro \& Silva (2018), 100\% dos trabalhadores expostos aos agrotóxicos afirmaram não haver fiscalização das condições de trabalho com agrotóxicos. Já em Souza et al. (2018), 50\% disseram não haver fiscalização quanto à utilização de agrotóxicos.

De acordo com Neto, Lacaz \& Pignati (2014), os representantes de órgãos responsáveis pelo monitoramento dos impactos dos agrotóxicos na saúde e no ambiente, afirmaram que as leis brasileiras não são firmes, fato que possibilita o uso de produtos que na Europa já foram proibidos.

\section{CONCLUSÃO}

Diante dos estudos apresentados nesta pesquisa, notase que há significante vulnerabilidade de trabalhadores rurais expostos aos agrotóxicos, visto que ações, como: a aquisição descontrolada, o transporte e o armazenamento irregulares, a falta de uso de EPI e o descarte incorreto das embalagens vazias são práticas comuns, sendo a realidade de inúmeros trabalhadores e agravada pela escassa fiscalização. Portanto, é fundamental o reforço e a efetividade das medidas de prevenção, de fiscalização, de conscientização para o cumprimento das leis e normas regulamentadoras, assim como, a intensificação da vigilância em saúde ocupacional, em virtude do expressivo número de intoxicação por agrotóxicos no ambiente de trabalho. Propõe-se que esta revisão sistemática possa ampliar o debate sobre as condições de trabalho com agrotóxicos e servir de base para novos estudos na área.

\section{REFERÊNCIAS BIBLIOGRÁFICAS}

ABREU, P. H. B.; ALONZO, H. G. A. O agricultor familiar e o uso (in)seguro de agrotóxicos no município de Lavras/MG. Revista Brasileira de Saúde Ocupacional, [S. 1.], v. 41, n. 18, p.1-12, abr. 2016.

BEGNINI, S.; TAVEIRA, A. V. A. Agrotóxicos agrícolas: do uso às intoxicações. Revista Ibero-americana de Ciências Ambientais, Aquidabã, v. 5, n. 2, p.87-95, jun/nov. 2014

BRASIL. Ministério do Trabalho e Emprego. Portaria MTb n. ${ }^{\circ} 3.214$, de 08 de junho de 1978 . Norma Regulamentadora - NR 6. Equipamento de Proteção Individual - EPI. Diário Oficial da União, Brasília, DF, 1978.

BRASIL. Lei no 7.802, de 11 de julho de 1989. Dispõe sobre a pesquisa, a experimentação, a produção, a embalagem e rotulagem, o transporte, o armazenamento, a comercialização, a propaganda comercial, a utilização, a importação, a exportação, o destino final dos resíduos e embalagens, o registro, a classificação, o controle, a inspeção e a fiscalização de agrotóxicos, seus componentes e afins, e dá outras providências. Diário Oficial da União, Brasília, DF, 12 jul. 1989.

BRASIL. Decreto-lei $\mathrm{n}^{\circ}$ 4.074, de 4 de janeiro de 2002 Regulamenta a Lei $\mathrm{n}^{\mathrm{o}} 7.802$, de 11 de julho de 1989, que dispõe sobre a pesquisa, a experimentação, a produção [...]. Diário Oficial da União, Brasília, DF, 8 jan. 2002.

BRASIL. Ministério do Trabalho e Emprego. Portaria MTE n. ${ }^{\circ} 86$, de 03 de março de 2005. Norma RegulamentadoraNR 31. Segurança e saúde no trabalho na agricultura, pecuária, silvicultura, exploração florestal e aquicultura. Diário Oficial da União, Brasília, DF, 2005.

BRASIL. Ministério da Saúde. Secretaria de Vigilância em Saúde. Departamento de Vigilância em Saúde Ambiental e Saúde do Trabalhador. Relatório Nacional de Vigilância 
em Saúde de Populações Expostas a Agrotóxicos. 1. ed. Brasília: Ministério da Saúde, 2016.

CARDOSO, F. D. P. et al. Expansão recente da fronteira agrícola e o consumo de produtos agroquímicos: indicadores e possíveis impactos na saúde do trabalhador do campo em Porto Nacional - Tocantins. Revista de Administração e Negócios da Amazônia, [S. 1.], v. 9, n. 3, p.37-59, maio/ago. 2017.

CARGNIN, M. C. S. et al. Cultura do tabaco versus saúde dos fumicultores. Texto \& Contexto - Enfermagem, Florianópolis, v. 25, n. 2, p.1-9, jun. 2016.

CARNEIRO, F. F. et al. (Org.). Dossiê ABRASCO: um alerta sobre os impactos dos agrotóxicos na saúde. Rio de Janeiro: Escola Politécnica de Saúde Joaquim Venâncio; São Paulo: Expressão Popular, 2015.

CASTRO, R. G. et al. Exposição de trabalhadores a agrotóxicos em hortas comunitárias de Palmas - Tocantins. Revista Cereus, [S. 1.], v. 10, n. 3, p.62-78, 1 set. 2018.

CEZAR-VAZ, M. R. et al. Abordagem socioambiental na enfermagem: focalizando o trabalho rural e uso de agrotóxicos. Revista Brasileira de Enfermagem, Brasília, v. 69 , n. 6 , p.1179-1187, dez. 2016.

KÓS, M. I. et al. Avaliação do sistema auditivo em agricultores expostos a agrotóxicos. Revista Cefac, Campinas, v. 16, n. 3, p.941-948, mai/jun. 2014.

LEITE, S. A. et al. Perfil dos fruticultores e diagnóstico do uso de agrotóxicos no polo de fruticultura de livramento de Nossa Senhora, Bahia. Revista Extensão Rural, Santa Maria, v. 23, n. 2, p.112-125, abr./jun. 2016.

MAIA, J. M. M. et al. Perfil de intoxicação dos agricultores por agrotóxicos em Alagoas. Diversitas Journal, Santana do Ipanema, v. 3, n. 2, p.486-504, 2 mai/ago. 2018.

MANZOLI, S. T.; IGUTI, A. M.; MONTEIRO, I. Condições de trabalho e saúde de plantadores de verduras de um município brasileiro. Trabajo y Sociedad, Santiago del Estero, n. 30, p.269-284, verão 2018.

MIORIN, J. D. et al. Percepções de agricultores sobre o impacto dos agrotóxicos para a saúde e o meio ambiente. Revista de Enfermagem do Centro-Oeste Mineiro, [S.1.], v. 6, n. 3, p.2410-2420, 2 set./dez. 2016.

MORIN, P. V.; STUMM, E. M. F. Transtornos mentais comuns em agricultores, relação com agrotóxicos, sintomas físicos e doenças preexistentes. Psico, Porto Alegre, v. 49, n. 2, p.196-205, 24 ago. 2018.

MURAKAMI, Y. et al. Intoxicação crônica por agrotóxicos em fumicultores. Saúde em Debate, Rio de Janeiro, v. 41, n. 113, p.563-576, abr./jun. 2017.

NETO, E. N.; LACAZ, F. A. C.; PIGNATI, W. A. Vigilância em saúde e agronegócio: os impactos dos agrotóxicos na saúde e no ambiente. Perigo à vista!. Ciência \& Saúde Coletiva, [S.1.], v. 19, n. 12, p.4709-4718, dez. 2014.

NETO, M. G. F.; ANDRADE, R. D.; FELDEN, E. P. G. Trabalho na agricultura: possível associação entre intoxicação por agrotóxicos e depressão. Revista Perspectiva: Ciência e Saúde, [S. 1.], v. 3, n. 1, p.69-82, 2018.
PEDRO, F. C. et al. Utilização de equipamentos de proteção individual e agrotóxicos por produtores rurais de três corações - MG. Revista da Universidade Vale do Rio Verde, [S.1.], v. 16, n. 3, p.1-8, 2018.

PIGNATI, W.; OlIVEIRA, N. P.; SIlVA, A. M. C. Vigilância aos agrotóxicos: quantificação do uso e previsão de impactos na saúde-trabalho-ambiente para os municípios brasileiros. Ciência \& Saúde Coletiva, [S.1.], v. 19, n. 12, p.4669-4678, dez. 2014.

RIBEIRO, L. A.; SILVA, J. S. Levantamento sobre a saúde do trabalhador rural nas lavouras de abacaxi do município Floresta do Araguaia - PA. Revista Craibeiras de Agroecologia, [S. I.], v. 1, n. 1, p.1-7, 2018.

SANTANA, C. M. et al. Exposição ocupacional de trabalhadores rurais a agrotóxicos. Cadernos Saúde Coletiva, Rio de Janeiro, v. 24, n. 3, p.301-307, set. 2016.

SILVA, F. M. et al. Percepção de risco no uso de agrotóxicos em cinco comunidades rurais no município de Pombal - PB. Revista Verde de Agroecologia e Desenvolvimento Sustentável, Pombal, v. 9, n. 5, p.1-9, dez. 2014.

SILVA, J. V. et al. A percepção dos trabalhadores rurais sobre a autoexposição aos agrotóxicos. Revista Saúde (Santa Maria), [S.1.], v. 43, n. 1, p.199-205, jan./abr. 2017.

SITOE, M. D.; MOIANE, G. S.; SITOE, C. C. Exposição dos agricultores do Posto Administrativo de Chaimite aos pesticidas agrícolas. Revista de Ciências Agroveterinárias, Lages, v. 16, n. 4, p.480-486, 2017.

SOUSA, D. G. et al. Uma percepção ambiental de agricultores da comunidade Águas Turvas sobre o uso de agrotóxicos na região da bacia hidrográfica do rio gramame, João Pessoa - PB. Revista Brasileira de Educação Ambiental, São Paulo, v. 13, n. 2, p.332-339, 2018.

TOKARSKI, P. C.; FRANÇA, D. V. R.; LACERDA, A. B. M. A percepção dos agricultores expostos aos agrotóxicos, frente às condições de trabalho, a audição e a prevenção. Revista Tuiuti: Ciência e Cultura, Curitiba, n. 58, p.9-11, 2019.

VEIGA, M. M.; ALMEIDA, R.; DUARTE, F. O desconforto térmico provocado pelos equipamentos de proteção individual (EPI) utilizados na aplicação de agrotóxicos. Laboreal, [S.1.], v. 12, n. 2, p.83-94, 2016.

VIERO, C. M. et al. Sociedade de risco: o uso dos agrotóxicos e implicações na saúde do trabalhador rural Escola Anna Nery - Revista de Enfermagem, [S.1.], v. 20, n 1, p.99-105, jan./mar. 2016.

\section{COPYRIGHT}

Direitos autorais: $\mathrm{O}(\mathrm{s})$ autor(es) é(são) o(s) único(s) responsável(is) pelo material incluído no artigo. 


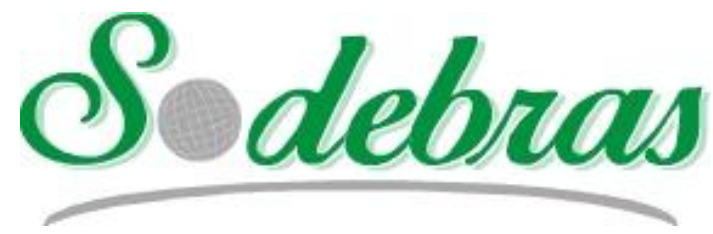

Volume $15-\mathrm{N}^{\mathrm{o}} 169$ - Janeiro / 2020

XLI International Sodebras Congress

04 a 06 de julho de 2019 - Maceió - AL.

\title{
O PROCESSO DECISÓRIO: A SISTEMATIZAÇÃO DO PROCESSO DECISÓRIO PARA TOMADAS DE DECISÃO MULTICRITÉRIO
}

\author{
THE DECISION-MAKING PROCESS: THE SYSTEMATIZATION OF THE \\ DECISION-MAKING PROCESS FOR MULTIRITHERARY DECISION-MAKING
}

\author{
MANOEL MESSIAS DOMINGOS DA SILVA; LESSO BENEDITO DOS SANTOS. \\ 1 - INSTITUTO FEDERAL DE ALAGOAS \\ manoel_mds@hotmail.com; lesso.santos@yahoo.com.br
}

\begin{abstract}
Resumo - O processo decisório tem se tornado uma atividade de alta complexidade, diariamente a quantidade de informações dentro de uma organização aumenta e se torna mais complexa, clamando cada vez mais por dados mais numerosos, específicos $e$ sensatos para auxiliar as tomadas de decisões multicritério. Nessa conjuntura percebe-se a relevância de uma estratégia que conduza a organização para que seja possível alcançar suas metas. $O$ objetivo desta pesquisa é descrever como se desenvolve a sistematização do processo decisório para tomadas de decisão multicritério e suas implicações. A metodologia no presente trabalho baseia-se em pesquisas bibliográficas de caráter descritivo perfazendo estudos que fundamentam o trabalho, com a finalidade de responder as indagações propostas auxiliando no entendimento do problema e na proposição da solução. Diante deste contexto, essa pesquisa propõe-se a levantar informações que demonstrem que a tomada de decisão deriva de um processo em que alternativas de escolha são propostas para possíveis soluções que possam gerar os melhores resultados para as organizações, sendo considerado, em muitas organizações, como a mais importante tarefa desempenhada pelos administradores.
\end{abstract}

Palavras-chave: Processo decisório. Sistematização. Tomada de decisão.

\begin{abstract}
The decision-making process has become a highly complex activity, the amount of information within an organization increases daily and becomes more complex, increasingly crying out for more numerous, specific and sensible data to aid multicriteria decision making. At this juncture it is possible to see the relevance of a strategy that leads the organization to achieve its goals. The objective of this research is to describe how the systematization of the decision-making process for multicriteria decision-making and its implications is developed. The methodology in the present work is based on descriptive bibliographical research, making studies that base the work, with the purpose of answering the questions proposed, helping in the understanding of the problem and in the solution proposition. In this context, this research proposes to gather information that demonstrates that the decision-making is derived from a process in which alternatives of choice are proposed for possible solutions that can generate the best results for the organizations, being considered, in many organizations, as the most important task performed by managers.
\end{abstract}

Keywords: Decision making process. Systematization. Decision making.

\section{INTRODUÇÃO}

No cenário atual, o processo decisório tem se tornado uma atividade de alta complexidade, em função da velocidade das alterações tecnológicas, dos elevados custos de investimentos e do aumento do nível de incerteza nos ambientes competitivos. Hoje as organizações se deparam com as exigências de um novo mercado globalmente competitivo.

A competitividade que é dinâmica e global imposta pelo mercado, obriga as empresas a estar sempre na busca de novas soluções organizacionais para sua produção e processo produtivo. Neste cenário as empresas necessitam não somente manter a sua fatia de participação no mercado, mas também aumentá-la. Por outro lado, o processo decisório também evoluiu bastante, tornando-se um processo que consta da identificação do problema, dos critérios, a forma de elaborar, analisar e escolher alternativas, verificando a eficácia da decisão.

Já na complexidade das organizações ocorre uma evolução muito profunda nos seus conceitos de administração, com a chegada da globalização e do avanço tecnológico, pode-se afirmar que o mercado torna-se mais complexo e competitivo a cada momento. Neste contexto, o ato de decidir está intrínseco na natureza humana sempre que envolve uma escolha na busca da resolução de um problema, ou mesmo quando há alternativas para alcançar um objetivo, assim o processo decisório se tornou muito mais complexo, sendo necessário o uso de indicadores como instrumentos a produtividade organizacional para dar suporte ao processo de tomadas de decisão.

\section{METODOLOGIA}

A metodologia no presente trabalho iniciou-se com o objetivo de entender como se desenvolve a sistematização do processo decisório para tomadas de decisão multicritério e suas implicações, consistindo em realizar uma revisão da literatura com abordagem de teorias e/ou conceitos que fundamentam o trabalho, fortalecendo-se nas interações do pesquisador. Todas as etapas descritas foram importantes, pois deram subsídios teóricos que possibilitaram todo um aprendizado para o pesquisador, apresentando um plano detalhado de como foi traçado técnica para se alcançar o objetivo e responder as indagações propostas auxiliando no entendimento do problema e na proposição da solução. 
Deste modo, foi feito um aprofundamento desse material, de modo a analisá-lo e interpretá-lo. Para isto, procedeu-se conforme sugerido por (GIL, 1999).

- Identificar as informações e os dados constantes dos materiais.

- Estabelecer relações entre essas informações e dados e o problema proposta.

- Analisar a consistência das informações e dados apresentados pelos autores.

\section{1 - Processo decisório}

Decidir é um processo cognitivo complicado, onde a dúvida a respeito de várias opções precisa culminar com uma escolha que elimine incertezas (MARQUIS; HUSTON, 2010). Destarte, Mañas (2002), defende a tomada de decisão de forma consciente de um curso de ação, entre as alternativas disponíveis, na busca do resultado que se deseja alcançar.

\begin{abstract}
"Dessa forma, o processo decisório envolve a identificação de um problema específico e a escolha de uma ação para resolvê-lo ou aproveitar uma oportunidade (JAMIL, 2006)."
\end{abstract}

Esse processo está vinculado à função do planejamento, inserido em uma forte etapa da Ciência da Administração, considerada como um caminho influente na tomada de decisão (MORITZ; PEREIRA, 2006).

A tomada de decisão é a sintetização das informações analisadas em ação. Os desafios impostos levam os administradores a buscar informações que espelhem fielmente a real situação das organizações, para que o processo decisório seja efetuado de forma eficaz, para alcançar os resultados pretendidos.

Neste sentido, entende-se que as decisões precisam ser tomadas de forma ágil e corretas, pois o desempenho das organizações depende da qualidade de seu gerenciamento. Portanto, decisão é a opção entre alternativas ou possibilidades, executada quando o administrador se encontra com uma situação-problema, objetivando à sua solução ou ao aproveitamento de oportunidades, em prol da maior eficiência organizacional (MAXIMIANO, 2009). Assim, as tomadas de decisão decorrem da capacidade dos administradores em escolher a alternativa que melhor satisfaz às necessidades organizacionais, em função das circunstancias temporais para assegurar os resultados desejados.

Evidencia-se que haja fatores que influenciam direta ou indiretamente no processo decisório. Um desses fatores é a incerteza, bem como a quantidade insuficiente de informações necessárias ao processo decisório. Conforme Anderson e Norman (2003), riscos podem ser calculados, enquanto as incertezas são originalmente desconhecidas, pois quando o impacto e a incerteza são combinados, o resultado é o risco. Portanto, o risco ocorre quando da incerteza de se antecipar os resultados.

Dessa forma, as medidas adotadas pelo gestor adquirem relevância em todas as etapas do processo decisório, para que possa haver sintonia entre os objetivos pretendidos e os resultados alcançados pela organização. $\mathrm{O}$ processo de tomada de decisão, portanto, não se constitui em tarefa fácil para o administrador, que tem que levar em conta as várias alternativas do complexo ambiente organizacional.

\begin{abstract}
"No processo de trabalho, a tomada de decisão é considerada a função que caracteriza o desempenho da gerência. Independentemente do aspecto da decisão, esta atitude deve ser fruto de um, que envolve o estudo do problema a partir de um levantamento de dados, produção de informação, estabelecimento de propostas de soluções, escolha da decisão, viabilização e execução da decisão e análise dos resultados obtidos (GUIMARÃES; ÉVORA, 2004)."
\end{abstract}

Para que as decisões organizacionais sejam tomadas com rapidez e qualidade, é relevante que as organizações disponham de um sistema de comunicação eficiente, que permita a rápida circulação da informação e do conhecimento, sendo, para isso, indispensável o suporte da tecnologia.

Portanto, a informação torna-se relevante quando passa a ter valor agregado. Esse valor agregado é o que confere importância à informação, fazendo-a constituir-se em subsídio essencial para a tomada de decisão. Dessa forma, a informação passa a ser produto qualificado, quando recebe tratamento e interpretação, para que possa gerar impacto nas pessoas que dela se utilizam. A informação é um recurso primordial para a tomada de decisão e que, quanto mais estruturado for este processo, mais indicado se faz o uso de sistemas de informação que possam responder às demandas e necessidades informacionais do administrador.

No cenário competitivo, um dos fatores que determina o diferencial das organizações é a forma como a informação é empregada. Assim sendo, as estreitas sintonias entre a informação e as escolhas dos administradores beneficiarão o processo decisório.

\section{2 - Classificação do processo decisório}

A decisão pode ser classificada como simples ou complexa, específica ou estratégica, e que suas consequências podem ser imediatas, em curto e longo prazo, ou a combinação entre as formas anteriores e podendo, inclusive, ter reflexos bem diversos (GOMES, 2014).

Ateemo-nos as categorias, as decisões podem ser divididas em duas categorias: as programadas e não programadas (SIMON, 1970).

Nas programadas, o desenvolvimento de alternativas é simples, seguindo as regras e procedimentos da empresa; já nas alternativas não programadas, existem vários tipos de alternativas, principalmente quando há prazos a cumprir (SOBRAL; PECI, 2010).

As decisões não programadas são específicas para cada situação, por serem distintas não podem ser solucionadas de forma padronizada. Para o autor são situações novas pelas quais a empresa está passando pela primeira vez e que necessitam de formas diferentes de serem resolvidas (MAXIMIANO, 2009).

É importante ressaltar que determinados autores, ainda levam em conta as chamadas decisões semi-programadas ou semi-estruturadas. Este tipo de decisão pode ser sistematizado até determinado ponto, dependendo de estruturas mais complexas do sistema de informações visando os resultados esperados para cada opção de escolha sejam selecionados de forma coerente, a partir dos mesmos critérios. Dessa forma, parte do problema pode ser acrescentada ao sistema de apoio às decisões e a outra parte 
não. Comumente, quando variáveis intervêm no processo decisório, é o momento em que entra em ação a capacidade de julgamento do administrador, levando-se em conta sua experiência com a situação do problema.

\section{3 - Fases do processo decisório}

Evidencia-se que as etapas do processo decisório podem ou não ser percorridas. Todavia, aplicá-las pode auxiliar na decisão mais apropriada, visto que serão considerados diferentes aspectos.

As fases do processo decisório podem ser divididas em 5 (cinco) etapas (CERTO, 2005):

- Identificação do problema ou oportunidade.

- Diagnóstico.

- Geração de alternativas.

- Escolha de uma alternativa.

- Avaliação da decisão.

Objetivando uma melhor gestão na tomada de decisão, diversas técnicas foram desenvolvidas. Porem, as mesmas não fornecem soluções automáticas para os problemas, pois o processo de tomada de decisão é uma atividade humana. $\mathrm{O}$ papel das técnicas é estruturar o processo decisório, ajudando os gerentes a eliminar a improvisação e aumentar o grau de certeza na tomada de decisão.

Enfim, a intervenção da opção escolhida pode ser bastante complexa, visto que é preciso lidar com as consequências da decisão tomada. Através de uma avaliação posterior das decisões pode-se aprender mais sobre o que falhou e melhorar as habilidades na solução de problemas (MARQUIS; HUSTON, 2010).

\subsubsection{Identificação do problema ou oportunidade}

O processo de tomar decisão tem origem em uma percepção do problema; nos entraves para atingir um determinado objetivo, algum fato irregular que necessita uma ação corretiva, ou a visualização de alguma oportunidade. É nessas situações que se faz necessário tomar uma decisão segura e precisa.

\subsubsection{Diagnóstico}

Nesta fase avalia-se a real situação, identificando as ameaças e oportunidades, considerando suas causas e consequências. Observando que algumas situações são de fácil avaliação, pois apresentam efeitos adversos evidentes, excluindo a necessidade de um estudo mais aprofundado da real situação. Por outro lado, exige situações, em que necessita de uma pesquisa mais detalhada do problema apresentado.

\subsubsection{Geração de alternativas}

Constatado a real situação do problema, a próxima etapa é criar alternativas para solucionar a situação em evidencia. Em algumas situações, as alternativas são facilmente visualizadas, podendo vir juntamente com o problema. Já em outras, exigem-se alternativas inovadoras. Dessa forma, os gestores terão que utilizar seus conhecimentos junto com o seu poder de criatividade, com o objetivo de resolver as situações problemas.

\subsubsection{Escolha de uma decisão}

As alternativas no processo de tomada de decisão são comparadas, analisadas e avaliadas, para que seja selecionada aquela que mais se adequei a situação. As decisões sempre envolvem riscos, seja em um grau quase nulo, seja um alto grau de risco, ou seja, em um estágio intermediário de risco entre o quase nulo e o alto grau.

Temos sempre que levar em consideração o grau de risco que temos em cada alternativa e escolher a alternativa que apresente comprovadamente o menor grau de risco. Analisar e estruturar criticamente as possibilidades de ação que foram geradas é fundamental para a escolha do caminho a ser seguido.

As informações, bem como as opções, estão disponibilizadas de forma restringida, sendo que as soluções são indicadas através do processo de estabelecimento de regras, conforme os interesses e objetivos dos envolvidos nesse processo.

Por fim, a execução da opção escolhida pode ser bastante complexa, visto que é preciso lidar com as consequências da decisão tomada. Através de uma avaliação posterior das decisões pode-se aprender mais sobre o que falhou e melhorar as habilidades na solução de problemas (MARQUIS; HUSTON, 2010).

\subsubsection{Avaliação da decisão}

Completando o ciclo, após ter sido identificado o problema, diagnosticado, geradas alternativas e tomadas decisões, é fundamental que seja feita uma avaliação das decisões tomadas. Tal avaliação pode gerar outro processo decisório, reiniciando o ciclo.

Figura 1 - Etapas do processo decisório

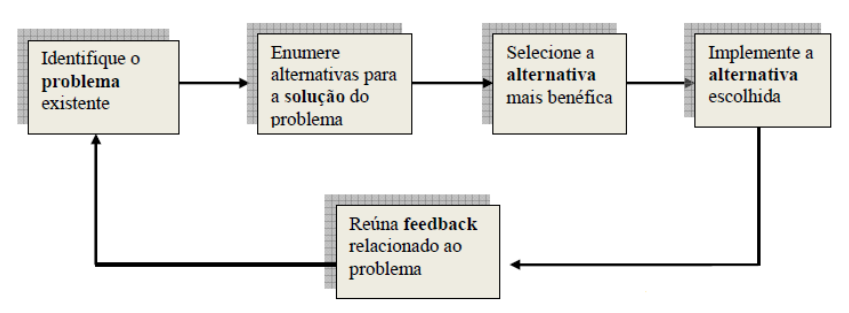

Fonte: Certo, 2005.

\section{4 - Tomadas de decisão}

A tomada de decisão é um processo que consta na identificação do problema, dos critérios, a forma de elaborar, analisar e escolher alternativas, verificando a eficácia da decisão, ou seja, um processo decisório eficaz deve ser composto da combinação de dados e de competências com a perspectiva de conquistar os resultados positivos.

A tomada de decisão é um processo de análise e escolha entre várias alternativas disponíveis do curso de ação que a pessoa deverá seguir (SIMON, 1970).

A habilidade em tomar decisões é a chave para o planejamento bem sucedido em todos os níveis da gestão. Isto envolve mais que uma simples seleção de planos de ação que assume pelo menos três fases: diagnóstico; descobertas de alternativas e análises.

$\mathrm{Na}$ complexidade das organizações, diante à competitividade atribuída pelo mercado, o processo 
decisório torna-se uma questão relevante de sobrevivência, tanto para questões na área operacional, tática ou estratégica. Portanto, o processo decisório nas organizações, converte-se na essência da habilidade do líder, em que a responsabilidade é decidir a melhor alternativa para cada momento em que se encontra a organização, de modo a garantir os resultados esperados.

As decisões são opções tomadas com base em propósitos, são atitudes orientadas para determinado objetivo, e o alcance deste objetivo determina o desempenho do processo de tomadas de decisão. Porem, fatores tais como: a globalização, o avanço tecnológico, o desenvolvimento das telecomunicações e a diminuição do tempo de processamento das informações, fazem com que o ambiente organizacional fique cada vez mais complexo, levando os administradores a reavaliarem constantemente o processo decisório. Deles é exigida visão sistêmica e cautela nas tomadas de decisão. Deste modo, pode-se afirmar que o processo de tomada de decisão envolve riscos para os líderes.

Neste sentido, entende-se que o processo de tomada de decisão deve estar embasado nas estratégias adotadas pelas organizações, com vista a enfrentarem os desafios que o mercado impõe, assim sendo, não se constitui em tarefa fácil para o líder, que tem que levar em conta as várias mudanças do complexo ambiente organizacional.

Assim, a decisão acertada é, consequentemente, o fator mais importante do processo decisório, e deve ser embasada pela análise e uso adequado da informação. A decisão é pautada pela opção ou seleção, dentre várias alternativas de cursos de ação, daquela que mais se adeque à organização.

\section{RESULTADOS}

Neste estudo, foram apresentados resultados referentes à implantação para tomada de decisões multicritérios em uma pequena empresa de comunicação visual, baseada em técnicas e ferramentas, bem como a sua interpretação, objetivando melhorar a qualidade das decisões e a evitar erros. Por meio de entrevistas, e de análise documental, foi possível coletar informações relevantes sobre a forma de intervenção e o procedimento do tomador de decisão. Foi constatado que fatores relacionados a assuntos pessoais e profissionais devem ser separados, pois, podem e devem ser prejudicial para o desenvolvimento na empresa.

Deste modo, a falta de capacitação do gestor, a ausência de um planejamento estratégico na empresa e também a falta de sistemas de informações gerencial para auxiliar as decisões são indicadores que precisam de atenção, pois permitem uma análise profunda e abrangente do desempenho da organização para que esta sobreviva a um mercado competitivo.

Assim, ter um bom sistema de indicadores permitirá uma análise profunda e abrangente do desempenho da organização. A medição sistemática e periódica dos resultados, por meio de indicadores, permite que o gestor faça intervenções precisas e baseadas que vão acrescentar valor à atividade da empresa.

Diante dos pontos abordados, foram elaboradas sugestões de melhorias, sendo elas relacionadas à qualificação do gestor, execução do planejamento estratégico e introdução de sistemas de informações gerenciais.

\section{CONCLUSÃO}

As considerações abordadas neste estudo sobre a sistematização do processo decisório e as suas implicações, tais como as habilidades essenciais dos administradores em decidir, a relevância da informação no processo decisório nas organizações, serviram para a elaboração deste estudo.

Em face ao exposto, verifica-se que a sistematização do processo decisório para tomadas de decisão multicritério, são etapas necessárias para se chegar a uma alternativa com a finalidade de dar resposta a um problema, em que alternativas de escolha são propostas para possíveis soluções que possam gerar os melhores resultados para as organizações.

Evidencia-se que, para as organizações obterem sucesso, deverão saber definir e aplicar, da melhor forma, as informações das alternativas de cursos de ação, para que esses possam auxiliá-las a atingirem os objetivos traçados.

A experiência de estudar o processo de tomada de decisão em pequena empresa de comunicação visual localizada na cidade de Maceió proporcionou conhecer melhor o ambiente das empresas desse segmento, as quais são relevantes para o crescimento econômico local. Também foi possível entender as dificuldades encontradas pelo gestor que luta para manter-se em um mercado desfavorecido e competitivo, agregando conhecimento profissional e competências relacionadas à tomada de decisão.

Em conclusão, sabemos que sempre existirão dúvidas a que direção seguir. Talvez seja observado pelos resultados que a decisão tomada não tenha sido a melhor, ou que deveria ter ido por outro caminho.

\section{REFERÊNCIAS BIBLIOGRÁFICAS}

ANDERSON, D.; NORRAN, A. Managing risk when outsourcing advanced logistics, $12^{\circ}$ International IPSERA Conference, 2003.

CERTO. S. C. Administração moderna. São Paulo: Pearson, 2005.

EDUARDO P. C.; CESAR R. B.; CARLOS N. F. O processo decisório nas organizações. Porto Alegre: Intersaberes. 2014.

GIL, A. C. Como Elaborar Projetos de Pesquisa. São Paulo: Atlas, 2010.

GOMES, L. F. Tomada de Decisão Gerencial: Enfoque Multicritério. São Paulo: Atlas, 2014.

GUIMARÃES, E. M. P.; ÉVORA, Y. D. M. Sistema de informação: instrumento para tomada de decisão no exercício da gerência. Ci. Inf., Brasília, v. 33, n. 1, p. $72-$ 80, jan./abril 2004.

JAMIL, G.L. Aspectos do ambiente gerencial e seus impactos no uso dos sistemas de inteligência competitiva para processos decisórios. In: Perspectivas em Ciência da Informação, v. 6, n. 2, jul./dez. 2001. Disponível em: $<$ http://www.eci.ufmg.br/pcionline/include/getdoc.php?id=5 $60 \&$ article $=366 \&$ mode $=$ pdf $>$ Acesso em 26 de Janeiro de 2018.

MAÑAS, A. V. Administração de sistemas de informação: como otimizar a empresa por meio de sistemas de informação. São Paulo: Érica, 2002. 
MARIA A. N. M.; MARIA G. V.; TELMA S. O. P.

Processo Decisório - Considerações sobre a Tomada de

Decisões. Curitiba: Juruá, 2011.

MARQUIS, B. L.; HUSTON, C. J. Administração e Liderança em Enfermagem. Porto Alegre: Artmed, 2010.

MAXIMIANO, A. C. A. Introdução à Administração. São Paulo. 2009.

MORITZ, G. O; PEREIRA, M. F. Processo decisório. Florianópolis: SEAD/UFSC, 2006.

SIMON, H. A. Os limites ou fronteiras da racionalidade. Entrevista. Disponível em: < http://www.youtube.com/watch? $\mathrm{v}=\mathrm{QFLxazu} 6 \mathrm{pCw}>$. Acesso em 25 de Janeiro de 2018.

SIMON, H. A. Comportamento Administrativo. Rio de Janeiro: FGV, 1970.

SOBRAL, F.; PECI, A. Administração: teoria e prática no contexto brasileiro. São Paulo: Pearson, 2010.

TEODÓSIO, A. S.; SILVA, E. E.; RODRIGUES, F. R. G. Discutindo o processo decisório: a contribuição dos principais modelos de análise. Disponível em: $<$ http://www.mettodo.com.br/pdf/Discutindo\%20o\%20Proc esso\% 20Decisorio.pdf>. Acesso em março 2019.

\section{COPYRIGHT}

Direitos autorais: $\mathrm{O}(\mathrm{s})$ autor(es) é(são) o(s) único(s) responsável(is) pelo material incluído no artigo. 